\title{
FINNEN IN DER NEUEN WELT 1865-1914
}

\author{
AMERIKA-BRIEFE ALS SPIEGELBILD DER ERSTEN \\ AUSWANDERERGENERATION
}

Schriftliche Abhandlung zur Erlangung des philosophischen Doktorgrades an der Philosophischen Fakultät der Georg-August-Universität Göttingen vorgelegt von Susanna Sallinen, geb. Kratz aus Palokka/Finnland 


\section{Vorwort}

Der Anstoß zu einer Beschäftigung mit Amerika-Briefen als dokumentarischen Selbstzeugnissen von finnischen Auswanderern der ersten Generation geht auf das Jahr 1989 zurück, als ein bilaterales Stipedium des DAAD und des finnischen

Bildungsministeriums mir einen einjährigen Studienaufenthalt an den Universitäten Helsinki und Turku ermöglichte. Zu dieser Zeit lernte ich das finnische Migrationsinstitut in Turku kennen und erhielt die Gelegenheit verschiedene Archivbestände mit von Auswanderen selbst verfassten Materialien durchzusehen. Dabei stieß ich auf die Briefsammlungen Süd-Ostbottnien und Satakunta und begann mich zugleich mit den Hintergrundsfaktoren der finnischen

Amerikaauswanderungsbewegung vertraut zu machen.

Nach meiner Rückkehr nach Deutschland folgte die eigentliche Materialerhebung, wobei ich Dutzende von Mikrofilmrollen, die mir aus Turku und Helsinki zugesandt wurden, kopieren und für die hier vorliegende Untersuchung auswerten konnte. Im Jahr 1995 - nach meinem dauerhaften Umzug nach Finnland - erhielt ich nochmals zahlreiche Anregungen und neue Impulse für meine Arbeit, nicht zuletzt durch die Mitarbeiter/Innen des Migrationsinstitutes in Turku, die mir bei vielen Fragen und auch praktischen Problemen mit Rat und Hilfe zur Seite standen. Ein Stipedium des Instituts ermöglichte es mir auch zeitweilig mich intensiv meinem Disserationsprojekt zu widmen. Ohne die Mitarbeiter/Innen namentlich nennen zu wollen, sei ihnen allen in diesem Zusammenhang für ihre Geduld und Ausdauer mit meinem „Briefprojekt“ gedankt.

Doch mein ganz besonderer Dank gilt dem Betreuer dieser Dissertation, Prof. Dr. R.W. Brednich, der mich bereits zu Beginn der 1990 Jahre zu diesem Forschungsprojekt motivierte, mir mit seiner Erfahrung und seinem Wissen zur Seite stand und mich über die weite Entfernung hinweg jederzeit mit fachkundigem Rat, vielen wertvollen Kommentaren sowie konstruktiver Kritik unterstützt hat.

Ebenso sei Prof. Dr. I. Futaky aufrichtig gedankt für sein Interesse an meinem Dissertationsprojekt und seiner Bereitschaft als Zeitgutachter die Arbeit zu bewerten. Auch den weiteren Mitgliedern der Prüfungskommission, Prof. Dr. H. Rosenbaum, Prof. Dr. F. Paul und Prof. D. J. Gulya möchte ich meinen Dank ausprechen. Des weiteren möchte ich Prof. Dr. R. Kero vom Institut für allgemeine Geschichte der Universität Turku danken, dass er meinem Projekt wohlwollend gegenüberstand und 
mir geholfen hat Details zu klären sowie Unklarheiten und Widersprüche aufzudecken. Zuguterletzt möchte ich noch einen Namen nennen, nämlich den eines Freundes und Migrationsforschers Phil.lis. J. Niemelä, der mir in unzähligen Gesprächen immer wieder das Gefühl gegeben hat auf dem richtigen Weg zu sein und einen wertvollen Beitrag zur finnischen Migrationsforschung zu leisten.

Meine Eltern und auch meine eigene Familie haben mir letztendlich erst die jahrelange Konzentration auf diese Abhandlung ermöglicht, ohne ihren unermüdlichen Glauben in meine Fähigkeiten wäre der Text niemals entstanden. Ihnen möchte ich herzlich danken und zugleich diese Arbeit widmen.

Palokka/Finnland im August 2002 


\section{INHALTSVERZEICHNIS}

\section{Einleitung}

\subsection{Aufgabe und Ziel der Untersuchung}

\subsection{Die Quellenlage}

1.2.1. Die Sammlung Süd-Ostbottnien

1.2.2. Die Sammlung Satakunta

\subsubsection{Amerika-Briefe aus Tageszeitungen}

\subsection{Der Auswandererbrief als Kommunikationsmedium}

\subsection{Der Quellenwert von Amerika-Briefen für die Migrationsforschung}

\section{Auswanderung aus Finnland}

2.1. Finnland als autonomes Großfürstentum des russischen Zarenreichs

2.1.1. Politische Entwicklungen

2.1.2. Die beginnende Industrialisierung und Strukturveränderungen in der Landwirtschaft

2.1.3. Die Sozialstruktur der Landbevölkerung

2.1.3.1. Regionale Unterschiede

2.2. Die Provinzen Süd-Ostbottnien und Satakunta als Auswanderungskerngebiet

2.2.1. Die Sprachstruktur

2.2.2. Sozio-ökonomische Charakteristika

2.2.3. Die Bevölkerungsentwicklung

\subsection{Die Quellen zur Auswanderererfassung}

2.3.1. Die Bedeutung der Paßverzeichnisse für die Emigrationsforschung 2.3.1.1. Paßverzeichnisse als Grundlage der offiziellen Emigrationsstatistik 2.3.2. Die Bedeutung der Passagierlisten für die Emigrationsforschung 


\subsection{Die chronologische Entwicklung des Auswanderungsverlaufs}

2.4.1. Die Binnenwanderung als Vorläufer der Amerikaemigration

2.4.2. Die Auswanderung nach Schweden und Rußland

2.4.3. Die Auswanderung nach Nord-Norwegen als erster Schritt der Überseemigration

2.4.4. Finnische Seeleute als erste Amerikafahrer

2.4.5. Die finnische Amerikauswanderung vor 1870

2.4.6. Der Auswanderungsverlauf 1870-1914

\subsection{Die Auswanderungsintensität in Gesamtfinnland}

2.5.1. Die Auswanderungsintensität im Untersuchungsgebiet

\subsection{Auswanderungsgründe und -motivationen}

2.6.1. Allgemeine Migrationstheorien

2.6.2. Ursachen der finnischen Emigrationsbewegung

2.7. Strukturelle Zusammensetzung der Auswanderer nach sozialer Herkunft, Alter und Geschlecht

2.7.1. Sozialstruktur der finnischen Auswanderer

2.7.2. Zusammensetzung der Auswanderer nach Alter und Geschlecht

\section{Einwanderung in die Vereinigten Staaten und nach Kanada}

\subsection{Die europäische Überseemigration}

3.1.1. Die finnische Amerikaeinwanderung als Bestandteil der europäischen Immigration

3.1.2. Finnen als Vertreter der "neuen Immigration"?

\subsection{Die große Reise und erste Schritte in der Neuen Welt}

3.2.1. Die Reiserouten der finnischen Auswanderer

3.2.1.1. Der Einfluß der Agententätigkeit auf das Auswanderungsgeschäft

3.2.2. Die Überfahrt und Ankunft auf der Grundlage von Erlebnisberichten

\subsection{Geographische Verteilung und regionale Mobilität}

3.3.1. Die wichtigsten Besiedlungsgebiete der finnischen Einwanderer 
3.3.2. Geographische Konzentration im Vergleich zu anderen skandinavischen Einwanderergruppen

3.3.3. Die Finnen im Bereich der Großen Seen

\subsection{Amerikanischer Arbeitsalltag aus finnischer Perspektive: Finnen unter sich}

3.4.1. Schichtarbeit untertage

3.4.1.1. Bergbau in Michigan

3.4.1.2. Bergbau in Minnesota

3.4.2. Mit Axt und Säge im Wald: Immer auf Wanderschaft

3.4.3. Aus Gruben- und Waldarbeitern werden Bauern: Finden einer neuen Heimat

3.4.4. In der Fabrik und am Hafen: Das Leben in amerikanischen Städten 3.4.4.1. Arbeitsbereiche für Frauen: "Immer zu Diensten" in städtischen Privathaushalten

\subsection{Der Auswandererbrief als Brückenschlag zwischen Finnland und der Neuen} Welt

3.5.1. Die Anwerbung potentieller Auswanderer

3.5.2. Die Warnung vor dem Auswanderungsentschluß

3.5.3. Heimwehäußerungen und Rückwanderungsabsichten

\section{Quellen- und Literaturverzeichnis}

Ungedruckte Primärquellen

Gedruckte Primärquellen

Briefeditionen

Biographische Werke zu finnischen Auswanderern

Literatur

Unveröffentlichte Werke

Veröffentlichte Werke

\section{Anhang: Verzeichnis der Tabellen und Karten}

Tabellen

Karten 
"An American letter was a little bit like a breath of fresh air from another planet."1

\section{$\underline{\text { 1. Einleitung }}$}

\subsection{Aufgabe und Ziel der Untersuchung}

Im Zeitraum 1865-1914 brachen rund 320.000 Finnen der ersten

Auswanderergeneration in die Neue Welt auf. Die überwiegende Mehrheit der finnischen Überseeauswanderer hatte entweder Nord-Amerika oder Kanada zum Ziel, wonach vereinfacht von der finnischen Amerikaemigration gesprochen werden kann. Die Größenordnung dieser Wanderungsbewegung aus Finnland ist ein bislang einmaliges historisches Ereignis geblieben. Zeitlich fällt sie in die Spätphase der europäischen Massenemigration nach Nord-Amerika und Kanada, die durch den Ausbruch des Ersten Weltkrieges unterbrochen wurde und im Verlauf der 1920er Jahre durch mehrfach verschärfte Einwanderungsbeschränkungen fast zum Erliegen kam.

Aufgrund der Tatsache, daß sich die meisten englisch- und deutschsprachigen Darstellungen zur finnischen Geschichte, über die Zeit von der unterdrückten Autonomie zur nationalen Unabhängigkeit, mit den Verflechtungen der politischen Ereignisse in Finnland und Rußland beschäftigen, ist der Massenexodus nach dem nordamerikanischen Kontinent weitgehend unbeachtet geblieben ${ }^{2}$. Diese allgemeine Unkenntnis der Emigrationsbewegung Finnlands an der Schwelle zum 20. Jahrhundert möchte die vorliegende Untersuchung zum Anlaß nehmen, um einen Beitrag zur Transparenz einer historischen Entwicklung zu leisten, dessen demographische Nachwirkungen bis in die heutige Zeit spürbar sind ${ }^{3}$.

\footnotetext{
${ }^{1}$ Ausspruch eines finnischen Amerikaauswanderers, entnommen aus Penti 1983, S. 314. ${ }^{2}$ Siehe beispielsweise die deutschsprachigen Monographien zur Geschichte Finnlands von Jutikkala $1976\left({ }^{1} 1964\right)$ und Klinge $1987\left({ }^{1} 1977\right)$ [auch in engl. Sprache] sowie die englischsprachige Darstellung von Alapuro 1988.

${ }^{3}$ In den Vereinigten Staaten lebten 1988 rund 230.000 Finnen der ersten und zweiten Einwanderergeneration, vgl. Korkiasaari 1989, S. 151.
} 
Das Augenmerk dieser Studie liegt sowohl auf den gesellschaftlichen und sozioökonomischen Rahmenbedingungen in Finnland, welche die Auswanderungsbewegung hervorgerufen haben, als auch auf den Anfängen der finnischen Überseemigration und dem Werdegang der ersten Einwanderergeneration in der Neuen Welt, wobei den aus Amerika und Kanada in die Heimat geschickten Briefen als Spiegelbild von vielschichtigen kollektiven Erfahrungen und Wahrnehmungsperspektiven der Immigranten ein besonderer Stellenwert zukommt. Zuleich wird die im gesamteuropäischen Emigrationsgeschehen als marginal angesehene - weil von zahlenmäßig geringem Umfang - finnische Amerikauswanderung erstmals in deutscher Sprache vorgestellt. Für die finnische Migrationsforschung wiederum bedeutet vorliegende Untersuchung den ersten Versuch, die erlebte Alltagsgeschichte der finnischen Amerikaauswanderer auf der Quellengrundlage von Briefen als persönlichen Zeitdokumenten zu reflektieren.

Dabei dienen die Briefsammlungen nicht nur gewissermaßen als "Steinbruch", um anhand von Briefzitaten einzelner Personen allgemeine Wahrnehmungstendenzen aufzuzeigen, sondern es werden vor allem zwei wesentliche Funktionen des Mediums Auswandererbrief analysiert: Zum einen bedeutete der Briefwechsel die einzige Kommunikationsform räumlich getrennter Personen, die sich unter anderen Lebensumständen nicht in diesem Ausmaß des Briefmediums bedient hätten, so daß die Briefkommunikation als Gesprächsersatz einen Brükkenschlag zwischen zwei Lebenswelten des Auswanderers dargestellt hat. Zum anderen sind Amerika-Briefe insbesondere für die gezielte Auswandereranwerbung von weiteren Familienangehörigen oder Bekannten aus den Herkunftsgemeinden der Emigranten relevant gewesen und haben somit den Emigrationsprozeß in seiner Gesamtheit erheblich beeinflußt.

Um auf diese Weise die Hintergrundfaktoren der finnischen Auswanderungsbewegung "von unten", aus der Sicht der Betroffenen zu betrachten, wird den finnischen Amerika-Briefen als authentischem Quellenmaterial zwar ein großer Stellenwert eingeräumt, doch ist diese Darstellung weder als Auswandererbriefedition mit ergänzenden Kommentaren konzipiert, noch hat sie den Anspruch, es bei der Erläuterung von Briefinhalten zu belassen. Vielmehr ist die vorliegende Arbeit darauf angelegt, ein Gesamtbild des Phänomens finnische Amerikaemigration entstehen zu 
lassen, um zugleich dem deutschsprachigen Leser einen Einblick in die Vielschichtigkeit der Emigrationsbewegung Finnlands, eines Landes an der europäischen Peripherie, zu vermitteln.

Zur Erfüllung diesen Anliegens sollen beide Seiten des "Salzwasser-Vorhanges durchdrungen" ${ }^{4}$ werden, wonach die Studie zum einen die Auswanderung aus Finnland und zum anderen die Einwanderung in die Neue Welt behandelt.

Im einzelnen gilt es den phasenweisen Verlauf der nach Übersee gerichteten Mobilität, welche bereits in einer Tradition der internen und grenzüberschreitenden Wanderungsbewegungen stand, zu erörtern, ohne dabei die politischen, gesellschaftlichen und sozio-ökonomischen Hintergründe im Finnland des ausgehenden 19. Jahrhunderts aus dem Blickfeld zu verlieren. Denn erst diese Rahmenbedingungen haben den Grundstein für die rasante Entwicklung der historisch beispiellos gebliebenen Wanderungsbewegung gelegt und nicht zuletzt die individuellen Auswanderungsentscheidungen erheblich beeinflußt. Zudem standen sie in enger Beziehung zur geographischen Ausbreitung der Emigrationserscheinung mit Konzentration auf die Provinzen Süd-, Mittel- und Nordostbottnien sowie die nördlichsten Ausläufer der Provinz Satakunta; einer Region, in der die meisten Amerika-Briefe gesammelt wurden.

Bei der Betrachtung spezifischer Faktoren, die hinter der expandierenden Emigrationsbewegung standen, werden sowohl den bislang veröffentlichten Forschungsergebnissen eines großangelegten Forschungsprojektes der Universität Turku sowie des Migrationsinstituts in Turku Rechnung getragen als auch die wichtigsten Quellen zur demographischen Bevölkerungsentwicklung und offiziellen Auswandererregistrierung in Finnland einer kritischen Analyse unterzogen.

Da jedoch die Kenntnis allein von den allgemeinen Rahmenbedingungen sowie Umfang und Ausbreitungsintensität der finnischen Emigrationsbewegung die Komplexität der Auswanderungsursachen noch nicht erklären kann, sollen die Motivationsfaktoren auf globaler und individueller Ebene, insbesondere anhand von Brief- und Interviewaussagen, gesucht werden. Persönliche Gründe werden sich jedoch nur ansatzweise rekonstruieren lassen, da sie den zurückgebliebenen Angehörigen und Freunden der Amerikafahrer meist hinreichend bekannt waren und von daher kaum Niederschlag in den späteren Briefen der Auswanderer gefunden haben.

\footnotetext{
${ }^{4}$ Dieser Begriff wurde von Kamphoefner (1982, S. 1) geprägt.
} 
Ergänzende Aspekte zur Aufteilung des Auswandererpotentials nach sozialer Herkunft, Alter und Geschlecht schließen dann den ersten Teil der Studie ab.

Die Neustrukturierung des Alltagslebens auf dem nordamerikanischen Kontinent sowie die ersten Arbeitserfahrungen in verschiedenen Erwerbsbereichen auf der Grundlage von Briefzitaten füllen den zweiten Teil der Abhandlung aus: Nach der einleitend dargestellten Bedeutung der finnischen Emigrationsbewegung für den gesamteuropäischen Emigrationsprozeß wird vor allem die bislang erst ansatzweise untersuchte Atlantiküberquerung finnischer Auswanderer besprochen. Die sich anschließende Betrachtung der geographischen Konzentration der finnischen Einwanderer auf bestimmte amerikanische Bundesstaaten und kanadische Provinzen leitet zu Aspekten der Lebenswelt und der Alltagsbewältigung in der multikulturellen amerikanischen Gesellschaft über. Besonderes Gewicht erhalten dabei die verschiedenen Beschäftigungsfelder, da dieser Lebensbereich in den Amerika-Briefen den größten Raum einnimmt. Abschließende Erörterungen sowohl zur Bedeutung und Funktion der Amerika-Briefe im Hinblick auf die Nachwanderung weiterer Familienangehöriger bzw. das bewußte Abraten vom Auswanderungsentschluß als auch zur Rückwanderung nach Finnland runden die vorliegende Arbeit zur finnischen Emigrationserscheinung ab.

Als Zeitrahmen der Untersuchung wurden die Jahre von 1865 bis 1914 gewählt, da dieses halbe Jahrhundert sowohl die Anfangs- als auch die Kernphase der finnischen Amerikaauswanderung umfaßt. Während der gesamten Zeitspanne stand Finnland als autonomes Großfürstentum unter russischer Vorherrschaft und befand sich in einer Umbruchsphase von einem zurückgebliebenen Land in einen modernen Agrarstaat mit vereinzelten, expandierenden Industriezentren. Der überwiegende Teil der Landesbevölkerung erhielt seinen Lebensunterhalt noch aus der Land- und Forstwirtschaft und rekrutierte sich gegen Ende des 19. Jahrhunderts zunehmend aus verschiedenen landbesitzlosen Sozialgruppen, die zugleich die Mehrheit der Amerikaauswanderer stellten.

In der Neuen Welt markierte das Jahr 1865 das Ende des amerikanischen Sezzesionskrieges und leitete die staatlich geförderte Besiedlung des Mittleren Westens ein. Lediglich drei Jahre zuvor war das Heimstättengesetz, der sogenannte 'HomesteadAct', erlassen worden, das europäische Einwanderer in großer Zahl über den Atlantik lockte. Zu dieser Zeit zählte Finnland noch nicht zu den europäischen Auswanderungsländern, doch in den skandinavischen Nachbarländern Finnlands, in 
Norwegen und Schweden, hatte das "Amerika-Fieber" bereits weite Teile der Bevölkerung ergriffen. Seit den 1870er Jahren breitete es sich dann allmählich auch unter finnischen Seeleuten, vereinzelten Küstenbewohnern der südwestlichen Landesteile und unter nordfinnischen Lachsfischern aus. Doch erst die Einrichtung einer direkten Schiffsverbindung von Finnland nach England zu Beginn der 1890er Jahre ermöglichte eine Massenauswanderung aus Finnland in bis dahin unbekanntem Ausmaß. Plötzlich konnten tausende Finnen gemeinsam mit anderen Skandinaviern, Schotten und Iren die Atlantiküberquerung vom britischen Festland aus antreten, ohne einen Umweg über schwedisches oder dänisches Festland mehr in Kauf nehmen zu müssen.

Auf der anderen Seite des Atlantiks angekommen, konkurrierten die Finnen dann mit Deutschen, Schweden, Iren und vor allem mit süd- und südosteuropäischen Einwanderern um niedrig bezahlte Arbeitsplätze in Bergwerken, Waldkamps und Sägewerken der Mittelwest- und Bergstaaten. Finnische Frauen hingegen wanderten erst nach der Jahrhundertwende verstärkt aus und erlangten häufig als Dienstboten in städtischen Privathaushalten eine gesicherte Existenz.

Kurz nach der Jahrhundertwende kulminierten die finnischen Auswandererzahlen und erreichten im Jahrzehnt vor dem Ersten Weltkrieg ihren historischen Höhepunkt, bis der Kriegsausbruch in Europa den transatlantischen Passagiertransport zeitweilig unterbrach. Mit dieser plötzlichen Zäsur in der nach Amerika gerichteten Mobilitätsbewegung wird auch der hier betrachtete Untersuchungszeitraum abgeschlossen.

Obwohl der Auswandererstrom dann in den 1920er Jahren - insbesondere nach Kanada - wieder auflebte, hatte die finnische Amerikaauswanderung als politisch motivierte Landflucht, eine Folgeerscheinung des finnischen Bürgerkrieges von 1918/19, mittlerweile eine neue Dimension erhalten. Auf dem amerikanischen Kontinent wiederum verbanden die Kinder finnischer Immigranten das kulturelle Erbe ihrer Eltern mit den Werten und Normen der multikulturellen amerikanischen Gesellschaft und prägten somit eine neue Generation der "Bindestrich-Amerikaner". Diese Finnen der zweiten Einwanderergeneration dominierten bereits in den ausgehenden 1920er Jahren 
die ethnische Gemeinschaft und hoben sich deutlich von den ersten Immigranten, den Hauptpersonen dieser Studie, $a b^{5}$.

\subsection{Die Quellenlage}

Seit den 1890er Jahren sind etwa eine halbe Million Postsendungen jährlich, in erster Linie Briefe, über den Atlantik nach Finnland geschickt worden, wobei die Gesamtanzahl während der ersten Dekade des 20. Jahrhunderts vermutlich noch höher lag. Demnach kann von einem Gesamtvolumen von schätzungsweise 12.000000 bis 15.000000 Amerika-Briefen während des Zeitraumes 1890-1914, der bedeutsamsten Phase der finnischen Amerikaauswanderung, ausgegangen werden ${ }^{6}$. War ein Brief vor der Jahrhundertwende noch rund einen Monat unterwegs, wurde er um 1910 bereits in 15-17 Tagen transportiert ${ }^{7}$.

Die Höhe des Briefportos wiederum betrug um 1850 noch 1,3 Dollar, sank dann bis 1875 auf 0,06 Dollar und wurde um 1900 auf 0,05 Dollar festgesetzt ${ }^{8}$, wobei die Fünf-Cent-Briefmarke als Portogebühr bis in die 1920er Jahre Gültigkeit behielt. Auch aus Kanada war die Korrespondenz nicht wesentlich teurer, ein Brief nach Finnland kostete zu Beginn des 20. Jahrhunderts 0,08 Dollar. Demnach hatte die Höhe der Postgebühr, bei einem durchschnittlichen Tagesverdienst eines männlichen Arbeiters von 1,5 Dollar, keinen nennenswerten Einfluß auf die finanzielle Belastung der Immigranten.

\footnotetext{
${ }^{5}$ Zu Finnen der zweiten Generation siehe Kostiainen 1986, bes. S. 31-39; Hummasti 1990, Virtanen 1993, S. 7-9.

${ }^{6}$ Die exakte Briefanzahl läßt sich aufgrund fehlender Quellen nicht rekonstruieren. Nach Information der Zeitung 'Uusi Suometar' (Neues Finnland) vom 19.8.1896 jedoch sollen im Jahr 1894479.470 Überseebriefe die Regierungsbezirke Oulu und Vaasa erreicht haben. Da im Zeitraum von 1895-1914 noch weitere 250.000 Finnen in die Neue Welt strömten, ist davon auszugehen, daß auch nach 1894 eine halbe Million Briefe oder mehr jährlich den Atlantik überquert haben werden. Auch für die dänische Amerikaauswanderung, die sich aus einer ähnlich großen Auswandererpopulation wie der finnischen zusammensetzte, konstatiert Hvidt (1971, S. 342), daß 1895 ca. eine halbe Million Briefe in Dänemark ankamen.

${ }^{7}$ In einem seltenen Antwortbrief aus Finnland vom 7.1.1882 wird die Brieftransportdauer von Ohio nach Süd-Ostbottnien mit einem Monat und vier Tagen angegeben. Die gleiche Zeitangabe findet sich auch in einem Brief von 1872 aus Minnesota nach Norwegen, vgl. Øverland/Kjærheim 1993, Bd. 3; S. 293-295, hier S. 294. 1910 benötigte ein Brief von Seattle, an der Westküste, nach Karvia in Satakunta wiederum 17 Tage, vgl. Vihtori Hautala, Brief vom 4.4.1910: TYYH:S:m:Satakunta:KAR:XIII/1.

${ }^{8}$ Helbich/Kamphoefner/Sommer 1988, S. 31f., Note 2.
} 
Die Briefe wurden von Personen geschrieben, die sich mit dem Schreiben häufig schwertaten und unter anderen Lebensbedingungen vermutlich kaum zur Feder gegriffen hätten, wie anhand einfacher Formulierungen, starker Dialektverwendung sowie zahlreicher orthographischer Fehler zu erschließen ist. Ebenso zeugen die zum größten Teil unbeholfenen Handschriften, wodurch einige Briefe nahezu unleserlich erscheinen, von den Anfangsschwierigkeiten der Auswanderer mit einem noch unvertrauten Kommunikationsmedium. Da jedoch nicht alle Auswanderer schreiben konnten, wurden Briefe auch diktiert, was das Auftreten verschiedener Handschriften bei mehreren Briefen eines Verfassers erklärt. Dennoch ist anzunehmen, daß der überwiegende Teil der finnischen Auswanderer zumindest lesen konnte, da innerhalb der finnischen Gesamtbevölkerung bereits um 1880 etwa jeder Dritte Einwohner lesen und jeder Zehnte schreiben konnte, obwohl die allgemeine Schulpflicht erst 1921 gesetzlich verankert wurde ${ }^{9}$. Im Hinblick auf den allgemeinen Bildungsstand hoben sich die finnischen Emigranten, und somit zugleich die Briefschreiber, denn auch deutlich von den ebenfalls um die Jahrhundertwende in großer Zahl ausgewanderten Süd- und Südosteuropäern $\mathrm{ab}^{10}$.

Die dieser Untersuchung zugrundeliegenden Briefsammlungen, die als Ausgangsmaterial für eine Stichprobenbildung gedient haben, stammen aus zwei von insgesamt 16 finnischen Provinzen ${ }^{11}$ : Süd-Ostbottnien im Regierungsbezirk Vaasa sowie dem südlich angrenzenden Satakunta im Regierungsbezirk Turku/Pori, zugleich die Heimat von mehr als einem Drittel der finnischen Überseemigranten. Zusammengenommen umfassen die beiden Sammlungen etwa 13000 Auswandererbriefe und Postkarten des Zeitraumes 1882-1964, die aus zahlreichen Orten und Städten der Vereinigten Staaten und Kanadas nach dem südwestlichen Teil Finnlands geschickt wurden. Ausnahmslos alle Briefe sind in finnischer Sprache geschrieben, da sich die Sammlungen vorwiegend auf Regionen mit mehrheitlich finnischsprachiger Bevölkerung konzentriert haben. Zugleich repräsentiert der

\footnotetext{
${ }^{9}$ Halila 1983; Olkkonen 1988, S. 500.

${ }^{10}$ Während des Zeitraumes 1899-1910 waren 68,2\% der einwandernden Portugiesen, 53,9\% der Süd-Italiener, 41\% der Südslaven sowie 38,4\% der Russen Analphabeten, die Rate der Finnen hingegen lag bei 1,3\%, vgl. Easterlin 1981, S. 478, Tab. 2. Siehe auch Smith 1969; Seller Schwartz 1978.

${ }^{11}$ Um die Jahrhundertwende war Finnland als zweisprachiges Autonomiegebiet in acht Regierungsbezirke und 16 landschaftliche Provinzen unterteilt, siehe hierzu Karten 1a und 1b im Anhang: Geographische Aufteilung Finnlands nach Regierungsbezirken und Provinzen um 1900 .
} 
überwiegende Teil der Amerika-Briefe einen einseitigen Briefwechsel, d.h. daß die Antwort-Briefe, die Finnland-Briefe, von einigen Ausnahmen abgesehen fehlen ${ }^{12}$. Bislang ist in Finnland die Existenz von etwa $25000-30000{ }^{13}$ noch erhaltenen Amerika-Briefen ausgewanderter Finnen bekannt geworden, wovon rund 18000 in kopierter Form als Mikrofilme an der Universität Turku archiviert sind. Die restlichen, noch erhaltenen Briefe, d.h. 7000 - 12000 Exemplare, befinden sich als Originale entweder im Migrationsinstitut in Turku oder aber in Privatbesitz. Die beiden Briefsammlungen mit insgesamt etwa 13000 Briefen, die als Grundgesamtheiten für die hier zu untersuchenden Amerika-Briefe gedient haben, gehen in das Kontingent der rund 18000 verfilmten Briefe ein. Eine dritte, ebenfalls kopierte Briefsammlung aus dem Jahr 1966 mit einem Ertrag von etwa 5000 Briefen blieb für diese Untersuchung jedoch unbeachtet ${ }^{14}$.

Die hier behandelten Briefsammlungen aus den Provinzen Süd-Ostbottnien und Satakunta, die den Zeitraum 1882-1964 umfassen, haben als Grundgesamtheiten für zwei Samples von insgesamt 478 Briefen, allesamt vor 1915 geschrieben, von 143 Briefschreibern - 100 Männern und 43 Frauen - gedient. Die Briefe des Samples 'SüdOstbottnien' stammen aus 19 Gemeinden und einer Stadt, für das Sample 'Satakunta' hingegen waren 20 ländliche Gemeinden der besagten Provinz bedeutsam. Diese Region von zusammengenommen 39 Gemeinden und der Stadt Vaasa wird hier als Untersuchungsgebiet bezeichnet ${ }^{15}$.

\footnotetext{
${ }^{12}$ Die Antwortbriefe sind auch bei anderen Sammlungen nicht gezielt, sondern eher zufällig gesammelt worden (z.B. Helbich/Kamphoefner/Sommer 1988), obwohl Blegen bereits 1929 (hier S. 25) die Bedeutung der Briefe aus der Heimat nach Amerika hervorhebt. Der fünfbändige Klassiker 'The Polish Peasant' $\left({ }^{1} 1918-21\right)$ von Thomas und Znaniecki hingegen gibt auf 2244 Seiten nur teilweise das Schicksal der polnischen Amerikaauswanderer in Briefen und Lebensberichten wieder. Dieses soziologische Mamutwerk, das vor allem der Fachdisziplin in Amerika zu Anerkennung verhalf, konzentriert sich auf in Polen geschriebene Briefe, da nämlich die Materialsammlung vornehmlich in Amerika erfolgte, und stellt somit eine Ausnahmeerscheinung innerhalb der Amerika-Briefeditionen dar. Siehe hierzu auch die Kurzedition des Werkes von Zaretsky 1984, S. 1-53.

${ }^{13}$ Kero (1991, S. 128) schätzt die erhaltene Briefanzahl auf rund 30000 Stück, Mitarbeiter des Migrationsinstitutes in Turku hingegen auf etwa 22000-25000 Exemplare.

${ }^{14}$ Dieser Briefbestand wurde 1966 in der Provinz Varsinais-Suomi (Eigentliches Finnland) auf Initiative von Prof. V. Niitemaa des Seminars für allgemeine Geschichte der Universität Turku erhoben, wobei die Sammelregion jedoch nicht dem vorrangigen Emigrationsgebiet der ersten Auswanderergeneration entsprach.

${ }^{15}$ Zur Bevölkerungsdichte und Auswanderungsintensität in den 40 Gemeinden des Untersuchungsgebietes siehe die Karte 5 und 6 im Anhang. Zur Briefanzahl pro Gemeinde siehe Tab. 8 im Anhang.
} 


\subsubsection{Die Sammlung Süd-Ostbottnien}

Die erste Sammlung, im folgenden als 'Sammlung Süd-Ostbottnien' benannt, wurde in den Jahren 1959-60 von Studenten der Universität Helsinki, die zugleich der studentischen Landsmannschaft 'Ostbottnien' angehörten, in rund 50 ländlichen Gemeinden und vier Städten der Provinz Süd-Ostbottnien zusammengestellt . Die Initiative für dieses Projekt ging von den Studenten aus und erbrachte einen Fundus von etwa 5000 Briefdokumenten, Postkarten und Fotographien aus dem Zeitraum 18821960. Zudem ging zahlreiches, den Briefen beigelegtes Material in die Sammlung mit ein, das u.a. von Zeitungsausschnitten, Kalendern verschiedener kultureller Organisationen, Quittungen über Bankwechsel bis hin zu Einbürgerungsurkunden, ausgestellt von amerikanischen Behörden, reichte. Bislang sind weder die Briefe noch das beigefügte Material wissenschaftlich ausgewertet worden.

$\mathrm{Zu}$ jeder Briefserie eines Verfassers entstand ein Fragebogen in Form einer Karteikarte mit 14 Angaben zur Person des Briefschreibers. Die Fragebögen umfassen Informationen zu Name und Adresse des Briefschreibers, Geburts- und Auswanderungsjahr, Geburtsort und Heimatgemeinde in Finnland, Familienstand und familiären Verhältnissen sowie erstem Arbeitsort in Amerika oder Kanada. Meist sind die Karteikarten nur lückenhaft ausgefüllt, doch im besten Fall finden sich sogar Eintragungen zur Mehrfachauswanderung, dauerhaften Rückkehr, den Lebensverhältnissen nach der Rückkehr sowie der sozialen Beziehung von Briefschreiber und Briefbesitzer.

Sämtliches Material wurde von den Helsinkier Studenten den Einsammlungsorten entsprechend sortiert, die Briefe eines Verfassers durchnumeriert und mit den Briefkuverts, dem beigefügtem Material sowie der Karteikarte, die über den Briefverfasser Auskunft gab, auf 16 Mikrofilmrollen kopiert ${ }^{16}$. Beim Kopiervorgang sind jedoch, vermutlich aus Datenschutzgründen, alle Namen der Briefverfasser, der adressaten sowie der Datums-, Orts- und Adressenangaben mit weißen Papierstreifen

\footnotetext{
${ }^{16}$ Es existieren drei Kopien der Sammlung ‘Süd-Ostbottnien' auf jeweils 16 Mikrofilmrollen, die in der Universitätsbibliothek Helsinki, dem Seminar für allgemeine Geschichte der Universität Turku sowie dem 'Immigration History Research Center' (IHRC) in Minneapolis/Minnesota zu finden sind.
} 
verdeckt und somit unkenntlich gemacht worden. Im Anschluß an die Vervielfältigung erhielten die meisten Briefbesitzer dann ihr Eigentum zurück.

Für die finnische Migrationsforschung kann es jedoch als Glücksfall angesehen werden, daß knapp die Hälfte dieser Briefsammlung, ca. 2000 Briefe aus dem Zeitraum 1882-1960, aus verschiedenen Gründen nicht an die Briefbesitzer zurückging und somit als Originalbestand erhalten blieb. Im Jahr 1985 gingen diese Originalbriefe dann als Schenkung der Landsmannschaft Ostbottnien in die Archivbestände des Migrationsinstituts von Turku über. Von daher sind bei der 'Sammlung SüdOstbottnien' zwar alle Briefe als Mikrofilmkopien einsehbar, doch lediglich die in Turku als Originalbriefe erhaltenen Exemplare geben Auskunft über die Namens-, Ortsund Zeitangaben des jeweiligen Schriftverkehrs.

Das für die vorliegende Untersuchung gebildete Sample aus der Sammlung „Süd-Ostbottnien“, dem ausschließlich die in Turku archivierten Originale zugrunde lagen, umfaßt Briefe, die vor 1915 aus Amerika und Kanada nach Finnland gesandt wurden. In Fällen, in denen eine Briefserie vor 1914 begann und über den Ersten Weltkrieg hinaus fortgesetzt wurde, fanden die jüngeren Briefe lediglich als Hintergrundmaterial Beachtung, d.h. sie dienten zum Verständnis der Gesamtsituation des entsprechenden Briefschreibers und wurden nur ausnahmsweise zur Interpretation der Alltagserfahrungen für die Zeit vor dem Ersten Weltkrieg herangezogen.

Dieses Sample besteht aus 125 Briefen von 50 Verfassern, 37 Männern und 13 Frauen. Die Briefe wurden in 19 ländlichen Gemeinden sowie der Stadt Vaasa gesammelt. Aufgrund der ergänzenden Angaben der Karteikarten kann davon ausgegangen werden, daß die Briefverfasser tatsächlich aus den entsprechenden Gemeinden stammten, in denen ihre noch erhaltenen Briefe aufgespürt werden konnten. Die meisten Briefverfasser, jeweils fünf oder sechs Personen, stammten aus Isokyrö, Jalasjärvi, Peräseinäjoki und Ylistaro. Die meisten Briefe wiederum, zwischen 11 und 36 Stück, wurden in Isokyrö, Jurva, Peräseinäjoki und Ylihärmä gesammelt.

Auf amerikanischer Seite hielten sich die Briefverfasser in 18 amerikanischen Bundesstaaten und drei kanadischen Provinzen auf, wobei jeweils mindestens 20 Briefe aus neun Ortschaften in den Grubenregionen von Michigan und Minnesota geschrieben wurden. Auch aus Massachusetts an der Atlantikküste gingen 33 Briefe aus acht Orten in dieses Sample ein. Weitere Staaten mit mehr als zehn Briefen waren Ohio und die 
kanadische Provinz Ontario. Aus den übrigen 14 Staaten $^{17}$ bzw. den verbleibenden kanadischen Provinzen Saskatchewan und British Columbia fanden bis zu sechs Briefen pro Staat oder Provinz aus ein bis drei Ortschaften Aufnahme in diese Untersuchung.

\subsubsection{Die Sammlung Satakunta}

Die Sammlung 'Satakunta' wiederum, die etwa 8000 Briefe, Postkarten sowie weiteres Material umfaßt und die Grundgesamtheit für das zweite, dementsprechend größer ausfallende Sample bildet, kam 1964 auf Initiative von Prof. V. Niitemaa und seinem Assistenten R. Kero vom Seminar für allgemeine Geschichte der Universität Turku zustande. Demnach entstand diese zweite Briefsammlung aus der Region Satakunta lediglich fünf Jahre nach dem Einsammlen der Amerika-Briefe aus SüdOstbottnien. Um die Provinz Satakunta, die südlich an die Region Süd-Ostbottnien angrenzt, auf Auswandererbriefe hin zu durchforsten, wurden die Bewohner von rund 30 ländlichen Gemeinden der Region sowie den Städten Rauma und Pori zur Bereitstellung ihres Amerika betreffenden Briefeigentums aufgefordert. Mehrere Zeitungs- und Rundfunkaufrufe versprachen Geldprämien für die Einsendung der umfangreichsten Briefserien. Zugleich erhielten die Briefbesitzer einen Fragebogen zugesandt, der jedoch im Gegensatz zu der Karteikarte der ostbottnischen Studenten von 14 auf 29 Rubriken erweitert worden war. Neu waren vor allem Fragen zur Nachwanderung von Familienangehörigen, zur Eheschließung in Finnland oder Amerika und Nationalität des Ehepartners, zu Reiseroute und Anzahl der zeitgleich ausgewanderten Verwandten oder Freunde, zu verschiedenen Aufenthaltsorten und Berufsfeldern in Amerika oder Kanada sowie dem späteren Werdegang des Auswanderers; bei Rückwanderern wurden zudem noch nach dem Grund der Rückkehr und dem weiteren Lebensverlauf im Heimatland gefragt.

Anhand der Fragebogenangaben kann auch für die Briefschreiber, deren Briefe in der Provinz Satakunta gesammelt wurden, eine Übereinstimmung von Herkunftsgemeinde des Briefverfassers und Zielort der Postsendungen konstatiert werden, wonach auch diese Auswanderer meist aus eben jenen Gemeinden stammten in die ihre Amerika-Briefe adressiert waren..

\footnotetext{
${ }^{17}$ Es sind folgende Staaten gemeint: Colorado, Conneticut, North Dakota, South Dakota, Idaho, Illinois, Indiana, Kalifornien, Montana, New York, Washington, West Virginia, Wisconsin und Wyoming.
} 
Der umfangreiche Ertrag dieser Briefsammlung wurde nach dem gleichen Ordnungsprinzip wie die Briefsammlung 'Süd-Ostbottnien' auf 25 Mikrofilmrollen kopiert, wobei diesmal jedoch keine Briefangaben verdeckt wurden. Im Anschluß an den Kopiervorgang gingen die Originalbriefe ausnahmslos an die Einsender zurück. Ein zusätzlich erstellter Indexband erleichtert den Zugang zu dieser sich im Besitz des Universität Turku befindenden Briefsammlung ${ }^{18}$. Die problemlose Handhabung dieses Briefbestandes hatte dann auch zur Folge, daß im Gegensatz zur Sammlung 'SüdOstbottnien' bisher zahlreiche Briefe aus Amerika nach Satakunta publiziert worden sind ${ }^{19}$.

Das hier betrachtete Sample 'Satakunta' umfaßt 353 vor 1915 geschriebene Amerika-Briefe von 63 Männern und 30 Frauen und ist damit fast dreimal so groß wie die Stichprobeneinheit 'Süd-Ostbottnien'. Als wichtigste Herkunftsgemeinden der Briefschreiber (mit jeweils mehr als zehn Briefverfassern) wären Hinnerjoki, Karvia, Lappi/TL ${ }^{20}$ und Siikainen zu nennen. In diese vier Gemeinden wurden denn mehr als die Hälfte der 353 Briefe geschickt, obwohl auch in Ikaalinen, Kiikka und Merikarvia jeweils mindestens 25 Briefe gesammelt wurden.

Die ausgewanderten Briefverfasser schrieben ihre Briefe wiederum in 16 amerikanischen Staaten und drei kanadischen Provinzen ${ }^{21}$. Dabei stammten die meisten Postsendungen, ebenso wie im Vergleichs-Sample 'Süd-Ostbottnien', aus den Staaten Michigan, Minnesota und Massachusetts, nämlich zwischen 46 und 91 Briefen aus 8 18 Grubenorten und Kleinstädten. Mehr als jeweils 20 Briefe gingen außerdem aus Ohio und Washington in diese Untersuchung ein. Als einzelne Ortschaften wiesen

\footnotetext{
${ }^{18}$ Eine weitere Kopie der 25 Mikrofilmrollen umfassenden Sammlung 'Satakunta' liegt im 'Immigration History Research Center' (IHRC) in Minneapolis/Minnesota zur Einsicht bereit. ${ }^{19}$ Die umfangreichsten Briefabdrucke finden sich bei Penti 1978, S. 22-40; Hoglund 1981b, S. 13-31 und 1990, S. 47-54; Kero 1985, S. 38-135. Die Artikel von Penti und Hoglund stellen die bislang einzigen analytischen Darstellungen zu finnischen Auswandererbriefen dar. Kero hat in einem Sammelband (Kuparinen 1985) zu finnischen Überseebriefen 62 vor 1914 geschriebene Briefe der Sammlung 'Satakunta' ohne begleitende Kommentare ediert (zitiert als Kero 1985). Sämtliche 62 edierte Briefe sind in das hier betrachtete Sample 'Satakunta' von 353 Briefen eingegangen.

${ }^{20}$ Lappi/TL steht für die Gemeinde Lappi im Regierungsbezirk Turku/Pori, um nicht mit der Provinz Lappland (finn. Lappi) verwechselt zu werden.

${ }^{21}$ Die 16 Staaten, aus denen die Briefe des Samples nach Satakunta geschickt wurden, sind im einzelnen: Colorado, Conneticut, Kalifornien, Massachusetts, Michigan, Minnesota, Montana, New Hampshire, New Jersey, New York, Ohio, Pennsylvanien, Vermont, Washington, West Virginia und Wisconsin. Aus Kanada gingen Briefe aus Ontario, British Columbia und Quebéc in diese Stichprobeneinheit ein.
} 
Cloquet, ein Sägewerkszentrum bei Dultuth in Minnesota gelegen, sowie die

Küstenstadt Aberdeen in Washington, ebenfalls bedeutsam für die Holzindustrie, mit 52 bzw. 36 Exemplaren die höchste Brieffrequenz auf.

Interessanterweise repräsentieren die vorwiegenden Aufenthaltsorte der Briefschreiber beider Sample-Regionen zugleich die geographische Konzentration der finnischen Einwanderer in ihrer Gesamtheit auf die Staaten Michigan, Minnesota und Massachusetts ${ }^{22}$, obwohl die Stichprobeneinheiten im Verhältnis zum Gesamtmaterial sehr klein gehalten sind.

\subsubsection{Amerika-Briefe in Tageszeitungen}

Neben den Briefen als Hauptquellen sind zudem zehn Interviews von Auswanderern aus den benannten Gemeinden berücksichtigt worden. Die Interviews wurden in den Jahren 1977-78 von einem Laienforscher mit finnischen Einwanderern der ersten Generation in mehreren Altenwohnheimen in Florida geführt und sind bislang noch nicht wissenschaftlich ausgewertet worden. Als schriftliche Transkripte gehören sie einer Sammlung von insgesamt 173 in Florida geführten Befragungen an und werden im Migrationsinstitut in Turku archiviert.

Die dritte Quellengattung, die in vorliegender Studie Verwendung gefunden hat, besteht aus in Finnland publizierten Tageszeitungen, in denen sowohl Artikel zur Amerikaauswanderung als auch Privatbriefe zu finden sind. Letztere, zumeist viele Detailinformationen beinhaltenden Briefexemplare wurden durch die Briefempfänger den Zeitungsredaktionen zugeführt und waren ursprünglich nicht für eine Veröffentlichung bestimmt. Im Gegensatz dazu stand der offene Brieftyp, d.h. ein direkt an die Zeitungsredaktion gerichteter Bericht, der lediglich in Briefform abgedruckt wurde $^{23}$. Als publikumsorientierte Quellengattung kann dem offenen Brief der private Charakter, welcher das Briefmedium im allgemeinen bestimmt, abgesprochen werden, weshalb er auch in der vorliegenden Studie keine Beachtung erfährt.

\footnotetext{
${ }^{22}$ Die Konzentration der Finnen auf einzelne amerikanische Bundesstaaten und kanadische Provinzen wird ausführlich in Kap. 3.3.1. behandelt.

${ }^{23}$ Kero (1985, S. 27-37) hat acht offene Amerika-Briefe abgedruckt, die an die Zeitungsredaktion von 'Pohjois-Suomi' (Nord-Finnland) in Oulu gerichtet und zwischen 1879 und 1884 veröffentlicht wurden.
} 
Aufgrund der Tatsache, daß die Briefsammlungen aus Süd-Ostbottnien und Satakunta keine Briefe aus der Zeit vor 1882 beinhalten, wurden insgesamt 50 Jahrgänge von zwei finnischsprachigen und einer schwedischsprachigen Zeitung auf abgedruckte Auswandererbriefe aus der Zeit vor 1882 durchgesehen. Die im Auswanderungsgebiet vielfach rezipierten Wochenzeitungen Oulun Wiikko Sanomia (Ouluer Wochennachrichten) und Wasabladet (Vaasa-Blatt) wurden für den Zeitraum 1865-79 bzw. 1865-85 durchgesehen. Die finnischsprachige Zeitung ,Ouluer Wochennachrichten' zählt zu den ältesten Presseorganen Finnlands. Sie erschien in Oulu, der größten Stadt Nordfinnlands ab 1829 in zwei Phasen und wurde ein halbes Jahrhundert später, im Jahr 1879, eingestellt. Die schwedischsprachige Zeitung ,VaasaBlatt' dahingegen wurde 1858 in der Küstenstadt Vaasa in der Region Süd-Ostbottinien gegründet und erschien bis in das 20. Jahrhundert hinein ${ }^{24}$. Als dritte Wochenzeitung wurde das 1871 ins Leben gerufene finnischsprachige Blatt Keski Suomi (MittelFinnland) mit dem Erscheinungsort Jyväskylä für die Jahre 1871-85 auf mögliche Briefabdrucke hin ausgewertet, da diese Zeitung durch einen eigenen AmerikaKorrespondenten ungewöhnlich gut über den Werdegang der Pioniere unter den finnischen Amerikaauswanderern informiert gewesen war. Die Zeitung ,Keski-Suomi’ erscheint heute noch als regionale Tageszeitung unter dem Namen ,Keskisuomalainen'.

Die untersuchten 50 Jahrgänge der drei Zeitungen sind als Mikrofilmkopien in der Universitätsbibliothek Helsinki einsehbar.

Im Hinblick auf mögliche Amerika-Briefe fiel der Ertrag dieser Zeitungsauswertung jedoch gering aus: In insgesamt 50 Jahrgängen der drei Zeitungen wurden lediglich acht Briefe gefunden, davon sieben in den 'Ouluer Wochennachrichten' veröffentlicht ${ }^{25}$, die das Kriterium eines "echten" Auswandererbriefes erfüllten, d.h. wo eine Verfälschung des Briefinhaltes durch die Zeitungsredaktion mit großer Wahrscheinlichkeit ausgeschlossen werden konnte. Dieses Ergebnis verwundert auch insofern, als der früheste nachgewiesene Auswandererbrief am 23.3.1859 in den 'Ouluer Wochennachrichten' publiziert wurde, sich jedoch in norwegischen und schwedischen Zeitungen bereits um 1838 und in deutschen

\footnotetext{
${ }^{24} \mathrm{Zu}$ der „Ouluer Wochenzeitung“" siehe Tommila 1984; zu „Wasabladet“" vgl. Tommila 1988b, S. 192.

${ }^{25}$ Die entsprechenden Briefe wurden am 22.6.1865, 27.9.1865, 2.3.1868, 24.2.1870, 11.12.1871, 25.4.1875 und 3.4.1876 in 'Oulun Wiikko Sanomia' veröffentlicht. Ein weiterer Brief in schwedischer Sprache findet sich in 'Wasabladet' vom 4.7.1865.
} 
Tageszeitungen schon ab 1830 zahlreiche Briefabdrucke befanden ${ }^{26}$. Auch in anderen zeitgenössischen, finnischen Zeitungen sind für den Zeitraum 1860-85 kaum mehr Amerika-Briefe zu finden ${ }^{27}$, wonach die wenigen abgedruckten Briefe keinen nenneswerten Einfluß auf den Emigrationsprozeß gehabt haben dürften.

Diesen Eindruck bestätigen auch Interviewaussagen mit finnischen Aus- und Rückwanderern, die von verschiedenen Migrationsforschern sowohl in Amerika, als auch in Finnland geführt wurden. Diese Interviews liegen jedoch nur teilweise in transkribierter und veröffentlichter Form vor, wobei einige Feldforscher es vorgezogen haben, die Informationen aus den Befragungen in biographische Lebensberichte umzuschreiben. Myhrman ist es sogar gelungen einige seiner schwedischsprachigen Interviewpartner zum Abfassen von autobiographischen Aufzeichnungen zu gewinnen, die er im Originalzustand veröffentlicht hat ${ }^{28}$. Zahlreiche Zitate aus diesen verschiedenen, bereits publizierten Lebensberichten und Interviews sollen als wertvolle Ergänzungsquellen die hier primär behandelten Amerika-Briefe vervollständigen.

\footnotetext{
${ }^{26}$ Der nachweislich älteste, finnische Amerika-Brief ist bei Kero (1985, S. 12-14) abgedruckt. $\mathrm{Zu}$ jeweils mindestens 40-50 norwegischen und schwedischen Briefabdrucken vor 1850 siehe Blegen 1929, 1930, und 1931 (Bd.1) S. 197 sowie Stephenson 1929. In Deutschland erschien ab 1847 sogar eine Zeitschrift 'Der deutsche Auswanderer', die sich auf den Abdruck von interessanten Amerika-Briefen spezialisiert hatte, vgl. Nickisch 1991, S. 210; Helbich/Kamphoefner/Sommer 1988, S. 46.

${ }^{27}$ Über die hier vorgestellte Auswertung hinaus hat Kero (1985, S. 75) zwei weitere AmerikaBriefe in den schwedischsprachigen Zeitungen Åbo Underrättelser vom 25.10.1860 und Österbotten vom 16.11.1867 nachweisen können.

${ }^{28}$ Siehe Myhrman 1974, 8 Bde (Biographische und autobiographische Aufzeichnungen auf der Grundlage von Interviews zwischen 1939-50 in Amerika geführt); Ahlbäck 1976 (Interviews mit schwedischsprachigen Rückwanderern 1971 in Finnland geführt); Ketonen 1976 (Autobiographische Kurzessays 1975 als Wettbewerbseinsendungen von einem Geschichtsverein gesammelt); Virtaranta 1996 (Biographische Aufzeichnungen auf Interviewgrundlage 1965, 1975 und 1980 in Amerika und Kanada geführt im Zusammenhang mit Sprachstudien zum finnisch-amerikanischen Dialekt).

Auch die Briefsammlung von schwedischsprachigen Auswanderern aus Munsala (Nyström 1985) umfaßt biographische Aufzeichnungen zu Auswanderern, deren Lebenswege aus anderen Quellen rekonstruiert werden konnten.

251 Interviews hat Kero zwischen 1964-67 in Finnland und Amerika geführt. Sie befinden sich als Tonträger in den Archivbeständen des Seminars für allgemeine Geschichte der Universität Helsinki und sind nach Angabe von Prof. Kero bislang nicht veröffentlicht worden. Zur namentlichen Auflistung der Interviewten siehe Kero 1974, S. 248-254. Auch Penti hat für ihre Dissertation (1983) zahlreiche Interviews geführt und diese in Auszügen ausgewertet. Eine mögliche Veröffentlichung der Befragungen über die genannte Arbeit hinaus ist nicht bekannt.
} 


\subsection{Der Auswandererbrief als Kommunikationsmedium}

Das Briefmedium gehört in den Bereich der indirekten verbalen Kommunikation und ersetzt das persönliche Gespräch zweier Personen in zeitlich verzögerter Form ${ }^{29}$. Durch die schriftliche Fixierung der Gedanken des Briefschreibers wird im Brief das dem mündlichen Gespräch eigene Flüchtigkeitsmoment des eben Gesagten aufgehoben. Der Zwang zu einer zusammenhängenden und sinngebenden Formulierung führt zu einer kontrollierten Distanz des Briefschreibers zu seinem Brieftext. Zudem verleiht die schriftliche Fixierung den Gedanken des Schreibers eine Beständigkeit, die zu einer wohlüberlegten Formulierung zwingt. Dieser Charakter der Endgültigkeit steht in gewisser Weise im Widerspruch zur Vergänglichkeit der übermittelten Information ${ }^{30}$.

Da das Briefmedium auf nonverbale Mittel verzichten muß, steht es in seiner Funktionalität deutlich hinter der direkten Verbalkommunikation zurück. Auch andere gesprächsbegleitende Elemente wie Mimik, Gestik oder Veränderung der Stimmlage kann der Brief nicht vermitteln. Im Brief fungiert die Schriftsprache demnach als vorwiegende Übermittlungsinstanz für die Kommunikationsinhalte, wenngleich beigefügte Dokumente wie Zeitungsausschnitte oder Fotographien sowohl den Briefinhalt erklären als auch als eigenständige Träger von Kommunikationsinhalten angesehen werden können ${ }^{31}$.

Die beim Gespräch konventionalisierten Formen der Begrüßung und Verabschiedung finden in der Briefkommunikation als floskelhafte Anrede-, Gruß- und Abschiedsformeln ihren Gegenpart. Auch in finnischen Amerika-Briefen haben sich derartige Stilmittel etablieren können, die als stereotype Phrasen mit gleichem Wortlaut wiederholt zu finden sind. Der Hauptteil des Brieftextes beinhaltet dann die eigentlichen Informationen, die einen oder mehrere thematische Bezüge aufweisen und über- bzw.

\footnotetext{
${ }^{29}$ Die Literaturwissenschaft bedient sich der Klassifikationsform Textsorte für den Brief, da er sich im Sinne von sprachlicher Mitteilung als literarisches Produkt versteht. Im Gegensatz zum literarischen Werk zeichnet sich der Privatbrief weder durch Idealität und Fiktionalität, sondern durch Realität aus, wonach ihm der Rang einer spezifischen Literaturgattung abgesprochen wird, vgl. Bürgel 1976, S. 289f.; Nickisch 1991, S. 98-101; zur Textsortenklassifikation siehe Ermert 1979, S. 50-52. Zum Brief als Quellengattung für die sozialhistorische Forschung vgl. Djupedal 1989.

${ }^{30} \mathrm{Zu}$ Intention und Funktion einer Briefäußerung siehe Ermert 1979, S. 55; zum Charakter der Endgültigkeit einer Briefäußerung siehe Brinkmann 1971, S. 884.

${ }^{31}$ Zur Bildersprache von Auswanderer-Fotographien siehe Assion 1983.
} 
untergeordnet oder aber gleichwertig nebeneinander in Erscheinung treten können ${ }^{32}$. Dabei lassen sich die inhaltlichen Briefmitteilungen drei Ebenen zuordnen: Die Sachinformation konzentriert sich nüchtern auf den darzustellenden Gegenstand, der für beide Kommunikationspartner von Interesse ist, beispielsweise die Arbeitsverhältnisse oder der Hinweis auf eine Geldsendung. Die Emotionsinformation kommt einer Schilderung oder Kommentierung der Bewußtseinslage des Briefschreibers gleich. In der Regel war dies eine Selbstdarstellung, um dem Briefpartner ein bestimmtes Bild der eigenen Person zu vermitteln. In diesen Bereich fallen Bemerkungen zur Beurteilung der eigenen Lebensumstände sowie zu Heimwehäußerungen und damit verbundenen Rückwanderungsplänen. Die dritte Ebene, die Beziehungsinformation, wiederum befaßt sich mit dem sozialen Kontakt der Beteiligten zueinander und verkörpert die interaktivste Mitteilungsform, da ein direktes Eingehen auf den Briefpartner notwendig wird. Hier wären vor allem Nachfragen und Erkundigungen zu den sozialen Vorgängen im Heimatort zu nennen. Der Briefschreiber wollte auf diese Weise Anteil nehmen an einer Lebenswelt, die er zwar bereits hinter sich gelassen hatte, zu der er sich aber noch zugehörig fühlte.

Demnach ist jeder Briefwechsel als Dialog konzipiert. Bei größeren Sammlungen von Auswandererbriefen, wie auch im vorliegenden Fall, fehlen häufig die Antwortbriefe, wonach diese Briefserien eine einseitige Kommunikation repräsentieren. Die Wirkung des Briefinhalts auf den Empfänger kann allenfalls indirekt erschlossen werden, indem Äußerungen des Briefschreibers, die sich auf die erhaltenen Antwortbriefe beziehen, Anhaltspunkte für die Rezeption der Mitteilungen durch den "stummen" Briefpartner liefern.

Der Briefwechsel diente also in erster Linie der Aufrechterhaltung der sozialen Beziehung zwischen Auswanderern und Daheimgebliebenen und stellte, unter Ausschluß anderer, weil nicht vorhandener Medien, die einzige Möglichkeit zur Kontaktaufnahme dar: Ein Faktum das in der medientechnischen Gegenwart besondere Beachtung verdient.

\footnotetext{
${ }^{32}$ Briefinhalte und -stilmittel anhand der Sammlung 'Satakunta' werden von Penti (1978 S. 22 40) eingehend analysiert, wobei der Autorin die Mikrofilmkopien des IHRC in Minneapolis zur Verfügung standen. Siehe hierzu auch Kap. 3.5.1.
} 


\subsection{Der Quellenwert von Amerika-Briefen für die Migrationsforschung}

Die hier behandelten Amerika-Briefe werden als Quellendokumente privaten Charakters, als Privat- oder Alltagsbriefe ${ }^{33}$ verstanden, die im historischen Ereignisstrom entstanden sind und als Zeugnisse gesellschaftlicher Entwicklungen einen seltenen Einblick in die Alltagsgeschichte finnischer Unterschichten geben. Im Sprachgebrauch der qualitativen Sozialforschung handelt es sich um nicht-reaktive, prozeßproduzierte Daten, die im Gegensatz zum Interview nicht primär zu

Forschungszwecken erstellt worden sind. Zugleich stehen sie für die indirekte

Übermittlung eines sozialen Kontaktes aus einer Gesellschaft, mit welcher der Forscher keine eigene Wirklichkeitserfahrung verbindet ${ }^{34}$.

Die Briefanalyse fungiert demnach als Mittel zur Rekonstruktion einer sozialen Wirklichkeit, welche sowohl auf der kontextgebundenen Interpretation der Briefinhalte als auch der Kommunikationssituation beruht, die den Briefwechsel determiniert hat.

Von einigen wenigen Briefbeispielen abgesehen, die in finnischen Zeitungen publiziert wurden, sind die meisten Auswandererbriefe nicht im Hinblick auf eine spätere Veröffentlichung geschrieben worden, d.h. daß die Briefinhalte der AmerikaBriefe in der Regel einen hohen Wahrheitsgehalt aufweisen ${ }^{35}$. Da die Briefe vor allem auch als Instrument zur Auswandereranwerbung dienten, konnten die vom Briefverfasser beschriebenen Lebensverhältnisse alsbald von nachgewanderten Familienangehörigen kontrolliert werden.

Bei den hier behandelten Stichprobeneinheiten finden sich mehrere Briefserien, in denen die Schreiber auf abhanden gekommene Briefe verweisen. Die Briefserien sind demnach unvollständig. Doch auch eine vorab praktizierte, bewußte Selektion einzelner Briefe durch die Briefadressaten oder späteren Briefbesitzer, welche beispielsweise Verwandte der ursprünglichen Adressaten sein können, ist denkbar. Gerade bei langen Briefserien kann das eine oder andere Dokument mit Absicht vernichtet worden sein,

\footnotetext{
${ }^{33}$ Privatbriefe bezeichnen Briefe, die an konkrete Adressaten, d.h. an vom Briefschreiber intendierte Empfänger, gerichtet sind und nicht auf eine breite Öffentlichkeit zielen. Ihre Themenbereiche beziehen sich auf die Lebenswelten der Briefpartner, vgl. Bürgel 1976, S. 281-283; Götz/Löffler/Speckle 1993, S. 165f.; speziell zu Auswandererbriefen Schwarzmeier 1978, S. 306.

${ }^{34}$ Atteslander 1975, S. 65 und S. 70f.; Albrecht 1972b, S. 250-252.

${ }^{35}$ Der Wahrheitsgehalt wird auch für deutsche und schweizerische Amerika-Briefe hervorgehoben, vgl. Hoerder 1985b, S. 13; Helbich/Kamphoefner/Sommer 1988, S. 33 sowie Schelbert/Rappolt 1977, S. 29.
} 
um alle Eventualitäten eines späteren Lesens durch eine Drittperson auszuschließen, da nämlich das Herumreichen im Verwandten- und Bekanntenkreis eines aus Amerika erhaltenen Briefes durchaus üblich war. Die Briefrezeption durch ein größeres Publikum ist auch aus Schweden, Norwegen, Dänemark und Deutschland überliefert, jeweils Länder mit hohem Auswandereraufkommen ${ }^{36}$.

Für die Auswertung größerer Briefsammlungen, die zahlreiche Briefserien sowie Einzelbriefe verschiedener Verfasser umfassen, ist es jedoch von marginaler Bedeutung, ob die Briefserien vollständig oder aber lückenhaft erhalten geblieben sind. Vielmehr geht es um einen Querschnitt von Briefäußerungen, welche facettenartig verschiedene Standpunkte der Briefschreiber in ähnlichen Lebenssituationen darlegen und somit vor allem die Mentalitätsverhaftung der Briefschreiber zum Ausdruck bringen. In Form von Wahrnehmungsäußerungen und Stellungnahmen zum noch ungewohnten, neuen Lebensumfeld wird die Gesellschaft des Ziellandes aus einer Perspektive beurteilt, welche die Werte und Normen des Herkunftslandes der Emigranten reflektiert ${ }^{37}$. Zugleich wird die Intention eines Briefes durch die sozialen und gesellschaftlichen Norm- und Wertvorstellungen beeinflußt, die beide Briefpartner internalisiert haben, wonach Briefe verschiedener Autoren immer auch bestimmte Zeitströmungen bzw. kollektive Wertvorstellungen widerspiegeln.

Aus diesem Grund soll insbesondere der zweite Teil der vorliegenden Untersuchung von den beiden Hauptfunktionen des Mediums Auswandererbrief, der Aufrechterhaltung des "sozialen Bandes" zwischen Alter und Neuer Welt sowie der Bedeutung der Briefanwerbung als Antriebskraft für den Emigrationsprozeß, getragen werden. Zusammen mit dem ersten Teil, den Hintergrundsfaktoren der finnischen Auswanderungsbewegung, welche nicht zuletzt die Rahmenbedingungen der Briefkommunikation abgesteckt haben, wird hier ein möglichst weitgefasster Überblick

\footnotetext{
${ }^{36}$ Siehe zeitgenössische Gemäldedarstellungen in der Emigrationsliteratur, auf denen eine Person mit einem Brief in der Hand von einer Menschengruppe umringt wird, z. B. Stich von C. Geyer nach einer Zeichnung von A. Niedmann (um 1856) bei Mesenhöller 1985, S. 110; Gemälde von Jakob Kulle (1881) bei Hoerder/Knauf 1992, S. 42; Stich von unbekanntem, dänischen Künstler in 'Illustreret Tidende' (1888) bei Stilling/Olsen 1994, S. 127 sowie Fotographie dieser Szene bei Barton 1993, S. 139.

Blegen (1929, S. 6) führt ein Beispiel von 1843 an, in dem ein Amerika-Werbebrief eines Norwegers in mehreren hundert Abschriften unter den Einwohnern des Hardanger-Bezirks kursierte.

${ }^{37}$ Zum Aspekt der Mentalitätsverhaftung deutscher Auswanderer anhand von Reise- und Auswandererberichten vgl. Brenner 1991, S. 1-44, bes. S. 8-12. Brenner hat vor allem auf den Dualismus der zeitgleichen Mentalitätsverhaftung sowie der Reflexion der eigenen Mentalität, ausgelöst durch die Konfrontation mit der als fremd empfundenen Kultur, hingewiesen.
} 
über den komplexen Forschungsgegenstand der finnischen Amerikaauswanderung gegeben. 


\section{Auswanderung aus Finnland}

\section{$\underline{\text { 2.1. Finnland als autonomes Großfürstentum des russischen Zarenreichs }}$}

In den Jahren 1809 bis 1917 war Finnland als autonomes Großfürstentum ein Teil des russischen Zarenreiches. In der Mitte des 19. Jahrhunderts befand sich das Land in einer Phase der politischen Reformen und allgemeinen Liberalisierung . Formaljuristisch verband die beiden Länder eine Art Personalunion unter der Leitung des russischen Zaren, wobei der finnischen Regierung jedoch ein weitgehend eigenverantwortliches Handeln bei innenpolitischen Fragen zugestanden wurde.

Neben einem eigenen Landtag, der aus einer Vierständevertretung ${ }^{2}$ bestand, einer eigenen Verwaltung und einem nationalen Postwesen manifestierte vor allem eine eigene Zollgrenze die Einheit Finnlands. Als eigentliches Regierungsorgan richtete der Zar einen aus finnischen Staatsbürgern bestehenden Senat ein. Obwohl dieser die schwedische Sprache ${ }^{3}$ beibehalten durfte, war er, anders als der Landtag, dem Zaren direkt unterstellt. In St. Petersburg residierte ein finnischer Ministerstaatssekretär, der als Fürsprecher Finnlands vor Ort eine Vermittlerrolle zwischen beiden Regierungen einnahm. Noch einflußreicher war jedoch die Position des russischen Generalgouverneurs, repräsentiert durch einen russischen Staatsbürger aus gebildeten oder adeligen Kreisen. Er vertrat in Helsinki direkt die Interessen des Herrschers und war für die Finnen eine Schlüsselfigur in der Verständigung mit dem Monarchen. Zugleich führte der Generalgouverneur den Oberbefehl über die russischen Streitkräfte in Finnland ${ }^{4}$ und war somit für die Aufrechterhaltung der öffentlichen Ruhe und Ordnung im Land verantwortlich.

\footnotetext{
${ }^{1}$ Zur politischen Entwicklung von 1860-1917 siehe Jutikkala 1976, S. 265-343; Paasivirta 1978, S. 195-403; Klinge 1987, S. 55-105; Alapuro 1988, S. 19-139.

${ }^{2}$ Die Ständevertretung setzte sich aus Adel, Geistlichkeit, Bürgerschaft sowie grundbesitzendem Bauernstand zusammen und vertrat nur ein Drittel der Bevölkerung direkt, vgl. Alapuro 1988, S. $37 \mathrm{f}$.

${ }^{3}$ Die Vormachtstellung des Schwedischen als Sprache der Wissenschaft und Administration führte im Verlauf des 19. Jahrhunderts zu einem heftigen Sprachenstreit zwischen den Verfechtern des Finnischen als einziger Landessprache, den Fennomanen, und der zahlenmäßig geringen schwedischsprachigen Elite, den Svekomanen, vgl. Jutikkala 1987, S. 289-303. ${ }^{4}$ Zur Stellung der russischen Streitkräfte in Finnland vgl. Närhi 1985, bes. S. 161-167.
} 
Trotz der russischen Vormachtstellung in Finnland genossen russische Untertanen im Großfürstentum weder staatsbürgerliche Rechte noch konnten sie ohne Sondergenehmigung wichtige Positionen in Senat und Verwaltung einnehmen. Dennoch verfügten zahlreiche russische Adlige, u.a. die russische Zarenfamilie, über einen Sommersitz an der finnischen Ostseeküste ${ }^{5}$, ebenso wie auch russische Straßenhändler das Stadtbild von Helsinki prägten. Vielfältige Handelbeziehungen zu Rußland führten zu einer starken Arbeitsmigration von finnischen Facharbeitern und Handwerkern vor allem aus Ostfinnland nach St. Petersburg. Diese Wanderungsbewegungen blieben jedoch nur ein kurzzeitiges Phänomen, da sie bereits in den 1890er Jahren von der Amerikaauswanderung abgelöst wurden, obwohl das sogenannte "Amerikafieber" in Ostfinnland zu keiner Zeit dieselbe Dimension erreichte wie in den westlich und südwestlich gelegenen Regionen Finnlands.

\subsubsection{Politische Entwicklungen}

Zeitgleich überschlugen sich auch die politischen Ereignisse in Finnland. Hatte zu Beginn des 19. Jahrhunderts den drei ersten russischen Zaren noch daran gelegen, die finnischen Bestrebungen nach kultureller Einheit und Selbständigkeit zu unterstützen, um somit einen erneuten Anschluß Finnlands an Schweden zu verhindern, so blies der finnischen Autonomie bereits in den 1870er Jahren ein schärferer Wind entgegen.

Infolge einer innenpolitischen Krise billigten nicht mehr alle einflußreichen Kreise in St. Petersburg die Erweiterung der finnischen Sonderrechte. Zar Alexander II., der dritte von insgesamt fünf autokratischen Herrschern der finnischen Autonomieepoche, geriet im eigenen Land immer mehr in Bedrängnis, vor allem aufgrund des wachsenden Einflusses der panslawistisch orientierten Nationalisten ${ }^{6}$, die in der Folgezeit den politischen Kurs Rußlands bestimmen sollten. Nach Ermordung des

\footnotetext{
${ }^{5} \mathrm{Zu}$ den Russen in Finnland allgemein vgl. Turpeinen 1985; zur Sommervillenkultur siehe Hämäläinen 1985, S. 121-124; zur finnischen Arbeitswanderung nach Rußland siehe Engman 1983, S. 215-289; zu Finnen in St. Petersburg vgl. Juntunen 1986; Alapuro 1988, S. 59-61; Engman 1990 und 1992.

${ }^{6}$ Die Ideologie des Panslawismus basierte auf dem Gedanken der Brüderlichkeit aller slavischen Völker und deren Vormachtstellung in der Welt, vgl. Jutikkala 1976, S. 304f.; Stökl 1983, S. 508-515; Rommi 1986, S. 249f.; Nygård 1988, S. 546.
} 
Zaren im Jahr 1881 rückte dessen Sohn Zar Alexander III. ${ }^{7}$ in der Thronfolge nach. Dieser ließ liberale Reformen kaum noch zu und stellte die panslawistische Vereinigungspolitik mit dem Ziel der Russifizierung Finnlands in den Vordergrund seiner politischen Ziele. Als Zar Alexander III. 1894 nach dreizehnjähriger Amtszeit starb, bestieg als letzter Zar dessen ältester Sohn Nikolai II. ${ }^{8}$ den kaiserlichen Thron.

Zur gleichen Zeit zeichnete sich bereits der allmähliche Zerfall des zaristischen Herrschaftssystems ab, das durch ein rigides Festhalten an der Autokratie die längst überfällige Anpassung des Staates an die fortschreitenden Entwicklungen des wirtschaftlichen und gesellschaftlichen Lebens verhinderte. Außerdem befand sich Rußland gegen Ende des 19. Jahrhunderts in einer schwierigen außenpolitischen Situation. Es hatte zwar Frankreich als neuen Verbündeten an seiner Seite, doch der aus Deutschland, Österreich-Ungarn und Italien gebildete Dreibund versuchte Rußland zu isolieren. Und als Hauptfeind beherrschte England nicht nur die durch Stützpunkte gesicherten, wichtigsten Seewege, sondern konkurrierte vor allem mit den imperialistischen Interessen Rußlands in Zentralasien.

Vor diesem Hintergrund erschien die militärstrategische Bedeutung Finnlands als Schutzzone vor St. Petersburg in einem neuen Licht. So wurde denn auch 1898 die Position des Generalgouverneurs mit dem militärisch geschulten Panslawisten Nikolai I. Bobrikov besetzt, dem die Russifizierung Finnlands als Selbstzweck und oberstes Staatsziel galt ${ }^{9}$. Unliebsamen Ruhm brachte ihm sogleich das Februar-Manifest von 1899 ein. Diese neue Reichsgesetzgebung kam einer Auflösung der finnischen Verfassung gleich und blockierte die politische Einflußnahme des finnischen Landtages, Ministerstaatssekretärs und Senats ${ }^{10}$.

Nunmehr mit allen Vollmachten ausgestattet, erließ Zar Nikolai II. 1901 ein neues Wehrpflichtgesetz für Finnland, das den allgemeinen Wehrdienst in der russischen Armee vorsah. Diese Mißachtung der innenpolitischen Autonomie Finnlands bewirkte wiederum einen landesweiten Boykottaufruf, so daß die Musterungen in den

\footnotetext{
${ }^{7}$ Zur Amtszeit von Alexander III. vgl. Jutikkala 1976, S. 308-310; Halila 1986, S. 305-317; Olkkonen 1988, S. 546-549.

${ }^{8}$ Zur Amtszeit von Nikolai II. vgl. Halila 1986, S. 317-320; Apunen 1987, S. 135-213; Nygård 1988, S. 546-587; Alapuro 1988, S. 101-127.

${ }^{9}$ Bobrikovs Amtszeit von nur sechs Jahren hatte die völlige Demontage der finnischen Autonomie zum Ziel und wirkte weit über die Jahrhundertwende hinaus, vgl. Apunen 1987, S. 135-171; Nygård 1988, S. 549-552.

${ }^{10}$ Speziell zum Februar-Manifest und seinen Auswirkungen vgl. Tuominen 1960.
} 
folgenden beiden Jahren durch den passiven Widerstand eines Drittels aller einberufenen jungen Männer erschwert wurden ${ }^{11}$. Auch der rapide Anstieg der Auswandererzahlen, die im Jahr 1902 mit mehr als 23.000 Amerikaauswanderern eine Rekordspitze erreichten, kann als direkte Reaktion auf das Wehrpflichtgesetz von 1901 gewertet werden.

Während des jahrelangen Boykotts hatte der Generalgouverneur Bobrikov sich mit zaristischen Sondervollmachten ausstatten lassen, um die ohnehin schon strenge Zensur für Druckschriften verschärfen zu können ${ }^{12}$, sämtliche finnische Politiker inhaftieren oder in die sibirische Verbannung schicken zu lassen und die alleinige Entscheidungsgewalt in allen Fragen der Zivil- und Kommunalverwaltungen zu übernehmen, bis er 1904 einem Mordattentat zum Opfer fiel.

Zur gleichen Zeit war Rußland in den Russisch-Japanischen Krieg verwickelt und erlebte 1905 eine herbe Niederlage. Im Landesinnern organisierte die russische Arbeiterbewegung einen erfolgreich verlaufenen, mehrmonatigen Generalstreik ${ }^{13}$, der im gleichen Jahr von der finnischen Arbeiterbewegung nachgeahmt wurde ${ }^{14}$. Beunruhigt durch diese sich zuspitzenden Konflikte setzte der Zar schließlich im Jahr 1905 das umstrittene Wehrpflichtgesetz in Finnland wieder außer Kraft und gab den Forderungen der streikenden finnischen Arbeiterbewegung nach: Er widerrief sämtliche Erlasse, die auf der Grundlage des Februar-Manifestes von 1899 Gültigkeit gehabt hatten, und hob die diktatorischen Vollmachten des neueingesetzten Generalgouverneurs in Finnland auf.

Nachdem schließlich die noch von Bobrikov verbannten Politiker ihre alten Plätze wieder eingenommen hatten, konnte mit dem Entwurf für eine demokratische Landtagsordnung begonnen werden. Die praktische Umwandlung des Landtages in eine parlamentarische Demokratie fand bereits im Sommer 1906 statt $^{15}$. Die Anzahl der Stimmberechtigten wurde verzehnfacht, indem auch die finnischen Frauen das

\footnotetext{
${ }^{11}$ Juva 1960; Lauerma 1960, S. 139; Apunen 1987, S. 156.

${ }^{12}$ Zur Zensur als politisches Druckmittel siehe Leino-Kaukiainen 1984.

${ }^{13}$ Zur revolutionären Bewegung in Rußland vgl. Stöckl 1983, S. 567-591.

${ }^{14}$ Zum finnischen Generalstreik vgl. Soikkanen 1960, S. 176-186.

${ }^{15} \mathrm{Zu}$ den Anfängen des finnischen Parlamentarismus vgl. Jutikkala 1976, S. 333-337; Nygård 1988, S. 564-572; Apunen 1987, S. 201-213 und S. 242-250.
} 
Wahlrecht ${ }^{16}$ erhielten. Die ersten Wahlen wurden 1907 durchgeführt, aus denen die Sozialisten als stärkste Partei mit 80 von insgesamt 200 Parlamentssitzen hervorgingen.

Noch vollständig mit der Organisation des neuen Parlaments beschäftigt, bemerkten die Finnen erst 1908, daß die durch Bobrikov begonnene Russifizierungspolitik lediglich einen kurzzeitigen Aufschub genommen hatte ${ }^{17}$. Nachdem nämlich die revolutionären Kräfte im Inneren Rußlands erfolgreich unterdrückt worden waren, wagte die russische Regierung einen erneuten Vorstoß gegen die finnischen Sonderrechte. 1910 verabschiedeten die beiden Kammern ${ }^{18}$ des russischen Reichstages eine neue Gesetzesgrundlage, die in ihrer Schärfe das FebruarManifest von 1899 noch übertraf: Alle Finnland betreffenden Gesetze sollten fortan vom russischen Reichstag erlassen werden. Auch der finnische Senat setzte sich in der Folge nur noch aus russischen Politikern zusammen und nahm damit dem noch jungen finnischen Parlament jede Entscheidungsgewalt. Nach Bekanntgabe der neuen Verordnungen breitete sich in Finnland eine resignative Stimmung aus, die sowohl politische Kreise als auch die Bevölkerung erfasste.

Die Maßnahmen der russischen Regierung waren in erster Linie durch militärstrategische Interessen motiviert. Da von dem zunehmend in die Isolation gedrängten, deutschen Kaiserreich eine neue Bedrohung für Rußland auszugehen schien, galt es, sowohl den Ostseezugang über finnisches Territorium zu sichern als auch die prodeutschen Sympathien des schwedischen Königs im Auge zu behalten. Vor diesem Hintergrund schien es folgerichtig, Finnland vollständig in das russische Imperium zu integrieren. Mit einem 1912 erlassenen Gleichberechtigungsgesetz ${ }^{19}$, das russischen Untertanen in Finnland sämtliche staatsbürgerliche Rechte einräumte, hatten die russischen Vereinigungsbefürworter schließlich ihr Ziel erreicht: Neben dem finnischen Senat wurden nun auch alle Verwaltungsposten mit russischen Beamten neu besetzt sowie ein russischer Prokurator auf das höchste Richteramt in Finnland berufen.

\footnotetext{
${ }^{16}$ Finnland war das erste europäische Land, das das Frauenstimmrecht einführte, vgl. Jutikkala 1976, S. 334; Apunen 1987, S. 243.

${ }^{17}$ Zur Veränderung der Machtverhältnisse in der russischen Regierung und den Auswirkungen auf Finnland vgl. Jutikkala 1976, S. 337-341; Paasivirta 1978, S. 374-382; Nygård 1988, S. $573-$ 578.

${ }^{18}$ Der Ministerrat sowie die beiden Kammern des russischen Reichstages, die Duma und der Kaiserliche Reichsrat, beeinflußten die politischen Entscheidungen der Folgezeit, vgl. Nygård 1988, S. 573-578.

${ }^{19}$ Die erneute Verschärfung der Russifizierungspolitik resultierte vor allem aus außenpolitischen Problemen Rußlands mit Österreich-Ungarn, vgl. Nygård 1988, S. 576.
} 
Erst der Ausbruch des Ersten Weltkrieges unterbrach den Russifizierungsprozeß, da innenpolitische Umwälzungen und Kriegsverluste die russische Regierung zunehmend schwächten. Die Finnen, welche nicht aktiv Krieg führten, richteten ihre Energie auf die Unterstützung revolutionärer Kräfte im In- und Ausland, um sich entgültig von der russischen Vorherrschaft lösen zu können. Obwohl dieser Prozeß auch in Finnland mit innenpolitischen Konflikten, die letztendlich in den Bürgerkrieg von 1918/19 mündeten, verbunden war, leitete er dennoch den Weg in die nationale Unabhängigkeit ein, die kurz nach der russischen Oktoberrevolution am 6. Dezember 1917 in Helsinki proklamiert wurde.

Bemerkenswerterweise erlebte die finnische Kultur um die Jahrhundertwende eine einzigartige Blütezeit. In der Malerei, bildenden Kunst, Architektur, Musik und Literatur wurden neue Werke geschaffen, die zu internationalem Ruhm gelangten ${ }^{20}$. Die nationale und kulturelle Abgrenzung zu Rußland entwickelte sich zum Hoffnungsträger für eine ganze Generation.

\subsubsection{Die beginnende Industrialisierung und Strukturveränderungen in der Landwirtschaft}

Im europäischen Vergleich setzte die finnische Industrialisierung relativ spät ein. Ihr Beginn wurde vor allem durch die geringe Bevölkerungsdichte des Landes sowie den Mangel an natürlichen Bodenschätzen und notwendigem Kapital zur Unternehmensgründung verzögert. Obwohl die ersten Schritte zur Industrialisierung bereits in den 1830er Jahren erfolgt waren, erlebte die Industrie erst in den 1870er Jahren einen deutlichen Produktionsanstieg, als der Einsatz von Maschinen den Übergang von Manufakturen zu Fabriken ermöglichte und verbesserte Verkehrsverbindungen den Außenhandel intensivierten ${ }^{21}$. Die Grundlage für diese Entwicklungen ist vor allem in der Erneuerung des Geldwesens ${ }^{22}$ zu sehen. Bereits 1865

\footnotetext{
${ }^{20}$ Vor allem die Weltausstellung in Paris 1900 ermöglichte es den Finnen, ihre kulturelle Eigenständigkeit unter Beweis zu stellen und den für diese Epoche typischen Stil der finnischen Nationalromantik, der sowohl in der Architektur, Literatur als auch in der Malerei seinen Ausdruck fand, zu repräsentieren, vgl. Koskimies 1960; Reitala 1987, bes. S. 30f.; Kallio 1988.

${ }^{21}$ Zur Entwicklung der finnischen Wirtschaft und des Außenhandels vgl. Heikkinen/Hoffman 1982; Rasila 1982, S. 89-113, Apunen 1987, S. 73-102; Olkkonen 1988, S. 514-518.

${ }^{22}$ Zur Reform des Geldwesens in Finnland siehe z. B. Jutikkala 1976, S. 296f.; Rasila 1982, S. 103-105; Olkkonen 1988, S. 512f.
} 
hatte Finnland praktisch eine eigene Währung, doch bis 1878 blieb in Finnland offiziell der russische Silberrubel gültig, als nämlich die Goldwährung eingeführt wurde. Fortan hatte das finnische mit dem russischen Münzwesen keine Gemeinsamkeit mehr. Zur gleichen Zeit enlasteten zahlreiche Gründungen von Geschäftsbanken und Sparkassen die finnische Zentralbank, da sie die Basis für Industrieinvestitionen sowie die Möglichkeit von privaten Spareinlagen für die arbeitende Bevölkerung schufen.

Von den wichtigsten Industriezweigen Finnlands kam der Textilindustrie eine Vorreiterrolle zu. Die erste Baumwolle und Leinen verarbeitende Fabrik wurde 1828 in Tampere gegründet, das sich schon bald zur ersten industriellen Metropole Finnlands entwickelte $^{23}$. Die Textilindustrie war von Beginn an auf großindustrielle Produktion angelegt und spezialisierte sich neben der Metallindustrie schon früh auf das Exportgeschäft mit Rußland ${ }^{24}$, dessen eigener industrieller Entwicklungsstand zu dieser Zeit noch deutlich hinter dem Finnlands zurückstand. Auf die finnische Warenausfuhr wirkte eine 1859 erlassene Zollverordnung impulsfördernd, die zahlreichen finnischen Handelswaren, im Gegensatz zu anderen europäischen Ländern, Zollfreiheit garantierte. In der Folgezeit bestand der finnische Außenhandel etwa zur Hälfte aus den Exporten nach Rußland, wobei vor allem die Hauptstadt St. Petersburg als Verbraucherzentrum beliefert wurde ${ }^{25}$. Hier war es insbesondere eine erhöhte Nachfrage nach Maschinen für die russische Landwirtschaft, Industrie, Schiffsbau sowie für die Rüstungsindustrie, die der finnischen Metallindustrie bis über die Jahrhundertwende hinaus einen Aufwärtstrend garantierte ${ }^{26}$.

Im Jahr 1885 jedoch führten das veränderte politische Klima sowie eine wirtschaftliche Krise in Rußland zu einer ersten Zollerhebung für finnische Waren. Die Folge war eine Umorientierung der finnischen Wirtschaft auf den einheimischen Markt, wo die private Kaufkraft mittlerweile gestiegen war, da vor allem die Gewinne aus der Holzindustrie der landbesitzenden Bevölkerungsgruppe zu einem unverhofften Wohlstand verholfen hatten.

\footnotetext{
${ }^{23}$ Lebten um Mitte des 19. Jahrhunderts nur etwa 3.000 Einwohner in der Stadt, so waren es um die Jahrhundertwende bereits 35.000 Personen. Auch andere große Industrie- und Hafenstädte wie Helsinki, Turku und Viborg verdoppelten ihre Einwohnerzahlen, insbesondere um 18801900, vgl. Apunen 1987, S. 77; Jaakkola 1987.

${ }^{24}$ Zur Bedeutung des russischen Absatzmarktes vgl. Apunen 1987, S. 84-92.

${ }^{25}$ Engman 1990, S. 75.

${ }^{26}$ Heikkinen/Hoffman 1982, S. 70-73.
} 
Die Entwicklung der finnischen Holzindustrie ${ }^{27}$ hingegen stand sowohl in engem Zusammenhang mit dem zügig vorangetriebenen Gleisausbau für die Eisenbahn als auch dem expandierenden Städtebau. Zudem setzte zur gleichen Zeit eine wirtschaftliche Neuorientierung in Richtung Westeuropa ein, die vor allem auf Butterund Holzexporten beruhte. Hand in Hand mit der zunehmenden Dampfschiffahrt sanken die Preise für Frachtgut, als Folgeerscheinung des Deutsch-Französischen Krieges stieg in Mitteleuropa die Nachfrage nach Bauholz rapide an ${ }^{28}$, und England lockte mit einer Freihandelspolitik ${ }^{29}$ ausländische Importwaren an, um die eigene Industrie zu stärken und somit eine führende Marktposition in Europa einnehmen zu können.

Holz als einziger natürlicher Rohstoff war vor allem in Mittelfinnland reichlich vorhanden, wo in ländlichen Gebieten zahlreiche, zunehmend mit Dampfkraft betriebene Sägewerke entstanden. Als Veredelungsprodukt der Holzindustrie ließ sich vor allem Papier auf dem europäischen Markt und in Rußland gut verkaufen. Nachdem die Papierherstellung auf chemische Verfahren umgestellt hatte, erreichte finnisches Papier bereits gegen Ende der 1890er Jahre eine internationale Spitzenqualität und entwickelte sich neben Holz zum wichtigsten Exportgut der Industrie.

Als Innovation für die industrielle Entwicklung schlechthin kann die Verbesserung der inländischen Verkehrsverbindungen angesehen werden. Dazu gehörten sowohl der Ausbau des finnischen Eisenbahnnetzes als auch die 1856 erfolgte Fertigstellung des Saima-Kanals, der einen direkten Zugang von der Ostseeküste, dem Nadelöhr zum Weltmarkt, zum Gebiet der Saima-Seen und damit zum finnischen Inland schuf. Nachdem 1862 die erste Eisenbahnverbindung zwischen Helsinki und Hämeenlinna in Betrieb genommen wurde, zweigte davon acht Jahre später die Streckenverbindung Helsinki - Viborg - St. Petersburg ab, die dem Außenhandel und Personenverkehr in Richtung Osten neue Impulse verlieh ${ }^{30} .1891$ wurde dann die Eisenbahnstrecke über Vaasa nach Oulu fertiggestellt, was für den Reisebeginn der finnischen Amerikaauswanderer aus Süd-Ostbottnien maßgeblich war und die

\footnotetext{
${ }^{27}$ Zur Bedeutung der Holzindustrie als Wirtschaftsfaktor siehe Heikkinen/Hoffman 1982, S. 6070.

${ }^{28}$ Rommi 1986, S. 215; Virrankoski 1983, S. 152.

${ }^{29}$ Bereits 1866 hob Großbritannien sämtliche Zollschranken auf, vgl. Halila 1986, S. 232.

${ }^{30}$ Zum finnischen Streckennetz siehe Karte 3 im Anhang: Das finnische Eisenbahnnetz 18621925.
} 
Massenauswanderung nach Übersee während der folgenden drei Jahrzehnte erst ermöglichte ${ }^{31}$.

Von dem Aufschwung der finnischen Wirtschaft im Zuge der einsetzenden Industrialisierung zeugt auch der achtfache Anstieg der Industriearbeiteranzahl in den Jahren 1860-1913 ${ }^{32}$. Bereits 1860 überstieg die Anzahl der Industriearbeiter die ebenfalls im Aufwärtstrend liegende Anzahl der Handwerker ${ }^{33}$, welche besonders in ländlichen Gebieten zunahm, ihren Höhepunkt aber erst 1939 erreichte.

Die traditionellen Handwerksberufe, welche aufgrund einer merkantilistischen Wirtschaftspolitik anfangs vorwiegend in den Städten angesiedelt waren ${ }^{34}$, erhielten durch die expandierende industrielle Güterproduktion keine ernstzunehmende Konkurrenz. Die Produktionsbereiche des Handwerks waren nämlich in erster Linie auf den alltäglichen Gebrauchsgüterbedarf der Bevölkerung zugeschnitten. Mit zunehmendem Erstarken der Geldwirtschaft, vor allem in ländlichen Gebieten, lösten handwerklich gefertigte Waren allmählich in Heimarbeit produzierten Gebrauchsgüter ab. Gegen Ende des 19. Jahrhunderts arbeiteten etwa die Hälfte aller Handwerker in ländlichen Gemeinden, vorwiegend in den Berufsfeldern des Schusters, Schneiders, Eisenschmiedes, Gerbers und Möbeltischlers. Lebten die meisten Handwerker anfangs zugleich von der Landwirtschaft, so stieg mit zunehmender Etablierung des Handwerks im ländlichen Raum auch die Anzahl der selbständigen Gewerbetreibenden ${ }^{35}$.

Zusammenfassend läßt sich festhalten, daß sich in den Jahren 1860-1913 neben der anwachsenden Anzahl an Industriearbeitern und Handwerkern auch das erwirtschaftete Bruttosozialprodukt des Landes verfünffachte ${ }^{36}$. Die holzverarbeitende Industrie entwickelte sich schon bald zum wichtigsten Standpfeiler der finnischen

\footnotetext{
${ }^{31} 1890$ verzeichnete die finnischen Eisenbahngesellschaft etwa 2,5 Millionen Fahrgäste und eine Million Tonnen Waren mit steigender Tendenz. Zum Ausbau des finnischen Eisenbahnnetzes siehe Klövekorn 1960, S. 190-197; Rasila 1982, S. 122-125; Halila 1986, S. 216-220; Olkkonen 1988, S. 509; Turpeinen 1991, S. 131-140.

${ }^{32}$ Hjerppe 1981, S. 219.

${ }^{33} \mathrm{Da}$ in der industriellen Frühphase der Übergang von handwerklicher zu industrieller Produktion noch fließend war, galten Einrichtungen mit weniger als fünf Beschäftigten als Handwerksbetriebe, vgl. Pulma 1988, S. 438f.

${ }^{34}$ Soininen 1974, S. 25. Dieser Zustand änderte sich erst nach 1859, als die Ausübung von ländlichem Handel und Handwerk ohne Einschränkungen gestattet wurde, vgl. Hjerppe 1981, S. $216 f$.

${ }^{35}$ Siehe hierzu die Mikrostudie zur Gemeinde Huittinen im Süden der Provinz Satakunta, Alapuro 1995, S. 37-39.

${ }^{36}$ Alapuro 1988, S. 31.
} 
Wirtschaft sowie zur Grundlage für das nach Westeuropa und nach Rußland orientierte Exportgeschäft.

Das Erstarken der Holzindustrie hatte jedoch auch Folgen für die finnische Landwirtschaft $^{37}$ : Aufgrund verstärkter Nachfrage aus der Metall- und Textilindustrie stieg nämlich innerhalb kurzer Zeit der Wert sowohl von Rohholz als auch von Waldgrundstücken deutlich an. Durch diese neugewonnene Kapitalquelle konnten zahlreiche Grundbesitzer, die neben Ackerland auch über Waldgrundstücke verfügten, die landwirtschaftliche Umstrukturierung ${ }^{38}$ vom traditionellen Brotgetreideanbau zur Milchviehwirtschaft und dem damit einhergehenden Futtermittelanbau durchführen.

Dabei ging es in erster Linie um eine Schwerpunktverlagerung innerhalb der drei Wirtschaftsbereiche Getreideanbau, Milchvieh- und Forstwirtschaft. Der Brotgetreideanbau rangierte nunmehr an letzter Stelle, da sich das mit veralteten Anbaumethoden gewonnene Getreide nicht mehr verkaufen ließ, nachdem billiges russisches und auch deutsches Importgetreide den finnischen Markt überschwemmte. Um die Jahrhundertwende mußten durchschnittlich 50\% des notwendigen Brotgetreides, d.h. Weizen, Gerste und Roggen, eingeführt werden ${ }^{39}$. Die waldreichen Regionen Finnlands, in denen die Schwende eine lange Tradition hatte, waren auf den Getreideankauf besonders angewiesen, wenngleich der Zukauf von Getreide auch in den traditionellen Ackerbauregionen Finnlands, beispielsweise in den Provinzen SüdOstbottnien und Satakunta, praktiziert wurde ${ }^{40}$.

Im Zuge der Erweiterung des Futtermittelanbaus wurde ab den 1870er Jahren verstärkt auf Hafer und Heu gesetzt, um durch eine bessere Winterfütterung die Milcherträge zu steigern. Gleichzeitig führte ein erweitertes Fachwissen um landwirtschaftliche Produktionssteigerung durch bewußte Rindviehzüchtungen zu neuen, mit europäischen Kühen gekreuzten Kuhrassen. Nach Erfindung der Milchzentrifuge gewann Butter als landwirtschaftliches Produkt an Bedeutung, sowohl

\footnotetext{
${ }^{37}$ Zur Verflechtung von Land- und Forstwirtschaft vgl. Soininen 1982, S. 47-51; Talve 1983, S. 458-462.

${ }^{38}$ Zur Umstellung auf Milchviehwirtschaft vgl. Soininen 1982, S. 30-46.Um die Jahrhundertwende waren etwa ein Drittel der vorhandenen Ackerbauflächen dem Heuanbau vorbehalten, aber auch Hafer wurde doppelt so häufig angebaut wie Weizen und Roggen, vgl. Kananen 1981, S. 238; Talve 1983, S. 447.

${ }^{39}$ Rasila 1982, S. 141.

${ }^{40}$ Toivonen 1963, S. 81; Kero 1970, S. 63 (unveröffentlichte Lizentiatsarbeit).
} 
für den einheimischen Markt als auch für den Export. Als Handelsziele galten in erster Linie Dänemark, England und Rußland ${ }^{41}$.

Der Verkauf von landwirtschaftlichen Produkten nach Schweden, vor allem von Fleisch und Butter, hatte lediglich aus der Region Süd-Ostbottnien eine gewisse Tradition. Aus diesem Grund trafen die durch die schwedische Krone errichteten Zollschranken im Jahr 1888 die südostbottnische Landwirtschaft hart, da die günstigen Exportmöglichkeiten nach Schweden auf einen Schlag entfielen und somit die landwirtschaftliche Wettbewerbsfähigkeit der Provinz Süd-Ostbottnien deutlich abnahm $^{42}$.

Im Hinblick auf das ganze Land führte die Umstellung der Landwirtschaft auf den vorwiegenden Futtermittelanbau jedoch zu einer Vergrößerung der vorhandenen Ackerbauflächen sowie zur Gewinnung neuer Felder durch Brandrodung und Austrocknung von Sümpfen und Seeufern. Zudem bewirkte der Einsatz von industriell gefertigten Werkzeugen sowie gegen Ende des Jahrhunderts auch von landwirtschaftlichen Maschinen eine deutliche Produktionssteigerung bei gleichzeitiger Verringerung von Arbeitskräften ${ }^{43}$.

\subsubsection{Die Sozialstruktur der Landbevölkerung}

Während der gesamten Autonomieepoche bestritt der überwiegende Teil der finnischen Bevölkerung seinen Lebensunterhalt aus der Landwirtschaft, wenngleich die Gesellschaft in der für diese Untersuchung relevanten Jahren von 1865-1914 einschneidenden Veränderungen ausgesetzt war. Diese Zeitspanne wurde vor allem durch Strukturveränderungen der Landwirtschaft und ein rapides

Bevölkerungswachstum geprägt, deren wechselseitiger Einfluß als eine Ursache der Massenemigration nach Übersee gewertet werden kann. Ernährte die Landwirtschaft 1860 noch 82\% der finnischen Gesamtbevölkerung, so erhielten 1910 nur noch rund $71 \%$ ihre Lebensgrundlage aus der Landwirtschaft ${ }^{44}$.

\footnotetext{
${ }^{41}$ Zum Butterexport vgl. Soininen 1982, S. 44f.; Apunen 1987, S. 53f.

${ }^{42}$ Soininen 1974, S. 400-402; Kummel 1980, S. 447.

${ }^{43}$ Beispielsweise konnte eine von zwei Pferden gezogene Mähmaschine bis zu zehn Arbeitskräfte ersetzen, vgl. Soininen 1982, S. 37.

${ }^{44}$ Kananen 1981, S. 242; Rasila 1982, S. 140.
} 
Das jährliche Bevölkerungswachstum hingegen zeigte einen konstanteren Trend: Es lag zwischen 1860-90 noch bei durchschnittlich 1\% und reduzierte sich nach 1890 auf $0,9 \%$, um diesen Stand bis in die erste Hälfte des 20. Jahrhunderts zu halten ${ }^{45}$. Die vor 1890 kontinuierlich anwachsenden Bevölkerungszahlen erlebten lediglich in den Jahren 1866-68 einen Einbruch, der auf eine katastrophale Hungersnot verbunden mit Typhus- und Ruhrepidemien zurückzuführen ist ${ }^{46}$, und kurzzeitig lag der jährliche Anteil der Verstorbenen deutlich über der Geburtenrate. Da die meisten Opfer der Hungersnot Säuglinge waren, nahm der Umfang der Säuglingssterblichkeit erst nach 1871 kontinuierlich $\mathrm{ab}^{47}$.

In den beiden Jahrzehnten 1870-90, einer Zeitspanne, in der auch die spätere Auswanderergeneration geboren wurde, wuchs die Bevölkerung schneller als in den übrigen Dekaden des 19. Jahrhunderts. 1879 wurde dann erstmals die Bevölkerungsgrenze von zwei Millionen erreicht ${ }^{48}$. Die Geschwindigkeit des finnischen Bevölkerungswachstums überstieg auch den gesamteuropäischen Durchschnitt. Diese Entwicklung hatte bereits im 18. Jahrhundert begonnen und ist auf einen starken Geburtenüberschuß, hervorgerufen durch ein allgemein niedriges Heiratsalter der finnischen Frauen, zurückzuführen ${ }^{49}$. Im Gesamtzeitraum 1860-1914 hatten sich sowohl die Bevölkerung als auch die Besiedlungsdichte des Landes fast verdoppelt ${ }^{50}$.

In den Städten vervielfachte sich die Einwohnerschaft durch Zuzug von grundbesitzlosen Landarbeitern besonders schnell, was sowohl als Indiz für den wachsenden Bevölkerungsdruck auf dem Land als auch für die rasche Entwicklung der städtischen Industrie gegen Ende der zweiten Jahrhunderthälfte zu werten ist.

\footnotetext{
${ }^{45}$ Rasila 1982, S. 135; Pitkänen 1994, S. 48, Tab. 2.2.

${ }^{46}$ Als detallierte Studie über die Hungerjahre und ihre sozialen Auswirkungen siehe Turpeinen 1986; Halila 1986, S. 203-205.

${ }^{47}$ Die Säuglingssterblichkeit sank von 20,6\% (1871-75) auf 13,1\% (1901-05) vgl. Rasila 1982, S. 133; Koskinen 1994, S. 323, Tab. 8.

${ }^{48}$ Interessant ist auch die Beobachtung, daß 68 Jahre vergehen mußten (1811-79), ehe die Bevölkerung von ein auf zwei Millionen angewachsen war. In weniger als der Hälfte der Zeit, in 32 Jahren (1880-1912), vermehrte sie sich dann um eine weitere Million, vgl. Vattula 1983, S. 17-19, Tab. 1.3.

${ }^{49}$ Valkonen 1985b, S. 14f.; Pulma 1988, S. 416; Pitkänen 1994, S. 43.

${ }^{50}$ Die Bevölkerung war in absoluten Zahlen von 1.746700 (1860) auf 3.069500 Personen (1914) angewachsen, wobei in den Zahlenwerten ab 1890 bereits die auswanderungsbedingte Dezimierung der Bevölkerung (Nettoauswanderung) berücksichtigt wurde, vgl. Vattula 1983, S. 17-19, Tab. 1.3.
} 
Obwohl der Industrialisierungsprozeß vor 1860 begonnen hatte, stieg die Anzahl der Industriearbeiter erst gegen Ende des 19. Jahrhunderts deutlich an, was mit einem Wachstum der städtischen Bevölkerung einher ging ${ }^{51}$ : In den Jahren 1860-1910 verdoppelte sich auch der Anteil der Stadtbewohner an der Gesamtbevölkerung von 6\% auf $15 \%{ }^{52}$. Der Anteil der in städtischer Industrie, Handwerk oder Bausektor arbeitenden Bevölkerung stieg im gleichen Zeitraum entsprechend von 5\% auf $13 \%$ an. Eine ähnliche Entwicklung fand auch in den Bereichen Handel, Verkehr und Dienstleistungssektor statt ${ }^{53}$.

Hinsichtlich der Bevölkerungsentwicklung erlebten die alten Küstenstädte die größten Zuwachsraten, im Inland expandierte lediglich die älteste Industriemetropole Finnlands, die Stadt Tampere. Das schnelle Wachstum der urbanen und zugleich industriellen Zentren wirkte sich auch auf den Anteil der in Land- und Forstwirtschaft arbeitenden Bevölkerungsgruppe aus: Während der Anteil der Industriearbeiter stetig zunahm, sank der prozentuale Anteil derjenigen Bevölkerungsgruppen, die ihren Lebensunterhalt aus dem Agrarbereich bestritt, obwohl sie noch immer die Mehrheit der Bevölkerung darstellten.

Gleichzeitig ging der größte Teil der um durchschnittlich 1\% pro Jahr anwachsenden Bevölkerung zu Lasten der ärmsten Bevölkerungsgruppe, der grundbesitz- und wohnsitzlosen Landarbeiter. Demzufolge verarmte die Landbevölkerung zunehmend und es enstand ein am Existenzminimun lebendes Landarbeiterproletariat, das aus demographischer Sicht eine relative Überschußbevölkerung darstellte. Die regional vorhandenen Erwerbsmöglichkeiten konnten dieser Bevölkerungsgruppe keine dauerhafte Lebensgrundlage bieten. Nachdem die Innovationen in der Landwirtschaft gegen Ende des 19. Jahrhunderts zu greifen begannen und immer mehr Maschinen die Arbeitskräfte verdrängten, verschlechterte sich die Situation für die landlose Bevölkerung sogar dahingehend, daß für immer mehr Menschen immer weniger Beschäftigungsalternativen vorhanden waren.

Da zudem die Verteilung der vorhandenen Aufgabenfelder ausschließlich in den Händen der Landbesitzenden lag und von deren Primärinteressen getragen wurde,

\footnotetext{
${ }^{51}$ Zur Entwicklung von Industrialisierung und Urbanisierung vgl. Jutikkala 1983, S. 14-17.

${ }^{52} \mathrm{Im}$ Jahr 1916 betrug der Anteil der Stadtbewohner bereits 21\%, vgl. Vainio 1978, S. 96; Virrankoski 1983, S.157.

${ }^{53}$ Rasila 1982, S. 140, Tab. 24; Pitkänen 1994, S. 58.
} 
waren die Beschäftigungsverhältnisse meist nur von kurzer Dauer, so daß die saisonale Arbeitslosigkeit zur Lebensrealität eines Großteils der landlosen Bevölkerung zählte. In dieser Situation half es auch nicht, daß in der Zeitspanne 1878-1913 die Tageslöhne sowohl für männliche als auch für weibliche Landarbeiter um durchschnittlich $70 \%$ bis $80 \%$ angestiegen waren ${ }^{54}$, denn nur eine kontinuierliche Vollbeschäftigung hätte zu einem deutlichen Anstieg des allgemeinen Lebensstandards der landlosen Bevölkerungsgruppen führen können.

Die Landbesitzer dahingegen profitierten von dem steigenden Waldwert, was ihnen das notwendige Grundkapital für den Erwerb von landwirtschaftlichen Maschinen einbrachte. Im Trend der Zeit reduzierten sie ihr Arbeitskräftepotential, um mit Hilfe der neuen Technologie Modernisierungsmaßnahmen in der Landwirtschaft durchzuführen. Zugleich gelang es ihnen, vor allem im Bereich der Milchviehwirtschaft, die landwirtschaftliche Produktion allmählich zu steigern. Ihre daraus resultierende, gesicherte bis wohlhabende Existenzposition vergrößerte noch den sozialen Unterschied zwischen den Landbesitzenden und den Landlosen in einer bis dahin unbekannten Weise.

Obwohl die Landbevölkerung, die ab 1890 auch den größten Teil der Amerikaauswanderer stellte, in erster Linie aus den beiden Hauptgruppen Landbesitzende und Landlose bestand, war sie in mehrere heterogene Sozialgruppenunterteilt ${ }^{55}$. Unterschied sich die Gruppe der Landbesitzenden vor allem durch die Größe des Grundbesitzes und die gesellschaftliche Stellung des Hausherrn, so läßt sich die Gruppe der Landlosen, die aufgrund mangelhafter Erwerbsalternativen von den Arbeitsangeboten der Landbesitzer abhängig war vor allem in festangestellte Landarbeiter und Dienstboten sowie sporadisch beschäftigte Tagelöhner einteilen.

Während des gesamten 19. Jahrhunderts profitierten lediglich die Landbesitzenden ${ }^{56}$, in erster Linie die Großbauern und Gutsherren, von dieser

\footnotetext{
${ }^{54}$ Soininen 1981, S. 98.

${ }^{55}$ Die deutsche Übersetzung der finnischen Terminologie für die Sozialgruppen ist problematisch, da die verwendeten deutschen Begriffe eine nuanciert andere Bedeutung haben können. Eine knappe Gegenüberstellung der englischen Termini soll den hier verwendeten deutschen Sprachgebrauch verdeutlichen: Landbesitzer, Bauer, Gutsherr = farmer; Pachtbauer $=$ crofter; Kätner = cottager; Instmann = tenant; wohnsitzloser Tagelöhner $=$ lodger; Knecht $=$ farmhand; Magd $=$ maid; Dienstbote $=$ servant; Landarbeiter $=$ workman. $\mathrm{Zu}$ dieser Problematik siehe auch Virtanen 1979, S. 99-102.

${ }^{56}$ Im Gegensatz zur landlosen Bevölkerungsmehrheit wurden die Großbauern im finnischen Landtag, einer Vier-Stände-Vertretung, bis 1906 durch einen eigenen Stand repräsentiert.
} 
Gesellschaftsordnung. Hatte der Bauer oder Großbauer meist einen oder mehrere Pachthöfe auf seinem Grundstück sowie einige Knechte und Mägde beschäftigt, so unterstand dem Gutsherren zudem noch eine ganze Schar von unselbständigen Landarbeitern und landwirtschaftlichen Angestellten, deren Arbeit durch Vorsteher koordiniert und überwacht wurde. Der Gutsherr selbst ging häufig einer nicht an die Landwirtschaft gebundenen Tätigkeit nach.

Das soziale Gefälle unter der landlosen Bevölkerung war groß, ebenso wie sich der Übergang von einer Sozialstufe zur nächsten fließend vollzog. Für eine gehobenere Stellung in der Sozialhierarchie der Landlosen war das Nutzungsrecht eines Wohngebäudes auf dem Grundbesitz des Arbeitgebers ausschlaggebend. Demnach führten die Pachtbauern ${ }^{57}$ das Sozialgefüge an, da sie nicht nur über einen gepachteten Hof, sondern auch über Ackerland zwischen drei bis zehn Hektar Größe verfügten, das sie eigenhändig gerodet oder in sumpfigen Gebieten trockengelegt hatten. Selbst Pachtbauern mit Getreidefeldern bis zu 25 Hektar waren keine Seltenheit. Sie verfügten jedoch niemals über Waldflächen, so daß sie nicht von den plötzlich steigenden Holzpreisen profitieren konnten.

Die Bedingungen des Pachtverhältnisses wurden in einem zeitlich befristeten Pachtvertrag geregelt, der häufig nur aus einer mündlichen Vereinbarung bestand, ab 1902 aber schriftlich fixiert werden mußte ${ }^{58}$. Neben dem ertragsabhängigen Pachtzins in Form von Naturalien und Geld an den Grundbesitzer hatten die Pachtbauern auch Kommunalsteuern zu entrichten sowie einen täglichen Arbeitseinsatz auf den vom Landbesitzer bewirtschafteten Feldern abzuleisten ${ }^{59}$. Trotz selbständigem Ackerbau war der Pachtbauer vor allem ein abhängiger Landarbeiter im Angestelltenverhältnis, den das gepachtete Land in besonderer Weise an seinen Arbeitgeber band. So waren denn auch viele Pachtbauern auf einen Nebenerwerb außerhalb der Landwirtschaft angewiesen, um überleben zu können, da ihr Lebensstandard sie kaum von den übrigen landlosen Sozialgruppen unterschied.

Die Kätner, die als Bewohner einer kleinen Kate weniger als einen Hektar Land vom Grundbesitzer angemietet hatten, verdienten ihren Lebensunterhalt als Angestellte des Landbesitzers in der Land- oder Forstwirtschaft oder aber als saisonabhängige

\footnotetext{
${ }^{57}$ Zum Status der Pachtbauern siehe Soininen 1974, S. 36f.; Peltonen 1992, S.253-303.

${ }^{58}$ Jutikkala 1958, S. 371 f; Alapuro 1995, S. 32 f.

${ }^{59}$ Alapuro 1995, S. 49; Ranta 1988, S. 892
} 
Gelegenheitsarbeiter. So zog beispielsweise ein Knecht, der eine eigene Familie gründete, aus dem Bereich des Haupthofes in ein kleines, separat stehendes Wohngebäude, womit sich seine soziale Stellung vom Einlieger zum Kätner verbesserte. Er verfügte allenfalls über einige wenige Haustiere und einen kleinen Gemüseacker für den Eigenbedarf. Da die Kätner jedoch nicht wie viele Pachtbauern vollständig selbstversorgend leben konnten, verschlechterte sich ihre Lebenssituation, sobald ein Überangebot an Arbeitskräften die allgemeinen Erwerbsmöglichkeiten reduzierte. Der Verlust der kleinen Kate und der Abstieg zu den Instleuten oder mittellosen Einliegern waren damit bereits vorgezeichnet.

Letztere, auf der untersten Stufe der ländlichen Sozialhierarchie stehende Bevölkerungsschicht lebte ohne soziale Absicherung auf den Gütern und Bauernhöfen der wohlhabenden Landbesitzer und verdingte sich als Tagelöhner. Gelang es ihnen nicht, in ein festangestelltes Dienstbotenverhältnis zu wechseln, d.h. als landwirtschaftlich festangestellte Knechte und Mägde ${ }^{60}$ beschäftigt zu werden, zogen sie mit ihren Familien von Hof zu Hof und wohnten in den Nebengebäuden auf den Höfen der Landbesitzer oder in der kalten Jahreszeit auch in deren Rauchsaunen.

Es ist äußerst schwierig, ein realitätsgetreues Bild von dem Größenordnungsverhältnis zu erhalten, in dem die einzelnen Sozialgruppen zueinander standen. Das größte Problem stellen dabei die uneinheitlichen Zahlenwerte der statistischen Berechnungen zu Beginn des 20. Jahrhunderts dar, welche sich auf Angaben aus dem 19. Jahrhundert beziehen ${ }^{61}$. Als Datengrundlage für die im nachhinein erstellten Statistiken dienten Kirchenbuchaufzeichnungen. Der größte Ungenauigkeitsfaktor entstand durch das Fehlen an zuvor definierten, allgemein verbindlichen Zuordnungskategorien für die einzelnen Personengruppen, was wiederum individuelle Eigeninterpretationen der Geistlichen zur Folge hatte.

So wurden beispielsweise Landarbeiter mit eigenem Wohngebäude, in erster Linie Kätner, ungeachtet ihrer sozialen Stellung mit wohnsitzlosen Einliegern oder Tagelöhnern als homogene Sozialgruppe zusammengefaßt. Auch bei den Berechnungen

\footnotetext{
${ }^{60}$ Der Dienstbotenstatus des Knechtes oder der Magd war meist nur eine Übergangsphase für junge ledige Landarbeiter ohne eigenen Grundbesitz. Sobald Mitglieder dieser Gruppe heirateten, änderte sich ihr Sozialstatus, was jedoch nicht unbedingt einer Verbesserung des Lebensstandards gleichkam.

${ }^{61} 1901$ veröffentlichte eine Arbeitsgruppe des finnischen Landtages eine detaillierte Erhebung über die in der Landwirtschaft arbeitende Bevölkerung sowie ihre Wohn- und Erwerbsverhältnisse. Zur Kritik an dieser offiziellen Statistik siehe Soininen 1976, S. 211-225.
} 
zur Größe der arbeitenden Landbevölkerung ergaben sich völlig falsche Zahlenwerte, da alle in der Landwirtschaft beschäftigten und verheirateten Frauen im arbeitsfähigen Alter einfach ausgeschloßen wurden ${ }^{62}$. Lediglich ledige Frauen, zumeist Mägde, gingen in die Statistiken mit ein. Ebenso wurden in Armeediensten stehende Männer, die in Friedenszeiten bis auf wenige Wochen des Jahres in der Landwirtschaft beschäftigt waren, in den Berechnungen ignoriert, wohingegen bereits aufs Altenteil verlegte Bauern wiederum zu den Erwerbstätigen gezählt wurden.

Im Ergebnis sind die im 19. Jahrhundert zusammengetragenen Zahlenwerte nicht miteinander vergleichbar. Es lassen sich allenfalls allgemeine Entwicklungstendenzen, wie das starke Anwachsen der untersten Sozialschichten innerhalb der Landbevölkerung, herauslesen. Um ein präziseres Gesamtbild von der prozentualen Verteilung der wichtigsten Sozialgruppen zu erhalten, hat Soininen, anhand von Stichprobenuntersuchungen für das Jahr 1910, eine Korrektur der zuvor veröffentlichten Zahlenwerte vorgenommen. Demnach läßt sich die Landbevölkerung grob in die drei Gruppen Landbesitzer, Pachtbauern und Landarbeiter, womit landwirtschaftliche Angestellte mit und ohne Festanstellung sowie größtenteils ohne eigene Wohnung gemeint sind, im Verhältnis 40: 20: 40 aufteilen $^{63}$ :

Tab. A Sozialstruktur der finnischen Landbevölkerung 1910

\begin{tabular}{|l|l|}
\hline Landbesitzer & $42,8 \%$ \\
\hline Pachtbauern & $18,4 \%$ \\
\hline Vorarbeiter & $0,4 \%$ \\
\hline Kätner/Instenleute & $2,6 \%$ \\
\hline Knechte/Mägde & $4,5 \%$ \\
\hline Tagelöhner & $31,3 \%$ \\
\hline & \\
\hline Insg. & $\mathbf{1 0 0} \%$ \\
\hline
\end{tabular}

\footnotetext{
${ }^{62}$ Soininen 1974, S. 20 und 1974, S. 213 f.

${ }^{63}$ Soininen 1976, S. 220, Tab. 5 und 1981, S. 91 . Zu den Landbesitzern wurden auch diejenigen Landvermieter (1,4 \%) gezählt, die z.B. als Kaufleute beschäftigt waren und ihr Landgut nicht hauptsächlich selbst bewirtschafteten. Die Pachtbauern schlossen sowohl Pächter ein, die einen ganzen Hof bewirtschafteten (z.B. im Fall eines Witwenhofes), als auch die Teilhofpächter. Die Vorarbeiter stellten den geringsten Prozentsatz dar, da sie in erster Linie nur in den wohlhabenden Großgrundbesitzerhöfen im Süden des Landes angestellt waren. Kätner, Instenleute und Dienstboten waren fest angestellte Landarbeiter, wohingegen die Tagelöhner, hier ohne festen Wohnsitz gemeint, auf Gelegenheitsarbeiten angewiesen waren.
} 


\subsubsection{Regionale Unterschiede}

Diese auf das ganze Land bezogene Darstellung vermittelt lediglich ein allgemeines Bild von der finnischen Landbevölkerung, da die Zusammensetzung der Sozialgruppen auch noch regionalen Differenzen unterworfen war ${ }^{64}$. Die ländliche Bevölkerungsstruktur war beispielsweise im Südwesten Finnlands eine völlig andere als in Ostfinnland. Daran hatten vor allem die unterschiedlichen Landschaftsstrukturen und Bodenbeschaffenheiten Anteil, welche die regionalen Lebensbedingungen, d.h. in erster Linie die Erwerbsmöglichkeiten in der Landwirtschaft, prägten.

Als gemeinhin wohlhabend galt der südliche Landesteil, der von einem milden Klima und großen Ackerbauflächen gekennzeichnet war. Die Regierungsbezirke ${ }^{65}$ Uusimaa (schwed. Nyland), die südlichen Gebieten von Turku/Pori (schwed. Åbo/Björneborg) und Häme (schwed. Tavastland) bildeten einen einheitlichen landwirtschaftlichen Nutzungsraum. Dort befanden sich auch die meisten Industriezentren des Landes, die entlang der südfinnischen Küstenregion angesiedelt waren sowie feudale Gutsherren- und Großbauernhöfe, deren Größe den Landesdurchschnitt mit Ausnahme von Nordfinnland übertrafen. Dies sprach wiederum für einen großen Anteil an festangestellten Dienstboten und Landarbeitern sowie Pachtbauern. Da jedoch in Südfinnland die Anzahl der Großbauernhöfe im Laufe der zweiten Jahrhunderthälfte stetig zurückging, sank auch der Anteil der fest an die Höfe gebundenen Arbeitskräfte, welche zum Teil als Industriearbeiter in die nahegelegenen Industriezentren abwanderten, nicht zuletzt in die Landeshauptstadt Helsinki im Regierungsbezirk Uusimaa gelegen, welche zugleich das größte urbane Zentrum Finnlands darstellte.

Die Gruppe der nicht fest angestellten Gelegenheitsarbeiter wuchs stetig, zum einen bedingt durch die allgemein hohe Geburtenrate und zum anderen durch die Verarmung von Mitgliedern aus höher stehender Gruppen der Sozialhierarchie. Dieser Trend zeigte sich gegen Ende des 19. Jahrhunderts im ganzen Land, er vollzog sich in

\footnotetext{
${ }^{64} J u t i k k a l a ~ 1958$, S. 339-370; Soininen 1974, S. 42-49; Rasila 1982, S. 145-148; Alapuro 1985, S. 44-60; Apunen 1987, S. 55f. und S. 62-65; Alapuro 1995, S. 27-49.

${ }^{65}$ Zur geographischen Aufteilung Finnlands in acht Regierungsbezirke vor der nationalen Unabhängigkeit siehe Karte 1a im Anhang. Seit 1918 fanden mehrfach Veränderungen in der Landesaufteilung statt und seit 1998 existieren nur noch fünf Regierungsbezirke in Finnland: Neben den 1938 gegründeten Bezirken Oulu und Lappland sind dies die Regierungsbezirke Süd-, West-, und Ost-Finnland.
} 
Südwestfinnland, aufgrund der stark anwachsenden Gruppe von Industriearbeitern, jedoch langsamer als in anderen Landesteilen ${ }^{66}$. Außerdem befanden sich hier die unteren Schichten der Sozialhierarchie auch in einer besseren Existenzposition als der Landesdurchschnitt. Unter ihnen waren die Kätner, d.h. die Tagelöhner mit eigenem Wohnsitz, zahlreicher vertreten als beispielsweise in Ostfinnland, wo die ärmsten Landarbeiter unter dem Dach ihres jeweiligen Arbeitgebers leben mußten.

Der spärlich besiedelte Regierungsbezirk Oulu (schwed. Uleåborg) im Norden des Landes nahm vor $1938^{67}$ fast die Hälfte der gesamten Landesfläche ein, wurde zu Beginn des 20. Jahrhunderts jedoch nur von $5 \%$ der Gesamtbevölkerung bewohnt ${ }^{68}$. Für die Anfänge der Überseeauswanderung hingegen war der nördlichste Landesteil Finnlands bedeutsam, stammten doch die Pioniere unter den Amerikafahrern größtenteils aus Nord-Finnland und traten gemeinsam mit zahlreichen Norwegern über Trondheim die Atlantiküberquerung an ${ }^{69}$.

Im Norden Finnlands bestanden weite Gebiete aus Wald und vegetationsarmen Tundraflächen in staatlichem Besitz. Der Regierungsbezirk Oulu läßt sich in drei landwirtschaftliche Nutzungsräume einteilen: In die Provinz Nord-Ostbottnien, die östlich angrenzende Provinz Kainuu, welche den Oulu-See umschließt, sowie die Provinz Lappland ${ }^{70}$. Schon um die Jahrhundertwende konzentrierte sich die Bevölkerung im Einflußbereich der Stadt Oulu, welche zugleich den nördlichsten Ostseezugang bildete und für die Verschiffung von Teerfässern aus der Region Kainuu bedeutsam war.

Die Gruppe der nicht festangestellten Gelegenheitsarbeiter mit und ohne eigenen Wohnsitz erfuhr in keiner anderen Region - mit Ausnahme Ostfinnlands - einen vergleichbar starken Zuwachs. Vor diesem Hintergrund ist auch das Anwachsen der Landbesitzer-Gruppe und der Pachtbauern bemerkenswert, wenngleich ihre Anzahl im Norden geringer war als in den übrigen Landesteilen. Doch aufgrund der klimatischen Verhältnisse mit sehr kurzen Wachstumsperioden blieb der Ernteertrag auch auf großen

\footnotetext{
${ }^{66}$ Soininen 1974, S. 44f.

${ }^{67} 1938$ wurde dieses Gebiet in zwei Hälften, in die Regierungsbezirke Oulu und Lappland aufgeteilt.

${ }^{68}$ Alapuro 1988, S. 77.

${ }^{69} \mathrm{Zu}$ den Anfängen der finnischen Auswanderungsbewegung siehe Kap. 2.4.3.

${ }^{70}$ Zur geographischen Aufteilung Finnlands nach Provinzen um 1900, wie sie heute noch größtenteils Gültigkeit haben, siehe Karte 1b im Anhang.
} 
Grundstücken gering. Der allgemeine Lebensstandard war bei allen

Bevölkerungsgruppen relativ gering.

In Ostfinnland hingegen, einer relativ einheitlichen Landschaft mit vielen Seen und Sumpfgebieten, hatte die Schwende eine jahrhundertelange Tradition. In den Regierungsbezirken Mikkeli (schwed. St. Michel) und Kuopio nahm die Gruppe der Gelegenheitsarbeiter den größten Raum ein. Zwei Drittel der gesamten Landbevölkerung dieser Bezirke waren wohnsitzlose Tagelöhner, die von der Saisonarbeit in der Land- und Forstwirtschaft lebten. Im Unterschied zu der ärmsten Bevölkerungsgruppe aus Nordfinnland wanderten zahlreiche landlose Arbeiter aus Ostfinnland nach Südfinnland oder Rußland ab, insbesondere in das Industriezentrum St. Petersburg $^{71}$. Die Anzahl der Pachtbauern war gering, und ihr Lebensstandard unterschied sie kaum von den landlosen Arbeitern. In den meisten Fällen waren auch sie auf einen Nebenerwerb angewiesen, der Mobilität erforderte.

Als eine charakteristische Region mit abweichender Sozialstruktur kann der Regierungsbezirk Viborg (finn. Viipuri) ${ }^{72}$ angesehen werden, der die Hälfte des Ladoga-Sees umschloß und die im nationalen Vergleich verhältnismäßig größte Bevölkerungsdichte in relation zur Gebietsgröße aufwies. Bereits 1880 lebten 14,6\% der Landesbevölkerung im Regierungsbezirk Viborg. Die Existenz vieler kleiner Grundbesitzerhöfe sorgte allgemein für einen höheren Lebensstandard als in den nördlich angrenzenden Regierungsbezirken Mikkeli und Kuopio. Dennoch waren auch die meisten Einwohner aus dem dem Regierungsbezirk Viborg auf einen Nebenerwerb außerhalb der traditionellen Landwirtschaft angewiesen: Fischerei, Gütertransporte und die saisonbedingte Arbeitswanderung nach Rußland waren die häufigsten Formen des lebensnotwendigen Nebenerwerbs, der sich für viele Familien allmählich zur Haupteinnahmequelle entwickelte ${ }^{73}$.

In Mittelfinnland, einem Gebiet, das die Schnittstellen der Regierungsbezirke Vaasa, Kuopio, Mikkeli und Häme vereinte, etablierte sich gegen Ende des 19. Jahrhunderts die finnische Holzindustrie. Die zunehmende Wertsteigerung von

\footnotetext{
${ }^{71}$ Die ostwärts gerichtete Auswanderung war in ihren Anfängen eine Notauswanderung. Sie wandelte sich jedoch schon bald zu einer von der russischen Konjunkturlage abhängigen, saisonalen Arbeitswanderung, vgl. Engman 1990, S. 74-84.

${ }^{72}$ Nach 1944 auf weniger als die Hälfte des ursprünglichen Gebiets reduziert, erhielt dieser Regierungsbezirk den Namen 'Kymi' (schwed. Kymmene) nach dem Kymi-Fluß, und ist seit 1998 in den Regierungsbezirk Ostfinnland integriert.

${ }^{73} \mathrm{Zu}$ den verschiedenen Nebenerwerbsmöglichkeiten siehe Soininen 1974, S. 302-306.
} 
Waldbesitz veranlaßte zahlreiche Landbesitzer dazu, große Waldflächen an neugegründete Waldgesellschaften zu verkaufen. Diese wiederum bauten ein dichtes Netz von Sägewerken auf, und boten somit der landlosen Tagelöhnerbevölkerung aus den umliegenden Regionen eine Erwerbsalternative zur Landwirtschaft ${ }^{74}$.

Der Regierungsbezirk Vaasa, der im Hinblick auf die Amerikaauswanderung besondere Aufmerksamkeit verdient, war um die Jahrhundertwende ein ungleich besiedeltes Gebiet mit zwei verschiedenen wirtschaftlichen Nutzungsräumen. Der westliche Teil des Regierungsbezirks, die Provinz Süd-Ostbottnien, kann zusammen mit den südwestfinnischen Regierungsbezirken Turku/Pori und Uusimaa als Kornkammer Finnlands bezeichnet werden. Der östliche Teil des Regierungsbezirks Vaasa hingegen dehnte sich bis nach Mittelfinnland in die Schwerpunktregionen der Holzindustrie aus.

In Bezug auf die Sozialstruktur der Landbevölkerung wies der Regierungsbezirk Vaasa, d.h. vor allem die dicht besiedelte Provinz Süd-Ostbottnien, eine von anderen Landesteilen abweichende Entwicklung auf. In den finnischsprachigen Gemeinden verdoppelte sich die Anzahl der selbständigen Bauernhöfe in den Jahren 1860-1910 als Ergebnis der traditionellen Realerbteilung ${ }^{75}$. Durch Aufteilung größerer Höfe wurden selbständige Bauernhöfe häufiger gegründet als Pachthöfe, obwohl auch die Anzahl der Pachthöfe in dem betrachteten Zeitraum zunahm ${ }^{76}$. In einigen Fällen sollte auch die ursprüngliche Größe der vererbten Höfe erhalten bleiben, und für die Geschwister und erwachsenen Kinder des Haupterben wurden neue Wohn- und Wirtschaftsgebäude errichtet. Letztere durch Erbregelung geschaffenen Pachtverhältnisse unterschieden sich von den landesweit üblichen Pachtverträgen zwischen nicht miteinander verwandten Parteien. In Süd-Ostbottnien war der Pachtzins meist nur nominell vorhanden, und auch der sonst übliche, regelmäßige Arbeitseinsatz der Pachtbauern auf den Haupthöfen entfiel. Problematisch wurde diese Erbregelung erst für die nachfolgende Generation der südostbottnischen Pachtbauern, da sich im ausgehenden 19. Jahrhundert das Pachtverhältnis nicht mehr automatisch auf die Kinder übertrug. Nach dem Tod des Pachtbauern wurden die Pachthöfe wieder in den Haupthof integriert, und den

\footnotetext{
${ }^{74}$ Zum saisonalen Charakter der Waldarbeit vgl. Talve 1983, S. 458-462.

${ }^{75}$ Ranta 1988, S. 876 und S. 923. Im Jahr 1860 wurden 5560 selbständige Höfe gezählt, 1910 waren es bereits 11630 Höfe.

${ }^{76}$ Die absolute Anzahl der Pachthöfe stieg von 7130 im Jahr 1860 auf 9104 ein halbes Jahrhundert später, was einem Zuwachs von 27\% entsprach, vgl. Ranta 1988, S. 924.
} 
Hinterbliebenen stand der soziale Abstieg zur Gruppe der Kätner oder wohnsitzlosen Landbevölkerung bevor ${ }^{77}$.

Obwohl sich ein Großteil der südostbottnischen Auswanderer aus eben diesen ärmeren Bevölkerungsgruppen rekrutierte, waren es vor allem in der Frühphase der Emigrationsbewegung, d.h. in der Zeitspanne 1865-79, zahlreiche Landbesitzer, die durch Veräußerung ihres Eigentums zu Pionieren der Atlantiküberquerung wurden. Auch zu Zeiten der Massenemigration war auf zahlreichen südostbottnischen Höfen noch keine derartige ökonomische Talsohle erreicht, welche die Reisefinanzierung gänzlich vereitelt hätte, wie es beispielsweise im Ostteil Finnlands der Fall war ${ }^{78}$. Landbesitzlose Auswanderer hingegen, deren Anzahl u.a. in Süd-Ostbottnien ständig anstieg, reisten in großer Zahl erst um die Jahrhundertwende in die Neue Welt, häufig sogar mit geliehenem Geld oder zugesandten Fahrkarten, die ihnen bereits ausgewanderte Verwandte in das Briefkuvert gelegt hatten.

Auch im Hinblick auf die Bevölkerungsentwicklung nahm die Provinz SüdOstbottnien eine Sonderstellung ein. Während des 19. Jahrhunderts verdreifachte sich die Bevölkerung. In keiner anderen Region vollzog sich die Bevölkerungszunahme mit derart großer Geschwindigkeit. Im Unterschied zu anderen Landesteilen verteilte sich der Bevölkerungszuwachs in Süd- Ostbottnien jedoch gleichmäßiger auf alle Sozialgruppen. In der Regel hatten die Landbesitzer in Süd-Ostbottnien nämlich mehr Kinder als die landlosen Bevölkerungsgruppen. Da sich die landlosen Bevölkerungsgruppen - wie im ganzen Land - in der Überzahl befanden, ging der größte Bevölkerungszuwachs auch in Süd-Ostbottnien zu ihren Lasten ${ }^{79}$.

Zusammenfassend läßt sich festhalten, daß die Sozialstrukturen in den verschiedenen Landesteilen Finnlands eng mit Faktoren wie Bodenbeschaffenheit und Besiedlungsdichte verknüpft waren. Die Verteilung der Besitzverhältnisse war nicht allein ausschlaggebend für die zunehmende Proletarisierung der Landbevölkerung. In erster Linie verursachte die Bevölkerungsexplosion ein Überangebot an Arbeitskräften, welche selbst in der expandierenden ländlichen Holzindustrie zu wenig Beschäftigungsmöglichkeiten vorfanden.

\footnotetext{
${ }^{77}$ Jutikkala 1958, S. 355; Soininen 1974, S. 371f.

${ }^{78}$ Diese Ansicht vertritt vor allem Soininen (1974, S. 402), wohingegen Toivonen (1963, S. 103) die Existenzgrundlage der südostbottnischen Bauern negativer beurteilt.

${ }^{79}$ Ranta 1988, S. 901.
} 
Zudem bewirkten die Innovationen in der Landwirtschaft eine weitere Reduzierung der Nachfrage nach Arbeitskräften. Trotz einer steigenden Anzahl von Ackerbauflächen und damit einhergehender Produktionssteigerung erforderte die Umstellung auf den Futtermittelanbau weitaus weniger Arbeitskräfte als der traditionelle Brotgetreideanbau. Auch die zunehmende Verwendung von zeitsparenden Arbeitsgeräten und Landwirtschaftsmaschinen machte einen großen Teil der Landarbeiter überflüssig. Demnach existierten gegen Ende des Jahrhunderts in der Landwirtschaft für immer mehr Menschen immer weniger Erwerbsmöglichkeiten, was sich in einer verstärkten Binnenwanderung in die Industriestädte und ab den 1880er Jahren vor allem in einem Massenexodus nach Nordamerika äußerte.

\subsection{Die Provinzen Süd-Ostbottnien und Satakunta als}

\section{$\underline{\text { Auswanderungskerngebiet }}$}

Im Hinblick auf die finnische Überseeauswanderung stellten die drei Provinzen Süd-, Mittel- und Nord-Ostbottnien sowie die nördlichsten Gemeinden der Provinz Satakunta das Emigrationsgebiet dar ${ }^{80}$. Zu Beginn des 20. Jahrhunderts verlief die administrative Grenze der Regierungsbezirke Oulu und Vaasa quer durch die Provinzen Nord- und Mittel-Ostbottnien. Zwischen Süd-Ostbottnien und Satakunta hingegen markierte die Provinzgrenze zugleich die Administrationsgrenze der Regierungsbezirke Vaasa und Turku/Pori ${ }^{81}$.

Obwohl zu Beginn der 1870er Jahre die ersten Auswanderer noch vorwiegend aus Nordfinnland stammten, griff das sogenannte Amerikafieber bald auf die im westlichen Mittelfinnland gelegenen Provinzen über und entwickelte sich zu einem Massenphänomen. Für den Zeitraum 1870-1914 hat Kero konstatiert, daß ca. 65\% aller finnischen Amerika-Auswanderer aus dem Emigrationsgebiet stammten ${ }^{82}$.

Als Herkunftsgebiete der hier zu untersuchenden Auswandererbriefe sind vor allem die angrenzenden Provinzen Süd-Ostbottnien und Satakunta, eine Teilregion des Emigrationsgebietes, von Interesse. Für den Zeitraum 1893-1914, d.h. mit Beginn der

\footnotetext{
${ }^{80}$ Kero (1974, S. 55) bewertet die gesamte Region als vorwiegendes Herkunftsgebiet der finnischen Amerikaauswanderer und nicht - wie bei Toivonen (1963, S. 27-29) hervorgehoben lediglich die Provinz Süd-Ostbottnien.

${ }^{81}$ Zur geographischen Aufteilung Finnlands um 1900 nach Regierungsbezirken und Provinzen siehe Karten 1a und 1b im Anhang.

${ }^{82}$ Kero 1974, S. 52.
} 
offiziellen Auswandererregistrierung bis zum Ausbruch des Ersten Weltkrieges, lassen sich die jährlichen Auswandererzahlen aus den beiden Provinzen miteinander vergleichen. Dabei stellte die Provinz Süd-Ostbottnien 31,7\% des landesweiten Auswandereraufkommens dieser Zeit, jedoch lediglich 12\% der Landesbevölkerung. Für die Provinz Satakunta lag der entsprechende Emigrantenanteil bei $6,1 \%{ }^{83}$ und in der gleichen Größenordnung bewegte sich auch der prozentuale Anteil der SatakuntaBewohner an der finnischen Gesamtbevölkerung. Denmach bestritten die Einwohner beider Provinzen zusammengenommen ca. 38\% der Überseeauswanderer, jedoch lediglich $18 \%$ der Landesbevölkerung ${ }^{84}$.

\subsubsection{Die Sprachstruktur}

Um die Jahrhundertwende lebten zwei Drittel der Bevölkerung des Regierungsbezirks Vaasa in der Provinz Süd-Ostbottnien und ein Drittel der Einwohner des Regierungsbezirks Turku/Pori in der Provinz Satakunta. Während die Grenzen der Regierungsbezirke als Verwaltungseinheiten nur selten Veränderungen unterworfen waren, variierte die Anzahl der Städte und ländlichen Gemeinden im ganzen Land ${ }^{85}$. Dies wirkte sich sowohl auf die Größe der Provinzen als auch auf die Provinzgrenzen aus, da einige Gemeinden grenzübergreifend zusammengelegt bzw. neu aufgeteilt wurden. Für den hier betrachteten Untersuchungszeitraum 1865-1914 bedeutet dies, daß das Bevölkerungsvolumen der Provinzen Süd-Ostbottnien und Satakunta schwankte.

Eine exakte Prüfung der Provinzgrenzen und ihrer jährlichen Einwohnerzahlen um die Jahrhundertwende wird zudem noch durch fehlende, offiziell erstellte Statistiken erschwert. Die bislang maßgeblichen 'Statistischen Jahrbücher' des Amtes für Bevölkerungsstatistik in Helsinki führen lediglich die jährlichen Einwohnerzahlen pro Gemeinde auf. Die Gemeinden wurden wiederum den Regierungsbezirken als administrativen Einheiten zugeordnet. Da die Provinzgrenzen aus diesen offiziellen Aufstellungen jedoch nicht hervorgehen, soll im Folgenden auch nicht versucht werden, die sich häufig verändernden Provinzgrenzen für den Untersuchungszeitraum zu

\footnotetext{
${ }^{83}$ Toivonen 1963, Tab.1, Anhang; Kero 1970 (unveröffentlichte Lizentiatsarbeit) S. 39.

${ }^{84}$ Der Durchschnittswert von 18\% bezieht sich auf den Zeitraum 1880-1920 und berücksichtigt lediglich alle registrierten Geburten, nicht die Nettoauswanderung, siehe Valkonen 1985b, S. 204, Tab. 4.1.

${ }^{85}$ 1885-1915 stieg die Anzahl der Städte von 38 auf 42, die der ländlichen Gemeinden von 458 auf 486 in Finnland an, vgl. Vattula 1983, S. 31, Einleitung.
} 
rekonstruieren. Der Einfachheit halber wird hier lediglich mit Durchschnittswerten operiert, um ein Gesamtbild der Region entstehen zu lassen.

Die Provinz Süd-Ostbottnien bestand aus durchschnittlich 50 Gemeinden und vier Städten. Das Verhältnis der finnisch- zu den schwedischsprachigen Gemeinden lag bei $3: 2^{86}$. Die Provinz Satakunta wiederum setzte sich aus durchschnittlich 30 Gemeinden und zwei Städten zusammen.

Satakunta wird als finnischsprachige Region angesehen, da der Anteil an schwedischsprachigen Einwohnern in keiner Gemeinde 50\% überstieg. Süd-Ostbottnien hingegen wird in ein finnisch- und ein schwedischsprachiges Gebiet unterteilt.

Obwohl die zweisprachige Provinz Süd-Ostbottnien hier als einheitliche Region behandelt wird, liegt der Schwerpunkt, der Herkunft der Briefschreiber zufolge, auf den finnischsprachigen Gemeinden des Landesinneren, denn in den Küstengebieten sprach die Bevölkerung fast ausschließlich Schwedisch. Die schwedisch- und finnischsprachigen Gebiete stießen jedoch derart unmittelbar aufeinander, daß von der Ausbildung einer Sprachgrenze gesprochen werden kann, die während des gesamten 19. Jahrhunderts nahezu unverändert bestehen blieb und zwei sich unabhängig voneinander entwickelnde Teilregionen schuf ${ }^{87}$.

In einer Untersuchung über die sprachliche Struktur Finnlands ${ }^{88}$ hat Klövekorn nachweisen können, daß im Jahr 1880 in 14 südostbottnischen Küstengemeinden mehr als 90\% der jeweiligen Ortsbevölkerung Schwedisch sprach. Die beiden südostbottnischen Küstenstädte Kristiinankaupunki (schwed. Kristinestad) und Vaasa wiesen 1880 ebenfalls einen schwedischsprachigen Bevölkerungsanteil von 85\%-90\% auf $^{89}$. In sechs weiteren Küstengemeinden variierte der Anteil der schwedischsprachigen Bewohner zwischen $87 \%$ und $64 \%{ }^{90}$.

Als südostbottnische Gemeinden mit überwiegendem finnischsprachigen Bevölkerungsanteil werden durchschnittlich 30 Gemeinden ohne direkten

\footnotetext{
${ }^{86}$ Toivonen 1963, S. $17 \mathrm{f}$.

${ }^{87}$ Ranta 1988, S. 429.

${ }^{88}$ Die schwedischsprachige Bevölkerung Finnlands lebte vorwiegend in den Küstenregionen von Süd- bis Mittelfinnland. Während des Untersuchungszeitraumes (1865-1914) verringerte sich ihr prozentualer Anteil an der Landesbevölkerung von 14\% auf 12\%, vgl. Sandlund 1985, S. 272, Tab. 6.1. und Jutikkala 1987, S. 369.

${ }^{89}$ Heute ist die Stadt Vaasa zum überwiegenden Teil finnischsprachig, in der Kleinstadt Kristiinankaupunki dahingegen dominiert weiterhin das Schwedische.

${ }^{90}$ Klövekorn 1960, S. 16, Abb. 1 und S. 50-56.
} 
Küstenzugang angesehen. Aus 20 dieser Gemeinden sind 125 finnischsprachige Auswandererbriefe in die hier zu behandelnde Stichprobeneinheit für die Provinz SüdOstbottnien eingegangen: Alajärvi, Ilmajoki, Isokyrö, Jalasjärvi, Jurva, Karijoki, Kauhajoki, Kuortane, Kurikka, Laihia, Lapua, Peräseinäjoki, Seinäjoki, Teuva, Töysä, Vimpeli, Väkäkyrö, Ylihärmä, Ylistaro sowie die Stadt Vaasa ${ }^{91}$.

Zwei der genannten Kommunen, Alajärvi und Vimpeli, gehören dem sogenannten Seengebiet an, einer Teilregion im finnischsprachigen Süd-Ostbottnien, die sich sowohl geographisch als auch dialektologisch abgrenzt. Das Seengebiet umfaßt insgesamt sieben Gemeinden: Alajärvi, Evijärvi, Kortesjärvi, Lappajärvi, Lehtimäki, Soini und Vimpeli, welche sich um die beiden großen Seen Evijärvi und Lappajärvi gruppieren. Die Bewohner des Seengebiets sprechen einen ostfinnisch beeinflußten Dialekt, in den übrigen Gemeinden wiederum wird ein für die Region typischer, südostbottnischer Dialekt gesprochen, der zur Gruppe der westfinnischen Dialekte zählt $^{92}$.

Da das Seengebiet von der Auswanderung in gleichem Umfang betroffen war wie die übrigen südostbottnischen Gemeinden, d.h. schwedisch- wie finnischsprachigen Regionen, hatten weder die Zugehörigkeit zu einer der beiden Landessprachen, noch zu einer bestimmten südostbottnischen Dialektgruppe, einen Einfluß auf die regionale Ausbreitung des Auswanderungsphänomens. Ebensowenig hat die Emigrationserscheinung an sich eine Veränderung der Sprachverhältnisse hervorgerufen. Dennoch wird die Sprachgrenze vor allem in der Frühphase der Auswanderungsbewegung, d.h. vor 1890, als Trennungslinie für den Kontaktaustausch zwischen den Küsten- und den Inlandbewohnern angesehen ${ }^{93}$. Dementspechend erhielten die finnischsprachigen Inlandbewohner Informationen über Amerika aus Briefen und von zurückgekehrten, finnischsprachigen Auswanderern, die ihre

\footnotetext{
${ }^{91}$ Alle genannten Gemeinden gehören noch heute als eigenständige Kommunen der Provinz Süd-Ostbottnien an. Die Gemeinden Alajärvi, Kurikka, Lapua und Seinäjoki haben jedoch heute Stadtrechte, vgl. Tilastollinen Vuosikirja 1994, toim. Tilastokeskus (Jahrbuch für Statistik 1994. Hrsg. vom Amt für Statistik). Helsinki 1994, S. 144-147, Anhang 2.

${ }^{92}$ Mit der Begründung, daß sich die im 16. Jahrhundert zugezogene Regionalbevölkerung aufgrund ihrer ostfinnischen Herkunft deutlich von der ursprünglichen südostbottnischen Einwohnerschaft unterscheide, klammert Toivonen (1963, S. 17) das Seengebiet aus ihrer Untersuchung aus. Die Autorin beurteilt das Seengebiet als eine Grenzregion. Mit Verweis auf diese Auslassung widmet sich Nygård (1983, S. 106-135) lediglich der Amerikaauswanderung aus dem Seengebiet.

${ }^{93}$ Der Frage der Informationsverbreitung haben sich vor allem Geer und Wester (1975, S. 72f.) gewidmet. Siehe auch Klövekorn 1960, S. 139; Geer 1977, S. 77.
} 
südostbottnischen Heimatgemeinden im Innern des Landes aufsuchten.

Schwedischsprachige Küstenbewohner dahingegen profitierten von den Berichten heimkehrender Seefahrer sowie schwedischsprachiger Landsleute, die sie ebenfalls durch Briefe und mündliche Informationen auf dem Laufenden hielten. Doch ein Kontaktaustausch zwischen Küsten- und Inlandsbewohnern, d.h. eine Informationsübertragung in West-Ost-Richtung, fand kaum statt.

In der Provinz Satakunta verteilte sich die Intensität der Auswanderungserscheinung weniger gleichmäßig auf alle Gemeinden der Provinz als dies in Süd-Ostbottnien der Fall war. Die Auswanderungsfrequenz war in den nördlichsten Gemeinden von Satakunta am höchsten, d.h. in denjenigen Orten, die direkt an die Provinz Süd-Ostbottnien angrenzten. Da die hier behandelten Briefe jedoch aus der gesamten Provinz Satakunta stammen, sind auch solchen Gemeinden vertreten, die weitaus weniger von der Auswanderung betroffen waren wie die südostbottnischen Gemeinden im Durchschnitt. Von rund 30 Gemeinden aus Satakunta finden sich 20 Kommunen in der Stichprobeneinheit des Samples für die genannte Provinz wieder: Eura, Hinnerjoki, Honkilahti ${ }^{94}$, Ikaalinen ${ }^{95}$, Jämijärvi, Kankaanpää, Karvia, Kiikka, Kiikoinen ${ }^{96}$, Kokemäki ${ }^{97}$, Kullaa, Köyliö, Lappi/TL ${ }^{98}$, Lavia, Loimaa ${ }^{99}$, Merikarvia, Siikainen, Pomarkku, Säkylä und Tyrvää. Aus diesen 20 Gemeinden sind insgesamt 353 Briefe in diese Untersuchung eingegangen.

\subsubsection{Sozio-ökonomische Charakteristika}

Im folgenden sollen die sozio-ökonomischen Hintergründe der beiden Provinzen näher betrachtet werden. Aufgrund zahlreicher Gemeinsamkeiten werden für die Provinz Satakunta lediglich diejenigen Faktoren erwähnt, welche deutlich von der gesellschaftlichen und wirtschaftlichen Entwicklung in Süd-Ostbottnien abweichen.

\footnotetext{
${ }_{95}^{94}$ Hinnerjoki und Honkilahti sind heute in die Gemeinde Eura integriert.

${ }^{95}$ Bereits 1858 fungierte Ikaalinen als Handels- und Verwaltungszentrum in der Provinz Satakunta, seit 1982 zählt die Stadt zur Provinz Pirkanmaa.

${ }^{96}$ Kiikoinen gehört heute zur Provinz Pirkanmaa.

${ }^{97}$ Kankaanpää und Kokemäki haben heute Stadtrechte.

${ }^{98}$ Lappi/TL steht für 'Lappi, Turun Lääni' (Lappi, Regierungsbezirk Turku), um nicht mit der Provinz Lappland (finn. Lappi) verwechselt zu werden.

${ }^{99}$ Loimaa zählt seit 1992 als Stadt zur Provinz Varsinais-Suomi.
} 
Bereits im 18. Jahrhundert hatten sich in Süd-Ostbottnien die Teerbrennerei und der Segelschiffsbau als Nebenerwerbsbereiche zur traditionellen Landwirtschaft etablieren können. Für zahlreiche Bauern stellten sie sogar die Haupteinnahmequelle dar. Der Segelschiffsbau konzentrierte sich auf die südostbottnische Küstenregion, die von ihm abhängige Teerbrennerei wurde in erster Linie in den finnischsprachigen Gemeinden ohne direkten Küstenzugang betrieben. Beide Erwerbszweige waren eng miteinander verbunden, da der in Süd-Ostbottnien gebrannte Teer sowohl als das wichtigste Exportgut der Region galt als auch für den Segelschiffsbau unabdingbar war. Dementsprechend traf der wirtschaftliche Rückgang, der sich vor allem in den letzten Jahrzehnten des 19. Jahrhunderts in den beiden genannten Erwerbszweigen bemerkbar machte, die südostbottnischen Bauern hart.

Bis in die 1870er Jahre hinein waren in zahlreichen Gemeinden der schwedischsprachigen Küstenregion kleine bis mittelgroße Segelschiffe gebaut worden. In den meisten Fällen hatten sich mehrere Bauern als Reeder zusammengeschlossen, die sowohl den Unterhalt der kleinen Werften finanzierten als auch Kapitäne und Seeleute für ihre Warentransporte anwarben. Mit zunehmender Verbreitung von Dampfschiffen auf europäischen Gewässern verloren die kleinen hölzernen Handelsschiffe Finnlands ihre internationale Wettbewerbsfähigkeit ${ }^{100}$. Da in Finnland zudem das Kapital für eine zeitgemäße Erneuerung der Handelsflotte fehlte, wurden finnische Handelswaren häufig von ausländischen Schiffen in die Hafenstädte der europäischen Handelsmetropolen transportiert. Lediglich in der einheimischen Küstenschiffahrt konnten sich hölzerne Segelschiffe bis über die Jahrhundertwende hinaus behaupten.

Im ausgehenden 19. Jahrhundert kam der einheimische Schiffsbau dann fast völlig zum Erliegen ${ }^{101}$, wobei sich der Rückgang in der Schiffsproduktion an der schwedischsprachigen Küste Süd-Ostbottniens noch frühzeitiger und schneller vollzog als in den Küstenregionen Südwestfinnlands. Die Eindämmung der Handelskontakte mit Schweden, verursacht durch die Zollschranke der schwedischen Krone des Jahres 1888,

\footnotetext{
${ }^{100}$ Zum Rückgang des einheimischen Schiffsbaus und dem damit einhergehenden Bedeutungsverlust der finnischen Handelsflotte vgl. Hautala 1956, S. 266-275; Jutikkala 1958, S. 356; Kaukiainen 1980 und 1991; Kummel 1980, S. 443-450; Virrankoski 1983, S. 153.

${ }^{101}$ Die durchschnittliche Größe des Gesamtvolumens der in Finnland gebauten Segelschiffe sank in den Jahren 1892-1910 von 139 auf 115 Bruttoregistertonnen, ohne daß ein Ausgleich durch einen verstärkten Dampfschiffahrtsbau stattgefunden hätte, vgl. Hautala 1956, S. 268f.
} 
begünstigten diese Entwicklung noch weiterhin. In wirtschaftlicher Hinsicht wurde Finnland in zunehmendem Maße abhängig von seinen Exporten nach Rußland ${ }^{102}$. In den finnischsprachigen Inlandsgemeinden Süd-Ostbottniens wiederum hatte die Teerproduktion ${ }^{103}$ eine große Rolle gespielt. In der Anfangsphase der Amerikaauswanderung, d.h. zu Beginn der 1870er Jahre, wurde noch die Hälfte des finnischen Teers in wenigstens 22 Gemeinden von Süd-Ostbottnien gebrannt, wobei sich die Gemeinden Isojoki, Kauhajoki, Alavus, Töysä und Soini zu lokalen Zentren der Teerproduktion entwickelt hatten. Da Pachtbauern das Teerbrennen untersagt war, wurde die Teergewinnung meist auf selbständigen Bauernhöfen betrieben, deren Besitzer zugleich über Waldgrundstücke und somit das Ausgangsprodukt für die Teerbrennerei verfügten. Die Teergewinnung bedurfte eines großen Arbeitskräfteaufgebots, was wiederum den landlosen Bevölkerungsgruppen zugute kam.

Doch durch den jahrhundertelangen verschwenderischen Umgang mit den natürlichen Holzvorkommen war der Rohstoff Holz allmählich knapp geworden. Immer häufiger fanden Baumstümpfe und Wurzelholz ihre Verwendung in der bereits rückläufigen Teerproduktion. Der Produktionsrückgang führte gleichzeitig zu einer Preisanhebung und auch zu Exporteinbußen. Lag das Volumen des Exports über die Hafenstadt Vaasa um 1870 noch bei ca. 80000 Tonnen Teer jährlich, so war es bis 1890 bereits auf ca. 20000 Tonnen gesunken. Als der finnische Teer schließlich der Konkurrenz von billigerem russischen Teer nicht mehr standhalten konnte, verlor der wichtigste Exportartikel der Region Süd-Ostbottnien seine Absatzchancen auf dem europäischen Handelsmarkt ${ }^{104}$. Diese Entwicklung bedeutete eine wirtschaftliche Talfahrt und führte zu einem Anstieg der Arbeitslosigkeit unter der landlosen Bevölkerung, was wiederum zur Folge hatte, daß das Ende der Teerproduktion in einigen Gemeinden des Seengebiets zeitlich mit dem Beginn der Amerikaauswanderung zusammenfiel $^{105}$.

Zur gleichen Zeit, als der Küstenschiffsbau und die Teerbrennerei allmählich im Verschwinden begriffen waren, geriet die traditionelle Landwirtschaft in Finnland

\footnotetext{
${ }^{102}$ Soininen 1974, S. 401.

${ }^{103}$ Ranta 1988, S. 644f.

${ }^{104}$ Hautala 1956, S. 305; Pulma 1988, S. 441; Ranta 1988, S. 656f.

${ }^{105}$ Hautamäki (unveröffentlichte Magisterarbeit von 1981, S. 68f.) führt exemplarisch die Gemeinden Soini und Lehtimäki an.
} 
immer mehr in eine Krise. Dies betraf auch die Region Süd-Ostbottnien, doch im Gegensatz zu anderen Landesteilen befand sie sich in einer besonders schwierigen Lage, da auf vielen Höfen das notwendige Kapital zur Einfürung der Milchviehwirtschaft mit dem dazugehörigen Futtermittelanbau fehlte.

Aufgrund der intensiven Holznutzung im Zeichen der Teerproduktion befanden sich die wenigen noch vorhandenen Waldgrundstücke in Süd-Ostbottnien nämlich in einem vergleichsweise schlechtem Zustand. Das Ende der Teerbrennerei hatte somit eine einschneidende Bedeutung für die Region, da der Einkommensverlust nicht durch Einnahmen aus der Forstwirtschaft ausgeglichen werden konnte, wie dies in anderen Landesteilen geschah.

Als Folge davon entstand in Süd-Ostbottnien gegen Ende des 19. Jahrhunderts eine Situation, die sich deutlich von der Entwicklung in anderen Landesteilen unterschied: Um die notwendig gewordenen, landwirtschaftlichen Innovationen durchzuführen, waren neue Nebenerwerbsquellen gefragt. Da sich jedoch in SüdOstbottnien kaum nennenswerte Industriebetriebe ansiedeln wollten ${ }^{106}$, von einigen Ziegeleien, Glasfabriken und kleineren Hausindustriebetrieben abgesehen, blieb die Anzahl der Erwerbsalternativen für die Landbevölkerung gering. Lediglich in den Küstenregionen konnte der Fischfang einigen Familien einen finanziellen Ausgleich bieten.

Das Ergebnis dieser Entwicklung bedeutete eine zwangsläufige Intensivierung des Brotgetreideanbaus in Süd-Ostbottnien, obwohl diese Maßnahme den Modernisierungstendenzen der zeitgenössischen Landwirtschaft widersprach ${ }^{107}$. Demzufolge nahm die landwirtschaftliche Wettbewerbsfähigkeit der Provinz SüdOstbottnien zunehmend ab und die Bevölkerung verarmte.

Die Beschäftigungsmöglichkeiten im Rahmen der traditionellen Landwirtschaft konnten dem Bevölkerungswachstum nicht standhalten, woraufhin schon bald eine relative Überschußbevölkerung entstand. Obwohl ein Teil dieser landbesitzlosen Bevölkerungsschichten in die Waldgebiete Mittel-Finnlands oder in die südlicher gelegenen Industriezentren abwanderte, war der Nährboden für die aufkeimende Amerikabegeisterung in der Region geschaffen.

\footnotetext{
${ }^{106}$ Toivonen (1963, S. 111) belegt für das Jahr 1884 die Existenz von lediglich fünf Sägewerken in Süd-Ostbottnien, die insgesamt 77 Arbeiter beschäftigten. Zur Entwicklung der südostbottnischen Hausindustrie vgl. Yli-Jokipii 1967, S. 96-100.

${ }^{107}$ Soininen 1974, S. 304 und S. 402.
} 
Auch in der Provinz Satakunta waren die Erträge aus der Landwirtschaft geringer als in den meisten anderen Landesteilen. Vor allem die nördlich gelegenen Gemeinden, welche an die Provinz Süd-Ostbottnien angrenzten und die höchsten Auswandererkonzentrationen aufwiesen, waren besonders auf die Getreideeinfuhr angewiesen $^{108}$. Anhand einer Stichprobenuntersuchung von zwölf Gemeinden hat Kero für die Jahre 1911-15 eine Korrelation von besonders niedrigen Landwirtschaftserträgen und hohen Auswandererzahlen ermitteln können ${ }^{109}$.

Ein Hauptproblem der Region Satakunta war die starke Repräsentanz der landlosen Bevölkerung. In der Inlandsgemeinde Huittinen beispielsweise war der Anteil der landlosen Bevölkerung größer der Anteil der Bauern und Pachtbauern zusammengenommen, obwohl die Gemeinde zugleich als eines der am besten entwickelten ländlichen Gebiete Finnlands galt ${ }^{110}$. In der Regel waren die selbständigen wie auch die gepachteten Bauernhöfe klein. So wurden in der Küstengemeinde Merikarvia lediglich auf 25 von insgesamt 488 Höfen mehr als fünf Hektar Ackerland bewirtschaftet. Andererseits war auch die Existenz von Gutsherrenhöfen, deren Größe 150 Hektar überstieg, typisch für die Region ${ }^{111}$.

Die meisten Bewohner Satakuntas waren, ebenso wie die Süd-Ostbottnier, auf Beschäftigungsmöglichkeiten außerhalb der Landwirtschaft angewiesen. In Satakunta hatte die Teerbrennerei lediglich eine Erwerbsalternative dargestellt, wonach die Abhängigkeit von diesem Wirtschaftsfaktor nicht mit der Situation in Süd-Ostbottnien zu vergleichen war. Stattdessen konnten sich in Satakunta während des gesamten 19. Jahrhunderts die Forstwirtschaft $^{112}$, das Handwerk ${ }^{113}$ und die Kleinindustrie, wie Wollspinnereien oder die Böttcherindustrie, sowie in den Küstengemeinden auch die Fischerei ${ }^{114} \mathrm{zu}$ wichtigen Wirtschaftsbereichen entwickeln.

\footnotetext{
${ }^{108}$ Kero (unveröffentlichte Lizentiatsarbeit) 1970, S. 63. Auch in Süd-Ostbottnien wurde gegen Ende des 19. Jahrhunderts Brotgetreide, insbesondere Roggen, eingeführt, vgl. Toivonen 1963, S. 80-82.

${ }^{109}$ Kero (unveröffentlichte Lizentiatsarbeit) 1970, S. 59-62.

${ }^{110}$ Alapuro 1995, S. 23 und S. 35.

${ }^{111}$ Heervä 1980, S. 78; Santavuori 1981.

${ }^{112}$ Zur Entwicklung der Forstwirtschaft siehe Kero (unveröffentlichte Lizentiatsarbeit) 1970, S. 66-70; Heervä 1980, S. 83-87.

${ }^{113}$ In Huittinen wurde jeder zehnte Haushalt durch einen Handwerksbetrieb ernährt, vgl. Alapuro 1995, S. 37.

${ }^{114}$ In Merikarvia wurde z. B. die Hälfte des gesamten Provinzertrages an Baltischem Hering gefischt und konserviert, vgl. Heervä 1980, S. 82.
} 
Dementsprechend hatten die Entwicklungen in der Forstwirtschaft einen entscheidenden Einfluß auf die Region. Schon während des gesamten 19. Jahrhunderts waren in Satakunta zahlreiche kleine Sägewerke entstanden ${ }^{115}$. Bereits gegen Ende des Jahrhunderts wurden die größten dieser Sägewerke modernisiert, d.h. Wasser- durch Dampfkraft ersetzt, und somit die vorhandenen Produktionskapazitäten effektiver ausgeschöpft. Innerhalb der beiden Jahrzehnte 1878-98 verfünffachte die regionale Sägewerksindustrie ihre Produktion und schuf auch eine steigende Nachfrage an Arbeitskräften für Wald- und Flößarbeiten. Diese neuen Erwerbsmöglichkeiten wußte insbesondere die landlose Bevölkerung zu nutzen, selbst wenn die Waldarbeit die Arbeitswanderung in entlegenere Teile der Provinz mit sich brachte ${ }^{116}$.

Anders als in Süd-Ostbottnien fanden sich demnach in Satakunta Nebenerwerbsalternativen, die den Rückgang der Einnahmen aus Landwirtschaft und Teerbrennerei auffangen konnten. Möglicherweise könnte dies als ein Grund für die relativ geringere Auswanderungsintensität der gesamten Provinz Satakunta angesehen werden. Lediglich in den nördlichen Gemeinden der Region wurden ähnliche Auswandererzahlen registriert, wie sie in nahezu allen Gemeinden Süd-Ostbottniens üblich waren.

\subsubsection{Die Bevölkerungsentwicklung}

Im Finnland des ausgehenden 19. Jahrhunderts hatten Flurbereinigungen und die Modernisierungsmaßnahmen der Landwirtschaft zu zahlreicheren und immer größeren Ackerbauflächen geführt. Da die Bevölkerung jedoch schneller wuchs als das durch Neurodung und Trockenlegung von Sümpfen gewonnene, zusätzliche Ackerbauland ${ }^{117}$, existierten gegen Ende des Jahrhunderts pro Kopf weniger Hektar an landwirtschaftlich nutzbarem Land als zu dessen Beginn. Vor allem in dem für diese Untersuchung relevanten halben Jahrhundert, in der Zeitspanne von 1865 bis 1914, wuchs die

\footnotetext{
${ }^{115}$ Um 1900 existierten allein in der Gemeinde Merikarvia in Satakunta 13 Sägewerke, im Gegensatz zu lediglich fünf Sägewerken der gesamten Provinz Süd-Ostbottnien, vgl. Heervä 1980, S. 85.

${ }^{116}$ Kero (unveröffentlichte Lizentiatsarbeit) 1970, S. 69f.

${ }^{117}$ Toivonen 1963, S. 80; Kero (unveröffentlichte Lizentiatsarbeit) 1970, S. 62.
} 
finnische Gesamtbevölkerung von 1.843200 auf 3.069500 Personen an, was einer Zuwachsrate von $66,5 \%$ entspricht ${ }^{118}$.

Der allgemeine Trend bewirkte, daß die Geburtenrate stetig über der Sterblichkeitsrate lag. Diese Entwicklung wurde vor allem durch die kontinuierlich sinkende Säuglingssterblichkeit ${ }^{119}$ sowie die allgemein verbesserte medizinische Versorgung der Gesamtbevölkerung verursacht. Des weiteren wirkte sich ein niedriges Heiratsalter der Frauen positiv auf die Kinderanzahl pro Ehepaar aus, so daß die finnische Bevölkerung schneller wuchs als die in der Gesellschaft vorhandenen Erwerbsmöglichkeiten. Es entstand ein zeitweiliger Bevölkerungsdruck, der sein soziales Ventil in der Amerikaauswanderung fand. Dennoch ist festzuhalten, daß erst die Diskrepanz zwischen zunehmender Bevölkerungsgröße und abnehmender Anzahl traditioneller Erwerbsbereiche diese relative Überschußbevölkerung schuf ${ }^{120}$.

Um nun zu erörtern, wie sich die Amerikaauswanderung auf den Bevölkerungszuwachs in den beiden Provinzen des Untersuchungsgebietes ausgewirkt hat, läge eine komparatistische Untersuchung der Bevölkerungsentwicklung des Untersuchungsgebietes mit Gesamtfinnland nahe. Bei näherer Betrachtung der amtlich registrierten Bevölkerungszahlen gestaltet sich ein solcher Vergleich jedoch als problematisch: Die Nettoauswanderung wurde lediglich bei Erstellung der Bevölkerungszahlen für Gesamtfinnland, nicht jedoch bei den Zahlenwerten für die genannten Provinzen berücksichtigt. Da nämlich für das Zustandekommen der Bevölkerungsstatistiken die Kirchenbucheintragungen, d.h. alle in einer Kirchengemeinde registrierten Geburten, auschlaggebend waren, geben die amtlichen Zahlenwerte keine Auskunft über die Aus- und Rückwandererzahlen bzw. die Nettoauswanderung aus den entsprechenden Gemeinden.

Aus diesem Grund vergleicht Toivonen lediglich die absoluten Zahlenwerte miteinander, d.h. die Anzahl aller registrierten Geburten in Süd-Ostbottnien und Gesamtfinnland, nicht jedoch die Anzahl aller tatsächlich in der Provinz bzw. im ganzen Land lebenden Einwohner. Die Autorin räumt jedoch ein, daß sich die Fehlerquote ihrer

\footnotetext{
${ }^{118}$ Vattula 1983, S. 17-19, Tab. 1.3.

${ }^{119}$ Starben 1870 noch $17 \%$ aller Neugeborenen innerhalb des ersten Lebensjahres, so waren es 1900 nur noch 13\%, vgl. Rasila 1982, S. 133; Valkonen 1985b, S. 23, Abb. 1.7.

${ }^{120}$ Kilpi (1917, S. 77-87) hat bereits zu Beginn des Jahrhunderts auf den Zusammenhang zwischen Überschußbevölkerung und verstärkter Auswanderung hingewiesen.
} 
Angaben mit zunehmender Auswanderungsfrequenz vergrößert ${ }^{121}$. Gänzlich unbeachtet läßt Toivonen den Faktor der sich schnell ändernden Provinzgröße, d.h. die sich nahezu jährlich verändernde Anzahl von ländlichen Gemeinden in den Provinzen.

Letzteres Problem erschwert denn auch den Vergleich des Bevölkerungszuwachses in den Provinzen Satakunta und Süd-Ostbottnien während des Untersuchungszeitraumes. Offizielle Statistiken basieren nämlich auf einer Einteilung der Gemeinden und Städte nach Regierungsbezirken. Letztere stellen jedoch keine homogenen ökonomischen, demographischen und ethnischen Regionen dar wie die landschaftlich geprägten Provinzen, die zugleich kleinere geographische Einheiten repräsentieren $^{122}$. Demzufolge sind Vergleiche auf dem Niveau von Regierungbezirken zwar möglich, bleiben jedoch unbefriedigend. Vergleiche auf dem Niveau von

Provinzen wiederum gestalten sich aufgrund fehlender Eingrenzungskriterien als nahezu unmöglich, da die tatsächliche Größe der Provinzen während des Untersuchungszeitraumes nicht mehr rekonstruierbar ist.

In Tabelle 5 im Anhang ${ }^{123}$ sind denn auch lediglich die statistisch erfaßten Volkszählungsangaben der 40 Gemeinden, welche die Herkunftsorte der Briefschreiber darstellen, einander gegenüber gestellt worden. Die Zahlenwerte beruhen auf den Angaben der Kirchenbücher der jeweiligen Gemeinden, d.h. sie geben den Stand aller registrierten Geburten am 31.12.1865 bzw. 31.12.1914 wieder; die Dezimierung der tatsächlichen am Ort lebenden Bevölkerung durch Binnen- und Auswanderung wurde nicht berücksichtigt. Demzufolge kann der jährliche Bevölkerungszuwachs für die einzelnen Gemeinden auch lediglich als statistischer Durchschnittswert verstanden werden, ebenso wie die Bevölkerungszuwachsraten in den einzelnen Gemeinden für den Zeitraum 1865-1914 lediglich als Tendenzwerte anzusehen sind.

Trotz dieses Ungenauigkeitsfaktors läßt sich festhalten, daß der jährliche Bevölkerungszuwachs in den meisten Gemeinden Süd-Ostbottniens zwischen 1\%-2,5\% lag, doch in der Provinz Satakunta höchstens 1,5\% betrug.

Für den Untersuchungszeitraum 1865-1914 lag die Zuwachsrate der Bevölkerung für Gesamtfinnland bei 66,5\%, was einer durchschnittlichen Zuwachsrate

\footnotetext{
${ }^{121}$ Toivonen 1963, S. 77.

${ }^{122} \mathrm{Zu}$ diesem Einteilungsproblem siehe Geer de/Wester 1975, S. 25.

${ }^{123}$ Siehe Tabelle 5 im Anhang: Durchschnittlicher jährlicher Bevölkerungszuwachs in 40 Gemeinden der Provinzen Süd-Ostbottnien und Satakunta 1865-1914 (Untersuchungsgebiet).
} 
von $1,3 \%$ pro Jahr entsprach ${ }^{124}$. Der Vergleich mit den Herkunftsgemeinden der Briefschreiber zeigt deutlich, daß der Bevölkerungszuwachs in beiden

Untersuchungsgebieten stärker war als im Landesdurchschnitt. In sieben Gemeinden der Provinz Satakunta und in dreizehn Gemeinden der Provinz Süd-Ostbottnien übertraf das Bevölkerungswachstum die Zuwachsrate des Landesdurchschnitts.

Die südostbottnische Stadt Vaasa, bis 1917 im administrativen Sprachgebrauch auch Nikolaistadt genannt, bildete mit einer Zuwachsrate von $437 \%$ innerhalb des Untersuchungsgebietes eine Ausnahme. Wie auch in anderen Industrie- und Hafenstädten bedingte eine starke Zuwanderung von Einwohnern ländlicher Gebiete diesen explosiven Bevölkerungszuwachs, der einer Vervierfachung der städtischen Bevölkerung innerhalb eines halben Jahrhunderts gleichkam ${ }^{125}$.

An der Schwelle zum Industriezeitalter herrschte im allgemeinen ein Geburtenüberschuß, d.h. daß die Anzahl der Geburten kontinuierlich über der Anzahl der Sterbefälle lag. Außerdem machte sich der durch Binnen- und Auswanderung verursachte Bevölkerungsverlust vor allem im Emigrationsgebiet, d.h. den Regionen, in denen die jährliche Auswanderungsfrequenz durchschnittlich fünf Personen pro Einwohnertausend überstieg, bemerkbar ${ }^{126}$.

Obwohl alle südostbottnischen Gemeinden dem Auswanderungsgebiet zuzurechnen sind, wodurch sie wesentlich stärker von einem Bevölkerungsverlust durch Auswanderung betroffen waren als die meisten anderen finnischen Gemeinden, ist der starke Bevölkerungszuwachs dieser Region auffallend.

Diese Beobachtung läßt sich auch für die nördlichen Gemeinden der Provinz Satakunta machen, wie beispielsweise für Jämijärvi, Karvia, Ikaalinen und Kankaanpää, die ebenfalls sowohl zum Auswanderungsgebiet zählten als auch durch eine hohe Zuwachsrate ihrer regionalen Bevölkerungsentwicklung geprägt waren.

In quellenkritischer Hinsicht gestaltet sich diese Verknüpfung von Auswanderungsintensität und Bevölkerungswachstum auf Gemeindeniveau jedoch als problematisch, da wie bereits erwähnt, die hier dargestellten Bevölkerungszuwachsraten lediglich als Anhaltspunkte zu verstehen sind. Ohne Berücksichtigung der

\footnotetext{
${ }^{124}$ Strömmer 1969, S. 39-57; Valkonen 1985b, S.14-29.

${ }^{125}$ Zur Städteentwicklung in Finnland siehe Jutikkala 1983.

${ }^{126}$ Zur Kartierung des Auswanderungsgebietes siehe Karte 2 im Anhang: Prozentuale Verteilung der Auswandererkonzentration in Finnland 1870-1914.
} 
Nettoauswanderung in den offiziellen Statistiken zur jährlichen Bevölkerungsgröße wird der tatsächliche Bevölkerungszuwachs nicht exakt zu ermitteln sein.

Auf diese Problematik weisen auch die Autoren Nygård und Ranta hin ${ }^{127}$. In mehreren Untersuchungen über den Bevölkerungszuwachs verschiedener Teilregionen der Provinz Süd-Ostbottnien basieren ihre Angaben ebenfalls auf den offiziellen Zahlenwerten des Zentralamtes für Statistik in Helsinki und sind somit unpräzise. Dennoch lassen sich ihre Beobachtungen über den zeitlichen Verlauf des regionalen Bevölkerungszuwachses auf das hier zu behandelnde Untersuchungsgebiet übertragen: Obwohl der Bevölkerungszuwachs für den gesamten Untersuchungszeitraum positiv ausfiel, wirkte sich die Auswanderung vor allem in den 1890er Jahren sowie zu Beginn des 20. Jahrhunderts verlangsamend auf den Bevölkerungszuwachs aus, d.h. daß der regionale Bevölkerungszuwachs eine rückläufige Tendenz aufwies ${ }^{128}$. Demzufolge wuchs während der drei Jahrzehnte von 1880 bis 1910 die durchschnittliche Bevölkerung in anderen Landesteilen, die weniger stark von der Auswanderung betroffen waren, schneller als im Emigrationsgebiet ${ }^{129}$.

Das gleiche Ergebnis wird denn auch von Forsberg in einer Detailuntersuchung über die schwedischsprachigen Küstengemeinden Süd- und Mittelostbottniens sowie von Heervä in einer Mikrostudie über die Küstengemeinde Merikarvia in NordSatakunta bestätigt ${ }^{130}$. Demnach sank die positive Zuwachsrate der Bevölkerung aus Gebieten mit starker Auswanderungsfrequenz in den Jahren 1870-1900 kontinuierlich, um in der Dekade 1900-10 in eine kurzzeitige Bevölkerungsdezimierung umzuschlagen $^{131}$.

In der Provinz Süd-Ostbottnien war jedoch nicht nur die Wachstumsintensität, sondern auch die Bevölkerungsdichte regionalen Schwankungen unterworfen. Das traditionelle landwirtschaftliche Anbaugebiet entlang des Ufers des Kyrö-Flußes wies die größte Bevölkerungsdichte auf, die südlich gelegene Region an der Grenze zur Provinz Satakunta wiederum die niedrigste. Mehr als jeweils 11000 Einwohner lebten in

\footnotetext{
${ }^{127}$ Nygård (1983, S. 30-74, bes. S. 30) und Ranta (1988, S. 896-902 und S. 925) untersuchen den Bevölkerungszuwachs im finnischsprachigen Seengebiet bzw. im finnischsprachigen Teil SüdOstbottniens, der auch das Seengebiet mit einschließt.

${ }^{128}$ Dieses Phänomen wird auch von Toivonen (1963, S. 76-79) bestätigt.

${ }^{129}$ Valkonen 1985b, S. 207; Ranta 1988, S. 899.

${ }^{130}$ Forsberg 1977, S. 213-219; Heervä 1980, S. 72-77.

${ }^{131}$ Für den ostbottnischen Küstenstreifen lag die negative Zuwachsrate in den Jahren 1900-10 bei $-8,1 \%$, vgl. Forsberg 1977, S. 219, Tab. 3 .
} 
den Gemeinden Kauhajoki, Jalasjärvi, Ilmajoki und Lapua, weniger als jeweils 3000 Einwohner hingegen in Lehtimäki, Karijoki und Ylihärmä. Das

Bevölkerungsaufkommen in den übrigen Gemeinden bewegte sich zwischen diesen Zahlenwerten $^{132}$.

Zusammenfassend läßt sich festhalten, daß sich die hier behandelten Gemeinden der Provinzen Satakunta und Süd-Ostbottnien stärker im Hinblick auf die Auswanderungsintensität als im Bezug auf das Bevölkerungswachstum voneinander unterscheiden. Während in Süd-Ostbottnien alle Gemeinden stark von der Auswanderung betroffen waren, so traf dies in Satakunta nur für den nördlichen Bereich der Region zu. Der Bevölkerungszuwachs hingegen war in beiden Provinzen stark ausgeprägt. In Süd-Ostbottnien und Nord-Satakunta gab es keine einzige Gemeinde mit hoher Geburtenrate und niedriger Auswanderungsfrequenz, wohingegen in Süd-

Satakunta sowie in anderen Landesteilen durchaus solche Regionen zu finden waren ${ }^{133}$.

Daraus läßt sich folgern, daß der starke Bevölkerungszuwachs allein kein ausschlaggebender Grund für die hohe Überseemobilität aus Süd-Ostbottnien und dem nördlichen Bereich von Satakunta gewesen sein kann, wohl aber eine verstärkende Funktion ausgeübt hat. Erst das Zusammenwirken mehrerer Faktoren, von denen der starke Bevölkerungszuwachs lediglich einen Faktor darstellte, hat den Nährboden für die überdurchschnittlich hohe Auswanderungsintensität in der Region geschaffen. Ohne an dieser Stelle auf die sogenannten 'Pull-Faktoren', d.h. auf die Anziehungskraft des nordamerikanischen Arbeitsmarktes eingehen zu wollen, sei für Süd-Ostbottnien vor allem die landwirtschaftliche Krise bei gleichzeitigem Mangel an alternativen Erwerbsmöglichkeiten genannt.

Aufgrund dessen bewertet Alapuro Süd-Ostbottnien zur Zeit der Jahrhundertwende auch als eine separate Region Finnlands, die zwischen den fortschrittlichen und weniger fortschrittlichen Landesteilen lag ${ }^{134}$. Durch den relativ späten Rückgang der traditionellen Nebenerwerbsbereiche Teerbrennerei und Schiffsbau fiel die wirtschaftliche Rückständigkeit Süd-Ostbottniens erst mit dem zunehmenden Einfluß der Industrie und der Forstwirtschaft in anderen Landesteilen ins

\footnotetext{
${ }^{132}$ Ranta 1988, S. 896-900 und S. 920, Abb. 65.

${ }^{133}$ Kero (unveröffentlichte Lizentiatsarbeit) 1970, S. 56.

${ }^{134}$ Alapuro 1988, S. 66-81.
} 
Gewicht $^{135}$. Dadurch enstand eine ökonomische Situation, die von zahlreichen Auswanderungswilligen als Sackgasse empfunden wurde.

Die Massenauswanderung als Lösungsversuch der regionalen und sozialen Probleme blieb denn auch nicht ohne Folgen für die gesellschaftlichen Entwicklungen der Provinzen Süd-Ostbottnien und Satakunta: Die jahrelange oder permanente Abwesenheit eines Zehntels der Regionalbevölkerung ${ }^{136}$ wirkte sich in positiver Weise auf den Bevölkerungsdruck aus. Andererseits führte jedoch die jahrzehntelange starke Auswanderung, vorwiegend junger Männer im heiratsfähigen Alter, zu einer rückläufigen Anzahl von Eheschließungen und Geburten, so daß das Gleichgewicht der Geschlechter innerhalb der Regionalbevölkerung zu Beginn des 20. Jahrhunderts bereits aus dem Lot geraten war.

Die Folge davon war ein deutlicher Frauen- und Kinderüberschuß, der sich vor allem aus den sogenannten Amerikawitwen und ihren Kindern rekrutierte. Meist ließ ein verheirateter männlicher Auswanderer nämlich seine Frau und durchschnittlich fünf Kinder zurück, um entweder seine Familie einige Jahre später nachreisen zu lassen oder aber innerhalb von fünf Jahren selbst wieder zurückzukehren ${ }^{137}$. Allerdings hat Nygård, anhand einer Stichprobenuntersuchung für das Jahr 1892, in sieben südostbottnischen Gemeinden durchschnittlich 1,9 zurückgelassene Familienmitglieder pro männlichen Auswanderer ermitteln können, wonach die Emigranten dieser

Stichprobenuntersuchung sehr jung gewesen sein müssen ${ }^{138}$.

Im schlimmsten Fall brach der Familienvater den Kontakt zu seiner Familie ab und kehrte nie wieder nach Finnland zurück. Ebenso konnte der plötzliche Tod des Ernährers bedingt durch ein Grubenunfall oder eine Krankheit aus den Amerikawitwen im Handumdrehen tatsächliche Witwen machen, und nur wenige Angehörige von in Amerika verstorbenen Einwanderern erhielten eine Schadensersatzleistung durch einen Fond für Gruben- oder Industriearbeiter. Blieb das dringend benötigte Geld, das für den Lebensunterhalt der Familie über den Atlantik geschickt wurde, nämlich aus, stand vielen Familien der soziale Abstieg zu Almosenempfängern der kommunalen

\footnotetext{
${ }^{135}$ Soininen 1974, S. 402.

${ }^{136}$ Kero 1974, S. 230.

${ }^{137}$ Nygård 1983, S. 126. Zu Amerikawitwen siehe auch Fågelbärj 1985, S. 141-145.

${ }^{138}$ In keinem einzigen Fall ließ eine weibliche Auswanderin ihren Ehemann und die gemeinsamen Kinder zurück, vgl. Nygård 1983, S. 125.
} 
Armenfürsorge bevor, ein Schicksal, daß auch von finnischen Auswanderungsgegnern mahnend heraufbeschworen wurde ${ }^{139}$.

Doch nicht nur die vernachlässigten Familien von Auswanderern bereiteten den Gemeinderäten Kopfzerbrechen, sondern auch die aus dem Lot geratene Altersstruktur der Regionalbevölkerung. Denn wie bereits dargestellt, schlug der sich verlangsamende Bevölkerungszuwachs im Emigrationsgebiet nach der Jahrhundertwende in einen Bevölkerungsrückgang um. Schuld daran trug in erster Linie eine rückläufige Geburtenrate, die wiederum durch die dauerhafte Abwesenheit junger Männer im heiratsfähigen Alter und zugleich stark zunehmende Frauenauswanderung verursacht wurde.

Als Folgeerscheinung veränderte sich die Altersstruktur der Regionalbevölkerung dahingehend, daß die Altersgruppe der 50-70jährigen, die durch die Abwanderung der jungen Leute ohnehin schon überdurchschnittlich groß war, weiterhin anstieg. Dieses Altersungleichgewicht schuf hinsichtlich des regionalen Arbeitskräftepotentials neue Probleme. Der Massenexodus der jungen Männer zwischen 20 und 35 Jahren hatte einen Arbeitskräftemangel vor allem im landwirtschaftlichen Bereich zur Folge, der erst in den 1920er Jahren allmählich durch Zuzug von Arbeitskräften aus anderen Landesteilen ausgeglichen werden konnte. Paradox erscheint diese Situation insofern, als ein Großteil der Auswanderer gerade aufgrund fehlender regionaler Erwerbsmöglichkeiten bzw. eines niedrigen Lohnniveaus die Amerikaüberquerung angetreten hatte. Es bleibt demnach zu bezweifeln, daß sich die Lebensbedingungen der Zurückgebliebenen tatsächlich durch eine Entlastung des Bevölkerungsdrucks in entscheidender Weise verbessert hatten.

\subsection{Quellen zur Auswandererfassung}

Um Aussagen über Umfang und Verlauf der finnischen Amerikaauswanderung treffen zu können, ist die Beschäftigung mit Paßverzeichnissen und Passagierlisten verschiedener finnischer und schwedischer Reedereien unumgänglich. Diese Quellengattungen sind, neben sporadisch geführten Kirchenbucheintragungen, die einzigen in Finnland archivierten historischen Dokumente der statistischen

\footnotetext{
${ }^{139}$ Siehe den Bericht von Teijula (1921), in dem die Auswirkungen der Emigrationsbewegung auf ländliche Gemeinden in Finnland aus der Zeitzeugenperspektive - in überraschend objektiver Weise - beschrieben werden.
} 
Emigrantenerfassung. Vor allem die Zusammenstellung der Personendaten aus Passagierlisten verschiedener Reedereien ergibt ein annähernd vollständiges Gesamtbild der finnischen Überseeauswanderung, wobei die in regionalen Amtsstuben geführten Paßverzeichnisse als wertvolle Ergänzungsquellen dienen. Ein Vergleich mit der Quellenlage anderer europäischer Länder, die im Verhältnis zur jeweiligen Landesbevölkerung weitaus stärker von der Auswanderungserscheinung betroffen waren als Finnland, macht deutlich, daß die Quellenlage in Finnland als ungewöhnlich gut zu bewerten ist und von daher keineswegs eine Selbstverständlichkeit darstellt ${ }^{140}$.

Eine weitere Quellengattung bilden die Verzeichnisse zur Immigrantenerfassung in Amerika, da alle Immigranten direkt am Anlegehafen nach Nationalitäten getrennt behördlich registriert wurden. In diesen Namenslisten sind die Finnen jedoch nur noch teilweise identifizierbar, da sie vor 1917, dem Jahr der finnischen Unabhängigkeitserklärung, mal als Russen und mal als Finnen gezählt wurden ${ }^{141}$ oder aber ihre Namen aufgrund von Verständigungsschwierigkeiten bis zur Unkenntlichkeit verändert wurden. Auch in Kanada wurden die vor 1901 eingereisten Finnen nicht als eigene Ethnie registriert.

Des weiteren gibt Kero zu bedenken, daß diese Verzeichnisse, die vor allem aus der Einwandererstation 'Ellis Island' bei New York erhalten geblieben sind, neben vielen Ungenauigkeiten und Fehlernauch aufgrund der immensen Datenmenge Probleme in der Handhabung bereiten. Im Gegensatz zur Auswertung der Daten aus den Volkszählungen, welche in Zehnjahresabständen in den Vereinigten Staaten nach Bundesstaaten und in Kanada nach Provinzen durchgeführt wurden, haben finnische Emigrationsforscher keine Versuche unternommen die Einwandererverzeichnisse der amerikanischen Hafenstädte genauer zu analysieren.

Dennoch hat das Immigrationsmuseum „Ellis Island“ in den letzten Jahren seine Aktenbestände größtenteils digitalisiert. Über das Internet sind derzeit der Name, der Herkunftsort - häufig jedoch nur mit Finnland oder Vaasa angegeben - das

\footnotetext{
${ }^{140}$ Als ein Beispiel führt Virtanen (1979, S. 43) Griechenland an, dessen Emigrationsforscher das Fehlen sämtlicher Statistiken zur Erfassung von Auswanderern bemängeln.

${ }^{141}$ Zur Einwandererregistrierung von Finnen in Amerika und Kanada siehe Ferenczi/Willcox 1969, S. 775. Vor 1901 wurden die Finnen in Kanada nicht als eigene Ethnie registriert, vgl. Kero 1976b, S. 7-16; Lindström-Best 1981c, S. 16-20.
} 
Einwanderungsjahr sowie das Alter des Einwanderers bei der Ankunft in New York, abrufbar $^{142}$.

Als weitere wichtige Datengrundlage wären die Zensus-Daten der offiziellen Volkszählungen zu nennen, welche sowohl in den USA als auch in Kanada im Zehnjahresabstand durchgeführt wurden. Diese Daten geben Aufschluß über die Anzahl aller in Finnland geborenen Personen, als 'foreign-born' kenntlich gemacht, die sich in verschiedenen Regionen Amerikas und Kanadas zum Zeitpunkt der Erhebung aufhielten. Aus der heutigen Perspektive wäre eine Rekonstruktion der geographischen Verteilung der Finnen in der Neuen Welt ohne diese zu Beginn des Jahrhunderts erhobenen Volkszählungsdaten nicht mehr möglich. Insbesondere Immigrationsforscher aus Amerika und Kanada, in vielen Fällen finnische Auswanderer der zweiten und dritten Generation, haben die Zensus-Daten interpretiert ${ }^{143}$.

\subsubsection{Die Bedeutung der Paßverzeichnisse für die Emigrationsforschung}

Für die Untersuchung des Ausmaßes der finnischen

Amerikaemigrationsbewegung sind die in Finnland erstellten Quellen von vorrangiger Bedeutung. Obwohl der Vergleich von Passagierlisten verschiedener Reedereien ein vollständigeres Bild über das Gesamtvolumen der Auswanderungsbewegung gibt als die Betrachtung von Paßverzeichnissen, dürfen die Paßverzeichnisse als einzige offiziell erstellte, historische Dokumente der staatlichen Emigrantenerfassung nicht übergangen werden. Da sie zudem die Grundlage für die vielbeachtete, wenn auch fehlerhafte Emigrationsstatistik des Statistischen Zentralamtes in Helsinki bilden, soll im Folgenden zuerst die Bedeutung der Paßverzeichnisse für die gegenwärtige Emigrationsforschung näher erläutert werden ${ }^{144}$.

\footnotetext{
${ }^{142}$ Kero (1970, unveröffentlichte Lizentiatsarbeit, S. 6) weist daraufhin, daß diese Verzeichnisse auf unterschiedlichen Quellen beruhen, deren Zuverlässigkeit nicht mehr überprüfbar ist. Auf das Handhabungsproblem der Einwandererverzeichnisse weist ebenso Sommer hin, vgl. Helbich/Kamphoefner/Sommer 1988, S. 42. Siehe auch http://www.ellisisland.org. ${ }^{143}$ Als vielzitierte Autoren siehe z.B. Wasastjerna 1957, S. 51-55; Hoglund 1960, S. 121f.; Holmio 1967, S. 555-564; Kolehmainen 1977, S. 38-42.

${ }^{144}$ Zur Quellenkritik der Paßverzeichnisse vgl. Toivonen 1963, S. 252-258; Savolainen/Kokkonen 1964, S. 596-600; Kero (unveröffentlichte Litzentiatsarbeit) 1970, S. 4-6 und S. 25-31; 1974, S. 5-8 und S. 35-47; 1986, S. 26-33; Vainio 1974; Geer de/Wester 1975, S. 89-103; Virtanen 1979, S. 45-60.
} 
Einer ersten Paßverordnung des Jahres 1862 zufolge wurden in Finnland alle seit 1861 ausgegebenen Pässe, die für die temporäre Arbeitswanderung in ein anderes Land bestimmt waren, behördlich registriert ${ }^{145}$. Vor 1888, dem Inkrafttreten der zweiten Paßverordnung, konnte ein $\mathrm{Pa} ß$ nur für eine Auslandsreise beantragt werden, wobei die maximale Gültigkeitsdauer fünf Jahre nicht überschreiten durfte. Nach 1888 hingegen, d.h. zeitgleich mit dem starken Anwachsen der Auswanderungsbewegung, konnte der $\mathrm{Pa}$ innerhalb der unverändert gebliebenen Fünfjahresfrist für beliebig viele Auslandsreisen benutzt werden.

Bereits die erste Paßverordnung legte fest, daß lediglich die Gouverneure der einzelnen Regierungsbezirke, die Amtmänner größerer Städte sowie der Amtmann der Ålandinseln befugt waren, Pässe auszugeben und zugleich ein Verzeichnis aller ausgegebenen Pässe zu führen. Obwohl es für das Anlegen der Paßverzeichnisse keine allgemein verbindlichen Vorschriften gab, wurden in den meisten Fällen folgende Angaben registriert: Vor- und Zuname des Paßinhabers, Beruf, Geburtsdatum, gesellschaftlicher Stand, letzter Wohnort in Finnland, soziale Stellung bzw. zurückgelassenes Vermögen, Anzahl der zurückgebliebenen Familienmitglieder, Reisezielort, der meist nur mit einem Landesvermerk angegeben wurde, Datum der Paßausstellung, Gültigkeitsdauer des Passes, Paßausstellungsgebühr sowie mögliche zusätzliche Angaben.

Für die Emigrationsforschung sind neben Namen und Zielortangaben vor allem das Geburtsjahr und der Herkunftsort des Auswanderungswilligen von Bedeutung, da diese Angaben nicht in den Passagierlisten der Schiffahrtsgesellschaften verzeichnet wurden. Demzufolge ist die allgemeine Altersstruktur der Auswanderer auch nur anhand der Paßverzeichnisse zu ermitteln, ebenso wie zwei Auswanderer gleichen Namens lediglich auf der Grundlage ihrer Altersangabe und ihres Herkunftsortes zu identifizieren sind.

Die Paßverzeichnisse haben für die Emigrationsforschung insofern einen besonderen Stellenwert, als sie die Grundlage für die erste offizielle Auswandererstatistik des Statistischen Zentralamtes in Helsinki darstellen. Bis 1974 waren diese offiziellen Zahlenwerte die einzigen statistischen Angaben zum jährlichen Auswandereraufkommen. Erst in den vergangenen zwei Jahrzehnten ist es durch ein großangelegtes, historisch orientiertes Migrationsprojekt der Universität Turku

\footnotetext{
${ }^{145}$ Alle noch erhaltenen Paßverzeichnisse sind im finnischen Staatsarchiv in Helsinki (Kansallisarkisto) als Mikrofilmkopien einsehbar.
} 
gelungen, detailliertere Angaben über die jährlichen Aus- und Rückwandererzahlen zu ermitteln.

\subsubsection{Paßverzeichnisse als Grundlage der offiziellen Emigrationsstatistik}

Bereits im letzten Drittel des 19. Jahrhunderts war der kaiserliche Senat auf das Problem der wachsenden Überseemigration aufmerksam geworden und forderte seit 1883 und 1884 Abschriften der Paßverzeichnisse aus den Regierungsbezirken Vaasa und Oulu ein. Das Statistische Zentralamt in Helsinki wiederum wertete diese Daten im Hinblick auf die Amerikaemigration aus, so daß für die Zeiträume 1883-92 bzw. 188492 offizielle Statistiken über alle Amerika-Paßinhaber aus den Regierungsbezirken Vaasa und Oulu vorliegen. Seit 1893 gingen diese beiden Statistiken dann in die offizielle Emigrationsstatistik für Gesamtfinnland ein, die 1905 erstmals in einer dreibändigen Buchausgabe veröffentlicht wurde ${ }^{146}$.

Doch 1963 hat Toivonen als erste Kritikerin auf die Unzuverlässigkeit dieser offiziellen Zahlenwerte aufmerksam gemacht: Bei einem Vergleich der offiziellen Statistiken des Regierungsbezirks Vaasa des Zeitraumes 1883-92 mit den diesen Zahlenwerten zugrundeliegenden Quellen, nämlich den Paßverzeichnissen der regionalen Paßbehörden, bemängelt die Autorin vor allem die zahlreichen Erhebungsfehler der Statistiker sowie den Verlust von einigen Verzeichnisjahrgängen bei Paßverzeichnissen verschiedener Behörden ${ }^{147}$.

Im Jahr 1974 haben sowohl Vainio als auch Kero für den Zeitraum 1865-92, d.h. vor dem Beginn der statistischen Auswanderererfassung, 22 behördliche Institutionen ermitteln können, die nachweislich Paßverzeichnisse geführt haben ${ }^{148}$, wenngleich auch sie den Verlust einiger Paßverzeichnissjahrgänge konstatieren. Ferner geben die Autoren zu bedenken, daß von der Existenz weiterer Paßbehörden ausgegangen werden muß, deren vor 1893 erstellten Verzeichnisse nicht bei der statistischen Erhebung in Helsinki berücksichtigt worden sind. Eine Rekonstruktion der exakten Anzahl von

\footnotetext{
${ }^{146}$ Suomen Virallinen Tilasto 28, Siirtolaisuustilasto 1-11. (Offizielle Statistik Finnlands 28. Auswandererstatistik 1-11) 3 Bde. Helsinki 1905-1915.

${ }^{147}$ Toivonen (1963, S. 259f.) weist den Statistikern auch Rechenfehler nach. Darüber hinaus wurden Auswanderer doppelt gezählt oder die Auswandererzahlen aus Gemeinden mit ähnlich klingenden Namen verwechselt, vgl. Kero 1974, S. 38-40. Zu fehlenden Paßverzeichnissen siehe Toivonen 1963, S. 254f.; Virtanen 1979, S. 46.

${ }^{148}$ Kero 1974, S. 5f.; Vainio 1974, S. 54 f.
} 
Paßbehörden und den von ihnen geführten Verzeichnissen ist demnach nicht mehr möglich, nicht zuletzt, da etliche Akten auch im Laufe der Zeit verloren gegangen sind.

Bei der Beschäftigung mit den Angaben aus den Paßverzeichnissen sind die Zielortangaben wesentlich, da die Selektion der Amerikaauswanderer von anderen Paßinhabern auf der Grundlage der Zielortangaben geschieht. Als Zielortangaben sind vor allem folgende Vermerke zu finden: Schweden, Rußland, andere europäische Länder, Amerika bzw. Übersee, Ausland und Unbekannt. In den meisten Fällen ist der Vermerk 'Übersee' mit Nord-Amerika gleichzusetzen, da die Pazifikauswanderung, insbesondere nach Australien und Neuseeland, zahlenmäßig kaum ins Gewicht fiel ${ }^{149}$. Problematisch ist jedoch die unbestimmte Angabe 'Ausland', da sich dahinter auch Auswanderer nach Amerika verbergen konnten, wie Virtanen an zahlreichen Einzelbeispielen belegt ${ }^{150}$. In einigen Paßverzeichnissen wurden zudem alle nicht für die Ausreise nach Rußland bestimmten Pässe einfach unter dem Auslandsbegriff subsumiert, wonach eine klare Trennung von Überseeauswanderern und Arbeitswanderern ins europäische Ausland nicht möglich ist ${ }^{151}$.

Toivonen konnte für den Zeitraum 1861-92 in 14 ihr zur Verfügung stehenden Paßverzeichnissen insgesamt 117160 ausgegebene Pässe ermitteln, wovon 20350 Pässe die Zielortangabe 'Ausland' trugen. Das Statistische Zentralamt hat jedoch alle diese Fälle konsequent aus seiner Emigrantenerfassung ausgeschlossen und nur die eindeutig mit 'Übersee' oder 'Amerika' markierten Paßeintragungen für seine statistische Erhebung berücksichtigt ${ }^{152}$.

Nach Vainio haben vor allem finnische Seeleute, deren Anzahl bereits 1870 ca. 11000 Personen betrug ${ }^{153}$, Pässe mit dem unbestimmten Vermerk 'Ausland' erhalten. Besonders in der Frühphase der Auswanderungsbewegung sollen zahlreiche Seeleute die Möglichkeit zur Desertion in amerikanischen Häfenstädten genutzt haben, wie auch der in Amerika tätige und vielgereiste finnische Pfarrer Salomon Ilmonen im Jahr 1919

\footnotetext{
${ }^{149}$ Nach den Zensus-Daten von 1921 lebten 1358 gebürtige Finnen in Australien und 314 Finnen in Neuseeland, vgl. Koivukangas 1986, S. 21 und 1996, S. 31f.

${ }^{150}$ Virtanen (1979, S. 47f. und S. 52) hat für die Stichprobengemeinden Elimäki, Jokioinen und Leppävirta höhere Auswandererzahlen als Paßinhaber mit der Zielortangabe 'Amerika' oder 'Übersee' ermitteln können.

${ }^{151}$ Geer de/Wester 1975, S. 94-96.

${ }^{152}$ Toivonen 1963, S. 256 und S. 259f.; Virtanen 1979, S. $47 \mathrm{f}$

${ }^{153}$ Vainio 1974, S. 58. Auch Kero (1986, S. 27) geht von einigen tausenden Seeleuten unter den ersten finnischen Auswanderern aus. Siehe auch Kaukiainen 1980, S. 470.
} 
bestätigt $^{154}$. Unter den Deserteuren sind mit Sicherheit auch zahlreiche Paßinhaber gewesen, die nicht in die offizielle Emigrationsstatistik eingegangen sind.

Für die finnische Emigrationsforschung kann es als ein Glücksfall gelten, daß die Jahrgänge verschiedener Paßverzeichnisse von neun Paßbehörden des Regierungsbezirks Vaasa nicht nur am vollständigsten, sondern zudem auch vergleichsweise sorgfältig und präzise geführt worden sind. Insbesondere in der Spalte 'Zielort' finden sich häufig detaillierte Angaben. Die unpräzisen 'Ausland'-Vermerke hingegen sind wesentlich seltener zu finden als in den Paßverzeichnissen anderer Regionen $^{155}$.

Allerdings wurden im Regierungsbezirk Vaasa in der Frühphase der Amerikaauswanderungsbewegung bedeutend mehr Pässe für die Ausreise nach Schweden mit einer Gültigkeitsdauer von weniger als sechs Monaten ausgestellt als Amerika-Pässe, deren Gültigkeitsdauer mindestens ein Jahr betrug. Nach 1880 kehrte sich dieses Verhältnis dann um, als die temporäre Arbeitswanderung nach Schweden von der zunehmenden Überseeauswanderung abgelöst wurde ${ }^{156}$.

Eine klare Trennung zwischen den für die Ausreise nach Schweden oder Amerika bestimmten Pässen wird zudem noch dadurch erschwert, daß etliche für die Ausreise nach Schweden oder Norwegen ausgestellte Pässe auch für die Weiterreise nach Amerika benutzt worden sind, selbst wenn dies zum Zeitpunkt des Paßausstellung nicht unbedingt beabsichtigt war. Demnach ist es allein auf der Grundlage der Paßverzeichnisse nicht möglich festzustellen, wie viele Paßinhaber mit der Zielortangabe 'Schweden', 'Norwegen' oder 'Ausland' tatsächlich nach Amerika ausgewandert sind. In die offizielle Emigrationsstatistik gingen diese zweifelhaften Fälle erst gar nicht ein, wonach die Berechnungen der Statistiker zumindest in dieser Hinsicht als ungenau zu bewerten sind.

Außerhalb des Einflußbereichs der Statistiker wiederum lag das Verhalten der Auswanderer. Nicht alle Paßinhaber sind auch wirklich ausgewandert, andere haben möglicherweise einen zweiten oder dritten Paß beantragt, bevor sie die Ausreise

\footnotetext{
${ }^{154}$ Ilmonen 1919, Bd.1, S. 76-79. Zur Person des Pfarrers Ilmonen, vgl. Wargelin 1987, S. 2-11. ${ }^{155}$ Geer de/Wester (1975, S. 94-96) haben für den Zeitraum 1861-1890 lediglich 200 Pässe, bei insgesamt 67388 ausgegebenen Pässen, mit dem Vermerk 'Ausland' in den Paßverzeichnissen des Regierungsbezirks Vaasa finden können; vgl. auch Vainio 1974, S. 57.

${ }^{156}$ Geer de/Wester 1975, S. 91f. und S. 98-103, Tab. 19.
} 
angetreten bzw. gänzlich unterlassen haben ${ }^{157}$. Wieder andere sind tatsächlich zweioder mehrfach ausgewandert, wozu sie mehrere Pässe beantragt haben. Virtanen schätzt den Anteil der Mehrfachauswanderer am Gesamtaufkommen aller Emigranten auf ca. $10 \%$, was etwa 30000 Personen entspricht ${ }^{158}$. Das Gesamtbild der offiziellen Statistik wurde demnach durch die Mehrfachauswanderer verzerrt, da diese Personen entsprechend der jeweiligen Paßausgabe auch zwei- oder mehrfach gezählt wurden.

Den mehrfachen Paßinhabern standen wiederum die nicht registrierten Emigranten gegenüber, wie beispielsweise Wehrpflichtverweigerer oder Kriminelle, denen daran lag, ihre Ausreise vor den staatlichen Behörden zu verbergen ${ }^{159}$. Obwohl aus den Amerika-Briefen nicht herauszulesen ist, aus welchem Grund die Briefschreiber emigrierten, konnte der finnlandschwedische Historiker Anders Myhrman noch in den 1940er Jahren in Interviews mit schwedischsprachigen Emigranten die Angst vor der Wehrpflicht als einen bedeutsamen Auswanderungsgrund ausmachen ${ }^{160}$. Demnach wird die bewußte paßlose Auswanderung junger, wehrpflichtiger Männer kein seltenes Phänomen gewesen sein.

Des weiteren fanden sich noch weitere Gründe, um die Atlantiküberquerung ohne offiziellen Reisepaß anzutreten, doch nicht zuletzt trug die lässige Handhabung der Paßverordnung des Jahres 1862 dazu bei, daß die paßlose Ausreise inbesondere in der Frühphase der Emigrationsbewegung relativ unkompliziert war und ohne staatliche Sanktionen blieb. Die in der Paßverordnung von 1862 erklärte Illegalität bei Ausreise ohne offiziellen Auslandspaß blieb aufgrund fehlender Grenzkontrollen wirkungslos. Gerade im dünn besiedelten Norden Finnlands, wo die finnische Auswanderungsbewegung ihren Anfang nahm, war ein Paßantrag häufig mit einer tagelangen Reise zu einer der wenigen Paßbehörden in der Region verbunden und wurde schon allein aus diesem Grund vielfach unterlassen.

\footnotetext{
${ }^{157}$ Anhand einer Stichprobenuntersuchung bei 13 Gemeinden und einer Stadt aus der Provinz Satakunta konnte Kero (1970 [unveröffentlichte Lizentiatsarbeit] S. 25f.) belegen, daß 7\% aller Paßinhaber des Zeitraumes 1881-1914 mehr als einen Amerika-Paß erhalten hatten.

${ }^{158}$ Virtanen 1979, S. 221.

${ }^{159}$ Zur Mehrfachauswanderung siehe Korkiasaari 1989, S.6; zur paßlosen Auswanderung von wehrpflichtigen, jungen Männern während der Russifizierungsperioide siehe Toivonen 1963, S. 122-134 und vor allem Kero 1996, S. 51; für die 1880er Jahre vgl. Onnela 1975b.

${ }^{160}$ Myhrman 1974 (Emigrantenbiografien), Bd. 7, George E. Evert (S. 36), Nils Otto Lind (S.40), Leonard Svedberg (S.61); Bd. 8: John J. Schublom (S.47). Zu den häufigsten Auswanderungsgründen siehe auch Kap. 2.6.2.
} 
Anhand von 26 nördlich von Oulu gelegenen Gemeinden haben Savolainen und Kokkonen nachweisen können, daß im Zeitraum 1871-90 lediglich etwa 200 Auswanderungswillige einen Amerika-Paß beantragt, sich jedoch 5.723 Personen bei den Geistlichen ihrer jeweiligen Kirchengemeinden abgemeldet hatten ${ }^{161}$. Da die Registrierung in den Kirchenbüchern praktisch gesehen eine freiwillige Handlung darstellte, liegt die Vermutung nahe, daß die tatsächliche Auswandereranzahl über Schweden und Norwegen mehr als 5732 Personen betragen hat.

Auch im südlichsten Inselgebiet Finnlands, den Ålandinseln, war die paßlose Auswanderung über Schweden nach Amerika eine alltägliche Erscheinung, wie Blomfeldt anhand einer Stichprobenuntersuchung der Inselgemeinden Föglö und Finström belegen kann ${ }^{162}$. Im Regierungsbezirk Vaasa hingegen war die Differenz zwischen Paßinhabern und tatsächlichen Auswanderern wesentlich geringer, was sehr wahrscheinlich auf das dichte Netz der Paßbehörden in der Region zurückzuführen ist $^{163}$.

Der paßlosen Auswanderung kam außerdem zugute, daß zumindest in der Frühphase der finnischen Amerikaauswanderung dem Paß außerhalb der finnischen Landesgrenzen oftmals keine Beachtung beigemessen wurde, wonach die Wirkung der Paßverordnung des Jahres 1862 als verbindliches Gesetz in Frage gestellt werden kann. Diesen Eindruck spiegelt auch folgendes Briefzitat von 1893 eines finnischen Auswanderers aus Ohio wieder ${ }^{164}$ :

"Und du brauchst keinerlei Papiere, gibt dem Steuermann lediglich zwei Mark, so wird er dich mitnehmen, und wenn du die finnische Küste hinter dir gelassen hast, fragt ohnehin niemand mehr nach den Papieren."

\footnotetext{
${ }_{162}^{161}$ Savolainen/Kokkonen 1964, S. 599.

${ }^{162}$ Blomfelt (unveröffentlichte Lizentiatsarbeit von 1968, Anhang, Tab. 26, 27, 36 und 37) stellt für den Zeitraum 1865-92 ca. 300 Paßinhaber aus den beiden Gemeinden 785 tatsächlichen Auswanderern gegenüber.

${ }^{163}$ Vainio 1974, S. 60f.

${ }^{164}$ Heikki Mikkola an G. Roslin in Merikarvia, Brief vom 8.4.1893 aus Asthabula Harbour, Ohio: TYYH:S:m:Satakunta: MER:XX/1; Brief auch bei Kero (1985, S. 51f.) abgedruckt.
} 
Erst nach Inkrafttreten der zweiten Paßverordnung des Jahres 1888 wurden Grenzkontrollen eingerichtet ${ }^{165}$. Dadurch wurde die illegale, paßlose Auswanderung zwar erschwert, konnte aber nicht gänzlich unterbunden werden.

Die paßlose Auswanderung stellt mit Sicherheit den größten Ungenauigkeitsfaktor der offiziellen Emigrationsstatistik dar, da letztere ausschließlich auf Paßverzeichnissen basiert. Ein Vergleich der offiziellen Auswandererzahlen mit den Angaben aus Passagierlisten verschiedener Reedereien legt denn auch den Umfang der paßlosen Auswanderung offen zutage.

\subsubsection{Die Bedeutung der Passagierlisten für die Emigrationsforschung}

Passagierlisten haben Paßverzeichnissen gegenüber den Vorteil, daß sie die tatsächlichen Auswanderer auflisten, ungeachtet der Tatsache, ob diese einen, mehrere oder gar keinen Paß beantragt hatten. Das Problem der Mehrfachauswanderung und damit einhergehenden Mehrfachzählung einzelner Auswanderer ist allerdings auch bei der Beschäftigung mit Passagierlisten gegeben.

Ebenso die Unterscheidung in Reisende und Auswanderer kann sich als problematisch gestalten, da nicht alle Zwischendeckspassagiere mit Auswanderern gleichzusetzen sind, obwohl ein Großteil der Auswanderer im Zwischendeck reiste ${ }^{166}$. Vor allem mit fortschreitender Massenauswanderung und damit einhergehender Intensivierung des Fährverkehrs nahm sowohl die Anzahl der Urlaubsreisenden als auch der Auswanderer in beide Richtungen zu. Bei der Beschäftigung mit den Auswandererwie auch den Rückwandererzahlen ist es schwierig zu ermessen, wie groß der Anteil der Reisenden, d.h. der kurzzeitigen Besucher, unter den dauerhaften Emigranten bzw. Rückkehrern gewesen ist.

Anhand eines 1989 ins Leben gerufenen, elektronischen Datenerfassungsprojekts des finnischen Migrationsinstitut in Turku lassen sich jedoch einzelne Personen in vielen Fällen als Auswanderer identifizieren. Die wichtigsten Quellengattungen für diese Datenerhebung sind denn auch die Passagierlisten der Finnischen Dampfschiffahrtsgesellschafts AG der Jahre 1892-1896, 1899-1914, 1920-39 und 194060, alle noch vorhandenen Paßverzeichnisse von zehn ehemaligen Paßbehörden in

\footnotetext{
${ }^{165}$ Vainio 1974, S. 53.

${ }^{166}$ Auf dieses Problem weist auch Dittrich (1985, S. 225) im Zusammenhang mit der Datenanalyse von Hamburger Passagierlisten hin.
} 
Finnland sowie verschiedene Archivquellen über alle im Ausland verstorbenen Finnen des Zeitraumes 1918-50 ${ }^{167}$. Der Vergleich der digitalisierten Eintragungen aus den Paßverzeichnissen und Passagierlisten ermöglicht in vielen Fällen eine Rekonstruktion der Auswanderungsdaten ganzer Familien oder sogar Dorfgemeinschaften. Auch die mögliche Mehrfachauswanderung einer Person läßt sich mit Hilfe der gespeicherten Daten ermitteln.

Was jedoch das Gesamtvolumen der finnischen Auswanderungszahlen für den hier untersuchten Zeitraum betrifft, sind die bereits in den 1970er Jahren von Kero in Zusammenarbeit mit einer Forschungsgruppe der Universität Turku vorgelegten Amerikaauswandererzahlen maßgebend. Dabei handelt es sich um einen Vergleich der offiziellen Auswandererzahlen anhand der Emigrationstatistik mit Angaben aus den Passagierlisten der Finnischen Dampfschiffahrtsgesellschaft AG sowie Passagierlisten verschiedener schwedischer und norwegischer Reedereien ${ }^{168}$. Da für die Zeit vor 1893 nur wenige offiziell veröffentlichte Auswandererzahlen vorlagen, hat sich die Forschungsgruppe für den Zeitraum 1870-92 hauptsächlich auf Angaben aus Passagierlisten schwedischer und norwegischer Reedereien gestützt, die seit 1869 in den Polizeibehörden von Göteborg, Stockholm, Malmö und Trondheim registriert wurden $^{169}$. Diese skandinavischen Hafenstädte galten als die wichtigsten Transitstationen für finnische Überseemigranten, bevor im Sommer 1891 erstmals eine direkte Schiffsverbindung von Hanko, der südlichsten finnischen Hafenstadt, nach Hull in England eingerichtet wurde und zugleich die Finnische Dampfschiffahrtsgesellschaft $A G$ ihre Tätigkeit aufnahm.

Viele Auswanderungswillige zogen die neueingerichtete Direktverbindung der Etappenwanderung über Schweden und Norwegen vor, obwohl bis zum Ausbruch des Ersten Weltkrieges noch etwa 14500 finnische Auswanderer in den Passagierlisten der Polizeibehörden von Göteborg vermerkt worden sind, was etwa 5\% des gesamten finnischen Auswandereraufkommens dieser Zeitspanne entsprach ${ }^{170}$.

\footnotetext{
${ }^{167}$ Siehe http://www.migrationinstitute.fi.

${ }^{168} \mathrm{Zu}$ den jährlichen Auswandererzahlen, wie sie von Keros Forschergruppe ermittelt wurden, siehe Tabelle 1 im Anhang: Anzahl der finnischen Überseeauswanderer 1870-1914.

${ }^{169}$ Diese Schifflisten liegen als Mikrofilmkopien am Seminar für allgemeine Geschichte der Universität Turku vor. Zur Quellenkritik speziell an den Göteborger Schiffslisten siehe Tedebrand 1972, S. 187-195.

${ }^{170}$ Kero 1974, S. 36, Tab. 4.
} 
Für die Folgezeit ab den 1890er Jahren bis 1914 gewinnen dann auch die Passagierlisten der Finnischen Dampfschiffahrtsgesellschafts $A G$ an Bedeutung. Lediglich für die drei Jahre 1891-93 mußten die Passagierangaben aus anderen Quellen, insbesondere Zeitungsberichten, rekonstruiert werden, da die ursprünglichen Schiffslisten abhanden gekommen sind ${ }^{171}$. Aufgrund dieser uneinheitlichen Quellenlage stellen die jährlichen Auswandererangaben für diesen Zeitraum lediglich Schätzwerte dar.

Finnische Emigranten sind jedoch auch über Kopenhagen nach England oder Deutschland gelangt, da neben Liverpool und Southampton auch von Bremerhaven und Hamburg aus Direktverbindungen nach Amerika bestanden. Anhand von Zeitungsberichten hat Kero ihre Anzahl für den Zeitraum 1883-1904 mit ca. 6000 Personen bestimmen können ${ }^{172}$. Ab 1904 war die Monopolstellung der Finnischen Dampfschiffahrtsgesellschaft $A G$ in finnischen Auswanderergeschäft dann derart gefestigt, daß die Atlantiküberquerung finnischer Auswanderer über deutsche Häfen oder Kopenhagen nur noch selten vorkam ${ }^{173}$.

Zusammenfassend läßt sich festhalten, daß auf der Grundlage der verschiedenen Passagierlisten während Zeitspanne 1870-1914 etwa 327000 Personen emigriert sind. Für den Zeitraum 1893-1914, d.h. mit Beginn der offiziellen Auswandererstatistik, stehen rund 266670 ausgewanderte Schiffspassagiere 253016 Amerika-Paßinhabern gegenüber, die in den offiziellen Statistiken registriert worden sind. Dementsprechend könnten 13654 Personen, nämlich die Differenz der beiden Zahlenwerte von 5\%, die Ausreise ohne offiziellen Amerikapaß angetreten haben. Es ist jedoch auch denkbar, daß ein Großteil dieser Emigranten einen Paß mit der Zielortangabe 'Ausland' oder 'Schweden' bei sich trug und aus diesem Grund nicht in der offiziellen Emigrationsstatistik erschien. Aufgrund der strengen Auswahlkriterien bei der Erstellung der offiziellen Statistik ist davon auszugehen, daß die Anzahl der

\footnotetext{
${ }^{171}$ Kero 1974, S. 29-33. Siehe hierzu auch Tabelle 1 im Anhang: Anzahl der finnischen Überseeauswanderer 1870-1914.

${ }^{172}$ Kero 1974, S. 45.

${ }^{173} 1904$ hatte die Reederei ihre einzige Konkurrentin, die 1903 gegründete Dampfschiffahrtsgesellschaft ,Nord', aufgekauft, die schätzungsweise 1700 Auswanderer transportiert hatte, vgl. Kero 1974, S. 45.
} 
ausgeschlossenen Auswanderer größer war als die irrtümliche Mehrfachzählung gleicher Personen $^{174}$.

Andererseits verwundert die geringe Abweichung des Auswandereraufkommens von lediglich 5\% zugunsten der Passagierlisten, vor allem wenn man die bereits erläuterten zahlreichen Auslassungen und Fehler beim Zustandekommen der offiziellen Emigrationsstatistik bedenkt. Es wäre vielmehr zu erwarten gewesen, daß z.B. der Verlust zahlreicher Paßverzeichnisse mit den darin enthaltenen Auswandererangaben zu einer größeren Differenz zwischen Amerika-Paßinhabern und tatsächlichen Auswanderern, d.h. Schiffspassagieren, geführt hätte. Daraus läßt sich schließen, daß das Gesamtbild des Auswanderervolumens des Zeitraumes 1893-1914 durch die offizielle Emigrationsstatistik nur geringfügig verzerrt wird, so daß die Angaben der noch erhaltenen Paßverzeichnisse durchaus als verläßliche Primärquellen angesehen werden können $^{175}$.

Anders sieht es hingegen im Falle der seit 1894 offiziell registrierten Rückwandererzahlen aus. Als Quelle für die historische Forschung sind sie nahezu unbrauchbar. Für den Zeitraum 1894-1914 stehen weniger als ein Drittel, d.h. 31902 offiziell registrierte Rückwanderer 100897 in Passagierlisten der Finnischen Dampfschiffahrtsgesellschafts $A G$ verzeichneten Rückreisenden gegenüber ${ }^{176}$. Der Grund hierfür liegt vor allem in der lückenhaften und unregelmäßigen Registrierung der Rückkehrer, da die offizielle Rückwandererregistrierung, anders als die Emigrationsstatistik, lediglich auf Kirchenbucheintragungen der einzelnen Gemeinden und Städte beruhte.

Doch auch bei der Beschäftigung mit den Rückwandererzahlen, welche durch Auswertung der Passagierlisten in Gegenrichtung, d.h. von Hull nach Hanko, erstellt wurden, sind Ungenauigkeiten zu berücksichtigen. Hiermit ist vor allem das Problem der Mehrfachauswanderer gemeint: Da nicht alle Rückreisenden auch eine dauerhafte Rückkehrabsicht verfolgten, wuchs mit zunehmender Massenauswanderung auch die Anzahl der Finnland-Besucher, die von Mehrfachauswanderern kaum zu trennen sind.

\footnotetext{
${ }^{174}$ Kero 1974, S. 41.

${ }^{175}$ Virtanen 1979, S. 43; Korkiasaari 1989, S. 3.

${ }^{176}$ Finnische Rückwandererangaben sind ab 1892 in den noch erhaltenen Passagierlisten der finnischen Reederei vermerkt. Siehe auch Tabelle 4 im Anhang: Anzahl der finnischen Rückwanderer 1892-1914.
} 
Anhand einer Stichprobenuntersuchung von fünf ländlichen Gemeinden und einer Stadt aus verschiedenen Regierungsbezirken hat Virtanen die durchschnittliche dauerhafte Rückwandererrate für Gesamtfinnland mit ca. 20\% bestimmen können, wobei er jedoch auf große regionale Unterschiede hinweist. Es stellt sich hier zudem die berechtigte Frage nach der Repräsentativität ${ }^{177}$ der von Virtanen ermittelten Rückwandererquote, da das Sample mit sechs Ortschaften bei durchschnittlich etwa 500 Ortschaften in Gesamtfinnland ${ }^{178}$ sehr begrenzt gehalten ist.

\subsection{Die chronologische Entwicklung des Auswanderungsverlaufs}

Nach den quellenkritischen Erläuterungen zum Zustandekommen der Auswandererzahlen soll nun der chronologische Verlauf der finnischen Auswanderungsbewegung nachgezeichnet werden. Einleitend werden die Anfänge der finnischen Amerikaemigration näher dargestellt.

Bereits vor Beginn der Massenemigration nach Amerika hat es vielfache Wanderungsbewegungen sowohl innerhalb Finnlands als auch über die Landesgrenzen hinweg gegeben. Die grenzüberschreitende Mobilität richtete sich in erster Linie in die Nachbarländer Norwegen, Schweden und Rußland. Vereinfacht lassen sich diese Wanderungsbewegungen als Reisen, temporäre Arbeitswanderungen und dauerhafte Auswanderungen charakterisieren ${ }^{179}$. Fiel bis zu Beginn des 20. Jahrhunderts der Anteil der Bildungs- und Vergnügungsreisen kaum ins Gewicht, so übten die temporären Arbeitswanderungen einen entscheidenden Einfluß auf die Bevölkerungsstruktur derjenigen Gemeinden aus, die stark von der Abwanderung ihrer arbeitsfähigen Bevölkerung betroffen waren. Charakteristisch für Mobilität auf Zeit war die Anziehungskraft des Zielgebietes, der sogenannte Pull-Effekt. Diese Anziehungskraft konnte aus besseren Arbeitsbedingungen in der Nachbargemeinde, der Konzentration industrieller Einrichtungen in ländlicher Umgebung oder aber einem urbanen Zentrum mit vielfältigen Arbeitsmöglichkeiten bestehen. Dabei war es von marginaler

\footnotetext{
${ }^{177}$ Diese methodische Kritik an Virtanens Vorgehensweise wird auch in einer Buchrezension von Rasila (1980, S. 85) geäußert.

${ }^{178}$ Die Anzahl der Städte und ländlichen Gemeinden zusammengenommen schwankte während des Zeitraumes 1885-1910 zwischen 496 und 519, vgl. Vattula 1983, S. 31, Einleitung.

${ }^{179}$ Geer de/Wester 1975, S. 22.
} 
Bedeutung, ob sich die Zielregion im Inland oder im benachbarten Ausland, d.h. vor allem in Rußland oder Schweden, befand.

\subsubsection{Die Binnenwanderung als Vorläufer der Amerikaemigration}

Die Rekonstruktion der internen Mobilität im Finnland der Jahrhundertwende wird durch eine 1878 gegründete Binnenwanderungsstatistik des Statistischen Zentralamtes in Helsinki ermöglicht. Diese bereits 15 Jahre vor Erscheinen der offiziellen Emigrationsstatistik begonnene Registrierung verzeichnete die jährlichen Zahlen über Ab- und Zuwanderung auf Gemeindeniveau und den dadurch entstandenen Binnenwanderungsgewinn bzw. -verlust ${ }^{180}$.

Während des gesamten 19. Jahrhunderts war die finnische Gesellschaftsstruktur darauf angelegt, daß jedes Mitglied der Landbevölkerung sowohl geographische als auch soziale Seßhaftigkeit anstrebte. Noch 1880 lebte 85\% der finnischen Bevölkerung in ihren Geburtsorten, und etwa 96\% aller Finnen hatten sich nicht aus jenen

Regierungsbezirken fortbewegt, in denen ihre Heimatgemeinde lag ${ }^{181}$. Von daher verwundert es auch nicht, daß die meisten saisonalen Arbeitswanderungen lediglich in die Nachbargemeinden gerichtet waren ${ }^{182}$. Meist waren es die landlosen Bevölkerungsgruppen, allen voran unverheiratete Knechte und Mädge, die jährlich ihre Arbeitgeber wechselten. In Gebieten mit überdurchschnittlich großen landwirtschaftlichen Anbauflächen war die Mobilität über kurze Distanzen am größten, wobei die Anzahl der wandernden Frauen die der Männer überstieg ${ }^{183}$.

Obwohl große Teile der Bevölkerung bereits seit Beginn des 19. Jahrhunderts häufig ihre Wohnorte wechselten, versuchte die Gesetzgebung, insbesondere mittels den Bestimmungen der Armenfürsorge, der ungehinderten Binnenmigration entgegenzuwirken. Die gesetzlichen Regelungen wurden erst in den 1870er Jahren

\footnotetext{
${ }^{180}$ Eine umfassende Auswertung der Binnenwanderungsstatistik wurde 1951 von Lento vorgelegt. Siehe auch Klövekorn 1960, S. 131f. und Vainio 1978, S. 97.

${ }^{181}$ Pitkänen 1994, S. 50.

${ }^{182}$ Zur finnischen Binnenwanderung vor den Ersten Weltkrieg siehe Klövekorn 1960, S.131138; Korkiasaari/Söderling 1994, S. 237f. Speziell zur Binnenwanderung in Süd-Ostbottnien vgl. Toivonen 1963, S. 30-39; Nygård 1983, S. 74-103; Ranta 1988, S. 902-908; zu Satakunta vgl. Kero (unveröffentlichte Lizentiatsarbeit) 1970, S. 71-76.

${ }^{183}$ Lento 1951, S. 71f. Auch Eheschließungen trugen zur verstärkten Mobilität von Frauen bei, vgl. Vainio 1978, S. 104.
} 
gelockert und 1898 schließlich durch die unbeschränkte Wanderungsfreiheit legalisiert ${ }^{184}$.

Im letzten Drittel des 19. Jahrhunderts jedoch zeichnete sich ein deutlicher Trend der verstärkten Abwanderung aus ländlichen Gemeinden ab, wobei die Mobilität in erster Linie auf Städte sowie Industrie- und Handelszentren, welche häufig in städtischen Einzugsbereichen lagen, gerichtet war. Die Zuwanderung in Ballungszentren entwickelte sich zu einem beständigerem Phänomen als die Abwanderung. Sie war zudem weniger saisonalen Schwankungen unterworfen, da die städtischen Industriebetriebe ganzjährig auf neue Arbeitskräfte angewiesen waren ${ }^{185}$. Außerdem trug die verbesserte Infrastruktur, vor allem das flächendeckende Eisenbahnnetz $^{186}$, in zweifacher Hinsicht zur Intensivierung der Binnenmobilität bei: Zum einen nahm der Anteil der Wanderungsbewegungen an sich zu, zum anderen waren die Wanderungsbewegungen häufiger über größere Distanzen angelegt, wobei die 1870er Jahre als Wendepunkt angesehen werden können ${ }^{187}$. Dementsprechend verzeichneten die meisten Landgemeinden Binnenwanderungsverluste, ausnahmslos alle finnischen Städte hingegen Zuwanderungsgewinne. Lag der durchschnittliche Bevölkerungsverlust in ländlichen Gemeinden jährlich bei 2,5 Personen pro Einwohnertausend für den Zeitraum 1891-1910, so wurde in den meisten Städten eine Bevölkerungsvermehrung durch Zuwanderung von 20-22 Promille registriert ${ }^{188}$.

In dieser Hinsicht unterschieden sich auch die Provinzen Süd-Ostbottnien und Satakunta nicht wesentlich von Gesamtfinnland. Die in einheimische Industriezentren gerichteten, internen Wanderungsbewegungen stellten nicht selten den ersten Schritt zu einer nach Amerika orientierten Etappenwanderung dar. Dieser Umstand erklärt auch den relativ hohen Anteil an städtischen Überseeauswanderern von 14\% für den Zeitraum 1900-14, obwohl in Finnland vor allem Bewohner aus ländlichen Gebieten an der Emigrationsbewegung teilnahmen ${ }^{189}$. Eine eingehende Untersuchung über den

\footnotetext{
${ }^{184}$ Lento 1951, S. 42f.

${ }^{185}$ Vgl. auch Nygård 1983, S. 77.

${ }^{186}$ Zum Ausbau des finnischen Eisenbahnnetzes siehe Klövekorn 1960, S. 190-195 und Karte 3 im Anhang: Das finnische Eisenbahnnetz im westlichen Finnland 1862-1925.

${ }^{187}$ Nygård 1983, S. 98; Ranta 1988, S. 907.

${ }^{188}$ Einen Überblick über diese Entwicklung gibt Lento 1951, S. 56, Tab. 1 und S. 209. Siehe auch Nygård 1983, S. 79.

${ }^{189}$ Kero 1974, S. 117, Tab. 16.
} 
Zusammenhang zwischen zugezogenen Stadtbewohnern und Amerikaauswanderern steht bislang jedoch noch aus ${ }^{190}$.

Für die Provinz Süd-Ostbottnien war es zudem charakteristisch, daß die Kanalisation der sogenannten Überschußbevölkerung, d.h. in erster Linie der landlosen Bevölkerungsgruppen, zu einer forcierten Amerikaauswanderung führte, während der wachsende Bevölkerungsdruck in anderen Landesteilen eher eine verstärkte Binnenmigration auslöste. Dementsprechend fiel der Binnenwanderungsverlust im Emigrationsgebiet auch kleiner aus als im Landesdurchschnitt, wobei der Auswanderungsverlust wiederum den Landesdurchschnitt deutlich überstieg.

In einigen älteren Untersuchungen zur finnischen Amerikaauswanderung ist versucht worden, das schnelle Anwachsen der Emigrationsbewegung in der Region Ostbottnien und insbesondere in der Provinz Süd-Ostbottnien mit mystischen Beschreibungen der "ostbottnischen Volksseele" zu erklären ${ }^{191}$, doch derartige Erklärungsansätze erscheinen heutzutage wenig glaubwürdig und überholt. Es ist eher davon auszugehen, daß ein allgemeiner Einstellungswandel sowie die bereits erwähnten, verbesserten Verkehrsverbindungen die Auswanderungsbewegung zum Massenexodus anwachsen ließen. Wurde nämlich noch gegen Ende der 1860er Jahre die Arbeitswanderung, ungeachtet dessen, ob das Ziel in der Nachbargemeinde oder im benachbarten Ausland lag, als ein "notwendiges Übel" betrachtet, so hatte sie in den 1890er Jahren bereits den Status der alltäglichen Normalität erlangt. Gerade in diesem allgemeinen Einstellungswandel könnte der geistige Nährboden für die in den Folgejahren expandierende Amerikaauswanderungsbewegung gelegen haben ${ }^{192}$.

Dennoch entwicklete sich die Emigrationsbewegung nach Amerika und Kanada nicht als isolierte Erscheinung, sondern entwickelte sich im Rahmen der verschiedenen Arbeitswanderungstraditionen in die finnischen Nachbarländer. Wie nämlich insbesondere aus Interviewaussagen hervorgeht, verfolgte ein Großteil der Emigranten

\footnotetext{
${ }^{190}$ Im Hinblick auf die schwedische Auswanderung hat Carlsson (1976, S. 134-136) dieses Problem kurz erörtert.

${ }^{191}$ Kilpi 1917, S. 151f.; Toivonen 1963, S. 163-65. Als kritische Stellungnahme siehe Kero 1996, S. 62-65.

${ }^{192}$ Kero (unveröffentlichte Lizentiatsarbeit) 1970, S. 74.
} 
von Anfang an bereits die Intention einer nach Übersee gerichteten, temporären Arbeitswanderung ${ }^{193}$.

Sofern der Daueraufenthalt jenseits des Atlantik nicht durch die äußeren Lebensumstände erzwungen wurde, fiel der Entschluß zum dauerhaften oder zumindest zeitlich unbestimmten Aufenthalt meist erst in Amerika, so daß von einem beinahe nahtlosen Übergang der temporären Arbeitswanderung zur Auswanderung gesprochen werden kann.

Von der zunehmenden Amerikaemigration wurde die finnische Binnenwanderung, d.h. die Mobilität vom Land in die Stadt, allerdings kaum beeinflußt. Beide Wanderungsbewegungen existierten parallel und zeitgleich nebeneinander: Bewohner aus Süd- und Südwestfinnland wanderten verstärkt nach Amerika aus, während die land- und forstwirtschaftlich geprägten Regionen Mittel- und Ostfinnlands die meisten internen Arbeitswanderer stellten.

\subsubsection{Die Auswanderung nach Schweden und Rußland}

Mit verstärkter Binnenmigration wuchs gleichzeitig auch die Mobilität in benachbarte ausländische Industriezentren, insbesondere in die russische Verwaltungsund Handelsmetropole St. Petersburg oder in die nordschwedischen Küstenregionen.

Vor allem die nach Schweden gerichtete Auswanderung blickte auf eine, durch die finnisch-schwedische Union bedingte, jahrhundertelange Tradition zurück ${ }^{194}$. Bereits gegen Ende des 16. Jahrhunderts kann von einer Massenwanderung ostfinnischer Bauern in bis dahin unbesiedelte Waldgebiete Mittel-Schwedens gesprochen werden $^{195}$.

Für das 19. Jahrhundert jedoch sind besonders die Seefahrts- und Handelskontakte über den bottnischen Meerbusen, an denen vor allem Bewohner der

\footnotetext{
${ }^{193}$ Bereits 1921 konnte anhand einer Auswertung von 712 Fragebögen und Interviews unter Auswanderungswilligen der ökonomische Faktor als entscheidender Emigrationsgrund herausgestellt werden, vgl. Myhrman 1972, S. 26. Rund 50 Jahre später bestätigte Virtanen (1979, S. 79) dieses Ergebnis aufgrund 263 persönlicher Interviews mit Auswanderern der ersten Generation.

${ }^{194} \mathrm{Zu}$ den Anfängen der Mobilität nach Schweden vgl. Smeds 1935, S. 106-108; Korkiasaari 1989, S. 14f.

${ }^{195}$ Einer Schätzung zufolge sollen zwischen 12000-20000 Finnen die landschaftliche Provinz Värmland in Mittel-Schweden besiedelt haben. Zu den sogenannten Waldfinnen vgl. Alanen 1983a, S. 24f.; Korkiasaari 1989, S. 15f.
} 
schwedischsprachigen Küstenregionen sowie der Ålandinseln beteiligt waren, von Bedeutung. In der zweiten Jahrhunderthälfte führten diese Handelskontakte zu einer verstärkten Mobilität von Arbeitskräften, welche besonders im Großraum Stockholm sowie in den Sägewerken nahe den schwedischen Küstenstädten Sundsvall und Härnosand im Regierungsbezirk Västernorrland vielfältige Beschäftigungsmöglichkeiten fanden ${ }^{196}$.

Anhand von Paßverzeichnissen konnten für den Zeitraum 1861-90 mehr als 33.000 nach Schweden ausgestellte Pässe ermittelt werden, wobei fast alle Paßinhaber aus dem Regierungsbezirk Vaasa und von den Ålandinseln stammten. Innerhalb des Regierungsbezirks Vaasa läßt sich jedoch eine regionale Konzentration der Paßaustellungen für die Ausreise nach Schweden feststellen: Ein Kerngebiet stellten die schwedischsprachigen Küstengemeinden von Nykarleby (finn. Uusikarlepyy) bis Närpes (finn. Närpiö) dar, wobei die höchste Auswanderungsintensität in der Gemeinde Petalax (finn. Petolahti) gemessen wurde. Aus den finnischsprachigen Inlandsgemeinden hingegen, mit Ausnahme von Alahärmä, Ylihärmä und Kauhava, war die Mobilität nach Schweden relativ gering ${ }^{197}$.

Die vermehrte Paßausstellung für die Ausreise nach Schweden blieb vorwiegend auf die Jahre 1870-85 begrenzt. Dieser Zeitraum deutet auf die Hochkonjunkturphase der nordschwedischen Sägewerksindustrie hin, welche in den 1870er Jahren begonnen hatte und bis zu Beginn der 1890er Jahre anhielt ${ }^{198}$. Die zum Ende des 19. Jahrhundert hin einsetzende Stagnation in der nordschwedischen Holzindustrie bewirkte dann einen starken Rückgang der finnischen Auswanderung nach Schweden. Diese Rezession fiel zeitlich mit den verschärften Einfuhrzöllen der schwedischen Krone von 1888 zusammen, wodurch die Handelskontakte zwischen den finnischen und schwedischen Küstenregionen fast zum Erliegen kamen ${ }^{199}$.

In der Folgezeit gewann Rußland sowohl für finnische Handelsreisende als auch für Auswanderungswillige zunehmend an Bedeutung. Doch auch die ostwärts gerichtete Auswanderung nach Karelien, Ingermanland und Estland wurde, ebenso wie schon die

\footnotetext{
${ }^{196}$ Geer de/Wester 1975, S. 15.

${ }^{197}$ Geer de/Wester 1975, S. 56f.; Wester 1977, S. 164-173; Geer de 1981, S. 51-56.

${ }^{198}$ Nach Tedebrand (1972, S. 104f., Tab. 19) war die Region um Sundsvall bis 1890 durch einen stetigen Überschuß an Zuwanderern geprägt. Zur Sägewerksindustrie in Västernorrland siehe ebend. S. 29-37.

${ }^{199} \mathrm{Zu}$ Seefahrts- und Handelskontakten siehe Kummel 1980, S. 443-450.
} 
nach Schweden hin orientierte Mobilität, durch eine jahrhundertelange Tradition geprägt. Schon gegen Ende des 17. Jahrhunderts waren 90\% aller Ingermanländer finnischer Abstammung ${ }^{200}$. Die Gründung von St. Petersburg nordöstlich der Region Ingermanland im Jahr 1703 sorgte für einen starken Zustrom an finnischen Handwerkern und Dienstboten in die russische Hauptstadt, wobei eine von der Arbeitsmarktlage abhängige, saisonale Mobilität charakteristisch war. Der wirtschaftliche Aufschwung in Rußland ${ }^{201}$, der nach dem Krimkrieg sowie den darauffolgenden Hungerjahren gegen Ende der 1860er Jahre einsetzte, sorgte für einen raschen Anstieg der finnischen Einwandererzahlen, welche in den 1880er Jahren kulminierten. Ein einmaliger Höhepunkt wurde bei der Volkszählung des Jahres 1881 mit mehr als 24.000 Finnen erreicht, was 2,6\% der russischen Hauptstadtbevölkerung entsprach. Zu diesem Zeitpunkt lebten nur in Helsinki mehr Finnen als in St.

Petersburg $^{202}$. Obwohl die Mobilität über die Ostgrenze zur Jahrhundertwende hin wieder deutlich abflaute, hatten sich bis zum Zusammenbruch des zaristischen Systems schätzungsweise 150.000 Finnen zeitweilig in Rußland niedergelassen ${ }^{203}$.

Aufgrund der starken Überzahl an Handwerkern und Facharbeitern unter den finnischen Auswanderern lagen die Herkunftsgebiete der Emigranten in erster Linie in ost- und mittelfinnischen Städten, wodurch sich der Charakter der nach Rußland gerichteten Mobilität deutlich von allen anderen Wanderungsbewegungen unterschied. Die südöstlich gelegenen Regierungsbezirke Viborg und Uusimaa stellten während des gesamten 19. Jahrhunderts mehr als 60\% aller finnischen Rußlandauswanderer ${ }^{204}$, so daß die Wanderungsbewegungen über eine relativ kurze Distanz verliefen ${ }^{205}$. Auf die Regierungsbezirke Turku/Pori und Vaasa entfielen durchschnittlich 7\% bzw. 2\%, wonach die Rußlandemigration in den Herkunftsregionen der hier zu behandelnden Briefschreiber, im Gegensatz zur Schweden- und Amerikaauswanderung, nur eine untergeordnete Rolle spielte.

\footnotetext{
${ }^{200}$ Korkiasaari 1989, S. 10.

${ }^{201}$ Zur Wirtschaftsentwicklung Rußlands siehe Engman 1983, S. 230-236.

${ }^{202}$ Alapuro 1988, S. 59-61; Engman 1990, S. 80f.

${ }^{203}$ Korkiasaari 1989, S. 12; Korkiasaari/Söderling 1994, S. 252; Engman 1995, S. 27, Tab.1.

${ }^{204}$ Engman 1983, S. 219, Tab. 22.

${ }^{205}$ Siehe hierzu die Abbildungen bei Engman/Jungar 1980, S. 26 sowie Engman 1983, S. 222225 .
} 
Für den Zeitraum 1861-90, der auch als Anfangs- und Zuwachsphase der finnischen Amerikaauswanderung gilt, haben die Autoren de Geer und Wester die Auswanderungsfrequenzen nach Schweden, Rußland und Amerika anhand von Paßverzeichnissen miteinander verglichen. Obwohl ihr Untersuchungsgebiet lediglich die fünf Regierungsbezirke Turku/Pori, Häme, Vaasa, Kuopio und Oulu sowie für bestimmte Zeitabschnitte auch die Bezirke Uusimaa und Viborg umfaßt, gibt dieser Vergleich der Paßausgabeintensität dennoch einen allgemeinen Eindruck über das Ausmaß der einzelnen Wanderungsbewegungen zu verschiedenen Zeiten ${ }^{206}$ :

Tab. B Anzahl und prozentuale Verteilung von Reisepässen nach Zielortangaben 1861-90

\begin{tabular}{|l|l|l|l|l|}
\hline Fünfjahresintervall & Rußland & Schweden & Ausland $^{\mathbf{2 0 7}}$ & Paßanzahl \\
\hline $1861-65$ & $70,7 \%$ & $21,1 \%$ & $8,2 \%$ & 8255 \\
\hline $1866-70$ & $76,4 \%$ & $13,0 \%$ & $10,5 \%$ & 10486 \\
\hline $1871-75$ & $43,9 \%$ & $44,0 \%$ & $21,0 \%$ & 14202 \\
\hline $1876-80$ & $34,2 \%$ & $41,7 \%$ & $24,0 \%$ & 14813 \\
\hline $1881-85$ & $17,1 \%$ & $44,3 \%$ & $38,6 \%$ & 23346 \\
\hline $1886-90$ & $8,1 \%$ & $22,5 \%$ & $69,4 \%$ & 34429 \\
\hline & & & & \\
\hline $\mathbf{1 8 6 1 - 9 0}$ & $\mathbf{2 8 , 8 \%}$ & $\mathbf{3 2 , 1 \%}$ & $\mathbf{3 9 , 1 \%}$ & $\mathbf{1 0 5 5 3 1}$ \\
\hline
\end{tabular}

Wie obenstehende Darstellung verdeutlicht, standen die verschiedenen Wanderungsbewegungen in Wechselwirkung zueinander. Während sich im letzten Fünfjahresintervall der Anteil an Rußlandpässen um ein Neunfaches verringerte, vermehrte sich der Anteil an Auslandspässen in der gleichen Größenordnung, zu denen auch alle Überseepässe gezählt wurden. Der Anteil der Schwedenpässe verdoppelte sich zu Beginn der 1870er Jahre, um sich dann gegen Ende des folgenden Jahrzehnts wieder zu halbieren. Im Verhältnis wurden in der Zeitspanne 1886-90 nur geringfügig mehr Schwedenpässe ausgegeben als im ersten Fünfjahreszeitraum von 1861-65. Die Amerikaemigration hingegen wuchs in den ausgehenden 1880er Jahren derartig an, daß der Anteil der nach Übersee ausgestellten Pässe den Anteil der Schwedenpässe um ein

\footnotetext{
${ }^{206}$ Tabelle entnommen aus Geer de/Wester 1975, S. 35, Tab. 6.

${ }^{207}$ Die Rubrik 'Ausland' bezeichnet Zielorte in Übersee, d.h. in erster Linie Amerika.
} 
Dreifaches überstieg, der Anteil der Rußlandpässe wurde sogar um ein Neunfaches übertroffen.

Die aus der Tabelle abzulesende, anfänglich stärkste Auswanderungsfrequenz nach Rußland ist mit der Konjunkturlage der russischen Wirtschaft, insbesondere in der zweiten Hälfte der 1860er Jahre, zu erklären. Doch bereits zu Beginn der 1880er Jahre ebbte die Mobilität nach Rußland wieder deutlich ab.

Die schwedische Hauptstadt Stockholm wirkte wiederum als eigener Anziehungsmagnet für finnische Saisonarbeiter, ebenso wie die expandierende Sägewerksindustrie im westlichen Teil Mittelschwedens für das Ansteigen der finnischen Paßausstellungen verantwortlich war, bis die Mobilität nach Schweden in den 1890er Jahren abflaute. Ein Großteil der finnischen Arbeiter kehrte wieder zurück, so daß die dauerhafte Auswanderung nach Schweden gering blieb: In den 1880er Jahren wurden lediglich ca. 4.200 Finnen in Schweden registriert und in der Folgezeit sank ihre Anzahl weiterhin $\mathrm{ab}^{208}$. Zur gleichen Zeit befand sich die Überseemigration bereits in ihrer Zuwachsphase und verdrängte zunehmend die traditionellen Auswanderungsziele Rußland und Schweden.

Es bleibt jedoch festzuhalten, daß sowohl die Binnenmigration als auch die saisonale Arbeitswanderung nach Schweden und Rußland im Emigrationsgebiet so lange alltägliche Erscheinungen darstellten, bis in den 1890er Jahren die Amerikaauswanderung die vorherrschende Mobilitätsrichtung vorgab. Als Denkmodell kann eine kausale Kette der Wanderungsbewegungen gebildet werden: Wenn die grenzüberschreitende Arbeitswanderung als eine in geographischer Hinsicht verlängerte Binnenwanderung angesehen wird, wäre die Überseeauswanderung lediglich die Fortsetzung dieser verlängerten Binnenwanderung, da nämlich der wichtigste Motivationsfaktor, die Suche nach verbesserten Erwerbsmöglichkeiten, keinen Unterschied zwischen den einzelnen Wanderungsbewegungen kannte.

${ }^{208}$ Geer de 1981, S. 56; Jokipii 1982, S. 54. 


\subsubsection{Die Auswanderung nach Nord-Norwegen als erster Schritt der Überseemigration}

Die nordwärts gerichtete Mobilität wies ebenso wie die Arbeitswanderung nach Rußland und Schweden eine lange Tradition auf, setzte sich jedoch, anders als die nach Schweden und Rußland gerichteten Auswanderungsbewegungen, noch bis zur Jahrhundertwende fort. Da ein Teil der finnischen Auswanderer von Nord-Norwegen aus nach Amerika emigrierte, d.h. an der Eismeerküste erst das notwendige Reisegeld verdiente, entwickelte sich die nördlichste Region Norwegens vielmehr zu einer Etappe im finnischen Auswanderungsverlauf nach Übersee.

Die nordwärts gerichtete Auswanderung von finnischen Bewohnern des TornioFlußtales begann im ausgehenden 18. Jahrhundert. Bei einer ersten Volkszählung des Jahres 1801 wurden 126 finnische Familien bzw. 773 Personen im Einzugsgebiet von Tromsø registriert. Auch nach 1809, dem Ende der finnisch-schwedischen Union, hielt die Auswanderung aus dem Tornio-Flußtal nach Nord-Norwegen weiterhin an. Da jedoch der Flußlauf fortan die Landesgrenze zwischen Finnland und Schweden markierte, wurden lediglich die von der finnischen Seite des Flußufers stammenden Finnen als solche in Norwegen registriert.

In der Folgezeit konzentrierten sich weitere finnische Siedlungen auf das AltaFjordgebiet, das Tana-Flußtal von Karasjok flußaufwärts bis Tana sowie insbesondere auf die nordöstliche Region um Vadsø im Varanger-Fjord. Diese Region im östlichen Teil der Finnmark wurde in der zweiten Hälfte des 19. Jahrhunderts vorherrschend für die finnische Emigration nach Norwegen ${ }^{209}$, wobei vor allem die Hungerjahre der ausgehenden 1860er Jahre für einen ersten Auswanderungshöhepunkt sorgten ${ }^{210}$. Einer ersten Untersuchung des Jahres 1870 zufolge sollen 1845 bereits 2722 Finnen in der norwegischen Provinz Finnmark gelebt haben. Bis 1865 stieg ihre Anzahl auf 5862 Personen an, wovon jedoch nur noch ein Drittel in Finnland geboren war ${ }^{211}$.

\footnotetext{
${ }^{209}$ Im Zeitraum 1875-85 stellten die Finnen mehr als 50\% der Stadtbewohner von Vadsø, vgl. Jokipii 1982, S. 42.

${ }^{210}$ Korkiasaari 1989, S. 19.

${ }^{211}$ Kolehmainen 1945, S. 226; Jokipii 1982, S. 55f.
} 
Schätzungsweise 4.000 aus Finnland emigrierte Auswanderer hatten bis 1910 die Eismeerküste erreicht ${ }^{212}$.

Die Gründe der Emigrationsbewegung nach Norwegen unterschieden sich nicht wesentlich von den Faktoren, die auch für die Wanderungsbewegungen nach Schweden und Rußland verantwortlich waren. Die vielfache Aufteilung kleiner und karger Bauernhöfe sowie der Bevölkerungsüberschuß der landlosen Sozialgruppen ließen die Abwanderung zwangsläufig zur einzigen Überlebensstrategie werden. Die fischreichen Küstengewässer des Eismeeres sowie von den einheimischen Norwegern ungenutzte Weideflächen für Milchvieh reichten als Anziehungsmagneten aus, um die ärmsten Bevölkerungsgruppen aus Nordfinnland in Bewegung zu setzten ${ }^{213}$. Im Gegensatz zur ost- oder westwärts gerichteten, grenzüberschreitenden Mobilität war die finnische Emigration nach Norwegen jedoch weniger saisonabhängig. Viele Auswanderer blieben ganzjährig an der Eismeerküste, woran sicherlich auch die mangelhaften Wegverbindungen sowie die rauhen Klimaverhältnisse ihren Anteil hatten.

In absoluten Zahlen wanderten wesentlich weniger Finnen nach Nord-Norwegen aus als nach Schweden. Bis 1890 wurden nach Schweden nämlich ca. 33500 Paßaustellungen registriert, wohingegen die Größenordnung der Rußlandemigration mit ca. 6500 Paßaustellungen nur geringfügig über der nordwärts gerichteten Mobilität $\operatorname{lag}^{214}$.

Für die beginnende Amerikaauswanderung jedoch war die Mobilität nach NordNorwegen richtungsweisend, so daß die Amerikaemigration als eine neue Alternative zu den bereits bestehenden Auswanderungszielen angesehen werden kann. Zum Ende des 19. Jahrhunderts führte dann die große Akzeptanz des neuen Fernzieles Übersee, womit neben Nord-Amerika auch die Auswanderungsbewegungen nach Süd-Amerika, Australien, Neuseeland und Süd-Afrika gemeint sind, zu einem deutlichen Rückgang der bisherigen Auswanderungsziele Norwegen, Schweden und Rußland.

Im Hinblick auf die Anfänge der finnischen Amerikaemigration war die im Jahr 1826 erfolgte Gründung eines Kupferbergwerkes im Kå-Fjord, einem Nebenarm des Alta-Fjordes, nicht unbedeutend. Das schnell expandierende Unternehmen sorgte für eine wachsende Regionalbevölkerung, die sich aus einem Völkergemisch von

\footnotetext{
${ }^{212}$ Jokipii 1982, S. 56.

${ }^{213}$ Saressalo 1982, S. 111-114; Korkiasaari 1989, S. 19 f.

${ }^{214}$ Jokipii 1982, S. 54.
} 
Norwegern, Schweden, Finnen, Engländern, Russen und Deutschen konstituierte. Bereits 1840 gehörten 472 im Kå-Fjord arbeitende Finnen, von den Norwegern 'Kvener' genannt, zur größten ethnischen Gruppierung am Ort und bildeten fast die Hälfte der Ortsbevölkerung. Im Jahr 1855 wurden immerhin noch 419 Finnen gezählt, obwohl die Ortsbevölkerung bereits auf 790 Personen zusammengeschrumpft war. Als Saisonarbeiter verbrachte etwa die Hälfte der Finnen jedoch lediglich die Sommermonate im Kå-Fjordgebiet ${ }^{215}$. Dennoch wies die Kå-Fjordregion zu dieser Zeit mehr finnische Einwohner auf als eine der vier Städte Nord-Norwegens: Tromsø, Hammerfest, Vadsø und Vardø.

In den 1860er Jahren bahnte sich dann die wirtschaftliche Talfahrt des Kupferbergwerkes im Kå-Fjordgebiet an, und nach Halbierung der Belegschaft im Jahr 1878 folgte die baldige Schließung der Grube. Vermutlich war diese Entwicklung vorauszusehen gewesen, da angeblich 1864 die ersten Bergleute aus dem KåFjordgebiet von einer amerikanischen Kupferbergwerksgesellschaft angeworben wurden $^{216}$. Dieser Zeitpunkt wird denn auch als der nachweisliche Beginn einer organisierten Auswandereranwerbung von amerikanischer Seite angesehen, die auch Finnen betraf.

Doch bereits seit den 1840-50er Jahren hatten sich einzelne Finnen unter die norwegischen Emigranten gemischt, zu einer Zeit, als die Auswanderungsbewegung in den südlichen Landesteilen Norwegens bereits die Dimension eines Massenexodus erreicht hatte $^{217}$. Kolehmainen schätzt die Anzahl der aus der norwegischen Provinz Finnmark ausgewanderten Finnen bis zum Jahr 1855 auf etwa 40 Personen ${ }^{218}$. Anhand von Kirchenbucheintragungen konnten Savolainen und Kokkonen wiederum 19 Finnen ermitteln, die vor 1860 über Norwegen nach Amerika ausgereist waren. Bis 1890 stieg ihre Anzahl auf 1102 Personen an. Diese Größenordnung stimmt ungefähr mit den von

\footnotetext{
${ }^{215} \mathrm{Zu}$ Finnen in Nord-Norwegen siehe Kolehmainen 1946, S.18; Jokipii 1982, S. 35-38; Raittila 1982, S. 11-13.

${ }^{216}$ Die Auswanderergruppe wird erstmals bei Ilmonen (1923, Bd. 2, S. 25-27) erwähnt. Über die Hintergründe der Anwerbung finden sich in der Literatur unterschiedliche Angaben. Als gesichert gilt lediglich, daß 1864 eine norwegische Emigrantengruppe über Tromsø nach NordMichigan emigrierte, zu der auch einige Finnen zählten, vgl. Blegen 1940, S. 415-417; Kero 1974, S. 160f.

${ }^{217}$ 1856-65 wanderten bereits ca. 40.000 Norweger nach Amerika aus; die Emigration aus den nördlichen Landesteilen betrug mit ca. 2800 Personen lediglich 7,2\% an der norwegischen Gesamtauswanderung, vgl. Blegen 1931, S. 358.

${ }^{218}$ Kolehmainen 1946, S. 20.
} 
Onnela und Kero ermittelten Zahlenwerte anhand von Auswandererprotokollen der Trondheimer Polizeibehörden überein. Während des Zeitraumes 1867-92 sollen demnach ca. 770 in Finnland geborene Personen die Atlantiküberquerung über Trondheim angetreten haben ${ }^{219}$. Von 3395 gleichzeitig emigrierten Norwegern trugen 40\% finnische Namen, das entspricht ca. 1.600 Personen, wonach diese zumindest teilweise Auswanderer der zweiten Generation gewesen sein könnten ${ }^{220}$. Die Mindestanzahl finnischsprachiger Auswanderer über Trondheim hat demnach rund 2000 Personen betragen, bis 1910 wuchs ihre Anzahl auf etwa 4000 Emigranten an. Vor diesem Hintergrund verwundert es auch nicht, daß die meisten finnischen Auswanderer die Reise aus solchen norwegischen Küstengebieten antraten, in denen die Konzentration finnischsprachiger Bewohner am größten war.

\subsubsection{Finnische Seeleute als erste Amerikafahrer}

Nach den bisherigen Ausführungen könnte der Eindruck entstehen, daß die im 19. Jahrhundert über Nord-Norwegen emigrierten Finnen die ersten finnischen Siedler in der Neuen Welt gewesen seien. Nach heutigen Erkenntnissen waren die ersten finnischen Siedler jedoch bereits 300 Jahre zuvor an die amerikanische Ostküste gelangt. Über die unter schwedischer Flagge segelnde Delegation des Jahres 1638, die im Delaware-Flußtal des heutigen Bundesstaates Pennsylvanien die erste skandinavische Kolonie 'New Sweden'gründete, ist viel geschrieben worden ${ }^{221}$. Die Frage, ob tatsächlich schon einige Finnen zu den ersten Entdeckungsreisenden zählten, kann aufgrund fehlender historischer Dokumente nicht beantwortet werden. Mit Sicherheit befanden sich jedoch finnischstämmige Personen auf den Segelschiffen der zweiten Delegation des Jahres 1641. Bis 1664, dem Ankunftsjahr der letzten skandinavischen Delaware-Siedler, sollen etwa 1.000 Personen aus dem Königreich Schweden, zu dem bis 1809 auch Finnland zählte, in der Kolonie gelebt haben. Doch bereits 1655 erfolgte die Einnahme der Kolonie durch holländische Eroberer und hatte die allmähliche Auflösung der Siedlung zur Folge. Von den Nachfahren der Delaware-Siedler wurde

\footnotetext{
${ }^{219}$ Kero (1974, S. 26-28) gibt die Gesamtanzahl mit 771 Personen an, Onnela (1975a, S. 169171) hingegen mit 769.

${ }^{220}$ Savolainen/Kokkonen 1964, S. 606, Tab. 4.

${ }^{221}$ Vor allem die 350-Jahrfeier der Delaware-Besiedlung des Jahres 1988 hat reichlich Literatur hervorgebracht, vgl. z.B. Koivukangas 1988 (Ausstellungskatalog); Carlsson 1988, S. 258-269; Kostiainen 1990b, S. 49-70; Kero 1996, S. 15-31.
} 
lediglich John Morton (1725-77) als einer der Unterzeichner der amerikanischen Unabhängigkeitserklärung bekannt ${ }^{222}$.

Während des 18. Jahrhunderts fanden immer wieder einzelne Seeleute und Handelsreisende finnischer Herkunft auf dem amerikanischen Kontinent eine neue Heimat, ihre Gesamtanzahl dürfte jedoch kaum mehr als einige hundert Personen betragen haben ${ }^{223}$.

Im 19. Jahrhundert, mit zunehmender Handelsschiffahrt auf den Weltmeeren, stieg auch die Anzahl der finnischen Seeleute. Insbesondere nach dem Krimkrieg überquerten sie unter fremder Flagge den Atlantik als Folge der weitgehenden Zerstörung der finnischen Handelsflotte.

Zwischen 1865-1913 schwankte die Größenordnung der finnischen Seeleute von 7950 bis 9740 Personen, um 1870 war ihre Anzahl mit ca. 11.000 Matrosen sogar ungewöhnlich hoch $^{224}$. Für die Seeleute war die Desertion in amerikanischen Anlegehäfen der einfachste Weg, um als Einwanderer in die Neue Welt zu gelangen. Im Zeitraum 1826-90 wurden denn auch 3336 Deserteure, die in England oder Amerika an Land gegangen waren, in 17 finnischen Seemannsämtern registriert ${ }^{225}$, wobei ihre tatsächliche Anzahl vermutlich noch höher gewesen sein kann. In den meisten Fällen verließen die Matrosen die finnischen Schiffe, um der besseren Bezahlung willen bei einem ausländischen Schiff anzuheuern. Da die Deserteure bei einer Rückkehr nach Finnland drakonische Strafen zu erwarten hatten, wagten sich viele von ihnen nicht mehr in ihr Heimatland zurück ${ }^{226}$.

Bei einer näheren Betrachtung der in den finnischen Seemannsämtern registrierten Desertionsfälle fällt ein deutlicher Anstieg auf, der bereits vor dem Krimkrieg begann. Allein in den Jahren 1849-60 sollen ca. 900 finnische Seeleute von ihren Schiffen geflohen sein, d.h. in einer Zeitspanne, die mit den kalifornischen

\footnotetext{
${ }^{222}$ John Morton war zwar finnischer Abstammung, jedoch kein Auswanderer der ersten Generation. Zu seiner Person siehe Koivukangas 1988, S. 65-69; Kero 1996, S. 26f. ${ }^{223}$ Kero 1974, S. 17. Zahlen ermitteln, wonach die tatsächliche Anzahl der Deserteure wahrscheinlich 3336 überstieg. Zur Seemannsdesertion allgemein sowie zu Einzelschicksalen siehe Ilmonen 1919, Bd.1, S. 88165.

${ }^{226} \mathrm{Zu}$ den gesetzlichen Bestimmungen, die erst 1865 gelockert wurden, siehe Hautala 1967, S. 111-117.
} 
Goldfunden ${ }^{227}$ zusammenfiel. Die Hafen- und ehemalige Hauptstadt Turku entwickelte sich zum zentralen Ausgangsort der Seeleute ${ }^{228}$, obwohl nur wenige Matrosen auch in Südfinnland beheimatet waren. Wahrhaft abenteuerlustige Goldsucher reisten dann in den 1850er Jahren von Kalifornien zu den australischen Goldminen weiter, ihre Anzahl wird auf etwa 200 Personen geschätzt ${ }^{229}$. Anhand von Paßverzeichnissen konnte jedoch nachgewiesen werden, daß bereits vor dem Krimkrieg neben der Seemannsdesertion eine zielgerichtete Auswanderung von Finnland nach Kalifornien existierte, wenn auch in sehr bescheidenem Ausmaß ${ }^{230}$.

Aufgrund der Tatsache, daß Mitte des 19. Jahrhunderts nur vereinzelte Handelskontakte zwischen Finnland und Amerika bestanden sowie wenig allgemeine Kenntnisse über den amerikanischen Kontinent unter der finnischen Bevölkerung vorherrschten, konnte die Nachricht über die kalifornischen Goldfunde wohl einige Hundert Seeleute in Bewegung setzten, nicht jedoch eine Wanderungsbewegung in größerem Umfang auslösen. In dieser Hinsicht unterschied sich die Situation in Finnland stark von den anderen skandinavischen und westeuropäischen Ländern, in denen die allgemeine Informationsverbreitung, nicht zuletzt durch einen wesentlich früheren Beginn der transatlantischen Wanderungsbewegungen, besser ausgeprägt war.

Zusammenfassend läßt sich festhalten, daß es in erster Linie Seeleute und über Nord-Norwegen ausgewanderte finnische Landarbeiter waren, welche die Frühphase der finnischen Amerikaauswanderungsbewegung prägten. Den Seeleuten kommt dabei eine besondere Bedeutung zu, da einige von ihnen wieder nach Finnland zurückkehrten und den Emigrationswilligen der nächsten Generation wertvolle Informationen über Reiserouten, Arbeitsplätze und Verdienstmöglichkeiten in Amerika und Kanada vermitteln konnten. Demzufolge kann auch eine Verbindung zwischen den ersten Auswanderergruppen der 1860er Jahre, die aus den schwedischsprachigen Küstenregionen Ostbottniens stammten, und der Informationsübermittlung durch Seeleute, die sich auf Heimatbesuch befanden, vermutet werden.

\footnotetext{
${ }^{227}$ Nach Finzsch (1982, S. 13) stieg die kalifornische Einwohnerzahl während des Jahrzehntes $1848-58$ von rund 14000 auf 380000 Personen an.

${ }^{228}$ Kero 1996, S. 35. Turku war bis 1827 die Hauptstadt Finnlands.

${ }^{229}$ Koivukangas 1986, S. 64-66.

${ }^{230}$ Für die Jahre 1849-53 konnte Kero (1969b, S. 167-169) elf Personen namentlich ermitteln, die einen Amerikapaß beantragt hatten.
} 
Der mündlich übermittelten Informationsübertragung kamen in der Frühphase der Auswanderungsbewegung auch die zahlreichen kirchlichen Zusammenkünfte zugute, allen voran die Gottesdienste, welche beispielsweise im schwedischsprachigen Küstendorf Petalax (finn. Petolahti) bis zu 200 Mal im Jahr stattfanden ${ }^{231}$. Briefe bereits ausgewanderter Emigranten konnten als Informationsträger erst in den nachfolgenden Jahrzehnten eine Breitenwirkung unter der Bevölkerung erzielen. Im Hinblick auf die Nachwanderung von Angehörigen der Briefschreiber hatten sie jedoch einen großen

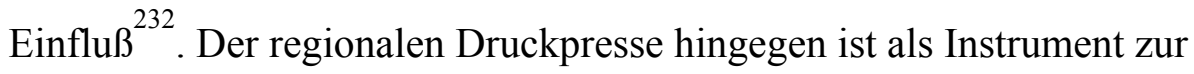
Auswandereranwerbung lediglich eine untergeordnete Rolle zuzuschreiben, da den persönlichen Erfahrungsberichten von vertrauten Personen eher geglaubt wurde.

\subsubsection{Die finnische Amerikaauswanderung vor 1870}

Der exakte Beginn der finnischen Emigrationsbewegung in die Neue Welt, mit Ausnahme der Siedlungsgründung der Delaware-Siedler, läßt sich nicht datieren. Vereinzelte finnische Seeleute haben bereits in den 1830er Jahren den amerikanischen Kontinent als Einwanderer betreten ${ }^{233}$. In den 1840er Jahren befanden sich dann einige Finnen unter den über Trondheim und Tromsø auswandernden Nord-Norwegern. Dennoch waren diese für die erste Hälfte des 19. Jahrhunderts nachgewiesenen Auswanderungsfälle lediglich Einzelerscheinungen, wenngleich in den ausgehenden 1850er Jahren die Zahl der desertierten Seeleute rapide anstieg. Selbst in den 1860er Jahren blieb die Anzahl der finnischen Überseeauswanderer insgesamt gering, obwohl in einigen Gemeinden der Regierungsbezirke Oulu und Vaasa bereits lokale Auswanderungstraditionen entstanden waren.

Zur gleichen Zeit sollen auch die ersten finnischen Siedlungen im amerikanischen Bundesstaat Minnesota entstanden sein ${ }^{234}$. In Alaska hingegen hatte sich schon in der ersten Hälfte des 19. Jahrhunderts eine finnische Kolonie gebildet, die untrennbar mit der Person des Pfarrers Uno Cygnaeus verbunden war. Während der

\footnotetext{
${ }^{231}$ Wester (1977, S. 124) bezieht sich auf den stichprobenartig untersuchten Zeitraum 1871-75, der noch die Frühphase der finnischen Amerikaauswanderung bezeichnet.

${ }^{232}$ Zur Bedeutung von Briefen für den Auswanderungsentschluß siehe Kap. 3.5.1.

${ }^{233}$ Kero (1971, S. 157-162) konnte z.B. die Biographie eines finnischen Seemannnes rekonstruieren, der 1833 nach Alabama ausgewandert war.

${ }^{234} \mathrm{Zu}$ den ersten landwirtschaftlich geprägten Siedlungen von finnischen Einwanderern siehe Kap. 3.4.3.
} 
Jahre 1840-45 stand er der lutherischen Kirchengemeinde der finnischen Kolonie in Sitka vor, zeitgleich mit der Amtsperiode des Generalgouverneurs und gebürtigen Finnen Arvid Adolf Etholén, der das bis 1867 unter russischer Herrschaft stehende Gouvernement Alaska leitete ${ }^{235}$.

Um ein Bild von der Größenordnung der Frühphase der finnischen Amerikaauswanderungsbewegung, d.h. der Zeit vor 1871, zu erhalten, lohnt es sich, die von den Autorenpaaren Savolainen und Kokkonen sowie de Geer und Wester mit den von Toivonen ermittelten Zahlenwerten zusammenzufügen. Dabei decken die Autoren Savolainen und Kokkonen auf der Quellengrundlage von Kirchenbucheintragungen das nördlichste Untersuchungsgebiet Finnlands $a b^{236}$. Die imaginäre Grenze zum übrigen Finnland verlief entlang der Gemeinden Ii, Yli-Ii, Pudasjärvi, Taivalkoski und Kuusamo. Aufgrund der weiten Entfernung nach Oulu ist davon auszugehen, daß von den Amerikaauswanderern dieser Region die wenigsten zuvor einen Ausreisepaß bei der Ouluer Paßbehörde beantragt hatten.

Die Paßverzeichnisse der beiden Paßbehörden des Regierungsbezirks Oulu, in den Küstenstädten Oulu und Raahe gelegen, sowie neun weitere Paßverzeichnisse aus sechs Regierungsbezirken dienten wiederum Toivonen ${ }^{237}$ als Quellenmaterial für ihre Gesamterhebung der finnischen Auswandererzahlen vor 1871. Insgesamt hat Toivonen die Paßverzeichnisse von elf verschiedenen Paßbehörden benutzt. Offenbar hatte die Autorin jedoch keinen Zugang zu vier weiteren, vor 1871 geführten Paßverzeichnissen, die sowohl von Kero als auch von Vainio eingesehen werden konnten ${ }^{238}$.

Aufgrund der Unvollständigkeit des von Toivonen verwendeten Ausgangsmaterials ist ihre Angabe von 333 Auswanderern für Gesamtfinnland während des Zeitraumes 1866-70 als Minimalanzahl anzusehen. Dieser Eindruck wird auch durch einen Vergleich der von Toivonen mit de Geer und Wester ${ }^{239}$ ermittelten Anzahl von Amerikapässen für den Regierungsbezirk Vaasa erhärtet: Toivonen konnte für den Zeitraum 1866-70 lediglich 33 Paßausstellungen für Amerika nachweisen, de Geer und Wester haben hingegen 174 Paßeintragungen gezählt. Nach de Geer und Wester sind

\footnotetext{
${ }^{235}$ Zu den Finnen in Alaska vgl. Järnefelt 1899, S. 224-234; Holmio 1967, S. 83-85; Kero 1996, S. 38 und vor allem das dreibändige Werk von Olin 1995-96.

${ }^{236}$ Savolainen/Kokkonen 1964, S. 598 und S. 606.

${ }^{237}$ Toivonen 1963, S. 254 und Tab.1, Anhang.

${ }^{238}$ Kero 1974, S. 6; Vainio 1974, S. 54f.

${ }^{239}$ Geer de/Wester 1975, S. 98-100.
} 
während des gesamten Jahrzehnts 1861-70 insgesamt 192 Amerikapässe im Regierungsbezirk Vaasa ausgestellt worden. De Geer und Wester haben jedoch ausschließlich Paßverzeichnisse aus dem Regierungsbezirk Vaasa untersucht.

Tab. C Mindestauswandereranzahl vor 1871

\begin{tabular}{|l|l|l|l|}
\hline Zeitraum & $\begin{array}{l}\text { Savolainen/ } \\
\text { Kokkonen (1964) }\end{array}$ & $\begin{array}{l}\text { de Geer/ } \\
\text { Wester (1975) }\end{array}$ & $\begin{array}{l}\text { Toivonen } \\
\mathbf{( 1 9 6 3 )}\end{array}$ \\
\hline $1841-1850$ & 8 & & \\
\hline $1851-1860$ & 13 & & 300 \\
\hline $1861-1870$ & 374 & 192 & \\
\hline & & & $\mathbf{3 0 0}=\mathbf{8 8 7}$ \\
\hline $\mathbf{1 8 4 1 - 1 8 7 0}$ & $\mathbf{3 9 5}$ & $\mathbf{1 9 2}$ & \\
\hline
\end{tabular}

Dieser Zusammenstellung zufolge sind bis 1870 mindestens 887 gebürtige Finnen nach Amerika emigriert. Aufgrund der hohen Anzahl von desertierten Seeleuten, die nach Hautala von 1826-60 bei 1645 Personen gelegen hat ${ }^{240}$, sowie der unbestimmten Anzahl von Auswanderern, die ohne Reisepaß bzw. Abmeldung beim örtlichen Gemeindevorsteher die Atlantiküberquerung angetreten haben, ist aber davon auszugehen, daß bis 1870 weitaus mehr als die hier angegebenen 887 Finnen den amerikanischen Kontinent erreicht hatten ${ }^{241}$.

\subsubsection{Der Auswanderungsverlauf 1870-1914}

Für die Zeit von 1870 bis 1914, d.h. für diejenigen Jahrzehnte, in denen die finnische Auswanderungsbewegung ihren Höhepunkt erreichte, hat Kero, wie bereits einleitend dargestellt, die jährlichen Emigrantenzahlen rekonstruieren können. Diese in Tabelle 1 im Anhang dargestellten Auswandererzahlen zeugen von einem phasenweisen Anwachsen der finnischen Auswanderungsbewegung.

\footnotetext{
${ }^{240}$ Hautala 1967, S. 102f. Es bleibt jedoch unklar, wieviele der in England und Amerika desertierten Seeleute als Einwanderer in Amerika seßhaft wurden.

${ }^{241}$ Kero (1996, S. 55) spricht von einigen Tausenden, ohne ihre Anzahl näher zu spezifizieren.
} 
Anders als vergleichsweise in Irland ${ }^{242}$ stiegen die finnischen Auswandererzahlen nicht durch die sogenannten Hungerjahre der ausgehenden 1860er Jahre an, obwohl die finnische Auswanderungsbewegung zu dieser Zeit bereits die südostbottnische Küstenregion erreicht hatte. Lagen die Herkunftsgebiete der Pioniere unter den finnischen Amerikaauswanderern, welche nicht den Umweg über die norwegische Eismeerküste antraten, in den beginnenden 1860er Jahren meist noch im Tornio-Flußtal $^{243}$, so nahmen im Verlauf des Jahrzehnts schon vereinzelte süd- und mittelostbottnische Küstengemeinden von Kristiinankaupunki bis nach Kalajoki am Emigrationsgeschehen teil. So sollen beispielsweise bereits sechs Personen vor 1860 die Küstengemeinde Munsala verlassen haben ${ }^{244}$. Aus Malax (finn. Maalahti) und aus Kronoby (finn. Kruunupyy) ist die Auswanderung je einer Person im Jahr 1861 belegt, und fünf Jahre später sprang der Auswanderungsfunke auch auf einige finnischsprachige Inlandsgemeinden über, wie beispielsweise Jepua, Alahärmä und Ähtävä ${ }^{245}$.

Von diesen vereinzelten Auswanderungsfällen abgesehen, kam die Emigrationsbewegung zu Beginn der 1870er Jahre erst allmählich in Gang. Ein erster Höhepunkt wurde 1873 erreicht, als sich die Gesamtanzahl von 980 Emigranten des entsprechenden Jahres der Eintausendgrenze näherte. Die Mehrheit dieser Ausreisewilligen stammte aus den schwedischsprachigen Küstengemeinden, welche in den Jahren 1871-75 ein zehnfach stärkeres Emigrantenaufkommen aufwiesen als der Regierungsbezirk Vaasa im Durchschnitt ${ }^{246}$.

Im weiteren Verlauf des besagten Jahrzehnts fielen die jährlichen Auswandererzahlen noch einmal rapide ab, um dann 1880 fast um das Vierfache des Vorjahres anzusteigen und erstmals die Eintausendgrenze zu überschreiten. Diese imaginäre Grenze von mindestens tausend Auswanderern pro Jahr wurde in der Folgezeit nicht mehr unterboten. In den 1880er Jahren bewegten sich die jährlichen Auswandererzahlen zwischen 1000 und 5000 Personen, wonach die Emigrationsbewegung zu Beginn der 1880er Jahre sowohl auf den gesamten

\footnotetext{
${ }^{242}$ Der Höhepunkt der irischen Amerikaauswanderung wurde in den 1850er Jahren mit ca. einer Million Emigranten erreicht, vgl. z. B. Daniels 1990, S. 126-145, bes. S. 134.

${ }^{243}$ Beispielsweise aus Alatornio und Utsjoki wanderte 1860 bzw. 1861 jeweils eine Person direkt nach Amerika aus, vgl. Kero 1974, S. 17, Note 12.

${ }^{244}$ Backman 1945, S. 12, Tab. 10.

${ }^{245}$ Smeds 1935, S. 335; Hautamäki (unveröffentlichte Magisterarbeit ) 1981, Anhang, Abb. 10.

${ }^{246}$ Kummel 1980, S. 462.
} 
Regierungsbezirk Vaasa sowie auf die angrenzenden nördlichen Gemeinden der Provinz Satakunta aus dem Regierungsbezirk Turku/Pori übergegriffen hatte.

Gleich zu Beginn der 1890er Jahre erlebte die Überseemobilität dann einen kräftigen Aufschwung, gefolgt von einem plötzlichen Einbruch im Jahr 1894 als Reaktion auf die amerikanische Wirtschaftsdepression des Vorjahres. Im weiteren Verlauf der 1890er Jahre bewegte sich die Größenordnung der jährlichen Emigrantenzahlen zwischen rund 2700 und 5300 Personen, womit auf dem gleichen Niveau lag wie bereits ein Jahrzehnt zuvor, um dann plötzlich im Jahr 1899 sprunghaft auf knapp 13000 Auswanderer anzusteigen.

Das Erstarken der Auswanderungsbewegung zum Ende des 19. Jahrhunderts hin wurde nicht zuletzt durch einen starken Geburtenanstieg der 1870er Jahre - im Anschluß an die sogenannten Hungerjahre - verursacht, wobei dieses Bevölkerungswachstum vor allem zu Lasten der ärmeren Bevölkerungsgruppen ging. Ab 1899 emigrierten dann jährlich mehr als zehntausend Finnen, wobei die Auswandererzahlen vor Ausbruch des Ersten Weltkriege lediglich in den Jahren 1908 und 1914 unter die 10.000-Marke absanken, was auf die Schwankungen der amerikanischen Konjunkturlage sowie den Kriegsausbruch in Europa zurückzuführen ist.

Die Kulmination der Emigrantenzahlen nach der Jahrhundertwende läßt den Terminus des Massenexodus für die finnische Auswanderungsbewegung angebracht erscheinen: Allein während der fünfzehnjährigen Zeitspanne 1900-14 wurden 228.100 Personen als Schiffspassagiere nach Übersee gezählt, das waren mehr als zwei Drittel des gesamten Auswandereraufkommens der Jahre 1870-1914. Im Durchschnitt wanderten jährlich etwa 15.000 Finnen aus, wobei der absolute Auswanderungshöhepunkt im Jahr 1902 mit rund 23.000 Emigranten erreicht wurde. Mehr als 20.000 Auswanderer pro Jahr wurden nochmals in den Jahren 1909, 1910 und 1913 registriert, wobei diese Spitzenwerte jedoch Ausnahmeerscheinungen blieben, die sich auch nach dem Ersten Weltkrieg nicht mehr wiederholten ${ }^{247}$.

Bei Betrachtung der geographischen Ausbreitung der fortschreitenden Emigrationsbewegung fällt zur Jahrhundertwende hin das Abflauen der Auswanderungsfrequenz in Nordfinnland auf, d.h. den Herkunftsgebieten der ersten Emigranten. Die schwedischsprachige Küstenregion Ostbottniens hingegen, die ebenfalls an der Frühphase der finnischen Amerikaemigration beteiligt war, zeigte auch

${ }^{247}$ Koivukangas 1993, S. 10. 
zu Zeiten der Massenemigration ein starkes Auswandereraufkommen ${ }^{248}$, wonach der gesamte Regierungsbezirk Vaasa sowie die südwestlichsten Ausläufer des Regierungsbezirkes Oulu während der Höhepunktsphase im Emigrationsverlauf die meisten Amerikafahrer stellten. In Dekaden dargestellt sah die Entwicklung der Auswandererzahlen folgendermaßen aus ${ }^{249}$ :

Tab. D Auswandererzahlen in Zehnjahresabständen 1870-1914

\begin{tabular}{|l|l|}
\hline $1870-1880$ & 4729 \\
\hline $1881-1990$ & 40182 \\
\hline $1891-1900$ & 65692 \\
\hline $1901-1910$ & 166968 \\
\hline $1911-1920(1911-1914)$ & $62000(49826)$ \\
\hline & \\
\hline $\mathbf{1 8 7 0 - 1 9 1 4}$ & $\mathbf{3 2 7 3 9 7}$ \\
\hline
\end{tabular}

Åkerman ${ }^{250}$ spricht in diesem Zusammenhang von einem vierphasigen Auswanderungsverlauf, der sich vereinfacht in Form einer glockenförmigen Kurve darstellt: den Einleitungs-, Zuwachs-, Sättigungs-, und Regressionsphasen. Anhand der finnischen Auswanderungszahlen läßt sich diese zeitliche Grobeinteilung folgendermaßen vornehmen: Die Einleitungsphase dauerte bis etwa 1870, sie kann als Auftakt der Emigrationsbewegung angesehen werden. Gefolgt von der Zuwachsphase, die etwa bis 1890 anhielt, nachdem alle Gemeinden des Auswanderungsgebietes von der Emigrationsbewegung erfaßt worden waren, schloß sich die Sättigungs- bzw.

Höhepunktsphase an, welche die Jahrhundertwende sowie das erste Jahrzehnt des 20. Jahrhunderts ausfüllte. Im Jahr 1914, an der Schwelle zum Kriegsausbruch, fielen die Auswandererzahlen wieder rapide ab, so daß die eigentliche Regressionsphase bereits außerhalb des hier betrachteten Zeitraumes lag.

Auf die finnische Amerikaauswanderung bezogen, erweist sich das Modell von Åkerman lediglich im Hinblick auf eine klare Trennung der zweiten von der dritten Phase als problematisch, d.h. dem Übergang von der Zuwachs- in die

\footnotetext{
${ }^{248}$ Vgl. Kero 1974, S. 19, Abb. 2; Kummel 1980, S. 464, Abb. 4.

${ }^{249}$ Die Tabelle D basiert auf den Zahlenwerten aus Tabelle 1 im Anhang: Anzahl der finnischen Überseeauswanderer 1870-1914.

${ }^{250}$ Åkerman 1976, S. 27-31.
} 
Kulminationsphase. De Geer und Wester geben als Kriterium für die Zuwachsphase die zunehmende Beteiligung von Einzelauswanderern und Unverheirateten am Auswanderungsgeschehen an ${ }^{251}$. Die Beteiligung einzeln auswandernder Frauen am finnischen Auswanderungsgeschehen verstärkte sich jedoch noch in der dritten Phase, wonach dieses Phänomen nicht für eine deutliche Zäsur zwischen der zweiten und dritten Phase stehen kann.

Virtanen hingegen faßt die Zuwachs- und Kulminationsphasen als eine untrennbare Einheit zusammen, die er mit dem Zeitraum 1894-1913 gleichsetzt ${ }^{252}$. Er orientiert sich dabei an einem zwei Jahrzehnte währenden Langzeitzyklus der amerikanischen Konjunktur ${ }^{253}$, welcher auch die finnische Emigrationsbewegung beeinflußt hat. Das den Zyklus einleitende Jahr 1894 wird durch einen plötzlichen Einbruch der jährlichen Auswandererzahlen sowie einen damit einhergehenden rapiden Anstieg der Rückwandererzahlen ${ }^{254}$ bestimmt. Die jährlichen Emigrationszahlen stiegen im weiteren Verlauf jedoch wieder rapide an und erreichten im Jahr 1902 ihren einmaligen Höhepunkt. Nach einem weiteren Einbruch der Auswanderungsfrequenz im Jahr 1908 zeigte sich ein zweiter Anstieg, der 1913 kulminierte, jedoch durch den Kriegsausbruch ein Jahr später wieder abrupt absank.

Demnach wurde der hier skizzierte Langzeitzyklus durch eine niedrige Emigrationsfrequenz eingeleitet und mit einer hohen Auswanderungsaktivität abgeschlossen. Dabei wurden in der gesamten Zeitspanne 1894-1913 etwa viermal soviele Auswanderer gezählt als in der davorliegenden Einleitungsphase, die dementsprechend mit der zwanzigjährigen Zeitspanne von 1874-93 beschrieben werden kann. Im Hinblick auf die finnische Rückwanderungsbewegung war denn auch lediglich der zweite Langzeitzyklus von Bedeutung 255 .

Abschließend noch ein Vergleich mit den Amerikaauswanderungsverläufen der anderen skandinavischen Länder ${ }^{256}$, wobei offensichtlich wird, daß der bereits dargestellte, finnische Emigrationsverlauf keineswegs typisch war. Auf der Grundlage

\footnotetext{
${ }^{251}$ Geer de/Wester 1975, S. 23f.

${ }^{252}$ Virtanen 1979, S. 85 und S. 223.

${ }^{253} \mathrm{Zu}$ den amerikanischen Konjunkturzyklen siehe B. Thomas 1954, S. 83-94.

${ }^{254} \mathrm{Zu}$ den Rückwandererzahlen siehe Tab. 4 im Anhang: Anzahl der finnischen Rückwanderer $1892-1914$.

${ }^{255}$ Virtanen 1979, S. 85.

${ }^{256}$ Kero 1974, S. 79.
} 
der amerikanischen Konjunkturschwankungen, d.h. der Langzeitzyklen im Rhythmus von ungefähr zwei Jahrzehnten, unterschied sich der finnische Auswanderungsverlauf gerade durch das starke Anwachsen der Zahlen während der zweiten Zeiteinheit von den übrigen skandinavischen Ländern, bei denen die Auswandererzahlen zur Jahrhundertwende hin bereits eine rückläufige Tendenz zeigten $^{257}$ :

Tab. E Vergleich der Auswanderungsverläufe der skandinavischen Länder 1874-93 und 1894-1913

\begin{tabular}{|l|l|l|}
\hline Land & $\begin{array}{l}\text { Konjunkturphase } \\
\mathbf{1 8 7 4 - 9 3}\end{array}$ & $\begin{array}{l}\text { Konjunkturphase } \\
\mathbf{1 8 9 4 - 1 9 1 3}\end{array}$ \\
\hline Finnland & 67989 & 251745 \\
\hline Schweden & 512306 & 370148 \\
\hline Norwegen & 284490 & 276524 \\
\hline Dänemark & 132170 & 126960 \\
\hline
\end{tabular}

\subsection{Auswanderungsintensität in Gesamtfinnland}

Als bislang einziger Historiker hat Kero die Auswanderungsfrequenz in Relation zur durchschnittlichen Bevölkerung für jede einzelne Gemeinde in Finnland ermittelt, um sowohl die geographische Ausbreitung des Auswanderungsphänomens als auch die Auswanderungsintensität in den Kernregionen näher bestimmen zu können. Der Autor hat für seine Erhebung die Paßverzeichnisse der einzelnen Regierungsbezirke ${ }^{258}$ und städtischen Paßbehörden genutzt, da sie im Gegensatz zu den Passagierlisten die Herkunftsgemeinde bzw. den letzten Wohnort des Paßinhabers angeben. Für die nördlichsten Regionen Finnlands, wo die paßlose Auswanderung unverhältnismäßig stark ausgeprägt war, wurden wiederum Kirchenbücher als ergänzende Quellen

${ }^{257}$ Die Zahlenwerte basieren auf den Angaben von Ferenczi und Willcox (1969, S. 667f., S. 748 und S. 756) und geben die Anzahl der Einwanderer in die Vereinigten Staaten an. 
herangezogen. Als Zusammenfassung von Keros Ergebnissen wird hier das Ausmaß der finnischen Emigrationsbewegung auf acht Regierungsbezirke verteilt dargestellt ${ }^{259}$ :

Tab. F Auswanderung nach Regierungsbezirken auf der Grundlage von Paßverzeichnissen 1870-1914

\begin{tabular}{|l|l|l|l|}
\hline Reg.bezirk & $\begin{array}{l}\text { Anzahl } \\
\text { Personen }\end{array}$ & $\begin{array}{l}\text { Anteil am gesamten } \\
\text { Auswandereraufkommen }\end{array}$ & $\begin{array}{l}\text { Jährl. } \\
\text { Durchschnittl. } \\
\text { Emigration /1000 d. } \\
\text { Gesamtbevölkerung }\end{array}$ \\
\hline Uusimaa & 13179 & $4 \%$ & 1,1 \\
\hline Turku/Pori & 43753 & $15 \%$ & 2,5 \\
\hline Häme & 8795 & $3 \%$ & 0,7 \\
\hline Viborg & 16041 & $5 \%$ & 1,0 \\
\hline Mikkeli & 5053 & $2 \%$ & 0,6 \\
\hline Kuopio & 9896 & $3 \%$ & 0,8 \\
\hline Vaasa & 158408 & $52 \%$ & 8,6 \\
\hline Oulu & 47657 & $16 \%$ & 4,3 \\
\hline & & & $\mathbf{2 , 8}$ \\
\hline Finnland & $\mathbf{3 0 2 7 8 2}$ & $\mathbf{1 0 0} \%$ & \\
\hline
\end{tabular}

Die Zahlenangaben aus Tabelle F sollen jedoch lediglich als Orientierungswerte gelten, da nämlich ungenaue Angaben und Auslassungen in den Paßverzeichnissen dazu geführt haben, daß die Auswandereranzahl einiger Gemeinden in den Paßverzeichnissen niedriger ausfiel, als sie aller Wahrscheinlichkeit nach gewesen ist ${ }^{260}$. Demzufolge liegt die hier errechnete Gesamtanzahl mit 302782 Emigranten unter der anhand verschiedener Passagierlisten ermittelten Summe von rund 327000 Personen ${ }^{261}$. Die Angaben der offiziellen Statistik wiederum liegen nochmals deutlich unter diesen Angaben, berücksichtigen jedoch lediglich den Zeitraum 1893-1914.

Wie bereits dargestellt, sind sowohl die Paßverzeichnisse als auch die Passagierlisten in ihrer Auswertung keine unproblematischen Quellen. Insbesondere der Faktor der Mehrfachauswanderung, welcher von Virtanen auf etwa 10\% am finnischen

\footnotetext{
${ }^{259}$ Die Tabelle basiert ursprünglich auf den von Kero (1974, S. 217-232) ermittelten Zahlenwerten. Für die Provinzen Uusimaa und Viborg konnten lediglich die Zahlenwerte der Jahre 1893-1914 berücksichtigt werden.

${ }^{260}$ Kero 1974, S. 48-55 und S. 217-232.

${ }^{261}$ Siehe hierzu Tabelle 1 im Anhang: Anzahl der Überseeauswanderer 1870-1914.
} 
Emigrantenaufkommen geschätzt wird ${ }^{262}$, verfälscht die Angaben beider Quellengattungen.

Beim Vergleich der Regierungsbezirke nach ihrem spezifischen Auswandereranteil am Gesamtvolumen aller Emigranten, wie in Tabelle F dargestellt, fällt eine Konzentration im Regierungsbezirk Vaasa mit mehr als der Hälfte aller registrierten Amerikareisenden auf. Dementsprechend war hier auch die Auswandererfrequenz, d.h. die durchschnittliche jährliche Emigration im Verhältnis zur durchschnittlichen Regionalbevölkerung mit 8,6 Auswanderern pro Einwohnertausend, deutlich höher als in den übrigen sieben Regierungsbezirken. Fast ausnahmslos alle Auswanderer des Regierungsbezirks Vaasa hatten Nord-Amerika oder Kanada zum Ziel, lediglich einige Hundert reisten nach Süd-Afrika, Süd-Amerika, Asien, Australien oder Neu-Seeland ${ }^{263}$.

In den Regierungsbezirken Oulu und Turku/Pori, die an den Regierungsbezirk Vaasa nördlich und südlich angrenzten, bewegten sich die absoluten Auswandererzahlen in annähernd gleicher Größenordnung. Im Unterschied zum Regierungsbezirk Vaasa verteilte sich die Auswanderungsintensität in den Regierungsbezirken Oulu und Turku/Pori jedoch sehr unterschiedlich auf die einzelnen Gemeinden. Dabei waren die an den Regierungsbezirk Vaasa südlich und nördlich angrenzenden Gemeinden stärker von der Auswanderung betroffen als die übrigen Regionen. Sie waren demnach deutlich vom Auswanderungskerngebiet beeinflußt.

Darin erschöpfen sich aber auch schon die Gemeinsamkeiten der nördlichen und südwestlichen Landesteile. Da nämlich der Norden Finnlands verhältnismäßig dünn besiedelt war, wirkte sich die Auswanderung dort fast doppelt so stark auf die Regionalbevölkerung aus wie im Südwesten Finnlands. Außerdem begann der chronologische Verlauf der Auswanderungsbewegung im Regierungsbezirk Oulu, zu einer Zeit, als in den Regierungsbezirken Vaasa und Turku/Pori allenfalls vereinzelte Auswanderer, die zumeist Seeleute waren, den Atlantik überquerten. In den fünf

\footnotetext{
${ }^{262}$ Virtanen 1979, S. 221.

${ }^{263}$ Der Anteil der südostbottnischen Australienauswanderer lag bis in $1890 \mathrm{er} \mathrm{Jahre} \mathrm{bei} 25 \%$, um sich bis 1893 auf 10\% zu verringern, siehe Koivukangas 1986, S. 102f. Bei den Auswanderern nach Neuseeland und Süd-Afrika dominierten Einwohner der schwedischsprachigen Küstengemeinde Munsala, vgl. Kuparinen 1991, S. 236-243; Koivukangas 1996, S. 246. Speziell zur Auswanderung aus Munsala siehe die Mikrostudie von Backman 1945. Insgesamt lebten 1921 etwa 1300 Finnen in Australien, 300 in Neu-Seeland und 100 in Süd-Afrika, nachdem sich bereits um 1900 rund 500 finnische 'Goldgräber' in Johannisburg aufgehalten hatten, vgl. Korkiasaari 1989, S. 45-50.
} 
übrigen Regierungsbezirken Uusimaa, Häme, Mikkeli, Kuopio und Viborg bewegten sich die Auswandererzahlen deutlich unter dem Niveau des Landesdurchschnitts von 2,8 Auswanderern jährlich pro Einwohnertausend.

Um das hauptsächliche Herkunftsgebiet der finnischen Amwerikaauswanderer nicht nur auf der Ebene der Regierungsbezirke regional einzugrenzen, zeigt die Karte 2 im Anhang die geographische Verteilung des Auswandereraufkommens auf Gemeindeniveau für den Zeitraum 1870-1914. Sie gibt Aufschluß über alle Gemeinden, deren jährliche Auswanderungsfrequenz durchschnittlich zehn Personen pro Einwohnertausend der Ortsbevölkerung überstieg, womit sie der Kernzone des Auswanderungsgebietes zuzurechnen sind.

Bewegte sich die jährliche Emigrationsfrequenz dahingegen zwischen 5 und 9,9 Promille, lassen sich die jeweiligen Gemeinden wiederum der Peripheriezone des Auswanderungsgebiets zuordnen. Außerhalb der Auswanderungsregion, d.h. der Kernund Peripheriezone, befand sich das von der Amerikaauswanderung geringfügig betroffene Gebiet, d.h. daß die jährliche Auswanderungsintensität im restlichen Finnland zwischen 0,9 und 4,9 Promille schwankte.

Das hauptsächliche Auswanderungsgebiet, das sowohl die Kern- als auch die Peripheriezone umfaßte, erstreckte sich etwa 500 Kilometer an der Westküste entlang von Pori bis Oulu. In östlicher Ausdehnung bildeten die Gemeinden Ulvila, Ikaalinen, Virrat, Saarijärvi, Viitasaari, Pihtipudas und Kestilä eine imaginäre Grenzlinie. Aus diesem Gebiet stammten insgesamt 65,9\% aller finnischen Auswanderer, was etwa 199600 Personen entsprach ${ }^{264}$. Das Auswanderungskerngebiet, d.h. die Region mit dem landesweit stärksten Emigrantenaufkommen, ist mit den Gemeinden Lohtaja im Norden, Laihia im Süden und Karstula im Osten einzugrenzen. Innerhalb dieser Region liegt auch die mittelostbottnische Gemeinde Toholampi, welche mit einem Spitzenwert von jährlich 15,9 Auswanderern auf 1000 Personen der durchschnittlichen Gemeindebevölkerung einen Auswandererrekord innerhalb der ländlichen Gemeinden Finnlands aufstellte ${ }^{265}$. Dieser Rekordwert wurde nur noch von der Kleinstadt Nykaarleby (finn. Uusikaarlepyy) mit durchschnittlich 16,7 Auswanderern jährlich pro Einwohnertausend überschritten, wobei jedoch davon ausgegangen werden muß, daß es

\footnotetext{
${ }^{264}$ Kero 1974, S. 50-52 und 1996, S. 56-58.

${ }^{265}$ Siehe hierzu die Detailstudie am Beispiel der Gemeinde Toholampi in Mittelostbottnien, welche die meisten Emigranten stellte: Kero/Kostiainen/Kuparinen 1978. Zur Verteilung der Auswanderungsintensität auf einzelne Gemeinden des Untersuchungsgebiets siehe Tab. 6 im Anhang.
} 
sich bei zahlreichen städtischen Emigranten ursprünglich um zugezogene Landarbeiter handelte. Auch in den beiden südostbottnischen Gemeinden Alajärvi und Isokyrö betrug die durchschnittliche jährliche Auswandererfrequenz mindestens 13 Personen pro Einwohnertausend und war somit extrem hoch.

Das Auswandererkerngebiet erstreckte sich demnach über zahlreiche Gemeinden Süd- und Mittelostbottniens, wobei jedoch zwischen der Kernzone, Peripheriezone und dem weniger stark betroffenen Umland keine scharfen Grenzlinien verliefen, sondern eher von einer graduellen Abschwächung der Auswanderungsintensität ausgegangen werden kann $^{266}$. Je größer die geographische Distanz zu den Gemeinden des Auswanderungskerngebietes war, desto schwächer gestaltete sich die Auswanderungsintensität der einzelnen Gemeinden.

Auch außerhalb des hier skizzierten, zusammenhängenden Auswanderungsgebietes lassen sich einzelne Gemeinden ausmachen, deren Auswanderungsintensität sich nicht von der des eigentlichen Auswanderungsgebiets unterschied. Dies waren in erster Linie die schwedischsprachigen Gemeinden Kalajoki, Korsnäs, Övermark (finn.Ylimarkku), Närpes (finn. Närpiö), Lappfjärd (finn. Lapväärtti) und Sideby (finn. Siipyy). Darüber hinaus fanden sich wiederum einzelne Gemeindegruppen, deren Auswanderungsintensität sich deutlich von den umgebenden Gemeinden abhob, jedoch nicht die Größenordnung der dem Auswanderungsgebiet zugehörigen Gemeinden erreichte. Als derartige Regionen können vor allem die Ålandinseln ${ }^{267}$, das Umland der Hafenstadt Rauma, das Tornio-Flußtal, der Küstenstreifen zwischen Oulu und Tornio sowie einige Gemeinden der KymiFlußmündung im Regierungsbezirk Viborg genannt werden. Auch im Inland finden sich vereinzelt solche Gemeinden bzw. Städte, wie Pudasjärvi, Puolanka, Suomussalmi, Taivalkoski, Kuusamo und Kemijärvi ${ }^{268}$. In den Regierungsbezirken Häme, Mikkeli und Kuopio hingegen machte sich die Amerikaauswanderungsbewegung kaum bemerkbar, wie folgende Darstellung verdeutlicht ${ }^{269}$ :

\footnotetext{
${ }^{266}$ Kero 1974, S. 50 und 1996, S. 58.

${ }^{267}$ Zur åländischen Emigration vgl. Geer de 1951, S. 86f.; Blomfelt (unveröffentlichte Lizentiatsarbeit) 1968, S. 77-79 und S. 87-93.

${ }^{268}$ Kero 1996, S. 58.

${ }^{269}$ Tabellenangaben nach Kero 1974, S. 217-232, Tab. 1.
} 
Tab. G Vergleich der Auswanderungsintensität in Städten und ländlichen Gemeinden anhand der Regierungsbezirke 1870-1914

\begin{tabular}{|l|l|l|l|}
\hline Reg.bezirk & $\begin{array}{l}\text { Jährl. durchschn. } \\
\text { Emigration / 1000 } \\
\text { d. Gesamtbevölk. }\end{array}$ & $\begin{array}{l}\text { Jährl. durchschn. } \\
\text { Emigration / 1000 } \\
\text { d. Stadtbevölk. }\end{array}$ & $\begin{array}{l}\text { Jährl. durchschn. } \\
\text { Emigration / 1000 } \\
\text { d. Landbevölk. }\end{array}$ \\
\hline Uusimaa & 1,1 & 2,4 & 0,5 \\
\hline Turku/Pori & 2,5 & 2,6 & 2,4 \\
\hline Häme & 0,7 & 2,3 & 0,7 \\
\hline Viborg & 1,0 & 1,1 & 0,9 \\
\hline Mikkeli & 0,6 & 1,4 & 0,6 \\
\hline Kuopio & 0,8 & 2,0 & 0,7 \\
\hline Vaasa & 8,6 & 8,8 & 8,6 \\
\hline Oulu & 4,3 & 5,4 & 4,2 \\
\hline & & $\mathbf{3 , 1}$ & $\mathbf{2 , 8}$ \\
\hline Finnland & $\mathbf{2 , 8}$ & & \\
\hline
\end{tabular}

Beim Vergleich der Auswanderungsintensität aus Städten ${ }^{270}$ und ländlichen Gemeinden, wie in Tabelle G dargestellt, fällt ein wesentlicher Unterschied auf: Im allgemeinen war die Auswanderungsintensität aus Städten größer als aus ländlichen Gemeinden $^{271}$, obwohl die Differenz in den Regierungsbezirken Viborg, Turku/Pori und Vaasa gering ausfiel. Diese höhere Emigrationsintensität aus Städten bedeutet jedoch lediglich, daß in Relation zur jeweiligen ortsansässigen Bevölkerung Stadtbewohner eine größere externe Mobilität aufwiesen als Landbewohner. So kamen auf durchschnittlich 10000 Städter 10,5 Auswanderer jährlich, jedoch lediglich 8,5 Emigranten auf 10000 Landbewohner ${ }^{272}$. Von 1870 bis zum Ausbruch des Ersten Weltkrieges überstieg der durchschnittliche Anteil der städtischen Emigranten innerhalb des gesamten Auswandereraufkommens jedoch kaum 12\%. Demnach stammte auch zu Zeiten der Industrialisierung und Urbanisierung die überwiegende Mehrheit der finnischen Auswanderer aus ländlichen Gebieten ${ }^{273}$.

\footnotetext{
${ }^{270}$ Nach Lento (1951, S. 20) war in zahlreichen ländlichen Gemeinden die Einwohnerzahl und Bevölkerungsdichte größer als in Städten.

${ }^{271}$ Die gleiche Tendenz ist auch in Norwegen, Schweden und Dänemark zu beobachten, vgl. Hvidt 1971, S. 105-123.

${ }^{272}$ Apunen 1987, S. 68.

${ }^{273}$ Kero 1974, S. 94 und 1986, S. 38f.; Geer de/Wester 1975, S. 38-55, bes. S. 42, Tab. 8.
} 
Wird das Verhältnis von Auswanderern aus Städten und ländlichen Gemeinden allerdings im Hinblick auf die Etappenwanderung betrachtet, so erweist sich der tatsächliche Anteil der städtischen Auswanderer am Gesamtauswandereraufkommen niedriger als 12\%. Der Etappenwanderung zufolge stammten die meisten, als Stadtbewohner registrierten Amerikaauswanderer ursprünglich aus ländlichen Gebieten, wonach dem Auswanderungsentschluß eine Binnenwanderung von Land zu Stadt vorausgegangen war. Kero schätzt die Größenordnung dieser Etappenwanderer auf drei Viertel aller städtischen Emigranten, weist jedoch darauf hin, daß bislang keine Untersuchung über die von finnischen Städten ausgehende Amerikaauswanderung vorliegt $^{274}$.

Bereits 1950 warf Semmingsen bezüglich der norwegischen Amerikaauswanderung die Frage auf, ob als städtische Auswanderer einzig gebürtige Städter oder aber bereits mehrere Jahre in Städten lebende, ursprüngliche Landbewohner zu zählen seien ${ }^{275}$. Da im Hinblick auf die finnische Amerikaemigration die Etappenwanderung als solche erst anfänglich untersucht worden ist, steht eine umfassende Erörterung dieser Problematik bislang noch aus.

\subsubsection{Die Auswanderungsintensität im Untersuchungsgebiet}

Nach diesem allgemeinen Vergleich der Auswanderungsintensität aus ländlichen Gebieten und Städten soll abschließend, wie in Tabelle 6 im Anhang dargestellt, die Auswanderungsintensität des hier zu behandelnden Untersuchungsgebiets näher betrachtet werden.

Die Auswanderungsintensität lag in den beiden Provinzen Süd-Ostbottnien und Satakunta erwartungsgemäß über dem Landesdurchschnitt von 2,8 Personen pro Einwohnertausend, da die meisten Herkunftsgemeinden der Briefschreiber die von Kero definierten Kriterien für die Zugehörigkeit zum Auswanderungsgebiet erfüllten. Dementsprechend war die Auswanderungsfrequenz in den meisten Gemeinden auch höher als der Durchschnittswert des jeweiligen Regierungsbezirks. Beim Vergleich der Herkunftsregionen der Briefschreiber aus Süd-Ostbottnien und Satakunta im Hinblick

\footnotetext{
${ }^{274}$ Kero 1986, S. 37 sowie persönliches Gespräch mit Prof. Kero im August 1996.

${ }^{275}$ Semmingsen 1950, S. 233-236. Zur schwedischen und dänischen Etappenwanderung siehe Nilsson 1970, S. 61-90, bes. S. 87-90; Hvidt 1971, S. 127-133.
} 
auf die Auswanderungsintensität geben die 19 südostbottnischen Gemeinden mitsamt der Stadt Vaasa ein einheitlicheres Bild ab als die 20 Gemeinden der Provinz Satakunta.

In Süd-Ostbottnien war die jährliche Auswanderungskonzentration in allen untersuchten Gemeinden hoch, da sich die Werte durchschnittlich zwischen 6,4 und 13,6 Emigranten pro Einwohnertausend bewegten ${ }^{276}$. Legt man Keros Maßstab von durchschnittlich mindestens fünf Auswanderern jährlich auf tausend Einwohner als Zugehörigkeitskriterium zur Peripheriezone des Auswanderungsgebietes an, so lassen sich zwölf Gemeinden und die Stadt Vaasa dazuzählen. Sieben Gemeinden des Regierungsbezirkes Vaasa gehören dieser Berechnungsgrundlage zufolge sogar zur Kernzone des Auswanderungsgebietes, nämlich Karijoki, Ylistaro, Isokyrö, Laihia, Lapua, Alajärvi und Vimpeli. In diesen Orten übertraf die durchschnittliche Emigrantenanzahl zehn Personen jährlich pro Einwohnertausend.

Für Gesamtfinnland hat Kero 37 Gemeinden und zwei Städte ermitteln können, die der Kernzone des Auswanderungsgebietes zuzurechnen sind und die sich allesamt bis auf eine Ausnahme im Regierungsbezirk Vaasa befinden. Damit entsprachen die genannten sieben Gemeinden knapp einem Fünftel des gesamten Auswanderungskerngebietes.

Die Provinz Satakunta im Regierungsbezirk Turku/Pori hingegen war von der Auswanderungsbewegung weniger stark betroffen. In den 20 hier untersuchten Gemeinden pendelte die Bandbreite zwischen durchschnittlich 1,1 und 8,0 Emigranten jährlich auf tausend Einwohner, wonach die Auswanderungsintensität ungefähr halb so groß war wie in der Provinz Süd-Ostbottnien. Die sieben Gemeinden Hinnerjoki, Ikaalinen, Jämijärvi, Kankaanpää, Karvia, Merikarvia und Siikainen können der Peripheriezone des Auswanderungsgebiets zugerechnet werden, da durchschnittlich jeweils zwischen 5 und 9,9 Auswanderer auf 1000 Ortsbewohner jährlich die Atlantiküberquerung antraten. Bei näherer Betrachtung dieser Gemeinden fällt auf, daß sie sich mit Ausnahme von Hinnerjoki im nördlichen Bereich der Provinz Satakunta befinden, einer Region, aus der Kero eine verstärkte Amerikaemigration nachgewiesen hat ${ }^{277}$.

Bei den verbleibenden 13 Gemeinden der Provinz Satakunta lagen die Werte von lediglich vier Gemeinden über dem landesweiten Durchschnittswert von

\footnotetext{
${ }^{276}$ Kero 1974, S. 227-230, Tab. 1.

${ }^{277}$ Kero (unveröffentlichte Lizentiatsarbeit) 1970, S. 30-34.
} 
durchschnittlich 2,8 Personen jährlich pro Einwohnertausend. Die

Abschwächungsrichtung der Auswanderungsintensität verlief demnach von Norden nach Süden durch die Provinz Satakunta hindurch, so daß eine imaginäre Grenzlinie zwischen den Gemeinden mit stärkerer und schwächerer Emigrationsintensität ausgehend von der Stadt Pori in östliche Richtung gezogen werden kann.

Nach dieser geographischen Eingrenzung des finnischen Auswanderergebietes sowie der näheren Bestimmung seiner Kern- und Peripheriezonen schließen sich nun folgende zentrale Themenkomplexe an: Zum einen sollen sowohl die gesamtgesellschaftlichen als auch die individuellen Auswanderungsgründe hinterfragt werden, die dem finnischen Emigrationsphänomen zugrunde lagen, zum anderen steht eine Erörterung der Zusammensetzung der Auswandererpopulation nach sozialer Herkunft, Alter und Geschlecht noch aus. In vereinfachter Form dargestellt, tritt folgende Fragestellung in den Vordergrund: Warum fand die Massenauswanderung überhaupt statt und wer nahm an ihr teil?

\section{$\underline{\text { 2.6. Auswanderungsgründe und -motivationen }}$}

Über Auswanderungsmotivationen und -gründe, sowohl im allgemeinen als auch speziell auf die finnische Amerikaauswanderung bezogen, ist viel geschrieben worden. Wenngleich theoretische Ansätze durchaus Aufschluß über die strukturellen Zusammenhänge der Konjunkturzyklen auf beiden Seiten des Atlantiks liefern können, ist in erster Linie davon auszugehen, daß es ebenso viele Auswanderungsgründe wie auch Auswanderer gab. Andererseits steht die breit gefächerte Skala der individuellen Emigrationsursachen in enger Beziehung zu den ökonomischen und politischen Rahmenbedingungen der Auswanderungsländer und ist unbedingt vor dem zeitgenössischen Hintergrund des jeweiligen Landes zu erörtern.

\subsubsection{Allgemeine Migrationstheorien}

Interessanterweise war der Beginn der europäischen Migrationsforschung nicht durch den Blick auf den einzelnen Auswanderer als Individuum geprägt, obwohl dies als Ausgangspunkt naheliegend gewesen wäre. Als Disziplin bereits 1885 durch den englischen Statistiker E. G. Ravenstein begründet, waren es in den Anfangsjahren vielmehr Sozialökonomen und Statistiker, die auf die anwachsende 
Auswanderungsbewegung aufmerksam wurden und nach ökonomisch motivierten Gründen für das Phänomen suchten.

Gewissermaßen als Wegbereiter formulierte Ravenstein erstmals Definitionen für freiwillige und erzwungene Wanderungsbewegungen, wobei er in der Tradition naturwissenschaftlicher Denkweise stehend, elf Gesetze für den Migrationsprozeß aufstellte, von denen die meisten noch heute aktuell sind. Hier wären u.a. die Feststellungen zu nennen, daß Wanderungsbewegungen größtenteils über kurze Distanzen und etappenweise verlaufen, Migrationen im zeitlichen Verlauf an Umfang zunehmen sowie die vorwiegende Wanderungsrichtung von Agrargebieten in urbane und industrielle Zentren verläuft ${ }^{278}$. Eine weitere vielzitierte These, wonach ein Migrantenstrom in eine Richtung unweigerlich eine Gegenbewegung in entgegengesetzter Richtung erzeugt, hat für das 20. Jahrhundert nur noch eingeschränkte Gültigkeit ${ }^{279}$.

Trotz Ravensteins deduktiver Vorgehensweise legte er mit seinem Vorstoß das theoretische Fundament für die nachfolgende Migrationsforschung des 20. Jahrhunderts, an der sich vor allen Sozialökonomen, Sozialwissenschaftler, Psychologen und, seit den 1960er Jahren, auch verstärkt Historiker ${ }^{280}$ beteiligten. Dementsprechend können zahlreiche spätere Migrationstheorien, denen Untersuchungen länderspezifischer Migrationsprozesse zugrunde liegen, als Modifikationen und Weiterentwicklungen von Ravensteins Postulaten angesehen werden.

Hier wäre als erstes die 1926 erschienene Arbeit von H. Jerome 'Migration and Business Cycles' zu nennen, worin der Autor auf die Bedeutung von amerikanischen Konjunkturzyklen, welche zu diesem Zeitpunkt bereits von Wirtschaftswissenschaftlern beschrieben worden waren, für den transatlantischen Migrationsprozeß hinweist ${ }^{281}$. Seine Theorie besagt in vereinfachter Form, daß der Emigrantenstrom der

\footnotetext{
${ }^{278}$ Ravenstein (1885, S. 267-285 und 1889, S. 241-305) gründete seine Aussagen auf die Auswertung internationaler Emigrationsstatistiken. Zur kritischen Auseinandersetzung mit Ravensteins Theorien siehe Jackson 1986, S. 14-16; Wulff 1987, S. 51f.; Daniels 1990, S. 1622; Koskinen/Martelin/Notkola 1994, S. 229 f.

${ }^{279}$ Virtanen 1979, S. 18; Korkiasaari/Söderling 1994, S. 229.

${ }^{280}$ Thistlethwaite publizierte 1960 erstmals einen vielzitierten Grundsatzartikel über die Aufgaben der zukünftigen, historisch orientierten Migrationsforschung, vgl. hierzu den Nachdruck von 1991, S. 25 und S. 43. Als Stellungnahme siehe Kamphoefner 1982, S. 4; Wulff 1987, S. 62-64.

${ }^{281}$ Jerome 1926, S. 205-208.Vgl. hierzu auch Hvidt 1971, S. 49f.; Odén 1971, S. 11f.; Wulff 1987, S. 52.
} 
Konzentration des Kapitals und damit den industriellen Investitionen folgt.

Dementsprechend betonte er die Relevanz der Anziehungskraft des amerikanischen Arbeitsmarktes, der sogenannten "Pull- Faktoren".

Da jedoch nicht alle Kritiker mit Jerome einer Meinung waren, entfachte sein Buch eine lebhafte Diskussion um die Gewichtung der sogenannten "Pull- und PushFaktoren". Als ein Beispiel sei die vielzitierte Arbeit von Dorothy S. Thomas aus dem Jahre 1941 genannt, worin die Autorin anhand der schwedischen Amerikaemigration die Bedeutung der "Push-Faktoren" - insbesondere während der Einleitungsphase der Emigrationsbewegung - unterstreicht. Neben der erstmals geleisteten, getrennten Untersuchung von Auswanderungsbewegungen aus ländlichen und urbanen Gebieten sieht sie die gesellschaftlichen Emigrationsursachen vor allem in der rasanten Bevölkerungszunahme sowie dem verspäteten Industrialisierungs- und Urbanisierungsprozeß in Schweden, Gründe, die ebenso auf die finnische Emigrationsbewegung zutreffen ${ }^{282}$.

Aufbauend auf Jeromes Gedanken ging der englische Autor Brinley Thomas im Jahr 1954 einen wesentlichen Schritt weiter, indem er den inzwischen klassisch gewordenen "Push- and Pull" - Begriff auflöste und auf eine dynamische Wechselwirkung der abstoßenden und anziehenden Faktoren im Migrationsprozeß hinwies. In seiner Theoriebildung folgte B. Thomas den Spuren von Jerome, modifzierte und spezifizierte jedoch dessen Ergebnisse derart, daß er die europäische Migrationsforschung auf eine neue Grundlage stellen konnte ${ }^{283}$. Er verstand die Länder beiderseits des Atlantiks als eine einheitliche atlantische Wirtschaftsgemeinschaft und prägte in diesem Zusammenhang den Begriff der 'Atlantischen Ökonomie'. Ausgehend von Tiefpunkten bei britischen Konjunkturzyklen, die mit Höhepunkten der amerikanischen Wirtschaftskurven korrespondierten, widmete B. Thomas seine Aufmerksamkeit den schwankenden Bewegungen des britischen Kapitals. Dabei wies er auf einen sich zyklisch wiederholenden Kreislauf von britischen Investitionen in Amerika und nachfolgender verstärkter Auswanderung aus Großbritannien sowie im Gegensatz dazu verminderter Emigration bei Stärkung der einheimischen Wirtschaft

\footnotetext{
${ }^{282}$ D.S. Thomas 1941, S. 165-175 und S. 318-326. Zu D.S. Thomas siehe auch Hvidt 1971, S. 50f.; Odén 1971, S. 13f.; Norman 1976, S. 151; Wulff 1987, S. 53f.; Norman/Runblom 1988, S. $113 \mathrm{f}$.

${ }^{283} \mathrm{Zu}$ B. Thomas siehe Hvidt 1971, S. 51-54; Odén 1971, S. 15-20; Kero 1974, S. 78f.; Åkerman 1978, S. 137f.; Kamphoefner 1982, S. 5f.; Wulff 1987, S. 54f.; Norman/Runblom 1988, S. 114.
} 
durch Kapitalfluß in die britische Industrie hin ${ }^{284}$. Die zentrale These von B. Thomas, daß sich nämlich die Einwanderungszahlen im gleichen Rhythmus mit der wechselnden Konjunkturlage in den USA bewegten, wurde in den folgenden Jahrzehnten durch angesehene Wirtschaftswissenschaftler bestätigt, beispielsweise durch Richard Easterlin und Thorvald Moe ${ }^{285}$.

Ebenfalls im Sinne von B. Thomas hat Virtanen - bezogen auf die finnische Emigrationsbewegung - deren Verknüpfung mit dem amerikanischen Arbeitsmarkt für den Zeitraum 1870-1914 untersucht. Analog zu den Ergebnissen von B. Thomas konnte er für die meisten Jahre ein Wechselspiel zwischen einem konjunkturellen Hoch in Amerika und einem wirtschaftlichen Tief in Finnland bzw. dem umgekehrten Fall feststellen, wobei jedoch die konjunkturellen Veränderungen in den Vereinigten Staaten, d.h. die "Pull-Faktoren", den gewichtigeren Anteil an den jährlichen Schwankungen der finnischen Emigrantenzahlen zu haben schienen ${ }^{286}$. Am deutlichsten ist diese Erscheinung an den plötzlich rapide ansteigenden Auswandererzahlen der Jahre 1882, 1893, 1899, 1902 und 1913 zu sehen. Nach Virtanens Meinung ist es jedoch schwierig zu ermessen, welchen definitiven Einfluß die einzelnen wirtschaftlichen Aufund Abschwünge auf die Schwankungen des finnischen Auswanderungsverlaufs gehabt haben.

Lediglich in der Frühphase der finnischen Amerikaauswanderung, die in den 1860er und 1870er Jahren mit dem Übergang von der Seemannsauswanderung zur vereinzelten Familienauswanderung beschrieben werden kann, ist die sogenannte "Push"-Wirkung größer gewesen. Sie wurde durch die sich verschlechternden sozioökomomischen Verhältnisse in Finnland ausgelöst, wie auch D.S. Thomas für die Einleitungsphase der schwedischen Amerikaemigration konstatiert hat .

Bei der ausschließlichen Betrachtung der ökonomisch motivierten Emigrationsursachen in Finnland sowie deren Verflechtungen mit dem amerikanischen Arbeitsmarkt bleiben jedoch einige Fragen unbeantwortet ${ }^{287}$. Die einfangs angesprochene Überlegung, daß vor allem persönliche Gründe zum individuellen

\footnotetext{
${ }^{284}$ B.Thomas 1954, S. 96-122.

${ }^{285}$ Easterlin 1972; Moe 1970. Zu Easterlins Ansätzen siehe auch Odén 1971, S. 21f.; zu Moes Theorie vgl. Åkerman 1973, S. 32-38 und 1978, S. 138-140.

${ }^{286}$ Virtanen 1979, S. 84-98, bes. S. 90f. Siehe hierzu auch Tabelle 3 im Anhang: Anzahl der finnischen Überseeauswanderer in Beziehung zur ökonomischen Situation in den Vereinigten Staaten und Finnland 1870-1914.

${ }^{287}$ Albrecht 1972a, S. 75.
} 
Emigrationsentschluß geführt haben, leitet zu soziologisch und psychologisch ausgerichteten Migrationsmodellen hin, welche vor allem in der jüngeren Migrationsforschung rege diskutiert wurden.

Als Wegbereiter dieser psychologisch ausgerichteten Wende in der Migrationsforschung sei Everett S. Lee genannt, der 1966 in seinem Artikel 'A Theory of Migration' darauf hinweist, daß in jeder Gesellschaft zwei Gruppen zu finden sind, nämlich sowohl die innovationssuchenden Auswanderungsbereiten als auch die anpassungswilligen Zurückbleibenden ${ }^{288}$. Dabei geht es dem Autor vor allem um die Fragestellung welche spezifischen Faktoren die Auswahl der Migranten bestimmt haben $^{289}$.

Als ersten Annäherungsversuch definiert Lee vier Faktoren, die den Akt der Emigration entscheidend prägen: Dies seien zum einen Faktoren, die der potentielle Auswanderer mit seinem persönlichen Herkunftsgebiet verbindet, zum anderen Vorstellungen, die er mit der anvisierten Zielregion assoziiert. Der dritte Faktor besteht aus einflußnehmenden Hindernissen, die zwischen der Herkunfts- und Zielregion existieren. Neben der zu überwindenden geographischen Distanz geht es hierbei in erster Linie um die beiden sozialen Systeme, zwischen denen sich der Auswanderer bewegt. Schließlich führt Lee noch persönliche Gründe an, die sehr individuell und mitunter ausschlaggebend für den Emigrationsentschluß sein können.

Lees Annäherungsweise an die Problemstellung hebt die Bedeutung des irrationalen Elementes hervor, das die Entschlußfindung des Auswanderungswilligen mitbestimmt: "The decision to migrate, therefore, is never completely rational, and for some persons the rational component is much less than the irrational". 290

Bereits drei Jahre nachdem Lees noch relativ allgemeingehaltener Erklärungsansatz die öffentliche Diskussion um die individuellen Auswanderungsgründe in Gang gebracht hatte, versuchte R. C. Taylor anhand einer Mikrostudie über britische Bergleute in West Durham die Faktoren zu ermitteln, welche die individuelle psychische Entwicklung einer zur Auswanderung prädisponierten Persönlichkeit begünstigen ${ }^{291}$. Einen ähnlichen Versuch unternahm Gert Raeithel mit

\footnotetext{
${ }^{288}$ Lee 1966. Zu kritischen Auseinandersetzungen mit Lees Theorien siehe Åkerman 1970 und 1973, S. 30-32; Virtanen 1979, S. 18-21; Koivukangas 1986, S. 348f.; Wulff 1987, S. 60-62.

${ }^{289}$ Vgl. hierzu Lüthke 1989, S. 25 f.

${ }^{290}$ Zitat aus Lee 1966, S. 51.

${ }^{291}$ Taylor 1969.
} 
seiner 1981 erschienen theoretischen Auseinandersetzung über die Mentalität der europäischen Auswanderer und der Amerikaner. Sein Ausgangspunkt war die Untersuchung von Objektbeziehungen, über die er Persönlichkeitscharakteristika zu definieren versuchte, welche angeblich Migranten von Nicht-Migranten unterscheiden $^{292}$. Dieser Ansatz ist nicht unumstritten geblieben, und auch im Bezug auf die finnische Einwanderung erscheint er wenig brauchbar.

\subsubsection{Ursachen der finnischen Emigrationsbewegung}

Die finnischen Migrationsforscher haben sich bislang der Bestimmung von angeblichen Persönlichkeitsmerkmalen enthalten, welche einen Erklärungsansatz für die Frage, wie sich Auswanderer von Nicht-Auswanderern abheben, liefern könnte ${ }^{293}$. Bei Interviews mit finnischen Aus- und Rückwanderern ließ sich jedoch feststellen, daß die persönlich motivierten Auswanderungsmotive in vielen Fällen nicht mit den öffentlich geäußerten Gründen übereinstimmten ${ }^{294}$, eine Beobachtung, die auch schon Taylor 1969 bei seinen britischen Gewährsleuten machte ${ }^{295}$. Für den individuellen Auswanderungsentschluß schienen vernünftig wirkende und sozial akzeptable Beweggründe lediglich einen Teilaspekt darzustellen, wesentlich hingegen waren die persönlichen Hintergründe, d.h. die individuellen Lebensumstände des potentiellen Auswanderers. Diese ausschlaggebenden Motive wurden jedoch häufig verschwiegen. Es fand sich vielmehr eine allgemeine Tendenz, die Emigrationsursachen in der Umwelt zu suchen, wodurch sich die Eigenverantwortung des Auswanderers am Emigrationsentschluß reduzierte ${ }^{296}$.

Virtanen gibt jedoch zu bedenken, daß auch der zum Teil sehr große zeitliche Abstand zwischen dem Aus- oder Rückwanderungsentschluß und der Interviewsituation die von den Befragten genannten Beweggründe beeinflussen kann. Vor allem in Fällen, in denen hauptsächlich persönliche Motive den Entscheidungsprozeß bestimmt haben,

\footnotetext{
${ }^{292}$ Raeithel 1981, S. 7-12 u. S. 23-41. Zu Kritik an Raeithel siehe Helbich/Haubold 1988, S. 40.

${ }^{293}$ Eine Ausnahme bildet hier lediglich die frühe Untersuchung von Kilpi (1917, S. 151f.), worin der Autor die 'Volksseele' der südostbottnischen Auswanderer zu beschreiben versucht. Als Kritik an Kilpi siehe Kero 1996, S. 62-65.

${ }^{294}$ Virtanen 1979, S. 175-180; Kero 1996, S. 67-71.

${ }^{295}$ Taylor 1969, S. 117. Vgl. hierzu auch die Untersuchung über deutsche Emigranten nach Australien von Lüthke/Cropley 1989, S. 366f.

${ }^{296}$ Lüthke/Cropley 1989, S. 367; Kero 1974, S. 67 f.
} 
erscheint eine Verklärung bzw. ein bewußtes Verschweigen der tatsächlichen Ursachen als wahrscheinlich ${ }^{297}$.

Werden die von den Auswanderern selbst genannten Gründe etwas genauer betrachtet, erscheint es schwierig zu ermessen, ob im Einzelfall die sogenannten "Pushoder Pullfaktoren" den Entscheidungsprozeß geprägt haben. Nach Kero und Myhrman wurde von nahezu allen Interviewten wirtschaftliche Not als Hauptgrund angegeben ${ }^{298}$. Auch in den knapp gehaltenen Fragebögen, die zu jeder Briefserie eines Schreibers dieser Untersuchung existieren, wurde zumeist die Bemerkung 'Geld verdienen' in die den Auswanderungsgrund erfragende Rubrik eingetragen, was darauf schließen läßt, daß viele Auswanderungswillige in Finnland keine ausreichenden Erwerbsmöglichkeiten fanden.

Die bereits ausführlich dargestellte sozio-ökonomische Situation in SüdOstbottnien begünstigte sowohl den Beginn als auch die Ausbreitung der Auswanderungsbewegung in dieser Region. Vor allem die sogenannte Überschußbevölkerung, die erst durch ein Ungleichgewicht zwischen Bevölkerungswachstum und den vorhandenen Nahrungsressourcen entstanden war, wandelte sich rasch zur Auswandererpopulation. Durch das rasante Bevölkerungswachstum waren es vor allem Kinder, Jugendliche und junge Erwachsene, die bei der Verteilung von Grund und Boden ausgeschlossen blieben ${ }^{299}$. Noch 1921 gab der Gemeindevorsteher der kleinen Ortschaft Lehtimäki in Süd-Ostbottnien bei einer Befragung an, daß es für Landbesitzlose unmöglich sei, eigenen Grund und Boden zu erwerben, da sie weder über ein festes Einkommen noch über gesicherte Beschäftigungsmöglichkeiten verfügten. Zum gleichen Zeitpunkt hielt sich bereits jeder fünfte Ortseinwohner der Gemeinde Lehtimäki in Amerika auf ${ }^{300}$.

Während der Frühphase der Emigrationsbewegung verhinderte die traditionelle Erbteilungsreglung in Süd-Ostbottnien noch ein Absinken großer Bevölkerungsteile auf das Niveau der ärmsten Sozialgruppen im ländlichen Gesellschaftsgefüge. Als regionale Besonderheit hatte sich nämlich die Gründung von mehreren Pachthöfen auf dem Grundstück des Haupterben für dessen Geschwister durchgesetzt. Dementsprechend

\footnotetext{
${ }^{297}$ Virtanen 1979, S. 176.

${ }^{298}$ Kero (unveröffentlichte Lizentiatsarbeit) 1970, S. 48; Myhrman (1972, S. 26) hat nur finnland-schwedische Emigranten befragt.

${ }^{299}$ Kilpi 1917, S. 77-134.

${ }^{300}$ Nygård 1983, S. 118.
} 
verfügten die Pioniere unter den südostbottnischen Auswanderern noch über eigenen oder gepachteten Grund und Boden, wenn auch zumeist nur über kleine Parzellen. Als möglicher Auswanderungsgrund könnte von daher die Furcht vor Verarmung größer gewesen sein als tatsächlich erlebte Not ${ }^{301}$.

Erst für die Kinder der Pachtbauern wurde diese Regelung problematisch, da sie entweder den Pachthof ihrer Eltern nicht übernehmen konnten und somit mittellos blieben oder aber lediglich ein Kind das Erbe antrat. Im Falle eines Haupterben mußte dieser seine Geschwister auszahlen, wobei das dazu notwendige Geld nicht selten in Amerika verdient wurde ${ }^{302}$. Dementsprechend nahmen zu Zeiten der Massenauswanderung verstärkt verschuldete Grundbesitzer an der Emigrationsbewegung teil.

Diesen späten Auswanderern kam wiederum der Vorteil von 'Prepaid Tickets' zugute, d.h. von in Amerika gekauften Fahrkarten, die ihnen bereits ausgewanderte Verwandte zuschickten. Der Anteil der Reisenden mit im Voraus bezahlten Fahrkarten betrug 30\% am gesamten finnischen Auswandereraufkommen der Jahre 1891-1914 ${ }^{303}$.

Mit den unterschiedlichen Besitzverhältnissen konnten auch die Beweggründe, die zum Auswanderungsentschluß geführt hatten, variieren: Für den einen war die in Finnland notwendig gewordene Schuldenaufnahme für den Kauf oder Ausbau eines Bauernhofes ein Motiv zur Arbeitsmigration nach Amerika; für den anderen war die Aussichtslosigkeit, jemals ein Stück Land erwerben zu können, die treibende Kraft in der Entscheidungsfindung.

Neben den ökonomischen Beweggründen fanden sich jedoch auch ganz persönliche Motive: Bei dem einen konnten diese in fortwährenden Streitigkeiten im Elternhaus liegen, das meistens mehrere Generationen beherbergte; bei dem anderen wurden die Folgen eines kriminellen Vergehens gefürchtet ${ }^{304}$, und dem dritten fehlten jegliche familiäre Bindungen an den Heimatort, beispielsweise bei Waisen. Die Palette der möglichen individuellen Gründe war breit gefächert und häufig schien die

\footnotetext{
${ }^{301}$ Diese Beobachtung machte Assion (1989, S. 259) auch im Bezug auf deutsche Amerikaemigranten.

${ }^{302}$ Jutikkala 1958, S. 355; Ranta 1988, S. 891f.

${ }^{303}$ Kero 1974, S. 174-195, bes. S. 176, Tab. 25. Die Ausreise mit zugeschickten Fahrkarten wird in Kap. 3.5.1. ausführlich behandelt.

${ }^{304}$ Ranta (1988, S. 651) nennt ein Fallbeispiel, in dem ein Großgrundbesitzer beim Teerbrennen ein Großfeuer verursacht hatte und aus Angst vor Strafe auswanderte.
} 
Auswanderung die beste Lösung für unlösbar anmutende Probleme jeglicher Art zu sein.

Im Falle von wehrpflichtigen jungen Männern ist auch die Furcht vor der Einberufung zur russischen Armee ein entscheidender Grund für die Amerikaüberquerung gewesen. Die bei Toivonen angeführten Episoden über einzelne Auswanderer, die ohne $\mathrm{Pa}$ nachts heimlich in ein kleines Boot stiegen, das sie über die bottnische Meeresenge zum schwedischen Festland brachte, können als exemplarische Fälle eines weit verbreiteten Phänomens, nämlich der Flucht vor dem Wehrdienst, angesehen werden.

Toivonen konnte denn auch einen direkten Zusammenhang zwischen der verstärkten Auswanderung junger Männer und den verfassungswidrigen Musterungsaufrufen der Jahre 1899 und 1901-02 durch den russischen Generalgouverneur sowie den landesweiten Musterungsboykotten der Jahre 1902-04 nachweisen $^{305}$. Beispielsweise in Jahr 1902 hatten 2544 junge Männer in SüdOstbottnien Einberufungsbescheide erhalten, jedoch nur 687 Personen befolgten sie auch. Es kann kein Zufall sein, daß gerade im Jahr 1902 eine einmalige Rekordspitze mit mehr als 23.000 registrierten Auswanderern erreicht wurde, wovon 69,4\% männlichen Geschlechts waren. Für den gesamten Zeitraum 1869-1914 lag der durchschnittliche Anteil von männlichen Auswanderern bei 64,7\%, wonach das Jahr 1902 eine Ausnahme im Hinblick auf den hohen Männeranteil innerhalb der Auswandererpopulation darstellte ${ }^{306}$. Selbst während des Ersten Weltkrieges, als sich im neutralen Finnland die innenpolitische Situation allmählich zuzuspitzen begann, war die nach Amerika gerichtete Flucht vor dem Militärdienst weiterhin üblich ${ }^{307}$.

Interessanterweise finden sich jedoch bereits seit 1880, d.h. noch zu Zeiten, als die finnische Autonomie relativ stabil war, Berichte in den Wochenzeitungen ,KeskiSuomi' und ,Wasabladet', die in der Flucht vor der allgemeinen Wehrpflicht für 21jährige Männer eine Emigrationsursache sahen ${ }^{308}$. Demnach bestand in Finnland eine

\footnotetext{
${ }^{305}$ Toivonen 1963, S. 125-132, bes. S. 127-129; Koskinen/Martelin/Notkola 1994, S. 251; Kero 1996, S. 51. Zu den Musterungsboykotten siehe auch Kap. 3.1.1.

${ }^{306}$ Kero 1974, S. 91f., Tab. 12.

${ }^{307}$ Siehe hierzu die Interviewberichte zweier finnlandschwedischer Emigranten, die beide 1916 ausgewandert sind: Ahlbäck 1976, S. 40-51.

${ }^{308}$ Keski-Suomi vom 5.9.1880; Wasabladet vom 8.1.1881, 5.10.1881 und 5.1.1883.
} 
längere Tradition für diesen Auswanderungsgrund, welcher auch im Nachbarland Schweden bekannt war ${ }^{309}$.

Wurden bei den "Push - Faktoren" ökonomische Beweggründe am häufigsten genannt, so waren diese auch unter den "Pull - Faktoren" vorherrschend. Hier waren es vor allem, neben den größeren persönlichen Freiheiten, die wesentlich besseren Verdienstmöglichkeiten in Amerika und Kanada, welche die finnischen Auswanderer reizten. Die in Amerika vorwiegend ausgeübten Tätigkeiten lagen im Bereich der Eisenerz- und Kohleförderung, der Wald- und Sägewerksarbeit, des Eisenbahngleisund Wegebaus sowie der Fabrik- und Hafenarbeit und hatten somit industriellen Charakter, wodurch die amerikanischen Tageslohnsätze auch die in der finnischen Landwirtschaft gezahlten Löhne bei weitem überstiegen ${ }^{310}$.

Für unverheiratete finnische Frauen, von denen die meisten ihren Alltag zwischen Kuhstall und Herd zubrachten, erschien eine Dienstbotentätigkeit in einem amerikanischen Großstadthaushalt attraktiv. Als besonderer Anreiz lockte die Möglichkeit, bei freier Unterkunft und Verpflegung einen Teil des Wochenlohnes sparen zu können. Viele finnische Hausangestellte heirateten nach einigen Jahren in Amerika einen Landsmann, um entweder nach Familiengründung erwerbslos zu bleiben oder als stundenweise Angestellte die Dienstbotentätigkeit fortzusetzten.

Bei der Erörterung der "Pull-Faktoren" als möglichen Auswanderungsursachen sind jedoch auch Faktoren wie Informationsübermittlung und verbesserte Transportbedingungen wesentlich. Die Autoren Norman und Runblom betonen sogar die Manifestation der "Pull-Faktoren" auf den drei Ebenen der persönlichen Kontakte, der Intensivierung der Transportbedingungen und der Anwerbungsversuche von amerikanischen Industrieunternehmen ${ }^{311}$. Im Falle der finnischen Auswanderung kommt den zuletzt genannten Anwerbungsversuchen lediglich eine untergeordnete Rolle zu, zumal die amerikanische Regierung seit 1885 die kommerzielle Anwerbung von europäischen Arbeitskräften gesetzlich verboten hatte ${ }^{312}$. Der wichtigste Aspekt war sicherlich die Informationsübertragung, denn erst durch die Kenntnis von möglichen

\footnotetext{
${ }^{309}$ Für den schwedischen Auswanderungsverlauf konnte Kälvemark (1973, S. 133-137 und 1976) einen rapiden Anstieg der Auswanderungszahlen von wehrpflichtigen Männern im Jahr 1902 als unmittelbare Reaktion auf die drastische Verlängerung der Wehrdienstzeit des Vorjahres nachweisen.

${ }^{310} \mathrm{Zum}$ Vergleich der Tageslöhne eines Arbeiters in Finnland und Amerika siehe Kap. 3.4.4.

${ }^{311}$ Norman/Runblom 1988, S. 114.

${ }^{312}$ Nähere Einzelheiten zum 'Contract Labor Law' z.B. bei Jones 1976, S. 61.
} 
Arbeits- und Lebensbedingungen jenseits des Atlantiks konkretisierte sich für viele Finnen ein möglicherweise bereits latent vorhandener Auswanderungswunsch. Hierbei kam vor allem den Amerika-Briefen von bereits ausgewanderten Verwandten, Nachbarn und Freunden eine ebenso entscheidende Bedeutung zu, wie auch den mündlichen Erfahrungsberichten zurückgekehrter Amerikafahrer ${ }^{313}$. Als Nachweis für den Einfluß von Briefen kann beispielsweise das plötzliche Absinken der Auswandererzahlen des Jahres 1894 angesehen werden, nämlich als schnelle Reaktion auf die 1893 einsetzende Depression der amerikanischen Wirtschaft ${ }^{314}$.

Obwohl Briefe einen bedeutenden Einfluß auf die Entscheidungsfindung potentieller Auswanderer gehabt haben, sind sie für eine Bestandsaufnahme möglicher Auswanderungsmotive unergiebig. Eine Reflektion von persönlichen Auswanderungsgründen findet sich in Briefen äußerst selten, gerade weil die Briefadressaten in vielen Fällen bereits vor dem Auswanderungsbeginn um die persönlichen Hintergründe und Auswanderungsmotive der späteren Briefschreiber wußten.

Andere mögliche Informationsquellen, wie beispielsweise Zeitungsberichte oder Ratgeberlektüre für Auswanderungswillige, können lediglich als Quellen zur Informationsergänzung angesehen werden, nicht zuletzt da sie nur von einem kleinen Teil der finnischen Bevölkerung rezipiert wurden.

Im Hinblick auf die Informationsübertragung weist Wester zudem auf den Stellenwert der kirchlichen Zusammenkünfte hin, wobei es weniger um die Einflußnahme des Geistlichen auf die ortsansässigen Gemeindemitglieder ging, sondern vielmehr um den mündlichen Informationsaustausch der Dorfbewohner untereinander $^{315}$.

Die Rolle der Mund-zu-Mundpropaganda erscheint auch im Hinblick auf die Agententätigkeit beachtenswert ${ }^{316}$. Hierbei standen die verbesserten Transportbedingungen in Wechselwirkung zu dem sich schnell ausbreitenden Netzwerk der finnischen Emigrationsagenten sowie ihrer Unteragenten. Letztere waren zumeist

\footnotetext{
${ }^{313}$ Die Bedeutung dieser direkten Form der Informationsübermittlung wird von z. B. von folgenden Migrationsforschern hervorgehoben: Greverus 1972, S. 159;

Helbich/Kamphoefner/Sommer 1988, S. 15; Kero 1996, S. 68.

${ }^{314}$ Nygård 1983, S. 119.

${ }^{315}$ Wester 1977, S. 124.

${ }^{316}$ Zur finnischen Agententätigkeit siehe Kero 1974, S. 131-152.
} 
selbst ehemalige Emigranten und mit dem Auswanderungsgebiet in Finnland bestens bekannt. Im Auftrag der Finnischen Dampfschiffahrts $A G$ sowie der großen englischamerikanischen Reedereien verkauften sie als herumziehende Händler Schiffsfahrkarten in den Heimatgemeinden der Auswanderer und trugen somit ihren Teil zur direkten Informationsübertragung bei ${ }^{317}$.

Dennoch schufen erst die intensivierten Verkehrsverbindungen, womit in erster Linie die direkte Schiffsverbindung von Hanko ins englische Hull gemeint ist, die Ausgangsvoraussetzungen für eine verstärkte Agententätigkeit und nicht zuletzt für die Intensivierung der Auswanderung an $\operatorname{sich}^{318}$. Insbesondere der 1891 abgeschlossene Ausbau der Eisenbahnlinie von Oulu über Mittel- und Süd-Ostbottnien bis in die südlichste Hafenstadt Hanko forcierte die Ausbreitung der Emigrationsbewegung ${ }^{319}$, so daß zu Zeiten der Massenemigration gewissermaßen von einer Modeerscheinung gesprochen werden kann ${ }^{320}$.

Auch im Zusammenhang mit der Hinterfragung der Auswanderungsmotive war ein allgemeiner Einstellungswandel zu beobachten: Die zu früheren Zeiten noch Aufsehen erregende Auswanderung einzelner Personen hatte sich um die Jahrhundertwende in ein allgemein akzeptiertes Verhaltensmuster gewandelt, das keine fundierte Rechtfertigung mehr erforderte: "Migration becomes a style, an established pattern, an example of collective behaviour".,

\footnotetext{
${ }^{317}$ Für die nicht-skandinavischen Länder mißt Greverus (1972, S. 158) der Informationsübertragung durch die Agentenwerbung keine große Bedeutung bei.

${ }^{318}$ Zur Bedeutung der Verkehrsverbindungen für den Emigrationsprozeß siehe Nilsson 1970, S. 37; Kero 1974, S. 59; Åkerman 1976, S. 32; Brattne/Åkerman 1976, S. 176-200; Norman/Runblom 1988, S. 114.

${ }^{319}$ Jutikkala 1963, S. 331. Siehe hierzu auch Karte 3 im Anhang: Das finnische Eisenbahnnetz im westlichen Finnland 1862-1925.

${ }^{320}$ Kero 1996, S. 61. Diese Entwicklung konnten Lüthke/Cropley (1989, S. 367) auch unter deutschen Australienauswanderern beobachten.

${ }^{321}$ Zitat aus Peterson 1958, S. 263.
} 


\subsection{Strukturelle Zusammensetzung der Auswanderer nach sozialer Herkunft, Alter und Geschlecht}

Nach näherer Betrachtung der möglichen Auswanderungsgründe stellt sich nun die Frage, aus welchen sozialen Bevölkerungsgruppen sich die Auswanderermehrheit zusammensetzte, wie sich die Verteilung der Geschlechter unter den Auswanderern gestaltete und welche Altersgruppen die Emigrantenmehrheit dominierten?

\subsubsection{Sozialstruktur der finnischen Auswanderer}

Wie bereits erläutert, lebten um 1910 mehr als zwei Drittel der finnischen Bevölkerung von landwirtschaftlichen Erträgen. Rund drei Viertel der Gesamtbevölkerung zählte zu den Landbewohnern, obwohl ihr Anteil im beginnenden 20. Jahrhundert zugunsten der wachsenden Stadtbevölkerung kontinuierlich abnahm. Die Landbevölkerung, die auch den größten Teil der Auswandererpopulation stellte, läßt sich grob in die drei Sozialgruppen der Landbesitzer, Pachtbauern und grundbesitzlosen Landarbeiter einteilen. Landbesitzer und Landlose waren zu jeweils gleichen Teilen mit je ca. 40\% an der Landbevölkerung beteiligt. Die in der Sozialhierarchie eine mittlere Position einnehmende Gruppe der Pachtbauern, die als zeitlich gebundene Landbesitzer angesehen werden können, machte etwa 20\% der Landbevölkerung aus ${ }^{1}$. Auf der Grundlage der offiziellen Emigrationsstatistik ${ }^{2}$ stellte sich die Sozialstruktur der finnischen Auswanderergruppe folgendermaßen $\mathrm{dar}^{3}$ :

\footnotetext{
${ }^{1}$ Soininen 1976, S. 220, Tab. 5.

${ }^{2} \mathrm{Zu}$ den Ungenauigkeiten, die mit den Zahlenwerten der offiziellen Emigrationsstatistik verbunden sind, siehe Kap. 2.3.1.1.

${ }^{3}$ Tabelle entnommen aus Kero 1974, S. 82, Tab. 9.
} 
Tab. H Sozialstruktur der finnischen Auswanderer 1893-1914

\begin{tabular}{|l|l|}
\hline Landbesitzer & $5,3 \%$ \\
\hline Kinder von Landbesitzern & $24,3 \%$ \\
\hline Pachtbauern & $2,7 \%$ \\
\hline Kinder von Pachtbauern & $9,7 \%$ \\
\hline Kätner & $26,8 \%$ \\
\hline Arbeiter $^{4}$ & $19,6 \%$ \\
\hline Andere $^{5}$ & $11,5 \%$ \\
\hline & \\
\hline Insg. & $\mathbf{9 9 , 9 \%}$ \\
\hline
\end{tabular}

Bei Betrachtung der Auswandererzusammensetzung nach Sozialstatus ist jedoch zu bedenken, daß die Zuordnung einzelner Personen zu einer der Sozialgruppen in den Paßverzeichnissen unpräzise ist: Zum Zeitpunkt der Paßausstellungen gaben die Antragsteller selbst ihren Sozialstatus an. Da einheitliche Definitionskriterien fehlten, die den Paßbeamten die Zuordnung einzelner Personen zu bestimmten Sozialgruppen erleichtert hätten, schien es häufig eine Ermessensfrage zu sein, zu welcher Kategorie der einzelne Antragsteller gezählt wurde.

Letztendlich ist es nicht genau nachvollziehbar, aus welchen Sozialgruppen die Auswanderer tatsächlich stammten. Bei Paßantrag gaben vermutlich einige ihren aktuellen Berufsstand an, andere wiederum hielten eher ihren Sozialstatus für bedeutsam. So konnte beispielsweise eine Magd, die als saisonabhängige Arbeitskraft auf einem fremdem Gut arbeitete, als Kind selbständiger Bauern in der Statistik erscheinen, da sie als solches geboren worden war. Dementsprechend sagen die Kategorien 'Kinder von Landbesitzern' und 'Kinder von Pachtbauern' auch nichts darüber aus, ob die herangewachsenen Kinder ihren Lebensunterhalt tatsächlich als Landbesitzer bzw. Pachtbauern bestritten haben. Da der Lebensstandard der unteren Sozialgruppen wenig Unterschiede aufwies, tat sich die soziale Schere in erster Linie zwischen einer Minderheit von Land-

\footnotetext{
4، Arbeiter' bezeichnet hier eine Mischgruppe aus landbesitzlosen Knechten, Mägden und Tagelöhnern, mobilen Wald- sowie städtischen Industriearbeitern.

${ }^{5}$ Die Bezeichnung 'Andere' umfaßt Handwerker, Kauf- und Seeleute, Künstler, die zahlenmäBig kleine Oberschicht sowie Personen ohne Berufsangabe.
} 
besitzern sowie wohlhabenden Pachtbauern und der Mehrheit von Landbesitzlosen auf, welche wiederum verschiedenen Sozialgruppen zugehörten.

Als problematisch gestaltet sich auch die Angabe des Sozialstatus im Falle von Mehrfachauswanderern. Am Beispiel der Gemeinde Karvia in Satakunta konnte Kero belegen, daß innerhalb des Zeitraumes 1870-1914 69 von insgesamt 947 Auswanderern mehr als einen $\mathrm{Pa} ß$ beantragt hatten. Von diesen 69 Mehrfachauswanderern gaben 21 Antragsteller bei jedem Paßantrag einen anderen Sozialstatus an ${ }^{6}$. Obwohl dieses Ergebnis nicht die gesamte finnische Auswandererpopulation repräsentiert, deutet es doch auf die uneinheitliche Benutzung der Sozialgruppenterminologie hin.

Wird die in Tabelle H angeführte durchschnittliche Verteilung der Auswandererzusammensetzung nach Sozialstatus lediglich auf Tendenzen hin untersucht, so läßt sich feststellen, daß unter den finnischen Auswanderern im Durchschnitt doppelt so viele Kinder von Landbesitzern vertreten waren wie Pachtbauern und deren Kinder zusammengenommen. Die Gruppe der Landbesitzer, welche die Sozialhierarchie anführte, machte den niedrigsten Anteil am Auswandereraufkommen aus. Verschiedene landbesitzlose Bevölkerungsgruppen waren hingegen mit mehr als der Hälfte am Auswandereraufkommen beteiligt, wobei jedoch korrekterweise auch ein Großteil der Kinder von Pachtbauern und Landbesitzern zu dieser Mehrheit gezählt werden muß.

In der sozialen Zusammensetzung der Auswanderer fallen regionale Unterschiede auf. Durch einen Vergleich der Emigranten aus Süd-Ostbottnien mit der gesamtfinnischen Auswandererpopulation soll hier auf die im zeitlichen Verlauf entstandenen Veränderungen in der Sozialstruktur beider Gruppen hingewiesen werden ${ }^{7}$ :

\footnotetext{
${ }^{6}$ Kero 1974, S. $82 \mathrm{f}$.

${ }^{7}$ Tabelle I in Anlehnung an Toivonen 1963, S. 40-43 und Tab. 4, Anhang. Toivonen bezieht sich auf die Paßverzeichnisse des Regierungsbezirks Vaasa und führt 20 Sozialgruppen auf, die hier zu sieben Kategorien zusammengefaßt wurden. Tabelle J basiert auf Keros Untersuchungen (1974, S. 84-87, bes. Tab. 10). Dabei hat er die offizielle Emigrationsstatistik auf die Stichprobenjahre 1873, 1882, 1893, 1902 und 1913 hin ausgewertet.
} 
Tab. I Soziale Auswandererzusammensetzung in Süd-Ostbottnien 1867-92 und 1910

\begin{tabular}{|l|l|l|}
\hline Sozialgruppe & $\mathbf{1 8 6 7 - 1 8 9 2}$ & $\mathbf{1 9 1 0}$ \\
\hline Landbesitzer & $10,1 \%$ & $5,8 \%$ \\
\hline Kinder v. Landbesitzern & $20,1 \%$ & $27,9 \%$ \\
\hline Pachtbauern & $7,5 \%$ & $2,7 \%$ \\
\hline Kinder v. Pachtbauern & $7,6 \%$ & $11,2 \%$ \\
\hline Kätner & $40,1 \%$ & $35,0 \%$ \\
\hline Arbeiter & $8,4 \%$ & $5,7 \%$ \\
\hline Andere & $4,7 \%$ & $10,5 \%$ \\
\hline & & \\
\hline Insgesamt & $\mathbf{9 8 , 5} \%$ & $\mathbf{9 8 , 8} \%$ \\
\hline
\end{tabular}

Tab. J Soziale Auswandererzusammensetzung in Gesamtfinnland 1873, 1893 und 1913

\begin{tabular}{|l|l|l|l|}
\hline Sozialgruppe & $\mathbf{1 8 7 3}$ & $\mathbf{1 8 9 3}$ & $\mathbf{1 9 1 3}$ \\
\hline Landbesitzer & $15,7 \%$ & $9,5 \%$ & $4,0 \%$ \\
\hline Kinder v. Landbesitzern & $37,9 \%$ & $24,8 \%$ & $24,4 \%$ \\
\hline Pachtbauern & $5,7 \%$ & $6,2 \%$ & $1,6 \%$ \\
\hline Kinder v.Pachtbauern & $5,5 \%$ & $7,9 \%$ & $9,2 \%$ \\
\hline Kätner & $14,6 \%$ & $29,0 \%$ & $23,5 \%$ \\
\hline Arbeiter & $8,7 \%$ & $11,5 \%$ & $24,0 \%$ \\
\hline Andere & $11,9 \%$ & $11,1 \%$ & $13,4 \%$ \\
\hline & & & \\
\hline Insgesamt & $\mathbf{1 0 0} \%$ & $\mathbf{1 0 0} \%$ & $\mathbf{1 0 0 , 1} \%$ \\
\hline
\end{tabular}

Obwohl der dargestellte Vergleich nicht auf den gleichen Stichprobenjahren beruht, lassen sich dennoch tendenzielle Veränderungen in der sozialen Zusammensetzung der Emigranten feststellen: Nach Tabelle J wanderten über vier auswanderungsstarke Jahrzehnte hinweg immer weniger Landbesitzer, deren Kinder sowie Pachtbauern aus. Ihr prozentualer Anteil am Gesamtaufkommen der finnischen Auswandererpopulation nahm deutlich ab. Als Gegenbewegung dazu wuchs die Beteiligung der in der Sozial-

${ }^{8}$ Im Fall von Süd-Ostbottnien sind mit Arbeitern fast ausschließlich Landarbeiter in saisonalen Arbeitsverhältnissen gemeint. 
hierarchie niedriger stehenden Gruppen, nämlich der Kinder von Pachtbauern, der Kätner und Instleute, der angestellten Land- und Industriearbeiterschaft, wohnsitzlosen Tagelöhner sowie aller anderen Berufsgruppen. Kurz vor Kriegsausbruch, im Jahr 1913, bildeten diese Sozialgruppen mit etwa zwei Drittel die Mehrheit der Auswanderer. Mit anderen Worten, je mehr Finnen emigrierten, desto größer wurde der Anteil der landbesitzlosen Bevölkerungsgruppen unter den Auswanderern, deren Möglichkeiten, eigenen Grund und Boden zu erwerben, lediglich durch einen Arbeitsaufenthalt jenseits des Atlantiks zu verwirklichen waren.

Dieser Entwicklungsprozeß der stetigen Zunahme der sozial niedriger stehenden Bevölkerungsschichten am Auswanderungsgeschehen spiegelt nicht zuletzt eine allgemeine Verarmungstendenz der Gesamtbevölkerung wider. So führte beispielsweise die allmähliche Auflösung der Pachthofinstitution zu einem sozialen Abstieg der Pachtbauern sowie deren Kindern auf das Niveau der Kätner oder Landarbeiter, wodurch die unteren Sozialgruppen neben dem natürlichen Bevölkerungszuwachs auch zunehmend Verstärkung aus den mittleren und oberen Sozialgruppen erhielten. Besonders im strukturarmen Ostteil der Landes, einer Region, die erst um die Jahrhundertwende von der finnischen Emigrationsbewegung erfaßt wurde, war der Zuwachs unter den abhängigen Landarbeitern größer als im Landesdurchschnitt. Dementsprechend groß war auch ihre Beteiligung am Emigrantenaufkommen.

Die Entwicklung in Süd-Ostbottnien ${ }^{10}$ dahingegen wich deutlich von derjenigen Gesamtfinnlands ab. Zwar stellte auch hier die Nachkommenschaft der Pachtbauern, die Kätner und Landarbeiter, im Jahr 1910 noch mehr als die Hälfte aller regionalen Auswanderer, ihre Beteiligung am Auswanderungsgeschehen zeigte jedoch im Laufe der Zeit eine abnehmende Tendenz. Im Gegensatz zum allgemeinen Trend nahm wiederum der prozentuale Anteil der Kinder von südostbottnischen Landbesitzern innerhalb der Sozialgruppenverteilung zu. Im Vergleich zur gesamtfinnischen Auswandererpopulation sind aus Süd-Ostbottnien jedoch deutlich weniger Handwerker, Industriearbeiter und Staatsbeamte ausgewandert, da diese Berufsgruppen relativ selten unter der Regionalbevölkerung vertreten waren.

${ }^{9}$ Unter Arbeiter sind hier vor allem Land-, Forstwirtschafts- und Industriearbeiter zu verstehen.

${ }^{10}$ Zur Sozialstruktur der südostbottnischen Auswanderer siehe auch Toivonen 1963, S. 40-47. 
Die Gründe für diese regionalen Besonderheiten sind vor allem in der besonderen Stellung der südostbottnischen Pachthofinstitution ${ }^{11}$, die auf Verwandtschafts-

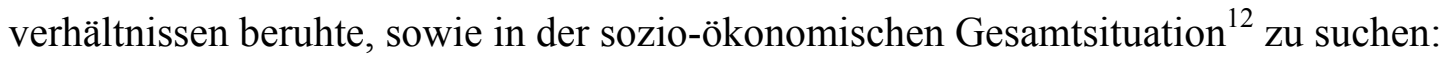
Obwohl die Anzahl der selbständigen Bauernhöfe in Süd-Ostbottnien den Landesdurchschnitt überstieg, waren die Landgüter in der Regel klein, so daß auch die Nachkommenschaft der Landbesitzer schlechtere Ausgangsvoraussetzungen zur selbständigen Landwirtschaftsausübung hatte als in anderen Landesteilen. Nach dem Wegfall der Einnahmen aus Teerbrennerei und Küstenschiffsbau konnte die Landwirtschaft als einziger Erwerbszweig nicht mehr die Bedürfnisse der rasant anwachsenden Regionalbevölkerung befriedigen. Da zudem Erwerbsalternativen in der industrie- und waldarmen Region fehlten, kann die Abwanderung großer Teile der Regionalbevölkerung beinahe als natürliche Folgeerscheinung angesehen werden.

Im folgenden stellt sich nun die Frage, wie sich die soziale Zusammensetzung des regionalen Auswandererpotentials in Satakunta gestaltete, das in den Jahren 18931914 lediglich mit 6,1\% am finnischen Auswandereraufkommen beteiligt war ${ }^{13}$.

Die Region Satakunta wies eine geringere Anzahl an Landbesitzern und Pachtbauern auf als Süd-Ostbottnien. Großbauern- und Gutsherrenhöfe hingegen, die in Süd-Ostbottnien gänzlich fehlten, boten der landbesitzlosen Bevölkerung in Satakunta landwirtschaftliche Erwerbsmöglichkeiten. Auch die Forstwirtschaft, d.h. in erster Linie zahlreiche Sägewerke, beschäftigten einen Teil der Landarbeiter; in den Kleinstädten Ulvila und Pori waren sogar Industriearbeiter gefragt.

Die Sozialstruktur der Bewohner der Provinz Satakunta kann als heterogener bezeichnet werden als die der südostbottnischen Bevölkerung. In Satakunta boten sich neben der Landwirtschaft noch alternative Erwerbsmöglichkeiten. Dennoch wuchs die soziale Kluft zwischen Landbesitzenden und Landlosen, da vor allem die plötzliche Wertsteigerung von Waldbesitz sowie die Senkung der Grundbesitzsteuer zahlreichen Landbesitzern zu einem unverhofften Wohlstand verholfen hatten ${ }^{14}$. Um den plötzlich kostbar gewordenen Waldbesitz nicht zu schädigen, verloren die landlosen Bevölkerungsgruppen alte Rechte, wie beispielsweise das Holzfällen für den Eigenbedarf, wodurch

\footnotetext{
${ }^{11}$ Zur südostbottnischen Pachthofinstitution siehe Ranta 1988, S. $891 \mathrm{f}$.

${ }^{12}$ Soininen 1974, S. 401.

${ }^{13}$ Der bei Kero (siehe unveröffentlichte Lizentiatsarbeit: 1970, S. 39) angegebene Zeitraum ergibt sich durch den Beginn der offiziellen Auswandererregistrierung im Jahr 1893 mit Erstellung der Emigrationsstatistik.

${ }^{14}$ Jutikkala 1958, S. 341.
} 
sich die Lebensbedingungen dieser Gruppe deutlich verschlechterten. Auch die Pachtbauern wurden durch steigende Steuerabgaben verstärkt an den Haupthof gebunden und wirtschaftlich geschwächt. Viele Pachtbauern mußten ihren Pachthof aufgeben und ihnen stand, wie den meisten Gruppen der ländlichen Sozialhierarchie, ein sozialer Abstieg bevor, so daß die ohnehin durch ein starkes Bevölkerungswachstum gezeichneten unteren Sozialschichten in doppelter Hinsicht Zuwachs erhielten.

Besonders in der Grenzregion zwischen Süd-Ostbottnien und Satakunta überstieg der jährliche Bevölkerungszuwachs in etlichen Gemeinden die durchschnittliche Zuwachsrate für Gesamtfinnland, die bei 1,3\% pro Jahr während des Zeitraumes 18651914 lag $^{15}$. In diesem Grenzgebiet befanden sich zudem die wenigsten Gutsherrenhöfe mit großen Ländereien, so daß die Landwirtschaftserträge der Region in der Regel niedriger ausfielen als für die Provinz allgemeinhin üblich. Für die landbesitzlose Bevölkerung ging dies wiederum mit geringeren Beschäftigungsmöglichkeiten einher. Letztendlich setzte sich im Norden Satakuntas die Mehrheit der Auswanderer aus den unteren Sozialgruppen zusammen, eine Erscheinung, wie sie auch für die südostbottnische Auswandererzusammensetzung charakteristisch war.

Anhand einer Stichprobenuntersuchung von 14 Gemeinden und der Stadt Pori im nördlichen Teil von Satakunta stellt sich die soziale Zusammensetzung des regionalen Auswandereraufkommens für den Zeitraum 1881-1914 folgendermaßen dar ${ }^{16}$ :

\footnotetext{
${ }^{15}$ Siehe hierzu Kap. 3.2.2.

${ }^{16}$ Die Tabelle K basiert auf den Untersuchungen von Kero (1970, S. 86f., Tab. 10). Dabei bezieht er sich auf Angaben aus den Paßverzeichnissen dieser Region, die in den Paßämtern der Küstenstädte Pori und Rauma erstellt worden sind.
} 
Tab. K Soziale Auswandererzusammensetzung in Nord-Satakunta 1881-1914

\begin{tabular}{|l|l|}
\hline Landbesitzer & $2,4 \%$ \\
\hline Kinder v. Landbesitzern & $12,6 \%$ \\
\hline Pachtbauern & $5,7 \%$ \\
\hline Kinder v. Pachtbauern & $19,4 \%$ \\
\hline Kätner & $25,2 \%$ \\
\hline Arbeiter & $21,3 \%$ \\
\hline Andere & $13,4 \%$ \\
\hline & \\
\hline Insgesamt & $\mathbf{1 0 0} \%$ \\
\hline
\end{tabular}

Ein Vergleich mit der prozentualen Verteilung des gesamtfinnischen Auswandereraufkommens nach Sozialgruppen, wie in Tabelle $\mathrm{H}$ dargestellt, zeigt, daß innerhalb des gesamtfinnischen Emigrantenaufkommens der Anteil an Landbesitzern sowie deren Kindern doppelt so hoch war wie im Norden Satakuntas. Der Anteil der Pachtbauern und deren Kinder wies wiederum eine gegenläufige Tendenz auf: Bei beiden Gruppen war der Anteil im Landesdurchschnitt nur halb so groß wie in der Stichprobenregion. Bei den übrigen Sozialgruppen, d.h. den Kätnern sowie Land- und Industriearbeitern in abhängigen Arbeitsverhältnissen, wichen die Prozentwerte im Norden Satakuntas nur geringfügig vom Landesdurchschnitt $a b$.

Interessant erscheint bei dieser Gegenüberstellung die starke Repräsentanz von Pachtbauern sowie deren Kindern unter den Auswanderern im Norden Satakuntas. Es ist durchaus denkbar, daß sich zahlreiche Pachtbauern dem Auswanderungsstrom anschlossen, um nach Aufgabe des Pachthofes nicht in der Sozialhierarchie absteigen zu müssen. Da vor allem die direkt an Süd-Ostbottnien angrenzenden Gemeinden besonders viele Pachtbauern unter ihren Auswanderern zählten ${ }^{17}$, ist davon auszugehen, daß die Sozialstruktur der Emigranten dieser Grenzregion große Ähnlichkeit mit der Auswandererzusammensetzung in Süd-Ostbottnien hatte.

Hierbei sei jedoch nochmals auf das eingangs angesprochene Verläßlichkeitsproblem der Quellengattung 'Paßverzeichnis' hingewiesen. Aufgrund der Tatsache, daß die Registrierung des Sozialstatus der Auswanderungswilligen auf individuellen Selbsteinschätzungskriterien beruhte, ist es im Nachhinein unmöglich zu ermessen, ob

\footnotetext{
${ }^{17}$ Beispielsweise die Gemeinden Ikaalinen, Karvia und Jämijärvi, vgl. Kero (unveröffentlichte Lizentiatsarbeit) 1970, S. 91.
} 
es sich z.B. bei den auswanderungswilligen Pachtbauern noch um aktive Landwirte oder aber bereits um ehemalige Pächter handelte.

Doch auch auch profan erscheinende Faktoren wie beispielsweise die Preisentwicklung der Schiffsfahrkarten können einen Einfluß auf die soziale Zusammensetzung der Emigranten gehabt haben: Kostete eine Schiffsüberfahrt via Schweden und England 1873 noch 270 Finnmark - was dem Jahreslohn eines Knechtes entsprach - so wurden die günstigsten Fahrkarten in den Jahren 1892-1894 und 1904 erworben, als die Fahrpreise für den Transfer von Hanko nach New York oder Quebéc unter den Betrag von 140 Finnmark sanken ${ }^{18}$. Die Schwierigkeiten, die mit der Finanzierung der Reisekosten verbunden waren, erklären den großen Anteil an Landbesitzern, d.h. an ökonomisch besser gestellten Auswanderern während der beginnenden Auswanderungsphase. Sinkende Fahrpreise sowie die Möglichkeit, mit geliehenem Geld bzw. einer im Voraus bezahlten Fahrkarte zu reisen, ermöglichten erst einen Massenexodus über den Atlantik, wie ihn Finnland zur Zeit der Jahrhundertwende erlebte.

Dennoch läßt sich festhalten, daß die regionalen Unterschiede in der Sozialstruktur der jeweiligen Regionalbevölkerung in ebensolcher Weise auch im Auswandereraufkommen reflektiert wurden ${ }^{19}$, wonach die Veränderungen der Gesellschaftsstruktur auch eine entscheidende Rolle für die Zusammensetzung der Auswandererpopulation spielten.

\subsubsection{Zusammensetzung der Auswanderer nach Alter und Geschlecht}

Das durch Analyse der Sozialstruktur gewonnene Bild des landbesitzlosen, noch jungen Erwachsenen im besten arbeitsfähigen Alter als dem typischen Auswanderer soll nun unter Berücksichtigung der Faktoren Alter und Geschlecht weiter präzisiert werden.

Während des gesamten Auswanderungsverlaufes war die finnische Emigrationsbewegung in stärkerem Maße männerdominant ausgeprägt als die Amerikaauswanderungsbewegungen aus anderen skandinavischen Ländern. Im Zeitraum 1869-1914 bestand durchschnittlich zwei Drittel der finnischen Auswandererpopulation aus Männern, wie folgende Darstellung anhand von Fünfjahresintervallen verdeutlicht ${ }^{20}$ :

\footnotetext{
${ }^{18}$ Kero 1974, S. $169-174$, bes. S. 172, Tab. 24.

${ }^{19}$ Kero 1974, S. 89.
} 
Tab. L Die Zusammensetzung der finnischen Auswanderer nach Geschlecht im Fünfjahresabstand 1869-1914

\begin{tabular}{|l|l|l|}
\hline Fünfjahresintervall & Männer & Frauen \\
\hline $1869-74$ & $82,6 \%$ & $17,4 \%$ \\
\hline $1875-79$ & $71,5 \%$ & $28,4 \%$ \\
\hline $1880-84$ & $73,7 \%$ & $23,9 \%$ \\
\hline $1885-89$ & $75,6 \%$ & $23,7 \%$ \\
\hline $1890-94$ & $67,2 \%$ & $32,6 \%$ \\
\hline $1895-99$ & $58,5 \%$ & $41,5 \%$ \\
\hline $1900-04$ & $63,7 \%$ & $36,3 \%$ \\
\hline $1905-09$ & $65,9 \%$ & $34,1 \%$ \\
\hline $1910-14$ & $60,2 \%$ & $39,8 \%$ \\
\hline & & \\
\hline $\mathbf{1 8 6 9 - 1 9 1 4}$ & $\mathbf{6 4 , 7} \%$ & $\mathbf{3 5 , 1} \%$ \\
\hline
\end{tabular}

Wie aus der Aufstellung zu ersehen ist, balancierte sich das Ungleichgewicht zwischen den Geschlechtern mit zunehmender Intensivierung der Emigrationsbewegung aus. Im Laufe der Zeit verschob sich der abnehmende Männeranteil zugunsten des wachsenden Frauenanteiles um 22\%, obwohl diese Entwicklung nicht kontinuierlich verlief. So war der Männeranteil beispielsweise Ende in den 1870er Jahren niedriger als im darauffolgenden Jahrzehnt.

Bei Betrachtung der anteiligen Männer- und Frauenverteilung stieg der Männeranteil jeweils in den Zeiten an, in denen die amerikanische Konjunktur einen Aufschwung erlebte ${ }^{21}$. Dieses Phänomen ist insofern nicht verwunderlich, als die Männern zur Verfügung stehenden Arbeitsplätze von Saisonarbeit gekennzeichnet waren und von daher auf konjunkturelle Schwankungen reagierten. Anders sah es hingegen bei den meisten Beschäftigungsfeldern für Frauen aus, bei denen die Abhängigkeit von der amerikanischen Wirtschaftsentwicklung weniger stark ausgeprägt war. Dementsprechend war der Frauenanteil unter den Auswanderern auch in ökonomischen Depressionszeiten hoch, was sich in den Jahren 1874, 1894 und 1897 sogar als Frauendominanz innerhalb der Auswandererpopulation auswirkte.

\footnotetext{
${ }^{20}$ Tabelle in Anlehnung an Kero 1974, S. 91f., Tab. 12.

${ }^{21}$ Siehe hierzu Tabelle 2 im Anhang: 'Verteilung der Auswanderer nach Geschlecht 1870-1914' sowie Tabelle 3 im Anhang: 'Anzahl der finnischen Überseeauswanderer 1870-1914 in Beziehung zur ökonomischen Situation in Amerika und Finnland'.
} 
Deutliche Unterschiede fallen allerdings beim Vergleich der Auswanderer aus ländlichen und städtischen Gebieten auf: Unter den städtischen Auswanderern war das Gleichgewicht zwischen den Geschlechtern ausgewogener als unter den ländlichen Emigranten. Obwohl auch die Auswanderung aus Städten insgesamt männerdominant blieb, war der Frauenanteil unter den städtischen Auswanderern größer war als im Landesdurchschnitt. Im Gegenzug dazu war der Männeranteil unter den städtischen Emigranten kleiner als unter den Auswanderern aus ländlichen Gebieten. Dieser Trend trat nach der Jahrhundertwende besonders deutlich in Erscheinung, so daß während der Zeitspanne 1900-14 durchschnittlich 51\% der städtischen und 65\% der ländlichen Emigranten Männer waren ${ }^{22}$. Da die städtischen Auswanderer beiderlei Geschlechts jedoch lediglich 14\% des gesamten finnischen Emigrantenaufkommens des genannten Zeitraumes ausmachten, wirkte sich dieser Unterschied im Geschlechteraufkommen der städtischen Emigranten kaum auf die gesamtfinnische Emigrationsbewegung aus.

Wird die Verteilung der Geschlechter nun im folgenden mit der Altersstruktur der Emigranten kombiniert, so konkretisiert sich das Bild der finnischen Auswandererzusammensetzung ${ }^{23}$ :

Tab. M Anteilige Zusammensetzung der Auswanderer nach Alter und Geschlecht in den Jahren 1900 und 1910 sowie während des Gesamtzeitraums 1893-1914

MÄNNER

\begin{tabular}{|l|l|l|l|}
\hline Alter & $\mathbf{1 9 0 0}$ & $\mathbf{1 9 1 0}$ & $\mathbf{1 8 9 3 - 1 9 1 4}$ \\
\hline $0-15$ & $11,7 \%$ & $7,8 \%$ & $8,8 \%$ \\
\hline $16-20$ & $24,4 \%$ & $23,4 \%$ & $24,9 \%$ \\
\hline $21-25$ & $23,5 \%$ & $32,0 \%$ & $29,0 \%$ \\
\hline $26-30$ & $19,6 \%$ & $16,7 \%$ & $18,1 \%$ \\
\hline $31-35$ & $7,7 \%$ & $9,7 \%$ & $9,4 \%$ \\
\hline $36-40$ & $5,8 \%$ & $5,5 \%$ & $5,0 \%$ \\
\hline $41-45$ & $3,2 \%$ & $2,2 \%$ & $2,7 \%$ \\
\hline $46<$ & $3,7 \%$ & $2,4 \%$ & $2,6 \%$ \\
\hline Unbekannt & $0,4 \%$ & $0,4 \%$ & $0,5 \%$ \\
\hline & & & \\
\hline Insg. & $\mathbf{1 0 0 , 1 \%}$ & $\mathbf{1 0 0 , 1} \%$ & $\mathbf{1 0 1 , 0} \%$ \\
\hline
\end{tabular}

${ }^{22}$ Kero 1974, S. 96-99; 1986, S. 67 und 1996, S. 104. 


\section{FRAUEN}

\begin{tabular}{|l|l|l|l|}
\hline Alter & $\mathbf{1 9 0 0}$ & $\mathbf{1 9 1 0}$ & $\mathbf{1 8 9 3 - 1 9 1 4}$ \\
\hline $0-15$ & $17,0 \%$ & $14,7 \%$ & $15,0 \%$ \\
\hline $16-20$ & $25,5 \%$ & $26,0 \%$ & $26,9 \%$ \\
\hline $21-25$ & $26,7 \%$ & $27,6 \%$ & $26,2 \%$ \\
\hline $26-30$ & $13,3 \%$ & $15,0 \%$ & $15,3 \%$ \\
\hline $31-35$ & $5,6 \%$ & $7,6 \%$ & $7,2 \%$ \\
\hline $36-40$ & $4,4 \%$ & $3,9 \%$ & $3,5 \%$ \\
\hline $41-45$ & $2,2 \%$ & $1,4 \%$ & $1,8 \%$ \\
\hline $46<$ & $4,4 \%$ & $2,8 \%$ & $3,0 \%$ \\
\hline Unbekannt & $1,0 \%$ & $1,1 \%$ & $1,2 \%$ \\
\hline & & & \\
\hline Insg. & $\mathbf{1 0 0 , 1 \%}$ & $\mathbf{1 0 0 , 1} \%$ & $\mathbf{1 0 0 , 1} \%$ \\
\hline
\end{tabular}

Dieser Darstellung zufolge war der typische Auswanderer männlich und zwischen 21 und 25 Jahre alt; knapp ein Drittel aller männlichen Auswanderer gehörte dieser Altersgruppe an. Ein weiteres Viertel ist der Altersgruppe der 16-20Jährigen zu zurechnen, so daß sich zusammengenommen mehr als 50\% aller männlichen Emigranten im Alter zwischen 16 und 25 Jahren befand. Wird die Altersgruppe der 26-30Jährigen noch hinzugefügt, so läßt sich festhalten, daß zum Zeitpunkt der Ausreise 72\% aller männlichen Auswanderer zwischen 16 und 30 Jahre alt waren. Bedenkt man außerdem, daß während des Zeitraumes 1893-1914 der Männeranteil an der gesamten Auswanderergruppe im Durchschnitt zwischen 58,5\% und 65,9\% variierte, so bedeutet dies, daß junge Männer im Entwicklungsstadium von Jugendlichen und jungen Erwachsenen am häufigsten unter allen finnischen Emigranten zu finden waren.

\footnotetext{
${ }^{23}$ Die Tabelle M ist eine Zusammenstellung der Tabellen bei Toivonen 1963, Tab. 5, Anhang
} und Kero 1974, S. 236f., Tab. C. 
Der Frauenanteil bewegte sich in der hier betrachteten Zeitspanne zwischen 34,1\% und 41,5\% am gesamten Auswandereraufkommen. Analog zur Altersstruktur der männlichen Auswanderer setzten sich die weiblichen Emigranten ebenfalls zu mehr als der Hälfte aus 16-25Jährigen zusammen, wobei die beiden Altersgruppen der 16-20 sowie der 21-25Jährigen zu gleichen Teilen vertreten waren. Bei Hinzuziehung der nächstfolgenden Altersgruppe der 26-30 Jährigen wächst der Gesamtanteil der Altersgruppe 16-30 Jahre auf 68,4\% aller weiblichen Auswanderer an.

Der auffallendste Unterschied bezüglich der geschlechtsspezifischen Altersstruktur zeigt sich bei der jüngsten Altersgruppe: Unter Kindern bis zu 15 Jahren waren Mädchen annähernd doppelt so häufig vertreten wie Jungen. Der Mädchenanteil bewegte sich bei durchschnittlich 15\%, der Jungenanteil hingegen lag im Durchschnitt bei lediglich 8,8\%. Die Tatsache, daß Mädchen vielfach im Alter von 14 Jahren, d.h. direkt im Anschluß an die Konfirmation, zu ihren bereits ausgewanderten Verwandten nach Amerika geschickt wurden, um dort als Hausangestellte zu arbeiten, könnte einen Grund für die weibliche Dominanz innerhalb dieser Altersgruppe darstellen.

Wird die Altersgruppe der 0-15jährigen Kinder anhand der drei Stichprobenjahre 1873, 1882 und 1905 näher analysiert, so läßt sich feststellen, daß im betrachteten Zeitraum der Anteil von Kleinkindern unter fünf Jahren von 1,7\% auf 5,2\% zunahm. Dieser Anstieg kann als Zeichen der verstärkten Nachwanderung von Frauen und Kindern bereits ausgewanderter Familienväter gewertet werden. Innerhalb der Altersgruppe der 015Jährigen war der Kleinkinderanteil während aller drei Stichprobenjahre am höchs$\operatorname{ten}^{24}$.

Die Stichprobenuntersuchung deckt jedoch auch unterschiedliche Altersangaben beim Vergleich der beiden Quellengattungen Passagierlisten und Paßverzeichnissen auf. Besonders bei den Kleinkindern unter fünf Jahren sowie den Elfjährigen war die Diskrepanz zugunsten der Passagierlisten besonders groß. Es kann also davon ausgegangen werden, daß in einigen Fällen die von den Erziehungsberechtigten genannten Altersangaben der Kinder mit Absicht zu niedrig ausfielen. Diese Annahme erscheint vor allem im Hinblick auf einen möglichen Preisnachlaß beim Fahrkartenkauf wahrscheinlich, da Kinder unter elf Jahren einen Preisrabatt von 50\% erhielten und Kinder unter fünf Jahren auf amerikanischen Eisenbahnstrecken kostenfrei fuhren.

${ }^{24}$ Zur Altersgruppe der 0-15 Jährigen siehe Kero 1974, S. 114 und S. 233f. 
Ähnlich wie bei der Betrachtung der Geschlechterverteilung fällt auch im Hinblick auf die Altersstruktur ein Unterschied zwischen städtischen und ländlichen Emigranten auf: Waren unter den städtischen Auswanderern die Kinder bis 16 Jahre sowie Erwachsene über 25 Jahre besonders häufig vertreten, so dominierte die Altersgruppe der 16-25Jährigen innerhalb der ländlichen Auswandererpopulation ${ }^{25}$. Ein möglicher Grund für diese Abweichung kann in der, wenn auch beschränkten, Nachfrage an industriellen Arbeitskräften in finnischen Städten gesehen werden. Es liegt auf der Hand, daß 16-25Jährige in urbanen Zentren die besten Beschäftigungschancen hatten und dementsprechend seltener unter den Überseeauswanderern anzutreffen waren.

Mit fortschreitender Auswanderungsbewegung verjüngte sich auch das Durchschnittsalter der Auswanderer, wenngleich aus der obenstehenden Tabelle M lediglich ein prozentualer Anstieg der 21-25Jährigen bei beiden Geschlechtern abzulesen ist. Lag das Durchschnittsalter im Stichprobenjahr 1882 bei etwa 27 Jahren, so sank es nach der Jahrhundertwende auf etwa 23,5 Jahre, wobei das durchschnittliche Auswanderungsalter der Frauen zwei Jahre unter dem der Männer lag.

Diese Entwicklung läßt darauf schließen, daß die zunehmend jüngeren Emigranten zum Zeitpunkt der Auswanderung noch unverheiratet waren und häufig alleine oder in einer Gruppe Gleichgesinnter, als sogenannte Einzelauswanderer, die Ausreise antraten. Nach Zivilstandsangaben, welche ab 1900 in der offiziellen Emigrationsstatistik vermerkt wurden, formierte sich das Auswandererpotential im Zeitraum 1900-14 tatsächlich zu drei Viertel aus ledigen Frauen und Männern, wozu jedoch auch Kinder gezählt wurden ${ }^{26}$. Kinder im Alter von 0-15 Jahren bestritten im besagten Zeitraum 19001914 etwa ein Zehntel des gesamten Auswandereraufkommens und können nicht als Einzelauswanderer gezählt werden. Es wäre jedoch falsch, alle Einzelauswanderer - unter Ausschluß des Kinderanteils - mit unverheirateten Emigranten gleichzusetzten, da auch zahlreiche verheiratete Familienväter alleine bzw. in einer Kleingruppe emigrierten. Sie ließen ihre Frauen und Kinder mit der Absicht zurück, entweder nach einigen Jahren wieder zurückzukehren oder aber die restliche Familie, geschlossen bzw. in Kleingruppen aufgeteilt, nachwandern zu lassen. Diese Rechnung ging jedoch nicht immer auf, denn nicht selten verstarb das Familienoberhaupt jenseits des Atlantik oder aber entfremdete sich seiner zurückgelassenen Familie derart, daß die Verbindung, wel-

${ }^{25}$ Kero 1986, S. 55. 
che in erster Linie durch Briefkontakt bestand, aufgegeben wurde. Auf der Quellengrundlage von Paßverzeichnissen und Passagierlisten ist es jedoch unmöglich, alle Fälle von unterlassener oder aber zeitlich verzögerter Nachwanderung von Familienmitgliedern männlicher, verheirateter Einzelauswanderer zu rekonstruieren. Allenfalls die zeitgleiche Auswanderung mehrerer Mitglieder einer Familie gleichen Namens läßt sich durch die computergestützte Auswertung der Passagierlisten näher bestimmen..

Als veröffentlichtes Forschungsergebnis ist diese Namensauszählung bislang lediglich für das Stichprobenjahr 1905 vorgenommen worden. Demnach wanderten im besagten Jahr 16,9\% aller Auswanderer im Familienverband und 83,1\% alleine oder in einer Kleingruppe gleichgesinnter Personen aus ${ }^{27}$. Aufgrund der mangelhaften Quellenlage bleibt ungeklärt, ob der Anteil an Familienauswanderern in der Frühphase der Auswanderungsbewegung den Anteil von Einzelauswanderern überragte. Fest steht lediglich, daß der Anteil von geschlossen ausgewanderten Familien in den 1870-90er Jahren größer gewesen war als in den beiden Jahrzehnten der Massenemigration. Die Verjüngungstendenz unter den Emigranten, von denen nach der Jahrhundertwende 75\% unverheiratet die Atlantiküberquerung antraten, kann als deutliches Indiz für eine Zunahme an Einzelauswanderern gewertet werden. Demzufolge läßt sich mit Ausbreitung der Emigrationsbewegung die Tendenz von der abnehmenden Familien- zur zunehmenden Einzelauswanderung konstatieren.

Abschließend stellt sich nun noch die Frage nach den regionalen Abweichungen und Entwicklungen in den Auswandererzusammensetzungen nach Alter und Geschlecht, wobei die Situation in den Regionen Süd-Ostbottnien und Satakunta im Vergleich mit Gesamtfinnland kurz erörtert werden soll.

Wie bereits erläutert, stellten die südostbottnischen Auswanderer bis zur Jahrhundertwende etwa die Hälfte der gesamten und etwa 70\% der ostbottnischen Auswandererpopulation $^{28}$. Nach der Jahrhundertwende nahm ihre anteilige Beteiligung am Gesamtaufkommen aller Emigranten deutlich ab. Dennoch befanden sich männliche Auswanderer auch unter den südostbottnischen Emigranten in einer deutlichen Mehrheit: Auf der Grundlage von Paßverzeichnisseintragungen lag ihr prozentualer Anteil bei

\footnotetext{
${ }^{26}$ Im Zeitraum 1900-14 standen durchschnittlich 23,9\% verheiratete 74,6\% unverheirateten Auswanderern gegenüber, vgl. Kero 1986, S. 59.

${ }^{27}$ Kero 1974, S. 124f., bes. Tab. 19.

${ }^{28}$ Toivonen 1963, Tab. 3, Anhang.
} 
$61,7 \%{ }^{29}$, wodurch ihre Beteiligung am Emigrantenaufkommen geringfügig niedriger war als der in Tabelle L aufgezeigte Landesdurchschnittswert von 64,7\%. Im Auswanderungsgebiet zeichnete sich jedoch auch die gleiche Entwicklung ab, wie sie bereits für Gesamtfinnland konstatiert wurde: Mit dem Anwachsen der Emigrationbewegung pendelte sich das Ungleichgewicht in der Geschlechterverteilung allmählich aus, so daß die Männerdominanz an der Schwelle zum Ersten Weltkrieg geringer ausfiel als in den 1870er Jahren.

In der nördlichen Region von Satakunta hingegen lag der Männeranteil im Zeitraum 1881-1914 bei knapp 70\% und bewegte sich somit deutlich über dem Landesdurchschnittswert von $64,7 \%$, wie in Tabelle L dargestellt ${ }^{30}$. Hierbei muß jedoch bemerkt werden, daß das Emigrantenaufkommen dieser Region mit ca. 6\% lediglich einen Bruchteil der finnischen Auswandererpopulation ausmachte.

Die Gründe für die hier dargestellten regionalen Abweichungen der prozentualen Männeranteile unter den Auswanderern sind kaum nachzuvollziehen. Es ist jedoch auch denkbar, daß Auswanderungstraditionen, welche aus einigen finnischen Gemeinden in bestimmte Städte und ländliche Industriezentren in Amerika und Kanada bestanden, zu einer forcierten Männer- oder Frauenauswanderung aus eben diesen Gemeinden geführt hatten. Somit könnte die verstärkte Konzentration von Männern oder Frauen unter den Auswanderern einer Gemeinde für die Abweichung des regionalen Durchschnittswertes verantwortlich gemacht werden ${ }^{31}$.

Für einen Vergleich der Alterszusammensetzung einer regionalen Auswandergruppe mit der gesamtfinnischen Auswandererpopulation stehen hier lediglich Zahlen aus Süd-Ostbottnien zur Verfügung. Demnach sah sie Altersverteilung in den Stichprobenjahren 1900 und 1910 folgendermaßen aus ${ }^{32}$ :

\footnotetext{
${ }^{29}$ Toivonen 1963, S. 50.

${ }^{30}$ Kero (unveröffentlichte Lizentiatsarbeit) 1970, S. 98, Tab. 12. Als Berechnungsgrundlage haben Paßverzeichnisse der Region gedient.

${ }^{31}$ Kero 1970, S. 104.

${ }^{32}$ Toivonen 1963, S. 48f. und Tab. 5, Anhang.
} 
Tab. N Alterszusammensetzung der Auswanderer aus Süd-Ostbottnien 1900 und 1910

\begin{tabular}{|l|l|l|}
\hline Alter & $\mathbf{1 9 0 0}$ & $\mathbf{1 9 1 0}$ \\
\hline $0-15$ & $11,7 \%$ & $9,6 \%$ \\
\hline $16-20$ & $30,0 \%$ & $27,9 \%$ \\
\hline $21-30$ & $42,5 \%$ & $46,0 \%$ \\
\hline $31-40$ & $10,6 \%$ & $13,4 \%$ \\
\hline $41-50$ & $3,1 \%$ & $0,2 \%$ \\
\hline $51-60$ & $1,7 \%$ & $1,5 \%$ \\
\hline $60<$ & $0,2 \%$ & $0,7 \%$ \\
\hline Unbekannt & $0,2 \%$ & $0,7 \%$ \\
\hline & & \\
\hline Insg. & $\mathbf{1 0 0} \%$ & $\mathbf{1 0 0} \%$ \\
\hline
\end{tabular}

Eine vergleichende Betrachtung der Tabellen $\mathrm{M}$ und $\mathrm{N}$ zeigt, daß in den beiden Stichprobenjahren 1900 und 1910 der Anteil der Kinder unter 16 Jahren in Gesamtfinnland höher war als in Süd-Ostbottnien. Bei der nächstfolgenden Altersgruppe der 1620Jährigen zeigt sich die umgekehrte Situation. Auch bei den 21-30Jährigen lagen die südostbottnischen Zahlen noch geringfügig über dem Landesdurchschnittswert, der Unterschied fiel mit etwa 1\% jedoch kaum ins Gewicht. Sowohl in Süd-Ostbottnien als auch in Gesamtfinnland stellte diese Altersgruppe mit mehr als 40\% die Mehrheit unter den Auswanderern. Dementsprechend gering, mit etwa 10\%, fiel die Beteiligung der 31-40Jährigen aus, wobei die Größenordnung dieser Altersgruppe sowohl in SüdOstbottnien als auch in Gesamtfinnland in etwa gleich ausfiel. 
Zusammenfassend läßt sich festhalten, daß die Unterschiede in der Altersverteilung zwischen den südostbottnischen Auswanderern und der gesamtfinnischen Auswandererpopulation gering ausfielen und insofern als bedeutungslos angesehen werden können. Die Altersgruppe der 16-30Jährigen besaß mit 65\% -70\% die absolute Majorität unter den finnischen Auswanderern, wobei die männlichen Auswanderer zu etwa zwei Dritteln und die weiblichen Emigranten zu einem Drittel am gesamten Auswandereraufkommen beteiligt waren. Kinder unter 15 Jahren machten etwa ein Zehntel der Emigranten aus, wobei wiederum junge Mädchen häufiger zu den Auswanderern zählten als Jungen. 


\section{Einwanderung in die Vereinigten Staaten und nach Kanada}

\subsection{Die europäische Überseeimmigration}

Innerhalb eines Jahrhunderts, von 1820-1924, erreichten knapp 36 Millionen Einwanderer aus allen Erdteilen ${ }^{1}$, darunter ca. 33 Millionen Europäer ${ }^{2}$, die Vereinigten Staaten in der Hoffnung auf bessere Verdienstmöglichkeiten und Lebensverhältnisse. Für den Zeitraum 1871-1914, in dem mehr als 24 Millionen Immigranten die Vereinigten Staaten erreichten, sahen die offiziellen Zahlenwerte der amerikanischen Einwanderungsbehörden folgendermaßen aus:

Tab. O Immigration in die Vereinigten Staaten 1871-1914

\begin{tabular}{|l|l|}
\hline Fünfjahresintervall & Einwandereranzahl \\
\hline $1871-1875$ & 1.726796 \\
\hline $1876-1880$ & 1.085395 \\
\hline $1881-1885$ & 2.975683 \\
\hline $1886-1890$ & 2.270930 \\
\hline $1891-1895$ & 2.123879 \\
\hline $1896-1900$ & 1.563685 \\
\hline $1901-1905$ & 3.833076 \\
\hline $1906-1910$ & 4.962310 \\
\hline $1911-1914$ & 4.133131 \\
\hline & \\
\hline $\mathbf{1 8 7 1 - 1 9 1 4}$ & $\mathbf{2 4 . 6 7 4 8 8 5}$ \\
\hline
\end{tabular}

\footnotetext{
${ }^{1}$ Auf der Grundlage der Einwandererstatistiken der amerikanischen Zensus-Behörden beträgt die von den Autoren Ferenczi/Willcox (1969, S. 261-273, Tab. 13) errechnete Gesamtanzahl aller Einwanderer (1820-1924) 35.999402 Personen. Angaben über die Finnen als eigenständige Nation finden sich in dieser Auflistung lediglich für den Zeitraum 1870-90. Unklar bleibt, weshalb die Finnen in den folgenden beiden Jahrzehnten 1891-1919 den russischen Einwanderern zugeordnet wurden, obwohl sie bereits 1900 in der amerikanischen Volkszählungsstatistik als eigenständige Nation erscheinen.

${ }^{2}$ Sowohl aufgrund von unpräzisen Zahlenwerten (vgl. Note 1) als auch durch historische Grenzverschiebungen in Europa ist es unmöglich, exakte Angaben über die Gesamtanzahl aller europäischen Einwanderer zu gewinnen. In der einschlägigen Literatur finden sich lediglich CircaAngaben zur Gesamtanzahl der europäischen Einwanderer, vgl. Dinnerstein/Reimers 1988, S. 15; Norman/Runblom 1988, S. 27; Thistlethwaite 1991 ( $\left.{ }^{1} 1960\right)$ S. 20.
} 
Abgesehen von einem temporären Auswanderungshoch, das bereits in den Jahren 1846-54 für einen Zustrom von 2,8 Millionen Einwanderern - davon allein 1,2 Millionen $\operatorname{Iren}^{3}$-verantwortlich war, stiegen die Einwandererzahlen erst nach dem amerikanischen Bürgerkrieg deutlich an. Da diese Entwicklung jedoch nicht kontinuierlich verlief, sondern Schwankungen unterworfen war, lagen die jährlichen Einwandererzahlen der Jahre 1876-79 und 1894-99 unter dem Niveau der übrigen Jahre. Die dadurch entstandenen Wellenbewegungen im Abstand von 15 bis 20 Jahren lassen sich für das gesamte Jahrhundert nachweisen und können in Beziehung zu den größeren Konjunkturschwankungen der amerikanischen Wirtschaft gesetzt werden. Mit einer durch den langsamen Informationsfluß bedingten Verzögerung von einigen Jahren reagierte der europäische Einwandererstrom demnach auf die instabile Arbeitsmarktlage des nordamerikanischen Kontinents, nicht zuletzt auch in Form einer verstärkten Rückwanderung in den Jahren wirtschaftlicher Depression ${ }^{4}$. Erst der Ausbruch des Ersten Weltkrieges unterbrach diese zyklische Auf- und Abwärtsentwicklung des Einwandereraufkommens $^{5}$. In den 1920er Jahren ebbte die europäische Einwanderungsbewegung dann allmählich ab, wobei die amerikanischen Restriktionsbestimmungen zur Einwanderungsbeschränkung der Jahre 1921 und - in verschärfter Form - 1924 Wirkung zeig$\operatorname{ten}^{6}$.

Obwohl das Ausmaß der europäischen Einwanderung in die Vereinigten Staaten historisch beispiellos geblieben ist, stieg die Anzahl der Immigranten nicht schneller an als das Wachstum der amerikanischen Bevölkerung in seiner Gesamtheit. Die Nettoeinwanderung, d.h. der Überschuß der Einwanderer über die Rückwanderer, betrug in keiner Dekade der Jahre 1871-1920 mehr als 40\% des Gesamtzuwachses der amerikanischen Bevölkerung ${ }^{7}$.

Völlig anders sah das Verhältnis in Kanada aus: In den Jahren 1900-14 ${ }^{8}$ entsprach das Bevölkerungswachstum in etwa der Einwandereranzahl ${ }^{9}$. Da sich der natür-

\footnotetext{
${ }^{3}$ Taylor 1971, S. 35; Burchell 1992, S. 191.

${ }^{4}$ Elschenbroich 1986, S. 26.

${ }^{5} \mathrm{Zu}$ den zyklischen Phasen im amerikanischen Einwanderungsverlauf, die in Langzeit-, Jahres-, und Saisonzyklen unterteilt werden, vgl. Virtanen 1979, S. 84-98.

${ }^{6} \mathrm{Zu}$ den amerikanischen Gesetzen zur Einwanderungsbeschränkung durch Quotenregelung für einzelne Nationalitäten vgl. Bennett 1963, S. 40-69; Harper/Chase 1975, S. 11-14; Bernard 1981.

${ }^{7}$ Thistlethwaite $1991\left({ }^{1} 1960\right)$ S. 36. Easterlin (1981, S. 476, Tab. 1) bezieht sich auf Zahlenwerte der amerikanischen Einwanderungsbehörden.

${ }^{8}$ Vor 1900 wurde lediglich das Gesamtvolumen der Einwanderung erfaßt, jedoch nicht nach Nationalitäten unterschieden, vgl. Ferenczi/Willcox 1969, S. 353, Note 3; Easterlin 1981, S. 479.
} 
liche Bevölkerungszuwachs jedoch nicht ausschließlich aus Einwanderern zusammengesetzt haben kann, ist davon auszugehen, daß zahlreiche Einwanderer nach einem kurzen Aufenthalt in Kanada in die Vereinigten Staaten übersiedelten oder aber in ihr Herkunftsland zurückwanderten ${ }^{10}$. Auf diese Weise wurden sie zwar als Einwanderer in kanadischen Hafenstädten gezählt, nicht jedoch bei den kanadischen Volkszählungen erfaßt.

Als Vergleichsergebnis bleibt festzuhalten, daß die Einwanderungsrate ${ }^{11}$ nach Kanada in der Dekade 1901-10 die der Vereinigten Staaten übertraf, obwohl die europäische Einwanderung in die Vereinigten Staaten in absoluten Zahlen fünfmal so hoch war wie die nach gerichtete Kanada Immigration. Kamen auf 100000 bereits seßhafte Einwohner in den Vereinigten Staaten 1000 Einwanderer, so waren es in Kanada 1500 Immigranten $^{12}$.

Bei Betrachtung der europäischen Auswandererpopulation im Hinblick auf ihre Zusammensetzung nach Nationalitäten fällt eine Schwerpunktverlagerung der hauptsächlichen Herkunftsgebiete der Emigranten auf. Der prozentuale Vergleich des europäischen Einwandereraufkommes für das Jahrhundert 1821-1920 verdeutlicht die Verteilung $^{13}$ :

Bei der Volkszählung von 1911 wurden erstmals die einzelnen Einwanderernationalitäten in den zwölf kanadischen Provinzen separat aufgeführt, vgl. Wilson 1977, S. 13, Tab. 1; Saarinen 1995, S. 22, Tab. 1.

${ }^{9}$ Zwischen 1901-14 stieg die kanadische Bevölkerung von rund 5.300000 Personen um ca. 2.700.000 auf etwa 8.000000 Menschen an. Im gleichen Zeitraum, d.h. von 1900-1914, wanderten 2.920000 Personen in Kanada ein, vgl. Sautter 1992, S. 213 und S. 309.

${ }^{10}$ Die Nettoeinwanderung nach Kanada kann hier aufgrund fehlender Rückwanderungszahlen nicht berechnet werden. Sie wird vermutlich deutlich niedriger ausgefallen sein als die Totaleinwanderung.

${ }^{11}$ Die Einwanderungsrate bedeutet die Einwandereranzahl in Relation zur Anzahl der bereits vorhandenen Bevölkerung im Aufnahmeland, vgl. Easterlin 1981, S. 477.

${ }^{12}$ Thistlethwaite $1991\left({ }^{1} 1960\right)$ S. 24.

${ }^{13}$ U.S. Bureau of the Census, Historical Statistics of the United States from Colonial Times to 1970, S. 105-109, Tab. 11; Tabelle auch bei Easterlin (1981, S. 480, Tab. 3) umfaßt ursprünglich den Zeitraum 1821-1970; Nord- und Westeuropa: Großbritannien, Irland, Norwegen, Schweden, Dänemark, Island, Niederlande, Frankreich, Belgien und die Schweiz; Ost- und Mitteleuropa: Deutschland, Polen, Österreich-Ungarn, Rußland, Finnland, Rumänien, Baltikum, Bulgarien und Türkei (europ. Teil); Südeuropa und andere: Italien, Spanien, Portugal, Griechenland und andere nicht gesondert aufgeführte Länder. 
Tab. P Europäische Verteilung am Gesamtaufkommen der Amerikaeinwanderer 1821-1920

\begin{tabular}{|l|l|l|l|}
\hline Dekade & $\begin{array}{l}\text { Nord- u. Westeu- } \\
\text { ropa }\end{array}$ & $\begin{array}{l}\text { Ost- u. Mitteleuro- } \\
\text { pa }\end{array}$ & Südeuropa u.a. \\
\hline $1821-30$ & $67,1 \%$ & & $2,1 \%$ \\
\hline $1831-40$ & $81,8 \%$ & & $1,0 \%$ \\
\hline $1841-50$ & $92,9 \%$ & $0,1 \%$ & $0,3 \%$ \\
\hline $1851-60$ & $93,6 \%$ & $0,1 \%$ & $0,8 \%$ \\
\hline $1861-70$ & $87,8 \%$ & $0,5 \%$ & $0,9 \%$ \\
\hline $1871-80$ & $73,6 \%$ & $4,5 \%$ & $2,7 \%$ \\
\hline $1881-90$ & $72,0 \%$ & $11,9 \%$ & $6,3 \%$ \\
\hline $1891-1900$ & $44,5 \%$ & $32,8 \%$ & $19,1 \%$ \\
\hline $1901-10$ & $21,7 \%$ & $44,5 \%$ & $26,3 \%$ \\
\hline $1911-20$ & $17,4 \%$ & $33,4 \%$ & $25,5 \%$ \\
\hline & & & \\
\hline
\end{tabular}

Wie aus der Tabellenübersicht hervorgeht, standen seit den 1890er Jahren immer mehr Einwanderer aus Süd- und Osteuropa immer weniger Neuankommenden aus Nord- und Westeuropa gegenüber. Vor allem Deutschland, Skandinavien sowie die Britischen Inseln stellten vor 1890 noch das höchste Auswandererkontingent. Obwohl die Einwanderung aus diesen Ländern in absoluten Zahlen weiterhin beachtlich blieb ${ }^{14}$, nahm ihr prozentualer Anteil am Gesamtaufkommen aller Immigranten deutlich ab.

Unter den Einwanderern dominierten in der Folgezeit die süd- und südosteuropäischen Immigranten, d.h. in erster Linie die unter Österreich-Ungarn zusammengefaßten Volksgruppen, die Russen ${ }^{15}$, zu denen auch Ukrainer und Polen ${ }^{16}$ gezählt wurden, die Italiener und Griechen sowie die meisten Volksgruppen des Balkans. Allein im Jahrzehnt 1905-14 strömten nahezu jährlich mehr als eine Million Arbeitskräfte in die Ver-

\footnotetext{
${ }^{14}$ Die Einwanderungszahlen aus Deutschland und aus Skandinavien erlebten jeweils in der Dekade 1881-1890 ihren Höhepunkt, die Einwanderung aus Skandinavien (davon ca. 50\% Schweden) lag in den darauffolgenden Dekaden sogar deutlich höher als in den Jahren vor 1880, vgl. Daniels 1990, S. 146, Tab. 6.6 und S. 165, Tab. 6.7.

${ }^{15}$ Unter den russischen Einwanderern befanden sich mehr als eine Million Juden, was $71 \%$ der gesamten jüdischen Einwanderung entsprach, vgl. Blake 1963, S. 368. Zur Judeneinwanderung siehe auch Daniels 1990, S. 223-232.

${ }^{16}$ Von den polnischen Amerikaeinwanderern kamen ca. 66\% aus russischen, 32\% aus österreichischen und nur 2\% aus deutschen bzw. preußischen Gebieten, ihre Gesamtzahl lag bei ca. 1.700000 Personen, vgl. Just 1988, S. 20; Daniels 1990, S. 214-223.
} 
einigten Staaten ${ }^{17}$, wobei erst der technische Fortschritt im Transportwesen, der mit einer Intensivierung des transatlantischen Personenverkehrs einherging, einen europäischen Massenexodus von diesem bis dahin ungekannten Ausmaß ermöglichte.

\subsubsection{Die finnische Einwanderung als Bestandteil der europäischen}

\section{Immigration}

Im Rahmen der gesamteuropäischen Überseeauswanderung nahmen die Finnen lediglich einen kleinen Prozentsatz ein. Nach Berechnungen von Ferenczi und Willcox, denen die Angaben der offiziellen finnischen Emigrationsstatistik - zwischen 1905-15 in drei Bänden veröffentlicht - vorlagen, variierte der finnische Anteil an der gesamteuropäischen Emigration zwischen 0,6\% und 1,5\% im Zeitraum von 1886-1915. Zu Zeiten der höchsten Auswanderungsfrequenz aus Finnland, d.h. während der Zeitspanne 1896-1910, bewegte sich der durchschnittliche Anteil am gesamteuropäischen Emigrationsaufkommen knapp über $1 \%$.

Vor dem Hintergrund der amerikanischen Zensus-Angaben wiederum, welche auch die nichteuropäische Immigration nach Nord-Amerika berücksichtigen, lag der finnische Anteil innerhalb der Gesamteinwanderung für den Zeitraum 1900-14 bei durchschnittlich 1,7\%. Im Jahr 1920 machten die Finnen der ersten Generation weiterhin etwa $1 \%$ aller in die Vereinigten Staaten strömenden Immigranten aus ${ }^{19}$.

Die finnische Einwanderung nach Kanada hingegen ${ }^{20}$, welche bereits um 1880 begonnen hatte, war weniger stark ausgeprägt: Im Zeitraum 1901-14 sind nach offiziellen Angaben der kanadischen Einwanderungsbehörden 21219 Finnen nach Kanada eingewandert, was einem prozentualen Anteil von durchschnittlich 0,7\% an der gesamten nach Kanada gerichteten Einwandererpopulation entsprach ${ }^{21}$. Lindström-Best hat in

\footnotetext{
${ }^{17}$ In den Jahren 1905-07, 1910 und 1913-14 erreichten jährlich mehr als eine Million Menschen die Vereinigten Staaten. In den dazwischen liegenden Jahren schwankte die Anzahl zwischen ca. 750.000 und 880.000 Personen, vgl. Adams 1992, S. 500, Tab. 6.

${ }^{18}$ Ferenczi/Willcox 1969, Part I: International Tables: S. 232, Tab. 2 ; Part II: National Tables: Finland, S. 776, Tab. 1.

${ }^{19}$ Vedder/Gallaway 1970, S. 160, Tab. 1.

${ }^{20}$ Die Finnen wurden erstmals bei der Volkszählung des Jahres 1901 als eigenständige Nation erfaßt. Zur finnischen Einwanderung nach Kanada siehe auch Raivio 1975 (Bd. 1) S. 111-113; Kero 1976b, S. 7-16; Kouhi 1976, S. 17-39; Lindström-Best 1985, S. 6-11 und 1988, S. 28-34; Saarinen 1995, S. 19-23.

${ }^{21} \mathrm{Zu}$ den jährlichen Einwandererzahlen von Finnen nach Kanada siehe Raivio 1975 (Bd. 1), S. 111. $\mathrm{Zu}$ den allgemeinen Immigrantenzahlen für Kanada vgl. Sautter 1992, S. 307.
} 
diesem Zusammenhang auf eine abnehmende Tendenz des finnischen Anteils am Gesamtaufkommen aller Kanada-Immigranten hingewiesen: Bewegte sich der Prozentsatz in der Dekade 1901-10 noch bei 0,8\%, so sank er in der folgenden Dekade 1911-20 auf $0,6 \% \mathrm{ab}^{22}$. Demnach stellten die Finnen einen kleineren Prozentsatz unter den Einwanderern nach Kanada dar als unter den Immigranten in die Vereinigten Staaten.

Bei einem derartigen Vergleich des finnischen Anteils am Einwanderergesamtaufkommen der nach Amerika und Kanada gerichteten Immigration ist jedoch der Übergangscharakter insbesondere bei der nach Kanada gerichteten Einwanderung zu bedenken. In vielen Fällen wurde Kanada nämlich lediglich als Transitland für die eigentliche Einreise nach Amerika passiert, was bei der bis in die 1920er Jahre hinein offenen Grenze problemlos war $^{23}$. Eine preisgünstigere und zeitsparendere Fährpassage von England nach einem kanadischen Hafen oder aber die Furcht vor den vermeintlich strengeren Grenzkontrollen auf amerikanischer Seite des Atlantiks können den Ausschlag für eine Einreise über kanadisches Territorium gegeben haben. Die Atlantiküberquerung von Liverpool nach Montreal, Halifax oder Québec war nämlich nicht nur kürzer als die Schiffsverbindung von England nach New York oder Boston, sie unterlag vor allem größeren Preisschwankungen, wodurch ein finnischer Einwanderer zu einem günstigen Zeitpunkt etwa 10\% beim Fahrkartenkauf sparen konnte ${ }^{24}$. Doch auch der umgekehrte Fall, eine Einreise über New York oder Boston mit anschließender Weiterfahrt nach Ontario der angeblich besseren Verdienstmöglichkeiten wegen ist nicht selten gewesen.

Eine statistische Doppelerfassung zahlreicher europäischer Auswanderer, u.a. finnischer Immigranten, ist wahrscheinlich. Diese Vermutung wird auch durch die Tatsache gestützt, daß die in Zehnjahresabständen durchgeführten Volkszählungen in Amerika und Kanada nicht zeitgleich, sondern mit Verzögerung von einem Jahr stattfanden.

\footnotetext{
${ }^{22}$ Lindström-Best 1985, S. 7, Tab. 1.

${ }^{23}$ Norman/Runblom 1988, S. 155; Thistlethwaite $1991\left({ }^{1} 1960\right)$ S. 20; Saarinen 1995, S. 19. Kero (1980, S. 12-15) konnte bei 152 finnischen Auswanderern als Interviewpartnern 12 Personen ermitteln, die vor 1914 über Québec eingereist waren, obwohl sie eine Fahrkarte in die Vereinigten Staaten besaßen. Auch von den 144 Briefschreibern dieser Untersuchung sind mindestens drei Personen über Halifax, Québec und Montreal in die Vereinigten Staaten eingereist.

${ }^{24}$ Nach Angaben der Passagierlisten der ,Finnischen Dampfschiffahrtsgesellschafts AG' kostete die Überfahrt von Hanko nach Montreal im Jahr 1902180 Finnmark. Ein Jahr später konnte die Distanz Hanko-New York für 202 Finnmark bewältigt werden. Zu den Preisschwankungen im Auswanderertransportwesen siehe Kero 1974, S. 169-174.
} 
Von daher könnten über Amerika eingereiste Finnen beispielsweise im Jahr 1900 in Amerika erfaßt und bereits 1901 in den kanadischen Zensus-Berichten aufgetaucht sein.

Vor diesem Hintergrund ist die finnische Einwanderung nach Kanada lediglich als relative Größe anzusehen. Die regionale Mobilität unter den Finnen war groß, wie auch aus zahlreichen Briefen und Lebensberichten hervorgeht. Die Arbeitsbereiche der meisten finnischen Einwanderer lagen in den grenznahen Regionen im Norden Michigans und Minnesotas bzw. auf der gegenüberliegenden Seite des Superior-Sees in Ontario $^{25}$. Da in zahlreichen Kupfer- und Eisenerzgruben lediglich während der Sommermonate gearbeitet werden konnte, waren nicht wenige Finnen in den Wintermonaten als Waldarbeiter auf kanadischer Seite beschäftigt. Eine durch die saisonalen Erwerbsmöglichkeiten motivierte Arbeitswanderung zwischen Amerika und Kanada gehörte somit zum Einwandererdasein tausender Finnen in der Neuen Welt.

\subsubsection{Finnen als Vertreter der "neuen" Immigration?}

Aufgrund der Tatsache, daß der finnische Anteil am Gesamteinwanderervolumen sowohl in die Vereinigten Staaten als auch nach Kanada gering ausfiel, finden die Finnen in zahlreichen, auch neueren Darstellungen, die sich mit nordamerikanischer Einwanderungsgeschichte befassen, allenfalls marginal Erwähnung. Äußerungen zur Größe der finnischen Einwandererpopulation finden sich kaum, am häufigsten werden sie im Zusammenhang mit ihren politischen Aktivitäten im ersten Jahrzehnt des 20. Jahrhunderts erwähnt ${ }^{26}$. Obwohl Finnland geographisch zu Skandinavien gehört, beschränken sich die meisten Angaben zu den skandinavischen Einwanderern auf die der skandinavischen Sprachfamilie angehörenden Nationalitäten ${ }^{27}$, d.h. auf Schweden, Norweger, Dänen und teilweise noch auf Isländer ${ }^{28}$.

Dieser in der amerikanischen Migrationsforschung übliche Ausschluß der Finnen aus der Gruppe der Skandinavier hat seinen Ursprung in erster Linie in den Zuordnungskriterien der sogenannten Dillingham-Kommission: Der von Senator W. P. Dil-

\footnotetext{
${ }^{25}$ So wurden z.B. 15 Briefe von vier Briefschreibern dieser Untersuchung in der zweigeteilten Stadt Sault Ste. Marie verfaßt, wobei zwei der Briefschreiber auf der amerikanischen Seite sowie die anderen beiden auf der kanadischen Seite der Stadt lebten.

${ }^{26}$ Jones 1974, S. 180 und S. 202-209; Bodnar 1987, S. 108 und S. 185; Daniels 1990, S. 98 und S. 236.

${ }^{27}$ Siehe z.B. Dinnerstein/Reimers 1988, S. 20f.; Daniels 1990, S. 164f.
} 
lingham geleitete und nach ihm benannte Untersuchungsausschuß zum Einwanderungsproblem der Vereinigten Staaten legte 1911 einen monumentalen, 41-bändigen Bericht vor, in dem die einzelnen Nationalitäten den Gruppierungen "alter" und "neuer" Einwanderung zugeordnet wurden ${ }^{29}$. Im dem Bericht wurden die Finnen zur Gruppierung der "neuen" Immigranten gezählt, im Gegensatz zu den skandinavischen Nachbarländern, welche die "alte" Einwanderergruppe repräsentierten. Das Kriterium der Zuordnung war in erster Linie der Zeitpunkt der beginnenden Masseneinwanderung einer Nationalität.

Der Untersuchungsausschuß verfolgte trotz scheinbarer Objektivität in seiner Berichterstattung eine klare politische Intention: Das Augenmerk galt den "neuen" Einwanderern, deren Zustrom es zu beschränken galt. Vor allem die Erfahrungen mit den Elendsquartieren der Einwandererghettos in zahlreichen amerikanischen Großstädten, in denen der überwiegende Teil der süd- und südosteuropäischen Einwanderer lebte ${ }^{30}$, ließen ernsthafte Zweifel an der Assimilierbarkeit dieser Immigrantengruppen aufkommen. Dementsprechend haben die Maßnahmen und Gesetze zur Einwanderungsbeschränkung von 1921 und 1924 ihren Ursprung im widersprüchlichen Denken des Dillingham-Ausschusses ${ }^{31}$, das zum einen durch gemäßigte rassistische Vorurteile geprägt war, zum anderen aber eine kompromißlose Forderung nach Assimilation propagierte.

Assimilation wurde hierbei ungefragt mit Amerikanisierung gleichgesetzt, galt es doch, das Bestehende zu bewahren und unverändert fortzuführen. Dieses Postulat der Totalintegration, welche die sogenannte "Schmelztiegel-Gesellschaft" hervorbringen sollte, spiegelte zugleich die allgemeine Einstellung der amerikanischen Regierung den Einwanderern gegenüber wieder: Diese wurden bereits als zukünftige Staatsbürger angesehen, die unter Aufgabe ihrer ethnischen und kulturellen Eigenheiten in der ameri-

\footnotetext{
${ }^{28}$ In absoluten Zahlen sind ca. 14000 Isländer eingewandert, wonach sie als eine der kleinsten Einwanderergruppen gelten, vgl. Kjartansson 1977; Norman/Runblom 1985, S. 31 u. S. 38-49. ${ }^{29}$ Obwohl die Unterscheidung von "Old and New Immigrants" bereits seit den 1880er Jahren in den allgemeinen Sprachgebrauch übergegangen war, manifestierte der Kommissionsbericht diese Aufteilung. Zur Zuordnung der einzelnen europäischen Nationalitäten siehe 'United States Immigration Commission: Reports of the Immigration Commission', 41 Bde, hier Bd. 4, Washington 1911, S. 22.

${ }^{30}$ Zur Ghettobildung in amerikanischen Großstädten vgl. Blake 1963, S. 370-372; Niels Conzen 1979; Seller Schwartz 1988, S. 109-120; Brenner 1991, S. 384; Harzig 1992, S. 139-143. Als umfassende Monographie zu Immigranten in Großstädten am Beispiel von Boston siehe Handlin 1959.

${ }^{31}$ Der Ausschuß widersprach in seinem Abschlußbericht teilweise den Ergebnissen des von ihm selbst zusammengestellten Datenmaterials, um eine Beschränkung weiterer Einwanderung zu legitimieren, vgl. Kamphoefner 1982, S. 4; Adams 1984, S. 303-307.
} 
kanischen Gesellschaft aufgehen sollten. Demnach war der amerikanische Nationalismus auch in erster Linie ideologisch und erst in zweiter Linie rassistisch, d. h. bestimmte Nationalitäten ausgrenzend, geprägt ${ }^{32}$.

Wird die Realität nüchtern betrachtet, spielte es eher eine untergeordnete Rolle, ob die der Zeitströmung entsprechende Anpassungsideologie "Anglo-Konformismus", "Schmelztiegel-Gesellschaft" oder "Kultureller Pluralismus" genannt wurde ${ }^{33}$. Tatsache blieb, daß zahlreiche Nationalitäten neben- und miteinander lebten, ohne ihre nationalen, religiösen und ethnischen Eigenheiten aufzugeben ${ }^{34}$. Erst die Kinder und Enkelkinder der Einwanderer, die zweite und dritte Generation, integrierte sich allmählich in die amerikanische Gesellschaft, wie es sich die Staatsväter bereits von der ersten Generation gewünscht hätten.Es stellt sich nun die Frage, ob die Finnen, die von der Dillingham-Kommission den "neuen" Einwanderern zugeordnet wurden, tatsächlich die für die Mehrheit der nach 1890 eingewanderten Europäer typischen Merkmale aufwiesen.

Die von der Kommission festgelegte, zeitliche Zäsur, welche die Unterscheidung in "alte" und "neue" Immigration legitimieren sollte, fiel nicht von ungefähr mit dem Ende der freien Landvergabe, den "frontiers" in den Präriestaaten, zusammen. Bis zu der gesetzlichen Neuregelung von 1891 hatte sich die Praxis der Besiedlung des Mittleren Westens durch einen Großteil der Einwanderer aus Nord- und Westeuropa durchgesetzt, wobei das Heimstättengesetz von 1862, als "Homestead-Act" bekannt geworden, die materielle Grundlage für die europäischen Siedler geschaffen hatte ${ }^{35}$. Obwohl ein Großteil der "neuen" Einwanderer aus Agrargesellschaften stammte, u.a. fast alle finnischen Einwanderer, strömten diese vielmehr als ungelernte Arbeiter auf den amerikanischen Arbeitsmarkt, wo sie besonders von der sich schnell entwickelnden Montan- und Eisenindustrie aufgesogen wurden. Ihre realen Zukunftsperspektiven entsprachen jedoch selten den mit dem Auswanderungsentschluß verknüpften Erwartungen, denn aufgrund mangelnder Englischkenntnisse sowie unzureichender Schulbildung mußten sich die meisten Immigranten mit den untersten Plätzen in den Arbeitsplatzhierarchien begnügen.

\footnotetext{
${ }^{32}$ Elschenbroich 1986, S. 27.

${ }^{33} \mathrm{Zu}$ den drei Anpassungsideologien siehe Gordon 1964, S. 84-159; Yoder 1973, S. 184f.; Gleason 1981, S. 38-47.

${ }^{34}$ Zur Kritik an der 'Melting-pot'-Theorie siehe Brenner 1991, S. 384. Zur kritischen Auseinandersetzung mit dem Begriff ‘Kultureller Pluralismus’ vgl. Steinberg 1989, S. 253-262.
} 
Hatten sich zur Jahrhundertwende hin bereits zahlreiche Einwanderer der "alten" Gruppierung als Landbesitzer oder Gewerbetreibende, zum Beispiel auf der Grundlage eines noch in Europa erlernten Handwerks ${ }^{36}$, eine gesicherte Existenzgrundlage schaffen können und sich dementsprechend assimiliert, so brachte der Alltag vieler Industriearbeiter kurzzeitige und schnellwechselnde Arbeitsverhältnisse mit sich, wobei auch die Finnen keine Ausnahme darstellten. Lediglich englischsprachige Einwanderer hatten Chancen auf qualifiziertere und besserbezahlte Tätigkeiten.

Diesen veränderten Anforderungen des amerikanischen Arbeitsmarktes entsprechend war die "neue" Immigration denn auch durch eine männerdominante Einzeleinwanderung geprägt, im Gegensatz zur noch im 19. Jahrhundert üblichen Familieneinwanderung. Im Falle der Finnen jedoch immigrierten nach der Jahrhundertwende zunehmend Frauen als Einzelauswanderinnen, so daß sich das Ungleichgewicht innerhalb der Geschlechter allmählich auspendelte.

Die extrem starke Männerdominanz unter den süd- und südosteuropäischen Einwanderern spiegelte sich auch in einer verstärkten Rückwanderungsfrequenz dieser Nationalitätengruppen wider, welche selten unter $70 \% \mathrm{lag}^{37}$. Die finnische Rückwanderungsquote wiederum lag bei etwa $20 \%$ und entsprach in ihrer Größenordnung in etwa derjenigen Dänemarks und Schwedens, zweier "alter" Einwanderungsländer ${ }^{38}$. Für die Rückwanderer gestaltete sich der Arbeitsaufenthalt in Amerika in den meisten Fällen zu einer zwei- bis vierjährigen Abwesenheit aus dem Heimatland. Auch mehr als die Hälfte der finnischen Rückwanderer kehrte vor Gültigkeitsablauf des Reisepasses innerhalb von fünf Jahren nach Auswanderungsbeginn zurück, so daß sich die Mehrheit der Rückwanderer zum Zeitpunkt der Heimkehr noch im arbeitsfähigen Alter befand. Im Bezug auf die Rückwanderung waren jedoch Verhaltensunterschiede unter den ver-

\footnotetext{
${ }^{35}$ Das Heimstättengesetz sicherte den Siedlern ein 160 Morgen bzw. ca. 65 Hektar großes Stück Land zu, unter der Bedingung es mindestens fünf Jahre lang zu bewirtschaften, vgl. z. B. Wasastjerna 1957, S. 75; Harzig 1992, S. 130; Kero 1996, S. 144.

${ }^{36}$ Der Anteil an Handwerkern war unter deutschen Einwanderern besonders groß und in den Städten der amerikanischen Ostküste herrschte gegen Ende des 19. Jahrhunderts ein Überangebot an Handwerkern, vgl. Harzig 1992, S. 137.

${ }^{37}$ Die höchste Rückwanderungsrate wiesen die Balkannationen, Griechenland, die Türkei, Italien und Russland auf, wobei der Männeranteil unter diesen Rückwanderern zwischen 76\% 96\% schwankte, vgl. Gould 1980, S. 56-63, bes. Tab. 2 u. Tab. 3; Tedebrand 1985, S. 357-362; Norman/Runblom 1988, S. 107-111.

${ }^{38}$ Virtanen 1979, S. 221 und 1985, S. 384.
} 
schiedenen Altersgruppen zu beobachten: Je älter die Auswanderer bei Emigrationsbeginn, desto höher gestaltete sich auch die Rückwanderungsfrequenz ${ }^{39}$.

Folglich zeigten die Finnen eher Gemeinsamkeiten mit den übrigen skandinavischen Immigranten als mit den zeitgleich eingewanderten Südosteuropäern. Besonders deutlich wird dies bei einem Vergleich des allgemeinen Bildungsstandards zwischen Finnen und einigen süd- und südosteuropäischen Nationalitäten: Für die Jahre 18991910 wurden beispielsweise 68,2\% der Portugiesen, 38,4\% der Russen und 26\% der Juden als lese- und schreibunkundig identifiziert, der Anteil der Finnen betrug für den genannten Zeitraum jedoch lediglich 1,3\% und rangierte damit in gleichen Größenordnung mit den übrigen Skandinaviern und Briten $^{40}$.

Geographisch bevorzugten die Finnen die nördlichen Regionen der MittelwestStaaten, in denen die Besiedlung durch Schweden und Norweger bereits eine lange Tradition hatte. Im Gegensatz zu den süd- und südosteuropäischen Immigranten lebten sie nicht in Großstädten, mit Ausnahme von alleinstehenden, finnischen Einwanderinnen. Die meisten Finnen arbeiteten in amerikanischen Kleinstädten, in isolierten Waldkamps sowie in der Nähe von Grubensiedlungen, wo sie in einfachen Blockhütten lebten. Aufgrund ihrer früheren Tätigkeit als Landbesitzer oder landwirtschaftliche Arbeiter in Finnland, gründeten viele, nicht rückwanderungswillige Finnen einen eigenen Bauernhof, wodurch ihr Lebensstil Ähnlichkeit mit der Lebensführung der "alten" Immigrantengruppen aufwies ${ }^{41}$. Häufig ließen sie sich in den ihnen bereits vertrauten Regionen entlang der Montanregionen nieder, so daß zumindest eine zeitweilige Rückkehr in das ehemalige Berufsfeld jederzeit möglich erschien.

Zu diesem Themenkomplex gibt Hoerder zu bedenken, daß die immer noch aktuelle begriffliche Unterscheidung in "Old and New Immigrants", wie am Beispiel der Finnen verdeutlicht, auch bei näherer Betrachtung der Lebensumstände anderer Einwanderernationalitäten Unstimmigkeiten aufweist ${ }^{42}$. Von daher plädiert er für eine neue Sprachregelung: Die "Siedlungsimmigranten" umfassen alle Einwanderer, gleich welcher Nationalität, die Vereinigten Staaten noch zu Zeiten der freien Landvergabe erreichten. Diese zumeist im Familienverband eingewanderten Europäer kamen mit dem festen Ziel, sich in der neuen Heimat eine dauerhafte Existenzgrundlage zu schaffen. Im

\footnotetext{
${ }^{39}$ Norman/Runblom 1988, S. 109.

${ }^{40}$ Smith 1969, S. 528f.; Easterlin 1981, S. 477f., bes. Tab. 2; Virtanen 1986, S. 151.

${ }^{41}$ Norman/Runblom 1988, S. 34.

${ }^{42}$ Hoerder 1985b, S. 7-13 und 1991, S. 78-80.
} 
Gegensatz hierzu stehen die "Arbeitsmigranten", deren Einwanderung einen völlig anderen ökonomischen und sozialen Prozeß darstellte als die "Immigration von Siedlern". Sie trug den Charakter einer temporären Arbeitswanderung, wobei der ökonomische Faktor, das schnelle Geldverdienen, im Vordergrund stand. Die Anpassungsbereitschaft unter den "Arbeitsmigranten" war gering, da die geplante Rückwanderung bereits als fester Bestandteil des Auswanderungsentschlusses galt. Hoerder geht in seiner Begriffsdefinition sogar so weit, daß er die "Arbeitsmigranten" nicht mehr als Immigranten im herkömmlichen Sinne klassifiziert ${ }^{43}$.

Im Unterschied zur Einteilung der Einwanderergruppen durch die DillinghamKomission setzt Hoerder keine zeitliche Zäsur. "Arbeitsmigranten" in dem von Hoerder dargelegten Sinn habe es bereits seit den 1820er Jahren gegeben, wonach in den Vereinigten Staaten des 19. Jahrhunderts sowohl "Arbeitsmigranten" als auch "Siedlungsimmigranten" zu finden waren. Doch erst das Ende der freien Landvergabe sowie die zunehmende Industrialisierung hatten eine veränderte gesellschaftliche Situation geschaffen, in der eine verstärkte Nachfrage nach "Arbeitsmigranten" bestand, die wiederum flexibel und mobil auf die Veränderungen der amerikanischen Arbeitsmarktlage reagieren mußten.

Mit diesen Realitätsanforderungen wurden auch die Finnen konfrontiert, wonach sie nach Hoerders Auffassung durchaus als "Arbeitsmigranten" bezeichnet werden können. In ihrer Rückwanderungsaktivität standen sie jedoch deutlich hinter den süd- und südosteuropäischen Immigranten zurück, wonach vermutlich in vielen Fällen eine möglicherweise geplante Rückwanderung nicht verwirklicht wurde. Trotz geringer Anpassungsbereitschaft der ersten Einwanderergeneration spricht die Dauerhaftigkeit ihres Aufenthaltes für eine Immigration nach dem klassischen Verständnis und weicht in dieser Hinsicht von Hoerders Deutung ab. Da nämlich die meisten Amerika-Finnen mit zunehmender Aufenthaltsdauer auch seßhaft wurden und jahrzehntelang an einem Wohnort verweilten, weist ihr Verhalten Parallelen zum Lebensstil der "Siedlungsimmigranten" des 19. Jahrhunderts auf. Folglich hatte der einmal gewagte große Schritt über der Atlantik eine dauerhafte Lebensraumveränderung zur Folge, ganz gleich ob der Lebensunterhalt in einer Eisenerzgrube, einem Sägewerk oder auf dem eigenen Ackerland erworben wurde.

\footnotetext{
${ }^{43}$ Hoerder 1985b, S. 8.
} 


\section{2. Die große Reise und die ersten Schritte in der Neuen Welt}

Die Atlantiküberquerung bedeutete für die meisten Auswanderer eine neuartige Erfahrung, die in lebhaften Schilderungen sowohl in zahlreichen Auswandererbriefen als auch in autobiographischen Aufzeichnungen reflektiert wurde ${ }^{44}$. Der erste Brief oder die erste Postkarte an die zurückgebliebenen Verwandten oder Nachbarn kam häufig aus einer englischen Hafenstadt, wo ein tagelanger Zwischenstop eingelegt werden mußte, bevor die aufeinander abgestimmten Fahrpläne der verschiedenen skandinavischen und englischen Reedereien einen relativ reibungslosen Überfahrtsablauf ermöglichten.

Als die finnische Amerikaauswanderung um 1870 einsetzte, wurde der transatlantische Linienverkehr bereits mit Dampfschiffen bestritten, die sich vorwiegend in der Hand von englischen und deutschen Reedereien befanden. Hier sind vor allem der Norddeutsche Lloyd und die Hamburg-Amerikanische Packetfahrt AG, kurz HAPAG, zu nennen, die von Hamburg und Bremerhaven aus verkehrten. Sämtliche englische Reedereien legten von Liverpool oder Southampton ab, wie die British-American Western Steam Ship Company bzw. die American Line, die Cunard Line, die Inman Line, die National Line, die Guion Line, die Allan Line, die State Line sowie die schottische Reederei Anchor Line ${ }^{45}$. Neben New York als wichtigstem Einwanderungshafen liefen die Schiffahrtsgesellschaften vor allem Philadelphia, Boston und Portland sowie auf kanadischer Seite Québec, Halifax und Montreal an.

Die Schiffahrtsgesellschaften waren allesamt in den 1850er und 1860er Jahren gegründet worden, mit Ausnahme der drei ältesten Reedereien American Line, Cunard Line und HAPAG. Sie hatten schon zu Beginn der 1840er Jahre den allmählichen Übergang von der Epoche der Segelschiffahrt zur Dampfschiffahrt markiert, nachdem 1843 das erste transatlantische Schraubendampfschiff, die Great Britain, vom Stapel gelaufen war ${ }^{46}$. Bis zur Jahrhundertmitte handelte es sich noch um reine Frachttranspor-

\footnotetext{
${ }^{44}$ Vgl. die Memoiren des populärsten finnischen Amerikaauswanderers, des späteren sozialdemokratischen Parlamentsabgeordneten und Gewerkschaftsführers Oskari Tokoi (1873-1963), zitiert als Tokoi 1949 und 1959. Zu seiner Person siehe Kirkpatrik 1975, S. 127; Kero 1996, S. 266-268. Siehe auch Myhrman 1974 (Emigrantenbiografien 8 Bde); Ahlbäck 1971, bes. zu Reiseberichten, S. 31-53. Speziell zu Reiseerlebnissen von Frauen vgl. Weatherford 1986, S. 172193.

${ }^{45}$ Niitemaa 1976, S. 82-84. Die Allan und Anchor Line legten außerdem auch von Glasgow ab. ${ }^{46}$ Zum Übergang von der Segel- zur Dampfschiffahrt siehe Gibbs 1957, S. 173-306; Guillet 1963, S. 233-248; Bretting 1992, S. 95-99. Bis zur Jahrhundertwende waren zahlreiche Dampf-
} 
te, der erste regelmäßige Linienverkehr für Passagiere wurde dann 1852 von der Inman Line eingerichtet ${ }^{47}$.

In den frühen 1870er Jahren drängten bereits weitere Reedereien auf den Markt, von denen vor allem die englische White Star Line, die englisch-amerikanische Dominion Line und die kanadische Beaver Line ${ }^{48}$ für den finnischen Auswanderertransport bedeutsam wurden. Zur gleichen Zeit transportierten auch zahlreiche Segelschiffe Auswanderer über den Atlantik, deren Überfahrtspreise noch deutlich unter denen der Dampfschiffahrtsgesellschaften lagen. Erst das Anwachsen der europäischen Emigrantenströme sorgte für eine starke Konkurrenz unter den einzelnen Reedereien und somit auch für sinkende Fahrpreise ${ }^{49}$.

Im Jahr 1860 erreichten noch rund 74000 Europäer New York per Segelschiff und 34000 per Dampfschiff ${ }^{50}$. Das Verhältnis änderte sich jedoch rasch zu ungunsten der Segelschiffe, die bereits zwei Jahrzehnte später vollständig aus dem Transatlantikgeschäft verdrängt worden waren ${ }^{51}$.

Die Vorteile der Dampfschiffahrt ergaben sich vor allem aus der exakteren Bestimmung und gleichzeitigen Verringerung der Fahrtdauer. Dadurch war erstmals die Aufstellung von Fahrplänen möglich geworden, welche die Grundlage für einen regelmäßigen Linienverkehr schufen und auch zu kürzeren Wartezeiten in den Abfahrtshäfen führten. Die verkürzte Fahrtdauer ermöglichte zudem die Mitnahme von frischen Lebensmitteln und Wasser, was - im Vergleich zum Zeitalter der Segelschiffahrt - den allgemeinen Gesundheitszustand unter den Zwischendeckspassagieren erheblich ver-

schiffe noch als Dampfsegler ausgerüstet. Erst die Erfindung der Dampfturbine 1898 und des Dieselmotors 1910 bedeuteten eine Innovation für den Passagiertransport, da sich durch Einsatz von Vierschornsteindampfern die Überfahrtszeit der Atlantiküberquerung auf die Hälfte reduzierte.

${ }^{47}$ Jones 1976, S. 39. Die bereits 1840 gegründete Cunard Line begann erst ab 1862 mit der Auswandererbeförderung und eroberte sich aufgrund des Postbeförderungsmonopols eine führende Marktposition, vgl. Hyde 1975, S. 58-89; Holmio 1967, S. 99; Hvidt 1971, S. 359; Bretting 1981, S. 29.

${ }^{48}$ Niitemaa 1976, S. 83f. Ab 1903 verkehrte diese Linie als Canadian Pacific Railway Line (C.P.R.), eine Tochtergesellschaft des gleichnamigen Eisenbahnunternehmens, zwischen Kanada und England.

${ }^{49}$ Zur Entwicklung der Fahrpreise, die gegen Ende des 19. Jahrhunderts starken Schwankungen unterworfen waren, siehe Kero 1974, S. 169-174.

${ }^{50}$ Bretting 1981, S. 29. Zu allgemeinen Darstellungen zum Zeitalter der Amerikaauswanderung mit Segelschiffen siehe Bonsor 1960; Guillet 1963; Taylor 1971, S. 131-144; Jones 1976, S. 24-39.

${ }^{51}$ Dieser Übergang konnte sich sogar innerhalb weniger Jahre vollziehen: Von norwegischen Häfen aus wurden 1866 noch 90\% aller Auswanderer im Segelschiff befördert, doch bereits ab 1874 verkehrten ausschließlich Dampfschiffe, vgl. Norman/Runblom 1988, S. 115. 
besserte. Lebensbedrohende Krankheiten und Seuchen an Bord kamen nur noch selten vor, so daß die Atlantiküberquerung nicht mehr als gefährliche Reise mit ungewissem Ausgang angesehen werden konnte ${ }^{52}$.

Die skandinavischen Auswanderer passierten England und in geringerem Ausmaße auch Deutschland als Transitländer, die ihnen als Ausgangspunkte für die Atlantiküberquerung dienten. Schon in der Frühphase der finnischen Auswanderung gab es mehrere Reiserouten zu den Hafenstädten der amerikanischen und kanadischen Ostküste. Bis 1891, d.h. bevor eine direkte Linienverbindung von der südlichsten Stadt Finnlands, Hanko nach Hull in England eingerichtet wurde, verliefen die Reisewege fast alle über Norwegen oder Schweden und Dänemark nach England und Deutschland ${ }^{53}$. Dabei reihten sich die finnischen Auswanderer in den r skandinavischen Emigranten ein und trafen vor allem auf Engländer und Iren, die mit ihnen die Erfahrung der Atlantiküberquerung teilten.

\subsubsection{Die Reiserouten der finnischen Auswanderer}

Über die genauen Reisewege der ersten Auswanderer in den 1840er und 1850er Jahren ist nichts bekannt. Da sich jedoch zu dieser Zeit die norwegische Amerikaemigration $^{54}$ bereits zu einem Massenphänomen entwickelte, schätzt Kolehmainen, daß zwischen 1846 und 1855 etwa 40 Finnen, die zu der in der norwegischen Finnmark lebenden finnischen Bevölkerung zählten, über nordnorwegische Häfen ausgewandert sind ${ }^{55}$. Im Frühjahr und Sommer 1964 sollen dann einige Dutzend finnische Grubenarbeiter aus der Kå-Fjord-Region in vier Reisegruppen über Tromsø ausgewandert sein, da sie an-

\footnotetext{
${ }^{52}$ Bereits für die Epoche der Segelschiffahrt konstatiert Bretting (1981, S. 25-27 und 1992, S. 108), daß Unglücksfälle an Bord, verursacht durch Feuer, Schiffbruch und Untergang, relativ selten vorkamen. Der Tod durch Krankheit war wesentlich häufiger.

${ }^{53} \mathrm{Ab} 1864$ und 1872 war es auch möglich, mit der französischen Reederei Compangie Générale Transatlantique von Le Havre bzw. mit der Dutch Holland-American Line von Rotterdam aus den Atlantik zu überqueren, doch für die skandinavischen Emigranten kamen diese Verbindungen kaum in Betracht, vgl. Niitemaa 1976, S. 83.

${ }^{54}$ Bis 1861 hatten bereits ca. 70000 Norweger die Neue Welt erreicht, in den 1860er Jahren kamen dann ca. 98000 weitere Norweger hinzu. Das Jahr 1865 wird als der Beginn der norwegischen Massenemigration angesehen, da es die erste von drei Auswanderungswellen einleitete, vgl. Haugen 1975, S. 9. Zur Norwegenauswanderung siehe auch Semmingsen 1960 und 1975.

${ }^{55}$ Kolehmainen (1946, S. 20) bezieht sich auf Blegen (1931), doch es bleibt unklar, welche Quellen für die Ermittlung dieser Angabe genutzt wurden.
} 
geblich von einer amerikanischen Kupferbergwerksgesellschaft angeworben worden waren $^{56}$.

Bedeutender noch als Tromsø war der Hafen von Trondheim, den die finnischen Auswanderer, aus nördlicher Richtung kommend, bereits per Küstensegler anliefen ${ }^{57}$. Dies belegt auch eine in Nord-Finnland 1871 verbreitete Werbebroschüre in finnischer Sprache des in Trondheim ansässigen norwegischen Agenten der Allan Line, der die Ausreise von Trondheim nach Hull offerierte ${ }^{58}$. Im Gegensatz dazu nutzten die meisten norwegischen Auswanderer die südlicher gelegenen Häfen Bergen und Christiania, dem späteren Oslo, zur Einschiffung. Bereits in den 1850er Jahren existierte von Bergen aus eine Direktverbindung nach Québec. In den Jahren 1871-76 existierte zudem eine Direktverbindung von Trondheim nach Québec, zur gleichen Zeit, als die norwegische Auswanderung ihren ersten Höhepunkt erreichte. Sie wurde von der NorwegianAmerican Line betrieben und stellte eine ernste Konkurrenz für die Allan Line dar ${ }^{59}$.

Ebenfalls im Jahr 1871 eröffnete ein schwedischer Agent der Allan Line ein Büro im nordschwedischen Haparanda, was zur Intensivierung der finnischen Emigration aus der Region der Tornio-Flußmündung und dem finnischen Hinterland führte. Die finnischen Auswanderer reisten nun in erster Linie von Tornio oder Haparanda in kleineren Dampfschiffen nach Stockholm. Der vielgereiste Pfarrer Salomon Ilmonen benennt 1923 einige Mitglieder einer finnischen Reisegruppe, die im Juni 1874 über Stockholm, Göteborg und Hull nach Minnesota und Michigan gereist sein sollen. Er schätzt die Gesamtanzahl dieser Emigrantengruppe auf etwa 500 Personen. Kero konnte anhand der Göteborger Passagierlisten tatsächlich mehr als 500 Finnen nachweisen, die Göteborg am 27.06.1874 verlassen hatten ${ }^{60}$.

Im Laufe der 1870er Jahre, als die Auswanderung aus den Küstenregionen SüdOstbottniens an Bedeutung gewann, schifften sich die Auswanderer dann vorwiegend in anderen Häfen ein. Hier wären vor allen Oulu, Vaasa, Kristiinankaupunki, Pori, Rauma,

\footnotetext{
${ }^{56}$ Diese Behauptung findet sich nur bei Ilmonen (1923, Bd. 2, S. 25-27) und wird, wie Kero (1974, S. 160f.) bemerkt, in der Literatur vielfach kritiklos zitiert, z. B. von Engelberg 1944, S. 23f.; Kolehmainen 1945, S. 230; Hoglund 1960, S. 9; Holmio 1967, S. 124f. Unter Berufung auf Ilmonen markieren diese Autoren das Jahr 1864 als den nachweislichen Beginn der finnischen Amerikaauswanderung.

${ }^{57}$ Alanen 1983a, S. 23.

${ }^{58}$ Nachdem diese Werbebroschüre dem finnischen Senat aufgefallen war, wurden die ersten restriktiven Maßnahmen zur Auswanderungseindämmung getroffen, vgl. Kero 1969a.

${ }^{59}$ Norman/Runblom 1988, S. 116f. Vgl. auch Semmingsen 1975, S. $52-55$ sowie die Abbildungen bei Taylor 1971, S. 136

${ }^{60} I l m o n e n$ 1923, Bd. 2, S. 32-36. Vgl. auch Kero 1974, S. 163-166.
} 
Hanko und Turku, das traditionelle Zentrum der Seeleute, zu nennen. Von Norden kommende Schiffe legten häufig noch mehrmals an der finnischen Küste an, bevor sie nach Stockholm aufbrachen, wie zahlreiche Schiffsanzeigen in der zeitgenössischen Tagespresse belegen ${ }^{61}$. Da es in den finnischen Küstenstädten keine großen Reedereien gab, waren es zumeist kleinere Frachtschiffunternehmen, die zusätzlich Passagiere beförderten.

Von Stockholm aus wurde die Reise dann per Eisenbahn oder Küstenschiff nach Göteborg und Malmö fortgesetzt, um die Nordsee nach Hull bzw. die Ostsee über Lübeck nach Hamburg oder Bremerhaven zu überqueren, von wo aus die Ozeandampfer nach Übersee ablegten.

Für die finnischen Auswanderer änderte sich die Reiseroute erst ab 1891 grundlegend, als die bereits 1883 gegründete Finnische Dampfschiffahrtsgesellschaft AG eine Direktverbindung von Hanko, der südlichsten Hafenstadt Finnlands, nach Hull einrichtete und in den Folgejahren das Monopol im finnischen Auswanderertransport einnahm.

Um das Ausmaß der finnischen Auswanderung vor $1892^{62}$ über Schweden und Norwegen zu ermitteln, hat Kero die finnischen Auswanderer gezählt, die in den ab 1870 geführten Passagierlisten der Polizeibehörden von Göteborg, Stockhom, Malmö und Trondheim verzeichnet sind ${ }^{63}$. Für den Zeitraum 1870-79 konnte er 2767 Finnen, die über Göteborg ausgewandert waren, einer Minimalanzahl von 76 Personen gegenüberstellen, welche in Trondheim die Atlantiküberquerung begonnen hatten. Für Stockholm waren keine und für Malmö lediglich fünf Auswanderer verzeichnet.

Für das folgende Jahrzehnt 1880-89 sah das Verhältnis mit 29776 GöteborgAuswanderern zu 593 Trondheim-Emigranten kaum anders aus. Obwohl auch die Auswanderung über Stockholm und Malmö zugenommen hatten, stellten die Emigranten über Göteborg immer noch $84 \%$ des finnischen Auswandereraufkommens. Die Emigration via Trondheim hingegen fiel mit weniger als $2 \%$ am Gesamtaufkommen nicht mehr ins Gewicht. Auch für die Jahre 1890 und 1891 sahen die Verhältnisse noch ähnlich aus, wenngleich die finnische Dampfschiffahrtsgesellschaft bereits ab dem Sommer

\footnotetext{
${ }^{61}$ Z. B. Wasabladet vom 11.3.1876, 13.6.1876, 23.10.1878 und 12.7.1979.

${ }^{62}$ Einer Information des Migrationsinstituts in Turku zufolge, verzeichnen die ältesten, noch erhaltenen Passagierlisten der Finnischen Dampfschiffahrtsgesellschafts AG erst ab Sommer 1892 Auswanderer.

${ }^{63}$ Kero 1974, S. 24-34, bes. S. 26. Die von Kero errechneten Zahlenwerte entsprechen ungefähr auch der Gesamtanzahl aller in diesem Zeitraum ausgewanderten Personen, da vor 1893 keine offiziellen Auswandererstatistiken für alle Regierungsbezirke Finnlands geführt wurden.
} 
1891 die genannte Direktverbindung von Finnland nach England anbot. 1892 wanderten dann bereits 25\% aller finnischen Auswanderer über Hanko aus.

Obwohl Kero die niedrigen Zahlenwerte für Trondheim aufgrund einer unzureichenden Quellenlage als extrem gering einstuft ${ }^{64}$, belegt seine Untersuchung dennoch, daß der überwiegende Teil der Finnen über Göteborg ausgewandert ist.

Beim Vergleich dieses Untersuchungsergebnisses mit einer Studie von Brattne, in der die Größenordnung aller skandinavischen Auswanderer über schwedische Häfen betrachtet wird, läßt sich eine interessante Übereinstimmung feststellen: Der Anteil von 84\% der finnischen Auswanderer über Göteborg für den Zeitraum 1880-89 korrespondiert nämlich mit der Gesamtanzahl aller skandinavischen Auswanderer über Göteborg innerhalb des gleichen Untersuchungszeitraumes, welche bei $81 \% \operatorname{lag}^{65}$. Nach Göteborg war Malmö mit ca. 14\% am stärksten in den Auswanderertransport involviert.

Innerhalb der skandinavischen Auswandererpopulation wiederum betrug der Anteil an Finnen über schwedische Häfen 9,8\% für die Zeitspanne 1880-89. Da jedoch der Vergleichswert für die Jahre 1870-79 lediglich bei etwa 3,5\% lag ${ }^{66}$, stieg bis 1890 nicht nur die absolute Anzahl der über schwedische Häfen auswandernden Finnen, sondern es verdreifachte sich auch ihr prozentualer Anteil am gesamtskandinavischen Auswanderervolumen, bevor der organisierte Auswanderertransportes von Finnland die Sitaution veränderte.

Zusammenfassend läßt sich festhalten, daß der Umfang der finnischen Auswanderung über Trondheim vermutlich auch schon vor 1870 deutlich hinter dem Göteborgs zurückstand. Dies ist insofern bemerkenswert als die Pioniere unter den finnischen Emigranten nachweislich aus den nördlichsten Regionen Finnlands stammten und sich die norwegische Amerikaauswanderung bereits in den 1860er Jahren in wesentlich gröBeren Dimensionen bewegt hatte als die Emigration aus Schweden.

\footnotetext{
${ }^{64}$ Kero 1974, S. 24-27. In den Eintragungen der Passagierlisten wurde nicht nach Nationalität unterschieden. Von daher ist es wahrscheinlich, daß zahlreiche Finnen, die bereits in NordNorwegen gelebt hatten, auch als Norweger gezählt wurden. Ihre tatsächliche Anzahl muß also sehr viel höher gewesen sein als in den Passagierlisten der Trondheimer Polizeibehörden ausgewiesen ist.

${ }^{65}$ Brattne 1973, S. 93, Tab. 4.

${ }^{66} \mathrm{Um}$ die Zahlenwerte für die 1870er Jahre zu ermitteln wurden die Werte aus den offiziellen schwedischen Auswandererstatistiken (Bidrag till Sveriges officiella statistik. Serie A, 18511900) zur Grundlage der Berechnung genommen. Da sie auf der Basis von Paßverzeichnissen erstellt sind, schließen sie weder das Ausmaß der illegalen Auswanderung ein noch weisen sie die übrigen skandinavischen Auswanderer über schwedische Häfen auf.
} 


\subsubsection{Der Einfluß der Agententätigkeit auf das Auswanderungsgeschäft}

Da es in Finnland bis 1886, dem Gründungsjahr der ersten finnischen Inman Line-Agentur, keine Möglichkeit gab, Fahrkarten für die großen Ozeandampfer zu kaufen, wandten sich die finnischen Auswanderer meist schon in Stockholm an schwedische Agenten, die im Auftrag englischer oder deutscher Reedereien die Weiterreise ihrer Kunden organisierten. Die Tätigkeit der Auswanderungsagenturen ${ }^{67}$ trat an die Stelle des früher üblichen Vertragsabschlusses zwischen Kapitän und Auswanderer im Einschiffungshafen. Als Schiffsexpedient vertrat der Agent eine oder mehrere Reedereien. In der Mitte des 19. Jahrhunderts unterhielten zahlreichen Agenten sowohl ein Hauptbüro in einer für den Auswandererverkehr bedeutsamen Hafenstadt als auch weitere Büros in anderen Städten oder Verkehrsknotenpunkten des Binnenlandes.

Zahlreiche schwedische Agenten ${ }^{68}$, die ihren Geschäftssitz in Göteborg hatten, beschäftigten als Unteragenten finnischsprachige, meist zurückgekehrte Auswanderer, welche ihre Landsleute bereits im Hafen von Stockholm empfingen ${ }^{69}$. Dort schlossen sie mit den Auswanderern Überfahrtskontrakte ab, worin die Reiseroute von Stockholm bis zum amerikanischen oder kanadischen Zielort festgelegt war. Die Auswanderer kauften ihre Schiffs- und Zugfahrkarten somit beim Agenten und legten sich auf die Benutzung bestimmter Reedereien und Eisenbahngesellschaften fest, die wiederum untereinander Verträge über die kombinierte Personenbeförderung abgeschlossen hatten ${ }^{70}$. An den Umsteigebahnhöfen bzw. Einschiffungs- und Ankunftshäfen erwarteten die Unteragenten dann ihre Kunden, um diese deren Reiseroute entsprechend weiterzuleiten ${ }^{71}$ bzw. bei mehrtägigen Aufenthalten in den Hafenstädten die von den Reedereien gestellte Verpflegung und Unterbringung der Reisenden zu organisieren. Der angebliche Komfort, mit dem die Agenten gerne ihre Kundschaft köderten, blieb zu Zeiten der Massenauswanderung jedoch auf der Strecke. In der Realität mußten viele Auswanderer ihr

\footnotetext{
${ }^{67}$ Bretting 1992, S. 91-95.

${ }^{68}$ Zum schwedischen Agententum vgl. Brattne 1973, S. 70-177; Lext 1977, S. 147-207; Hvidt 1978.

${ }^{69}$ Kero 1974, S. 133, siehe auch Brief von Frans Lendén [11.4.1903] TYYH:S:m:Satakunta:HTi:III/1, auch bei Kero (1976a, S. 71f.) abgedruckt.

${ }^{70}$ Die beiden größten Eisenbahngesellschaften jenseits des Atlantik waren die Union Pacific Railroad Company und die Canadian Pacific Railroad Company, die nach der Jahrhundertwende auch mit der Finnischen Dampfschiffahrts AG zusammenarbeiteten, vgl. Tokoi 1959, S. 28; Kero 1974, S. 155; Brattne/Åkerman 1976, S. 179.

${ }^{71}$ Zum organisierten Netzwerk des Agententums in Schweden vgl. Brattne/Åkerman 1976, S. 189-191.
} 
Nachtquartier auf dem Fußboden der überfüllten Auswandererherbergen aufschlagen oder aber unter freiem Himmel schlafen.

Wie schon erwähnt, verließen die meisten finnischen Auswanderer Schweden über Göteborg, um nach Hull überzusetzen. Eine eigens für den Emigrantenverkehr eingerichtete Bahnverbindung brachte die Auswanderer dann nach Liverpool, dem englischen Anlegehafen der Ozeandampfer. Es gab auch die weniger frequentierte Route von Hull nach Southampton, von wo die Emigranten anschließend nach Boston übersetzen konnten.

Für die Nordseeüberquerung war hauptsächlich die Wilson Line verantwortlich ${ }^{72}$. Ein in Göteborg lebender Sohn des englischen Reedereigründers hatte schon früh das schwedische Agentennetz der Wilson Line ausgebaut und mit den großen Liverpooler Reedereien Vereinbarungen über den Weitertransport der skandinavischen Emigranten getroffen. Obwohl es noch kleinere Reedereien gab, die Skandinavier von Göteborg nach Hull transportierten, agierte die Wilson Line auf dieser Strecke ohne ernstzunehmende Konkurrenz. Ab 1875 eröffnete die Wilson Line dann sogar eine eigene Verbindung zwischen Hull und New York.

Unter den englischen Transatlantik-Reedereien wiederum herrschte eine starke Konkurrenz: Mindestens zehn englische Reedereien transportierten skandinavische Auswanderer in den Jahren 1868-90 über den Atlantik ${ }^{73}$, von denen in den 1870er Jahren wenigstens vier und in den 1880er Jahren acht auch finnische Auswanderer beförderten. Anhand der Stichprobenjahre 1873 und 1882 hat Kero in den Göteborger Passagierlisten folgende Reedereien ausmachen können: White Star, Allan, Inman und National Line (1873) sowie zusätzlich American, Cunard, Anchor und Dominion Line (1882). Bis zum Ausbruch des Ersten Weltkrieges transportierten dann die White Star, Cunard und Allan Line zusammengenommen mehr als 65\% aller finnischen Auswande$\operatorname{rer}^{74}$.

Die genannten Reedereien wurden allein in Göteborg von bis zu 23 verschiedenen Hauptagenten vertreten, von denen die meisten noch Büros in Stockholm und Malmö unterhielten. Zwei weitere Agenten in Göteborg repräsentierten die beiden deut-

\footnotetext{
${ }^{72}$ Die Wilson Line wurde bereits 1825 als Segelschiffahrtsgesellschaft in England gegründet, verkehrte aber seit 1850 ausschließlich mit Dampfschiffen. Sie erhielt das Postbeförderungsmonopol zwischen Schweden und England und transportierte neben Frachtgut vor allem Auswanderer, vgl. Hvidt 1971, S. 361.

${ }^{73}$ Lext 1977, S. 145, Tab. 2.

${ }^{74}$ Kero 1974, S. 132f. u. S.156.
} 
schen Reedereien. Ab der Mitte der 1880er Jahre dehnten die schwedischen Agenten dann ihre Aktivitäten auf Finnland aus, so daß die finnischen Auswanderer entweder am finnischen Ausgangshafen oder aber bereits in ihrer Heimatgemeinde die Fahrkarten kaufen konnten.

Im Hinblick auf die überproportional starke Repräsentation englischer Reedereien unter den schwedischen Agenten, hing die von den Auswanderern bestrittene Reiseroute weniger von Faktoren wie der kürzesten Distanz oder der direktesten Verbindung $\mathrm{ab}$, sondern vielmehr von der Effizienz, mit der die einzelnen Agenturen ihr Geschäft betrieben. Auch die Betrachtung der Auswanderung über Kopenhagen ${ }^{75}$ oder die deutschen Häfen bestätigt diesen Eindruck. Hatten sich die finnischen Emigranten in Schweden nämlich an einen Agenten gewandt, der mit einer deutschen Reederei kooperierte, so verlief die Reise von Stockholm mit Zwischenstop in Kopenhagen nach Lübeck, wo Züge zu den Einschiffungshäfen Hamburg und Bremerhaven bereitstanden. Es waren in erster Linie schwedische Schiffahrtsgesellschaften, die über Stockholm ausreisende Emigranten nach Lübeck beförderten. Von deutschen Häfen aus wurden die Skandinavier dann direkt nach New York oder Boston gebracht.

Diese aufwendigen Reiseverbindungen verwundern um so mehr, als in den Jahren 1869-74 bereits eine Direktverbindung von Kopenhagen nach New York bestand, welche von der amerikanisch-dänischen Aktiengesellschaft Baltischer Lloyd unterhalten wurde $^{76}$. Bereits fünf Jahre später, im Jahr 1879, nahm eine neue Gesellschaft, die dänische Reederei Thingvalla Line, ab 1902 mit neuem Namen Scandinavian-American Li$n e$, diese Direktverbindung mit großem Erfolg wieder auf ${ }^{77}$.

In den Jahren 1868-96 wurden 503 Finnen registriert, die in Kopenhagen ein Schiff bestiegen hatten ${ }^{78}$. Da vor 1874 lediglich zwei Personen auswanderten, ist davon auszugehen, daß der Baltische Lloyd in Finnland noch so gut wie unbekannt war, wo-

\footnotetext{
${ }^{75}$ Auch die Wilson Line bot eine Verbindung von Malmö über Kopenhagen nach Hull an, vgl. Brattne 1973, S. 93.

${ }^{76}$ Hvidt 1971, S. 362. Diese Linie war besonders für Schweden interessant, da es von Schweden aus vor 1915 keine Direktverbindung nach Amerika gab. Schon im Gründungsjahr 1869 sollen von ca. 12100 Passagieren des Baltischen Lloyd zwei Drittel schwedische Emigranten gewesen sein.

${ }^{77}$ Siehe Nilsson 1970, S. 267. Diese Verbindung wurde auch vielfach von Norwegern genutzt, da die norwegische Direktverbindung nach Amerika bereits 1876 wieder eingestellt worden war.

${ }^{78}$ Die Auflistung der finnischen Auswanderer über Kopenhagen ist aus dänischen Passagierlisten im 'Danske Utvandrerarkiv' in Aalborg, Dänemark erstellt woren. Es wurden jedoch nicht
} 
hingegen die Thingvalla Line möglicherweise schon einen Großteil der registrierten Auswanderer befördert hat ${ }^{79}$, wobei insgesamt gesehen das finnische Auswanderungsaufkommen über Kopenhagen jedoch kaum ins Gewicht fiel.

In Anbetracht der umständlichen Reiseverbindungen für finnische Auswanderer stellt sich die Frage, ob die Etappenreise mit Zwischenstop in Schweden bzw. Dänemark nicht schon vor 1891 zu vermeiden gewesen wäre. Eine Überprüfung von Schiffsanzeigen in 15 Jahrgängen der in Oulu und Vaasa erschienenen Wochenzeitungen $\mathrm{Ou}$ lun Wiikko Sanomia und Wasabladet der Jahre 1864-1879 förderte eine bereits 1865 bestehende Dampfschiffahrtsverbindung von Vaasa nach Lübeck zutage. Demnach wurden auf dem Dampfer Pohjola am 3. und 29. September 1865 Passagiere und Frachtgut von Lübeck über Stockholm nach Pori und Vaasa transportiert ${ }^{80}$. Da es sich in der Anzeige um die Retourfahrt des finnischen Dampfers handelt, ist davon auszugehen, daß den ganzen Sommer über bereits Passagiere zwischen Finnland und Deutschland befördert worden sind und dementsprechend Zwischendeckseinrichtungen vorhanden gewesen sein müssen.

In den Jahren 1867-75 finden sich immer wieder Anzeigen über Dampfschiffe, die ausschließlich Frachtgut, in erster Linie Holz und Eisen, von Oulu, Vaasa und Turku nach Lübeck transportieren ${ }^{81}$. Im Winter 1875 wird dann über den finnischen Dampfer Fennia berichtet, der von Hull kommend vor dem Hafen von Hanko im Treibeis steckenblieb $^{82}$. Die Fennia verkehrte bereits ab 1874 regelmäßig von Vaasa nach Hull und wurde von der finnischen Reederei Vaasa-Nordsee Dampfschiffahrts $A G$ unterhalten $^{83}$. Im Sommer 1876 wiederum fallen zahlreiche Anzeigen auf, die für Passagiere und Frachtgut der Fennia warben. Allein in der einmonatigen Zeitspanne vom 19.5. bis zum 15.6.1876 wurden drei Abfahrten der 'Fennia' ab Vaasa bekanntgegeben. Im gleichen Jahr erschienen noch zwei Anzeigen des Dampfers Pehr Brahe, der Passagiere und

die Reiserouten ab Kopenhagen, sondern lediglich die Zielhäfen in Amerika und Kanada vermerkt.

${ }^{79}$ Immerhin zählt der Zeitzeuge Järnefelt (1899, S. 36) die Thingvalla Line zu einer der beliebtesten Schiffahrtsgesellschaften.

${ }^{80}$ Wasabladet vom 28.10.1865.

${ }^{81}$ Dieser Frachtverkehr per Dampfschiff war bereits in den 1850er Jahren eingerichtet worden und verband die Städte Viborg, Helsinki, Turku und Lübeck, vgl. Kaukiainen 1980, S. 472.

${ }^{82}$ Wasabladet vom 31.12.1875.

${ }^{83}$ Holmio 1967, S. 101; Engelberg 1944, S. 29. 
Frachtgut von Vaasa über Turku nach Lübeck transportierte. Im Jahr 1879 verkehrte der Dampfer dann ab Oulu über Vaasa und Turku nach Lübeck ${ }^{84}$.

Dieser zufälligen Auswertung von Schiffsanzeigen zufolge gab es bereits 1865 zumindest eine Direktverbindung für Auswanderungswillige von Vaasa nach Lübeck ohne Zwischenetappen in Schweden oder Dänemark. Seit 1874 konnte die Überfahrt dann auch von Finnland nach England ohne Umsteigen in Schweden angetreten werden.

Der geringe Bekanntheitsgrad dieser gradlinigen Verbindungen läßt die Vermutung aufkommen, daß die genannten Zeitungen nur eine geringe Rezeption erfahren hätten, was jedoch anhand von Untersuchungen über die Verbreitung der Zeitungen widerlegt werden $\mathrm{kann}^{85}$. Dennoch liegt die Vermutung nahe, daß sie weniger von der einfachen Landbevölkerung gelesen wurden als vielmehr von Vertretern des Bildungsbürgertums. Doch ungeachtet der Größe der Leserschaft scheinen vor allem zwei Faktoren auf die Entscheidung für eine bestimmte Reiseroute Einfluß gehabt zu haben: Zum einen dürften die Erfahrungsberichte zurückgekehrter Auswanderer eine große Bedeutung gehabt haben Zum anderen haben Auswandererbriefe die allgemeinen Kenntnisse über potentielle Reiserouten und Agententätigkeiten erweitert.. Die Agenten boten den Auswanderern nämlich durch einen organisierten und betreuten Reiseablauf ein gewisses $\mathrm{Maß}$ an Sicherheit, den gewünschten Zielort in Amerika auch tatsächlich zu erreichen. Obwohl sich in den Erfahrungsberichten immer wieder Klagen über nicht eingehaltene Versprechungen der Agenten finden, betonen doch alle Auswanderer den Vorteil der sprachkundigen Reisebegleiter.

Wie bereits dargestellt, tauchen schon in den 1870er Jahren vereinzelte Anzeigen von schwedischen Agenten in finnischen Zeitungen auf ${ }^{86}$. Ihre Tätigkeit in Finnland beschränkte sich jedoch lediglich auf die Informationsverbreitung und Reservierung von Schiffspassagen ${ }^{87}$. Nachdem 1886 ein Unteragent der schwedischen Inman LineVertretung die erste finnische Agentur in Vaasa eröffnet hatte, war der Fahrkartenkauf auch in Finnland möglich geworden. Es folgten bald weitere Neugründungen, die in den meisten Fällen von schwedischen Agenturen initiiert wurden.

\footnotetext{
${ }^{84}$ Wasabladet vom 11.3.1876 und 17.5.1876; Oulun Wiikko Sanomia vom 12.7.1879.

${ }^{85}$ Tommila 1988b, S. 191f. und S. 222f.; Landgren 1988, S. 286-288.

${ }^{86}$ Die Ausdehnung der schwedischen Agententätigkeit in Finnland ist von Kero (1974, S. 131169) untersucht worden.

${ }^{87}$ Wasabladet vom 9.5.1883.
} 
Ähnlich wie in Schweden erweiterten die finnischen Agenten innnerhalb kurzer Zeit ihren regionalen Aktionsradius und unterhielten bald ein dichtes Netz an Agenturbüros in den größeren Städten des Landes. Im Auswanderungskerngebiet warben dann ihre Mitarbeiter bzw. Unteragenten direkt vor Ort, d.h. in den Heimatgemeinden der Auswanderungswilligen, ihre Kunden $\mathrm{an}^{88}$. Sie brachten vor allem Flugblätter mit Fahrplan- und Preisangaben in Umlauf und inserierten in den regionalen Wochenzeitungen. Ab 1889 wurden dann so viele neue Agenturen gegründet, daß die Konkurrenz unter den einzelnen Agenten ein bis dahin einzigartiges Ausmaß annahm. Vor allem die Spaltung der Agenten in zwei Lager, in die Vertreter der englischen Reedereien sowie die Repräsentanten der deutschen Gesellschaften, kulminierte um 1890 in einen regelrechten Kampf um die finnische Auswandererkundschaft, den die Agenten der HAPAG und des Norddeutschen Lloyd zwar kurzzeitig gewannen, der sie jedoch langfristig aus dem finnischen Agentengeschäft ausschlo $\beta^{89}$.

Das Jahr 1891 markierte einen Wendepunkt in der finnischen Agententätigkeit. Die Tatsache, daß bis 1890 allein in Hanko zwölf transatlantische Reedereien durch Agenten vertreten waren, erleichterte die vertraglich festgelegte Kooperation der Finnischen Dampfschiffahrtsgesellschaft AG mit den führenden englischen Reedereien. Bereits im Herbst 1891 konnten die Auswanderer kombinierte Fahrkarten für die Direktverbindung Hanko - Hull und für die Atlantiküberquerung von Liverpool aus für eine von zehn englischen Reedereien kaufen. Für diejenigen Agenten, die fortan nicht mit der Finnischen Dampfschiffahrtsgesellschafts $A G$ zusammenarbeiteten, hatte die neueingerichtete Direktverbindung meist die Geschäftsaufgabe zur Folge. Einigen hartnäckigen Vertretern gelang es noch bis 1894, weiterhin Finnen über Schweden nach England oder Deutschland zu lotsen, doch die Finnische Dampfschiffahrtsgesellschafts AG erreichte bald die uneingeschränkte Monopolstellung, nicht zuletzt aufgrund des Einsatzes von zwei Eisbrechern, welche die regelmäßige Überfahrt erstmals auch im Winter ermöglichten.

Fast zeitgleich mit der neuen Schiffsverbindung wurde auch die Eisenbahnstrecke von Oulu über Seinäjoki nach Hanko fertiggestellt ${ }^{90}$, wo die Auswanderer in einer

\footnotetext{
${ }^{88}$ So gab es z. B. in den ländlichen Gemeinden Kauhajoki, Ilmajoki und Ylistaro, aus denen einige Briefschreiber dieser Untersuchung stammten, Agenten der White Star Line. In den Verkehrsknotenpunkten Seinäjoki und Vaasa waren sogar alle großen Reedereien vertreten, vgl. Kero 1974, S. 138 und S. 144.

${ }^{89}$ Kero 1974, S. 135-148.

${ }^{90}$ Zum Ausbau der Infrastruktur in Finnland vor 1914 siehe Rasila 1982, S. 122-125.
} 
am Hafen gelegenen Reiseherberge, dem "Emigrantenhotel", übernachten konnten ${ }^{91}$. Dementsprechend entwickelte sich Hanko mit dem Beginn der finnischen Massenauswanderung zum führenden Einschiffungshafen, so daß die übrigen westfinnischen Hafenstädte für den Passagiertransport allmählich an Bedeutung verloren.

\subsubsection{Die Überfahrt und Ankunft auf der Grundlage von Erlebnisberichten}

In den dieser Untersuchung zugrundeliegenden 478 Briefen von 143 Briefschreibern aus den Provinzen Satakunta und Süd-Ostbottnien äußern sich 26 Personen direkt zu ihrer Atlantiküberquerung. In drei weiteren Briefen versuchen die Auswanderer, jeweils einen nahen Angehörigen für die Ausreise zu gewinnen, indem sie detaillierte Anweisungen zum Fahrkartenkauf einer bestimmten Reederei sowie zum Verhalten am Ankunftshafen in Amerika erteilen. Außerdem wurde noch die Reisebeschreibung von Oskari Tokoi aus dem Jahr 1891 berücksichtigt, da der Autor aus der Gemeinde Kannus in Mittel-Ostbottnien stammte. Aus dem gleichen Grund findet auch ein finnlandschwedischer, männlicher Auswanderer mit den Initialen A.K. Aufnahme in dieser Untersuchung, dessen mündlicher Erfahrungsbericht als einer der wenigen Überlebenden des Titanic-Untergangs im Jahr 1976 publiziert wurde ${ }^{92}$.

Bei drei weiteren Reiseberichten, die zugleich zu den ältesten Überfahrtsschilderungen finnischer Auswanderer zählen, ist nicht mit Sicherheit zu sagen, ob die Briefschreiber aus Satakunta oder Süd- Ostbottnien stammten; einzig im Fall des Adam Onkamo, eines Briefschreibers des Jahres 1868 aus Nord-Finnland, ist dies mit Sicherheit auszuschließen. Diese drei Amerika-Briefe wurden in den Wochenzeitungen KeskiSuomi (Mittelfinnland) und Oulun Wiikko Sanomia (Ouluer Wochennachrichten) veröffentlicht. Keski-Suomi wurde in Jyväskylä in Mittelfinnland herausgegeben, hatte jedoch eine liberale und amerikafreundlich gesinnte Redaktion, der es auch in Zensurzeiten gelang, relativ vorurteilsfrei über die Verhältnisse in Amerika zu berichten ${ }^{93}$. Oulun

\footnotetext{
${ }^{91}$ Niitemaa 1976, S. 81; siehe auch die Reisebeschreibung von Tokoi (1959, S. 24), der im Winter 1891 in der neu eingerichteten Gruppenunterkunft übernachtete.

${ }^{92}$ Hier Ahlbäck 1976, S. 37-40. Zu weiteren Auswanderern aus Munsala auf der Titanic siehe Neuman 1985. Zur Amerikaauswanderung aus Munsala allgemein vgl. Backman 1945.

${ }^{93}$ Die Zeitung hatte ab 1876 einen eigenen Amerikakorrespondenten, was zu dieser Zeit einmalig war. Alexander Leinonen, 1869 nach Minnesota ausgewandert, hatte zwischen 1871-76 bereits 17 Berichte an 'Oulun Wiikko Sanomia' geschickt. Von 1876-81 schrieb er dann weitere 54 Berichte für 'Keski Suomi'. Zu seiner Person vgl. Kero 1978a, S. 41-50 und 1997, S. 148151.
} 
Wiikko Sanomia wiederum war das Sprachrohr der gebildeten Bürgerschaft sowie das Anzeigenblatt einer lebhaften Handels- und Küstenstadt. In den 1860er Jahren erschien sie als einzige Zeitung in Nordfinnland ${ }^{94}$. Wie bereits dargestellt, brachen gerade in dieser Zeit die ersten Finnen - bis 1873 waren es weniger als tausend Personen pro Jahr vorwiegend aus dem Regierungsbezirk Oulu ${ }^{95}$ nach Übersee auf, wonach sie ihre Informationen über die möglichen Reiserouten gerade aus Oulun Wiikko Sanomia erhalten haben könnten.

Naturgemäß finden sich die Erlebnisberichte über den Reiseverlauf im ersten Brief wieder, den die Auswanderer aus Amerika nach Finnland schickten. Diese Briefe sind der Mehrzahl an nahe Verwandte wie Eltern oder Geschwister gerichtet. War das persönliche Verhältnis zwischen Briefschreiber und Adressat jedoch distanziert freundschaftlich, so finden sich kaum detaillierte Schilderungen über den Reiseverlauf, sondern eher oberflächliche Bemerkungen über den aktuellen Aufenthaltsort, das Wetter und das allgemeine Wohlbefinden. Zudem wurde diesen außerhalb des Familienkreises stehenden Personen auch gerade deshalb geschrieben, um im Antwortbrief Neuigkeiten über das soziale Leben im finnischen Heimat- oder Nachbarort zu erhalten. Erst im Zusammenhang mit der Anwerbung von potientiellen Auswanderungswilligen bzw. mit dem Versprechen, in Amerika gekaufte Fahrkarten, die sogenannten 'Prepaid Tickets', im nächsten Brief mitzuschicken, wurden häufig Ratschläge zur empfohlenen Reiseroute und zum Verhalten während des Reiseverlaufs erteilt, wie noch näher erläutert wird.

Die geringe Ausbeute von nur 26 Briefschreibern, die sich zu ihrer Reise äußern, bei insgesamt 143 Auswanderern, ist vor allem auf die Unvollständigkeit der einzelnen Briefserien zurückzuführen. Es sind selten alle Briefe eines Briefschreibers erhalten, häufig fehlen gerade die ältesten Briefe, die Aufschluß über den Reiseverlauf geben könnten. Ebenso kann der Zufall in einigen Fällen gerade die Briefe den Sammlungen zugetragen haben, in denen die Auswanderer nicht an nahe Verwandte, sondern eher an Bekannte geschrieben haben. Andere Auswanderer wiederum verspürten kein Bedürfnis, über ihre Reise zu berichten, sondern gingen nach den einleitenden Grußworten gleich zu einem Zustandsbericht ihrer aktuellen Lebensumstände über.

\footnotetext{
${ }^{94}$ Tommila 1988b, S. 191f. und S. 222f.

${ }^{95}$ Die Grenzen des Regierungsbezirks Lappland, der nördlich an den Regierungsbezirk Oulu angrenzt, wurden erst 1938 festgelegt. Zuvor dehnte sich der Regierungsbezirk Oulu bis an die norwegische Grenze aus, vgl. Karte 1a im Anhang: Geographische Aufteilung Finnlands nach Regierungsbezirken.
} 
Die hier zugrundeliegenden Reiseberichte geben vor allem Auskunft über die Reiseroute und -dauer, über die Betreuung der Passagiere an Bord und an Land durch das Schiffspersonal bzw. die Unteragenten der einzelnen Reedereien sowie die Ankunft am Anlegehafen und die damit verbundenen Einreiseformalitäten.

Der älteste bislang bekannte Originalbrief eines finnischen Auswandererpioniers, der zugleich eine Reiseschilderung des Jahres 1866 liefert, ist auf den 2.3.1868 datiert und wurde am 30.5.1868 in Oulun Wiikko Sanomia veröffentlicht ${ }^{96}$. Bei dieser Art von in Wochenzeitungen veröffentlichten Amerika-Briefen ist es aus heutiger Sicht schwer zu ermessen, inwieweit der abgedruckte Text dem Originalbrief entspricht. Eine Manipulation durch die Zeitungsredaktion ist in der Regel nicht auszuschließen, obwohl sie im vorliegenden Fall als wenig wahrscheinlich erscheint ${ }^{97}$. In diesem Brief beschrieb der noch von den Hungerjahren gekennzeichnete Auswanderer Adam Onkamo seinem Bruder im nordfinnischen Kuolajärvi indirekt den eigenen Reiseverlauf, indem er ihn aufforderte, über folgende Route auszuwandern:

"Du mußt zuerst nach Haparanda fahren, von dort weiter mit dem Dampfschiff nach Stockholm, dann mit der Eisenbahn nach Göteborg, und dort kaufst Du eine Fahrkarte nach New York in Amerika. Dorthin [nach New York] gelangst Du über England, von Hull nach Liverpool mit der Eisenbahn. Und von Göteborg aus hast Du freies Kost über den Atlantik bis nach New York. In New York kaufst Du dann in dem ersten Raum, in den sie Dich führen werden, eine Fahrkarte nach St. Paul, der Hauptstadt Minnesotas."

Aufgrund der zu dieser Zeit noch fehlenden Eisenbahnverbindungen innerhalb Finnlands traten die Pioniere unter den finnischen Auswanderern, die nicht aus Nordnorwegen über Trondheim aufbrachen, die Ausreise über Haparanda oder Tornio an. Dies hatte eine längere Reisedauer zur Folge, als sie gegen Ende des 19. Jahrhunderts üblich war. Seine gesamte Reisezeit gibt Adam Onkamo mit neun Wochen an, wovon er 19 Tage auf dem Atlantik zugebracht habe. Diese Überfahrtsdauer lag über der durch-

\footnotetext{
${ }^{96}$ Adam Onkamo (Ongamo) Brief hier entnommen aus Kero 1985, S. 15-18. Der Auswanderer war bereits 1866 nach Red Wing, in Minnesota, gereist und siedelte später in Kingston. Er galt als Mitbegründer einer der ersten finnischen Siedlungen auf amerikanischem Boden, vgl. Ilmonen 1923, Bd. 2, S. 166.

${ }^{97}$ Die Zeitungsredaktion hatte dem Brief vom 2.3.1868 eine kurze Notiz vorangestellt, worin betont wird, daß der Briefabdruck nicht als Aufforderung zur Auswanderung zu verstehen sei.
} 
schnittlichen Fahrtzeit von 10 bis 14 Tagen für die Atlantiküberquerung von Liverpool nach New York ${ }^{98}$, was zudem auch der Frühphase der Passagierdampfschiffahrt, d.h. den technisch noch nicht ausgereiften Antriebsmaschinen der frühen Dampfsegler, zugeschrieben werden kann.

Allerdings wird die Reisedauer der etwas kürzeren Entfernung von Liverpool nach Québec 1871 in dem bereits erwähnten Werbeprospekt des norwegischen Agenten der Allan Line mit neuen bis elf Tagen angegeben ${ }^{99}$. Demnach war auch die Größe der eingesetzten Dampfschiffe bzw. die Wahl der Reederei ausschlaggegend für die Dauer der Reise ${ }^{100}$.

In den zwei weiteren, in der Zeitung Keski Suomi abgedruckten Briefen ohne Namensangaben der Einsender nutzte der eine Auswanderer die zwölftägige Verbindung von Le Havre nach New York, vermutlich mit der Gesellschaft Compagnie Générale Transatlantique. Der andere Emigrant beschrieb 1880 detailliert die allgemein übliche Reiseroute über Stockholm und Göteborg nach Hull, von wo aus er in zehn Tagen den Atlantik überquerte ${ }^{101}$.

Gegen Ende des Jahrhunderts reduzierte sich die Überfahrtsdauer dann auf sieben bis neun Tage ${ }^{102}$, nicht zuletzt durch den Einsatz der mit Dampfturbinen angetriebenen Schnelldampfer, die zuerst von den marktführenden Reedereien Cunard, White Star und Inman Line sowie vom Norddeutschen Lloyd eingesetzt wurden ${ }^{103}$.

\footnotetext{
${ }^{98}$ Norman/Runblom (1988, S. 115) geben als Überfahrtsdauer von Liverpool nach New York weniger als 14 Tage an. Auch Jones (1960, S. 185) und Taylor (1971, S. 151) gehen von Zeitangaben bei 10-12 Tagen aus. Zum Vergleich: Während des Zeitalters der Segelschiffahrt betrug die Überfahrtsdauer noch durchschnittlich 6-7 Wochen, in einigen Fällen sogar drei Monate, vgl. Semmingsen 1975, S. 52; Assion 1985b, S. 139.

${ }^{99}$ Kero 1969b, S. 7-16.

${ }^{100}$ Michael Höglund, ein schwedischsprachiger Auswanderer betont in seinem Lebensbericht, daß er 1892 mit einem alten Schiff der Guion Line gefahren sei, wobei die Überfahrt von Liverpool nach New York elf Tage gedauert habe, vgl. Myhrman 1974, Bd. 3, S. 16. Die Guion Line war eine der kleineren englischen Reedereien.

${ }^{101}$ Der erste Brief ist auf den 26.5.1876 datiert und stammt aus New York, er wurde am 17. 6. 1876 in 'Keski Suomi' abgedruckt. Der zweite Brief wurde in zwei Teilen publiziert und stammt aus Calumet, einem Bergwerksort in Nord-Michigan, der schon früh von finnischen Auswanderern besiedelt wurde. Der erste Teil ist auf den 9.10.1880 datiert und in 'Keski Suomi' vom 13.11.1880 abgedruckt. Der zweite Teil trägt das Datum: 2.1.1881, veröffentlicht in 'Keski Suomi' am 5.2.1881.

${ }^{102}$ Bickelmann 1982, S. 331. Zwei finnische Auswanderer berichten von siebentägigen Überfahrten: Jalmari Ikala [29.4.1904], TYYH:S:m:Satakunta:KOK:VIII/3; Anselmi Neva [6.7.1906], TYYH:S:m: Satakunta:MER: XLVI/1.

${ }^{103}$ Hier wären z. B. die 'City of Paris' der Inman Line (1889), der White Star Liner 'Oceanic' (1899) und vor der Erfindung des Dieselmotors der alle Rekorde brechende Cunard Liner 'Mauretania' (1907) zu nennen, vgl. Taylor, 1971, S. 150f.; Jones 1976, S. 45. Der Stolz des
} 
Die gesamte Reisedauer von Hanko zum amerikanischen oder kanadischen Zielort im Landesinneren variierte nun im Durchschnitt zwischen 17 und 21 Tagen. Die Brüder Juho und Isak Kuusisto benötigten in den Jahren 1902 und 1905 jeweils 17 Tage, um von Hanko nach Cloquet in Minnesota bzw. nach Warren in Ohio zu gelangen. Auch Anselmi Neva und Kalle Pykälä reisten 1906 bzw. 1910 in 18 Tagen von Hanko nach Negaunee in Nord-Michigan und Boston ${ }^{104}$. Da viele Auswanderer jedoch bereits tagelang am Hafen von Hanko auf ihre Einschiffung warten mußten, verlängerte sich die gesamte Reisezeit nicht selten auf bis zu vier Wochen ${ }^{105}$.

Die erste Etappe wurde in der Regel in fünf Tagen mit einem Schiff der Finnischen Dampfschiffahrts $A G$ bestritten ${ }^{106}$. Die anschließende Zugfahrt von Hull nach Liverpool fiel mit fünf Stunden kaum ins Gewicht. In Liverpool waren dann jedoch Wartezeiten von bis zu vier Tagen keine Seltenheit ${ }^{107}$. Dabei hatten die Auswanderer genügend Gelegenheit, das rege Treiben in den Straßen Liverpools zu beobachten: Gleich drei Auswanderer berichten von den Pferde-Straßenbahnen "mit gläsernen Wänden"108, von den vielen Tausend Auswanderern, die auch auf ihre Einschiffung warteten, und von den schmutzigen Straßen mit betrunkenen Männern und Frauen in verwahrlostem Zustand $^{109}$.

Wie bereits dargestellt, verbrachten die Auswanderer bis zu neun Tage auf den englischen Ozeanlinern und setzten ihre Reise dann per Eisenbahn, in den meisten Fäl-

Norddeutschen Lloyd waren die Vierschornsteindampfer 'Kronprinz Wilhelm' und 'Kaiser Wilhelm II.', beide um 1900 erbaut, vgl. Bretting 1992, S. 87.

${ }^{104}$ Juho Kuusisto [20.5.1902], TYYH:S:m:Satakunta:HIN:II/1; Isak Kuusisto [25.6.1905],

TYYH:S:m: Satakunta:HIN:III/2; Anselmi Neva [6.7.1906], TYYH:S:m:Satakuta:MER:XLVI/1; Kalle Pykälä [26.4.1910], TYYH:S:m:Satakunta:TYRV:V/1. Siehe auch Engelberg 1944, S. 31.

${ }^{105}$ Als Beispiel sei hier Otto Malinen genannt, der im Sommer 1911 vier Wochen benötigte, um von Karvia in Satakunta nach Sudbury in Ontario zu gelangen, da er jeweils vier Tage in Hanko und Liverpool warten mußte (Brief vom 24.7.1911: TYYH:S:m:Satakunta:KAR:XLII/1. Kustaa Tienhaara wiederum wartete freiwillig eine Woche in Liverpool, um mit dem White Star Liner 'Oceanic' zu fahren (Brief vom 11.3.1901: Samml. Süd-Ostbottnien, unsigniert).

${ }^{106}$ Von Hanko nach Hull verkehrten die Schiffe 'Arcturus', 'Polaris', 'Astrea' und 'Urania', allesamt kleine Dampfschiffe, die für etwa 350-500 Passagiere ausgerüstet waren, vgl. Ahlbäck 1976, S. 13. Die Ozeandampfer konnten bis zu 2.000 Passagiere transportieren, vgl. Taylor 1971, S. 157.

${ }^{107}$ Matti Rantaaho [1.5.1911], Samml. Süd-Ostbottnien, Sig.Nr. 1161; Otto Malinen [24.7.1911], TYYH: S:m: Satakunta:KAR:XLII/1.

${ }^{108}$ Jalmari Ikala [29.4.1904], TYYH:S:m:Satakunta: KOK:VIII/3.; Juho Kuusisto [20.5.1902], TYYH:S:m: Satakunta:HIN:II/1; Nestori Kuusisto [23.5.1906], TYYH:S:m:

Satakunta:HIN:IV/1.

${ }^{109}$ Jalmari Ikala [29.4.1904], TYYH:S:m: Satakunta: KOK:VIII/3.; Brief in 'Keski Suomi' in zwei Teilen, veröffentlicht am 13.11.1880 und 5.2.1881 
len über Chicago, einem Verkehrsknotenpunkt, nach Minnesota und Nord-Michigan fort. Drei Tage dauerte die Zugfahrt 1902 von Boston nach Cloquet in Minnesota bzw. 1903 von New York nach Michigamme in Michigan ${ }^{110}$. Lag das Ziel auf kanadischer Seite, wurden die Großen Seen per Dampfschiff überquert ${ }^{111}$. Doch auch weiter entfernte Staaten wurden erreicht; so benötigte beispielsweise Oskari Tokoi 1891 noch eine Woche, um von New York nach Wyoming zu gelangen. 1892 dauerte die Zugfahrt von New York nach Utah nur einen Tag weniger. Allerdings erreichte Anna Ylismäki zwei Jahrzehnte später, im Jahr 1911, Colorado bereits in vier Tagen von der Ostküste aus. Und 1905 durchquerte August Jalo den Kontinent in sechs Tagen, nämlich von New York nach Aberdeen in Washington ${ }^{112}$.

Der Aufbruch von Liverpool aus gestaltete sich für die Auswanderer zum Höhepunkt ihrer Reise. Die meisten reisten als Zwischendeckspassagiere, der sogenannten dritten Klasse. Nur ein Briefschreiber hatte auf einem Schiff der White Star Line die zweite Klasse, eine Kabinenkategorie, gebucht, was jedoch eine Ausnahme darstellte. Die Einrichtung eines durchgängigen Zwischendecks, zwischen Oberdeck und Laderaum gelegen, war bereits auf den meisten Segelschiffen üblich gewesen. In den Dampfschiffen waren die Zwischendecks mit langen Reihen von dreistöckigen eisernen Bettgestellen versehen, die häufig so wenig Platz boten, daß sich die Passagiere in den unteren Betten nicht aufsetzen konnten. Gegen Ende des 19. Jahrhunderts standen die Reedereien ihren Passagieren dann auch einen minimalen Komfort in Form von hölzernen Tischen und Bänken zu, damit die Mahlzeiten nicht mehr im Stehen oder an der Bettstelle eingenommen werden mußten. Das Zwischendeck wurde nur zum Essen und Schlafen genutzt ${ }^{113}$, bei gutem Wetter hielten sich die Auswanderer tagsüber auf dem Oberdeck auf. Von den Kabinenpassagieren, denen eigene Salons und Restaurants zur Verfügung standen, wurden sie jedoch separiert.

Auf den großen Ozeandampfern, wo die finnischen Auswanderer in der Masse der übrigen Skandinavier, Engländer und vor allem Iren untergingen, ertönte auf dem

\footnotetext{
${ }^{110}$ Juho Kuusisto [20.5.1902], TYYH:S:m:Satakunta:HIN:II/1; Frans Lendén [11.4.1903], TYYH:S:m: Satakunta:H-Ti:III/1.

${ }^{111}$ Aleksi Koskela [7.7.1907], Samml. Süd-Ostbottnien, Sig.Nr. 1480.

${ }^{112}$ Tokoi 1959, S. 29; Anna Ylismäki [14.7.1911], TYYH:S:m:Satakunta:LOIM:XVI/1; August Jalo [5.7.1905], TYYH:S:m:Satakunta:HIN:X/1; Lebensbericht von Michael Höglund, vgl. Myhrman 1974, Bd. 3, S. 16.

${ }^{113}$ Helmi Nytery, Brief ohne genaue Datumsangabe von 1903: TYYH:S:m: Satakunta:HIN:XXVII/1.
} 
Oberdeck häufig auch Musik und Gesang. Salomon Haanpää berichtete in melancholischer Stimmung während seiner Atlantiküberquerung um 1900 folgendes ${ }^{114}$ :

"Dort hinten sitzen irische Frauen mit kleinen Kindern auf dem Schoß, so alt wie unsere Irja. [...] Männer und Frauen tanzen auf dem Deck. Sie haben ihre eigenen Musikanten, und fast alle Frauen können ein Instrument spielen. Ja - wenn jemand aus so stillen Verhältnissen wie unsereins stammt, verwundert dieses Treiben der großen Welt doch sehr, und schon oft habe ich mir gedacht, wenn ich denn nur bald wieder in die vertraute Ruhe zurückkehren könnte, um dann nie wieder die Heimat zu verlassen."

Den singenden und tanzenden Iren mag es ähnlich ergangen sein: gemeinsames Musizieren diente nicht nur dem bloßen Zeitvertreib, sondern auch der kollektiven Verdrängung von Heimweh und den ersten Zweifeln am Auswanderungsentschlu $\beta^{115}$. Von Musik und Tanz an Bord berichten auch 1880 der namentlich nicht genannte Auswanderer, dessen Reiseerlebnisse in Keski Suomi publiziert wurden, sowie Jalmari Ikala und eine finnlandschwedische Auswanderin von den Ålandinseln, beide 1904 ausgewan$\operatorname{dert}^{116}$. Es bleibt jedoch unklar, ob es sich bei den Musikanten um finnische Auswanderer handelte oder aber Emigranten einer anderen Nationalität. Wohl aber findet sich ein Beleg über eine Gruppe von lautstark singenden Finnen, die 1891 mit dem Zug zum finnischen Einschiffungshafen unterwegs war ${ }^{117}$.

Am häufigsten finden sich in den Briefen Bemerkungen zu den Wetterverhältnissen auf dem Atlantik. Ein Sturm war ein gefürchtetes und beängstigendes Erlebnis. Die Schiffsluken mußten geschlossen werden, so daß die Zwischendeckspassagiere nicht selten seekrank in ihrer engen Koje lagen und bereits an ihre letzte Reise glaubten.

Das einzige dokumentierte Schiffsunglück, bei dem auch finnische Amerikaauswander umkamen, ist der legendäre Untergang des White Star Liners Titanic am 14.4.1912, zu der Zeit das größte Schiff der Welt. An Bord der Titanic auf dem Weg von Southampton nach New York befanden sich etwa 2210 Menschen, darunter min-

\footnotetext{
${ }^{114}$ Salomon Haanpää, Brief undatiert, verm.um 1900; Samml. Süd-Ostbottnien, Sig. Nr. 1235/8. ${ }^{115}$ Zur emotionalen Verarbeitung des Abschiedes siehe Assion 1985b, S. 139.

${ }^{116}$ Brief aus 'Keski Suomi' in zwei Teilen, veröffentlicht am 13.11.1880 und 5.2.1881; Jalmari Ikala [29.4.1904], TYYH:S:m:Satakunta: KOK:VIII/3. Die finnlandschwedische Auswanderin mit den Initialen J.G. wurde 1971 in Norwood, Mass. interviewt, siehe Ahlbäck 1976, S. 31-33. ${ }^{117}$ Kero 1974, S. 67. Diese Begebenheit wurde ursprünglich in der finnischamerikanischen Zeitung 'Työmies' (Der Arbeiter) vom 29.7.1891 kommentiert.
} 
destens 63 Finnen, 20 von ihnen fanden Platz in einem der Rettungsboote und überleb$\operatorname{ten}^{118}$. Einer der geretteten Auswanderer, der aus der schwedischsprachigen Küstengemeinde Munsala in Süd-Ostbottnien stammte, wurde 1971 in Tacoma, Washington zu diesem Ereignis interviewt ${ }^{119}$ :

"Ich bin in Vexala geboren. Und zog nach Peltmo, Munsala.[...] But course ich habe Finnland am 29 of march in 1912 verlassen. And then. Wollt ihr etwas über die Titanic wissen?

Ich hatte drei Kameraden. Wir mußten auf ein anderes Schiff warten, when wir to England in Southampton kamen. And wir mußten eine ganze Woche warten. Ich hatte ein Ticket für ein anderes Schiff, the Swedish American Line. Ja. And then mußte sich acht Dollar mehr bezahlen, um mit der Titanic zu fahren. And wir verließen Southampton in England am 10 of april. And everything seemed to be all right. Es war ein großes Schiff, diese Titanic. [...] See, ich war nur seventeen years. Und dann war ich seekrank. Ich hatte mich ins Bett gelegt. And then kam eine Art von "Gong", als das Schiff an den Eisberg prallte. And I thought may be, ich dachte es sei an der Zeit essen zu gehen. And trug noch meine Kleider. Als ich auf das Deck kam, waren dort Menschen all over, crying and praying. And a young man from Munsala, er sagte:" Oh, wir gehen unter. Ich weiß es genau, das Schiff sinkt." "Oh" I said "no, es kann nicht sinken. Wir können an Deck stehen bleiben und es kann nicht tief genug sinken." You see, wie wenig ich verstand. Es gab acht storeys, die konnten nicht sinken, glaubte ich. Und dann sagte er: "Ich versuche, die anderen beiden zu finden" und "ich hoffe, daß meine Mutter jetzt für mich betet". And dann traf ich ein anderes Mädchen aus Schweden. Sie hatte zwei Freunde dabei. And die wollten, daß wir nach oben gingen, dort gab es Rettungsboote. But the steps were all closed. Ich war in der dritten Klasse, die billigste, die ich finden konnte. Da waren emergency-steps. And we climed up. Wir hatten Rettungswesten an. And das war hart. Dann kam ein Mann and helped me over the railing. And then he pointed to the lifeboats. But die anderen waren noch da unten. Course, sie wußten von

\footnotetext{
${ }^{118}$ Wetterholm hat 1988 eine detaillierte Untersuchung über den Verbleib der skandinavischen Passagiere bei Schiffsuntergang vorgelegt und listet im Anhang namentlich alle skandinavischen Passagiere, basierend auf der Passagierliste der 'Titanic', auf. Die Angaben der Überlebenden sind jedoch unvollständig geblieben, es fehlt z.B. der Name des hier zitierten Finnen aus Munsala. Eine Ergänzungliste mit 19 weiteren Namen von finnischen Überlebenden liefert der amerikanische Stammbaumforscher Timothy Laitila (1998, S. 27f.). Zum Titanic-Untergang siehe auch Neuman 1985 und Björkfors 1998.

${ }^{119}$ Zitat aus Ahlbäck 1976, S. 37-40.
} 
dem Unglück. But, sie hatten keine große Chance mehr. Die Gitter waren geschlossen, like you close a door. But das Mädchen und ich und diese Männer, sie zogen mich und sie to the emergencystep. Just small that we stepped on to get up. And die anderen, als I looked down, da sind sie just underneath. And du konntest hören how they prayed. [...]

And cause the boat struck the 14 of april. Which was my birthday. Und es versank in der Nacht um halb zwei am Morgen des fünfzehnten. And I didn't want to go, ich wollte nicht in das kleine Rettungsboot steigen. But I had to gehorchen, denen, die die Anweisungen gaben, die eine andere Mütze trugen. So gingen das Mädchen und ich, wir gingen gemeinsam. And es waren fünf schwedische Jungen im selben Boot, die mußten rudern. And die Leute hatten Nachthemden an. And viele Kinder saßen auf dem Boden.[...] And dann ging es unter. Ich konnte erst ein klares light sehen. And then war es wie ein Topf, der überkocht. You know. And then it was so still. Because alle die Menschen, die noch am Deck gestanden hatten. Für die es keine Rettungsboote mehr gab. Sie waren gone. [...] Es war, als wenn ich versteinert gewesen wäre.

And als das Schiff verschwunden war. Die Menschen kamen hoch auf lifebelts. And before they froze to death, there was such a screaming and noise that I put my fingers into my ears. I couldn't stand it. It was just a screaming. [...] And we didn't expect to be rescued. But I wasn't afraid. And then um fünf Uhr morgens sahen wir ein light. [...] And then waren wir gerettet etwa gegen sieben Uhr morgens ${ }^{120}$. Das Schiff stand still. Es konnte nicht too close to the icebergs kommen.[...] And als wir an Bord kamen da sah ich erst was geschehen war. Ich sah people and chairs and things floating around. And ich sah viele, viele, die ihre Bekannten verloren hatten. And one Mädchen from Danmark. Ich konnte ein wenig Norwegisch und Dänisch verstehen. Sie hatte ihren Geliebten verloren. Sie hatte ihren Verstand verloren. In New York wurde sie wieder zurückgeschickt. Es wären da noch viele, viele Dinge, die I can tell you. Wenn ich denn nur richtig gutes Schwedisch sprechen könnte."

In den Auswandererbriefen dieser Untersuchung finden sich keine Kommentare zu dem Titanic-Untergang. Nur in einem Brief fragt sich Ellen Luoma am 4.6.1912 aus

\footnotetext{
${ }^{120}$ Die Rettungsboote wurden von der 'Carpathia', einem Schiff der Cunard Line, gesichtet und die Überlebenden an Bord genommen, vgl. Wetterholm 1988, S. 117-134.
} 
Glassport, Pennsylvanien, aus welchem Grund der Briefwechsel mit der Adressatin in Ikaalinen, Satakunta, ins Stocken gekommen war ${ }^{121}$ :

"Wie kann es sein, vielleicht sind unsere Briefe mit dem versunkenen Schiff verloren gegangen oder sind sie in anderer Weise abhanden gekommen."

Das tragische Ereignis wurde sowohl in Finnland als auch in Amerika von einer breiten Öffentlichkeit rezipiert, wenngleich für die Auswanderer eine größere Wahrscheinlichkeit bestand, bei einem Grubenunfall in einem amerikanischen Bergwerk das Leben zu verlieren als auf dem Atlantik umzukommen.

Die Verpflegung seitens der Reedereien an Bord der Schiffe und an Land ist ein weiteres Thema, zu dem sich viele Briefschreiber äußerten. Da die meisten von ihnen, mit Ausnahme von fünf Personen, die Direktverbindung von Hanko nach Hull genutzt hatten, wird vor allem der Service der Finnischen Dampfschiffahrtsgesellschafts AG mit dem diverser englischer Reedereien verglichen. Dabei wird fast einstimmig die Unterbringung und Verpflegung auf den kleinen Dampfschiffen von Hanko nach Hull beklagt $^{122}$. Die angebotenen Speisen, in erster Linie Kartoffeln, Hering und trockenes Brot, seien unappetitlich zubereitet oder bereits verdorben und vor allem viel zu knapp bemessen gewesen ${ }^{123}$. Die meisten Auswanderer führten schon vorsorglich eigenen Reiseproviant in Form von gesalzenem Fisch oder Fleisch, Käse sowie getrocknetem Brot und Butter mit sich.

Auch bei der Ausreise über Schweden vor 1891 sah der Reisebeginn kaum anders aus: Oskari Tokoi, der im Winter 1891 auf dem Frachtschiff Capella von Hanko nach Kopenhagen mit Anschluß nach Bremerhaven fuhr, erlebte überhaupt keine Beköstigung während der Ostseeüberquerung. Wie seine Mitreisenden hatte auch er sich bereits in Hanko mit Lebensmitteln eingedeckt und darüber hinaus eigenes Eßbesteck

\footnotetext{
${ }^{121}$ Ellen Luoma [4.6.1912], TYYH:S:m:Satakunta:IKA:LVII/4. Da die Cunard Line, die ursprünglich das Postmonopol für England besaß, später mit der White Star Line fusionierte, könnte die 'Titanic' tatsächlich Postsendungen an Bord gehabt haben, vgl. Hyde 1975, S. 191218 , bes. $213 \mathrm{f}$.

${ }^{122}$ Nur Isak Kuusisto ([25.6.1905], TYYH:S:m: Satakunta: HIN:III/2) äußerte sich 1905 zufrieden über die Beköstigung an Bord der 'Polaris', einem Schiff der Finnischen Dampfschiffahrts AG. Dem Service an Bord des White Star Liners 'Baltic' stellte er hingegen ein Armutszeugnis aus.

${ }^{123}$ Juho Kuusisto [20.5.1902], TYYH:S:m:Satakunta:HIN:II/1; Helmi Nytery [1903], TYYH:S:m: Satakunta:HIN:XXVII/1; Julia Salmentausta berichtet in einem Interview von ihren Reiseerlebnissen des Jahres 1909, vgl. Kero 1974, S. 200.
} 
und Bettzeug besorgt, was bis gegen Ende der 1880er Jahre üblich war. Besonders eindrucksvoll beschreibt ein namentlich nicht genannter Auswanderer aus Calumet in Nord-Michigan im Jahr 1880 die Verpflegung an Bord des Dampfers Rolly zwischen Göteborg und Hull ${ }^{124}$ :

"Nachdem wir auf offener See waren, sah ich die Leute auf das Oberdeck strömen mit Tellern und Bechern in der Hand. Auch ich hatte mir tags zuvor Eßgeschirr gekauft und folgte nun den anderen nach oben, wo ich zwei große Körbe gefüllt mit "Butterbroten" sah. Jeder durfte sich bedienen, doch für meinen Teil und den etlicher anderer blieben die Brote im Korb - sie waren über und über mit Butter beschmiert und zudem sehr schmutzig, da ein jeder sie drehte und wendete, daß es mir unmöglich erschien, Derartiges zu essen. Ein Stück weit vom Brotkorb entfernt sah ich einen Koch stehen mit einer Schöpfkelle in der Hand, der etwas aus einem Zinkgefäß schöpfte. Sie nannten es Kaffee, doch es war vielmehr eine ungenießbare Brühe, die niemand zu sich nehmen mochte, mit Ausnahme einiger ostbottnischer Frauen, die beinahe für die alle finnischen Auswanderer tranken. [...] Später durften wir erfahren, daß dieser Kaffee aus gerösteten Erbsen bestand. [...] Am folgenden Tag erhielten wir wieder diesen Kaffee mit Butterbroten sowie einen Erbseneintopf, außerdem Kekse. Die Kekse waren nicht schlecht, wenn es denn nur gelang, unter den ersten zu sein, bevor auch die Kekse be- schmutzt waren. [...] Ohne meinen eigenen Reiseproviant hätte mich der Hunger auf der dreitägigen Überfahrt von Göteborg nach Hull begleitet, um nicht zu sagen wie einen "Gefangenen bei Wasser und Brot".

Herrschte unter den Briefschreibern noch allgemeine Einigkeit über den schlechten Service an Bord der finnischen Schiffe, so unterscheiden sich die Erfahrungsberichte über die Beköstigung auf den diversen Ozeandampfern. Von denjenigen, die in ihren Briefen eine bestimmte Reedererei benennen, empfehlen zwei Personen die Dominion Line (1899 und 1902), zwei weitere die White Star Line (1901und undatierter Brief, ca. 1900), einer die Cunard Line (1893), einer die American Line (1899) und der bereits zitierte Auswanderer die National Line (1880). Vier andere Briefschreiber hingegen raten von folgenden Gesellschaften ab: Beaver Line (1902), American Line (1905), White

\footnotetext{
${ }^{124}$ Brief aus 'Keski Suomi' in zwei Teilen, veröffentlicht am 13.11.1880 und 5.2.1881. Die in Anführungsstrichen gesetzten Begriffe sind bereits im Originaltext derart kenntlich gemacht.
} 
Star Line (1905 und 1912). In den meisten Fällen begründen die Auswanderer ihre Wertungen mit dem reichhaltigen und hygienisch zubereiteten Speiseangebot bzw. dem Gegenteil. Zwei weitere Auswanderer äußern sich auch zu den Zuständen auf Dampfern des Norddeutschen Llyod, der sogenannten 'Bremen Linie" ${ }^{, 25}$. Der eine von ihnen bestritt die Überfahrt im Winter 1891 und äußerte sich zufrieden über seine Schlafstätte. Die Beköstigung an Bord schilderte er nur kurz in neutralen Worten. Nur zwei Jahre später riet der andere Auswanderer einem Bekannten eindringlich von der Ausreise über Bremerhaven ab, da es an Bord weder ausreichend Nahrung noch Wasser gegeben habe. Eine andere Auswanderin wiederum zog die Konsequenz aus ihrer Reiseerfahrung, indem sie einer Freundin empfahl, auf dem finnischen Dampfer in der zweiten Klasse, einer Kabinenkategorie, zu reisen und erst ab Liverpool das Zwischendeck, die sogenannte dritte Klasse, zu buchen ${ }^{126}$.

Dieses Stimmungsbild ist nicht repräsentativ für die finnischen Auswanderer, doch es verdeutlicht die unterschiedlichen Wahrnehmungen von Menschen, die fast alle aus kleinbäuerlichen Lebensverhältnissen einer strukturell relativ gleichförmigen Agrarregion in Finnland stammten und innerhalb von zwei Jahrzehnten dieselbe Reiseroute nutzten.

Die Entscheidung, die Überfahrt mit einer bestimmten Reederei zu bestreiten, war jedoch nicht allein von den Erfahrungsberichten bereits ausgewanderter Geschwister und Freunde abhängig, sondern auch von der Tatsache, daß ein Drittel aller finnischen Auswanderer mit im voraus bezahlten Fahrkarten reiste, die sie einem Brief aus Amerika beilagen $^{127}$. Geschäftstüchtige finnische Auswanderer boten die Fahrkarten ihren Landleuten in amerikanischen Grubensiedlungen und Städten mit hohem Finnenaufkommen feil. Ein solcher Agent warb 1903 mit folgenden Worten ${ }^{128}$ :

"Fahrkarten nach Finnland und zurück.

Meine Mitbürger, denkt daran, wenn Ihr Eure Verwandten und Bekannten aus Finnland hierher holen wollt, so kauft die Fahrkarten am besten bei mir, denn ich ver-

\footnotetext{
${ }^{125}$ Tokoi 1959, S. 24-29; Heikki Mikkola [8.4.1893], TYYH:S:m:Satakunta: MER:XX/1; Brief auch bei Kero (1985, S. 50f.) abgedruckt.

${ }^{126}$ Aini Fredman [24.12.1909], Sammlung Süd-Ostbottnien, Sig. Nr. 1379.

${ }^{127}$ Nach Kero (1974, S. 174-195) sind im Zeitraum 1891-1914 durchschnittlichen $30 \%$ aller Finnen mit in voraus bezahlten Fahrkarten, den 'Prepaid Tickets', gereist. Siehe hierzu auch Jones 1976, S. 44.
} 
trete alle Linien. William Maki, Finnish Steamship \& Railroad Ticket Agent, Box 434, Ironwood, Michigan."

Auch in mindestens acht Briefen dieser Untersuchung haben 'Prepaid Tickets' beigelegen, wie die Käufer der Fahrkarten betonen. Andere Briefschreiber hingegen versprachen Geldscheine oder einen Wechsel zu schicken, der für den Fahrkartenkauf bestimmt sei. Diesen Briefen ging meist schon eine schriftliche Anwerbung voraus, worin der Briefschreiber versuchte, den Adressat für die Auswanderung zu gewinnen, sofern dies nicht zuvor zwischen den Briefpartnern abgesprochen war. So z. B. im Fall der jungverheirateten Eheleute Matti und Hilja Toopakka: 1899 wanderte er nach Worcester in Massachusetts aus und schrieb häufig seiner Frau nach Peräseinäjoki in Süd-Ostbottnien. Am 10.3.1900 schickte dann auch Hilja Toopakka den ersten Brief aus Worcester an ihre Eltern ${ }^{129}$.

In den Briefen, in denen Auswanderer nahe Angehörige oder Freunde anwarben, finden sich neben Beschreibungen des angeratenen Reiseverlaufs vor allem Anweisungen zum Verhalten bei der Einschiffung und im Ankunftshafen. Salomon Haanpää, der einem Freund in Süd-Ostbottnien eine Schiffsfahrkarte aus Virginia in Minnesota schickt, gibt folgende Instruktionen ${ }^{130}$ :

"Ich schreibe Dir jetzt hier, wie Du dich in Hanko und während der Überfahrt zu verhalten hast: Wenn Du Deine Fahrkarte vorzeigst und sie Dich fragen, wie alt Du bist, ob Du in Amerika Bekannte hast und wohin Du reist, dann sage ihnen: Ich habe einen Bruder mit dem Namen Salomon Haanpää. [...] Wenn sie Dich fragen, wieviel Geld Du hast, so antworte: 50 Mark ${ }^{131}$. Und diese Antworten, die Du dem Agenten in Hanko gibst, merke sie Dir gut, wenn sie dich am Hafen in Amerika wieder fragen. Dort untersuchen sie Dich auch. Doch sei mutig. Du darfst keine Angst haben, auch wenn sie

\footnotetext{
${ }^{128}$ Holmio 1967, S. 100; ursprünglich im 'Finnisch-Amerikanischen Kalender' des Jahres 1903 abgedruckt.

${ }^{129}$ Matti Toopakka [1.12.1899], Sig.Nr.1235/20; [8.1. 1900], Sig.Nr. 1235/1; [26.1.1900], Sig.Nr. 1235/13 und Hilja Toopakka [10.3.1900], Sig.Nr. 1243/2. Alle Briefe stammen aus der Sammlung Süd-Ostbottnien.

${ }^{130}$ Salomon Haanpää, Brief undatiert, vermutlich um 1900: Sammlung Süd-Ostbottnien, Sig.Nr. $1235 / 8$

${ }^{131}$ Über die Höhe des Geldbetrages, der bei der Einreise vorzuzeigen war, herrschte Uneinigkeit unter den Auswanderern: 1893 empfahl Heikki Mikkola ([8.4.1893], TYYH:S:m:Satakunta: MER:XX/1), 100 Mark mitzuführen, 1910 gab Ludvik Hälli ([17.8.1910], TYYH:S:m:Satakunta: KAR:LVI/1) den Betrag mit 125 Mark an.
} 
Dich fragen, darfst Du nicht erstaunt aussehen. Und vor allem darfst Du nicht einfach in die Stadt losziehen, denn dort hast Du dich schnell verlaufen und weißt nicht mehr zurück. [...] Wenn Du an Land gehst, mußt Du 50 Mark vorzeigen, sie werden Dich danach fragen. ",

Die im Brief angesprochene Gesundheitskontrolle wurde gegen Ende des 19. Jahrhunderts an allen größeren Landeplätzen der amerikanischen Ostküste eingerichtet. Häufig hatten die Schiffe bereits einige Seemeilen vor dem Zielhafen zu ankern, so daß Beamte und ein Arzt die Zustände auf dem Auswandererschiff inspizieren und außergewöhnliche Begebenheiten wie Todesfälle oder eine Seuchenkrankheit an Bord protokollieren konnten. Für den Fall einer Epidemie unterhielt die Stadt New York, bereits seit 1825 der führende Einwanderungshafen Amerikas, eine Quarantänestation sechs Seemeilen vor der Stadt gelegen. In der Regel wurden die Auswanderer jedoch zu den Landeplätzen am Hafen gebracht. Von 1855 bis 1892 diente ein ehemaliges Vergnügungslokal am Pier von New York als Einwanderungsdepot mit dem Namen 'Castle Garden'. Als das hölzerne Empfangsgebäude den Massen der Einwanderer nicht mehr gewachsen war, wurde ab 1892 eine der Stadt vorgelagerte Insel 'Ellis Island' als Registrierungs- und Durchgangsstation für Immigranten eingerichtet. Einer von sechs Einwanderungskommissaren der sogenannten 'Dillingham Kommission' beschreibt im Jahr 1870 die Abfertigungsprozedur in 'Castle Garden' mit folgenden Worten ${ }^{132}$ :

"After an examination of the luggage, it is checked, and the passengers, with their luggage, are transferred to the barges and tugs, and landed at the Castle Garden pier. On landing, the passengers are examined by a Medical Officer, to discover if any sick have passed the Health authorities at Quarantine, [...] and likewise to select all subject to special bonds under the law - as blind persons, crippels, lunatics, or any others who are likely to become a future charge. This examination being ended, the emigrants are directed into the Rotunda, a large-roofed circular space in the centre of the depot [...], to the registering department, where the names, nationality, former place of residence, and intended destination of the emigrants, with other particulars, are taken down, thus forming an interesting record for future reference. The passengers are then

${ }^{132}$ Kapp 1969 (1. Aufl. 1870), S. 105-124, Zitat von S. 112. Zu Castle Garden siehe Schmidt 1965, S. 336-339 u. S. 353; Assion 1987, S. 245-253. 
directed to the agents of the railroad companies, from whom they can procure tickets to all parts of the United States and Canada, without the risk of fraud."

Zwischendeckpassagiere wurden bereits ab 1855 an 'Castle Garden', das an einer Seite vom Wasser aus zugänglich war, angelandet und auf diese Weise dem Zugriff jeglicher Art von Betrügern entzogen ${ }^{133}$. Von den finnischen Briefeschreibern dieser Untersuchung durchliefen noch vier Personen vor 1892 die Einreiseformalitäten in 'Castle Garden'. Besonders eindrucksvoll schildert ein in Le Havre eingeschiffter finnischer Auswanderer die Ankunft auf der St. Laurent in New York im Jahre $1876^{134}$ :

"Schon gestern morgen, am 25. [Mai] füllte sich das Küstengewässer mit kleinen Segelbooten und Lotsenschiffen. Alle Passagiere kamen in ihren Sonntagskleidern ${ }^{135}$ auf das Oberdeck, die eine mehr, die anderen weniger neugierig. Gegen 11 Uhr gelangten wir in die Hafenmündung von New York. [...] Das Schiff verlangsamte seine Fahrt und wurde bald von einem gewaltigen amerikanischen Zollschiff eingeholt, das an unser Schiff anband. Der Anker wurde geworfen, und eineinhalb Stunden verbrachten die [an Bord gekommenen] Zollbeamten mit ihren Papieren. Das Zollschiff legte wieder ab, doch ein Beamter blieb auf unserem Schiff, damit keine Betrügereien geschehen konnten, und wir setzten die Fahrt fort. [...] Der Hafen war wie ein Pferdestall in kleine Parzellen unterteilt, wo jede Reederei ihren eigenen Holzverschlag hatte. Die St. Laurent warf wieder ihren Anker und feuerte zwei Kanonenschüsse ab. Daraufhin erschien ein kleines Schiff, um die Passagiere und das Gepäck an Land zu holen. Als wir an Land gingen, begannen die Zollbeamten unser Gepäck zu kontrollieren. Doch dies geschah mit einer unglaublichen Höflichkeit [...]. Es war überhaupt sehr ruhig wie in einer Kirche, und alle sprachen mit gedämpften Stimmen. [...] Alle Beamten waren stattlich und sauber gekleidet, ganz wie in Deutschland, und auch die übrigen Passagiere waren gut gekleidet, kein einziger Arbeiter war zu sehen. [...] Als die Zollabfertigung passiert war, hatte die Uhr schon 5 am Nachmittag erreicht, und erst dann durfte ich den Omnibus besteigen, der mich zu meiner Herberge brachte."

\footnotetext{
${ }^{133} \mathrm{Zu}$ den sogenannten 'Runnern' in New York City siehe Bretting 1981, S. 39-47.

${ }^{134}$ Brief aus 'Keski Suomi' in zwei Teilen, veröffentlicht am 13.11.1880 und 5.2.1881.
} 
Über eine medizinische Untersuchung an Bord oder an Land verliert dieser Auswanderer kein Wort, ebensowenig wie der bereits zitierte Auswanderer, der 1880/81 seine Reise in Keski Suomi schilderte, noch Oskari Tokoi, der als einer der letzten Passagiere 1891 die Einwandererregistrierung in 'Castle Garden' durchlief ${ }^{136}$.

Diese Situation änderte sich schlagartig als 1892 der neue Landeplatz auf 'Ellis Island' in Betrieb genommen wurde ${ }^{137}$, wo zwischen 1892 und 1924 täglich 6000 8000 Immigranten die Grenzkontrollen passierten. Als im Eröffnungsjahr eine Cholera-Epidemie unter europäischen Einwanderern grassierte führte dies zu verschärften Gesundheitskontrollen sowohl in den amerikanischen Einwanderungshäfen als auch in zahlreichen europäischen Einschiffungshäfen ${ }^{138}$. Insbesondere auf 'Ellis Island' wurden die medizinischen Untersuchungen derart systematisiert, daß jeweils ein Arzt die Neuankömmlinge auf eine bestimmte Krankheit hin untersuchte. Die Augenuntersuchungen waren besonders gefürchtet ${ }^{139}$, bei Verdacht auf Trachom wurden die Betroffenen sofort zurückgeschickt.

In vier Jahrzehnten ihres Bestehens hatten ca. 12 Millionen Europäer die Einwandererstation passiert, von denen jedes Jahr durchschnittlich 20\%- 40\% abgelehnt und zurückgeschickt wurden. Diese Sorge erregte auch die finnischen Einwanderer, die darum fürchteten, ihr mühsam erspartes oder geliehenes Reisegeld vergebens ausgegeben zu haben ${ }^{140}$. So schrieb Hilja Toopakka 1900 ihren Eltern, sie sollten die Schwester nicht auf die große Reise schicken ${ }^{141}$ :

\footnotetext{
${ }^{135}$ Siehe auch Bretting 1981, S. 30f. Auch Heikki Mikkola empfiehlt seinem Bruder, während der Überfahrt die besten Kleider zu tragen, Brief vom 8.4.1893: TYYH:S:m:Satakunta: MER:XX/1.

${ }^{136}$ Tokoi (1959, S. 24-29) erreichte New York im Winter 1891 und am 1. Januar 1892 wurde Ellis Island als Einwandererstation eröffnet, siehe Jones 1976, S. 54.

${ }^{137}$ Die Einwanderungsstation Ellis Island war einzigartig für die Vereinigten Staaten, vgl. Taylor 1971, S. 129; Elschenbroich 1986, S. 25; Tommola 1989, S. 68-71; Daniels 1990, S. 273. Als aktuellste Bearbeitung von Erfahrungsberichten europäischer Einwanderer auf 'Ellis Island' in deutscher Sprache gilt Perec/Bober 1998.

${ }^{138}$ Isak Kuusisto berichtet am 25.6.1905, daß bereits am Hafen von Hanko 109 Finnen wieder zurückgeschickt wurden (TYYH:S:m: Satakunta: HIN:III/2). Zu den Auswirkungen der Cholera-Epidemie vgl. Jones 1976, S. 38-44; Hoerder 1989, S. 287; Bretting 1992, S. 88-91.

${ }^{139}$ Interessanterweise finden sich in zahlreichen Publikationen zur Geschichte der amerikanischen Einwanderung immer wieder Fotografien, die Einwanderer während der Augenuntersuchung abbilden, siehe z. B. Jones 1976, S. 61; Weatherford 1986, S. 204; Daniels 1990, S. 373. ${ }^{140}$ Bereits 1895 sind Finnen nachweislich zurückgeschickt worden, vgl. Järnefelt 1899, S. 37; Taylor 1971, S. 128.

${ }^{141}$ Hilja Toopakka [10.3.1900], Samml. Süd-Ostbottnien, Sig.Nr. 1243/2,
} 
"Denn wenn sie in New York untersucht wird, und dort stellen sie fest, daß sie nicht ganz gesund ist, dann schicken sie wieder zurück, und das Reisegeld war umsonst."

Auch Matti Suovanniemi, der mit einer kleinen Gruppe von Bekannten reiste, kommentierte seine Erfahrung 1902 mit den Worten $^{142}$ :

"Und die anderen hatten schon Sorge, daß sie mich nicht passieren lassen würden, aber irgendwie bin ich doch durchgekommen."

Als logische Konsequenz empfahl er seinem Bruder Samuel Suovanniemi die Einwanderung über Kanada. Dieser befolgte den Ratschlag jedoch nicht, sondern passierte ein Jahr später ebenfalls 'Ellis Island' mit der lakonischen Bemerkung, daß niemand zurückgeschickt würde, der nur gute Augen habe. Auch Oskar Laakso berichtete 1910 von einer ähnlichen Erfahrung ${ }^{143}$ :

"Was die Augen angeht, bin ich ganz gut durchgekommen. Ich bin überhaupt nicht viel untersucht worden, aber viele Russen haben sie zurückgeschickt. Finnen eigentlich gar nicht, vielleicht nur zwei oder drei."

Nicht nur ein schlechter Gesundheitszustand war ein Ablehnungsgrund, sondern auch die seit 1885 gesetzlich verbotene, kommerzielle Anwerbung von europäischen Arbeitskräften für amerikanische Unternehmen. So wurde bereits 1892 eine Gruppe von neun Finnen abgewiesen, als bei einem Gruppenmitglied ein Brief eines Unternehmers aus Michigan gefunden wurde, worin dieser den Adressaten bat, weitere Finnen für die Waldarbeit in Michigan zu gewinnen ${ }^{144}$. Traten die finnischen Auswanderer, zumeist junge Männer im Alter von 20-30 Jahren, die Ausreise allein oder im Gruppenverband Gleichgesinnter an, so mutete die Zurückweisung allenfalls als Ärgernis, nicht aber als

\footnotetext{
${ }^{142}$ Matti Suovanniemi [8.6.1902], Samml. Süd-Ostbottnien, Sig.Nr.1243/14.

${ }^{143}$ Samuel Suovanniemi [30.6.1903], Samml. Süd-Ostbottnien, Sig.Nr. 1211/4; Oskar Laakso [10.9.1910]; TYYH:S:m:Satakunta:HIN:VI/1.

${ }^{144}$ Kero 1976a, S. 71. Nähere Einzelheiten zum 'Contract Labor Law' bei Jones 1976, S. 61; Weatherford 1986, S. $173 f$.
} 
Tragödie an. Anders sah das bei Familien aus, bei denen einer zurückgewiesen und die restlichen Familienmitglieder vor eine schwere Entscheidung gestellt wurden ${ }^{145}$.

Im ersten Jahrzehnt des 20. Jahrhunderts, als in 'Ellis Island' die Einwandererabfertigung Rekordzahlen erreichte, waren tagelange Wartezeiten auf der Insel eher die Regel als die Ausnahme. Musik und Tanz halfen die Langeweile zu bekämpfen ${ }^{146}$. Wenn aber selbst schon die große Empfangshalle überfüllt war, hatten die übrigen Auswanderer noch einige Tage auf ihrem Schiff zu warten. August Jalo bemerkt hierzu im Jahr 1905, daß er schon am Vorabend des ersten Pfingsttages New York erreichte, doch erst am Morgen des zweiten Pfingsttages das Schiff verlassen durfte ${ }^{147}$.

Insgesamt haben mehr als 270000 Finnen zwischen 1892 und 1914 die Atlantiküberquerung angetreten, wovon ein Großteil über New York und Boston eingereist ist. Obwohl sich in den hier dargestellten Briefzitaten einige Klagen über den Reiseverlauf und die Zustände an Bord der Dampfschiffe finden, scheint die Überfahrt für die meisten ein positives Erlebnis gewesen zu sein, war sie doch ein Abenteuer bislang unbekannter Art und bedeutete zugleich den Aufbruch in einen neuen Lebensabschnitt. Auch die Tatsache, daß zahlreiche Briefschreiber die Atlantiküberquerung zwei- oder mehrfach antraten, um heimzukehren oder aber ihre Verwandten in Finnland zu besuchen, deutet darauf hin, daß die Reise kein von großer Angst gekennzeichnetes Unterfangen war. Alle Briefschreiber beteuerten nach ihrer Ankunft, daß die Reise insgesamt gut verlaufen sei. Im zweiten Brief verloren die Auswanderer dann kein Wort mehr über ihre Reiseerlebnisse, die Organisation des neuen Alltags drängte nun die Erinnerung an überfüllte Zwischendecks und die bohrenden Fragen der Einwanderungsbeamten zurück.

\section{3. Geographische Verteilung und regionale Mobilität}

Auf der Grundlage der offiziellen Emigrationsstatistik der finnischen Behörden hatten 99,7\% aller finnischen Auswanderer des Zeitraumes 1900-23 die Vereinigten Staaten oder Kanada zum Ziel, so daß im Falle der finnischen Überseeimmigration von

\footnotetext{
${ }^{145}$ Weatherford (1986, S. 175) führt ein Beispiel von verfolgten russischen Juden an.

${ }^{146}$ Bei Taylor (1971, S. 169) findet sich eine Fotografie einer Szene mit tanzenden Immigranten auf 'Ellis Island' aus dem Jahr 1905.

147August Jalo, Brief vom 5.7.1905: TYYH:S:m:Satakunta:HIN:X/1.
} 
einer nahezu ausschließlichen Amerikaaeinwanderung gesprochen werden kann ${ }^{148}$. Dabei rangierten die Vereinigten Staaten an erster Stelle, lediglich ein Bruchteil der finnischen Auswanderer wurde in Kanada registriert. Obwohl die finnische Kanadaeinwanderung im Verlauf des 20. Jahrhunderts zu ungunsten der Immigration in die Vereinigten Staaten anstieg, blieb im Bezug auf die finnische Einwandererverteilung ein deutliches Ungleichgewicht bestehen. Selbst bei den Volkszählungen der Jahre 1920 und 1921 entfielen vom gesamten finnischen Einwandereraufkommen lediglich 12,5\% auf Kanada.

Hierbei ist jedoch der sogenannte Übergangscharakter der nach Kanada gerichteten Immigration zu bedenken: Die Mobilität der Immigranten zwischen den Vereinigten Staaten und Kanada war groß, so daß vor allem die Anzahl der Kanada-Finnen stark variieren konnte. Die kanadischen Zensus-Angaben sind demnach auch eher als "Momentaufnahmen" der im jeweiligen Jahr registrierten Anzahl von Finnen zu verstehen, obwohl sie deutlich den Trend einer zunehmenden Population von Kanada-Finnen reflektieren.

Betrachtet man die finnische Amerika- und Kanadaeinwanderung wiederum als einen Bestandteil der europäischen Überseeimmigration, so fällt die finnische Beteiligung kaum ins Gewicht: Im Jahr 1900 lag der Anteil der Finnen am Gesamtaufkommen aller europäischen Immigranten bei lediglich 0,6\%. Ein Jahrzehnt später bestritten die Finnen dann 1,6\% aller nicht in Amerika geborenen Ausländer. Auf der Zahlengrundlage der amerikanischen Zensus-Behörde verdoppelte sich die finnische Einwandereranzahl von 62641 auf 149824 Personen $^{149}$. Demnach erhöhte sich im Zeitraum 1900-14 sowohl der finnische Anteil der ersten Einwanderergeneration ${ }^{150}$ an sich als auch seine proportionale Beteiligung an der gesamten Immigrationswegung in die Vereinigten Staaten.

\footnotetext{
${ }^{148}$ Virtanen 1979, S. 145.

${ }^{149}$ Vgl. Vedder/Gallaway 1970, S. 160, Tab. 1. Der bei Vedder/Gallaway fehlende Prozentsatz für 1910 läßt sich auf der Grundlage aller Einwanderer des Zeitraumes 1901-10: 9.243.958 Personen (vgl. Adams 1992, S. 500, Tab. 6) sowie der Zensus-Angabe des Jahres 1910 für die in Amerika registrierten Finnen (vgl. Kero 1980, S. 69f., Tab. 2) ermitteln.

${ }^{150}$ Finnen der zweiten und dritten Generation, d.h. in Amerika geborene Kinder finnischer Eltern und Großeltern, bleiben aus dieser Darstellung ausgeschlossen. Ihr Anteil am Gesamtaufkommen aller Amerika-Finnen jedoch nahm im Verlauf des 20. Jahrhunderts rapide zu. Bei der Volkszählung des Jahres 1980 gaben etwa 616000 Personen eine finnische Abstammung an, doch lediglich 230000 Befragte waren selbst in Finnland geboren oder hatten finnische Eltern, vgl. Kultalahti 1989, S.12; Korkiasaari 1989, S. 111 und S. 151.
} 
Im Vergleich dazu sank die proportionale Beteiligung der finnischen Einwandererpopulation am Gesamtaufkommen aller nach Kanada einreisenden Immigranten zu Beginn des 20. Jahrhunderts geringfügig: Betrug der durchschnittliche Anteil der Finnen an der Gesamtimmigration nach Kanada im Zeitraum 1901-10 noch 0,8\%, so war er bis 1920 auf 0,6\% abgesunken, obwohl in absoluten Zahlen eine Versechsfachung der finnischen Einwandereranzahl zwischen den beiden Volkszählungen der Jahre 1901 und 1911 stattgefunden hatte ${ }^{151}$.

In diesem Zusammenhang erscheint noch eine kurze Betrachtung der Amerikaund Kanada-Finnen in Beziehung zur Gesamtbevölkerung der Vereinigten Staaten und Kanadas interessant: Im Zeitraum 1900 bis 1910 stieg der Prozentsatz der Finnen an der US-Bevölkerung von $0,08 \%$ auf $0,14 \%{ }^{152}$. Für Kanada sah die Entwicklung ähnlich aus: Zwischen den beiden Volkszählungen 1901 und 1911 stieg der finnische Anteil an der Gesamtbevölkerung von $0,05 \%$ auf $0,22 \% \mathrm{an}^{153}$. Diese Entwicklung ist jedoch besonders im Hinblick auf die Situation in den Vereinigten Staaten bemerkenswert, da während des betrachteten Zeitraumes der prozentuale Anteil aller Immigranten an der USBevölkerung abnahm, obwohl die Einwanderungsbewegung in ihrer Gesamtheit einen bis dahin einmaligen Höhepunkt erreichte. Der prozentuale Anteil aller Immigranten an der US-Bevölkerung sank im Zeitraum 1900-10 nämlich von 10,8\% auf 6,9\% bei einer gleichzeitigen Rekordspitze der absoluten Einwandererzahlen ${ }^{154}$. Dieses Phänomen ist lediglich durch die Tatsache eines starken natürlichen Bevölkerungszuwachses sowie der Amerikanisierung eines Großteils der bereits früher eingewanderten Immigranten zu erklären.

\section{3. 1. Die wichtigsten Besiedlungsgebiete der finnischen Einwanderer}

Von den 62641 in den Vereinigten Staaten registrierten Finnen des Jahres 1900 lebten 53530 Personen und dementsprechend 82,2\% aller Amerika-Finnen in den zehn Bundesstaaten Michigan, Minnesota, Massachusetts, New York, Ohio, Wisconsin,

\footnotetext{
${ }^{151} 1901$ befanden sich 2.502 finnische Einwanderer in Kanada, zehn Jahre später waren es bereits 15.497 Personen, vgl. Lindström-Best 1985, S. 6f.

${ }^{152}$ Kultalahti 1989, S. 13, Fig. 5.

${ }^{153}$ Lindtröm-Best 1985, S. 7, Tab. 2.

${ }^{154}$ In der besagten Dekade wanderten mehr als acht Millionen Immigranten in die Vereinigten Staaten ein, vgl. Archdeacon 1983, S. 115, Tab. V-2.
} 
Montana, Washington, Oregon und Kalifornien ${ }^{155}$. Es waren vor allem die amerikanischen Mittelwest-Staaten im Bereich der Großen Seen, die Neuenglandstaaten Massachusetts und New York sowie der gesamte westliche Küstenstreifen von Washington bis Kalifornien, die eine deutliche Konzentration der finnischen Einwanderer erfuhren. In jedem der hier aufgeführten Staaten lebten mehr als 2000 Finnen bzw. mindestens 2,1\% der gesamten finnischen Einwandererpopulation. Als weitere Staaten mit einem Anteil von mehr als 1\% der finnischen Einwandererschaft wären South Dakota, Illinois, Pennsylvanien und Wyoming zu nennen. Geographisch gesehen liegen sie entweder im Nordosten oder Mittleren Westen der Vereinigten Staaten und grenzen an zumindest einen der bereits aufgeführten zehn Staaten an. Im Jahr 1900 hielten sich zudem je 1\% der finnischen Einwanderer in den Staaten North Dakota, Colorado und Utah auf. In New Jersey hingegen, in unmittelbarer Nähe zu New York City gelegen, wurde die 1\% -Marke erst 1910 erreicht.

Die den Finnen zu Verfügung stehenden Beschäftigungsmöglichkeiten lagen in erster Linie in der Montanindustrie Michigans, Minnesotas und Montanas sowie auf kanadischer Seite in Ontario und British Columbia. Ebenso stellte die Waldarbeit, d.h. vornehmlich die Holzgewinnung in den waldreichen Staaten des Mittleren Westens bis hin zur Westküste, insbesondere in Oregon, Washington und Kalifornien, eine wichtige Erwerbsquelle dar. Die Verschiffung von Holz, Kohle und Eisenerz beschäftigte wiederum viele Männer als Hafenarbeiter sowohl in Duluth und Marquette am Ufer des Superior-Sees als auch in den Zielhäfen Conneaut, Astabula und Fairport Harbour am Ufer des Erie-Sees in Ohio.

Des weiteren konnten die Finnen in unzähligen Sägewerken sowie im Eisenbahngleis- und Straßenbau von ihrer bereits im Heimatland gewonnenen Arbeitserfahrung profitieren. Dies traf auch für den Bereich der Landwirtschaft zu, da mehr als zwei Drittel der finnischen Auswanderer in Finnland in einem agraren Umfeld gelebt hatte: In den Vereinigten Staaten und in Kanada erfüllte sich nämlich rund ein Viertel der finnischen Einwanderer, nach einigen Jahren der abhängigen Lohnarbeit, den Traum von einer eigenen Farm; hauptsächlich in Minnesota, Michigan, Wisconsin, South Dakota und Idaho. ${ }^{155}$ Siehe hierzu Tabelle 7 und Karte 5 im Anhang, welche die Verteilung der Finnen auf einzel-
ne Bundeststaaten um 1900 darstellen.Vgl. auch Hoglund 1960, S. 121. 
Nicht wenige Finnen zogen in den Mittel-Weststaaten von einem Staat in den nächsten, ständig auf der Suche nach besserbezahlten Arbeitsplätzen. Andere wiederum blieben gleich nach Einwanderungsbeginn in den Industriestädten der Ostküste, wo zahlreiche Fabriken, wie beispielsweise die Eisendrahtfabrik in Worcester in Massachusetts, fortlaufend ihre Belegschaften erweiterten. An der amerikanischen Westküste hingegen lockte Astoria im Bundesstaat Oregon, wo tausende Finnen ihr Auskommen als Lachsfischer fanden oder das sonnige Kalifornien mit seinen großen Obstplantagen. Doch auch auf zahlreichen Baustellen in den schnell wachsenden Städten der Ost- und Westküste waren kräftige Einwanderer gefragt, denen der Umgang mit Hammer und Säge vertraut war.

Als nach der Jahrhundertwende zudem verstärkt junge finnische Frauen einwanderten, konnten diese vor allem in den Städten der Ostküste, insbesondere in den Staaten Massachusetts und New York, am ehesten eine Anstellung in einem privaten Wohlstandshaushalt bei einer amerikanischen "Missis" finden. Nicht wenigen gelang es auch im Bereich der Textilindustrie, beispielsweise in der Wollspinnerei von Fitchburg in Massachusetts, Fuß zu fassen ${ }^{156}$.

In Kanada bevorzugten die Finnen eindeutig die Provinzen Ontario, British Columbia und Alberta, wobei vor allem das Grenzgebiet zwischen Ontario, Michigan und Minnesota stark frequentiert wurde. Hier war es vor allem die Montanindustrie, d.h. Bergwerksgesellschaften von Silber-, Eisenerz-, und Kohlegruben, die neben den zahlreichen Waldgesellschaften und dem einflußreichsten Arbeitgeber, der 'Canadian Pacific Railroad Company', die meisten Finnen beschäftigte. Da die industriellen Erwerbsmöglichkeiten in erster Linie die regionale Konzentration der Finnen bestimmten, blieben finnische Einwanderer in einigen kanadischen Provinzen auch nach 1920 so gut wie unbekannt.

Im Anhang wird in Tabelle 7 die geographische Verteilung der Finnen dargestellt, wobei zehn amerikanische Bundesstaaten mit jeweils mehr als 2000 finnischen Einwanderern fünf kanadischen Provinzen mit großem Finnenaufkommen gegenübergestellt werden.

Hierbei fällt besonders die Konzentration der finnischen Einwanderer in den Bundesstaaten Michigan und Minnesota auf. Zu Beginn des Jahrhunderts befanden sich mit 45,5\% knapp die Hälfte aller finnischen Immigranten in den beiden Staaten, zwei

${ }^{156} \mathrm{Zu}$ den Arbeitsbereichen der Finnen vgl. Kero 1996, S. 123-141 und 1997, S. 17. 
Dekaden später waren es immerhin noch mehr als ein Drittel. Wird die Anzahl der in Michigan und Minnesota registrierten Personen lediglich mit der Gesamtanzahl aller Finnen der Vereinigten Staaten, d.h. unter Ausschluß der Kanada-Finnen, verglichen, so ergeben sich verständlicherweise höhere Prozentwerte: 47,3\% für das Jahr 1900, 44,5\% für 1910 sowie 39,5\% für 1920.

Bemerkenswerterweise betrug der Anteil der in Wisconsin lebenden Finnen bei allen drei Volkszählungen weniger als 4\%, obwohl Wisconsin geographisch zwischen den beiden Staaten Minnesota und Michigan liegt. Innerhalb aller in den Vereinigten Staaten gezählten Finnen schwankte der prozentuale Anteil der Wisconsin-Finnen zwischen $3,5 \%$ und $4,5 \%$.

Als weitere Bundesstaaten mit relativ hoher Finnen-Konzentration können die benachbarten Neuenglandstaaten Massachusetts und New York genannt werden, welche durch die beiden großen Anlegehäfen der Städte Boston und New York City bedeutsam für die westwärts gerichtete Arbeitswanderung gewesen sind. Mit zunehmender finnischer Einwanderungsbewegung wuchs auch die Präsenz der Finnen im Westküstenstaat Washington, nicht zuletzt aufgrund der geographischen Angrenzung an British Columbia auf kanadischer Seite ${ }^{157}$.

Als Ergebnis dieser Entwicklung bleibt festzuhalten, daß die absolute Finnenanzahl während der ersten beiden Jahrzehnte des 20. Jahrhunderts in den meisten Bundesstaaten zunahm. In acht von zehn Staaten, die Ausnahmen waren Michigan und Ohio, hatte von 1900-10 eine Verdopplung der Einwandererzahlen stattgefunden. Lediglich in der Prioritätsreihenfolge der zehn von Finnen am stärksten besiedelten Bundesstaaten fanden Verschiebungen statt: Blieben die Bundesstaaten Michigan, Minnesota, Massachusetts und New York in dieser Reihenfolge unverändert die vier wichtigsten Besiedlungsgebiete, so verdrängte Washington bei den Volkszählungen der Jahre 1910 und 1920 Ohio vom fünften Platz der Rangliste. Ohio stand 1910 nur noch an zehnter Stelle, um dann bis 1920 wieder auf Platz acht in der finnischen Besiedlungshierarchie vorzurücken.

Ständig zunehmende Einwandererzahlen hatten zur Folge, daß die Finnen um 1920 zudem in mehr Bundesstaaten vertreten waren als vor der Jahrhundertwende. Dementsprechend nahm auch der Finnenenteil in einigen Staaten der Ost- und Westküste im Laufe der Jahrzehnte zu, wie z.B. in Massachusetts, New York und Washington.

\footnotetext{
${ }^{157}$ Hoglund 1981a, S. 365.
} 
Als Gegenbewegung nahm die Beliebtheit solcher Staaten besonders stark ab, die schon vor der Jahrhundertwende als Anlaufziele für finnische Immigranten galten und kaum noch neue Anreize bieten konnten. Hier wären u.a. Michigan, Ohio und Montana zu nennen, wo regionale Schließungen von Eisenerz- und Kohlegruben zur Abwanderung von Arbeitskräften in andere Bundesstaaten bzw. in die angrenzende kanadische Provinz Ontario führten. In Kalifornien wiederum stagnierte der Finnenanteil über zwei Jahrzehnte hinweg. Allen zehn hier näher betrachteten Bundesstaaten war jedoch gemeinsam, daß die Anzahl der in einem Staat lebenden Finnen zu keinem Volkszählungszeitpunkt weniger als 2000 Personen betrug.

Zwischen den beiden kanadischen Volkszählungen der Jahre 1911 und 1921 war die absolute Anzahl sowohl der in British Columbia als auch der in Gesamt-Kanada registrierten Finnen deutlich angestiegen, wenngleich der prozentuale Finnenanteil der Provinz British Columbia am Gesamtaufkommen aller finnischen Überseeinwanderer abgenommen hatte. Für alle kanadischen Provinzen zusammengenommen läßt sich jedoch ein deutlicher Anstieg des Finnenanteils um ein Dreifaches, von 3,8\% zu Beginn des Jahrhunderts auf 12,5\% zwei Jahrzehnte später, feststellen. Dieser Trend verstärkte sich noch in der Folgezeit, da Kanada nach dem Inkrafttreten der amerikanischen Einwanderungsbeschränkungen der Jahre 1921 und 1924 sowie der gleichzeitigen Schließung der vormals offenen Grenze zwischen Kanada und den Vereinigten Staaten zum erstrangigen Einwanderungsland für europäische Arbeitssuchende und zukünftige Farmer avancierte ${ }^{158}$. Selbst in den 1920er Jahren stand in Kanada - im Gegensatz zu den Vereinigten Staaten - noch genügend Ackerland zum Verkauf an.

Auch im Hinblick auf die Entstehung von Migrationstraditionen ${ }^{159}$ kann Ohio als Exempel herangezogen werden: Bei einer Stichprobenuntersuchung der in den südostbottnischen Nachbargemeinden Ylistaro und Isokyrö ausgegebenen Amerika-Pässe des Jahres 1882, beides zugleich Herkunftsgemeinden von 12 Briefschreibern des hier zu behandelnden Untersuchungsgebiets, gaben 50\% aller Auswanderungswilligen Ohio als Zielort an. Im nationalen Vergleich planten lediglich 5,3\% aller finnischen Emigranten im besagten Jahr die Einreise nach Ohio. Für das nächstfolgende Stichprobenjahr 1890, für das bereits Passagierlisten als Ergänzungsquellen berücksichtigt werden konnten, beabsichtigten immerhin noch 12,3\% der Paßantragssteller aus Ylistaro und Isokyrö

\footnotetext{
${ }^{158}$ Norman/Runblom 1988, S. 156.
} 
in Ohio das erste Arbeitsverhältnis auf amerikanischem Boden einzugehen, wenngleich es lediglich 2,5\% des gesamten finnischen Auswandererpotentials in diesen Bundesstaat zog. Interessanterweise wurden dann bei der Volkszählung des Jahres 1900 bereits mehr als 2800 Finnen in Ohio gezählt, was einem Prozentanteil von 4,5\% aller zu diesem Zeitpunkt in den Vereinigten Staaten registrierten Finnen entsprach. Demnach hatte die Anziehungskraft des Staates Ohio während der Dekade von 1890-1900 zugenommen, was in gewissem Umfang sicherlich durch Auswanderer aus Ylistaro und Isokyrö begünstigt wurde. Im Jahr 1905 wanderten nämlich wieder rund ein Viertel der Emigranten dieser beiden Gemeinden in Ohio ein. Folglich kann von einer regionalen Migrationstradition von Ylistaro und Isokyrö nach Ohio über mehr als zwei Jahrzehnte hinweg gesprochen werden.

Ähnliche Migrationstraditionen von einzelnen Gemeinden des finnischen Auswanderungskerngebietes konnten vom ländlichen Einzugsgebiet der Stadt Vaasa nach Utah, von den südostbottnischen Gemeinden Laihia, Jurva und Teuva nach New York und Massachusetts sowie von der schwedischsprachigen Küstengemeinde Munsala nach Washington festgestellt werden ${ }^{160}$. Auch für den Auswanderungsbeginn nach Ontario in Kanada war die starke Auswandererpräsenz aus sechs Gemeinden südöstlich der Stadt Vaasa entscheidend ${ }^{161}$, wobei sich die im Umfeld des Superior-Sees gelegenen Städte Thunder Bay, Sudbury und Sault Ste. Marie schnell zu den wichtigsten Einzugsgebieten dieser Finnen entwickelten.

In einigen Fällen ließen sich sogar direkte Migrationsbeziehungen einzelner Gemeinden in Finnland mit bestimmten Orten oder Städten in den Vereinigten Staaten ausmachen, wie beispielsweise im Fall der mittelostbottnischen Gemeinden Veteli und Toholampi mit einer starken Immigration in den Bergwerksort Red Lodge in Montana bzw. nach Fitchburg in Massachusetts. Auch von Emigranten aus Kälviä, nördlich der mittelostbottnischen Küstenstadt Kokkola gelegen, konnte eine verstärkte Übersiedlung nach Astoria in Oregon, einem Zentrum der Lachsfischerei, belegt werden ${ }^{162}$.

\footnotetext{
${ }^{159}$ Folgende Beispiele stammen aus den Untersuchungen von Kero 1974, S. 9-13; 1980, S. 2936 und 1991, S. 114-120.

${ }^{160}$ Backman 1945, S. $15 f$.

${ }^{161}$ Gemeint sind die Gemeinden Karvia, Karijoki, Kauhajoki, Jalasjärvi, Alavus und Lapua (Kero 1976b, S. 9f.); mit Ausnahme von Alavus auch zugleich Herkunftsgemeinden der Briefschreiber des Untersuchungsgebietes.

${ }^{162}$ Zur Auswanderung aus Toholampi siehe Kero/Kostiainen/Kuparinen 1978, S. 18-64, bes. S. 46f. Zur Emigration aus Veteli siehe Toivonen 1955, S. 1-17. Zur finnischen Immigration nach Red Lodge vgl. Kuhlman (unveröffentlichte Magisterarbeit) 1987 , S. 63-86. Zur Auswande-
} 
Auf Gemeindeniveau betrachtet, nahm mit zunehmender Auswanderungsbewegung auch die Anzahl einzelner Zielorte bzw. Städte in den Vereinigten Staaten zu, wonach beispielsweise die Emigranten aus dem südostbottnischen Alahärmä 1882 in drei, 1890 in acht und 1905 bereits in neunzehn Staaten zu finden waren ${ }^{163}$. Vor dem Hintergrund von wachsender Auswandererzahlen und intensiverer Informationsverbreitung über die Erwerbsmöglichkeiten in den einzelnen Staaten erscheint diese Entwicklung als natürlich und folgerichtig.

Möglicherweise fällten auswanderungswillige Finnen ihre Entscheidungen unter dem Informationseinfluß von Bewohnern nahegelegener Gemeinden, deren Vertreter bereits früher an der Auswanderungsbewegung teilgenommen hatten. Demnach kann eine Kettenreaktion vermutet werden, sowohl im Bezug auf den Emigrationsbeginn benachbarter Gemeinden als auch auf die Zielortentscheidungen einander bekannter Personen $^{164}$. Im Hinblick auf den zuletzt genannten Aspekt kam auch der Briefanwerbung durch bereits ausgewanderte Dorfbewohner eine besondere Bedeutung bei, wie jedoch noch eingehend erörtert wird ${ }^{165}$.

\section{3. 2. Geographische Konzentration im Vergleich zu anderen skandinavi-} schen Einwanderergruppen

Bei einer Gegenüberstellung der geographischen Verteilung der einzelnen skandinavischen Immigrantengruppen - unter Ausschluß der Isländer - fallen Unterschiede auf, die auf bestimmte Besiedlungstraditionen einer jeden Einwanderergruppe schließen $\operatorname{lassen}^{166}$. Unter den Skandinaviern stellten die Schweden die zahlreichste Immigranten-

rung aus Kälviä siehe Hummasti 1988. Zu Finnen in Astoria vgl. Passi 1975; Hummasti 1978. Für die schwedische Migrationsforschung wiederum kann die vorbildliche Analyse von Ostergren (1988) genannt werden, der über acht Jahrzehnte hinweg die Migrationstradition aus der Gemeinde Rättvik der Provinz Dalarna in den Agrarbezirk 'Isanti County' in Minnesota verfolgt hat.

${ }^{163}$ Kero 1991, S. 119.

${ }^{164}$ Vgl. Kero 1991, S. 117 und S. 132. Zum zeitlich aufeinander abgestimmten Auswanderungsbeginn von benachbarten Gemeinden in Süd-Ostbottnien siehe Hautamäki (unveröffentlichte Magisterarbeit) 1981, Abb. 10, Anhang.

${ }^{165}$ Zur Briefanwerbung siehe Kap. 3.5.1.

${ }^{166}$ Die Zensus-Angaben von 1910 für die einzelnen skandinavischen Länder finden sich bei Norman/Runblom 1988, S. 292f., Tab. 3. Angaben über isländische Immigranten standen hierbei nicht zur Verfügung. Da in absoluten Zahlen jedoch nur ca.14000 Isländer eingewandert sind, fiel ihr Anteil am Gesamtaufkommen aller Skandinavier kaum ins Gewicht, vgl. Kjartansson 1977, S. 38 f.; Norman/Runblom 1988, S. 31. 
gruppe dar, gefolgt von den Norwegern und Dänen, deren Auswanderungshöhepunkte bereits in den 1880er Jahren stattgefunden hatten. Aufgrund des relativ späten Beginns der finnischen Auswanderungsbewegung standen die finnischen Einwanderer - in absoluten Zahlen gemessen - im innerskandinavischen Vergleich an letzter Stelle ${ }^{167}$.

Werden nun diejenigen fünf Bundesstaaten, welche bei der Volkszählung des Jahres 1910 am dichtesten mit jeweils einer skandinavischen Immigrantengruppe besiedelt waren, als Vergleichsmaßstab herangezogen, so ergibt sich folgendes Bild: 66,3\% aller Finnen der Vereinigten Staaten lebten in Michigan, Minnesota, Massachusetts, New York und Washington, wobei die Reihenfolge der Staaten die hauptsächliche Konzentration der finnischen Einwanderer angibt. In absoluten Zahlen entsprach dieser Prozentsatz 86004 Personen.

Die Schweden ${ }^{168}$ wiederum bevorzugten neben Minnesota ${ }^{169}$ vor allem Illinois, New York, Massachusetts und Washington. Im Jahr 1910 hielten sich 55,5\% aller Amerika-Schweden in diesen fünf Bundesstaaten auf, was 363318 Personen gleichkam. Bis auf Michigan waren die Schweden demnach in all denjenigen Bundesstaaten zahlreich vertreten, in denen auch die meisten Finnen lebten. Da das Aufkommen der Amerika-Schweden jedoch in absoluten Zahlen alle anderen skandinavischen Einwanderergruppen in den Schatten stellte, ist korrekterweise festzuhalten, daß 1910 auch in Michigan 26374 Amerika-Schweden registriert wurden, obwohl dieser Bundesstaat bei den Schweden erst an siebter Stelle der Besiedlungshierarchie stand. In absoluten Zahlen entsprach die Größenordnung der Schweden in Michigan wiederum in etwa der Finnenanzahl von Minnesota, dem zweitwichtigsten Bundesstaat der Amerika-Finnen.

Die Norweger, als zweitstärkste skandinavische Einwanderergruppe ${ }^{170}$, waren am zahlreichsten in Minnesota, Wisconsin ${ }^{171}$, North Dakota, Illinois und Washington

\footnotetext{
${ }^{167}$ Im Zeitraum 1851-1930 wanderten ca. 1.200000 Schweden, 800000 Norweger, 400000 Dänen und 380000 Finnen in die Vereinigten Staaten und nach Kanada ein, vgl. Kero 1980, S. 2527; Norman 1982, S. 10; Korkiasaari 1989, S. 24. Zur skandinavischen Überseeimmigration allgemein siehe Wittke 1967, S. 257-296; Semmingsen 1972; Norman/Runblom 1985 und 1988, S. 141-276; Daniels 1990, S. 165-183.

${ }^{168}$ Im Jahr 1910 wurden 655207 Schweden der ersten Generation in den Vereinigten Staaten registriert, vgl. Norman/Runblom 1988, S. 292f., Tab. 3. Zur schwedischen Einwanderung allgemein siehe Ljungmark 1973; Carlsson 1976; Beijbom 1981 sowie die Gesamtdarstellungen von Nelson 1943 und Barton 1994.

${ }^{169} \mathrm{Zu}$ den Schweden in Minnesota siehe Qualey 1950, S. 27f.; Rice 1981.

${ }^{170} 1910$ betrug die Gesamtanzahl aller Norweger der ersten Generation in den Vereinigten Staaten 403877 Personen, vgl. Norman/Runblom 1988, S. 292f., Tab. 3. Zur norwegischen Immigration allgemein siehe Haugen 1975, S. 7-35, bes. S. 11-14; Munch 1981; Nelson 1981, die äl-
} 
anzutreffen. 1910 wurden 403877 Personen, d.h. 66,7\% aller Amerika-Norweger, in diesen fünf Staaten gezählt. Demnach war ihr prozentualer Anteil in den genannten Staaten ebenso groß wie der Finnenanteil in den für die Amerika-Finnen vorrangigen Staaten. Interessanterweise befanden sich bei beiden Immigrantengruppen die Staaten Minnesota und Washington an erster bzw. fünfter Stelle der Besiedlungshierarchie. Im Falle der Amerika-Norweger jedoch überstieg das Einwanderungsvolumen in den fünf Staaten - in absoluten Zahlen ausgedrückt - um ein Dreifaches die finnische Population der fünf Vergleichsstaaten, so daß beispielsweise 1910 in New York 25013 Norweger im Gegensatz zu 8760 Finnen registriert wurden. Trotzdem rangierte New York an vierter Stelle in der Bundesstaatenhierarchie der Finnen, doch erst an sechster Stelle in der Besiedlungsskala der Norweger.

Die Größenordnung des dänischen Gesamtaufkommens in den Vereinigten Staa$\operatorname{ten}^{172}$ wiederum wich weniger stark vom Volumen der finnischen Einwandererpopulation ab: 1910 wurden 181649 Dänen im Vergleich zu 129680 Finnen registriert. Dennoch fällt die im innerskandinavischen Vergleich geringe geographische Konzentration der Dänen mit lediglich 45,2\% ihres Gesamtaufkommens in den fünf Staaten Iowa, Illinois, Wisconsin, Minnesota und Kalifornien auf ${ }^{173}$. Von allen skandinavischen Einwanderergruppen lebten die Dänen demnach am gleichmäßigsten auf die amerikanische Staatenlandschaft verteilt. Dafür spricht auch die Präsenz von lediglich 17961 Dänen in Iowa, obwohl dieser Bundesstaat den höchsten Dänenanteil der Vereinigten Staaten stellte. Die Finnen hingegen waren mit 31144 Personen in Michigan am stärksten vertreten.

Zusammenfassend läßt sich festhalten, daß alle vier skandinavischen Gruppen in den Staaten Minnesota und New York stark vertreten waren. In Michigan und Massachusetts lebten viele Finnen und Schweden, in Wisconsin wiederum jeder siebte Norweger, neben zahlreichen Schweden und Dänen. Ebenso zogen Iowa und Illinois als südliche Grenzstaaten von Minnesota und Wisconsin in besonderem Maße Schweden, Norweger und Dänen an. Beispielsweise jeder sechste Schwede lebte 1910 in Illinois,

teren Gesamtdarstellungen von Blegen 1931 und 1940 sowie Semmingsen 1975 (in engl. Übersetz. 1978).

${ }^{171}$ Zur norwegischen Präsenz in Minnesota siehe Qualey/Gjerde 1981; zu Norwegern in Wisconsin siehe Fapso 1977, S. 1-39.

${ }^{172}$ Zur dänischen Einwanderung allgemein siehe die Monographien von Hvidt 1971, Hale 1984 und Flemming Larsen/Bender 1992 sowie die Essays von Burton Skårdal 1981 und Stilling/Olsen 1994, S. 11-19. Zu Dänen in Kanada siehe Bender/Flemming Larsen 1991. ${ }^{173} \mathrm{Zu}$ Dänen in Wisconsin siehe Hale 1981, S. 1-32; Stilling/Olsen 1994, S. 79-91, zu Dänen in Iowa vgl. ebenda, S. 96-100. 
woran insbesondere das hohe Schwedenaufkommen im schwedischen Ghetto von Chicago, im "Swede Town", seinen Anteil hatte ${ }^{174}$. Auch für die finnischen Einwanderer gewann Illinois zunehmend an Bedeutung für, wenngleich sich 1910 lediglich 1,8\% aller Finnen der Vereinigten Staaten in Illinois aufhielten. Iowa hingegen übte keine nennenswerte Anziehungskraft auf die Finnen aus, ihre Anzahl betrug zur gleichen Zeit nicht mehr als 140 Personen.

Erwähnenswert sind noch die Westküstenstaaten Washington und Kalifornien, wobei erst genannter bei Finnen, Norwegern und Schweden an fünfter Stelle der vorrangigsten Besiedlungsgebiete stand, letztgenannter wiederum Platz fünf bei den dänischen, Platz sechs bei den finnischen und erst Platz acht bei den schwedischen Einwanderern einnahm. In absoluten Zahlen dominierten jedoch die Schweden in Kalifornien, die mit mehr als 26000 Personen fast doppelt so häufig vertreten waren wie die Dänen. Andere Staaten wiederum waren nur für jeweils eine Einwanderergruppe attraktiv, wie beispielsweise South Dakota für die Norweger oder Nebraska und Utah für die Dänen.

Die skandinavische Einwanderung nach Kanada hingegen sah - kurz dargestellt - folgendermaßen aus: Im Zeitraum 1900-14 wanderten nach offiziellen Zählungen 27645 Schweden, 21.220 Finnen, 19757 Norweger und lediglich 6111 Dänen nach Kanada ein $^{175}$. Im Verhältnis zum Gesamtaufkommen der Überseeauswanderer eines jeden Landes wiesen die Finnen eindeutig die stärkste Präsenz in Kanada auf.

Durch die Öffnung der kanadischen Prärielandschaften zur freien Besiedlung seit den 1890er Jahren hatten zahlreiche Skandinavier bereits vor 1900 ihren Weg nach Kanada gefunden. Selbst um 1920 stand in Kanada noch vielerorts Ackerland zum Verkauf an, das von den kanadischen Regierung durch eine Werbekampagne angepriesen wurde, während die Vereinigten Staaten zur gleichen Zeit, nämlich 1921 und 1924, massive Einwanderungsbeschränkungen erließen. Vor allem Schweden und Norweger zogen von Minnesota aus nach British Columbia, Alberta, Sasketchewan und in geringerem Ausmaß auch nach Manitoba und Ontario, in erster Linie um in diesen Provinzen Farmen zu gründen. Dabei dominierte die Schwedenanzahl in British Columbia, die Norweger hingegen bevorzugten eher Saskatchewan. Die Dänen wiederum, welche in Ka-

\footnotetext{
${ }^{174}$ Zur schwedischen Präsenz in Chicago siehe Beijbom 1971 und 1973, S. 179-211; Norman/Runblom 1988, S. 170-174; Olson 1991; zur skandinavischen Bevölkerung in Chicago allgemein Lovoll 1991 sowie Runblom 1991.

${ }^{175}$ Zahlenwerte aus Norman/Runblom 1988, S. 294f., Tab. 4. Zur skandinavischen Präsenz in Kanada siehe ebenda S. 155-159.
} 
nada ohnehin am geringsten vertreten waren, hielten sich hauptsächlich in Manitoba auf. Die Finnen hatten dann vornehmlich in Ontario Wurzeln geschlagen, wobei es vor allem größere Städte waren, wie Toronto, Sudbury, Sault Ste. Marie und Thunder Bay, letztere zu Beginn des Jahrhunderts noch Port Arthur genannt, die einen Großteil der finnischen Zuwanderer anzogen ${ }^{176}$. Zum Zeitpunkt der kanadischen Volkszählung des Jahres 1911 lebten bereits 55,6\% aller in Kanada registrierten Finnen in Ontario. Zehn Jahre später war ihr Anteil bereits auf 58,3\% aller Kanada-Finnen angestiegen, was in absoluten Zahlen einem Zuwachs von 8619 auf 12540 Personen gleichkam ${ }^{177}$. Wie aus Tabelle 7 im Anhang hervorgeht, stand die Provinz British Columbia bei den Finnen an zweiter Stelle, gefolgt von den Provinzen Alberta und Sasketchewan.

In Kanada hielten sich demnach die einzelnen skandinavischen Gruppen vorwiegend in verschiedenen Provinzen auf, d.h. dort wo viele Finnen waren, fanden sich kaum Schweden oder Norweger. Diesbezüglich unterschied sich die Besiedlungstradition der verschiedenen skandinavischen Einwanderergruppen in Kanada denn auch deutlich von derjenigen der Vereinigten Staaten.

\section{3. 3. Die Finnen im Bereich der Großen Seen}

Die an natürlichen Mineralvorkommen reichen Staaten Michigan und Minnesota zählten über Jahrzehnte hinweg zu den wichtigsten Arbeitsregionen der finnischen Einwanderer und verdienen von daher besondere Beachtung ${ }^{178}$ : Bereits zu Beginn des Jahrhunderts hielten sich knapp die Hälfte aller bis dato eingewanderten Finnen, das entsprach knapp 30.000 Personen, in den beiden Mittelwest-Staaten im Bereich der Großen Seen auf. Im Vergleich zur Gesamtbevölkerung der entsprechenden Staaten, die bei jeweils etwa zwei Millionen Einwohnern lag, betrug der Finnen-Anteil in Michigan jedoch nur 0,8\% und in Minnesota 0,6\%. Bis 1920 stieg das Finnenaufkommen ledig-

\footnotetext{
${ }^{176}$ Zur geographischen Verteilung der Finnen in Kanada sowie insbesondere zur Konzentration in Ontario siehe Järnefelt 1899, S. 243-251; Kero 1976b; Kouhi 1976; Lindström-Best 1985, S. 3-19 sowie die unveröffentlichten Magisterarbeiten von Saarinen 1981, S. 16-22 und Huhta 1982, S. 71-101, bes. S. 97-99. Speziell zu Frauen in Ontario vgl. Sangster 1981; LindströmBest 1988, S. 22-34.

${ }^{177}$ Ravio 1979, Bd. 2: S. 303-305; Saarinen 1981, S. 20, Tab. 2.

${ }^{178}$ Zu Finnen in Minnesota siehe Ilmonen 1923, Bd. 2, S. 130-232 u. 1926, Bd. 3, S. 164-200; Kolehmainen 1944; Wasastjerna 1957, S. 67-764; Puotinen 1979, S. 123-130; Riippa 1981; Karni 1991. Zu Finnen in Michigan siehe Hirvonen 1920; Holmio 1967, S. 117-596; Virtanen 1977; Puotinen 1979, S. 109-122.
} 
lich in Minnesota auf 1,2\% der Gesamtpopulation an, in Michigan blieb das Verhältnis unverändert bestehen. Auch in Relation zum gesamten Einwandereraufkommen der beiden Staaten lag die prozentuale Beteiligung der finnischen Immigranten deutlich unter 10\%: Trotz zunehmender Tendenz stellten die Finnen 1920 in Michigan lediglich $4 \%$ und in Minnesota $6 \%$ aller europäischen Immigranten ${ }^{179}$.

Der Einfluß der finnischen Einwanderer fällt erst auf Regionalebene wirklich ins Gewicht: Um die Jahrhundertwende bildeten die Finnen nämlich die größte Ausländergruppe in den Montangebieten von Nord-Michigan und Nordost-Minnesota. Um 1900 lebten etwa 20000 Finnen in sieben, im folgenden noch näher auszuführenden, Bergwerksregionen, wobei die Kupfergruben auf der Halbinsel Nord-Michigans und das Eisenerzgebirge Mesabi im Nordosten Minnesotas die meisten Finnen beschäftigten. Bemerkenswerterweise hatte sich keine andere europäische Einwanderergruppe dem Montan- und Waldgebiet der Großen Seen derart verschrieben wie die Finnen, obwohl ihnen die Montanindustrie, mit Ausnahme der ersten über Nord-Norwegen ausgewanderten finnischen Pioniere, völlig fremd war. Ihre mitgebrachte Arbeitserfahrung stammte vorwiegend aus dem Agrarbereich sowie der erst ansatzweise industrialisierten Holzindustrie Finnlands.

Bei näherer Betrachtung der geographischen Verteilung der Finnen fällt eine deutliche Konzentration auf bestimmte Bezirke ${ }^{180}$ im Bereich der Großen Seen auf: In Michigan, das 83 Bezirke zählt, waren der nördliche Bereich, d.h. diejenigen 15 Bezirke, die unmittelbar an die Nordgrenze von Wisconsin angrenzen, besonders stark von Finnen besiedelt. Diese Bezirke, auch als Nordhälfte Michigans bekannt, ergeben ein einheitliches geographisches Gebiet, welches das südliche Ufer des Superior-Sees vom nördlichen Uferstreifen des Michigan-Sees trennt. Hier lebten im Zeitraum 1900-10 zwischen 95,7\% und 94,3\% aller in Michigan registrierten Finnen, was in absoluten Zahlen ca. 18000 bzw. 29600 Personen entsprach. Im Jahr 1920 betrug dieser Prozentsatz nur noch 88,2\%, wonach die Entwicklung der Autoindustrie in Detroit, im Bezirk

\footnotetext{
${ }^{179} \mathrm{Zu}$ Beginn des Jahrhunderts hatte der finnische Prozentanteil innerhalb aller Immigranten bei 3,5\% in Michigan und 2\% in Minnesota gelegen, vgl. Kultalahti 1989, S. 14, Abb. 8 und 9.

${ }^{180}$ Hier und im Folgenden wird der englische Begriff 'County' mit Bezirk wiedergegeben. Zur geographischen Konzentration der Finnen im Bereich der Großen Seen siehe auch Karte 6 im Anhang.
} 
Wayne gelegen, die finnischen Einwandererzahlen zu Beginn der 1920er Jahre auch im südlichen Teil von Michigan langsam anwachsen lie $\beta^{181}$.

Um die Jahrhundertwende befanden sich in Nord-Michigan in elf Bezirken vier separate Bergwerksregionen ${ }^{182}$, in denen untertage Kupfer, Nickel und Eisenerz abgebaut wurde. Lediglich in den vier östlich gelegenen Bezirken Schoolcraft, Luce, Mackinac und Chippewa, welche an Kanada angrenzen, war keine Montanindustrie anzutreffen. Die Kupferbergwerksregion 'Copper Country', welche als langgestreckte Halbinsel 'Upper Penisula' im Bezirk Keweenaw in den Superior-See hinein ragt, galt als die größte und älteste Produktionsstätte, welche über mehrere Jahrzehnte hinweg einen Knotenpunkt für die Arbeitsplatzsuche zahlreicher finnischer Einwanderer darstellte. Südwestlich dieser auch 'Kupferinsel'genannten Landzunge schloß sich die 'Gogebic Range' an, ein Eisenerzgebirge, das von der Staatsgrenze zwischen Michigan und Wisconsin zweigeteilt wurde. Von der Gebirgskette Gogebic in nordöstlicher Richtung gelegen war das Eisenerzgebirge 'Marquette Range' und in südöstlicher Ausdehnung die 'Menominee Range' zu finden. Das letztgenannte Grubengebiet wiederum lag ebenso wie die 'Gogebic Range' im Grenzbereich zwischen Michigan und Wisconsin.

In Minnesota wiederum, einem Bundesstaat von 87 Bezirken, konzentrierten sich die Finnen hauptsächlich auf 14 Bezirke, von denen die Bezirke Cook, Lake, St. Louis und Carlton das westliche Ufer des Superior-Sees bilden ${ }^{183}$. Die übrigen zehn Bezirke füllen den nordöstlichen Teil des Bundesstaates aus und erstrecken sich dabei fast bis an die westliche Staatsgrenze zu North und South Dakota. In diesen 14 Bezirken, welche ein weniger einheitliches geographisches Gebiet darstellen als die nördliche Hälfte Michigans, lebten zwischen 1905 und 1920 nahezu unverändert 95\% aller in Minnesota-Finnen der ersten Einwanderergeneration. In absoluten Zahlen entsprach dies einer Spannbreite von ca. 19000 bis 27600 Personen. Da die Finnen der zweiten Generation, d.h. die in Minnesota geborenen Kinder finnischer Eltern, aus dieser Be-

\footnotetext{
${ }^{181}$ Es sind folgende 15 Bezirke gemeint: Keweenaw, Hougthon, Ontonagon, Baraga, Gogebic, Iron, Marquette, Dickinson, Menominee, Delta, Alger, Schoolcraft, Luce, Mackinac und Chippewa. Im Jahr 1900 waren in diesen Bezirken jeweils zwischen 135 und 7241 Finnen zu finden, siehe Virtanen 1977, S. 78f. und S. 86, Tab. 5.

${ }^{182}$ Zur geographischen Lage der Eisenerz-und Kupferbergwerke in Michigan und Minnesota siehe Karte 7 im Anhang.

${ }^{183}$ Im Jahr 1905 lebten in folgenden 14 Bezirken jeweils zwischen 237 und 12076 finnische Einwohner der ersten Einwanderergeneration: Cook, Lake, St. Louis, Carlton, Itasca, Aitkin, Crow Wing, Wadena, Becker, Otter Tail, Hennepin, Meeker, Pine und Wright. Siehe hierzu Riippa 1981, S. 299f.,Tab. 15.2.
} 
rechnung ausgeschlossen wurden, liegt es auf der Hand, daß die tatsächliche Anzahl der Finnen in Minnesota weitaus größer gewesen ist; ein Tatbestand der ebenso auf alle anderen Bundesstaaten mit hoher Finnenkonzentration zutrifft ${ }^{184}$. Innerhalb von Minnesota wies der für die Montanindustrie bedeutsame Bezirk St. Louis den höchsten Finnenanteil auf: Wurden 1895 noch 42\% aller Minnesota-Finnen der ersten Einwanderergeneration hier registriert, so lag ihr Prozentsatz nach 1905 fast konstant bei 60\%. Dieser hohe Finnenanteil kam jedoch nicht zuletzt durch die Hafenstadt Duluth, am Ufer des Superior-Sees gelegen, zustande, wo sich die finnische Einwohneranzahl von 1900-20 vervierfachte, als die finnische Einwohnerschaft nämlich von 702 auf 3210 Personen anstieg $^{185}$.

Diese regionale Konzentration auf den Nordosten des Staates Minnesota ist auf die Erschließung zweier separater Bergwerksregionen zurückzuführen ${ }^{186}$, in denen um 1880 mit dem Eisenerzabbau begonnen wurde: Nahe der kanadischen Grenze war die 'Vermilion Range' zu finden, die jedoch an Größe und Produktionskapazität von der südlicher gelegenen 'Mesabi Range' in den Schatten gestellt wurde.

Südwestlich von Duluth an der Schnittstelle der Bezirke Crow Wing und Aitkin, und damit mehrere hundert Kilometer vom Mesabigebirge entfernt, lag die dritte und kleinste Gebirgskette Minnesotas, die 'Cuyuna Range', deren Eisenerzvorkommen gegen Ende des 19. Jahrhunderts sogar von einem Finnen entdeckt worden waren. Kapitalmangel sowie fehlende Investoren führten jedoch dazu, daß der Gebirgszug erst im Jahr 1911 von einer amerikanischen Bergwerksgesellschaft industriell erschlossen wur$\mathrm{de}^{187}$.

Von der isoliert gelegenen 'Cuyuna Range' abgesehen, kann in Minnesota - im Gegensatz zu Nord-Michigan - von einem einheitlichen, großflächigen Montangebiet im Bezirk St. Louis gesprochen werden.

In Wisconsin dahingegen, einem Bundesstaat von insgesamt 71 Bezirken, konzentrierte sich die finnische Einwanderung insbesondere auf den zwischen Michigan

\footnotetext{
${ }^{184}$ Im Jahr 1920 beispielsweise wurden insgesamt 29108 Finnen der ersten sowie 32730 Finnen der ersten und zweiten Generation in Minnesota gezählt, siehe Riippa 1981, S. 299f., Tab. 15.2. ${ }^{185}$ Kaups 1981, S. 63,Tab. 1; Kero 1996, S. 127.

${ }^{186}$ Puotinen 1979, S. 123-130.

${ }^{187}$ Zur Geschichte der Entdeckung der 'Cuyuna Range' siehe Wasastjerna 1957, S. 148f.; Puotinen 1979, S. 129f.
} 
und Minnesota gelegenen südlichen Uferstreifen des Superiors-Sees ${ }^{188}$. Diese Uferregion besteht aus den vier Bezirken Douglas, Bayfield, Ashland und Iron, wo im Zeitraum 1900-20 62\% aller Wisconsin -Finnen lebten ${ }^{189}$. An den Uferstreifen schließen sich wiederum vier weitere von Finnen bevorzugte Bezirke an, nämlich Vilas, Forest, Florence und Marinette, die gleichsam die Ostgrenze zu Nord-Michigan bilden. Da diese acht Bezirke ein geographisches Verbindungsstück zwischen Nord-Michigan und Nordost-Minnesota darstellen, kann von einem geographisch zusammenhängenden Gebiet der Amerika-Finnen gesprochen werden, das sowohl die südliche Seite des Superior-Sees als auch die nördliche Hälfte des Michigan-Sees umgab. Obwohl auch in Wisconsin Eisenerz abgebaut wurde, wovon nicht zuletzt der Bezirksname 'Iron County' am Ufer des Superior-Sees zeugt, galt der Bundesstaat in erster Linie als Holzlieferant. Vor allem in der Wintersaison fanden unzählige Finnen hier vorübergehende Beschäftigungsmöglichkeiten als Holzfäller oder Sägewerksarbeiter, bevor sie bei Frühjahrsbeginn wieder in die Grubenorte oder in größere Städte zurückwanderten.

Finnische Einwanderer arbeiteten demnach in erster Linie in den Bergbaugebieten im Norden Michigans und im Nordosten Minnesotas sowie in den endlosen, erst spärlich erschlossenen Kiefernwäldern des Mittleren Westens. Beide Arbeitsbereiche waren eng miteinander verbunden, da sich zahlreiche Waldgebiete im Besitz von Eisenbahngesellschaften befanden, die große Mengen an Holz für den Eisenbahngleisbau benötigten. Eine verbesserte Infrastruktur in Form eines flächendeckenden Eisenbahnnetzes war wiederum für die Intensivierung der Förderproduktion von Eisenerz, Quarz, Kupfer und Kohle unumgänglich. Hiervon profitierte vor allem die Sägewerksindustrie, welche ihrerseits ein großes Arbeitskräftepotential benötigte und aufgrund der ständigen Holznachfrage expandieren konnte. Somit schufen sowohl die Eisenbahngesellschaften als auch die Holzindustrie als Waldeigentümer immer wieder neue Arbeitsplätze im Bereich der Waldrodung und des Holztransports.

Doch nicht allen Finnen, die mit Waldkamps und Bergwerken vertraut waren, gewöhnten sich an die mit dem ständigen Wechsel der Arbeitsplätze verbundene Mobi-

\footnotetext{
${ }^{188}$ Zur finnischen Einwanderung nach Wisconsin siehe Kolehmainen/Hill 1965, S. 27-105; Knipping 1977, S. 3-39.

${ }^{189}$ Bei den Volkszählungen 1910 und 1920 wurde knapp die Hälfte aller Wisconsin-Finnen in den Bezirken Douglas und Iron in der Grenzregion zu Michigan und Minnesota registriert, vgl. Kolehmainen/Hill 1965, S. 154f. Außerdem sind hier Namensgleichheiten zu beachten: 'Douglas County' in Minnesota sowie 'Iron County' in Michigan. Sämtliche Bezirke wurden zahlreich von Finnen bewohnt.
} 
lität über Jahre und Jahrzehnte hinweg. Sobald ein gewisser finanzieller Grundstock erreicht war, stellte sich die Frage nach einer dauerhaften Rückwanderung nach Finnland, wie zumeist bei Auswanderungsbeginn geplant, oder aber der Gründung einer eigenen Farm in Amerika, was vor allem für Auswandererfamilien eine Alternative bedeutete. Die meisten finnischen Farmen waren denn auch in unmittelbarer Nähe der Grubenorte oder Waldkamps zu finden, da die Landwirtschaft für viele Familienväter lediglich einen Nebenerwerb darstellte. Im Jahr 1920 erhielten bereits rund ein Viertel aller Amerika-Finnen ihren Lebensunterhalt zumindest teilweise aus dem Bereich der Landwirtschaft. Allein in den drei Staaten Michigan, Minnesota und Wisconsin waren im Jahr 1920 nach offiziellen Angaben der amerikanischen Zensus-Behörden 11167 Farmen in finnischer Hand ${ }^{190}$.

Vor allem in der Zeit um die Jahrhundertwende enstanden zahlreiche von Finnen gegründete Siedlungen in ländlichen Gebieten, die finnische Namen trugen: Die meisten davon lagen in Minnesota wie Finland, Finlayson, Palo, Makinen, Toivola, Heinola, Esko und Alango ${ }^{191}$. Aber auch in Wisconsin und Michigan zeugten Ortsnamen wie Oulu und Salo bzw. Kaleva und Onnela von finnischer Präsenz, und in South Dakota galt Savo als eine der größten von Finnen gegründete Siedlung ${ }^{192}$.

Westwärts gelegene finnische Siedlungen entwickelten sich neben South und North Dakota vor allen in Montana, Wyoming und in bescheidenem Ausmaß auch in Idaho. An der Westküste wiederum lockten ein wärmeres Klima und große Obstplantagen die finnischen Landwirte von Washington über Oregon bis hin nach Kalifornien an.

Doch auch auf kanadischer Seite waren finnischsprachige Ortsnamen zu finden, wie beispielsweise New Finland in Sasketchewan, Sointula in British Columbia sowie Suomi, Lappe ${ }^{193}$ und Pohjola in Ontario. Letztgenannte Siedlungen gehörten zu dem von Finnen bevorzugten Gebiet im nördlichen Bereich der Großen Seen, welches das nördliche und westliche Ufer des Superior-Sees umgab. Insbesondere die beiden Städte Thunder Bay, vormals Port Arthur genannt, unweit der Grenze zu Minnesota sowie die zweigeteilte Stadt Sault Ste. Marie, deren eine Hälfte in Ontario und die andere in Michigan liegt, galten als urbane Knotenpunkte für finnische Arbeitssuchende. Viele Holz-

\footnotetext{
${ }^{190}$ Kero 1996, S. 156 und S. 163.

${ }^{191} \mathrm{Zu}$ finnischen Siedlungsnamen in Minnesota siehe Kaups 1966; speziell zu Alango vgl. Kero 1996; S. 136-138.

${ }^{192} \mathrm{Zu}$ Savo in South Dakota vgl.Torma 1988, S. 101f.

${ }^{193} \mathrm{Zu}$ den kanadischen Siedlungen Suomi und Lappe siehe Timothy 1995, S. 19-23; zu New Finland siehe Anderson/Niskala 1981, S. 159-161; Virtaranta 1983; Kero 1996, S. 138-141.
} 
fäller sowie Eisenbahngleis- und Straßenbauarbeiter hielten sich die Sommermonate über in diesen Städten auf ${ }^{194}$.

Beide Städte verband eine etwa 700 Kilometer lange Eisenbahnstrecke mit zahlreichen kleineren Ortschaften, in denen ebenfalls Finnen zu finden waren. Östlich von Sault Ste. Marie beschäftigte die Montanindustrie zahlreiche Finnen, wo in der Nähe der Städte Sudbury, North Bay und Copper Cliff in erster Linie Kupfer- und Nickelvorkommen ausgeschöpft wurden. Im Umkreis dieser Bergwerksregionen wiederum bildeten sich ländliche Siedlungen, deren finnische Bewohner vornehmlich von der Landwirtschaft lebten, wie Beaver Lake, Waters Township, Long Lake und Wanup. An der Provinzgrenze zu Québec befanden sich weitere bekannte Siedlungsgebiete der Finnen, wie die nördlich von Sudbury gelegenen Orte Cobalt mit einem großen Silberbergwerk, Kirkland Lake und Larder Lake sowie die benachbarten Orte South Porcupine und Timmins, wo wiederum Gold gewonnen wurde und sich zahlreiche finnische Farmen befanden.

An der Westküste wären noch die Kohlebergwerke der Provinz Alberta mit den für Finnen bedeutsamen Städten Blairemore, Coleman, Bellevue und Canmore zu nennen ${ }^{195}$. In British Columbia waren Finnen entweder als Hochseefischer oder Grubenarbeiter in Nanaimo auf Vancouver Island zu finden, wo zu Beginn des Jahrhunderts auch die kurzlebige finnische Siedlung 'Sointula' entstand, die auf einer utopischen Gründungsideologie von Matti Kurikka basierte und zugleich unter allen finnischen Siedlungsgründungen die größte Aufmerksamkeit erregte ${ }^{196}$.

\footnotetext{
${ }^{194}$ Wilson 1977, S. 19.

${ }^{195}$ Lindström-Best 1985, S. 9. Zu finnischen Arbeitern in der kanadischen Montanindustrie siehe Raivio 1975, Bd. 1, S. 41-50 sowie die Artikel von Seager 1981, 1983 und 1986.

${ }^{196}$ Zur Gründung der Utopie-Siedlung 'Sointula' siehe Kolehmainen 1976b; Wilson 1981 und 1988; Kratz 1993.
} 


\subsection{Amerikanischer Arbeitsalltag aus finnischer Perspektive: Finnen unter sich}

\subsubsection{Schichtarbeit untertage}

Die Finnen stellten um die Jahrhundertwende die größte Ausländergruppe in der Region der Großen Seen dar. Sowohl auf amerikanischer wie auf kanadischer Seite waren sie in allen Montanregionen zahlreich vertreten und darüber hinaus in unzähligen Waldkamps, Sägewerken und bei Gleisbautrupps diverser Eisenbahngesellschaften vereinzelt oder in größeren Gruppen zu finden. Im folgenden werden in erster Linie die Lebensbedingungen in sieben verschiedenen Gebirgsregionen in Michigan und Minnesota näher betrachtet, die mit Ausnahme der Stadt New York die höchsten Konzentrationen von Finnen auf dem nordamerikanischen Kontinent aufwiesen. In fünf von diesen sieben Grubengebieten beherrschten Finnen das Straßenbild vor den kanadischen, britischen, irischen, schwedischen, italienischen und südslavischen Einwanderergruppen, nämlich auf der sogenannten Kupferinsel, der Gogebic und Marquette Range in NordMichigan sowie auf der Mesabi und Cuyuna Range in Minnesota. Lediglich in den Grubengebieten Menominee Range im Grenzgebiet von Michigan und Wisconsin und Vermilion Range in Minnesota dominierten Schweden und Immigranten aus ÖsterreichUngarn, die in erster Linie Südslaven waren ${ }^{197}$.

\subsubsection{Bergbau in Michigan}

Ein eindrucksvolles Bild von der Dominanz der finnischen Immigrantengruppe geben die Bevölkerungszahlen der Volkszählung des Jahres 1900 der Bezirke Keweenaw und Houghton in Nord-Michigan, wo sich die einzige Kupferproduktionsstätte im Bereich der Großen Seen befand, die zugleich die größte ihrer Art in den Vereinigten Staaten war. In beiden Bezirken, als Kupferinsel bekannt geworden, lebten bereits 1880 nach offiziellen Angaben 754 zugezogene Finnen ${ }^{198}$. Im Jahr 1900 wurden in der Region bereits 7951 Finnen gezählt, was 42\% aller in Michigan lebenden Finnen entsprach.

${ }^{197}$ Alanen 1983b, S. 5f. 
Der überwiegende Teil dieser knapp 8000 Finnen hielt sich in Houghton County auf, dem eigentlichen Zentrum des Kupfererzabbaus.

Zur gleichen Zeit bestand der Bezirk mit insgesamt 66063 Einwohnern zu 42,6\% aus europäischen Einwanderern der ersten Generation. Innerhalb dieser Einwandererpopulation stellten die Finnen wiederum 25,7\%, wonach jeder vierte Einwanderer des Bezirks finnischer Abstammung war ${ }^{199}$. Die Briten, zu denen auch Schotten und Cornwall-Bewohner gezählt wurden, bildeten mit 14\% die zweitgrößte Ausländergruppe des Bezirks, gefolgt von den Kanadiern, Slowenen und Kroaten - als Österreich-Ungarn registriert -, Italienern sowie Vertretern der früheren Einwanderergruppen, wie Deutschen, Schweden, Norwegern und Iren.

Bei der Volkszählung des Jahres 1910 wurden bereits 12736 Finnen der ersten Generation, d.h. 40,9\% aller in Michigan lebenden Finnen, im Bezirk Houghton registriert, da insbesondere während des ersten Jahrzehnts des 20. Jahrhunderts zahlreiche neue Arbeitsplätze in dieser Region entstanden waren.

Obwohl die Kupfervorkommen bereits in den 1840er Jahren entdeckt worden waren, begann die industrielle Erschließung der Kupferinsel erst im Jahr $1864^{200}$. Dieser Zeitpunkt fiel nicht von ungefähr mit der nachweisbaren Ankunft von Finnen, Schweden und Norwegern zusammen, welche zuvor an der norwegischen Eismeerküste Kupfer abgebaut hatten. Die erfahrenen Bergleute wurden 1864 oder 1865 im Auftrag der ersten amerikanischen Kupferbergwerksgesellschaft, der 'Calumet and Hecla Cooperation', mit einem freiem Überfahrtsangebot angeworben, was vermutlich die unmittelbare Nachwanderung mehrerer hundert Personen aus den norwegischen Kå-Fjord- und Vadsjø-Gebieten nach sich $\operatorname{zog}^{201}$.

In der Folgezeit entwickelte sich insbesondere das Einzugsgebiet der Kleinstadt Calumet, nördlich von Hancock für die Finnen zur wichtigsten und häufig auch zur ersten Anlaufsstelle bei ihrer Arbeitssuche in den Vereinigten Staaten. Von 7241 in 'Houghton County' registrierten Finnen des Jahres 1900 hielten sich etwa 6000 Perso-

\footnotetext{
${ }^{198}$ Kaups (1975, S. 59f.) bewertet diese Ziffer jedoch als zu niedrig, seiner Schätzung nach müßten 1880 bereits mehr als 1500 Finnen in der Region gelebt haben.

${ }^{199} \mathrm{Zu}$ den Zahlenwerten siehe Thurner 1974, S. 13 und 1984, S. 21.

${ }^{200}$ Zur Industriegeschichte der Kupferinsel siehe Murdoch 1964, S. 36-150, zu den Anfängen bes. S. 36-72; Thurner 1994, S. 19-122.

${ }^{201}$ Die näheren Umstände der Anwerbung werden erstmals 1920 bei Hirvonen (S. 46f.) erwähnt und bei Ilmonen (1923, Bd. 2, S. 65-71) weiter ausgeführt. Über den genauen Zeitpunkt der ersten Reisegruppe besteht Unklarheit.
} 
nen im Umkreis von Calumet auf, wonach die Kleinstadt auch als regionaler Knotenpunkt für die Nachwanderung weiterer Familienangehöriger diente ${ }^{202}$.

Bereits 1871 wurde in Calumet die erste finnische Kirchengemeinde auf amerikanischen Boden gegründet. Außerdem erschien in Calumet von 1879-95 die erste Wochenzeitung in finnischer Sprache, die 'Finnisch-Amerikanische Zeitung' mit einer Auflagenstärke von 800 Stück $^{203}$. Im naheliegenden Hancock wiederum wurde 1898 die einzige Bildungseinrichtung der Amerika-Finnen mit akademischem Anspruch, das 'Suomi College', gegründet. Das heute noch bestehende College entstand aus dem Bestreben nach christlicher Bildung und dem Erhalt des finnischen Sprach- und Kulturerbes, das den Gründungsvätern, Vertretern des finnischen Kirchenverbandes in Amerika, der sogenannten 'Suomi Synode', ein besonderes Anliegen war ${ }^{204}$. Dementsprechend kann die gesamte Region um Hancock und Houghton als ein Zentrum der frühen finnisch-amerikanischen Einwandererkultur in Michigan angesehen werden.

Die Kupferproduktion hielt die abgeschiedene Region wirtschaftlich am Leben. Zeitweilig waren mehr als 40 Gruben in Betrieb, von denen die 'Calumet and Hecla Mine' mit mehr als 5000 Beschäftigten, die 'Osceola Mine', die ‘Ahmeek Mine' sowie die 'Tamarack Mine’ mit jeweils etwa 1000 Arbeitern zu den größten Produktionsstätten zählten ${ }^{205}$. Im Zeitraum von 1870-1907 stieg die Anzahl der Bergwerksarbeiter der Kupferregion von 4188 um ein Fünffaches auf 21014 Personen an.

In nahezu allen Kupfergruben wurde das Erz untertage in zwei Arbeitsschichten, d.h. in Tag- und Nachtschichten, abgebaut. Eine Sechs-Tage-Woche war üblich, und die unflexiblen Arbeitszeiten lagen bei 10-11 Stunden pro Schicht. Der Acht-Stunden-Tag hielt auf der Kupferinsel erst 1914 Einzug, obwohl bereits 1910 die Arbeitsschichten für Industriearbeiter in den meisten Bundesstaaten gesetzlich auf acht Stunden festgeschrieben wurden ${ }^{206}$. In vielen Gruben benutzten die Arbeiter ihr eigenes Werkzeug, das

\footnotetext{
${ }^{202}$ Als Zeit- und Augenzeuge beschreibt Järnefelt bereits 1899 (S. 91-101) den finnischen Einfluß auf die Calumet-Region.

${ }^{203}$ Diese Zeitung war strenggenommen bereits die zweite Auswandererpublikation der Finnen, das erste gleichnamige Blatt erschien 1876 nur wenige Monate lang in Hancock, unweit von Calumet gelegen. Zur 'Finnisch-Amerikanischen Zeitung' siehe die ausführliche Darstellung von Kero (1978a) und Pilli (1986, S. 59-62). Weitere Hinweise bei Hirvonen 1920, S. 86f.; Thurner 1974, S. 20-24; Kaups 1975, S. 64-66.

${ }^{204}$ Zum 'Suomi College' siehe Ollila 1969, S. 189; Niemi 1971, S. 67f.; Jalkanen 1976;

Korkiasaari 1989, S. 41f.; Kero 1997, S. 29f.

${ }^{205}$ Steele 1982, S. 12.

${ }^{206}$ Holmio 1967, S. 395; Ross 1982, S. 99.
} 
sie in werkseigenen Schmiedewerkstätten instand halten konnten ${ }^{207}$. Auch ihre Schutzkleidung mußten sich die Arbeiter selbst besorgen, was bei dem allgemein niedrigen Lohnniveau einen kostenträchtigen Faktor des Alltagslebens darstellte.

Die Tiefe der senkrecht oder schräg abfallend in die Erde eingelassenen Schächte variierte in den verschiedenen Gruben zwischen 500 und 1500 Metern, und eine Vielzahl von 48 Stollengängen, wie beispielsweise in der 'Quincy Mine', war keine Seltenheit. In den untersten Stollengängen konnten die Temperaturen auf mehr als $80^{\circ}$ Grad Celsius ansteigen, was das Kerzenwachs an Stahlhelmen der Bergleute schmelzen ließ. ${ }^{208}$ Ständiger Staub, Ruß und Kerzenrauch verursachten Kopfschmerzen, tränende Augen und auf längere Sicht die dauerhafte Erkrankung der Lungen und Atemwege. Die Arbeiter benutzten hölzerne Leitern und Förderkörbe, um von einem Stollengang in den nächsten zu gelangen. Nach der Jahrhundertwende wurden in den größeren Gruben, z. B. in der 'Tamarck Mine', doppelstöckige Aufzüge für etwa ein Dutzend Bergleute eingeführt, und nach 1910 hielt die Elektrizität allmählich in allen Gruben der Kupferinsel Einzug, was zu einer besseren und gefahrloseren Ausleuchtung der Stollengänge führte ${ }^{209}$.

Die Sozialhierarchie unter den Bergleuten konstituierte sich sowohl aus den verschiedenen Aufgabenbereichen als auch aus ethnischen Gruppenzugehörigkeitsmerkma$1 \mathrm{le}^{210}$, wobei oftmals beide Faktoren einander bedingten: Die Pioniere unter den Grubenarbeitern zählten zugleich zu den älteren Einwanderergruppen, wie den Briten, Iren, Deutschen und Schweden. Den zuletzt eingewanderten Immigranten gegenüber nahmen sie zahlreiche Vorrechte in Anspruch, wie u.a. die besser bezahlten Positionen der Vorarbeiter, welche als 'Mining Captains' den Kupferabbau in den Stollengängen überwachten. In den meisten Fällen waren es englischsprachige Immigranten, d.h. insbesondere Männer aus Cornwall, die aufgrund ihres frühen Einwanderungsbeginns in den 1840er Jahren sowie ihrer mitgebrachten Arbeitserfahrung als Bergleute an die Spitze der Sozialhierarche aufsteigen konnten ${ }^{211}$. An den Maschinen wurden gebürtige Amerikaner eingesetzt, die sich auch in den oberen Rängen der Stufenleiter befanden. Die

\footnotetext{
${ }^{207}$ Taylor 1971, S. 202. Siehe hierzu auch den Erfahrungsbericht von Tokoi 1949, S. 59f.

${ }^{208}$ Järnefelt 1899, S. 89 u. S. 104; Thurner 1974, S. 35.

${ }^{209}$ Steele 1982, S. 55 u. S. 66.

${ }^{210}$ Zum ethnischen Konglomerat der Bergleute siehe Hoglund 1960, S. 63f.; Thurner 1974, S. 13-18.

${ }^{211}$ Zur besonderen Stellung der Einwanderer von der Cornwall-Halbinsel als Vorgesetzte der Finnen siehe Hiipakka Lockwood 1988, S. 464-473, bes. S. 467.
} 
Mehrzahl der Arbeiter schlug jedoch mit Schlegel und Eisen als gewöhnliche Bergleute, als 'Miner', das Erz aus den Stollenwänden. Um 1900 kamen dann zusätzlich Bohrmaschinen in Gebrauch, was den Arbeitertyp des 'Drillers' hervorbrachte. Auch hier waren es in erster Linie englischsprachige Immigranten, allen voran Kanadier und Briten sowie gelegentlich Schweden oder Norweger, die den Mittelbau der Sozialhierarchie bildeten. Auf der nächstunteren Stufe standen die Zimmerleute, die als 'Timbermen' für die Holzauskleidung und Reperatur der Stollenwände und -decken verantwortlich waren, unter ihnen waren viele Finnen und Südost-Europäer. Der vornehmlichste Aufgabenbereich der Finnen lag jedoch im Beladen der Förderwaggons, welche auf Schienen die langen Stollengänge entlang geschoben werden mußten. Diese Arbeit als 'Trammer' erforderte enorme Muskelkraft und Ausdauer, da untertage nur selten Zugtiere eingesetzt wurden ${ }^{212}$. Das Beladen und Schieben der mit Gestein beladenen Waggons bildete zumeist auch die erste Tätigkeit für noch unerfahrene Einwanderer. An den Schachtöffnungen am Stollenende mußte das Erz dann in Förderkörbe verladen und maschinell ans Tageslicht gehoben werden, was im Hinblick auf die Unfallstatistik als eine der gefährlichsten Aufgaben galt.

Obwohl die Finnen auf der Kupferinsel die größte Ausländergruppe stellten, waren sie unter den Arbeitern des Mittelbaus kaum vertreten. Ironischerweise zählten sie zu den gebildetesten innerhalb der europäischen Einwanderergruppen ${ }^{213}$ - viele waren des Lesens und Schreibens kundig - , doch als unerfahrene Bergleute arbeiteten sie in schlechtbezahlten Aufgabenbereichen. Insbesondere die Sprachbarriere erschwerte ihren sozialen Aufstieg, wodurch sie gemeinsam mit den Südslaven und Italienern auf den niedrigsten Stufen der sozialen Leiter standen ${ }^{214}$. Lediglich jugendliche Helfer verschiedener Nationalität im Alter von 13-16 Jahren, 'Drill Boys' genannt, welche täglich mit ihren Vätern in die Gruben hinabstiegen, nahmen die untersten Plätze der Sozialhierarchie ein ${ }^{215}$.

\footnotetext{
${ }^{212}$ In der Frühphase der amerikanischen Montanindustrie wurden Mulis oder Esel lediglich übertage zum Antrieb von riesigen Zahnrädern eingesetzt, welche den Hebemechanismus der Förderkörbe in den Schächten regulierten, siehe Murdoch 1964, S. 57. Zur Arbeit der 'Trammer' siehe Stichwort: 'Trammari' im finnisch-amerikanischen Wörterbuch von Virtaranta 1992, S. 211.

${ }^{213}$ Zum Vergleich des allgemeinen Bildungsstands der einzelnen europäischen Einwanderergruppen siehe Seller Schwartz 1988, S. 102 und S. 137.

${ }^{214}$ Kaups 1975, S. 63.

${ }^{215}$ Für die häufig kinderreichen Familien der Bergleute war Kinderarbeit ein ökonomisch notwendiger Überlebensfaktor, vgl. Thurner 1974, S. 39; Hollingsworth 1982, S. 61.
} 
Die Arbeitsverhältnisse in den Schächten und Stollen waren extrem gefährlich und gesundheitsgefährdend ${ }^{216}$ : Stehende Luft im Sommer, Staub und Ruß sowie kalte Zugluft im Winter ließen die Bergleute wiederholt an Augen- und Lungenentzündungen erkranken, und nach Wassereinbrüchen verstärkten Feuchtigkeit und naßkalte Luft das Auftreten von Rheuma und anderen Krankheiten. Dementsprechend hoch war auch die krankheitsbedingte Sterblichkeit unter den Bergleuten, wobei neben Lungenentzündungen und -krebs vor allem Seuchenerkrankungen wie Tuberkulose, Typhus und Scharlach zu den häufigsten Todesursachen zählten ${ }^{217}$.

Doch besonders der plötzliche Tod durch Unfälle gehörte allerorts zum Grubenalltag. In zahlreichen Briefen, Interviewaussagen und Lebensberichten finden sich immer wieder Hinweise auf die Gefährlichkeit des unterirdischen Gesteinsabbaus. Fast täglich wurden Bergleute untertage verletzt oder getötet, doch auch größere Unfälle mit mehreren Dutzend Todesopfern kamen häufig vor, wie beispielsweise im Jahr 1893, als 27 Bergleute durch einen Wasseneinbruch in einem Stollen der Menominee Range, einem Eisenerzgebiet an der Grenze zu Wisconsin, ertranken ${ }^{218}$.

Im Hinblick auf Grubenunfälle mit finnischen Opfern haben zwei tragische Gasexplosionen die Öffentlichkeit erregt, welche sich in den Bergstaaten Utah und Wyoming ereigneten: Im Jahr 1900 führte eine Detonation im Bergwerk von Scofield, südlich von Salt Lake City zu 325 Todesofern, von denen 63 als Finnen identifiziert werden konnten. Nur drei Jahre später starben dann bei einem Grubenunfall in Hanna, an der Eisenbahnstrecke von Cheyenne nach Rock Springs in Wyoming gelegen, 169 Bergleute. Mehr als die Hälfte von ihnen, insgesamt 93 Personen, waren Finnen ${ }^{219}$. Vor der Einführung von Karbidlampen arbeiteten die Bergleute im Schein von Kerzenlicht, das an einem Kerzenhalter an den Stahlhelmen befestigt war. Dies erhöhte das ohnehin schon große Brandrisiko, welches durch die Holzabstützung der Stollengänge gegeben war. Doch neben Bränden mit starker Rauchentwicklung zählten auch Steinschlag durch herabfallende Geröllbrocken, Unfälle beim Umfüllen der Gesteinsmassen aus den Schienenwaggons in die Förderkörbe an der Schachtöffnung, Stolleneinbrüche durch Wassermassen, Abrutschen von Leitern und Schachtrampen sowie vor-

\footnotetext{
${ }^{216}$ Siehe die unveröffentlichte Magisterarbeit von Saarelainen 1974, hier S. 59-62.

${ }^{217}$ Holmio 1967, S. 230; Kolehmainen 1967, S. 260. Vgl. auch den Erfahrungsbericht von Eli Kiviaho, der 52 Jahre lang in einem Kupferbergwerk bei Sudbury in Ontario arbeitete (Ketonen 1976, S. 16f.).

${ }^{218}$ Hill 1976, S. 60.

${ }^{219}$ Ilmonen 1926, Bd. 3, S. 222 u. S. 230; Sulkanen 1951, S. 38; Kolehmainen/Hill 1965, S. 34.
} 
zeitige Explosionen durch unsachgemäßen Sprengstoffgebrauch zu den häufigsten Unfallsursachen.

"Many men were killed in accidents in the mines every day. There were hundreds of men around the mine offices looking for work. [...] A miner from North Tamarack was staying with us, and I asked him to help Mike and me find work - which he did. The mine was about three miles from our house, and every morning, no matter what the weather was like, I was on my way at four o'clock. My pay was thirty-two dollars a month. It was a big help to my father and mother. [...] The mine where I worked was a five-thouseand-foot vertical shaft. It was hot underground, and the men wore shoes but no socks. Men wore trousers but were bare from waist up, exept for a hardhat worn as protection against small rocks. It took the trammers about a half-hour to fill a tram car; when they emerged from the shaft, their shoes were full of sweat. In that place, everything possible was taken out of a man. [...] Men were free, but timbers were expensive. Since the mining company had to pay for timbers, the shoring-up of the mine's shaft and drifts was inadequate. Rocks falls were frequent. Many workers offered token resistance to company policy, but nearly always got their time slips; or they were forced to work in the most dangerous places of the mine - so that they could be sent to the surface as corpses. There were always men who were willing to take the places of the dead. [...] I worked there for three years and was witness to many tragic events."

Mit diesen Worten schildert ein junger Finne die gefährlichen Arbeitsbedingungen in der 'Tamarack Mine' im Jahr $1894^{220}$. Bei der näheren Untersuchung der Umstände, die während drei Jahrzehnten, von 1887-1917, zum Tod von 1128 Bergleuten in der gleichen Grube geführt hatten, konnte in 999 Fällen die Todesursache ermittelt werden $^{221}$ : Dabei waren 405 Arbeiter durch herabfallende Gesteinsbrocken erschlagen worden, 172 in Unfälle mit Waggons und Förderkörben beim Erzumladen verwickelt gewesen, 162 in die Schächte gefallen und 145 durch Explosionen und Grubenbrände gestorben. Lediglich in 115 Fällen wurden andere Gründe als Unfallursachen angegeben.

\footnotetext{
${ }^{220}$ Zitat aus der Autobiographie von Isaac Polvi, herausgegeben und ins Englische übersetzt von Damrell 1991, S. 133f.
} 
Diese Zahlen, die für eine von rund 40 Gruben der Kupferregion galten, rücken die Frage nach Einstellung und Moral der Bergwerksgesellschaften in den Vordergrund, welche für mangelnde oder gänzlich fehlende Sicherheitsvorkehrungen in den Stollen und Schächten verantwortlich waren. Obwohl allen Bundesstaaten mit mehr als fünf Bergwerken im Jahr 1906 ein staatlicher Grubeninspekteur zugeteilt wurde, rissen die Serien der sich ständig wiederholenden Grubenunfälle mit gleicher Ursache nicht ab. Wenn beispielsweise finnische Bergleute - der englischen Sprache unkundig - mit der Detonation von Sprengstoffen betraut wurden, deren Gebrauchsanleitung sie nicht verstehen konnten ${ }^{222}$, liegt die Vermutung nahe, daß hier einfach Achtlosigkeit und Desinteresse der Bergwerksleitung am physischen Wohlergehen ihrer Beschäftigten vorherrschte. Dennoch sind auch Schadensersatzforderungen dokumentiert, wonach die Bergwerksgesellschaften entweder dem arbeitsunfähig gewordenen Bergmann bzw. im Todesfall seiner Ehefrau einen einmaligen Betrag von einigen hundert Dollars zahl$\operatorname{ten}^{223}$.

Vor diesem Hintergrund verwundert es nicht, daß den Arbeitern der Kupferinsel ein demokratisches Mitspracherecht in Betriebsangelegenheiten verwehrt blieb. Die Entscheidungsgewalt konzentrierte sich in den Händen der Betriebsdirektoren dreier großer Bergwerksgesellschaften, welche nicht zuletzt auch das Alltagsleben der Grubenarbeiter und ihrer Familien reglementierten ${ }^{224}$.

Gefährliche Arbeitsbedingungen bei schlechter Bezahlung waren denn auch die zentralen Streikgründe, die wiederholt zu Arbeitsniederlegungen in verschiedenen Gruben führten. Als Großstreik ging der sogenannte 'Copper Country Strike' in die amerikanische Industriegeschichte ein, der die gesamte Kupferproduktion der Halbinsel

\footnotetext{
${ }^{221}$ Während des Untersuchungszeitraumes waren in der 'Tamarack Mine', einer der größten regionalen Kupfergruben, durchschnittlich 650-750 Männer beschäftigt, vgl. Steele 1982, S. 56 und S. 68.

${ }^{222}$ Unwissen und unsachgemäßer Sprengstoffgebrauch führte zum Tod der Finnen Olaf Hendrickson und Matias Flenk am 9.12.1891 in der 'Tamarack Mine', vgl. Steele 1982, S. 65. ${ }^{223}$ Als Beispiel sei ein Grubenunfall in Crystal Falls, dem Zentrum der Eisenerzregion 'Menominee Range', genannt, wo ein finnlandschwedischer Bergmann 1890700 \$ als Schadensersatz für eine lebenslange körperliche Behinderung erhielt, vgl. Myhrman 1974, Bd. 3, S. 14. Zur Gründung von Schadensersatzfonds für die Angehörigen der Unfallopfer siehe Puotinen 1979, S. 138f. In Calumet gründeten Finnen bereits 1878 den ersten nationalen Schadensersatzfond, siehe Alanen 1981b, S. 51.

${ }^{224}$ Dunbar 1970, S. 499f.
} 
lahmlegte. Der 265-tägige Arbeitskampf der Jahre 1913-14 225 , an dem etwa 16000 Bergleute teilnahmen, wurde von politisch aktiven Finnen maßgeblich organisiert. Doch die unnachgiebige Haltung der Bergwerksgesellschaften führte zu einem allmählichen Abbröckeln der Streikfront, und als bereits mehr als 2500 Grubenarbeiter das Gebiet verlassen hatten, endete der Streik schließlich mit einer Niederlage für die Arbeiterschaft.

Interessanterweise befinden sich unter den in diese Untersuchung eingegangenen Briefen keine Postsendungen aus der Kupferinsel trotz der großen Anzahl von finnischen Grubenarbeitern im Kupferbergbau der Bezirke Houghton und Keweenaw. Angaben zum Stunden- oder Monatslohn im Verhältnis zu den notwendigen Ausgaben des Alltagslebens finden sich jedoch wiederholt in Lebensschilderungen und Zeitzeugenberichten: Laut Angaben eines Augenzeugen und zugleich ersten Verfassers einer Monographie über Finnen in Amerika variierte der durchschnittliche Tageslohn auf der Kupferinsel in den einzelnen Gruben um 1895 zwischen 1,85 \$ und 2 \$, was bei einer Sechs-Tage-Woche und 24 Arbeitstagen pro Monat einem Monatslohn von 45 \$ - 48 \$ gleichkam. In der größten Grube, der 'Calumet and Hecla Mine', wurde 1898 sogar 2,37 \$ pro Tag gezahlt, wobei dies exakt dem durchschnittlichen Industriearbeiterlohn in den Vereinigten Staaten entsprach ${ }^{226}$.

Die Entlohnung der meisten Finnen lag jedoch deutlich unter diesen Werten. Als Belader von Erzwaggons, als 'Trammer', verdienten sie beispielsweise in der 'Atlantic Mine' 1895 lediglich 1,46 \$ pro Tag bzw. 35 \$ im Monat. Der bereits zitierte Isaac Polvi, ein junger Finne der zweiten Generation, verdiente 1894 sogar nur 32 \$ monatlich auf der Kupferinsel. Da Berichten der 'Finnisch-Amerikanischen-Zeitung' zufolge bereits um 1880 zwischen 30 und 40 \$ im Monat für 'Trammer' und 'Timbermen' gezahlt wurde, kann daraus geschlossen werden, daß die Entlohnung auf der Kupferinsel auch zum Jahrhundertwende hin noch keine Steigerung erfahren hatte ${ }^{227}$. Dies änderte sich erst ein Jahrzehnt später: 1913 lag der tägliche Verdienst eines ‘Trammers' nämlich schon bei $2,63 \$$, und der Monatslohn betrug dementsprechend $68 \$^{228}$.

\footnotetext{
${ }^{225} \mathrm{Zu}$ Details des Großstreiks vgl. Syrjälä 1925, S. 158-165; Murdoch 1964, S. 219-229; Holmio 1967, S. 395-40; Puotinen 1975 u. 1978, S. 242-288 sowie die Monographie von Thurner 1984.

${ }^{226}$ Järnefelt 1899, S. 89-91.

${ }^{227}$ Kaups 1975, S. 62 f.

${ }^{228}$ Hollingsworth 1982, S. 79; Holmio 1967, S. 394.
} 
Ein familienloser Arbeiter mußte für Kost und Logis in einer Gruppenunterkunft etwa 15 \$ - 20 \$ aufbringen und konnte im Idealfall zwei Drittel seines Lohnes sparen. Ein Familienvater hingegen konnte ein Haus für 3-8 \$ im Monat mieten, je nach Größe und Ausstattung der Behausung ${ }^{229}$. Obwohl die Mietkosten auf der Kupferinsel deutlich unter den Niveau der anderen Montanregionen Michigans und Minnesotas lagen, reichte das Gehalt eines Arbeiters kaum für die Ernährung einer mehrköpfigen Familie aus, so daß Haustiere und ein kleines Gemüsebeet in vielen Fällen das Überleben der Familienmitglieder sicherten. Auch die allgemein übliche Aufnahme eines Untermieters, zumeist eines alleinstehenden Bergmannes der gleichen Nationalität, bedeutete für zahlreiche Familien eine zusätzliche Einnahmequelle.

Doch nicht alle Finnen arbeiteten in Michigan auf der Kupferinsel. Von den drei weiteren Gebirgsketten Gogebic, Menominee und Marquette Range kann die zuletzt genannte als die größte und auch für die Finnen bedeutendste Grubenregion des Eisenerzabbaus bezeichnet werden. Auf der Marquette Range hatte die Erzförderung bereits 1846 begonnen. Im Umfeld der benachbarten Kleinstädte Ishpeming und Negaunee, die das regionale Zentrum der Eisenerzproduktion darstellten, waren vor 1880 schon neun Gruben in Betrieb. Die ersten Finnen sollen sich um 1873 in der Region südlich von Marquette niedergelassen haben, d.h. zur gleichen Zeit, als auch die nordöstlich gelegene Kupferinsel Zulauf von arbeitsuchenden Finnen erhielt. 1885 wurde der erste Abstinenzlerverein gegründet, zwei Jahre später erhielt die Region eine finnische Kirchengemeinde. Im Jahr 1908 lebten bereits knapp 3000 Finnen in Marquette, von denen ein Drittel als Grubenarbeiter beschäftigt war und fast ebenso viele als Hafenarbeiter am Ufer des Superior-Sees das Eisenerz auf Schiffe luden ${ }^{230}$. Obwohl die Eisenerzproduktion der Region nach 1890 eine Steigerung von knapp zwei auf drei Millionen Tonnen innerhalb von fünf Jahren erlebte, führte dies nicht zu einer Lohnanhebung und Verbesserung der allgemeinen Arbeitsbedingungen ${ }^{231}$.

Berichte über das entbehrungsreiche Einwandererleben in den Eisenerzregionen von Nord-Michigan sind in 34 Briefen dieser Untersuchung überliefert. Aus dem Umfeld der Städte Ishpeming und Negaunee, den wichtigsten Abbaugebieten der 'Marquet-

\footnotetext{
${ }^{229}$ Murdoch 1964, S. 153; Thurner 1974, S. 44.

${ }^{230}$ Järnefelt 1899, S. 106 f.; Hoglund 1960, S. 62; Holmio 1967, S. 208-211.

${ }^{231}$ Puotinen 1979, S. 116.
} 
te Range', sind 19 Briefe von neun Briefschreibern dokumentiert. Bereits 1887 schrieb Matti Jaaksi aus Ishpeming seinen Eltern im südostbottnischen Laihia:

"Ich möchte euch wissen lassen, daß ich immer noch in der gleichen Grube arbeite [seit etwa 4 Jahren]. Diese Arbeit ist sehr gefährlich [...], es starben vor kurzem drei Männer, von denen waren zwei Finnen."

36 Jahre später, im Jahr 1923, berichtete der gleiche Briefschreiber von dem tödlichen Grubenunfall seines Schwiegersohnes in der gleichen Grube ${ }^{232}$. Von den Gefahren der Grubenarbeit schrieb 1910 auch Kalle Pykälä aus Negaunee seinem Bru$\operatorname{der}^{233}$ :

"Selten ein Tag an dem nicht jemand zum Opfer der Grubenarbeit wird. Während meiner Zeit sind hier etliche Männer untertage gestorben und ich bin erst seit drei Monaten hier."

Im gleichen Brief verwies Kalle Pykälä zudem auf die ungleiche Behandlung der Finnen, die als Neuankömmlinge erst ein halbes Jahr lang Eisenerzwagggons beladen durften, bevor sie in die besser bezahlte Position des Bergmanns aufsteigen können. Trotz seiner Unzufriedenheit blieb der Briefschreiber in Negaunee, erlebte Phasen der Arbeitslosigkeit und erhielt dann 1913 wieder längerfristig Arbeit, wobei ihm seine neuerworbenen Englischkenntnisse zum Vorteil gereicht haben sollen. Ein Jahr später riet er seinem Bruder dann in drei Briefen mit dem Hinweis auf Grubenschließungen entschieden von der Auswanderung ab, was im nachhinein als Vorzeichen der sich bereits anbahnenden politischen und wirtschaftlichen Krise mit Ausbruch des Ersten Weltkrieges gewertet werden kann. Von plötzlicher Entlassung war 1914 nämlich auch der 42jährige Juho Heinäjoki betroffen, der nach 12jähriger Grubenarbeit in Negaunee zu den "Veteranen" unter den Montanarbeitern zählte ${ }^{234}$.

\footnotetext{
${ }^{232}$ Matti Jaaksi an Mikko Kannasto in Laihia, zwei Briefe vom 19.9.1887 und 7.5.1923, Sammlung Süd-Ostbottnien, Sig. Nr. 984/2-3.

${ }^{233}$ Kalle Pykälä an Oskar Pykälä in Tyrvää: Brief vom 18.8.1910, TYYH: S: m: Satakunta: TYRV: V/2.

${ }^{234}$ Juho Heinäjoki an Richard Ylinen in Siikainen: Brief vom 26. 10.1914, TYYH: S: m: Satakunta: SIIK: LXXIX/5.
} 
Derartige wirtschaftliche Einbrüche waren typisch für das industrialisierte Amerika, denn bereits zehn Jahre zuvor, im Jahr 1904, hatte Juho Sippola in einem Schreiben aus Ishpeming seinem Bruder von einer potientiellen Auswanderung mit dem Hinweis auf bevorstehende Massenentlassungen in den Gruben abgeraten ${ }^{235}$. Ein Jahr später war denn auch eine Gruppe von finnischen Familien aus Negaunee in die nördlich gelegene Wildnis gezogen, um sich am Silbersee, dem 'Silver Lake', vom Fischfang zu ernähren $^{236}$.

Im Hinblick auf unbeständige Arbeitsverhältnisse und eingeschränkte Verdienstmöglichkeiten unterschied sich die Marquette Range nicht wesentlich von der Kupferinsel: 1903 gab Frans Lendén an, in einer Grube bei Michigamme, westlich von Negaunee und Ishpeming gelegen, etwa 2 \$ pro zehnstündigem Arbeitstag zu verdienen. Bei einer Sechs-Tage-Woche entspricht dies einem Monatslohn von 48 \$. Für die Unterbringung und Verpflegung in einer Gruppenunterkunft hatte der Briefschreiber monatlich 17 \&u zahlen ${ }^{237}$. Ein Jahr später gab Vihtori Myllymäki an, 1,85 \$ pro Tag in Negaunee zu erhalten, wobei er sehr wahrscheinlich als Belader von Schienenwaggons gearbeitet hatte und dementsprechend gering entlohnt wurde ${ }^{238} .1910$ wiederum berichtet Kalle Pykälä aus Negaunee, daß er monatlich 18 \$ für Unterkunft, Verpflegung und Wäscheservice in einem von Finnen geführten "Hotel” zu zahlen hatte ${ }^{239}$. Zur gleichen Zeit lag der Stundenlohn in Negaunee für unerfahrene Bergleute noch bei 2,25 \$ pro Tag, soll allerdings im Laufe der Jahrzehnts auf 4,50 \$ angehoben worden sein, obwohl die tägliche Arbeitszeit von zehn auf acht Stunden reduziert worden war ${ }^{240}$. Diesen Einzelbeispielen zufolge war der Monatslohn in Negaunee zu Beginn des 20. Jahrhunderts von 48 auf 54 \$ angestiegen, die Unterhaltskosten hatten sich jedoch kaum verändert.

Westlich der Marquette Range lag die Gogebic Range im gleichnamigen Bezirk, ein Eisenerzgebirge an der unmittelbaren Grenze zu Wisconsin. Die Kleinstädte Bes-

\footnotetext{
${ }^{235}$ Juho Sippola an Elias Sippola, Brief von 1904, ohne nähere Datumsangabe, Sammlung SüdOstbottnien, Sig. Nr. 798/1.

${ }^{236}$ Holmio 1967, S. 212.

${ }^{237}$ Frans Lendén an Frans Uusikartano in Honkilahti, Brief vom 11.4.1903, TYYH: S:m: Satakunta: H-TI: III/1.; Brief auch bei Kero (1985, S. 64-67) abgedruckt.

${ }^{238}$ Vihtori Myllymäki an Heikki Myllymäki in Siikainen: Brief vom 31.8.1904, TYYH:S:m:Satakunta: SIIK: LXXVIII/2; Brief auch bei Kero (1985, S. 68f.) abgedruckt. Der 20jährige Briefschreiber hielt sich 1904 erst seit einem Jahr in Amerika auf, wonach eine höhere Position in der Grubenarbeiterhierarchie wenig wahrscheinlich erscheint.

${ }^{239}$ Kalle Pykälä an Eltern in Tyrvää, Brief vom 26.4.1910: TYYH: S:m: Satakunta: TYRV: V/1.

${ }^{240}$ Dies berichtet der schwedischsprachige Auswanderer Victor Björklund, der Negaunee 1910 im Alter von 18 Jahren erreichte, vgl. Myhrman 1974, Bd. 8, S. 5 f.
} 
semer und Wakefield können zusammen mit dem Verkehrsknotenpunkt Ironwood als regionale Zentren für die Eisenerzproduktion und die Holzindustrie angesehen wer$\operatorname{den}^{241} .1884$ wurde in Ironwood die erste Eisenerzgrube in Betrieb genommen, ein Jahr später bestand bereits eine finnische Siedlung am Ort mit zahlreichen Geschäften und Saloons in finnischer Hand. Im Jahr 1887 wurden als erste finnische Organisationen ein Abstinenzlerverein und eine Kirchengemeinde gründetet, eine sozialistische Vereinigung folgte dann um die Jahrhundertwende. Um 1895 lebten dann mehr als 1000 Finnen in Ironwood bei einer Ortsbevölkerung von etwa 14000 Personen.

In den 1890er Jahren sorgte die gestiegene Eisennachfrage auf dem Weltmarkt zu einer zehnfachen Produktionssteigerung auf der Gogebic Range, die zwar in absoluten Tonnen lediglich die Hälfte der gleichzeitig anwachsenden Produktionsmenge der Marquette Range ausmachte, für Michigan jedoch eine einmalige Rekordspitze darstell$\mathrm{te}^{242}$. Dieser kurzzeitige Produktionsboom schlug bereits 1900 in eine Welle der Massenentlassungen von Grubenarbeitern um, als nämlich eine ökonomische Depressionsphase die Eisenerznachfrage auf dem Weltmarkt rapide absinken lie $\beta^{243}$. Hiervon berichteten auch zwei Briefschreiber dieser Untersuchung sowie zwei von Myhrman interviewte Finnlandschweden, die den Grubenalltag auf der Gogebic Range erlebt hatten $^{244}$ : Demnach verdiente Jalmari Ikala 1905 noch 2,20 \$ pro Tag in Ironwood. Erick Johnson hingegen, der 1904 bereits fünf Jahre in einer Grube in Bessemer gearbeitet hatte, klagte über eine Lohnreduzierung von 2,10 \$ pro Tag auf 1,85 \$, wovon er seine siebenköpfige Familie nicht mehr ernähren konnte. Auch der Grubenarbeiter John Schublom verwies auf eine große Anzahl von Arbeitsuchenden in der Region um 1902, und Victor Roos hielt sich Ende des Jahres 1905 bereits arbeitslos in Bessemer auf.

Ähnliche Einzelschicksale von finnischen Bergleuten lassen sich auch von der dritten großen Eisenerzregion in Michigan, der Menominee Range, berichten. In diesem südlich der Marquette Range gelegenen Gebirge wurde 1851 Eisenerz entdeckt und 1877 mit der systematischen Erzförderung begonnen. Regionale Grubenorte waren die Kleinstädte Stambaugh, Crystal Falls und Iron River im Grenzgebiet der Bezirke Iron

\footnotetext{
${ }^{241}$ Järnefelt 1899, S. 112-115; Holmio 1967, S. 200-205; Myhrman 1972, S. 194-200.

${ }^{242}$ Puotinen 1979, S. 121.

${ }^{243}$ Vgl. hierzu Tabelle 3 im Anhang: Anzahl der finnischen Überseeauswanderer in Beziehung zur ökonomischen Situation in Amerika und Finnland 1870-1914.

${ }^{244}$ Jalmari Ikala an Frans Ikala in Kokemäki, Brief vom 19.12.1905:

TYYH:S:m:Satakunta:KOK VIII/1. Lebensberichte von Erick Johnson und John Schublom bei
} 
und Dickinson, unweit der Staatsgrenze zu Wisconsin. Crystal Falls war mit bis zu 30 verschiedenen Waldkamps zugleich auch ein Zentrum der Holzindustrie und zog ab 1887 Finnen in größerer Anzahl an. Hier, wie auch in vielen anderen Montanregionen, war es üblich, in der Wintersaison im Wald als Holzfäller zu arbeiten und bei Frühjahrsbeginn eines der naheliegenden Bergwerke aufzusuchen. Auch eine Doppelbeschäftigung als Farmer auf eigenem Ackerland mit zeitweiliger Bergbautätigkeit waren vor allem bei Einwanderern mit Familien üblich. Einzelne Finnen mit gesichertem finanziellen Hintergrund und höherer Ausbildung gründeten Arztpraxen, Apotheken oder Rechtshilfebüros in den größeren Grubensiedlungen und konnten auf diese Weise ihren Landsleuten Dienstleistungen in finnischer oder schwedischer Sprache anbieten. In Stambaugh erlangte ein Finne sogar die Position des Bürgermeisters, was jedoch als Ausnahmeerscheinung gewertet werden kann ${ }^{245}$.

Obwohl auch die Bergwerksgesellschaften der Menomiee Range vom Erz-Boom der Jahrhundertwende finanziell profitierten, wirkte sich dies kaum auf die Erwerbsmöglichkeiten der Grubenarbeiter aus ${ }^{246}$. Der Arbeitsalltag untertage glich in seiner Eintönigkeit und Gefährlichkeit der Grubenarbeit anderer Regionen. Nach 1910 wurden die Belegschaften sowohl in Stambaugh als auch anderorts reduziert. Allein 1914 sollen mehr als die Hälfte aller Grubenarbeiter in Stambaugh entlassen worden sein. Der Briefschreiber Axel Lepistö beispielsweise hielt es für einen Glücksfall, daß er selbst acht Jahre lang fast ununterbrochen als Grubenarbeiter beschäftigt gewesen war, wie er in fünf Briefen aus Stambaugh und Iron River berichtete ${ }^{247}$. Aufgrund seiner langjährigen Arbeitserfahrung war es Axel Lepistö nämlich gelungen, in der Sozialhierarchie der Grubenarbeiter aufzusteigen und eine qualifiziertere Position mit besserer Entlohnung zu erzielen als viele seiner Landsleute. Im Gegensatz zu den meisten anderen Darstellungen aus den Grubengebieten spiegelt der Grundtenor seiner Briefe Zufriedenheit mit der persönlichen Erwerbssituation wider.

Myhrman 1974, Bd. 3, S. 51 und Bd. 8, S. 48. Victor Roos an Kustaa Laine, Brief vom 29.11.1905: TYYH:S:m:Satakunta: LAP XI/15; Brief auch bei Kero (1985, S. 77f.) abgedruckt. ${ }^{245}$ Holmio 1967, S. 218-223.

${ }^{246}$ Puotinen 1979, S. $117 \mathrm{f}$.

${ }^{247}$ Um die langjährige Entwicklung des Briefschreibers zu dokumentieren, wurden ausnahmsweise auch drei Briefe aus der Zeit nach 1914 berücksichtigt: Axel Lepistö an Valio Lepistö in Peräseinäjoki, Sammlung Süd-Ostbottnien, Sig. Nr. 1231: Fünf Briefe vom 14.7.191320.2.1921. Insgesamt haben fünf Briefschreiber dieser Untersuchung aus den drei genannten Orten der Menominee Range nach Finnland geschrieben, zwei von ihnen waren Frauen. 


\subsubsection{Bergbau in Minnesota}

Zu einer Zeit, als in Nord-Michigan bereits zahlreiche Kupfergruben in Betrieb waren wurde im nordöstlichen Bereich von Minnesota, im Bezirk St. Louis, erst mit geologischen Untersuchungen begonnen, welche die angeblich reichhaltigen Goldvorkommen der Region bestätigen sollten ${ }^{248}$. Anstelle von Gold wurden jedoch riesige Eisenerzvorkommen entdeckt, deren industrielle Nutzbarmachung im Vermilion-Gebirge 1884 begann. Die Vermilion Range wurde demnach in gleichen Jahr eröffnet wie auch die im Grenzgebiet von Michigan und Wisconsin gelegene Gogebic Range. Als erste organisierte Siedlungen bildeten sich im Vermilion-Gebirge die Orte Tower, Soudan und Ely heraus, die um 1890 Stadtrechte erlangten.

Die Erschließung der größten und wirtschaftlich bedeutendsten Grubenregion Minnesotas wiederum, der Mesabi Range, erfolgte dann im Jahr 1892, nachdem der Ölmillionär Rockefeller als finanzstarker Investor aufgetreten war und die durch ihn kontrollierte Gesellschaft 'Lake Superior Consolidated Iron Mines' gegründet hatte. Dieses Unternehmen verschmolz 1901 mit zwei weiteren Gesellschaften zum Monopolunternehmen 'United States Steel Company', das über 125 Gruben in Minnesota verfügte $^{249}$.

Im Mesabi-Gebirge lagen die meisten Bergwerke in den Grubensiedlungen Hibbing, Eveleth, Chisholm und Virginia mit durchschnittlich jeweils mehr als 1500 Finnen sowie in Gilbert und Biwabik, zwei kleineren Siedlungen mit jeweils mehreren hundert Finnen. Im Unterschied zu den Grubenregionen Michigans wurde in Nord-Minnesota Eisenerz sowohl unter- als auch übertage, in den sogenannten 'Open-Pit-Mines' gefördert. Auch in diesen offenen Bergwerken wurden nach Abtragung der oberen Gesteinsschichten Sprengungen erforderlich, wonach die oberirdische Eisenerzförderung nicht weniger gefährlich war als der Erzabbau untertage. Unter den Bergleuten waren die offenen Gruben jedoch vielfach unbeliebt: Näße und Kälte sowie eine schlechtere Bezahlung ließen die finnischen Grubenarbeiter immer zuerst nach einem Arbeitsplatz untertage Ausschau halten ${ }^{250}$.

\footnotetext{
${ }^{248} \mathrm{Zu}$ den Eröffnungsjahren der Gruben siehe Alanen 1991b, S. 368; Miller 1991.

${ }^{249}$ Zur Industriegeschichte der beiden Montangebiete in Minnesota siehe Wasastjerna 1957, S. 403-407 und S. 461-464; Blegen 1963, S. 368-372; Saarelainen (unveröffentlichte Magisterarbeit) 1974, S. 22-27; Puotinen 1979, S. 123-129; Alanen 1991a; Guggisberg 1993, S. 134-136. ${ }^{250} \mathrm{Zu}$ den Arbeitsvorgängen in der überirdischen Erzförderung siehe Ross 1982, S. 107f.; Kolehmainen/Hill 1965, S. 35.
} 
Die unterirdischen Gruben in Minnesota wiederum waren niedriger als in NordMichigan. Natürliche Felsvorkommen dienten vielerorts als Abstützung der Stollenwände, wodurch Stolleneinbrüche und Brände seltener vorkamen als in den mit Holzgerüsten ausgestatteten Bergwerken Nord-Michigans. Dennoch waren Grubenunfälle auch in der Mesabi-Region derart an der Tagesordnung, daß sie für die Bergleute fast schon Normalitätscharakter angenommen hatten. 1910 klang dies aus der Feder eines Briefschreibers von insgesamt zehn Schreibern der Mesabi-Region folgendermaßen ${ }^{251}$ :

" Ich bin immer wieder in den Gruben beschäftigt, auch wenn dies lebensgefährliche Arbeitsplätze sind. Jeden Tag sterben Bergleute bei Unfällen, doch daran hat man sich hier schon so sehr gewöhnt, daß man diese Ereignisse kaum mehr beachtet. Was mich betrifft, so habe ich bisher Glück gehabt."

Allein in den Jahren 1906-08 starben durchschnittlich 5,5 Bergleute auf 1000 Beschäftigte, wonach die statistische Wahrscheinlichkeit, in Minnesota durch ein Grubenunglück das Leben zu verlieren, größer war als in Michigan ${ }^{252}$.

Drei Jahre nach Erschließung der Mesabi Range, im Jahr 1895, lag die Anzahl der produzierenden Gruben der Region bei 16, um sich ein Jahrzehnt später auf 63 Bergwerke zu vervierfachen. Im Zuge dieser industriellen Expansion nahm auch die Präsenz der finnischen Bergleute auf der Mesabi Range zu: Für das Jahr 1905 kann eine Anzahl von rund 6000 Finnen belegt werden, wobei ihr Anteil im Verhältnis zum gesamten Einwandereraufkommen der Region bei 40\% lag. In Relation zur Gesamtbevölkerung der Mesabi Range wiederum bewegte sich der Anteil an finnischen Einwanderern bei $22 \%$, d.h. daß jeder fünfte Einwohner finnischer Nationalität war ${ }^{253}$. Unter den "Mesabi-Finnen" fanden sich zudem auch zahlreiche Vertreter der schwedischsprachigen Minorität aus den südostbottnischen Küstenregionen Finnlands, schätzungsweise mehr als 1000 Grubenarbeiter ${ }^{254}$.

\footnotetext{
${ }^{251}$ Erik Hautala an Viktor Hautala in Karvia, Brief vom 2.1.1910: TYYH: S: m: Satakunta: KAR XII/3. Zu Erfahrungsberichten über Unfälle in den Gruben siehe auch die unveröffentlichte Magisterarbeit von Lappalainen-Lilja 1981, S. 61-63.

${ }^{252}$ Puotinen 1979, S. 140, Tab. 7; Saarelainen (unveröffentichte Magisterarbeit) 1974, S. 61.

${ }^{253}$ Kaups 1975, S.77, Tab. 4.

${ }^{254}$ Saarelainen 1974, S. 54; Kaups 1975, S. $76 f$.
} 
Demnach bildeten die Finnen auf der Mesabi Range, wie auch auf der Kupferinsel, die größte Ausländergruppe ${ }^{255}$, welche aufgrund der Beschäftigungsmöglichkeiten im Bergbau stark männerdominant geprägt war. Eine Mikrountersuchung der finnischen Bewohner der Mesabi Range für das Stichprobenjahr 1895 hat ergeben ${ }^{256}$, daß vor der Jahrhundertwende ein Geschlechterverhältnis von 4:1 bestand. In Prozentwerten ausgedrückt bedeutet dies, daß von allen "Mesabi-Finnen" 81,5\% männlichen und lediglich 18,5\% weiblichen Geschlechts waren. Als wenig überraschende Tatsache kann daraus gefolgert werden, daß sich die finnischen Einwanderer als alleinstehende Männer ohne Familienverband in der Grubenregion aufhielten.

Im Vergleich dazu stellte sich die Geschlechteraufteilung im Bergwerksort Crosby, unweit der Kleinstadt Calumet in Nord-Michigan, mit 62\% Männern und 38\% Frauen dar, wie eine Stichprobenuntersuchung für das Jahr 1900 belegt $^{257}$. Diese Prozentwerte wiederum kamen den Durchschnittswerten aller finnischen Amerikaeinwanderer der Fünfjahresperiode 1900-04 sehr nahe, welche bei 63,7\% männlicher und $36,3 \%$ weiblicher Immigranten lagen und ein Verhältnis von 3:1 repräsentierten ${ }^{258}$.

Nach der Jahrhundertwende jedoch schien sich die Tendenz der zunehmenden Frauenpräsenz auch im Mesabi-Gebirge zu vollziehen, da beispielsweise für das Jahr 1903 in Virginia, einem Bergwerksort der Region, eine Geschlechteraufteilung von 71\% Männern zu 29\% Frauen konstatiert werden konnte ${ }^{259}$. Dennoch blieb die finnische Einwanderergruppe auf der Mesabi-Range stärker männerdominant geprägt als die finnische Einwandererpopulation in ihrer Gesamtheit.

Mit zunehmender Einwanderungsbewegung kamen die finnischen Immigranten auch immer seltener aus anderen Bundesstaaten nach Minnesota und Michigan, sondern reisten vielfach direkt nach ihrer Ankunft in New York oder Boston in die Grubenregionen. Für diese zielgerichtete Arbeitswanderung vor allem von jungen Männern spricht die Tatsache, daß in den Stichprobenjahren 1882 und 1890 39,4\% bzw. 30,2\% aller finnischen Auswanderer bei Beginn der Atlantiküberquerung bereits eine Fahrkarte in die Staaten mit Montanindustrie bei sich trugen ${ }^{260}$.

\footnotetext{
${ }^{255}$ Alanen 1991b, S. 372, Tab. 16.2.

${ }^{256}$ Hier Kaups 1975, S. 73; siehe auch Saarelainen 1974, S. $39 f$.

${ }^{257}$ Alanen 1988, S. 69.

${ }^{258}$ Siehe hierzu Tabelle L in Kap. 2.7.2.

${ }^{259}$ Karni 1981c, S. 167.

${ }^{260}$ Kero 1980, S. 16f., Tab. 1.
} 
Kaum in den Grubensiedlungen angekommen, fanden sich die Finnen in einem Konglomerat von etwa dreißig Nationalitäten wieder, suchten sich jedoch schon bald eine Herberge in einer von Finnen geführten Gruppenunterkunft. In diesen sogenannten 'Boarding Houses' ${ }^{261}$ teilten sich nicht selten zwei, in verschiedenen Schichten arbeitende Männer eine Schlafstätte. Zum Service gehörten Vollverpflegung mit drei Mahlzeiten pro Tag sowie in einigen Häusern auch die Reinhaltung der Kleidung. Diese "Hotels" sicherten den wenigen finnischen Frauen, die in den Grubensiedlungen lebten, ein bescheidenes, aber eigenes Einkommen. Im Jahr 1902 beispielsweise verdiente eine Frau im Bergwerksort Ely als Dienstbotin oder Geschirrwäscherin 12 \$ im Monat bei freier Kost und Logis ${ }^{262}$. Einige finnische Familien nahmen auch alleinstehende Landsleute in ihre Häuser auf und boten somit ein Privatquartier mit Vollverpflegung und Familienanhang für einige Dollars im Monat $\mathrm{an}^{263}$.

Dem eintönigen Leben in den Grubensiedlungen wurde nicht selten mit Alkohol und Glücksspielen in Saloons der nahen Umgebung getrotzt. Sobald sich einige hundert Finnen an einem Ort aufhielten, entstanden dort schon bald kleine Geschäfte und "Hotels" in finnischer Hand. Im Alltagsleben kamen die finnischen Bergleute problemlos mit ihrer Muttersprache zurecht, die Notwendigkeit zur Anpassung an die multikulturelle Gesellschaft war weder gegeben, noch wurde sie von den Finnen favorisiert. Von daher waren auch die wenigsten Finnen bemüht, die Sprachbarriere, die zu ihrer Isolation maßgeblich beitrug, aktiv zu durchbrechen und Englisch zu lernen, geschweige denn die amerikanische Staatsbürgerschaft anzunehmen. Da zudem der bescheidene Lebensstandard einen idealen Nährboden für sozialistisches Gedankengut ${ }^{264}$ bot, wurden die Finnen von Vertretern anderer Nationalitäten häufig als eigensinnig betrachtet und stereotyp als 'Russian Finns' oder 'Red Finns' tituliert ${ }^{265}$.

Alkohl wurde allein in der Mesabi-Region in etwa 350 Saloons reichlich und teuer angeboten ${ }^{266}$, obwohl in den Grubensiedlungen selbst der Alkohlverkauf in jegli-

\footnotetext{
${ }^{261}$ Im finnisch-amerikanischen Dialekt wurden diese Unterkünfte auch "poortitalo" (von 'boarding house') und "poikatalo" (Haus der Junggesellen) genannt, vgl. Virtaranta 1992, S. 155 und S. 158.

${ }^{262}$ Wasastjerna 1957, S. 422.

${ }^{263}$ Laitila 1991, S. 41.

${ }^{264}$ Nach Ollilas Schätzung (1975, S. 156f.) können 10\% aller finnischen Grubenarbeiter als Sozialisten eingestuft werden, weitere $20 \%$ sympatisierten mit der politischen Bewegung.

${ }^{265}$ Tokoi 1949, S. 121; Ross 1982, S. 115. Zu stereotypen Vorstellungen, mit denen die Finnen vielfach konfrontiert wurden, siehe Karni 1990, S. 97-107; Roinila 2000, S. 43f..

${ }^{266}$ Alanen 1982, S. 100; Ross 1982, S. 110.
} 
cher Form verboten war. Neben ihrer Funktion als soziale Treffpunkte dienten zahlreiche Saloons zudem als Freudenhäuser, in denen möglicherweise auch finnische Einwanderinnen gearbeitet hatten ${ }^{267}$. Fehlende Untersuchungen über finnische Prostituierte in Amerika lassen jedoch kein Urteil darüber zu, in welchem Ausmaß diese in der Mesabi-Region oder in anderen Grubenorten zu finden waren ${ }^{268}$.

In den abgeschiedenen Grubenorten traten soziale Probleme innerhalb der finnischen Gemeinschaft denn auch in zugespitzter Form auf, beispielsweise waren Bewohner aus der südostbottnischen Region nicht immer gut auf ihre geographischen Nachbarn aus Mittel-Ostbottnien zu sprechen. Auch Konflikte mit anderen Immigranten waren an der Tagesordnung, wobei häufig übermäßiger Alkohlgenuß eine Rolle spielte. In gelegentlich auftretende Messerstechereien waren oftmals Finnen, Iren und Auswanderer aus Cornwall verwickelt ${ }^{269}$. Dies brachte wiederum die gesamte finnische Einwanderergruppe in Verruf, obwohl sich religiöse Finnen und auch Anhänger der AntiAlkoholvereinigungen ${ }^{270}$ deutlich von den Unruhestiftern unter den Landsleuten zu distanzieren versuchten.

In seinem autobiographischen Lebensbericht erklärt der Zeitzeuge Oskari Tokoi $^{271}$ diese Zweiteilung der finnischen Gemeinschaft in den Grubenorten derart, daß der Großteil der alleinlebenden finnischen Bergleute Vergnügungen und nicht selten dem sozialistischen Gedankengut zuneigte, der verbleibende Rest hingegen Stütze und Halt in konservativen Traditionsmustern suchte. Trotz der Distanz beider Gruppen zueinander schirmten sie sich deutlich von der nicht finnisch- oder nicht schwedischsprachigen Außenwelt ab und zeigten somit ein sozial wenig anpassungsbereites Verhalten.

Die Ursache für die Isolation der finnischen Einwanderergruppe schien, zumindest teilweise, in direkter Beziehung zu den schwierigen Lebensbedingungen in den Grubenorten zu stehen: Neuankommende Finnen erlebten nämlich schon bald den starken Einfluß der Bergbaugesellschaften auf die Bestimmung und Entwicklung des sozialen Lebens vor Ort, wobei sich ein gewisser Widerspruch zeigte:

\footnotetext{
${ }^{267}$ Puotinen 1979, S. 219; Kero 1996, S. 225-227.

${ }^{268}$ Die einzige Untersuchung über finnische Prostituierte in Ontario wurde 1988 von LindströmBest (S. 110-114) vorgelegt, wonach die meist 30-40jährigen Frauen über einen gewissen Bildungsgrad verfügten und ihre Dienste im eigenen Heim anboten. Aufschlußreich ist auch der Essay von Rotenberg (1974, S. 39-41) über den Anteil von europäischen Prostituierten innerhalb des gesamten häuslichen Dienstpersonals von Toronto um 1900.

${ }^{269}$ Hoglund 1960, S.63; Alanen 1981b, S. 44f.

${ }^{270} \mathrm{Zu}$ den Abstinenzlervereinigungen in Minnesota siehe Kolehmainen 1941; Karni 1981c.

${ }^{271}$ Tokoi 1949, S.166.
} 
Die Leitung der Bergwerke, welche meist das gesamte Land in Grubennähe besaß, schien tatsächlich an der positiven Entwicklung der gesellschaftseigenen Grubensiedlungen, den 'Company Locations', interessiert zu sein, von denen allein im Mesabi-Gebirge mehr als 175 innerhalb von zwei Jahrzehnten gegründet wurden ${ }^{272}$. Diese im geometrischen Rastermuster angelegten Holzhaussiedlungen für Bergleute und ihre Familien wurden mit kleinen Vorgärten und halbwegs begradigten Schotterwegen ausgestattet. Einige der größeren Siedlungen erhielten nach der Jahrhundertwende sogar Elektrizität und im besten Fall auch fließendes Wasser.

Zeitzeugenberichte erhärten jedoch den Anschein, daß die Lebensverhältnisse in den Siedlungen alles andere als vielversprechend waren: Die von rotem Erzstaub bedeckten, einfachen Holzhäuser glichen eher Baracken. Sie waren häufig zu niedrig zum aufrechten Stehen und für die Anzahl ihrer Bewohner viel zu klein, zumal etliche Einwanderer unterschiedlicher Nationalität noch Schweine und Kleinvieh in den Vorgärten und Hinterhöfen hielten. Freilaufende Haustiere, räumliche Enge sowie fehlende sanitäre Einrichtungen sorgten denn auch für die schnelle Ausbreitung von Seuchenkrankheiten, wie beispielsweise der Typhus-Epidemie des Jahres 1892 in Hibbing ${ }^{273}$. Darauf reagierten die Bergwerksgesellschaften wiederum in Form von Hygieneaufklärung und medizinischer Versorgung durch Krankenschwestern ${ }^{274}$, welche die Familien der Bergleute in ihren Häusern aufsuchten; doch das wohlgemeinte Angebot erwies sich als unzureichend.

Auch hohe Lebenshaltungskosten durch teure Mieten und Lebensmittel sowie Mangel an Heizmaterial in kalten Wintermonaten erschwerten das Alltagsleben der Siedlungsbewohner. Viele Finnen zogen es von daher vor, ein kleines Grundstück von der Bergwerksgesellschaft zu pachten und sich außerhalb der Arbeitersiedlungen eine eigene Blockhütte zu errichten. Dies ermöglichte den Familien der Grubenarbeiter einen kleinen Kartoffelacker anzulegen und auch Kleinvieh oder sogar eine Kuh in den eigenen Stallungen zu halten ${ }^{275}$. Derartige Ansammlungen von selbst errichteten Behausungen führten zu zufällig entstandenen, ungeordneten Siedlungen, die oftmals einem

\footnotetext{
${ }^{272} \mathrm{Zu}$ den sozialen Verhältnissen der 'Locations' allgemein siehe Alanen 1981b, S. 39-43, speziell zum Mesabi-Gebirge Alanen 1982 und zum Vermilion-Gebirge Alanen 1991a.

${ }^{273}$ Puotinen 1979, S. 141; Alanen 1981b, S. 39. Noch 1921 fehlten bei der Hälfte aller Häuser in Hibbing sanitäre Einrichtungen, siehe Alanen 1982, S. 100.

${ }^{274}$ Für die medizinische Versorgung hatten die Bergleute einen Dollar monatlich pro Person zu zahlen, siehe Alanen 1991b, S. 376 u. S. 384f; Hollingsworth 1982, S. 59.

${ }^{275}$ Alanen 1982, S. 97 und 1983b, S. 7.
} 
Slumgebiet glichen und nicht selten der Eröffnung einer neuen Grube weichen mußten, sobald die Bergwerksgesellschaften ihre Produktionsaktivitäten ausdehnten.

Der ständige Zuzug von Arbeitsuchenden verschlechterte weiterhin die bestehenden Verhältnisse in den Grubensiedlungen. Als Folge davon war die Anzahl der Einwohner pro Quadratkilometer in den Grubenorten bald höher war in den urbanen Zentren Minnesotas ${ }^{276}$. Vor diesem Hintergrund verwundert es nicht, daß die sozialen Zustände in den multikulturellen Grubensiedlungen nicht vor Ort lebenden Augenzeugen als verheerend erschienen. Noch 1926 beschrieb ein zugereister Beobachter die Wohnverhältnisse in einer Mesabi-Siedlung, die ironischerweise den Namen 'White City' trug, mit folgenden Worten ${ }^{277}$ :

"Unbelievable, log huts for they cannot be called houses, underground rooms with no ventilation and with sheep and pigs as part of the family."

Insgesamt gesehen hat es den Anschein, daß die halbherzigen Bemühungen der Bergwerksgesellschaften, den Lebensstandard in den Grubensiedlungen zu verbessern, nicht den wahren Bedürfnissen der Siedlungsbewohner gerecht wurden. Die meisten Bergleute und ihre Familien kämpften täglich ums Überleben, sowohl im Hinblick auf die geringe Bezahlung, welche kaum das Existenzminimum sicherte, als auch in den unterirdischen Stollengängen, in denen jede Unachtsamkeit zum tödlichen Verhängnis werden konnte.

In diesen Punkten blieben die Bergwerksgesellschaften jedoch unnachgiebig: Das allgemeine Lohnniveau wurde bewußt niedrig gehalten, und auch im Hinblick auf die Praktik der Bezahlung war das Vorgehen der Arbeitgeber alles andere als beispielhaft.

In den offenen Gruben galt anfangs noch das Tageslohnprinzip bei fester Arbeitszeit, doch da die Eisenerzförderung nur in frostfreien Monaten möglich und somit saisonabhängig war, wurde bald auf das Akkordlohnsystem umgestellt und der Arbeitstakt dadurch unbarmherzig beschleunigt ${ }^{278}$.

\footnotetext{
${ }^{276}$ Wasastjerna 1957, S. 289. Zum Problem der Besiedlungsdichte siehe auch Karni 1986, S. 206.

${ }^{277}$ Alanen 1982, S. 99.

${ }^{278}$ Tokoi 1959, S. 48.
} 
In den unterirdischen Mesabi-Gruben wurde der Arbeitseinsatz von Anbeginn vorwiegend nach erreichter Leistung entlohnt, was die Aufhebung fester Arbeitszeiten sowie zahlreiche weitere Nachteile mit sich brachte: Der Arbeitsdruck wuchs, Pausen gingen zu Lasten der Arbeiter, und bei der Beurteilung und Bezahlung der geleisteten Arbeit durch Vorarbeiter und Grubenchefs ging es häufig nicht mit fairen Methoden zu. Immigranten wurden durchweg schlechter bezahlt als amerikanische und kanadische Bergleute, da sie lediglich zwei Drittel eines vollen Gehaltes erhielten ${ }^{279}$. Die Mißachtung mündlicher Lohnabsprachen führte zu gedrückten Akkordlöhnen, und auch die vorläufige Einbehaltung eines Teiles des Akkordlohnes war üblich, um den entsprechenden Arbeiter bis zum Jahresende in der Belegschaft zu halten. Bei Sprengungen wurden die Kosten für Sprengstoff, Zündschnur und Zündkapsel direkt vom Lohn des mit der Detonation beauftragten Grubenarbeiters abgezogen, so daß die Summe der ausbezahlten Dollars häufig niedriger ausfiel als erwartet ${ }^{280}$. Ganz zu schweigen von Sicherheitsvorkehrungen bei Bohrungen und Sprengungen, die von den unter Zeitdruck arbeitenden Bergleuten und ihrer Vorarbeiter bewußt mißachtet wurden.

Die Arbeitsverhältnisse als Akkordarbeiter in Gilbert, einem Nachbarort von Virginia, beschreibt der finnische Auswanderer Matti Pelto aus dem südostbottnischen Kuortane in seinen in englischer Sprache veröffentlichten Tagebuchaufzeichnungen folgendermaßen ${ }^{281}$ :

"In May 1909 the miners were put on a contract. The idea was to squeeze out even more from the miners. The truth is, it brought about tremendous competition where the stronger ones won out. Perhaps now the contract miner might have a little more freedom and less fear of his boss, but this was not to be. Instead the miner found out way too soon that he could not surface for a breath of fresh air even one minute early, although he had pressed beyond endurance to get the contract for the day filled. [...] A crime was committed if anyone was caught heading for the shaft or stairs half a minute to quitting time. At least the miner who happened to be first in line got fired.

\footnotetext{
${ }^{279}$ Kivisto 1982, S. 166.

${ }^{280}$ Die Kosten für Sprengmaterial konnten bis zu sieben Dollar pro Monat betragen, vgl. Ross 1982, S. 109.

${ }^{281}$ Die Tagebuchaufzeichnungen von Matti Pelto wurden von dessen Verwandten im Jahr 1966 zur posthumen Veröffentlichung freigegeben. Bislang sind die Aufzeichnungen jedoch nur auszugsweise in englischer Übersetzung publiziert worden, vgl. Pelto 1982, S. 28-33.
} 
That was a grim lesson and warning to the others. [...] On the sur- face there were always the unemployed hoping to get into that "underground hell".

Als Resümee dieser Behandlung konstatiert der Memoirenschreiber an anderer Stelle:

"You can kill yourself with work or slowly starve to death if you are unemployed. There is no choice - you take one or the other."

Auch der Auswanderer Vihtori Myllymäki, der 1903 aus Siikainen in Satakunta auswanderte und über Negaunee in Michigan nach Eveleth, der zentralen Grubensiedlung des Mesabi-Gebirges, gelangte, hatte in einem Brief an die Eltern und Geschwister, datiert auf den 21.3.1909, wenig Gutes zu berichten ${ }^{282}$ :

”Aus Eurem Brieflese ich, daß Kalle [der Bruder] nicht nach Hause geschrieben hat. Ich selbst habe ihm seit drei oder vier Wochen nicht mehr geschrieben, doch als ich seinen letzten Brief erhielt, berichtete er, daß er in einer Grube arbeite und versprach im Frühjahr hierhin zu kommen. Er ist doch wohl nicht gestorben. Ich werde ihm bald schreiben, obwohl man hier nie sicher sein kann wen das Schicksal zuerst trifft. Denn im letzten Jahr sind in Amerika 35 tausend Menschen bei Unfällen gestorben und 2 Millionen wurden verletzt.

So sollte ich vielleicht ein wenig von den Sklavenverträgen [wörtl. Sklavenkontrakten] der amerikanischen Eisengesellschaften schreiben. Die pflegen nämlich solche Sklavenlisten zu gebrauchen, in die jeder Arbeiter seinen Namen eintragen muß. Sobald ein Arbeiter verletzt wird oder stirbt trägt die Gesellschaft keine Verantwortung und braucht auch nichts für die Verletzung oder den Todesfall zu bezahlen. Also, dem verkrüppelten Arbeiter bleibt keine andere Wahl, als sich selbst das Leben zu nehmen, aber das wäre zuviel, um hier alles zu berichten.

Hier verschlechtern sich die Bedingungen für die Arbeiter von Jahr zu Jahr, die Arbeit wird immer härter. Ein älterer Mann kann da gar nicht mehr mithalten und wird gleich entlassen. Ich habe Gerüchte gehört, wonach die Gesellschaften vorhaben keine

\footnotetext{
${ }^{282}$ Vihtori Myllymäki an Heikki Myllymäki in Siikainen, Brief vom 21.3.1909 aus Eveleth, Minn.: TYYH: S:m:Satakunta:SIIK:LXXVIII/11; Brief auch bei Kero (1985, S. 75f.) abgedruckt.
} 
Männer mehr zu beschäftigen, die älter als 45 Jahre sind, weil sie nicht mehr schnell genug sind, ja und wovon soll man leben?"

Wie aus diesen beiden Berichten des Jahres 1909 der finnischen Grubenarbeiter im Mesabi-Gebirge zu entnehmen ist, unterschied sich auch das größte Montangebiet hinsichtlich der Arbeitsbedingungen nicht von den übrigen Eisenerzregionen bzw. der Kupferinsel in Nord-Michigan. Demnach war die Mobilität unter den Bergleuten groß; die überwiegende Mehrheit der finnischen Bergleute hielt sich maximal ein bis drei Jahre in einem Grubenort auf ${ }^{283}$. Hinweise auf die niedrige Entlohnung, die Angst vor Unfällen sowie die Sorge über die Beständigkeit des Arbeitsverhältnisses dominieren denn auch in den übrigen 19 Briefen, die von neun Briefschreibern aus Nordost-Minnesota nach Finnland gesandt wurden.

Trotz Akkordlohnsystem differierte das Lohnniveau auf der Mesabi Range nicht wesentlich von den in Nord-Michigan üblichen Gehältern. Aus Briefhinweisen wird ersichtlich, daß z. B. William Mäki, der sich 1893 in Virginia aufhielt, 1,80 \$ pro zehnstündigen Arbeitstag verdiente und von seinem Monatslohn, der im besten Fall bei $45 \$$ lag, 18 \$ für Unterkunft und Verpflegung aufzubringen hatte ${ }^{284} .1890$ verdiente ein Belader von Erzwaggons 1,60 \$ pro Tag in den unterirdischen Gruben von Ely, und ein Zimmermann bekam 1,75 $\$ 285$. Das Lohnniveau auf der benachbarten Vermilion Range hingegen bewegte sich zur gleichen Zeit zwischen 1,90\$ bis 2,50 \$ pro $\mathrm{Tag}^{286}$. Lediglich auf der Kupferinsel Nord-Michigans wurde vor der Jahrhundertwende weniger gezahlt als in Minnesota.

Doch auch nach der Jahrhundertwende beklagten sich die Briefschreiber der 'Mesabi Range' über plötzlich gesunkene Tageslöhne, beispielsweise in Eveleth von 1,75 \$ auf 1,60 \$ pro Tag, wie auch die "Eveleth Mining News" im Jahr 1904 zu berichten wußte ${ }^{287}$. Bereits 1903 wurde diese Lohnreduzierung durch sporadische Entlassungen einzelner Bergleute in den Bergwerken von Biwabik, unweit von Virginia gelegen,

\footnotetext{
${ }^{283}$ Kaups (1975, S. 85, Abb. 10) hat die Aufenthaltsdauer der finnischen Bergleute in Eveleth für das Stichprobenjahr 1905 untersucht, wobei von 884 Bergleuten mehr als ein Drittel, nämlich 316 Personen, Eveleth nach einem Jahr oder weniger wieder verlassen hatten.

${ }^{284}$ William Mäki an Emilia Hautala, Brief von 27.2.1893: TYYH:S:m:Satakunta:KAR:XI/1.

${ }^{285}$ Wasastjerna 1957, S. 422.

${ }^{286}$ Lamppa 1991, S. 29.

${ }^{287}$ Kaups 1975, S. $86 f$.
} 
angekündigt, wie John Mattila in seinen Briefen mitteilte ${ }^{288}$. Den Warnungen seiner Landsleute zum Trotz kam der bereits zitierte Briefschreiber Vihtori Myllymäki aus Negaunee in Michigan im Herbst 1904 nach Eveleth, wo er fünf Jahre lang in verschiedenen Gruben untertage arbeitete. Aus dieser Zeit sind acht Briefe an den Bruder überliefert, in denen sich der erst zwanzigjährige Bergmann vor allem über die geringen Löhne und schlechte Zeiten beklagt.

Besonders aufschlußreich ist ein Brief vom 5. 8. 1907, in dem Vihtori Myllymäki von dem ersten Großstreik der Region berichtet:

"Hier ist ein großer Streik, wir sind etwa dreißigtausend Mann. Ich weiß nicht wie lange der Streik dauern wird, er begann vor zweieinhalb Wochen. Das hier ist $\ddot{u}$ berhaupt nicht lustig. Die Gesellschaft hat hunderte von bewaffneten Wächtern eingesetzt, welche die Arbeiter jagen wie Waldtiere. Als Arbeiter kann man sich hier nicht mehr auf die Straße trauen, jeden Tag werden immer wieder einige von uns eingesperrt. Dieses Amerika nennt sich ein freies Land, doch das ist eine Lüge. [...] Falls dieser Streik lange andauert, werde ich hier weggehen müssen. Die Arbeiter haben vor lange zu streiken, sogar ein Jahr wollen sie nicht arbeiten, falls ihre Forderungen nicht erfüllt werden. Sie verlangen drei Dollar pro Tag und einen achtstündigen Arbeitstag. Falls wir den Streik gewinnen, werde ich Kalle sofort eine Fahrkarte zuschicken”.

Dieser im Brief angesprochene $\operatorname{Streik}^{289}$ wurde von verschiedenen sozialistischen Arbeitervereinigungen initiiert, die in drei nationalen Sektionen, in eine italienische, eine slawische und eine finnische, aufgeteilt waren. Zahlreiche Finnen hatten sich bereits ein Jahr zuvor in Hibbing zur 'Finnischen Sozialistischen Vereinigung' formiert und sich unter diesem Namen sogleich der Sozialistischen Partei Amerikas angeschlos$\operatorname{sen}^{290}$. Obwohl nicht alle finnischen Grubenarbeiter Sozialisten waren, sympatisierten viele mit der politischen Bewegung ihrer Landsleute. Unter den Grubenarbeitern waren

\footnotetext{
${ }^{288}$ John Mattila an Jaakko Mattila, drei Briefe vom 20.7.1903, 14.8.1903, 22.11.1903: Samml. Süd-Ostbottnien, Sig. Nr. 287/1-3.

${ }^{289}$ Der Streik von 1907 wird bei Betten (1967, S. 340-347) ausführlich dokumentiert. Siehe auch Puotinen 1979, S. 210-217; Kivisto 1982, S. 162-170; Ross 1982, S. 106-118. Neun Jahre später, im Jahr 1916, fand dann der größte Arbeitskampf der Region statt, der sogenannte 'MesabiStreik', vgl. Kivisto 1982, S. 212-223.

${ }^{290}$ Die 'Finnische Sozialistische Vereinigung' (1906-14) war aus 29 sozialistischen Lokalbüros mit 2450 Mitgliedern in verschiedenen Mesabi-Orten entstanden, bis zum Jahr 1912 zählte sie bereits mehr als 11000 Mitglieder, vgl. Ollila 1975, S. 156f.
} 
die Finnen denn auch am besten politisch organisiert. Gemeinsam mit italienischen Sozialisten leiteten sie den zweimonatigen Arbeitskampf, an dem mindestens 10000 Arbeiter teilnahmen und dessen Ziel es war, sowohl der Akkordarbeit als auch der ungleichen und niedrigen Bezahlung ein Ende zu setzen.

Die Bergwerksleitungen reagierten auf den Arbeiteraufstand jedoch mit Härte und Gewalt. Allein in einem Monat wurden 1124 Streikbrecher, allen voran Kroaten und Montenegriner, angeworben, welche, von einer bewaffneten Privatarmee geschützt, die Erzförderung aufrecht erhielten. Die im Brief angesprochene Aggressivität der Wachleute den Streikenden gegenüber wurde auch von dem Augenzeugen und Zeitungsredakteur F. J. Syrjälä bestätigt, der die Zahl von etwa 3600 bewaffneten Schützen nannte ${ }^{291}$. Nach zwei Monaten war die Streikfront gebrochen, und die Streikenden gingen leer aus. Da die Finnen zudem den militantesten Ruf unter den Aufständigen genossen, waren ihre Namen in der Folgezeit besonders häufig auf den sogenannten "schwarzen Listen" zu finden, welche aktive Sozialisten von jeglicher Montanarbeit in allen Staaten des Mittleren Westens ausschlossen. Der Anteil der finnischen Bergleute der Mesabi-Region schrumpfte beispielsweise in den Gruben der Bergwerksgesellschaft 'Oliver Company' von 18\% auf 8\% aller Beschäftigten, was in absoluten Zahlen den Ausschluß von rund 1200 finnischen Bergleuten bedeutete ${ }^{292}$.

Der Briefschreiber Vihtori Myllymäki verlor nicht seinen Arbeitsplatz in Eveleth, doch als im Jahr 1908 eine ökonomische Depressionsphase die Vereinigten Staaten erschütterte und zur verstärkten Rückwanderung tausender Europäer führte ${ }^{293}$, klang das aus der Feder des desillusionierten Briefverfassers folgendermaßen ${ }^{294}$ :

"Hier sind schlechte Zeiten. Hier bekommt man nur Arbeit, wenn jemand in der Grube stirbt. Viele Männer sind entlassen worden, auch in dieser Stadt. In ganz Amerika wächst die Anzahl der Arbeitslosen in die Millionen. Allein letztes Jahr im November verloren eine Million ihre Arbeit. Schuld daran ist der Geldmangel, hier in Amerika fehlt das Geld. Die Arbeiter werden mit Papierstreifen ausbezahlt, die sie dann in Wa-

\footnotetext{
${ }^{291}$ Syrjälä 1925, S. 71.

${ }^{292}$ Ross 1982, S. 113; Karni 1986, S. 211.

${ }^{293}$ Auch die finnischen Rückwanderungszahlen erlebten 1908 mit mehr als 12000 Personen einen einmaligen Höhepunkt, vgl. Tabelle 4 im Anhang: Anzahl der finnischen Rückwanderer 1892-1914.
} 
ren umtauschen können. Doch in anderen Orten sind diese Papierstreifen dann wieder wertlos, und die Arbeiter streiken. Sie sagen sie kämen nicht zur Arbeit bevor sie Geld erhielten. Daraufhin schicken die 'Herren' Soldaten aus, um auf die armen Arbeiter zu schießen, die es gewagt haben nach Geld für Nahrung und Kleidung zu verlangen."

Bei Betrachtung dieser Alltagsschilderungen aus Nordost-Minnesota stellt sich nun die Frage, wie es einzelne Arbeiter tatsächlich schafften, eine größere Summe von Dollars zusammenzutragen, um entweder in Amerika oder Finnland eine Existenz als Landwirt zu verwirklichen.

Hierzu soll ein Blick auf die Kohle- und Kupferbergwerke der Bergstaaten Montana und Colorado geworfen werden, die sowohl im Hinblick auf das relativ hohe Lohnniveau als auch auf besonders entbehrungsreiche Arbeitsbedingungen berühmt und berüchtigt waren: In den Kupferbergwerken von Butte sowie den Kohlebergwerken von Red Lodge, beide in Montana gelegen und zugleich als größte Bergwerksstädte der Vereinigten Staaten bekannt ${ }^{295}$, lagen die Durchschnittslöhne deutlich über dem bisher betrachteten Lohnniveau von Michigan und Minnesota: 1895 wurde durchschnittlich 3,20 \$ pro Tag gezahlt, um 1913 stieg der Lohn auf bis zu 3,50 \$. Aus 13 Briefen von sieben Briefschreibern geht hervor, daß Finnen in den Gruben von Montana im Höchstfall 3,60 \$ täglich erhielten ${ }^{296}$, wenngleich die Lebenshaltungskosten in der abgeschiedenen Montanregion etwa um ein Drittel höher ausfielen als im Bereich der Großen Seen. In Red Lodge, wo im Jahr 1900528 Finnen lebten und zugleich ein Viertel der Ortsbevölkerung stellten, wurde der Acht-Stundentag bereits 1903 per Vertrag festgeschrieben, was als deutlicher Fortschritt im Vergleich zu den Forderungen der 1907 und 1913 erfolglos streikenden Bergleute von Michigan und Minnesota gewertet werden kann $^{297}$. Für Verpflegung und Unterkunft in einem werkseigenen Wohnheim mußten die Männer in Montana monatlich 28 \$ - 35 \$ aufbringen, wonach bei einem durch-

\footnotetext{
${ }^{294}$ Vihtori Myllymäki an Heikki Myllymäki in Siikainen, acht Briefe vom 25.10.1904 1.10.1909: TYYH:S:m:Satakunta:SIIK:LXXVIII/3-10; Zitate aus zwei Briefen vom 5.8.1907 und 10.1.1908.

${ }^{295} \mathrm{Zu}$ finnischen Einwanderern in Red Lodge siehe die unveröffentlichte Magisterarbeit von Kuhlman 1987. Obwohl zu Finnen in Butte, Montana keine Untersuchung vorliegt, liefert Emmons (1989) eine detaillierte Schilderung der Grubenarbeiterverhältnisse am Beispiel der Iren. ${ }^{296}$ Järnefelt 1899, 156f.; Hollingsworth 1982, S. 105. Siehe auch ein 1971 geführtes Interview mit einem Finnlandschweden, der 1913 nach Butte emigrierte (Ahlbäck 1976, S. 63-66). Die Verdienstobergrenze von 3,60 \$ pro Tag wird in der Untersuchung von Kuhlman (1987, S. 70) für die Gruben von Red Lodge bestätigt.

${ }^{297}$ Kuhlman 1987, S. 21 und S. 69.
} 
schnittlichen Tageslohn von 3,50 \$ und 24 Arbeitstagen pro Monat noch mindestens 49 $\$$ des Verdienstes übrig blieben. Dies war in den Augen der Finnen eine enorme Summe, da allein der Betrag von 49 \$, d.h. etwa 250 Finnmark, in etwa dem zwei- bis dreifachen Monatslohn eines männlichen Land-, Wald- oder Gelegenheitsarbeiters in Finnland entsprach ${ }^{298}$. Im Vergleich zu dem bescheidenen Gehalt eines finnischen Knechtes fiel die Lohndifferenz sogar noch größer aus: In Montana konnte innerhalb eines Monats das gesamte Jahresgehalt eines in Finnland arbeitenden Landwirtschaftsgehilfen verdient werden, und ein Jahr Vollbeschäftigung reichte zumindest rechnerisch aus, um anschließend ein kleines Haus in Finnland zu erwerben ${ }^{299}$.

Vor diesem Hintergrund verwundert es nicht, daß Finnen in nahezu allen Bergstaaten mit Montanindustrie zu finden waren, beispielsweise in den Orten Carbon, Rock Springs und Cumberland im Staat Wyoming, in Mullan, Idaho, in Salt Lake City und Scofield, Utah sowie in Denver, Telluride und Leadville, Colorado ${ }^{300}$. Die Vorkommen an natürlichen Bodenschätzen waren vielfältig und reichten von Kupfer und Kohle hin zu Blei, Quarz, Gold und Silber, welche allesamt industriell abgebaut wurden.

Vor allem in Colorado zogen die hoch in den Bergen liegenden Silber- und Goldgruben der Städte Telluride und Leadville Einwanderer jeglicher Nationalität nahezu magisch an. In Leadville wurden bereits um 1892 Tageslöhne bis zu 4 \$ gezahlt $^{301}$. Den Staat Colorado haben auch drei Briefschreiberinnen dieser Untersuchung passiert, darunter zwei Schwestern, die in Telluride um 1911 als Dienstpersonal in einer von Finnen geführten Gruppenunterkunft ein zeitweiliges Auskommen gefunden hatten. Im abgeschiedenen Pueblo wiederum unterhielt die dritte Finnin zusammen mit ihrem

\footnotetext{
${ }^{298} \mathrm{Um} 1900$ konnte ein US-Dollar für 5,15 Finnmark umgetauscht werden, vgl. Toivonen 1963, S. 146. In den Jahren 1890-1913 schwankte der durchschnittliche Tageslohn für einen männlichen Arbeiter ohne Pferd in Finnland zwischen 2,07 und 3,32 Finnmark, vgl. Vattula 1983, S. 407f., Tab. 13.1. Lediglich Arbeitskräfte mit eigenen Arbeitspferden konnten im Sommer beispielsweise im Eisenbahngleisbau bis zu 6 Finnmark pro Tag verdienen, vgl. Tokoi 1959, S. 18. Zum allgemeinen Lohnniveau in Finnland siehe auch Orta 1975, S. 29, Tab. 3; Soininen 1981.

${ }^{299}$ Tokoi 1949, S. 69 und 1959, S. 14. Den Lohnvergleich mit dem Jahresgehalt eines Knechtes wendet auch Juho Kuusisto aus Cloquet, Minn.an, Brief vom 14.9.1902:TYYH:S:m:Satakunta: HIN:II/8.

${ }^{300} \mathrm{Zu}$ Finnen in Bergstaaten allgemein siehe Järnefelt 1899, S. 155-179; Ilmonen 1926, Bd.3, S. 213-235; Kero 1996, S. 127. Speziell zu Carbon in Wyoming siehe den Erfahrungsbericht von Tokoi 1959, S. 40-45. Zur Montanindustrie der Bergstaaten vgl. Guggisberg 1993, S. $128 \mathrm{f}$.

${ }^{301}$ Järnefelt 1899, S. 176; Tokoi 1959, S. 48. Zu Finnen in Colorado siehe Myhrman 1972, S. 274-280.
} 
Mann ein eigenes 'Hotel', das im Jahr 1911 jedoch kaum Gäste beherbergte, wie die Briefschreiberin in zwei Briefen beklagt ${ }^{302}$ :

" Wir arbeiten nicht mehr als zwei oder drei Tage pro Woche, auch nach Weihnachten ist das Geschäft noch nicht besser gelaufen. Mein Mann meint, daß wir im Frühjahr von hier weggehen sollten, aber wer weiß? [...] Ich denke oft an die Zeit in Finnland zurück, denn ich mag die Zustände in Amerika nicht, zumindest nicht an diesem Ort. Hier sind kaum Finnen, vielleicht höchstens zehn. Und mir gefällt es nicht, daß ich die Leute niemals etwas anderes reden höre als diese fremde Sprache.”

Frauen waren in den Bergstaaten seltener vertreten als in Michigan, Minnesota und Wisconsin, galten doch die 'Rocky Mountains' eher als Eldorado für zupackende Männer. Dennoch lebten beispielsweise in Red Lodge, Montana 1910240 erwachsenen Frauen, von denen 57 unverheiratet waren. Die meisten von ihnen arbeiteten in den Gruppenunterkünften für finnische Bergleute, den 'Boarding Houses', als Köchinnen, Dienstpersonal und Wäscherinnen, wenngleich auch eine finnische Hebamme vor Ort $\mathrm{zu}$ finden war $^{303}$. Das Lohnniveau der finnischen Frauen lag jedoch deutlich unter dem der männlichen Landsleute. Mit 15 \$ - 20 \$ pro Monat, die Hebamme verdiente sogar nur 14 \$, bei freier Unterkunft und Verpflegung, machte ein Frauengehalt lediglich ein Drittel des Verdienstes eines Bergmanns aus.

Hierbei ist jedoch zu bedenken, daß die Arbeitsverhältnisse in den Gruben der Bergstaaten zu den gefährlichsten der Vereinigten Staaten zählten und die Bergleute für das relativ hohe Unfallrisiko entsprechend gut entschädigt wurden, wie die tragischen Grubenunfälle durch Gasexplosionen im Jahr 1900 in Scofield, Utah und 1903 in Hanna, Wyoming belegen.

Das hohe Lohnniveau der Region der 'Rocky Mountains' wurde lediglich von den Goldgruben in Alaska übertroffen, wo an einem Tag sogar der gesamte Wochenlohn eines Grubenarbeiters aus Michigan oder Minnesota erzielt werden konnte. Zu Beginn der 1890er Jahre, als das Goldfieber allmählich um sich griff, sollen Finnen sogar bis zu $15 \$$ pro Tag in Klondike verdient haben ${ }^{304}$.

\footnotetext{
${ }^{302}$ L. Hissa an Jaakko Mattila, drei Briefe aus Pueblo, Colorado vom 19.8. 1911 und 11.11.1911 sowie 19.1.1912, Samml. Süd-Ostbottnien, Sig. Nr. 276/3, 276/5-6.

${ }^{303}$ Zur Frauenpräsenz in Red Lodge, Montana siehe Kuhlman 1991, S. 15.

${ }^{304}$ Järnefelt 1899, S. 224-234.
} 
Im Jahr 1912 machte sich der Finnlandschwede Alfred Backlund - wie bereits zahlreiche Immigranten vor ihm - von Seattle aus auf den langen und beschwerlichen Weg nach Alaska: Zuerst fuhr er mit dem Schiff von Seattle bis nach Valdez, um anschließend nach Fairbanks im Landesinneren zu gelangen. Für den etwa 600 Kilometer langen Fußmarsch hatte der Finne neun Tage gebraucht. Über seine Zeit in Fairbanks berichtet er in nachhinein:

"Der Tageslohn in der [Gold-] Grube war hoch: 7 \$ pro Tag und eine freie Mahlzeit. Aber alles war sehr teuer in Fairbanks zu dieser Zeit. Kaffee kostete $1 \$$ das Pfund, ein Sack Mehl mit 49 Pfund kostete 5 \$, hundert Pfund Kartoffeln waren 10 \$, Butter war 75 Cents das Pfund, Zucker 25 Cents, ein Dutzend Eier machten 1 \$ und Speck und Schinken waren je 1 \$ das Pfund. Anderes Fleisch bekam man durch die Jagd, denn es gab viele wilde Tiere und auch Elche in der Umgebung. Bohnen gab es jeden Tag bei Tisch. Wir hatten genug zu essen in unserer Gruppenunterkunft, auch wenn es dort nicht so sauber war.[...]- Im Herbst gab es keine Arbeit mehr in Fairbanks. Ich fand, daß es sowohl teuer als auch langweilig werden könnte den ganzen langen Winter ohne Arbeit zu verbringen. Von daher beschloß ich nach Seattle zurückzukehren. "305

Bei einem bescheidenen Lebensstil und mehreren Jahren Vollbeschäftigung war es demnach zumindest theoretisch möglich, genügend Geld für den Erwerb eines Bauernhofes in Amerika oder Finnland zu verdienen. Nach Keros Schätzung war es einem sparsamen Bergmann oder Waldarbeiter sogar möglich, bis zu 300 \$ pro Jahr zur Seite zu legen, was 1500 Finnmark entsprach. In Finnland wäre einem Arbeiter allenfalls eine jährliche Ersparnis von 200-300 Finnmark gelungen ${ }^{306}$.

Hatte der Einwanderer jedoch eine vielköpfige Familie in Finnland zu versorgen, so sicherte er durch mehr oder weniger regelmäßige Geldsendungen das Überleben der Familienangehörigen oder ermöglichte ihnen die Nachwanderung nach Amerika. Zahlreiche Finnen tilgten auch eine alte Schuldenlast in Ratenzahlungen durch Geldsendungen an nahe Angehörige. Ebenso verwendeten zahlreiche finnische Immigranten ihre ersten verdienten Dollars zum Abbezahlen der fremdfinanzierten Atlantiküberquerung

\footnotetext{
${ }^{305}$ Autobiographische Aufzeichnungen von Alfred Backlund in Myhrman 1974, Bd. 8, S. 7.

${ }^{306}$ Kero 1969c, S. 60.
} 
sowie zum Kauf von neuen Fahrkarten, die sie eifrig an auswanderungswillige Verwandte schickten. Über den Verwendungszweck der dem Brief beigefügten oder durch einen Bankwechsel geschickten Dollars finden sich in den Briefen immer wieder Hinweise. Bis zum Ausbruch des Ersten Weltkrieges sollen die Amerika-Finnen etwa 275.000000 Finnmark bzw. 50.000000 Dollar über den Atlantik gesandt haben ${ }^{307}$.

Nicht selten unterbrachen jedoch zeitweilige Krankheit oder Arbeitslosigkeit den Geldfluß in die alte Heimat, und die Ersparnisse mußten für Arztrechnungen, Lebensmittel und Reisekosten in andere Bundesstaaten mit potentiell besseren Erwerbsmöglichkeiten aufgewendet werden. Insofern verbrachten zahlreiche Einwanderer etliche Jahre länger in Amerika als bei Auswanderungsbeginn geplant. Häufig änderten sich die individuellen Zukunftsperspektiven auch mit der Dauer des Amerika-Aufenthalts, und die Ersparnisse wurden zum Landkauf und Hausbau im Mittleren Westen oder den Westküstenstaaten verwendet, vor allem in solchen Fällen, in denen die meist noch jungen Einwanderer erst in den Vereinigten Staaten heirateten und eine Familie gründeten.

Werden die bisher dargestellten Briefe der finnischen Grubenarbeiter aus Michigan, Minnesota und Montana als Stimmungsbarometer verstanden, so ergibt sich ein allgemeines Bild der Unzufriedenheit, das sowohl die vorherrschenden Arbeitsbedingungen als auch die Höhe der Bezahlung betrifft. Dennoch fällt dem kritischen Leser auf, daß in nahezu allen Briefen die Äußerungen zu den wesentlichen Bereichen des Grubenalltages lediglich spärlich verstreut und knapp gehalten sind. Details zu den Arbeitsvorgängen unter- oder übertage, zu Art und Weise der Unterbringung sowie zu sozialen Kontakten und Freizeitaktivitäten fehlen fast gänzlich. Selbst Beurteilungen der aktuellen Lebensumstände oder direkte Klagen über das entbehrungsreiche Leben finden sich nur vereinzelt. Lediglich kurze Bemerkungen zur Länge des gegenwärtigen Arbeitsverhältnisses, zur Gefährlichkeit der Grubenarbeit oder der Anzahl von Finnen am gleichen Arbeistplatz sind immer wieder zu finden. Den größten Raum nehmen die Angaben zur Entlohnung ein.

Es liegt demnach die Vermutung nahe, daß sich die Briefschreiber bewußt über die realen Verhältnisse in den Gruben ausschwiegen. In Interviewaussagen und Lebensberichten aus zweiter Hand hingegen finden sich häufiger Hinweise zu diesen nicht un-

\footnotetext{
${ }^{307}$ Nach der Währungsreform in Finnland des Jahres 1962 entsprach diese Summe 58.600000 Finnmark, vgl. Toivonen 1963, Tab. 6, Anhang. Tokoi (1949, S. 97) wiederum bezieht sich auf eine amerikanische Studie, wonach die Finnen etwa vier Millionen Dollar pro Jahr nach Finnland gesandt haben sollen.
} 
wesentlichen Bereichen des Alltagslebens. Möglicherweise fiel es den finnischen Bergleuten leichter, mit einem größeren zeitlichen Abstand, im nachhinein, über die tatsächlichen Mißstände und Schwierigkeiten des Bergarbeiterdaseins zu berichten. Auch die Tatsache, daß der Interviewer meist eine fremde Person war, kann einen Einfluß auf die Bereitwilligkeit der Befragten gehabt haben, eine möglichst realitätsgetreue Schilderung des Erlebten zu geben.

Im folgenden soll nun erörtert werden, ob sich diese Annahme auch für das Verhalten der Briefschreiber aus anderen Regionen Amerikas, aus Waldkamps, Sägewerken und städtischen Arbeitsbereichen bestätigen läßt.

\section{4. 2. Mit Axt und Säge im Wald: Immer auf Wanderschaft}

Waldarbeit wurde in nahezu allen Staaten von der Ost- zur Westküste angeboten. Im Zuge der westwärts gerichteten Besiedlung entstanden besonders viele Waldkamps sowohl in den Staaten des Mittleren Westens als im auch westlichen Teil Amerikas, wo vor allem für große Zedernwälder erfahrene Waldarbeiter angeworben wurden. In Kanada kann die Waldarbeit sogar als bedeutendster Erwerbszweig für europäische Immigranten angesehen werden. Den finnischen Einwanderern war die Waldarbeit, im Gegensatz zur Grubenarbeit, bereits aus dem Heimatland vertraut, obwohl sich die Arbeitsbedingungen in Amerika und Kanada vielfach von dem unterschieden, woran die Finnen gewöhnt waren.

Die meisten Waldkamps ${ }^{308}$ lagen weit ab in noch unbesiedelten Landstrichen, die erst allmählich durch den Bau von Eisenbahnstrecken und öffentlichen Wegen der Zivilisation zugänglich gemacht wurden. Sie wurden von Wald- oder Eisenbahngesellschaften betrieben und lediglich für einen zeitlich begrenzten Arbeitseinsatz unterhalten. Dementsprechend kurzlebig waren auch die provisorischen Gruppenunterkünfte, in denen die Waldarbeiter höchstens zwei bis drei Winterhalbjahre zubrachten. Sobald die Holzvorkommen einer Region erschöpft waren, wurde das Lager an anderer Stelle wieder neu aufgebaut. Ebenso wanderten ganze Waldkamps im Zuge der Fertigstellung einzelner Streckenabschnitte im Eisenbahngleisbau gemeinsam mit den Arbeitern landeinwärts. 
Aus diesem Grunde investierten die Arbeitgeber weder Geld noch Material in den Bau der Waldkamps, welche einen äußerst primitiven Standard aufwiesen. Die Behausungen bestanden aus unbehandelten Baumstämmen, die in blockbauweise übereinander geschichtet und mit Moos abgedichtet wurden. Als Fußboden diente die nackte Erde, und die Dachabdeckung bestand aus Holzbalken, einfachen Brettern und im besten Fall noch etwas Teerpappe. Die Eingangstür, ein oder zwei kleine Fenster sowie eine Dachluke waren denn auch die einzigen Öffnungen der Wohngebäude. Sofern die Küche nicht im Haupthaus integriert war, wurde ein separates Kochhaus mit einem Vorratsschuppen gebaut. In Kamps mit vielen Finnen hatte auch eine Sauna ihren Platz gefunden, wobei sie nicht nur zur Körperreinigung, sondern auch zur Wäschepflege diente. Pferdestallungen, Heuscheunen und Geräteschuppen ergänzten das Lager zu einer in sich abgeschlossenen Einheit, die bis zu mehreren hundert Männern eine vorläufige Bleibe bot. Der Finnlandschwede Anders Willman hielt sich bereits 1885 in White Cloud, nördlich von Grand Rapids in Süd-Michigan gelegen, auf ${ }^{309}$ :

” Ich fuhr mit der Eisenbahn nach White Cloud. Die kleine Stadt war zugleich ein Mittelpunkt für die Holzindustrie. Im Umkreis befanden sich 15 große Waldkamps mit etwa 90 Männern in jedem Kamp. Die Kamps zogen nach einigen Jahren weiter, nachdem die Wälder kahl geschlagen worden waren. In diesen Kamps arbeitete ich neun Jahre lang. "

In den Kamps war vor allem die spartanische Inneneinrichtung des Haupthauses von Enge gekennzeichnet: In der Raummitte befand sich ein langer Holztisch mit Sitzbänken zu beiden Seiten. An den Längsseiten des Gebäudes waren zweistöckige Schafkojen in die Wände eingelassen, in denen Stroh als Matratzenersatz sowie zwei Wolldecken zur Grundausstattung zählten. In besonders überfüllten Häusern mußten sich auch zwei Männer ein Bett teilen. Kerosinlampen dienten als Lichtquellen, und ein Kamin in der Raummitte sorgte für etwas Wärme.

Dennoch waren Kälte und Feuchtigkeit neben stehender Luft mit dicken Rauchschwaden von Zigarettenrauch ein alltägliches Problem in den primitiven Unterkünften,

\footnotetext{
${ }^{308}$ Zu Waldkamps allgemein siehe Engberg 1959; Haynes 1971; Dye/Dye 1975; speziell zu Finnen in Waldkamps vgl. Knipping 1977, S. 19-21; Radforth 1981; Järvinen 1994, S. 11-13; Kero 1996, S. 168-172.

${ }^{309}$ Lebensbericht von Anders Willman vgl. Myhrman 1974, Bd. 8, S. 59.
} 
welches noch durch das Trocknen von nasser Wollkleidung verstärkt wurde. Kritik an der einfachen Bauweise wurde denn auch in Auswandererbriefen geäußert, wie beispielsweise in einer Schilderung aus Wisconsin aus dem Jahre $1905^{310}$ :

"Hier im Kamp ist es nicht so lustig - bei kaltem Wind und Frost. Selbst drinnen zieht es derartig, daß die Lampen kaum brennen. Aber das ist auch kein Wunder, da die Häuser nicht besser gebaut sind als in Finnland eine Heuscheune, nur Holzbalken ringsherum [...]. Es gibt kein Zwischendach und das Regendach ist aus modrigen Brettern gezimmert und mit Teerpappe abgedeckt."

Interessanterweise findet sich der Vergleich des provisorischen Wohnhauses mit einer Heuscheune in diesem Wortlaut in drei Briefen finnischer Waldarbeiter, obwohl sich die betreffenden Personen mit Sicherheit nicht gekannt haben ${ }^{311}$.

Selbst ein Jahrzehnt später hatten sich die Lebensbedingungen in den Kamps kaum gebessert; aus Kanada klang der Mißmut an den mangelnden hygienischen Verhältnissen um 1914 folgendermaßen ${ }^{312}$ :

"Alles war so schlecht, die Haare froren an den Wand fest, in den Dachbalken waren große Löcher und auch der Atem gefror einem, während die Füße am anderen Ende so langsam auftauten. Nirgendwo konnte man seine nassen Kleider zum Trocknen aufhängen, die verschwitzten Kleider voller Flöhe, und - meine Güte - wie die stanken. Am nächsten Morgen mußte man die gleichen Kleider wieder anziehen. Es gab keine andere Waschgelegenheit außer einer kleinen Waschschüssel neben der Eingangstür."

” Im Winter war ich im Waldkamp, was eine meine schlechtesten Erfahrungen war. Ich war nicht an derart schlimme Verhältnisse gewöhnt, wie sie dort an der kanadischen Grenze vorherrschten. Das Kamp wurde von einem Franzosen betrieben. Ich

\footnotetext{
${ }^{310}$ Brief von Viktor Roos aus Lac du Flambeau Indian Reservation, Wisc. an Kustaa Laine in Chester, Mass. vom 12.03.1905: TYYH:S:m:Satakunta: LAP:XI/13; Brief auch bei Kero (1985, S. 85) abgedruckt.

${ }^{311}$ Viktor Nummela aus Cloquet, Minn. an Erland Heinilä in Lappi, TL, Brief vom 18.1.1902: TYYH:S:m:Satakunta: LAP:I/4; Isak Kuusisto aus Newberry, Mich. an Wilhelm Kuusisto in Hinnerjoki, Brief vom 22. 9. 1905: TYYH:S:m:Satakunta: HIN: III/6.

${ }^{312}$ Erstes Zitat von Reino Keto, entnommen aus Lindström-Best/Sutyla 1984, S. 63; zweites Zitat von Herman Koivisto, interviewt von Kalle Mustonen im Jahr 1977 in Florida, vgl. Mustonen Interviewtranskripte, S. 80.
} 
weiß nicht, ob sie immer noch so schmutzig sind, aber sie waren so schmutzig die Männer dort, daß einem richtig die Mutter fehlte. Immerhin habe ich es dort einen Monat ausgehalten."

Der folgende Bericht des Waldarbeiters Viktor Lehtinen aus dem Jahr 1910 ist jedoch in einer milderen Tonart gehalten, wonach die Verhältnisse nicht in allen kanadischen Kamps gleichermaßen miserabel gewesen sein können ${ }^{313}$ :

"Das Kamp war aus massiven Baumstämmen als Blockhaus gebaut. In dem langen Gebäude waren mehr als hundert Männer untergebracht mit Betten an beiden Längsseiten. In allen Kamps waren Etagenbetten, es gab ein unteres und ein oberes Bett. Das untere Bett war beliebter. Unten war die Luft besser. War der Winter kalt und der große Kamin brannte, so war es im oberen Bett meist so heiß, daß man nicht schlafen konnte. Von der Waldgesellschaft erhielt jeder ein Kissen und zwei Decken.

Die Gehilfen ${ }^{314}$ waren für den Kamin zuständig. In den großen Kamps gab es zwei Gehilfen, die befeuerten den Kamin abends um 9.00 Uhr und bis zum nächsten Morgen mußte kein Holz mehr nachgelegt werden. [...] In den Kamps herrschte Disziplin. Dort durfte man nicht mit anderen prügeln, sonst hatte man gleich zu gehen. Dort wurde auch nicht getrunken. Schnaps durfte man überhaupt nicht in die Kamps bringen. Dort war eine solche Strenge, daß man sofort zu gehen hatte, sobald Schnaps im Spiel war. Ja, die haben einen wirklich hinausgeworfen. Wenn Schnaps dort erlaubt gewesen wäre, hätte das gesamte Leben im Kamp auf dem Kopf gestanden."

Trotz der bescheidenen Wohnverhältnisse schien die Verpflegung in den meisten Kamps ausreichend gewesen zu sein, da diesbezüglich selten Klagen geäußert wur$\operatorname{den}^{315}$. Den Arbeitern wurden mindestens zwei warme Mahlzeiten pro Tag angeboten. Ein Lunch-Paket ersetzte dann häufig die Mittagsmahlzeit, da die Männer meist erst bei Einbruch der Dunkelheit zu ihrer Wohnstätte zurückkehrten. Zu den gewöhnlichsten

\footnotetext{
${ }^{313}$ Zitat von Viktor Lehtinen, interviewt von Virtaranta (1996, S. 47) im Jahr 1980.

${ }^{314}$ Bei den männlichen Gehilfen handelte es sich meist um ältere Waldarbeiter, siehe Stichwort 'Suupoika' im amerikanisch-finnischenWörterbuch von Virtaranta, 1992, S. 198; Järvinen 1994, S. 12.

${ }^{315}$ Als positive Beispiele über die Waldkampbeköstigung in Michigan siehe die Lebensberichte des Jahres 1885 von Anders Willman (Myhrman 1974, Bd. 8, S. 59) und Jacob Dye (1975, S.
} 
Nahrungsmitteln zählten Kaffee, Brot, Butter, Kartoffeln, Bohnen, gebratenes Fleisch oder Fisch und Pfannkuchen. Zusammen mit einigen notwendigen Gebrauchsgütern wurden die Nahrungsmittel wöchentlich von der nächstgelegenen Eisenbahnstation abgeholt. Der bereits zitierte Waldarbeiter Viktor Lehtinen äußerte sich 1910 zufrieden zur täglichen Verpflegung:

"Ich war viele Jahre im Waldkamp. Ich war gerne dort. Dort gab es gutes Essen, gute Köchinnen. Dort durfte man sich so viel Butter aufs Brot schmieren wie man nur wollte. Die Männer bestimmten über die Köchinnen. Eine schlechte Köchin durfte sofort gehen! Die Köchinnen waren meistens Finninnen. Gelegentlich hatten wir auch französische Köche und die waren auch gut. Dann gab es noch viele Küchengehilfen, die sowohl im Kochhaus als auch im Vorratsschuppen alles instand hielten. Im Kamp war auch ein Boss, der jeden Tag kontrollierte, ob auch alles in Ordnung war. Das Kamp durfte nicht sich selbst überlassen werden."

Dieser Zeitzeugenbericht deutet auch auf die Präsenz von Frauen in den Waldkamps hin, obwohl in nicht selten ausschließlich Männer beschäftigt waren ${ }^{316}$. Waren die Lebensverhältnisse bereits für Männer schwer zu ertragen gewesen, so muß das Leben in den abgeschiedenen Waldlagern für Frauen noch anstrengender gewesen sein, vor allem da sie nicht selten kleine Kinder zu betreuen hatten, wie zahlreiche Fotografien bestätigen ${ }^{317}$. Frauen arbeiteten in erster Linie als Köchinnen und "Mädchen für alles". Zu ihren Aufgaben gehörten die Nahrungszubereitung, wobei vor allem das tägliche Brotbacken als arbeits- und zeitintensiv galten, die Reinhaltung des Wohnhauses und in einigen Fällen auch das Waschen der Kleidung der Waldarbeiter. In großen Kamps hingegen wurden die Aufgabenbereiche unter mehreren weiblichen und männlichen Angestellten aufgeteilt.

Viele in Waldkamps arbeitende Frauen waren zugleich mit einem Waldarbeiter verheiratet und bewohnten mit ihrer Familie ein separates Haus. Für Familien fand sich zudem die Möglichkeit, einen Auftrag von einer Waldgesellschaft anzunehmen und die-

15). Auch Isak Kuusisto äußert sich 1905 zufrieden aus Newberry in Michigan, Brief vom 21.11.1905: TYYH:S:m: Satakunta: HIN:III/ 8. Zu Kamps in Kanada vgl. Radforth 1981, S. 25. ${ }^{316}$ Siehe Fotografien bei Engberg 1959, S. 160 und Haynes 1971, S. 170.

${ }^{317}$ Siehe Fotografien bei Myhrman 1972, Anhang, Abb. 9; Radforth 1981, S. 23 und S. 26; Sangster 1981, S. 51; Korkiasaari 1989, S. 30; Järvinen 1994, S. 11 und S. 13; Kero 1996, S. 173. 
sen eigenverantwortlich auszuführen. In diesen Fällen bestand ein Waldkamp dann aus den Wohnhäusern mehrerer Familien ${ }^{318}$.

Der in den Kamps zu erzielende Lohn war für die Frauen reiner Verdienst, da sie keine weiteren Ausgaben für Kost und Unterkunft aufzubringen hatten. Noch 1908 verdiente die Briefschreiberin Miina Ylismäki in einem Kamp in Trout Creek in Michigan als Köchin für neun Waldarbeiter lediglich 15 \$ im Monat ${ }^{319}$, doch um 1920 wurden schon drei- bis vierfache Summen gezahlt. In Kanada war denn auch die Stellung als Köchin eines Waldkamps eine der am besten bezahlten Berufspositionen, die eine finnische Einwanderin erreichen konnte. Aino Norkooli schilderte ihren Arbeitsalltag 1925 in einem kanadischen Kamp mit folgenden Worten $^{320}$ :

"Hier sind 20 Männer und ich koche für sie alle. Ein Junge hilft mit bei der Arbeit.[...] Ich bekomme im Monat 60 \$, das ist ein guter Lohn, aber ich darf dafür auch arbeiten. [...] Morgens muß ich um fünf Uhr aufstehen und dann darf ich abends bis um neun Uhr so viel arbeiten wie ich nur schaffe. Es gibt immer viel zu backen, da die Männer viel Brot essen. Ich versuche als Köchin noch dazuzulernen, denn für Köchinnen gibt es immer Arbeit und einen guten Lohn. Hier gibt es Kamps wo einige [Frauen] mehr als 100 \$ im Monat verdienen, wenn sie für etwa 50 Männer das Essen zubereiten, das ist schon eine nette Summe. [...] Sobald ich $300 \$$ zusammen bekommen habe, werde ich nach Finnland zurückkehren, wie ich es versprochen habe."

Die Anzahl der Waldarbeiter in einem Kamp schien demnach die Höhe des Lohnes der Köchin zu beeinflussen, so verdiente beispielsweise Maria Mäntylä lediglich 40 \$ monatlich in einem kleinen Kamp bei Nipigon in Ontario, da sie 1928 für nur vier Männer zu kochen und waschen hatte ${ }^{321}$. Doch auch dieses Gehalt war viel wert zu einer Zeit, als sich die Weltwirtschaftskrise bereits anbahnte und die allgemeine Arbeitslosigkeit beständig zunahm.

\footnotetext{
${ }^{318}$ Radforth 1981, S. 26; Järvinen 1994, S. 11.

${ }^{319}$ Miina Ylismäki an Nikolai Ylismäki, Brief ohne nähere Datumsangabe von 1908 : TYYH:S:m: Satakunta: LOIM:V/1.

${ }^{320}$ Briefzitat vom 15.12.1925, entnommen aus Lindström-Best 1988, S. 86.

${ }^{321}$ Maria Mäntylä aus einem Waldkamp bei Nipigon in Ontario, Brief vom 25.1.1925, Sammlung Süd-Ostbottnien, Sig. Nr. 2316/2. Diese Brief wurde aufgrund seiner Datierung von 1925 nur ausnahmsweise berücksichtigt und ist nicht in die Aufstellung der beiden Briefsammlungen eingegangen (Anhang, Tab. 8: Briefanzahl und -verfasser in 40 Gemeinden des Untersuchungsgebietes 1870-1914).
} 
Im Gegensatz zu den in Waldkamps beschäftigten Frauen waren die meisten Waldarbeiter unverheiratet, 1885 sollen beispielsweise $71 \%$ aller Waldarbeiter in Michigan ledig gewesen $\operatorname{sein}^{322}$. Andere hatten Frau und Familie im Heimatland zurückgelassen oder waren bereits Landbesitzer in Amerika geworden. Während des Winterhalbjahres in einem Waldkamp versuchten sie dann den Lebensunterhalt für ihre Familien zu verdienen.

Die Waldarbeiter waren in erster Linie für das Fällen von Baumstämmen und den Holztransport zuständig. Sie belieferten Sägewerke mit Baumstämmen oder Eisenbahngleisbaustellen mit vorgefertigten Holzbalken. Die Tätigkeitsbereiche im Wald reichten von der wohl üblichsten Arbeit des Holzfällens, wobei die Arbeiter - von den Finnen "Lumperjäkki” genannt - häufig paarweise zusammenarbeiteten, über die Arbeit des Sägens der Baumstämme in Stücke von 8-16 Fuß bzw. 2,4-4,8 Metern, bis hin zum Transport des Holzes auf Land- und Wasserwegen zur weiteren Bearbeitung in ein Sägewerk. In den Staaten der Westküste mußten Waldarbeiter auch in Höhen von rund 25 Metern Baumkronen abschlagen, wie ein finnlandschwedischer Arbeiter aus einem kanadischen Waldkamp bei Vancouver in British Columbia zu berichten wußte ${ }^{323}$. Im allgemeinen herrschte in den Waldkamps die Spezialisierung der Arbeiter auf verschiedene Tätigkeiten vor, die von Vorarbeitern kontrolliert wurden.

In den Wintermonaten wurde hauptsächlich Holz geschlagen und die Baumstämme mit mehrspännigen Pferdeschlitten zu Sammelplätzen transportiert. Das Frühjahr wiederum galt als geeignete Jahreszeit für das Entrinden der Baumstämme, wobei diese Arbeit bis zum Sommer hin andauern konnte. Nach der Schneeschmelze wurden dann auch natürliche Wasserwege, Flüsse und Seen, soweit vorhanden, zum Flößen genutzt. Dies stellte zugleich einen der besser bezahlten Arbeitsbereiche dar und war unter Finnen beliebt, da ihnen hier die mitgebrachte Arbeitserfahrung aus dem Heimatland zugute $\mathrm{kam}^{324}$. Über den Holztransport im Wald schreibt Kaarlo Pietilä aus einem Waldkamp bei Aberdeen in Washington im Jahr 1910 folgendes $^{325}$ :

\footnotetext{
${ }^{322}$ Engberg 1959, S. 157.

${ }^{323}$ Siehe Interview mit einem 1910 ausgewanderten Finnlandschweden, ohne Namensangabe, bei Ahlbäck 1976, S. 66f.

${ }^{324}$ Juho Kuusisto berichtet 1903 von der Entlohnung der Flößer in Minnesota, die über dem Niveau von Sägewerks-und Waldarbeitern gelegen haben soll: Brief vom 15.4.1903:

TYYH:S:m:Satakunta: HIN:II/12.
} 
"Ich arbeite hier an einem Weg, an dem eine Dampfmaschine Baumstämme in den Fluß zieht. Hier werden die Baumstämme nicht von Pferden gezogen wie in Finnland. Das ginge auch gar nicht, da die Baumstämme so groß sind, daß drei Stämme bereits die Last von einem Eisenbahnwaggon stellen. Die größten Baumstämme haben einen Durchmesser von neun Fuß."

Die Werkzeuge der Waldarbeiter bestanden aus verschiedenen Sägen, Äxten, Hämmern und selbstentwickelten Arbeitsgeräten zur Handhabung von großen Baumstämmen $^{326}$. Über den Werkzeuggebrauch in einem Waldkamp bei Seattle um 1900 wiederum berichtete der schwedischsprachige Auswanderer Joseph Mann in seinen Lebenserinnerungen $^{327}$ :

"Wir arbeiteten mit Handsägen, und jeder Mann hatte eine Säge. Die Sägen bestanden aus einem Sägeblatt von sieben Fuß Länge ohne Bogen, doch mit einem beweglichen Griff, der an beiden Enden befestigt werden konnt. Den einen Tag sägte man mit dem Griff an der einen Seite, den nächsten Tag mit dem Griff an der anderen Seite. Am Abend im Kamp angekommen überließ man die Säge den Schleifern, die in einem Schleifschuppen arbeiteten. [...]

In den größeren Kamps waren gewöhnlich 100-200 Männer zu finden. Hier hatte jeder Mann zwei Sägen, während die eine geschärft wurde, konnte man mit der anderen arbeiten. Sie waren numeriert und die Männer mußten sich ihre Nummern merken. Es muß jedoch gesagt werden, daß die Männer in den kleinen Kamps ihre Sägen selbst instand halten mußten. Es gab dort keinen Schleifer und jedem stand nur eine Säge zur Verfügung.

Vor dem Ersten Weltkrieg lag der Tageslohn in den Kamps bei 2,50 \$- 3 \$. Dabei kam es auf die Art der Arbeit an. Jedes Kamp oder jede Waldgesellschaft hatte auch ihre eigene Lohnskala, aber die Unterschiede zwischen den einzelnen Kamps waren ziemlich gering. Alle Männer, welche die gleiche Arbeit ausführten wurden gleich entlohnt. Ein Vorarbeiter ging umher und gab Anweisungen. Aber solche 'Unions' oder Vereinigungen, welche die Interessen der Arbeiter überwachten, gab es nicht.

\footnotetext{
${ }^{325}$ Kaarlo Pietilä an Bruder in Hinnerjoki, Brief vom 17.4.1910: TYYH:S:m:Satakunta:HIN:YVII/1.

${ }^{326}$ In seiner autobiographischen Schilderung listet Jacob Dye acht verschiedene Werkzeuge auf, die er als Waldarbeiter in Michigan um 1890 benötigte, vgl. Dye/Dye 1975, S. 14.
} 
Bis 1917 hatte der Arbeitstag im Wald noch zehn Stunden. Er begann morgens um 6.00 Uhr. Die Länge des Arbeitstages variierte mit den Jahreszeiten. Im Winter war er kürzer als zehn Stunden aufgrund der Dunkelheit, im Sommer wiederum länger, sogar bis zu zwölf Stunden ${ }^{328}$.,

Das in diesem Ausschnitt aus einem Lebensbericht angesprochene Lohnniveau nimmt auch in zahlreichen Brief- und anderen Lebensschilderungen großen Raum ein. Ähnlich wie bei Briefen aus Grubenorten finden sich auch in den Postsendungen aus entlegenen Waldkamps in erster Linie kurze und knappe Hinweise zum Charakter der auszuführenden Tätigkeiten sowie zur Höhe der Bezahlung. Beim Vergleich der Angaben verschiedener Briefschreiber in der Zeit um die Jahrhundertwende entsteht der Eindruck, daß die allgemeine Bezahlung für Waldarbeit geringfügig unter dem Lohnniveau für Grubenarbeit lag. Hier waren jedoch regionale Unterschiede zu beobachten: In den Staaaten der Westküste wurde durchgängig ein höherer Lohn gezahlt als in Michigan und Minnesota. Dies bestätigen 36 Briefe von sechs Briefschreibern aus den benachbarten Küstenstädten Aberdeen und Hoquiam in Washington, welche ausnahmlos in Sägewerken und Waldkamps der Region beschäftigt waren ${ }^{329}$. Beispielsweise 1885 erhielt ein Hölzfäller in Michigan lediglich 1 \$ 1,35 \$ bei einem elfstündigen Arbeitstag, doch in Washington oder Oregon lag der Tageslohn bereits einen Dollar höher, dort wurde durchschnittlich $2 \$$ - 2,5\$ gezahlt. Zu Zeiten der wirtschaftlichen Depressionsphase der Jahre 1893-94 jedoch ${ }^{330}$, mit denen eine Welle der Entlassungen und Massenarbeitslosigkeit einherging, sanken die Löhne in allen Industriebereichen drastisch ab. Die Waldarbeiter in Minnesota mußten sich zeitweilig mit einem Monatslohn von 6 \$ 10 \&ufrieden geben, womit noch nicht einmal die notwendigen Ausgaben des täglichen Lebens gedeckt werden konnten ${ }^{331}$. Nach der Jahrhundertwende stiegen die Löhne dann allmählich wieder an und hatten in Michigan 1905 ein Niveau von 1,90 \$ pro Tag

\footnotetext{
${ }^{327}$ Zitat aus Lebensbericht von Joseph Mann, vgl. Myhrman 1974, Bd. 7, S. 44f.

${ }^{328}$ Von zwölfstündigen Arbeitstagen bei einem Tageslohn von 2,5 \$ und 3 \$ berichtet auch Kaarlo Pietilä 1910 aus einem Kamp bei Aberdeen in Washington, Briefe vom 4.10.1910 und 6.12.1910; TYYH: S:m:Satakunta: HIN:XVII/3 und HIN:XVII/ 5.

${ }^{329} \mathrm{Um} 1900$ zählte die finnische Gemeinschaft in Aberdeen lediglich 70 Personen, doch im benachbarten Hoqiuam wurden 1910 bereits 1.695 Finnen registriert, vgl. Finns/Hoqiuam 1987, S. 4 und S. 18.

${ }^{330} \mathrm{Zu}$ den Auswirkungen der Depression von 1893 auf den amerikanischen Arbeitsmarkt vgl. Sautter 1986, S. 284-287.

${ }^{331}$ Wasastjerna 1957, S. 582.
} 
bzw. 57 pro Monat erreicht ${ }^{332}$. Die Länge des Arbeitstages hingegen war, zumindest in Minnesota, bereits 1902 von zwölf auf zehn Stunden reduziert worden ${ }^{333}$, doch an der Westküste wurde auch 1909 noch hartnäckig am zwölfstündigen Arbeitstag festgehalten $^{334}$.

In vielen Kamps wurde die ganze Woche gearbeitet, d.h. auch an Sonn- und Feiertagen. Die pausenlose Waldarbeit läßt sich durch die Tatsache erklären, daß die Waldarbeiter jeglichen Verdienstausfall, der durch schlechte Wetterverhältnisse verursacht wurde, aus eigener Tasche zu tragen hatten ${ }^{335}$. In dieser Hinsicht unterschied sich der Wochenrhythmus der Waldarbeiter deutlich von dem der Grubenarbeiter. Letztere arbeiteten lediglich sechs Tage in der Woche; Sonntag war ein allgemeiner Ruhetag in der Montanindustrie.

Auch in den Sägewerken sahen die allgemeinen Arbeitsbedingungen nicht besser aus, eine Sieben-Tage-Woche bei 10-12stündigen Arbeitstagen waren die Regel. Ebenso glich das Schema der Entlohnung dem der Waldkamps: Vor der Jahrhundertwende lagen die Löhne in den Sägewerken durchschnittlich bei 1 \$ bis 1,25\$ pro Tag, nach 1900 konnten im besten Fall bis zu 2 \$ erzielt werden ${ }^{336}$. Lediglich zu Zeiten der ökonomischen Krise des Jahres 1893 wurden den Arbeitsuchenden in Michigan und Wisconsin einfache Tätigkeiten, wie das Bretterstapeln oder das Beladen von Eisenbahnwaggons, für 16 \$-24 \$ im Monat angeboten, was einem Tagessatz von weniger als einem Dollar entsprach ${ }^{337}$. Demnach arbeiteten die meisten Waldarbeiter auch nur kurze Zeitspannen in einem Kamp oder Sägewerk, die Mobilität innerhalb dieser Berufsgruppe war extrem groß.

\footnotetext{
${ }^{332} 1885$ verdiente Anders Willman lediglich 1 \$ in White Cloud, Mich. (Myhrman 1974, Bd. 8, S. 59) und Jacob Dye erhielt 1,35 \$ in Boyne Falls, Mich. (Dye/Dye 1975, S. 17). 1888 wurde in Escabana, Mich. 1,60 \$ gezahlt (Herman Reeth, vgl. Myhrman 1974, Bd. 4, S. 35) und Isak Kuusisto erhielt 1910 in Newberry, Mich. 1,90 \$ (Brief vom 22.9.1905: TYYH:S:m:Satakunta: HIN:III/6).

${ }^{333}$ Juha Kuusisto aus Cloquet, Minnesota, Brief vom 26.10.1902: TYYH:S:m:Satakunta: HIN:II/9.

${ }^{334}$ Dies berichtet Alfred Backlund aus Eureka in Kalifornien, vgl. Myhrman 1974, Bd. 7, S. 6.

${ }^{335}$ Siehe hierzu die bereits zitierten Briefe von Kaarlo Pietilä aus Aberdeen, Wash. von 1910.

${ }^{336}$ Viktor Nummela erhielt 1901 1,75 \$ pro Tag in einem Sägewerk bei Cloquet, Minn. (Brief vom 22.9.1901: TYYH:S:m: Satakunta:LAP:I/1); 1907 wurde Selim Kaukonen ebenda mit 1,85\$ täglich entlohnt (Brief vom 5.7.1907: TYYH:S:m:Satakunta: Kiik:II/12). Siehe auch Haynes 1971, S. 164.

${ }^{337}$ Bericht von Erick Johnson aus Wisconsin und Michigan 1894, vgl. Myhrman 1974, Bd. 3, S. $51 \mathrm{f}$.
} 
Die Sommermonate, d.h. die Zeit von April bis September, verbrachten die Waldarbeiter dann in häufig Städten, wie Duluth und Port Arthur, heutzutage Thunder Bay genannt. Dort ernährten sie sich entweder mit Zimmermannsarbeiten im Baugewerbe oder wanderten nach einem kurzzeitigen Stadtaufenthalt in einen der zahlreichen Grubenorte weiter. Zu Erntezeiten waren die leicht anzuwerbenden Arbeitskräfte dann auch auf Farmen gern gesehen, und ihnen wurde in der Landwirtschaft häufig ein höherer Tageslohn gezahlt als im Wald ${ }^{338}$. In ökonomischen Depressionszeiten jedoch blieb auch so mancher Waldarbeiter arbeitslos und mußte seine im Winter erworbenen Ersparnisse für den Lebensunterhalt im Sommer aufbrauchen, wie beispielsweise ein Waldarbeiter im Winter 1883 aus Hancock in Michigan zu berichten wußte ${ }^{339}$ :

” In Minneapolis da war ein Mann, der im vergangenen Winter für mehr als hundert Dollar auf Kosten anderer gelebt hatte. Im Sommer hatte dann er gearbeitet, doch sein Verdienst reichte noch nicht aus um den Schuldenberg abzutragen. Jetzt ist er wieder arbeitslos und beginnt nun in diesem Winter erneut seinen Verdienst vom kommenden Sommer aufubrauchen. Also auch in Minnesota sieht es nicht sehr rosig aus."

Im Oktober kehrten die Waldarbeiter dann wieder in die endlosen Wälder und die Einöde der Waldkamps zurück. Ein solcher Jahreslauf entwickelte sich für viele zur beständigen Lebensform über Jahre und Jahrzehnte hinweg, doch entfremdete dieses Leben die 'Lumberjacks' zugleich von der übrigen Gesellschaft und nicht zuletzt von ihren eigenen Landsleuten.

Im Hinblick auf die Härte der Arbeitsbedingungen, das niedrige Lohnniveau sowie die bescheidenen Wohnverhältnisse unterschied sich das Alltagsleben eines finnischen Wald- oder Sägewerksarbeiters kaum von dem einen Bergmannes. Letzterem war jedoch ein freier Tag in der Woche vergönnt, ebenso wie sich der Acht-StundenTag zumindest in Montana bereits um 1900 durchgesetzt hatte. Lediglich die Unfallrate mit tödlichem Ausgang war in der Montanindustrie deutlich höher als in den Arbeitsbereichen der Holzindustrie, wenngleich auch Unfälle im Wald nicht selten waren. So berichtet beispielsweise Kaarlo Pietilä 1910 aus einem Waldkamp bei Aberdeen in Washington, daß ein Kamerad beim Holzfällen vom Baum erschlagen wurde. Meldungen

${ }^{338}$ Engberg 1959, S. 155. 
von derartigen Arbeitsunfällen in Amerika fanden sich gelegentlich auch in der finnischen Presse, hier ein Beispiel von 1885 aus einer schwedischsprachigen Zeitung ${ }^{340}$ :

"Finne im Ausland umgekommen. Der Bauerssohn Karl Johan Johanson Brådd aus der Gemeinde Närpes und dem Dorf Rangsby wurde am 17. November des vergangenen Jahres [1884] während der Waldarbeit in Amerika von einer umstürzenden Baumkrone getroffen. Die Baumkrone wurde von seinem Kameraden und zugleich jüngerem Bruder in großer Höhe abgesägt, mit der Folge, daß die Schädeldecke [von Karl Johan] eingedrückt wurde. Und obwohl der junge Mann umsorgende Hilfe erhielt, starb er nach 15 qualvollen Stunden am 18. November in blühendem Alter, er war nämlich erst 22 Jahre alt."

\section{4. 3. Aus Gruben- und Waldarbeitern werden Bauern:} Finden einer neuen Heimat

Den Lebensberichten und Briefen der finnischen Auswanderer zufolge, hatte fast jeder finnische Waldarbeiter auch zeitweilig in einer Grube gearbeitet. Viele hatten auch Erfahrungen im Eisenbahngleis- oder Straßenbau gesammelt, doch da das allgemeine Lohnniveau keine großen Unterschiede aufwies, gaben häufig eher die äußeren Umstände wie Arbeitsplatzangebot und Bezahlung den Ausschlag für eines dieser Beschäftigungsfelder. Die durch ständige Arbeitsuche bedingte Mobilität unter den finnischen Einwanderern war groß. Von daher galt das seßhafte Leben als Landwirt mit eigenem Grund und Boden als Idealberuf, den die einen in Finnland und die anderen in Amerika zu verwirklichen suchten.

Träumten nicht wenige finnische Immigranten bei Beginn ihres Amerikaaufenthaltes noch von einem eigenen Bauernhof in ihrem Heimatdorf oder zumindest im Heimatland, so gestaltete sich eine Rückkehr in die vertraute Umgebung der Jugendzeit häufig als schwer umsetzbar. Nicht allen Finnen gelang es tatsächlich, eine beträchtliche Summe Geld zu sparen oder ihren Gesundheitszustand zu erhalten. Auch eine Heirat in Amerika - häufig ehelichten die Finnen nur eigene Landsleute - und damit einhergehender Familiengründung, hatten den Leben möglicherweise eine neue Zielrich-

\footnotetext{
${ }^{339}$ Jacob Junsola an Wilhelm Kangas in Ylihärmä, Brief vom 1.12.1883, Sammlung SüdOstbottnien, unsigniert.
} 
tung gegeben. Da lediglich ein Fünftel aller finnischen Auswanderer auch wieder nach Finnland zurückwanderte ${ }^{341}$, gewinnt der Aspekt der Neuorientierung des Immigrantendaseins nach einigen Aufenthaltsjahren in Amerika an Bedeutung.

In vielen Schilderungen der Betroffenen wird immer wieder der Wunsch nach einem selbstbestimmten Leben auf eigenem Grund und Boden geäußert. Gründe für das sogenannte "Land-Fieber" gab es viele: Unbeständige Arbeitsverhältnisse und ein niedriges Lohnniveau enttäuschten die Einwanderer, die in erster Linie zum Gelderwerb in die Vereinigten Staaten gekommen waren. Ältere Bergleute hielten häufig dem Tempo der Akkordarbeit untertage nicht mehr stand und wünschten der ständigen Bevormundung durch Vorarbeiter und Chefs zu entgehen. Und nicht wenigen blieb der Zugang zu den Bergwerken sogar dauerhaft verwehrt, da ihre Namen auf den berüchtigten "schwarzen Listen" standen.

Dementsprechend bedeutete die Erfüllung des langgehegten Traumes von eigenem Grund und Boden nicht nur Existenzsicherung und zugleich Schaffung eines Altersruhesitzes, sondern vor allem auch Freiheit und Unabhängigkeit - Ideale, die sich die amerikanische Gesellschaftsordnung zwar auf ihre Fahnen geschrieben hatte, die aber jeder Einwanderer sich selbst erkämpfen mußte.

Minnesota kann dabei in zweifacher Hinsicht als bevorzugter Bundesstaat für finnische Farmer angesehen werden: Zum einen siedelten die Pioniere unter den finnischen Amerikaeinwanderern gegen Ende des Sezessionskrieges gerade in Minnesota. Zum anderen stieg die Anzahl der finnischen Farmen besonders in Minnesota zu Beginn des 20. Jahrhunderts an, nachdem die ehemaligen Bergleute und Holzfäller das erforderliche Kapital für den Landkauf zusammengetragen hatten.

Die ersten Finnen erreichten Minnesota zur gleichen Zeit, d.h. Mitte der 1860er Jahre, als auch die Kupferregion im Norden Michigans von finnischen Grubenarbeitern, welche zuvor Kupfer in Nord-Norwegen abgebaut hatten, besiedelt wurde. Diese Pioniere der finnischen Amerikaeinwanderung traten die Atlantiküberquerung gemeinsam mit anderen im Familienverband ausgewanderten Landarbeitern aus den nördlichsten Regionen Finnlands an und beabsichtigten noch eine dauerhafte Übersiedlung in die Neue Welt. Vor allem durch Seeleute und norwegische Rückwanderer erfuhren die im

\footnotetext{
${ }^{340}$ Kaarlo Pietilä, Brief vom 6.12.1910: TYYH:S:m:Satakunta: HIN:XVII/5. Siehe hierzu auch Haynes 1971, S. 168. Das Pressezitat stammt aus der finnlandschwedischen Zeitung 'Wasabladet' vom 21.1.1885.

${ }^{341}$ Virtanen 1979, S. 67.
} 
Norden Finnlands oder Norwegens lebenden Fischer und Bergleute von der offiziellen Grundstücksvergabe, insbesondere in den Staaten Minnesota, Michigan, Wisconson, Dakota, Washington und Oregon. Die Landvergabe basierte auf dem 1862 in Kraft getretenen Heimstättengesetz, als 'Homestead-Act' bekannt geworden: Die Verpflichtung der europäischen Siedler bestand darin, mindestens fünf Jahre lang bis zu 160 Morgen, d.h. etwa 65 Hektar, Ackerland zu bebauen, um somit noch unbesiedelte Prärieregionen in Zentral-Amerika zu kultivieren. Nach fünf bis sieben Jahren war der Heimstättenvertrag erfüllt, und das Anwesen ging in den Besitz der Siedler über ${ }^{342}$. Die Einwanderer erhielten die Möglichkeit, das Land gegen ein geringes Entgeld zu erwerben oder aber wieder zu verkaufen. In den 1890er Jahren erklärte die amerikanische Regierung dann schließlich die Phase der Erschließung und Bebauung der Vereinigten Staaten als abgeschlossen, wodurch auch das Heimstättengesetz allmählich seine Wirkung verlor.

Die ersten finnischen Bauernhöfe in Minnesota ${ }^{343}$ bildeten zugleich auch die ersten landwirtschaftlich orientierten Siedlungen der Finnen in den Vereinigten Staaten überhaupt. Bereits 1864 entstand eine anfängliche Siedlung am Ufer des MissisippiFlußes, an der Grenze zu Wisconsin. Die Kleinstadt Red Wing im Bezirk Goodhue, südostlich von Minneapolis, wo sich zuvor schon deutsche und skandinavische Siedler niedergelassen hatten, entwickelte sich zum wichtigen Knotenpunkt für später ankommende Finnen, die von dort aus die Weiterreise in westwärts gelegene Regionen von Minnesota antraten.

Die bescheidenen Lebensverhältnisse der ersten Finnen in Red Wing waren zumindest in einem Fall von purer Armut gekennzeichnet, wie ein verzweifelter finnischer Auswanderer in einem Brief vom 27.9.1865 berichtet, den die Redaktion der Wochenzeitung 'Oulun Wiikko Sanomia' (Ouluer Wochenzeitung) wiedergab mit der Intention vor der Auswanderung zu warnen:

"Ich möchte euch wissen lassen, daß es nicht lohnt hierher zu kommen. Hier lebt man schlecht. Alles was man braucht ist teuer. Es gibt zu wenig Unterkünfte und zu viele Menschen [...] Wir wohnen in einer hölzernen Scheune. Meine Frau und die Kinder

\footnotetext{
${ }^{342}$ Zum Heimstättengestz siehe z.B. Helbich/Haubold 1988, S. 41; Hoerder/Knauf 1992, S. 130.

${ }^{343} \mathrm{Zu}$ den ersten Finnen in Minnesota siehe Kolehmainen 1944, S. 318; Mead 1954, S. 10; Wasastjerna 1957, S. 88-97; Riippa 1981, S. 299; Raittila 1982, S. 14-17. Die meisten Detailangaben zu den ersten finnischen Dorfgründungen finden sich bei Ilmonen 1923, Bd. 2: zu Franklin: S. 132-142,Holmes City: S.182-191, Cokato: S. 146-177, New York Mills: S. 191-218, Red Wing: S. 142-146
} 
weinen vor Hunger und Kälte, wir haben kein Bett und keine Kleider. Wir haben alles verloren, uns sind nur die Kleider geblieben, die wir am Leib tragen. [...]Bis zum Winter sind noch drei Monate, ich weiß nicht wie wir den Winter überstehen sollen. Wald gibt es hier überhaupt nicht. Holz wird von anderswo hierher gebracht. Ich würde von hier fortgehen, doch wir haben kein Geld mehr. [...] Ein Kind ist schon vor Hunger gestorben."

Die Pioniere unter den finnischen Siedlern verließen die Region um Red Wing doch bereits nach 1866 wieder, da eine Choleraepidemie zwei Dutzend Finnen das Leben gekostet hatte. Die meisten Familien wanderten daraufhin ins Landesinnere von Minnesota weiter und erhielten hauptsächlich in drei Gebieten 'Homestead'- Grundstücke, in den weit auseinander liegenden Bezirken Renville, Douglas und Wright. Es handelte es sich dabei in den meisten Fällen um Waldgrundstücke, welche die Pioniere ohne vorherige Kenntnis, lediglich als Markierung auf einer Karte festgehalten - in tagelangen Fußmärschen aufsuchen mußten. Zentral-Minnesota war zu dieser Zeit erst spärlich besiedelt, und so trafen die Finnen auf vereinzelte Bauernhöfe von deutschen, schwedischen und norwegischen Siedlern, welche die Region schon zu Zeiten der Indianerunruhen erreicht hatten.

Im Jahr 1865 gründeten fünf finnische Familien dann die erste dauerhafte finnische Dorfsiedlung nahe der Ortschaft Franklin im Bezirk Renville. Nur drei Jahre zuvor sollen Sioux- Indianer noch Massaker an europäischen Siedlern verübt haben, doch nach Errichtung einer von amerikanischen Soldaten bewachten Schutzanlange brachen ruhigere Zeiten an. Im Jahr 1883 wurden dann bereits mehr als 200 Finnen aus 40 Familien in Franklin gezählt.

Um 1866 entstanden zwei weitere finnische Dörfer bei Holmes City und Cokato in den Bezirken Douglas und Wright. Von diesen frühen Siedlungsgründungen entwickelte sich Cokato zur größten von Finnen besiedelten Landwirtschaftsregion der Vereinigten Staaten vor der Jahrhundertwende. Ein Zeitzeuge hatte bereits 1879 etwa 450 Finnen aus 95 Familien in Cokato gezählt ${ }^{344}$. Auch im Nachbarort Dassel, der dem Namen nach zu urteilen auf die Entstehung durch deutsche Siedler zurückgeht, sollen sich im Jahr 1885 bereits 17 finnische Bauernhöfe befunden haben, wonach schät-

${ }^{344}$ Ilmonen 1923, Bd. 2 , S. 151. 
zungsweise 100 Finnen dort gelebt haben könnten ${ }^{345}$. In westlicher Richtung waren die finnischen Siedlungen von Cokato und Dassel durch eine Eisenbahnverbindung an Minneapolis angeschlossen, was einen nicht unwesentlichen Faktor für den Verkauf von Agrarprodukten darstellte.

In einer Mikrountersuchung über die Entwicklung von Cokato vor der Jahrhundertwende hat Alanen ${ }^{346}$ festgestellt, daß schwedische Siedler etwas mehr als die Hälfte aller 'Homestead'-Grundstücke für sich beanspruchten, nämlich 115 von insgesamt 209 Farmen im Jahr 1880 sowie 122 von 223 Farmen im Jahr 1894. Der Zuwachs von sieben schwedischen Farmen in 14 Jahren ist jedoch als gering zu bewerten im Vergleich zum Zulauf von finnischen Landwirten: Die Anzahl der finnischen Farmen stieg nämlich von 46 auf 72 an, und auch die durchschnittliche Größe der finnischen Farmen war von 69 auf 80 Morgen angewachsen.

Holmes City im Bezirk Douglas - nicht zu verwechseln mit dem gleichnamigen Bezirk in Wisconsin - kann als die kleinste und abgeschiedenste Siedlung der finnischen Pionierphase angesehen werden. 1883 wurden dort 133 erwachsene Finnen gezählt. Einer von vier Gründungsvätern, Johan Piippo, der 1866 seine 'Homestead-farm' mit 160 Morgen Land entgegennahm, schildert in einem Zeitungsbericht aus dem Jahr 1881 seine Anfangsschwierigkeiten mit folgenden Worten $^{347}$ :

"Im Frühjahr rang ich dem Boden mit meiner Hacke ein Stück Ackerland ab und hatte Weizen darauf gesäät. Doch die Blaukrähen fraßen alle Samen auf. Ich hätte nur zwei Bund Weizenstroh ernten können, doch die Blaukrähen waren schneller. Im Sommer gelang es mir, einen Morgen Ackerland zu bestellen, ich baute Kartoffeln und Tabak an. Im dritten Winter erlegte ich genügend Wölfe, um mir von den Tierfellen ein Ochsenpaar und eine Kuh kaufen zu können. Aber das Unglück war gescheiter als ich, denn im folgenden Frühjahr geschah etwas ganz Schreckliches: Als ich einem Nachbar beim Hausbau geholfen hatte, fand ich abends bei meiner Heimkehr den ganzen Hof in Schutt und Asche liegen. Mir blieb nichts übrig außer meiner Axt und meinen zerlumpten Kleidern."

\footnotetext{
${ }^{345}$ Mead 1954, S. 10.

${ }^{346}$ Alanen 1988, S. 74, Tab. 3. und Tab. 4.

${ }^{347}$ Bericht vom 17.12.1881 aus der Zeitung 'Uusi Kotimaa' [Neue Heimat] aus New York Mills, Minn.
} 
Waldbrände stellten für die Landwirte zu jeder Zeit eine große Gefahr dar. Um 1880 sollen auch finnische Pioniere in Cokato ihr gesamtes Hab und Gut durch eine Feuersbrunst verloren haben ${ }^{348}$. Der Pionier Johan Piippo ließ sich jedoch nicht entmutigen: Bereits 1872 hatte er wieder 100 Morgen Land eingezäunt und 17 Morgen davon als Ackerland bebaut. In den Erinnerungen der Bewohner von Holmes City blieb er aber vor allem aufgrund seiner außerordentlichen Eigenschaften als Jäger und Fallensteller lebendig ${ }^{349}$.

Einen weiteren Einblick in das Leben zu Pionierzeiten geben vier Briefe des 1881 ausgewanderten Antti Kangas ${ }^{350}$, der nach zweijährigem Aufenthalt in Asthabula Harbour in Ohio und Minneapolis, ab dem Frühjahr 1884 aus Franklin im Bezirk Renville an seinen Bruder in Finnland zu schreiben begann:

" Ich möchte dir mitteilen, daß ich auf einem finnischen Hof arbeite. Sie haben mich gut behandelt, wofür ich sehr dankbar bin. [...] Die Bauern hier pflügen bereits ihre Felder und säen Weizen, obwohl der Winter sehr kalt war. Menschen sind erfroren. Sie hatten sich verlaufen, als sie von einem Hof zum anderen gehen wollten. In dieser Wildnis steht einem der Tod bevor, wenn man in einen Schneesturm gerät."

Im Winter des gleichen Jahres schloß sich der Briefschreiber einer Gruppe von Waldarbeitern an:

"Ich befinde mich in der Nähe einer finnischen Siedlung, in der gleichen Gegend, in der ich auch den vergangenen Winter verbracht habe. Aber jetzt bin ich unter Deutschen, und ich habe seit drei Monaten kein einziges finnisches Wort mehr gehört. Am kommenden Sonntag jedoch werde ich Finnen besuchen, die mich immer sehr freundlich aufgenommen haben."

Zu Beginn des Jahres 1885 schrieb Antti Kangas, daß er sich weiterhin in dem erwähnten Waldkamp befinde. Außerdem habe er wieder drei finnische Familien be-

\footnotetext{
${ }^{348}$ Vgl. Ilmonen 1931, Bd. 2, S. 106. Der Pfarrer Salomon Ilmonen erreichte 1891 Amerika und hatte jahrelang Namen und Lebensgeschichten seiner Landleute aufgezeichnet. Zur Person Ilmonens siehe Wargelin 1987.

${ }^{349}$ Alanen 1981a, S. 77.

${ }^{350}$ Antti Kangas an Jacob Kangas in Ylistaro, Briefe vom 30.3.1884, 29.11.1884, 24.1.1885 und 24.2.1886, Sammlung Süd-Ostbottnien, unsigniert.
} 
sucht und dort freundliche Bewirtung erfahren. Im Februar 1886 meldete sich der Briefschreiber dann zum letzten Mal aus Franklin, er gab an, arbeitslos zu sein und plante das Frühjahr als Arbeiter beim Eisenbahngleisbau zu verbringen. Ob ihm sein Vorhaben gelungen ist, läßt sich nicht mehr in Erfahrung bringen.

Aus diesem kurzen Fallbeispiel des Antti Kangas wird deutlich, daß es für landlose Einwanderer vor der Gründung der Eisenerzgruben im Nordosten von Minnesota schwierig gewesen sein muß, ein regelmäßes Auskommen zu finden. Vor den 1880er Jahren bot die finnische Siedlung von New York Mills im Bezirk Otter Tail eine der wenigen Erwerbsalternativen: Die meisten Dorfbewohner betrieben Landwirtschaft als Nebenerwerb und verdienten ihren Lebensunterhalt im regionalen Sägewerk, das seit 1874 zur Entstehung der Siedlung beigetragen hatte. In den folgenden Jahrzehnten dehnte sich die finnische Besiedlung von New York Mills dann über die Bezirksgrenzen von Otter Tail in die angrenzenden Bezirke Wadena und Becker aus. Der Zeit- und Augenzeuge Akseli Järnefelt hat die finnische Präsenz der Region im Jahr 1895 sogar auf 6000 Personen geschätzt, doch nach Angaben der offiziellen Registrierung befanden sich im besagten Jahr lediglich 1725 Finnen der ersten Generation in den drei Bezirken. Dennoch ist es offensichtlich, daß Ausdehnung und Einwohneranzahl des finnischen Siedlungsgebietes ausgehend von New York Mills bei weitem die zuvor genannten, finnischen Landwirtschaftsregionen Minnesotas in den Schatten stellte ${ }^{351}$.

Obwohl diese ersten finnischen Landwirte in Minnesota eine strenge Frömmigkeit und der Glauben an die Lehren des Wanderpredigers Lars Levi Laestadius ${ }^{352}$ verband, kann nicht von einer organisierten Gruppenauswanderung einer religiösen Glaubensgemeinschaft gesprochen werden. Vielmehr fungierte die freikirchliche Glaubensbewegung, deren Ursprung in den nördlichsten Regionen Finnlands lag, als soziale Brücke zwischen den sogenannten Lestadiern in der Alten und Neuen Welt. Da die lutherische Kirche Finnlands zur Jahrhundertwende hin jedoch auch eine deutliche Vormachtstellung unter den gläubigen Amerika-Finnen errungen hatte, verlor sich der Einfluß der Lestadierbewegung in zunehmendem Maße.

\footnotetext{
${ }^{351}$ Järnefelt 1899, S. 137 und ders. 1921, S. 54-58. Zu New York Mills siehe auch Wasastjerna 1957, S. $155-159$ u. S. 198.

${ }^{352}$ Der Wanderprediger Lars Levi Laestadius war bereits 1861 gestorben, seine Lehren verbreiteten sich jedoch unter finnischen Bauern und Fischern vom Norden Finnlands bis an die norwegische Eismeerküste. Zum Einfluß des Lestadier-Glaubens auf das Leben der frühen AmerikaFinnen siehe Raittila 1982, bes. S. 24-55.
} 
Gemeinsam war diesen frühen finnischen Dorfgründungen außerdem ihre abgeschiedene geographische Lage in waldreichen Gebieten, die in den Augen der Amerikaner als ungeeignet für die Landwirtschaft galten ${ }^{353}$. Die Anfangsjahre der neuen Farmer waren beschwerlich und voller Hindernisse: Nicht selten mußte Wald gerodet und das neugewonnene Gelände von Baumstümpfen, Büschen und Steinen gereinigt werden. Die Wachstumsperiode lag mit 90-120 Tagen pro Jahr deutlich unter dem Landesdurchschnitt, und die Bodenbeschaffenheit eignete sich nur bedingt für den Getreideund Kartoffelanbau.

In den ausgedehnten Prärieregionen des Mittleren Westens, die geradezu geschaffen für den Weizenanbau zu sein schienen, waren Finnen hingegen nur vereinzelt zu finden, da die begehrtesten Landflächen auch nach Erlaß des Heimstättengesetzes selten kostenfrei abgegeben wurden. Sie befanden sich vielmehr in den Händen von Wald- und Industriegesellschaften, die bis zu 100 Dollar für jeden Morgen Ackerland verlangten $^{354}$. Günstig gelegene und fruchtbare Grundstücke wurden jedoch auch von früher immigrierten Deutschen, Schweden und Norwegern in Anspruch genommen. Zum Zeitpunkt der Volkszählung des Jahres 1890 sollen mehr als die Hälfte von insgesamt 650000 Landbesitzern der Vereinigten Staaten deutscher oder skandinavischer Herkunft gewesen $\operatorname{sein}^{355}$.

Die meisten Finnen hatten jedoch bereits vor der Jahrhundertwende, als das von der Regierung kostenfrei abgegebene Land allmählich knapp wurde, Ackerlandparzellen von Wald- und Eisenbahngesellschaften im Bereich der Großen Seen gekauft. Die gezielte Werbung für Ackerland und der Verkauf an finnische Einwanderer ist auch von Grundstücksmaklern überliefert ${ }^{356}$. Nachdem die Landstriche für die industrielle Nutzung durch die Waldgesellschaften nutzlos geworden waren, konnten sich die zukünftigen Farmer, denen die Region meist durch vorausgegangene Waldarbeit bereits bestens vertraut war, günstig gelegene Grundstücke aussuchen. Dies war wiederum im Hinblick auf die erst im Entstehen begriffene Infrastruktur der ländlichen Gebiete bedeutsam:

\footnotetext{
${ }^{353}$ Alanen 1983b, S. 10.

${ }^{354}$ Ein norwegischer Auswanderer berichtet 1870 in einem Brief aus der Grenzregion von Minnesota und Iowa, daß die Grundstückspreise für gutes Ackerland bei 50-100 \$ pro Morgen lagen: Brief von Juul Gulliksen Daaset aus Bratsberg, Bezirk Fillmore, Minn.; abgedruckt bei Øverland/Kjærheim 1993 , Bd. 3, S. 186f.

${ }^{355}$ Taylor 1971, S. 182. 1890 betrug der Anteil der Farmer an der Gesamtbevölkerung der Vereinigten Staaten 42\%, vgl. Adams 1992, S. 506.

${ }^{356}$ Knipping 1977, S. 21. Im Jahr 1910 warben z. B. Agenturen in New York potentielle finnische Farmer für die Neuenglandstaaten an, vgl. Hoglund 1964, S. 144f.
} 
Die Siedler profitierten von neuen Wegen, die eigens für den Holztransport angelegt worden waren, und erweiterten ihrerseits das regionale Straßennetz durch neue Wege; ebenso wie auch in der Nähe von schon fertiggestellten Eisenbahnstrecken die ländlichen Siedlungen schnell anwuchsen.

Nach der Jahrhundertwende war es bereits schwierig geworden, Ackerland auf der Grundlage des Heimstättengesetzes zu erhalten. Wer eigenes Land bestellen wollte, mußte zuvor erhebliche Investitionen für den Landkauf, Hausbau sowie den Erwerb von Vieh und Gerätschaften leisten. Allein die Grundstückspreise lagen bei 1000 \$-2000 \$, die Anfangsinvestitionen für Vieh und Gerätschaften können etwa weitere 500 \$ betragen haben ${ }^{357}$. Eine genaue Schätzung der erforderlichen Summe ist schwer zu ermessen, da beispielsweise ein Pferd in Minnesota 1870 bereits 100 \$-300 \$ gekostet haben soll, fünf Jahr später jedoch schon für $20 \$$ zu haben war ${ }^{358}$. Vermutlich lag der wahre Preis für das Zugtier zwischen beiden Summen. Fest steht jedoch, daß die Gründung eines eigenen Farmanwesen nicht ohne erhebliche finanzielle Mittel zu verwirklichen war. Aus diesem Grund bestand die Berufsgruppe der finnischen Landwirte auch in erster Linie aus ehemaligen Bergleuten und Waldarbeitern, die sich bereits seit Jahren oder Jahrzehnten in Amerika aufgehalten und somit einen finanziellen Grundstock erworben hatten.

Da die aufzubringende Summe, zumindest theoretisch betrachtet, dem gesamten Lohn von wenigstens fünfjähriger, ununterbrochener Gruben- oder Waldarbeit entsprach, verwundert es nicht, daß die meisten Landwirte zu Beginn ihres Farmerdaseins nicht jünger als 35 Jahre waren. In der Praxis reichten fünf Jahre Erwerbstätigkeit jedoch selten aus: Zahlreiche Finnen bezahlten zuerst die fremdfinanzierte Fahrkarte für die Atlantikquerung zurück, schickten wiederholt Geld oder eine Fahrkarte zur Atlantiküberquerung an nahe Angehörige in Finnland oder waren mehrfach von zeitweiliger Arbeitslosigkeit und Krankheit betroffen, was wiederum eine Schmälerung der Ersparnisse bedeutete.

Die individuelle Aufenthaltsdauer in Amerika vor dem Landerwerb lag bei 6 bis 20 Jahren, wie Kero anhand einer Detailanalyse von 156 Interviewaussagen ermitteln

\footnotetext{
${ }^{357}$ Helbich/Haubold 1988, S. 41.

${ }^{358}$ Siehe Amerikabrief vom 24.2.1870, abgedruckt in 'Oulun Wiikko Sanomia' (Ouluer Wochennachrichten) vom 2.7.1870 sowie Brief vom 25.4.1875, ebenda vom 17.7.1875.
} 
konnte $^{359}$. In den meisten Fällen hatten die Finnen 6 -10 Jahre lang in abhängigen Arbeitsverhältnissen gestanden, bevor sie den Status von vorläufigen oder dauerhaften Landbesitzern erlangten. Dieses Ergebnis deckt sich mit dem Resultat einer Untersuchung von Alanen ${ }^{360}$, in der die Besitzverhältnisse von 25 finnischen 'Homestead'Höfen in zwei Siedlungen von Wisconsin und Minnesota im Zeitraum 1888-1907 untersucht wurden. Dabei lag das Durchschnittsalter der männlichen Farmer bei Erfüllung des Heimstättenvertrages bei 42 Jahren, wonach die Bauern zu Beginn ihres Farmerdaseins zwischen 35-37 Jahren alt gewesen sind. Das Durchschnittsalter aller finnischen Männer bei Auswanderungsbeginn variierte wiederum zwischen 21-25 Jahren ${ }^{361}$, wonach davon ausgegangen werden kann, daß zahlreiche finnische Farmer zuvor mindestens ein Jahrzehnt in Amerika zugebracht hatten.

Vor diesem Hintergrund mag es auch kein Zufall sein, daß einige Finnen ihren Wunsch vom Farmerdasein direkt im Anschluß an eine Heirat mit einer finnischen Einwanderin verwirklichten, da die Braut möglicherweise jahrelang als Dienstbotin gearbeitet hatte und bei freier Unterkunft und Verpflegung einen Großteil ihres Lohnes hatte sparen können. Nach der Eheschließung wurden die Ersparnisse beider Eheleute für den Neubeginn zusammengelegt und nicht selten ein weiterer Teil der Anfangsinvestitionen durch geliehenes Geld vorfinanziert ${ }^{362}$. Obwohl eine detaillierte Untersuchung über den Landerwerb nach vorheriger Eheschließung bislang noch aussteht, geben einige Fallbeispiele Anlaß zu der Vermutung, darin ein allgemein übliches Verhaltensmuster vorzufinden ${ }^{363}$.

Den neuen Landbesitzern war es vielfach in den ersten Jahren nach dem Landerwerb noch nicht möglich, die abhängige Erwerbsarbeit völlig aufzugeben. Von daher kauften nicht wenige Bergleute Ackerland in der Nähe von Grubensiedlungen auf, um weiterhin in den Bergwerken beschäftigt zu bleiben. Außerdem verdienten viele Bauern gemeinsam mit ihren jugendlichen Söhnen in Waldkamps und Sägewerken, beim We-

${ }^{359}$ Die Interviewpartner stammten alle aus der finnischen Provinz Satakunta, die von Kero 196869 sowohl in Amerika als auch in Finnland befragt wurden, vgl. Kero 1986, S. 156.

${ }^{360}$ Alanen 1981a, S. 84.

${ }^{361}$ Kero 1974, S. 236, Anhang, Tab. C. Die Zusammensetzung der finnischen Auswandererpopulation nach Alter und Geschlecht wird auch in Kap. 2.7.2. behandelt.

${ }^{362}$ Järnefelt 1899, S. 134; Hoglund 1978, S. 6; Kero 1986, S. 156.

${ }^{363}$ Als Beispiele seien hier genannt: Heirat und Farmgründung von John Korvola mit Ida Haarala 1902, vgl. Briefe von J. Korvola, Sammlung Süd-Ostbottnien, Sig. Nr. 261; Konsta Gustafson mit Ida Kallio 1900, vgl. Alanen 1981a, S. 86; Ville Turpeinen mit Finnin um 1900, vgl. Tokoi 1949, S. 148f; Karl Öling mit Finnlandschwedin 1915, vgl. Myhrman 1974, Bd. 4, S. 11 . 
ge- und Eisenbahngleisbau oder in einer Fabrik einer nahegelegenen Kleinstadt den Lebensunterhalt für die Familien. Besonders häufig war der saisonbestimmte Wechsel von abhängiger Lohnarbeit in der kalten und selbständiger Landarbeit in der warmen Jahreszeit. Zwei jugendliche Finnen beschrieben im Jahr 1900 die ersten Jahre des Farmerlebens auf den elterlichen Bauernhöfen in Nord-Michigan und in Ontario, nahe der Grenze zu Minnesota, folgendermaßen ${ }^{364}$ :

"Es war keine Kleinigkeit in der Wildnis eine Farm zu gründen; das benötigte Zeit, Kraft und gewisse andere Hilfsmittel, besonders da man zur gleichen Zeit den Lebensunterhalt für die Familie verdienen mußte. Dies durften wir zur Genüge auf unserem eigenen Homestead-Land erfahren. Wir sammelten Holz in unserem eigenen Wald, wir arbeiteten in Waldkamps und Sägewerken für andere, wir beluden Schiffe mit Planken und Brettern, die zu den größeren Städten des Michigan-Sees transportiert wurden."

"Ein halbes Jahr hatte unsere Familie in Fort William gewohnt, dann kam der Umzug nach Nolalu, wo Vater eine Farm kaufte. Dort befand sich damals eine kleine Hütte mit einem Zimmer. Das Zimmer war sofort voll, als wir alle dort einzogen. In der Nähe wuchsen große Bäume. Wir fällten die Bäume und klärten das Land. Wir bekamen gerade soviel Ackerland, daß wir etwas Heu für eine Kuh und ein Pferd anbauen konnten. Wir hackten Holz, das wir nach Port Arthur brachten, wo alle Häuser mit Holz befeuert wurden. [...] Wenn Vater ein Tier geschlachtet hatte, gerbte er das Leder. Hier gab es einen finnischer Schuster, der daraus Schuhe fertigte. [...] Mutter war eine gute Näherin. [...] Sechs Monate war ich in der Schule, mehr nicht. Als ich 14 Jahre alt wurde, sagte mein Vater, daß erwachsene Männer nicht auf der Schulbank zu sitzen hätten. Ich sollte arbeiten gehen. Ich begann Holz zu hacken. [...] Die Holzscheite aus Birken- und Kiefernholz haben wir an Familien verkauft, Espenholz ging an die Ziegelei. Später habe ich dann im Wald gearbeitet."

\footnotetext{
${ }^{364}$ Erstes Zitat von Ville Ojala aus Nolalu, Ontario, der bei Beginn des Farmlebens sechs Jahre alt war, interviewt von Virtaranta im Jahr 1980, vgl. Virtaranta 1996, S. 65. Zweites Zitat aus dem Lebensbericht des Finnlandschweden John A. Markstum aus Cedarville, Bezirk Mackinac, Mich., vgl. Myhrman 1974, Bd. 5 , S. 37.
} 
Mit diesen Berichten ließen sich die in Finnland zurückgebliebenen Verwandten vermutlich kaum beeindrucken. In den meisten Briefen finden sich von daher eher nüchterne Angaben über Kaufpreis und Größe des Ackerlandes und Viehbestandes. Detaillierte Schilderungen über die entbehrungsreichen Anfangszeiten auf dem eigenen Bauernhof fehlen fast gänzlich. Wohl aber sind gelegentlich Lobhymen auf die scheinbar unbegrenzten Möglichkeiten der Landwirtschaft in Amerika zu lesen. In folgendem Briefbeispiel des Jahres 1902 versuchte der Auswanderer Emil Aalto seinen noch in Finnland lebenden Bruder nach Süd-Michigan in den Bezirk Manistee zu locken ${ }^{365}$ :

"Kaleva liegt in Süd-Michigan am Ufer des großen Michigan-Sees in der Nähe der Städte Maniste [Manistee] und Onekana [Onekama]. Die Gegend ist sehr fruchtbar, davon zeugen die großen Obstplantagen, in denen die Baumäste auch in diesem Jahr unter der Erntelast zu Boden neigen. Ich habe noch niemals so große Äpfel gesehen wie hierzulande. Außerdem werden hier unzählige Obstsorten angebaut, die ich zuvor noch nie gesehen habe.[...] Weinreben wachsen wild im Wald und winden sich um große Baumstämme herum. Mais wird auf den Farmen angebaut, ebenso Kartoffeln, doch die schmecken anders als dort [in Finnland]. Auch die Hühnerzucht wird in dieser Gegend von zahlreichen Finnen betrieben. Die Eier werden unter anderem nach Chicago geschickt, und das Geschäft läuft gut. Einige Farmer haben ausschließlich Hühner.

Die ersten Finnen haben sich in dieser Gegend vor etwa zwei Jahren niedergelassen. Jetzt strömen sie aus allen Richtungen Amerikas hierher und sie loben die Verhältnisse vor Ort als ausgezeichnet für die Landwirtschaft. Diejenigen, die über etwas Geld verfügen, kaufen fertige Häuser von den Amerikanern, den ersten Bewohnern dieser Gegend.[...] Letztes Jahr wurde das Land hier sehr günstig angeboten, aber jetzt wo so viele nach Land fragen, sind die Preise um 20\% gestiegen, aber mit 2000-3000 Dollar bekommt man noch gute Farmen von 80-100 Morgen. Die weniger Wohlhabenden kaufen noch ungesäubertes Land, das man für 6-8 \$ den Morgen bekommt. Der Boden ist guter Sandboden und völlig ohne Steine und beinhaltet Gips in großen Mengen. [...] Falls Du wirklich vorhast als Landwirt hierher zu kommen, dann ist Zeit gleich Geld, hier falls überhaupt irgendwo.[...] Ich habe gerade vor kurzem gehört, daß ein Amerikaner seine Farm für 3000 \$ verkaufen würde. Eine Farm, wo er mit seiner Frau jähr-

${ }^{365}$ Emil Aalto an Bruder in Eura, Brief vom 3.9.1902: TYYH:S:m:Satakunta: EURA II/1. Zur 
lich $1000 \$$ durch den Obstverkauf verdient hat. Zu dieser Farm sind es von hier aus sechs Meilen und Land gibt es dort 100 Morgen."

Obwohl dieser enthusiatische Briefton eher die Ausnahme darstellte, können die von Emil Aalto genannten Fakten als glaubwürdig angesehen werden. Die ersten Finnen erreichten die Region um Kaleva im Jahr 1899, als eine Eisenbahngesellschaft Land verkaufte. An der Schnittstelle zweier Eisenbahnstrecken mit dem Namen 'Manistee Crossing' entstand die von Finnen gegründete Siedlung, deren Bewohner es tatsächlich zu einem gewissen Wohlstand gebracht haben sollen, da sie sich neben der Hühnerhaltung vor allem auf den Anbau von Bohnen und Gurken spezialisieren konnten. In Kaleva wurde, wie auch in anderen landwirtschaftlich geprägten Siedlungen, bald eine finnische Schule gegründet. 1902 erhielt die Siedlung sowohl einen finnischen Abstinzlerverein als auch eine evangelisch-lutherische Kirchengemeinde, das erste Gotteshaus entstand dann im Jahr $1913^{366}$.

Dem Brief des Emil Aalto ist jedoch noch eine weitere, zu beachtende Nuance zu entnehmen: Der Briefschreiber berichtete von den steigenden Preisen für Ackerland, bedingt durch eine gestiegene Nachfrage von Kaufinteressenten. Dieser vermutlich allgemeine Trend der Preissteigerung wurde auch in einem Brief des Otto Brosi von 1902 aus North Dakota bestätigt: Die Bodenpreise bewegten sich im Umfeld der Ortschaft Brocket gleichfalls bei 2.000 \$ für 160 Morgen $^{367}$. Zudem berichtete dieser Briefschreiber von seinem Vorhaben an der amerikanischen Westküste einen neuen Versuch als Landwirt zu starten. Im folgenden Jahrzehnt wurde Otto Brosi dann tatsächlich von dem vielgereisten, finnischen Pfarrer Salomon Ilmonen in Hood River in Oregon angetroffen, wo etwa zwei Dutzend finnische Familien Obst- und Getreideanbau betrieben ${ }^{368}$.

Die in den Briefbeispielen genannten Farmen von 100-160 Morgen galten für finnisch-amerikanische Verhältnisse bereits als große Anwesen. 160 Morgen, d.h. 65 Hektar Land entsprach wiederum der maximalen Größe einer 'Homestead'- Farm, welche von den ersten Besitzern häufig weiterverkauft wurde. Demnach könnte es sich bei den von Emil Aalto und Otto Brosi benannten Farmen auch um ehemalige 'Homestead'-Höfe handeln, die bereits ein- oder mehrfach den Besitzer gewechselt hatten.

finnischen Siedlung Kaleva im Bezirk Manistee, Süd-Michigan siehe Yli-Jokipii 1971, S. 5-16. ${ }^{366}$ Holmio 1967, S. 252-256.

${ }^{367}$ Otto Brosi (vormals Häggblom) an Frans Häggblom in Karijoki, Brief vom 5.3.1902, Sammlung Süd-Ostbottnien, Sig. Nr. 534. 
Ein anderer Briefschreiber, Juho Kuusisto aus Cloquet in Minnesota, äußerte nämlich offen sein Vorhaben, ein Landstück unentgeltlich als 'Homestead' zu erwerben, um es dann nach Vertragserfüllung gewinnbringend an eine Waldgesellschaft zu verkaufen ${ }^{369}$.

Die von Alanen untersuchten finnischen 'Homestead'- Höfe in Wisconsin und Minnesota hingegen wiesen eine Durchschnittsgröße von lediglich 53 Hektar auf, was wiederum 130 Morgen gleichkam und somit in der Größenordnung, nämlich 54-59 Hektar, der amerikanischen Durchschnittsfarm für die Jahre 1880-1910 lag $^{370}$.

Auch in anderen Briefberichten finden sich immer wieder Angaben zur Größe der von den Finnen erworbenen Farmen, wonach die meisten Auswanderer über 40-80 Morgen Land verfügten. Als Fallbeispiel sei hier der Briefschreiber und dreifache Farmer Juha Korvola aus Isokyrö in Südostbottnien genannt, der 1893 im Alter von 24 Jahren auswanderte und sich sogleich in amerikanischer Manier John Korvola nannte ${ }^{371}$. Über einen Zeitraum von 43 Jahren hielt er den Briefkontakt nach Finnland aufrecht und kehrte aller Wahrscheinlichkeit nach nicht mehr nach Finnland zurück. Der erste in diese Untersuchung eingegangene Brief erreichte den später auch emigrierten Bruder Herman Korvola im Jahr 1895, worin der Auswanderer sich von einer 40 Morgen bzw. 16 Hektar großen 'Homestead'- Farm in Finlayson, Bezirk Pine, im Grenzgebiet von Minnesota und Wisconsin, meldete:

"Du kannst Dir denken, daß das Leben als Siedler nicht bedeutet auf Rosen zu spazieren, aber hier hat man trotzdem seine eigene Freiheit, die einem Arbeiter in der Kompanie [war zuvor als Grubenarbeiter in Negaunee, Mich.] fehlt. [...] Ansonsten ist das Leben hier ziemlich eintönig, denn ein Haus ohne Bäuerin - da hilft nichts als selber zu kochen, zu waschen und die zerissenen Kleider auszubessern. Denn mit der Armut habe ich hier so meine Probleme. Ich war wieder etwa drei Wochen lang unterwegs, um hier in der Nähe in einer kleinen Stadt namens Sandotooni [Sandstone] Geld zu verdienen, denn zuweilen meldet sich der Hunger."

\footnotetext{
${ }^{368}$ Ilmonen 1926, Bd. 3, S. 259.

${ }^{369}$ Juho Kuusisto an Isak Kuusisto in Hinnerjoki, Brief vom 10.8.1903:

TYYH:S:m:Satakunta:HIN:II/14.

${ }^{370}$ Helbich/Haubold 1988, S. 42; Adams 1992, S. 506, Tab. 15; Kolehmainen/Hill 1965, S. 71.

${ }^{371}$ John Korvola an Brüder Jaakko und Hermanni Korvola in Isokyrö, Sammlung SüdOstbottnien, Sig.Nr. 261: 3 Briefe (1895) aus Minnesota, 4 Briefe (1900) von den Philippinen, 1
} 
Dieser erste Versuch als selbständiger Bauer währte jedoch nicht lange. Von der Abenteuerlust gepackt, verkaufte John Korvola seinen Hof bereits im Jahr 1898 wieder und hielt sich als freiwilliger Soldat der amerikanischen Armee anderthalb Jahre auf den Philippinen auf, von wo aus vier Briefe erhalten sind. Nach der Rückkehr nach San Francisco im Jahr 1901 erhielt John Korvola als Verdienstauszeichnung die zu dieser Zeit selten gewordene Gelegenheit eine günstig gelegene 'Homestead'-Farm in einer finnischen Siedlung in 'Long Valley' in Idaho zu erwerben, welche er nach Eheschließung mit einer Finnin im Jahr 1902 wahrnahm. Über die Größe dieser Farm bei Roseberry ist nichts bekannt, doch da sich der Viehbestand des Ehepaares Korvola aus 14 Kühen, 5 Pferden und Federvieh zusammensetzte, ist davon auszugehen, daß das Anwesen mindestens 100 Morgen, d.h. 40 Hektar, groß gewesen sein muß. Des weiteren stand John Korvola im Ruf, ein geschickter Zimmermann zu sein, da er zahlreiche Wirtschaftsgebäude eigenhändig in Blockbauweise errichtete und seine Bauvorhaben auch in den Briefen an die Brüder dokumentierte. In den 1980er Jahren wurde sein gut erhaltenes Haupthaus dann von der regionalen Gesellschaft für Denkmalpflege in eine $\mathrm{Mu}$ seumsanlage der nahegelegenen Stadt Roseberry überführt ${ }^{372}$.

Das Ehepaar Korvola lebte 20 Jahre lang gemeinsam mit seinen sieben Kindern auf der Farm bei Roseberry und erlangte in dieser Zeit einen gewissen Wohlstand. Im Jahr 1921 schließlich kehrte die Familie Idaho den Rücken zu und kaufte eine dritte Farm in Pendleton im Staat Oregon mit 153 Morgen Ackerland zum Preis von 12.500 \$ auf $^{373}$, von wo aus der bereits 70jährige John Korvola seinem Bruder Jaakko Korvola im Jahr 1938 zum letzten Mal schrieb. Das Todesdatum des Briefschreibers ist nicht bekannt.

Der dreifache Erwerb einer Farm, wie im dargestellten Fall des John Korvola, schien eher die Ausnahme zu sein. Dennoch ist es unmöglich, eine genaue Anzahl von Amerika-Finnen zu nennen, die ein oder zwei Mal im Leben eine Farm besessen haben. Als einziger Anhaltspunkt können erstmals bei der amerikanischen Volkszählung des Jahres 1920 erhobene Daten gelten, wonach sich 53,4\% aller eingewanderten Finnen in Städten und 46,6\% in ländlichen Gebieten aufhielten ${ }^{374}$. Als eindeutig von der Land-

Brief (1901) aus San Francisco, 3 Briefe (1905-1912) aus Roseberry in Idaho, 2 Briefe (1921 u. 1938) aus Pendleton in Oregon. Zitat aus Brief vom 8.6.1895.

${ }^{372}$ Vgl. Finns/Idaho 1990, S. 36.

${ }^{373}$ Diesem Briefbeispiel des John Korvola zufolge hatte sich der Wert für fruchtbares Ackerland innerhalb von zwei Jahrzehnten vervielfacht.

${ }^{374}$ Kaups 1981, S. 63. 
wirtschaft lebend wurden 37944 Finnen der ersten Generation registriert, was 25,3\% aller Amerika-Finnen und zugleich mehr als der Hälfte der in ländlichen Gebieten gezählten Personen entsprach. Diese Berechnung schloß jedoch alle in Amerika geborenen Kinder der Einwandererfamilien aus, so daß die tatsächliche Anzahl der Farmbewohner mindestens doppelt so hoch gewesen sein muß. Demnach waren schätzungsweise 80000 Amerika-Finnen der ersten und zweiten Generation auf etwa 15000 Farmen zu finden. Dabei wurden allein in den drei Staaten Minnesota, Michigan und Wisconsin 11167 Farmen gezählt, 2490 entfielen auf die West- und 957 auf die Ostküstenstaaten ${ }^{375}$. Im Verhältnis zu allen von europäischen Einwanderern bewirtschafteten Bauernhöfen des Jahres 1920 betrug der Anteil der finnischen Farmen in den Vereinigten Staaten jedoch lediglich 2,6 \% und fiel damit kaum ins Gewicht fiel.

Aufgrund fehlender Angaben ist die Anzahl der finnischen Farmen in Kanada nicht mehr zu rekonstruieren. Bei der Volkszählung des Jahres 1921 wurden etwa 15000 Finnen als in ländlichen Gebieten lebend registriert, was 70\% aller KanadaFinnen entsprach. Die Hälfte, d.h. 7700, dieser finnischen Landwirte, Gruben- und Waldarbeiter hielt sich in Ontario auf, wobei die meisten ihr Auskommen nicht ausschließlich in der Landwirtschaft fanden ${ }^{376}$. Lediglich für die fruchtbaren Prärieprovinzen Manitoba und Saskatchewan ist anzunehmen, daß ein Großteil der in beiden Provinzen registrierten 2443 Finnen des Jahres 1921 tatsächlich als Farmer vom Getreideanbau leben konnte, zumal die größte kanadische Eisenbahngesellschaft, die 'Canadian Pacific Railroad Company', zu Beginn der 1920er Jahre verstärkt um neue Siedler $\operatorname{warb}^{377}$.

Sowohl in Kanada als auch in den Vereinigten Staaten bestanden die finnischen Farmen in der Regel aus 5-6 Wirtschaftsgebäuden ${ }^{378}$. Als erstes Mehrzweckgebäude wurde häufig die Sauna im Blockhausstil errichtet, welche zugleich das Erkennungsmerkmal einer finnischen Farm darstellte ${ }^{379}$. Die Rauchsauna diente als Waschhaus und nicht selten auch als erste vorläufige Behausung, bis das Wohnhaus fertiggestellt war. Einem Viehstall für die größeren Nutztiere folgten verschiedene Scheunen und Schup-

\footnotetext{
${ }^{375}$ Kero 1996, S. 163.

${ }^{376}$ Vgl. die unveröffentlichte Magisterarbeit von Huhta 1982, hier S. 99 sowie Lindström-Best 1985, S. 9.

${ }^{377}$ Van Cleef 1952, S. 258-261, hier. S. 260.

${ }^{378}$ Zur Gebäudeanordnung der Farmen von Amerika-Finnen vgl. Knipping 1977, S. 27-30, Alanen/Tishler 1980, S. 69f.; Riippa 1981, S. 305.

${ }^{379}$ Zur Bedeutung der finnischen Rauchsaunen in Amerika siehe Kaups 1976, S. 11-20.
} 
pen für Kleinvieh, Gerätschaften, Heu und Hackfrüchte. Im Gegensatz zu den westlichen Regionen Finnlands, der vornehmlichen Herkunftsregion der Amerikaauswanderer, lagen die Gebäude der Amerika-Finnen ungeordnet über die Hofanlage verstreut.

Auch wenn die Farm-Grundstücke für eine Familie reichlich bemessen waren, so dauerte es jedoch bei neugegründeten Farmen Jahrzehnte, bis der größte Teil der Landfläche in bebautes Ackerland umgewandelt war. Die Bodenbeschaffenheit und geographische Lage des Hofes waren dabei von großer Bedeutung. Nach Alanen brauchte es in Minnesota und Wisconsin durchschnittlich fünf Jahre, um 3,5 Hektar Ackerland von Baumstümpfen, Büschen und Steinen zu säubern. Für Wisconsin gibt Knipping wiederum den Zeitraum von 2-3 Morgen pro Jahr an, was in fünf Jahren 4-6 Hektar von gesäubertem Ackerland entsprach ${ }^{380}$.

Vor diesem Hintergrund verwundert es nicht, daß ein zusätzliches Gehalt für das Überleben der Familien notwendig war. Nach Alanens Untersuchung waren sowohl in Minnesota als auch in Wisconsin 80\% der finnischen Landwirte zugleich Ehemänner und Familienväter einer häufig zehnköpfigen Kinderschar, welche während Phasen von monatelanger Abwesenheit die Verantwortung für den Hof ihren Ehefrauen übertrugen. Letztere hatten dann sowohl die Betreuung der Kinder und des Viehbestandes als auch die Feldarbeit zu meistern, wobei der Arbeitstag nicht selten eine Länge von 16 Stunden erreichte. Doch auch bei Anwesenheit des Bauern mußte sich nach alter finnischer Tradition die Bäuerin um das Vieh kümmern, lediglich die Feldarbeit und Instandhaltung der Gerätschaften wurde vom Bauern übernommen.

In einigen, relativ seltenen Fällen übernahm eine Frau alleine die Führung eines Hofes ohne die Hilfe eines Ehemannes der Bruders an ihrer Seite. Im Jahr 1886 erhielt beispielsweise eine finnische Bäuerin in Brule, Bezirk Douglas in Wisconsin, die alleinigen Rechte auf ein 'Homestead'- Grundstück von 160 Morgen bzw. 65 Hektar. Nach fünf Jahren hatte sie zehn Morgen davon in Ackerland umgewandelt und einige Gebäude errichtet. In den Ablösedokumenten wurde der Wert ihres Anwesen mit 1200\$ angegeben $^{381}$.

\footnotetext{
${ }^{380}$ Knipping 1977, S. 23; Alanen 1981a, S. 11.

${ }^{381}$ Alanen 1981a, S. 81.
} 
In diese Untersuchung sind lediglich drei Briefe von finnischen Bäuerinnen eingegangen, zwei Briefe aus Minnesota und einer aus Washington, die allesamt Zufriedenheit mit der Lebenssituation ausstrahlen ${ }^{382}$ :

"Wir haben erst zwei Kammern fertiggestellt, die Küche und eine Schlafkammer, alles ist noch nicht fertig. [...] Wir müssen noch die Erde umgraben, und gegen Ende des kommenden Monats werden wir dann säen. Wir hatten schon im vergangenen Sommer allerhand Bepflanzungen .[...] Ich habe mich hier sehr wohl gefühlt und noch kein Heimweh nach Finnland gehabt, und Hilda fängt sofort an zu weinen, wenn wir nur davon reden, daß wir noch mal nach Finnland zurückkehren werden. Uns geht es wirklich gut hier."

In den beiden anderen Briefen aus Minnesota nehmen die Beschreibungen zur Größe der Viehbestände ${ }^{383}$, die dem Durchschnitt von mittelgroßen Farmen entsprachen, beachtlichen Raum ein. Interessant erscheinen jedoch die Bemerkungen zu mehreren landwirtschaftlichen Helfern auf beiden Höfen, die den Bäuerinnen während der Abwesenheit der Ehemänner zur Hand gingen. In der einschlägigen Emigrationsliteratur wird hingegen das Bild von der alleingelassenen Bäuerin in unzugänglicher Wildnis vermittelt $^{384}$.

Die landwirtschaftlichen Helfer wiederum waren zumeist Saisonarbeiter, die zu Erntezeiten einige Wochen auf den Farmen ihrer Landsleute aushalfen. Obwohl bereits vor der Jahrhundertwende Arbeitskräfte aus den Waldkamps gezielt von Farmern abgeworben wurden ${ }^{385}$, lag die Entlohnung der landwirtschaftlichen Helfer deutlich unter dem Verdienstniveau in der Holz- und Montanindustrie. So berichtet beispielsweise ein landwirtschaftlicher Helfer einer finnischen Farm aus Massachusetts im Jahr 1912, daß

\footnotetext{
${ }^{382}$ Liisa Salty an Bekannte in Vähäkyrö; Brief vom 22.2.1889 aus Edmonds, Wash., Samml.Süd-Ostbottnien, Sig. 1493/1.

${ }^{383}$ Lisi Wirtanen an Verwandte in Isokyrö, Brief vom 28.1.1908 aus Palo, bei Eveleth, Minn., Sammlung Süd-Ostbottnien, Sig. Nr. 284/1; Olga Nieminen an Richard Westergard in Siikainen, Brief vom 1.5.1911 aus Ray, Minn.: TYYH: S: m: SIIK: LXXXIX/4. Beide Briefschreiberinnen verfügten über 6-8 Kühe, 2 Pferde, Schafe, Schweine und etwa 80 Hühner.

${ }^{384} \mathrm{Zu}$ finnischen Bäuerinnen in Amerika siehe Kolehmainen/Hill 1965, S. 59 u. S. 73; Alanen 1981a, S. 81f.; zu norwegischen Bäuerinnen: Blegen 1940, Bd. 2, S. 48; allgemein zu europäischen Bäuerinnen: Weatherford 1986, S. 157-169, bes. S. 165.

${ }^{385}$ Engberg 1959, S. 155.
} 
seine monatliche Entlohnung bei freier Unterkunft und Verpflegung lediglich bei $20 \$$ lag, während zur gleichen Zeit in Kanada das Doppelte verdient werden konnte ${ }^{386}$.

Selbst wenn landwirtschaftliche Helfer auf finnischen Farmen, zumindest in der Erntezeit, eher die Regel als die Ausnahme bildeten, bleibt dennoch unbestritten, daß der Arbeitseinsatz der Bäuerinnen entscheidend zur Aufrechterhaltung eines landwirtschaftlich geführten Hofes beitrug. Trotz selbstbestimmter Arbeitseinteilung gestaltete sich das Farmerleben für Einwandererfrauen mit Sicherheit entbehrungsreicher und anstrengender als das vergleichbare bäuerliche Dasein in Finnland. Die häufig monatelange Abwesenheit des Bauern sowie das fehlende soziale Netzwerk durch Verwandte im gleichen Dorf erschwerten das auf Selbstversorgung beruhende Dasein. Zudem lebten die auf sich selbst gestellten Bäuerinnen häufig in geographisch abgeschiedenen Regionen, wodurch sie weniger Kontakt zur amerikanischen Gesellschaft hatten als die finnischen Einwanderer im allgemeinen.

Vor diesem Hintergrund verwundert es nicht, daß in den Augen junger Einwanderinnen, welche nach der Jahrhundertwende in New York oder Boston an Land gingen, die Aussicht auf ein einsames Leben als Farmersfrau in Amerika wenig verlockend erschien. Es waren eher die schnell wachsenden Metropolen mit sicheren Arbeitsaussichten in den Bereichen der Dienstbotentätigkeit und Textilindustrie, die Ihre Anziehungskraft auf die finnischen Bauerstöchter und Mägde nicht verfehlten.

\subsubsection{In der Fabrik und am Hafen: Das Leben in amerikanischen Städten}

Die rasante Expansion der amerikanischen Städte in der zweiten Hälfte des 19. Jahrhunderts führte auch zu einer verstärkten Präsenz von finnischen Einwanderern in urbanen Zentren. Dieser Trend wirkte sich vor allem in den ersten Jahrzehnten nach der Jahrhundertwende aus: Hielten sich 1900 lediglich 19,3\% aller Amerika-Finnen in 120 Städten mit mehr als 25000 Einwohnern auf, so waren es 1920 bereits 53,4\%, d.h. mehr als die Hälfte der gesamten finnischen Einwandererpopulation, die verstreut auf 246 Städte der Vereinigten Staaten lebten ${ }^{387}$.

\footnotetext{
${ }^{386}$ Matti Rantaaho an Elina Rasinmäki in Töysä, Briefe vom 1.5.1911 und 1.6.1912 aus South Sandisfield, Mass., Sammlung Süd-Ostbottnien, Sig. Nr. 1161/1-2; Maija Kallio aus unbekanntem Ort in Ontario an Kustaa Laine in Lappi, TL, Brief vom 2.5.1913:

TYYH:S:m:Satakunta:LAP:XI/40.

${ }^{387}$ Kaups 1981, S. 63.
} 
Auch im Hinblick auf die allgemeine Binnenmigration der Vereinigten Staaten läßt sich die gleiche Tendenz feststellen: Um 1920 lebten mehr Menschen in Städten mit mehr als 25000 Einwohnern als auf dem Land ${ }^{388}$. Das Städtewachstum ging jedoch sehr ungleichmäßig vor sich: Bereits um 1890 waren mehr als die Hälfte aller Stadtbewohner in lediglich fünf Staaten zu finden, nämlich in New York, Pennsylvanien, Massachusetts, Illinois und Ohio. Die Metropolen New York City, inklusive Brooklyn, mit mehr als vier Millionen Einwohnern im Jahr 1910, sowie Chicago und Philadelphia, beides Millionenstädte, bildeten die wichtigsten Anziehungsmagneten sowohl für Arbeitssuchende aus anderen Bundesstaaten als auch für den nicht abreißenden Strom der europäischen Immigranten. In gleicher Weise konnten die Hafenstädte Boston und Baltimore jeweils mehr als eine halbe Million Einwohner verzeichnen, und bis 1910 hatten vier weitere Städte ebenfalls diese Größe erreicht: Cleveland, Detroit, Milwaukee und St. Louis. Im gleichen Jahr setzten sich die Einwohnerzahlen der größten Städte Amerikas zu drei Viertel aus Immigranten der ersten und zweiten Generation zusammen ${ }^{389}$. Dabei waren Deutsche nahezu überall zahlreich vertreten. In rund 80 Städten mit mehr als 25000 Einwohnern stellten sie die größte europäische Einwanderergruppe innerhalb der Immigranten der ersten Generation ${ }^{390}$.

Im Gegensatz zu den Anfangsjahren der Industrialisierung hatte sich die Situation um 1900 auf dem amerikanischen Arbeitsmarkt bereits stark verändert. Die industrielle Produktion war gleichbedeutend mit Massenproduktion und Serienfertigung geworden. Fließbänder und Akkordarbeit in riesigen Werkhallen mit Tausenden von Beschäftigten bestimmten den Rhythmus der zehn- bis zwölfstündigen Arbeitstage. Neben der Eisen- und Stahlindustrie waren es vor allem das metallverarbeitende Gewerbe, die Elektroindustrie und in Detroit auch die Automobilindustrie, welche einen unersättlichen Bedarf an angelernten Arbeitskräften zeigten. Männer und Frauen ohne hohe Verdienstansprüche waren gleichermaßen gefragt, wenngleich weibliche Arbeitskräfte in der expandierenden Textil- und Bekleidungsindustrie der Ostküsten- und Neuenglandstaaten am häufigsten anzutreffen waren.

\footnotetext{
${ }^{388}$ Zum amerikanischen Städtewachstum siehe Blake 1963, S. 365; Taylor 1971, S. 180 und S. 187-190; Sautter 1986, S. 158; Adams 1992, S. 133-139; Harzig 1992, S. 136; Guggisberg 1993, S. 137-139.

${ }^{389}$ Blake 1963, S. 365; Gutman 1973, S. 561; Dinnerstein/Reimers 1988, S. 47.

${ }^{390}$ Hutchinson 1976, S. 26; Neils Conzen 1979, S. 608.
} 
Die zunehmende Urbanisierung der finnischer Einwanderer ging auf drei Stoßrichtungen zurück: Auf die direkte Einwanderung aus Finnland, auf die Binnenmigration ausgehend von den Grubenorten und kleineren Ortschaften in waldreichen Gebieten sowie aus ethnisch homogenen, ländlichen Siedlungen. Interessanterweise waren die finnischen Einwanderer, mit Ausnahme von New York City, jedoch nicht größtenteils in den städtischen Metropolen zu finden, deren Einwohnerzahlen bei jeder Volkszählung neue Rekordmarken erreichten. Beispielsweise in Chicago, der zweitgrößten Stadt der Vereinigten Staaten nach 1900 und zugleich als ethnisches Zentrum für Schweden und Norweger bekannt, wurden 1920 lediglich 1500 Finnen registriert, was weniger als die Hälfte der in Astoria, Oregon oder Asthabula Harbour, Ohio lebenden Finnen ausmachte. Unter Berücksichtigung von Städten mit mehr als 25000 Einwohnern stellte sich die Hierarchie der zehn, von finnischen Immigranten am zahlreichsten bewohnten Städte folgendermaßen dar, wobei Finnen allerdings auch zahlreich in amerikanischen Kleinstädten zu finden waren ${ }^{391}$ :

Tab. Q Verteilung der Amerika-Finnen in zehn amerikanischen Städten mit jeweils mehr als 25000 Einwohnern 1900 und 1920

\begin{tabular}{|l|l|}
\hline $\mathbf{1 9 0 0}$ & $\mathbf{1 9 2 0}$ \\
\hline 1. New York, NY (3733) & 1. New York, NY (10240) \\
\hline 2. Worcester, MA (1143) & 2. Duluth, MN (3210) \\
\hline 3. Duluth, MN (1143) & 3. Fitchburg, MA (2823) \\
\hline 4. Fitchburg, MA (963) & 4. Seattle, WA (2256) \\
\hline 5. San Francisco, CA (935) & 5. Worcester, MA (2175) \\
\hline 6. Seattle, WA (702) & 6. San Francisco, CA (1810) \\
\hline 7. Chicago, IL (416) & 7. Detroit, MI (1785) \\
\hline 8. Butte, MO (414) & 8. Chicago, IL (1577) \\
\hline 9. Minneapolis, MN (348) & 9. Portland, OR (1394) \\
\hline 10. Portland, OR (98) & 10. Quincy, MA (1338) \\
\hline
\end{tabular}

${ }^{391}$ Tabelle in Anlehnung an Kaups 1981, S. 64, Tab. 1. Die Angaben in Klammern geben die Finnenanzahl an.Finnen waren z. B. auch zahlreich vertreten in Fitchburg/Mass., Marquette/Mich.,Asthabula Harbour/Ohio, Superior/Wisc.und in Astoria/ Oreg. 
New York City stellte demnach nicht nur die größte Stadt mit dem höchsten Einwandereraufkommen - nämlich $42 \%$ - der Vereinigten Staaten dar ${ }^{392}$, sondern wies zugleich die dichteste Konzentration von Finnen auf dem amerikanischen Kontinent auf: Innerhalb von zwei Jahrzehnten verdreifachte sich die Finnenanzahl von 3733 auf 10240 Personen, wobei bereits 1920 mehr als die Hälfte der finnischen Stadtbewohner aus Frauen bestand. Zudem blickte die finnische Gemeinschaft in New York City auf eine lange Tradition zurück: Für die zahlreich anlandenden Seeleute war bereits 1883 eine finnische Seemannskirche in der Stadt gegründet worden, die sich bald zum ethnischen Zentrum der frühen finnischen Immigranten etablieren konnte ${ }^{393}$. Zum Ende des 19. Jahrhunderts hin nahm die finnische Einwanderung über New York City, als Anlegenhafen und oftmals auch erstem Aufenthaltsort, dann weiterhin an Bedeutung zu, da die von England aus verkehrenden Ozeandampfer in erster Linie New York City bzw. die Grenzkontrollstation 'Ellis Island' vor den Stadttoren zum Ziel hatten.

Für das Jahr 1895 hat der bereits mehrfach zitierte, finnische Zeitungsredakteur Akseli Järnefelt die finnische Einwanderung nach New York genauer untersucht ${ }^{394}$ : Demnach wurden in 'Ellis Island' im besagten Jahr 2437 Finnen registriert, wovon 1309 männlichen und 1128 weiblichen Geschlechts waren. In dieser Ziffer sind auch 259 Kinder unter 15 Jahren, d.h. knapp 10\% aller in New York City an Land gegangenen Finnen miteinbezogen ${ }^{395}$.

Als mehrheitlich ungelernte Arbeiter und Repräsentanten einer sprachlichen Minderheit führten die Finnen in New York City in erster Linie mechanische oder Muskelkraft erfordernde Tätigkeiten aus, die weder große Vorbildung noch besondere Sprachkenntnisse verlangten. Dennoch fällt bei Järnefelts Berufsanalyse auf, daß 60 männliche Finnen ihre Berufe als Seeleute, 41 als Handwerker und 33 als Landbesitzer angegeben hatten. 772 Männer nannten sich Arbeiter und etwa ein Drittel der Frauen, 396 Personen, Dienstboten. Mehr als 800 erwachsene Personen wurden ohne Berufsbezeichnung registriert. Obwohl davon auszugehen ist, daß New York City auch für die meisten dieser 1895 eingewanderten Finnen nur eine Durchgangsstation ins Landesin-

\footnotetext{
${ }^{392}$ Unter den Immigranten von New York City dominierten Deutsche und Iren, vgl. Taylor 1971, S. 180 und besonders die Monographie von Bretting 1981. Zu Finnen in New York vgl. Widén 1972, S. 120-127; Tommola 1989, S. 25-229.

${ }^{393}$ Tommola 1989, S. 75f.

${ }^{394}$ Järnefelt 1899, S. 31-36.

${ }^{395}$ Auch innerhalb der gesamten finnischen Einwandererpopulation lag der durchschnittliche Kinderanteil bei7 \%- 9\% (1870-1914), vgl. Kero 1974, S. 236, Tab. C und 1990, S. 72.
} 
nere darstellte, geben diese Zahlenwerte jedoch einige Anhaltspunkte für die Beschäftigungsmöglichkeiten, die den Finnen in der Weltstadt zur Auswahl standen.

Neben der Dienstbotentätigkeit stellte vor allem die stark expandierende Bekleidungsindustrie einen bedeutenden Beschäftigungsfaktor für Frauen dar, da drei Viertel der in den Vereinigten Staaten hergestellten Damenoberbekleidung aus New York City stammte ${ }^{396}$.

Den finnischen Männern wiederum boten sich neben vielfältiger Fabrikarbeit vor allem das Be- und Entladen von Frachtschiffen im Hafengebiet sowie Bau- und Zimmermannsarbeiten auf den zahlreichen Baustellen der expandierenden Großstadt an. Auch im Straßen- und Brückenbau waren finnische Arbeiter zu finden, so sollen bereits um 1880 einige Finnen am Bau der ersten Brücke von Brooklyn nach New York beteiligt gewesen $\operatorname{sein}^{397}$.

Die Arbeit im Baugewerbe wurde häufig nach dem Akkordsystem entlohnt, im Gegensatz zu Fabrikarbeit, beispielsweise in der Maschinenbauindustrie, wo Stundenlöhne üblich waren. Die Entlohnung war jedoch nicht mit dem Niveau der Grubenarbeit im Mittleren Westen zu vergleichen, so verdiente beispielsweise 1903 der erst 17jährige Einwanderer Arthur Wilson in einer New Yorker Manufakturwerkstatt für Kühlschränke 30 \$ im Monat, wovon ihm nach Abzug für Unterkunft und Verpflegung lediglich 16 \$übrig blieben. Der Auswanderer beklagt denn auch die hohen Ausgaben für Kleidung: ein Paar Schuhe sollen 2 \$-3 \$ und ein Herrenanzug 10 \$-12 \$ gekostet haben $^{398}$. Zur gleichen Zeit konnte ein Bergmann in Minnesota etwa 45 \$ monatlich und in Montana sogar das Doppelte verdienen. Trotz höherer Lebenshaltungskosten in den Montanregionen standen den Grubenarbeitern mindestens zwei Drittel ihres Monatslohnes zur freien Verfügung.

Den zweiten und dritten Platz in der finnischen Städtehierarchie nahmen 1900 die Städte Worcester und Fitchburg in Massachusetts ein, welche zwei Jahrzehnte später an dritte und fünfte Stelle abgesunken waren. Bei der vergleichenden Betrachtung der vorwiegenden Konzentration der Finnen in einzelnen Bundesstaaten, wie in Tabelle 7 im Anhang dargestellt, fällt die konstante Präsenz von Finnen in dem relativ kleinen

\footnotetext{
${ }^{396}$ Ewen 1985 , S. 24 f.

${ }^{397}$ Zu Finnen im Baugewerbe von New York siehe Tommola 1989, S. 58-65.

${ }^{398}$ Lebensbericht von Arthur Wilson, vgl. Myhrman 1974, Bd. 4, S. 76. Die angegebenen Preise für Kleidung decken sich mit den Angaben einer Untersuchung über die durchschnittlichen Lebenshaltungskosten in Pittsburgh um 1900: Der Preis für einen Herrenanzug von mittlerer Qualität betrug 10 \$ und für ein Paar Damenschuhe 3,5 \$, vgl. Shergold 1983, S. 88, Tab. 5.
} 
Ostküstenstaat auf: Von 1900-20 rangierte Massachusetts auf Platz drei der Staatenrangfolge, d.h. daß zwischen 7,4\% -8,5\% aller in den Vereinigten Staaten und in Kanada registrierten Finnen dort zu finden waren. Im Hinblick auf die urbane Konzentration erscheint dies bemerkenswert, da aus dem südöstlichen Teil von Massachusetts lediglich eine größere finnische Siedlung ländlichen Charakters mit etwa 420 Personen bekannt wurde ${ }^{399}$.

Die meisten Finnen in Massachusetts waren demnach nicht in Boston, eine der größten Metropolen Amerikas, sondern in Worcester und der Kleinstadt Fitchburg anzutreffen. Beides waren Industriestädte, erstere stand für große Eisendrahtfabriken und Stahlhütten, letztere wiederum für die baumwollverarbeitende Textilindustrie. Bereits im Jahr 1900 wurden in Worcester mehr als 1000 Finnen gezählt bei einer städtischen Gesamtbevölkerung von 118000 Einwohnern. Der Anteil der Finnen an der Stadtbevölkerung betrug demnach weniger als ein Prozent, schwedische Immigranten hingegen stellten mehr als ein Zehntel der Einwohnerschaft von Worcester. Dennoch rekrutierte sich im Jahr 1915 die Belegschaft des größten lokalen Arbeitgebers, der 'American Steel and Wire Company', zu 8,5\% aus Finnen ${ }^{400}$.

Der Finnlandschwede Eric Quist ${ }^{401}$, der in seiner Lebensrückschau auf ein zehnjähriges Beschäftigungsverhältnis zu Beginn des Jahrhunderts in der Eisendrahtfabrik von Worcester zurückblickt, berichtet von einem Monatslohn, der zwischen 32 und 40 \$ lag. Nach der Umstellung auf Akkordarbeit im Jahr 1909 verdoppelten sich seine Verdienstmöglichkeiten auf bis zu 80 \$ monatlich, wobei seine Aufgabe in der Fertigung von Drahtgestellen bestand, welche in Damenkorsetts eingenäht wurden.

Auch drei Briefschreiber dieser Untersuchung ${ }^{402}$ hatten zur gleichen Zeit Arbeitserfahrungen in Worcester gesammelt, doch vermittelt der Grundtenor ihrer Briefe das Bild einer unsteten Arbeitsmarktlage vor Ort: Bereits im Mai 1900 weiß Hilja Toopakka von Massenentlassungen und allgemeiner Arbeitslosigkeit in der Stadt zu berichten, wovon auch ihr Ehemann betroffen war, der erst zum Jahresende wieder in der Ei-

\footnotetext{
${ }^{399}$ Järnefelt 1899, S. 64; Penti 1981.

${ }^{400} \mathrm{Zu}$ Finnen in Worcester siehe Ausstellungskatalog: Finns/Worcester 1994, S. 17-37 sowie Hoglund 1960, S. 61. Zu Schweden in Worcester vgl. Norman/Runblom 1985, S. 53f;

${ }^{401}$ Lebensbericht von Eric Quist, vgl. Myhrman 1974, Bd. 7, S. 50.

${ }^{402}$ Hilja Toopakka, geb. Suovanniemi, an Eltern in Peräseinäjoki, sechs Briefe vom 21.5.190028.12.1903: Samml. Süd-Ostbottnien, Sig.Nr. 1211/4; 1243/2-3, 7,13; 1235/4; Samuel Suovanniemi (alias Mattson) an Eltern in Peräseinäjoki, acht Briefe vom 30.6.1903-4.12.1904, Samml. Süd-Ostbottnien, Sig, Nr. 1211/2-3, 6-7, 9-11, 15; Heikki Peräkoski an Schwester in Peräseinäjoki, Brief vom 8.3.1905, Samml. Süd-Ostbottnien, Sig.Nr. 181/1.
} 
sendrahtfabrik angestellt wurde und 36\$ im Monat erhielt. Drei Jahre später teilte die Briefschreiberin mit, daß ihr Ehemann trotz erneuter Massenentlassungen weiterhin in der Fabrik beschäftigt sei, doch durch eine allgemeine Lohnreduzierung weniger verdiene als zuvor.

Der Bruder von Hilja Toopakka, Samuel Suovanniemi, der sich in Worcester Samuel Mattson nannte, berichtete 1903 gleichfalls von reduzierten Löhnen und 1904 von zeitweiliger Arbeitslosigkeit. Zum Jahresende hin war der Briefschreiber dann wieder in der Fabrik beschäftigt, konnte aber von seinem Tageslohn von 1,30 \$ für einen zehnstündigen Arbeitstag keinen Cent zur Seite legen. Dieser Lohn reichte gerade für die Deckung der notwendigsten Ausgaben aus, wie auch der erst im Januar 1905 eingewanderte Briefschreiber Heikki Peräkoski zu Papier brachte. Auf die täglichen Schlangen von Arbeitsuchenden am Fabriktor kam er in seinem Brief gleich zweimal zu sprechen.

Dennoch wuchs die finnische Gemeinschaft von Worcester innerhalb zweier Jahrzehnte von rund tausend auf zweitausend Personen im Jahr 1920 an. Zur gleichen Zeit waren etwa zwei Dutzend Einzelhandelsgeschäfte und Dienstleistungsunternehmen in finnischer Hand ${ }^{403}$.

Nördlich von Worcester liegt die Kleinstadt Fitchburg, aus der 23 Briefe von sieben Briefschreibern, fünf Frauen und zwei Männern, in diese Untersuchung eingegangen sind. Fitchburg stand im Jahr 1900 an vierter und 1920 an dritter Stelle der in Tabelle Q dargestellten Städterangfolge. Interessanterweise hatten bereits vor 1890 zahlreiche finnische Immigranten aus der mittelostbottnischen Gemeinde Toholampi, welches zugleich die am stärksten von der Auswanderungsbewegung erfaßte Ortschaft Finnlands bildete, in Fitchburg Wurzeln geschlagen: Allein im Zeitraum 1885-90 reiste jeder fünfte Toholampi-Bewohner in die Kleinstadt von Massachusetts, in absoluten Zahlen 60 Männer und 50 Frauen, wonach sich eine Migrationstradition von Toholampi nach Fitchburg entwickelt hatte ${ }^{404}$. Die sieben Briefschreiber dieser Untersuchung kamen mehrheitlich aus Satakunta, doch auch hier waren die benachbarten Gemeinden Ikaalinen und Jämijärvi ihre Ausgangsorte.

Doch auch innerhalb der gesamten finnischen Einwanderergruppe gewann die Kleinstadt Fitchburg schon früh eine besondere Bedeutung durch die Gründung der so-

\footnotetext{
${ }^{403}$ Finns/Worcester 1994, S. 35-45.

${ }^{404}$ Kero/Kostiainen/Kuparinen 1978, S. 45-48 und S. 76f., Tab. 10.
} 
zialistischen Zeitung 'Raivaaja' (dt. der Siedler) im Jahr 1905, welche sich vor allem durch ihre lange Erscheinungsdauer von mehr als einem halben Jahrhundert in das Bewußtsein der Amerika-Finnen mehrerer Generationen einprägte ${ }^{405}$. Auch in Worcester war bereits 1903 ein finnisch-amerikanisches Sprachrohr der sozialistischen Arbeiterbewegung mit dem Namen 'Työmies' (dt. der Arbeiter) gegründet worden. Diese Zeitung stand in den Anfangsjahren jedoch wirtschaftlich auf schwachen Beinen und erst nachdem die Redaktion aus Hancock in Michigan im Umfeld der finnischen Bergarbeiter zu publizieren begann, konnte sich 'Työmies' zur bedeutendesten politischen Tageszeitung der Amerika-Finnen im Mittleren Westen entwickeln. Um 1911 überschritt die Auflagenstärke bereits die 10000er Marke, das Fitchburger Blatt 'Raivaaja' hingegen wurde zur gleichen Zeit von etwa 4300 Amerika-Finnen in den nordöstlichen Staaten rezipiert.

Neben diesen bedeutenden Blättern gründeten Amerika-Finnen in mehreren Städten und ländlichen Ortschaften zahlreiche, zum Teil nur kurzlebige Zeitungen, die als Sprachrohre von politischen, religiösen und moralisch-sittlichen Vereinigungen dienten. Vor allem nach der Jahrhundertwende war das Spektrum der finnischen Einwandererpresse in den Vereinigten Staaten und in Kanada - mit allein 111 politisch motivierten Zeitungsgründungen - zunehmend unüberschaubar geworden ${ }^{406}$.

Im Jahr 1920 waren bereits mehr als 2800 Finnen in der für seine Baumwollspinnereien bekannten Kleinstadt Fitchburg zu finden, welche vor allem alleinstehenden Frauen, neben der wohl üblichsten Arbeit als Dienstpersonal in privaten Haushalten, Beschäftigungsmöglichkeiten boten. ${ }^{407}$ Die Textilindustrie hatte sich bereits in der zweiten Hälfe des 19. Jahrhunderts zu einem bedeutenden Industriezweig der Region etablieren können, der in der nahegelegenen Stadt Lowell ihr Zentrum hatte. Obwohl keine Untersuchung über die Arbeitsbedingungen finnischer Frauen in Fitchburg vorliegt, ist davon auzugehen, daß diese, ähnlich wie die Immigrantinnen in Lowell, in den am niedrigsten bezahlten Aufgabenbereichen zu finden waren, d.h. beim Spinnen, Stricken und Weben. Zu Beginn des 20. Jahrhunderts verdienten Männer 9 \$ die Woche und Frauen 7,5 \$, jugendliche Mädchen und Jungen wurden in Lowell mit 5,5 \$ wö-

\footnotetext{
${ }^{405}$ Siehe die Monographie über die 50jährige Geschichte der Zeitung 'Raivaaja'(Kolehmainen 1955).

${ }^{406}$ Pilli 1986, S. 74f., S. 82 und S. 87.

${ }^{407}$ Zum sozialen Leben der Finnen in Fitchburg vor dem Ersten Weltkrieg siehe Järnefelt 1899, S. 61-63; Kirkpatrick, 1975, S. 113-130.
} 
chentlich entlohnt. Bei der Kleidungsherstellung wiederum besetzten ausgebildete Näherinnen, vor allem Amerikanerinnen und Engländerinnen, die bestbezahlten Positionen mit einem Wochenlohn von etwa $12 \$$.

Männliche Arbeitskräfte waren auch in Fitchburg im Bereich der Textilindustrie anzutreffen. So hatte beispielsweise die 1906 ausgewanderte Briefschreiberin Hilda Paananen ${ }^{409}$ ihren späteren finnischen Ehemann in einer Wollspinnerei kennengelernt. Obwohl diese Auswanderin bereits 1908 von allgemein schlechten Zeiten und tausenden Arbeitslosen berichtete, blieb sie selbst mindestens sieben Jahre lang beschäftigt. Angaben zur den genauen Arbeitsvorgängen, der Länge des Arbeitstages oder der Höhe ihres Verdienstes finden sich nicht in ihren Briefen. Es ist jedoch anzunehmen, daß ihre Arbeitszeit mindestens 10 Stunden bei sechs Tagen in der Woche betrug.

1910 wiederum schrieb Oskar Laakso ${ }^{410}$, daß er in einer Fitchburger Papierfabrik $9 \$$ pro Woche verdiene, dafür allerdings nur acht Stunden täglich zu arbeiten brauche. Nach Abzug von 18,5 \$ monatlich für Unterkunft und Verpflegung blieben ihm noch 17,5 \$ zur freien Verfügung.

In der benachbarten Kleinstadt Gardner, in der um 1900 etwa 400 Finnen lebten, wurde sogar im Jahr 1913 noch zehn Stunden täglich gearbeitet. Die meisten Finnen, unter waren auch viele Finnlandschweden aus der Region um Vaasa, verdienten in der angeblich größten Stuhlfabrik der Welt ihren Lebensunterhalt. Im Jahr 1905 fertigten die erst 18jährigen schwedischsprachigen Auswanderer John Berg und Axel Immanuel Eklund $^{411}$ gebogene Holzstäbe für Korbstühle und Kinderwagen an, wofür sie ebenfalls 9 \$ in der Woche erhielten. Nach Abzug von 16 \$ monatlich für die notwendigsten Ausgaben des täglichen Lebens verblieben ihnen noch 20 \$ bzw. 5 \$ pro Woche.

Die Entlohnung von 9 \$ pro Woche bzw. 1,5 \$ pro Tag schien in der Region von Lowell, Fitchburg und Gardner ein Standardverdienst für männliche Fabrikarbeiter zu sein. Ebenso der knappe finanzielle Spielraum, der nach Abzug der Lebenshaltungskos-

\footnotetext{
${ }^{408}$ In Lowoll arbeiteten bereits im ausgehenden 19. Jahrhundert mehr als 1000 Frauen in der baumwollverarbeitenden Industrie, vgl. Taylor 1971, S. 203; Dublin 1979, S. 145-164, hier S. $148-150$.

${ }^{409}$ Hilda Paananen an Robert Ronumäki in Ikaalinen, neun Briefe vom 11.7.1908 -16.12.1913 aus Fitchburg, Mass.: TYYH:S:m:Satakunta: IKA: LXVIII/1-9. Zu männlichen Arbeitern in der Textilindustrie siehe Taylor 1971, S. 203.

${ }^{410}$ Oskar Laakso an Verwandte in Hinnerjoki, Brief vom 10.9.1910: TYYH:S.m:Satakunta: HIN: VI/1.

${ }^{411}$ Lebensberichte von John Berg und Axel Immanuel Eklund, vgl. Myhrman 1974, Bd. 7, S. 14 und Bd. 8, S. 22.
} 
ten das Leben der zuletzt genannten Fabrikarbeiter bestimmte, lag in gleichen Größenordnung wie im genannten Fall des finnischen Kühlschrankmonteurs aus New York. Da auch in der Stahlindustrie von Pennsylvanien, die sich vor allem in und um Pittsburgh konzentrierte, der gewöhnliche Tageslohn für ungelernte Arbeiter um 1905 bei 1,50 \$ und somit bei 9 \$ in der Woche lag ${ }^{412}$, liegt die Vermutung nahe, daß weniger die einzelnen Industriebranchen die Höhe des Lohnes bestimmten, sondern vielmehr die manuelle Fabrikarbeit an sich an einen bestimmten Mindestlohn gebunden war.

Aufgrund dieser relativ schlechten Verdienstmöglichkeiten fungierten die angeführten Städte der Ostküstenstaaten für viele Finnen lediglich als Sprungbrett, um nach der Atlantiküberquerung genügend Geld für die Weiterreise ins Landesinnere zu verdienen ${ }^{413}$. Die Eisenbahnverbindungen in die Mittel-Weststaaten waren dabei ausschlaggebend für den westwärts gerichteten Einwandererstrom. Die meisten Immigranten nutzen den Wasserweg von New York nach Albany, von wo aus die Weiterreise mit der Eisenbahn nach Buffalo fortgesetzt werden konnte. Ein weiteres Schiff brachte die Einwanderer dann über den Erie-See nach Conneaut, Asthabula und Fairport Harbour sowie in die angehende Millionenstadt Cleveland in Ohio oder aber auf direktem Weg nach Detroit, der größten Stadt von Michigan, einem Zentrum der Automobilindust$\mathrm{rie}^{414}$.

In Ohio, wo zahlreiche Finnen die erste Etappe der Arbeitsuche begannen, konzentrierte sich die finnische Präsenz auf sechs Bezirke im nordöstlichen Winkel des Staates an der Grenze zu Pennsylvanien. Die meisten Finnen waren in Asthabula Harbour zu finden; um 1920 hatte ihre Anzahl bereits etwa 4000 Personen erreicht $^{415}$. Vor allem in den Sommermonaten entluden die Finnen als Schwerstarbeiter in den Hafenstädten von Ohio die mit Eisenerz oder Holz beladenen Schiffe, welche zuvor in Duluth, Marquette und Asland, teilweise wiederum von Finnen, beladen worden waren. Für den Rückweg wurden die Schiffe erneut mit Steinkohle als Energielieferant für die Bergwerke beladen. Ein Zeitungsredakteur aus Conneaut, der Nachbarstadt von Asthabula Harbour mit 333 Finnen im Jahr 1900, hatte berechnet, daß ein Hafenarbeiter, der mit

\footnotetext{
${ }^{412}$ In Pittsburgh verdiente ein Stahlarbeiter 1,55 \$- 2 \$ für einen zehnstündigen Arbeitstag (Taylor 1971, S. 202; Gutman 1973, S. 553; Shergold 1983, S. 82, Tab. 1), im nördlich gelegenen New Castle 1,50 \$-2,40 \$ und in der Zinngießerei von Monessen, südöstlich von Pittsburgh, 2,50 \$, vgl. Kolehmainen 1977, S. 66-68.

${ }^{413}$ Virtanen 1979, S. 153.

${ }^{414} \mathrm{Zu}$ den Reiserouten siehe Assion 1987, S. 249.
} 
10,5 Cents für das Schaufeln einer Tonne Eisenerz entlohnt wurde, nahezu 50 Tonnen, d.h. etwa 6250 Mal schaufeln mußte, um fünf Dollar zu verdienen. ${ }^{416}$ In Asthabula Harbour hingegen arbeiteten die Männer in Gruppen zu 14 Leuten zusammen, die der Reihe nach die Schiffe be- und entluden und im Anschluß den Lohn untereinander aufteilten $^{417}$.

Von Cleveland und Astahula Harbour aus, wurde das Erz dann über den Schienenweg nach Pittsburgh in das Zentrum der Eisen- und Stahlindustrie transportiert, was zahlreiche Arbeitsplätze für Einwanderer mit sich brachte. In Pittsburgh selbst waren Finnen jedoch nur spärlich vertreten ${ }^{418}$.

Südlich der genannten Hafenstädte in Ohio arbeiteten Finnen im Umkreis der Stadt Youngston, vor allem in den naheliegenden Kleinstädten Warren und Girard ${ }^{419}$, wo Eisenhütten sowie die 'Northern Pacific Railroad Company' Arbeitskräfte für den Eisenbahngleisbau suchten. In Girard hatte auch Oskar Harju, der 1906 ausgewandert war, zusammen mit Freunden aus dem finnischen Hinnerjoki in Satakunta seine ersten Arbeitserfahrungen gesammelt, wie er seinen Eltern in drei, noch erhaltenen Briefen der Jahre 1908-09 schilderte. Im letzten Brief vom 8.3.1909 berichtete der 22jährige Fin$n \mathrm{e}^{420}$ :

"So allmählich gewöhnt man sich an die Arbeit hier in Girard. Hier sind etwa hundert Finnen. Hakala [ein Freund] hat gestern in der Eisenhütte begonnen, dort wo auch Heuru war und wo Laiho immer noch arbeitet. Doch ich finde, die Arbeit ist zu anstrengend für Hakala, er ist noch zu jung, um sich selbst zu ruinieren, auch wenn er zwischen 4 \$ -5 \$ pro Tag verdienen kann. [...] Ihr versteht sicherlich, daß es anstrengend ist Eisenstücke von gut hundert Kilogramm Gewicht vom Boden zu heben und in einen Behälter zu werfen, wo sie zerkleinert werden. Ich selbst bekomme die Eisenstücke gerade noch hochgehoben, doch nach etlichen Wochen hat man sich selbst ruiniert.

${ }^{415}$ Zu Finnen in Asthabula Harbour siehe Kolehmainen 1977, S. 43-46; Kero 1990. Zu Finnen in Ohio allgemein siehe Kolehmainen 1977, S. 39-61.

${ }^{416}$ Kolehmainen 1977, S. 45 und S. 49.

${ }^{417}$ Tokoi 1949, S. $110 \mathrm{f}$.

${ }^{418}$ Nach den Zensus-Daten von 1920 hielten sich lediglich 100 Finnen in der ansonsten von Einwanderern überfüllten Großstadt auf, vgl. Ross 1986b, S. 44.

${ }^{419}$ Nicht zu verwechseln mit den gleichnamigen Ortschaft in Pennsylanien, in unmittelbarer Nähe der Stadt Erie, am Ufer des Erie-Sees gelegen.

${ }^{420}$ Oskar Harju an Eltern in Hinnerjoki, drei Briefe vom 17.3.1908, 24.5.1908 u. 8.3.1909 aus Girard, Ohio: TYYH:S:m:Satakunta: HIN:XXVIII/1-3. Auch der vielgereiste Pfarrer Salomon Ilmonen wußte von Oskar Harju in Lowellville zu berichten, vgl. Ilmonen 1926, Bd. 3, S. 85. 
Bald wird hier in der Stadt mit den Grabungsarbeiten für Wasser- und Abflußrohre begonnen und da werden bis Weihnachten viele Arbeiter gebraucht. Der Lohn liegt bei 1,80 \$ pro Tag. Unterkunft und Verpflegung kosten lediglich 50 Cents, so daß ich rund einen Dollar täglich sparen könnte."

Wie es Oskar Harju bei den Rohrverlegungsarbeiten ergangen ist, läßt sich nicht mehr ermitteln. Im darauffolgenden Frühjahr jedoch hatte er eine gefährliche Arbeit in einer Schießpulverfabrik in Lowellville, einer kleinen Ortschaft am Stadtrand von Youngston, angenommen. Aus zwei Briefen von anderen Finnen erfuhren die Eltern und Geschwister in Hinnerjoki, daß Oskar Harju in der Fabrik tödlich verunglückt war. Der von ihm selbst benannte Freund August Heuru schrieb am 29.3.1910 dem Bruder des Verstorbenen $^{421}$ :

"Heute schreibe ich Dir nun zum ersten Mal und darf die traurige Botschaft übermitteln, daß ein tragischer Unfall zum Tod deines Bruders geführt hat. Er arbeitete in einer Schießpulverfabrik als seine Kleider plötzlich Feuer fingen und seine Haut verkohlte. Das war am 21.März [1910] gegen ein Uhr am Tage als es geschah, und um 7 Uhr abends entschlief er dann im Krankenhaus. Ich hätte euch schon früher geschrieben, aber wir haben es selbst nicht direkt erfahren, da es nicht in dieser Stadt war. Aber nachdem wir davon hörten, sind wir gleich losgefahren, Juha Hakala und ich. [...] Ein Pfarrer aus Fairport Harbour hat ihn beerdigt, doch es waren keine Angehörigen dabei. Die Kompanie hat die Kosten für seine Grabstätte übernommen. Sie sagen, daß er kein Geld hinterlassen habe, da er zwei oder drei Wochen arbeitslos gewesen war. Er gehörte einem Abstinzlerverein an und aus der Kasse des Vereins werden $50 \$$ für die Angehörigen gezahlt, das Geld wird noch nach Finnland geschickt."

Rund zwei Wochen später, am 10.4.1910, konkretisierte ein den Eltern des Oskar Harju unbekannter Finne aus Lowellville, dem Unglücksort, die Details des tödlichen Unfalls $^{422}$ :

\footnotetext{
${ }^{421}$ August Heuru an K. Wanka aus Girard, Brief vom 29.3.1910: TYYH:S:m: Satakunta: $\mathrm{HIN}: \mathrm{XXVI} / 1$.

${ }^{422}$ August Tuomisto an Eltern des Oskar Harju in Hinnerjoki, Brief vom 10.4.1910 aus Lowellville, Ohio: TYYH:S:m:Satakunta: HIN:XXV/1.
} 
"Seine Kleider fingen Feuer, welches von einem Stromkabel ausging. Da die Kleider voller Schießpulverstaub waren, ergriff das Feuer rasch den ganzen Körper. Seine Brandwunden waren so groß, daß er nach sieben Stunden im Krankenhaus starb. Ich möchte denn hier auch gleich anfragen, ob die Adresse stimmt, damit wir seinen letzten Besitz nach Finnland schicken können."

Der im dargelegten Fall gut dokumentierte Verlauf eines tödlichen Unfalles und der Kontaktaufnahme mit den Angehörigen in Finnland stellt eine Ausnahme innerhalb der hier betrachteten Amerikabriefe dar. Gelegentliche Hinweise auf Arbeitsunfälle in der Industrie finden sich hingegen in den Briefen verschiedener Schreiber. Dennoch war die Unfallrate in Fabriken, auf Werften und in Waldkamps nicht mit der der Montanindustrie zu vergleichen. Denn trotz der im allgemeinen besseren Entlohnung war es vor allem die Angst um das eigene Leben, die in vielen Fällen den Ausschlag für das frühzeitige Verlassen der Grubenregionen gab. Als ein stellvertretendes Beispiel für diese weitverbreitete Einstellung steht die Briefaussage des Hermann Hissa aus dem Jahr 1901 aus Joliet in Illinois, wo er von zwei "Übeln” das Kleinere gewählt hatte ${ }^{423}$ :

"Ich arbeite jetzt hier in Joliet jeden Tag in einer Stacheldrahtfabrik. [...] Ich verdiene zwei Dollar pro Tag und gelegentlich auch mehr. Ich habe einen Akkordlohn. Direkt als ich aus Finnland kam, war ich in einem Bergwerk in Black Hills [Lead City, South Dakota], doch ich mochte die Arbeit nicht. Es war sehr gefährlich dort, auch wenn ein guter Lohn gezahlt wurde. Dort waren auch die Ausgaben viel höher als hier, vor allem das Essen war schrecklich teuer.

Für amerikanische Verhältnisse habe ich jetzt eine leichte Arbeit. Ich stehe an zwei Maschinen, durch die Stacheldraht entsteht. Als ich hierher kam, mußte ich zuerst [den Maschinengebrauch] lernen und einige Zeit ohne und später mit niedrigem Lohn arbeiten. Das ist schon eine ziemlich pedantische Arbeit und gefällt mir eigentlich nicht. Aber in diesem Land hat man keine Wahl. Im allgemeinen sind die Arbeiten so hart und anstrengend, daß unsereins daran nicht gewöhnt ist, wenn man aus Finnland kommt. [...] Hier muß alles immer sofort fertig sein; immer steht der Vorarbeiter vor

\footnotetext{
${ }^{423}$ Herman Hissa an Jaakko Mattila in Isokyrö, Brief vom 28.11.1901, Sammlung SüdOstbottnien: Sig.Nr. 276/1.
} 
einem und treibt an. Insofern habe ich es jetzt gut, da ich im Akkord arbeite und keinem Rechenschaft schuldig bin."

Nur wenige Finnen äußerten sich derart offen über die Arbeitsverhältnisse und die damit verbundenen physischen und psychischen Risiken wie der oben zitierte Maschinist aus Illinois. Dennoch entsteht der Eindruck, daß die finnischen Einwanderer nicht sehr wählerisch bezüglich der Erwerbstätigkeiten waren, zumal Phasen der Arbeitslosigkeit zum Erfahrungsrepertoire der meisten Arbeiter zählten. Von daher waren in schnell wachsenden Industriezentren mit großer Nachfrage an Arbeitskräften häufig auch Finnen zu finden, wie sich an Detroit exemplarisch darstellen läßt:

Das Zentrum der amerikanischen Automobilindustrie war eine der am schnellsten expandierenden Städte der Vereinigten Staaten und bot den Arbeitern ein ganzjähriges Auskommen. Von 1910-20 verdoppelte sich sowohl der Immigrantenanteil als auch die städtische Bevölkerung in ihrer Gesamtheit. Um 1920, als Detroit bereits eine Millionenstadt war, bestand die Hälfte der Stadtbewohner aus europäischen Einwanderern, allen voran aus Polen, Deutschen und Italienern. Obwohl bei einer Belegschaftsgröße von rund 150000 Fabrikarbeitern die Beteiligung der Finnen kaum ins Gewicht fiel, war ihre Anzahl bis 1920 von 4 auf 1785 Personen angewachsen ${ }^{424}$. Aus Detroit sind jedoch keine Briefe in diese Untersuchung eingegangen.

In der Region der Großen Seen, welche mit ihren zahlreichen Montanregionen den größten Teil der finnischen Einwanderer beschäftigte, liegen auch die Städte Duluth und Minneapolis in Minnesota, von den Finnen selbst als "Nestplätze" benannt ${ }^{425}$. Insbesondere die Hafenstadt Duluth am Ufer des Superior-Sees war für die meisten Finnen ein wichtiger Durchgangs- und Aufenthaltsort mit einer großen finnischen Gemeinschaft. Zahlreiche Sägewerke und ein großer Lasthafen beschäftigten Finnen in den Sommermonaten, nachdem in den Waldkamps der nahen Umgebung die Sommerpause begonnen hatte. Auch im Bereich des Gütertransports auf der 1870 fertiggestellten Eisenbahnstrecke von Minneapolis nach Duluth fanden zahlreiche Finnen Arbeit.

\footnotetext{
${ }^{424}$ Zu Finnen in Detroit siehe Holmio 1967, S. 258-263; Virtanen 1977, S. 75; Loukinen 1981, S. 109; zum ethnischen Konglomerat in Detroit vgl. Just 1988, S. 33 und Daniels 1990, S. 220. ${ }^{425}$ Der Begriff Nestplatz (finn. pesäpaikka) taucht wiederholt in der Literatur auf und war unter Amerika-Finnen eine gebräuchliche Bezeichnung für einen Ort mit einer großen finnischen Gemeinschaft, vgl. Kero 1996, S. 123f. Zu Finnen in Minneapolis vgl. Wasastjerna 1957, S. 119-136, Riippa 1981, S. 298; zu Finnen in Duluth siehe Järnefelt 1899, S. 131f.; Wasastjerna 1957, S. 228-381; Kaups 1981, S. 63-86; zu Finnlandschweden in Duluth vgl. Myhrman 1963.
} 
In seiner Bedeutung als Beschäftigungsort für die Sommerzeit wies Duluth Gemeinsamkeiten mit dem auf kanadischer Seite gelegenen Port Arthur, heute Thunder Bay genannt, auf ${ }^{426}$. In beiden Städten waren Eisenbahngesellschaften die größten saisonalen Arbeitgeber und die finnische Gemeinschaft wuchs mit dem Angebot der "Sommerjobs" jeweils um mehrere hundert Mitglieder, bis im Herbst die zahlreichen Waldkamps wieder um Arbeitskräfte konkurrierten.

Die finnische Gemeinschaft war in Duluth weniger männerdominant ausgeprägt als in den Grubenorten oder Waldkamps im allgemeinen: 1895 standen 61\% an Männern 39\% an Frauen gegenüber, die Geschlechterverteilung in Port Artur hingegen entsprach dem für die Region der großen Seen üblichen Verhältnis von $83 \%$ zu 17\% ${ }^{427}$. Die finnischen Stadtbewohnerinnen arbeiteten zumeist in den von Finnen geführten Gruppenunterkünften als Köchinnen, Wäscherinnen und Dienstpersonal sowie in einer Streichholzfabrik.

Mehr als in anderen Städten hatte die Arbeit in Duluth für viele Finnen einen saisonalen Charakter, wie sechs Briefe aus Duluth sowie 52 Briefe aus dem benachbarten Cloquet, einem Zentrum der holzverarbeitenden Industrie, von insgesamt elf Briefschreibern belegen. Alle Briefverfasser arbeiteten in Sägewerken direkt in der Stadt oder in Waldkamps der nahen Umgebung und verdienten 1,50 \$ bis 1,75 \$ pro Tag. Nach Möglichkeit wurde ein Arbeitsverhältnis in der Stadt, schon allein aufgrund des lebhaften sozialen Lebens der ethnischen Gemeinschaft, einer Beschäftigung in den Wäldern vorgezogen.

Von 1900 bis 1920 verfünfachte sich die finnische Population in Duluth. Mit 3200 Personen im Jahr 1920 übertraf sie auch bei weitem die finnische Gruppe in Minneapolis, die 1200 Finnen zählte und deren Vertreter größtenteils in einer Ziegelsteinbrennerei arbeiteten. In Duluth wurden bereits im ausgehenden 19. Jahrhundert eine Kirchengemeinde und ein Abstinenzlerverein gegründet, wodurch sich die Stadt jedoch nicht von anderen Orten mit großen finnischen Gemeinschaften unterschied. Mehrere Sport- und Musikvereine, Theatergruppen sowie genossenschaftliche und politische Organisationen in finnischer Hand ergänzten das kulturelle Angebot.

Einzigartig war jedoch die 1904 in religiöser Intention gegründete 'Finnische Volksschule' in Duluth, die wenige Jahre später von der sozialistischen Arbeiterbewe-

\footnotetext{
${ }^{426}$ Zu Finnen in Port Arthur siehe Järnefelt 1899, S. 243-251, bes. S. 248f.; Kouhi 1976, S. $17-$ 27; Wilson 1977; Timothy 1995.
} 
gung vereinnahmt und als politische Institution in 'Work People's College' umbenannt wurde $^{428}$. Allein im Jahr 1913-14 waren 157 finnischen Studenten eingeschrieben, von denen ein Großteil als Zeitungsredakteure die politisch motivierte Presse der folgenden Jahrzehnte bestimmte. Da die zweite Generation der Amerika-Finnen dem sozialistischen Gedankengut kritischer gegenüberstand, zeigten die Studentenzahlen in der Folgezeit eine rückläufige Tendenz . Als das 'Work People's College' 1941 endgültig seine Pforten schloß, blieb das 'Suomi College' in Hancock, Michigan, die einzige von Finnen ins Leben gerufene Bildungseinrichtung mit akademischem Anspruch.

Die meisten Finnen waren jedoch zum Arbeiten und Geldverdienen nach Amerika gekommen, höhere Bildung blieb das Privileg einer verschwindend kleinen Gruppe. Die Mobilität der finnischen Einwanderer galt in erster Linie der ständigen Suche nach einem Arbeitsplatz mit dem größtmöglichen Verdienst bei optimalen Arbeitsbedingungen. Auf der oftmals jahrzehntelangen Wanderung führte die westwärts gerichtete Binnenmigration denn auch zahlreiche, bereits erfahrene Wald-, Gruben- und Fabrikarbeiter in die Westküstenstaaten mit den größtenteils besseren Erwerbsmöglichkeiten.

In Kalifornien hatte San Francisco schon zu Zeiten des Goldrausches finnische Seeleute angelockt und auf diese Weise eine eigene Seemannskirche finnischer Prägung erhalten. Auch zum Ende des 19. Jahrhunderts hielten sich noch verhältnismäßig viele Seeleute und Hafenarbeiter unter den rund tausend Personen zählenden, finnischen Stadtbewohnern auf. So beklagt denn auch der Zeit- und Augenzeuge Akseli Järnefelt im Jahr 1899 den "sittlichen Verfall” der finnischen Matrosen in San Francisco, welche

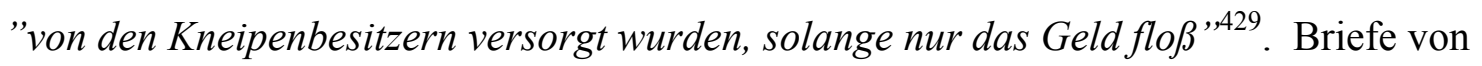
Seeleuten sind jedoch nicht erhalten, lediglich ein Briefschreiber dieser Untersuchung hielt sich auf der Durchreise kurz in der Stadt auf.

Auch in Seattle in Washington mit einer finnischen Gemeinschaft von rund 500 Einwanderern waren Seeleute stark vertreten. Dementsprechend groß war denn auch der Anteil der männlichen Immigranten, wie Adams-Hegstad ${ }^{430}$ anhand einer Mikrountersuchung über die Präsenz der einzelnen skandinavischen Einwanderergruppen in Seattle nachweisen konnte: Nach den Zensusangaben des Jahres 1900 hielten sich 485 erwach-

\footnotetext{
${ }^{427}$ Kouhi 1976, S. 25; Kaups 1981, S. 79.

${ }^{428}$ Zur Geschichte des 'Work People's College', vgl. Kostiainen 1980; Hoglund 1993, S. 47-53.

${ }^{429} \mathrm{Zu}$ Finnen in San Francisco vgl. Järnefelt 1899, S. 183-186, Zitat von S. 185; Myhrman 1972, S. 295-305.

${ }^{430}$ Adams Hegstad 1985, S. 57, Tab. 1 und S. 62, Tab. 2.
} 
sene Finnen der ersten Generation in der Stadt auf, wovon lediglich 78 bzw. 16\% Frauen waren. Von den verbleibenden 407 männlichen Finnen gaben 148 Personen an als Seeleute beschäftigt zu sein, und weitere 147 Männer arbeiteten in den Kohlegruben der naheliegenden Umgebung. Die restlichen 112 Einwanderer verdienten in Sägewerken, im Baugewerbe, als Fischer und als Gelegenheitsarbeiter ihren Lebensunterhalt. Die Anziehungskraft der expandierenden Küstenstadt zeigte sich vor allem in der rasanten Entwicklung der Einwohnerzahlen, welche von 1900 bis 1920 um ein Vierfaches von etwa 80000 auf 315000 anstiegen. Im gleichen Zeitraum hatten sich auch die finnischen Immigrantenzahlen in Seattle auf 2256 Personen vervierfacht, wenngleich Schweden und Norweger mit jeweils etwa 10000 Vertretern die städtische Einwandererpopulation dominierten.

Seattle galt nicht zuletzt als Durchgangsstation für nordwärts wanderende Waldund Sägewerksarbeiter aus dem Umfeld von Aberdeen und Hoquiam sowie als Tor nach British Columbia, wo der Tageslohn in zahlreichen Kohlegruben um einen Dollar höher lag als im Mittleren Westen. In den beiden einzigen Briefen aus Seattle, die hier berücksichtigt wurden, finden sich keine Hinweise zur Lebensführung von Finnen in der Stadt.

In Oregon wiederum lockte die Küstenstadt Astoria an der Flußmündung des 'Columbia River' mit seinen ausgezeichneten Fischgründen zahlreiche Finnen $\mathrm{an}^{431}$. Bereits im Jahr 1870 gründete eine kleine Gruppe von Finnen, die San Francisco den Rücken gekehrt hatte, ein finnische Gruppenunterkunft in der Stadt und bot somit weiteren Landsleuten die Möglichkeit sich durch die Lachsfischerei ein Auskommen zu sichern. Ein Jahrzehnt später, als Astoria mehr als 5700 Einwohner zählte, hielten sich 260 erwachsene Finnen in Astoria auf, was vor dem Hintergrund der Gesamtanzahl aller bis zu diesem Zeitpunkt in die Vereinigten Staaten eingewanderten Finnen, nämlich rund 3.700 Personen, bemerkenswert erscheint. Von diesen 260 registrierten finnischen Stadtbewohnern des Jahres 1880 waren lediglich 14 Frauen, wonach die finnische Gemeinschaft auch in Astoria männerdominante Züge aufwies. 30 von insgesamt 175 finnischen Fischern gründeten 1882 eine Fischfabrik und 28 weitere Männer ließen sich verschiedenen Dienstleistungsberufen zuordnen.

In der Hochsaison waren die Arbeitstage in der Flußmündung und auf hoher See lang. Ein erfolgreicher Fischer konnte jedoch während vier oder fünf Monaten den Le-

${ }^{431} \mathrm{Zu}$ Finnen in Astoria siehe Järnefelt 1899, S. 196-211; Hummasti 1975, S. 16-22 u. 1978; Passi 1975. 
bensunterhalt einer Familie für ein ganzes Jahr verdienen. Die Fischer wurden von den Fischfabriken nach Stückzahl entlohnt, doch der von den Fischern kritisierte Fischpreis von einem Dollar pro Lachs entflammte mehrere spontane Streikaktionen. Auch die gefährlichen Arbeitsbedingungen, die allein im Jahr 1906 zu 78 tödlichen Unfällen geführt hatten, waren ständige Streitpunkte zwischen den Parteien, zumal die Schuld an den häufigen Todesfällen im allgemeinen den Fischern als Folge von Trunksucht und Leichtsinnigkeit zugeschrieben wurde. Obwohl sich an der Gefährlichkeit der Lachsfischerei im Laufe der Jahrzehnte nichts wesentliches änderte, so konnten die protestierenden Fischer im Jahr 1893 immerhin eine Preisanhebung von 25 Cents pro Fisch erzielen, und dem Beruf somit weiteren Zulauf von finnischen Einwanderern sichern ${ }^{432}$.

Im Jahr 1905 stellten die Finnen dann, im Gegensatz zu Seattle, bereits die größte ethnische Immigrantengruppe in Astoria dar: Mit mehr als 2000 Bewohnern machten sie $18 \%$ der gesamten städtischen Bevölkerung aus und stellten auch die Mehrheit der Lachsfischer. Die ebenfalls im Fischfang erfolgreichen Norweger bildeten die zweitgrößte Einwanderergruppe vor Ort. Bis 1920 verdoppelte sich die finnische Population in Astoria auf rund 4000 Personen und bestimmte mit 28\% der Stadtbevölkerung das allgemeine Straßenbild erheblich. Unter den finnischen Stadtbewohnern waren Auswanderer aus der mittelostbottnischen Gemeinde Kälviä besonders häufig vertreten, so daß - ebenso wie im Falle Fitchburg, wo viele Finnen aus Toholampi lebten - von der Ausprägung einer Migrationstradition gesprochen werden $\mathrm{kann}^{433}$.

Lediglich zwei Briefschreiber dieser Untersuchung haben sich kurzzeitig in Astoria aufgehalten, sie waren jedoch nicht als Fischer, sondern als Sägewerksarbeiter beschäftigt. Einer der beiden betonte 1912, daß es in der Stadt von finnischen Fischern nur so wimmele, und er schätzte ihre Anzahl auf etwa 5000 Personen. Ein weiterer Briefschreiber plante 1914 von Butte in Montana nach Astoria zu reisen, um mit dem Lachsfang endlich genügend Geld zur finanziellen Unterstützung seiner in Finnland lebenden Mutter zu verdienen. Obwohl er tatsächlich westwärts wanderte, blieb sein Vorhaben unverwirklicht: Der besagte Briefschreiber meldete sich aus einem Waldkamp

\footnotetext{
${ }^{432} \mathrm{Zu}$ den Protestaktionen der Fischer in Astoria siehe Passi 1975, S. 92-98; Finns/Hoquiam 1987, S. 19.

${ }^{433}$ Hummasti 1988, S. 154-165, bes. S. 158 f.
} 
bei Spokane in Washington, an der Grenze zu Idaho, wieder, wo er sich die nächsten fünf Jahre aufhielt ${ }^{434}$.

In den beschriebenen Fallbeispielen sind Frauen, mit Ausnahme der Textilarbeiterinnen aus Fitchburg in Massachusetts, bewußt ausgeklammert worden, obwohl in den meisten amerikanischen Städten mit beachtlichem Finnenanteil gerade die Einwanderinnen für eine konstant anwachsende finnische Gemeinschaft sorgten. Aus diesem Grund gilt das Augenmerk im folgenden besonders dem wichtigsten Erwerbsbereich der finnischen Immigrantinnen in Amerika und Kanada: Der Dienstbotentätigkeit in privaten Haushalten und kommerziell geführten Gasthäusern.

\subsubsection{Arbeitsbereiche für Frauen: "Immer zu Diensten" in städtischen}

\section{Privathaushalten}

Wie bereits erläutert, setzte sich die finnischen Einwandererpopulation zu zwei Drittel aus Männern und einem Drittel aus Frauen zusammen. Für den Zeitraum 18701914 standen durchschnittlich 64,7\% Männer 35,1\% Frauen gegenüber, was einem 3:1 Verhältnis entsprach. Der in diesen Werten bereits enthaltene Anteil von Kindern unter 15 Jahren betrug rund 10\%, wobei Mädchen zahlreicher vertreten waren als Jungen. Um 1900 nahm die Männerdominanz im Verhältnis der Geschlechter jedoch graduell ab, d.h. daß mit zunehmender Emigrationsbewegung auch der Anteil der weiblichen Emigranten wuchs. Lediglich in drei den Jahren 1874, 1894 und 1897 wanderten mehr Frauen als Männer aus, wobei der prozentuale Frauenanteil jedoch in keinem Jahr der betrachteten Zeitspanne $55 \%$ überstieg ${ }^{435}$.

Zum Zeitpunkt der Atlantiküberquerung waren etwa 80\% aller Finnen jünger als 30 Jahre und größtenteils unverheiratet. Frauen waren in der Regel jünger als Männer, da 68,1\% aller Frauen in Gegensatz zu 62,7\% aller Männer maximal das 26. Lebensjahr erreicht hatten. Für die Zeitspanne 1900-14, in der mehr als zwei Drittel der finnischen Emigranten des hier betrachteten Zeitraumes 1865-1914 die Auswanderung an-

\footnotetext{
${ }^{434}$ Viktor Nummela an Erland Heinilä in Lappi/TL, Brief vom 15.6.1912: TYYH: S:m: Satakunta: LAP: I/25. Selim Kaukonen an Roosa Kaukonen in Kiikaa, zwei Briefe vom 3.2.1914 und 2.11.1914 aus Butte, Mon. sowie Spokane, Wash.: TYYH:S:m:Satakunta: KIIK:II/32/34.

${ }^{435}$ Zur Geschlechteraufteilung der finnischen Einwanderer nach Jahren siehe Tabelle 2 im Anhang sowie Kap. 2.7.2.
} 
traten, kann der Anteil der ledigen Amerikafahrer mit 74,6\% als sehr hoch bewertet werden.

Da bereits in den 1880er und 1890er Jahren vor allem junge Männer der Emigrationsbewegung angeschlossen hatten, machte sich zur Jahrhundertwende hin in zahlreichen finnischen Gemeinden ein allgemeiner Mangel an Männern im heiratsfähigen Alter bemerkbar. Den sich allmählich in der Überzahl befindenden, jungen Frauen mit Heiratsabsichten blieb zur Partnersuche die Wahl der Binnenwanderung in die größeren Städte des Heimatlandes oder die direkte Überseeauswanderung. In letzterem Fall lagen die von den Frauen selbst geäußerten Auswanderungsgründe jedoch in erster Linie im Gelderwerb und einer selbstbestimmten Lebensführung. 1900-14 entschieden sich knapp 80000 finnische Frauen zur Amerikaauswanderung, was 36,6\% der gesamten Auswandererpopulation dieses Zeitraumes gleichkam ${ }^{436}$.

Die allein oder in einer Gruppe Gleichgesinnter reisenden Frauen hatten zumeist urbane Zentren in den Ostküstenstaaten zum Ziel, allen voran New York und Massachusetts, wo sie von bereits früher ausgewanderten Verwandten oder Freunden erwartet wurden und zugleich Hilfe bei den Anfangsschwierigkeiten im neuen Land erhielten. 1920 übertraf die Anzahl der finnischen Frauen die der Männer in fünf Großstädten, in New York City, Manhattan, Chicago, Boston und Pittsburgh. In Cleveland, Minneapolis, Portland, San Francisco und Detroit hingegen lag die Frauenpräsenz nur geringfügig unter dem Aufkommen der Männer ${ }^{437}$.

New York City mit der größten finnischen Gemeinschaft bildete denn auch ein Eldorado für finnische Frauen. Von mehr als 10000 Finnen insgesamt waren etwa 5500 weiblichen Geschlechts und weitere 3000 finnische Frauen lebten im benachbarten Manhattan. Wieviele von Ihnen im Großraum New York City den Dienstbotenberuf ausübten, läßt sich nicht mit Exaktheit sagen, dennoch ist anzunehmen, daß der überwiegende Teil zumindest zeitweilig als Hausangestellte oder Wäscherin gearbeitet hat$\mathrm{te}^{438}$.

Vor diesem Hintergrund erscheint ein Exkurs zur Bedeutung des Einwanderererpotentials bezüglich des Dienstbotenberufes angebracht.

\footnotetext{
${ }^{436}$ Kero 1974, S. 97, Tab. 13.

${ }^{437}$ Ross 1986b, S. 44.

${ }^{438}$ Järnefelt (1921, S. 109) schätzt ihre Anzahl 1921 auf einige Tausend. Zu finnischen Dienstboten in New York City siehe auch ebenda, S. 33 u. S. 44-46; Tommola 1989, S. 42-57.
} 
Der Dienstbotenberuf an sich war in erster Linie ein Frauenberuf. Zwischen 1870-1930 bewegte das Frauenaufkommen unter allen Beschäftigten der Branche zwischen $83,8 \%$ und $87,5 \%{ }^{439}$. Auch innerhalb der europäischen Einwanderer waren es vor allem Frauen, die als Haus- oder Hotelangestellte ihren Lebensunterhalt bestritten ${ }^{440}$. Im Jahr 1900 betrug der Anteil der weißen Einwanderinnen der ersten Generation am Dienstbotenpotential der Vereinigten Staaten insgesamt 27,6 \%, d.h. daß jede dritte europäische Einwanderin in den Dienst ging. Auch 1910 bewegte sich der Anteil der Europäerinnen noch in der gleichen Größenordnung, sank jedoch 1920 bereits auf rund $21 \%$ ab. Dabei machten sich regionale Unterschiede bemerkbar. Beispielsweise in Boston wurden 1895 etwa $80 \%$ der Haus- und Hotelangestellten als 'foreign-born' registriert und in New York City waren 1910 noch 72\% aller Dienstboten nichtamerikanischer Herkunft, wobei jedoch auch außereuropäische Immigranten miteingeschlossen wurden $^{441}$. Dennoch fällt auf, daß diese Werte deutlich größer waren als die Beteiligung der europäischen Immigrantinnen am amerikanischen Erwerbsleben überhaupt, welche um die Jahrhundertwende bei lediglich 17,4\% $\operatorname{lag}^{442}$.

Innerhalb der europäischen Dienstboten hingegen waren Frauen aus Deutschland, Irland und den skandinavischen Ländern, d.h. Schweden, Norwegen und Dänemark, mit einem Anteil von insgesamt knapp drei Viertel besonders häufig vertreten ${ }^{443}$. Als einzelne Gruppe dominierten die Irinnen im Jahr 1900 mit 33,7\% aller europäischen und $41 \%$ aller nichtamerikanischen Hausangestellten ${ }^{444}$.

Obwohl die finnischen Dienstboten zahlenmäßig kaum ins Gewicht fielen, erhielt der Dienstbotenberuf innerhalb der finnischen Gemeinschaft eine tragende Funktion, da zum einen ein Großteil der Finninnen erwerbstätig war und zum anderen die meisten berufstätigen Frauen wiederum als Hausangestellte arbeiteten. Lediglich für die

\footnotetext{
${ }^{439}$ Katzman 1978, S. 45.

${ }^{440} \mathrm{Zu}$ Einwanderinnen als Dienstboten allgemein siehe Dickinson 1980, S. 96-124; Weatherford 1986, S. 146-156; Seller Schwartz 1994, S. 85-93 und S. 110-117. Für Kanada vgl. Genevieve 1974, S. 71-125; Light/Parr 1983.

${ }^{441}$ Taylor 1971, S. 200, Abb. 12; Weatherford 1986, S. 146.

${ }^{442}$ Katzman 1978, S. 64, Tab. 2.7.; Wehner-Franco 1994, S. 55 und S. 69.

${ }^{443}$ Katzman 1978, S. 67, Tab. 2.9.

${ }^{444} \mathrm{Zu}$ den Zahlenwerten des irischen Dienstbotenpotentials vgl. Katzman 1978, S. 66-68 und Wehner-Franco 1994, S. 69 und S. 342f., Tab. 3.3 und Tab 3.4; siehe auch Klaczynska 1976, S. 81f. und vor allem Groneman 1978.
} 
schwedische Gemeinschaft in Amerika kann das Gleiche behauptet werden: Im Jahr 1900 waren 61,5\% der schwedischen Frauen als Dienstpersonal beschäftigt ${ }^{445}$.

Bislang ist die Situation der finnischen Dienstboten in den Vereinigten Staaten erst ansatzweise untersucht worden. Fehlende Zahlenwerte über Größe und Umfang der finnischen Dienstbotengruppe um die Jahrhundertwende sind unter anderem auf die Registrierungspraxis der amerikanischen Zensus-Behörden zurückzuführen, welche vielfach die Angaben für Finnen und Russen zusammengelegt und mit 'Russen' kenntlich gemacht hatten ${ }^{446}$. Als Ausnahme kann die Auswertung von Adams Hegstad für Seattle angesehen werden: Die Autorin konnte durch ein intensives Archiv- und Quellenstudium belegen, daß im Jahr 1900 von 78 finnischen Frauen 43 als Hausfrauen, 28 als Dienstmädchen in Privataushalten und eine als Hotelangestellte klassifiziert worden waren. Von den übrigen sechs Frauen arbeitete eine in der Textilbranche und bei fünf weiteren stand keine Berufsangabe ${ }^{447}$. Eine ähnliche Auswertung unternahm auch Kolehmainen für die Hafenstadt Conneaut in Ohio. Dort waren im Jahr 1900 von 31 Frauen 12 als Dienstboten beschäftigt, fünf arbeiteten in Geschäften und Saloons, und bei 14 fand sich keine Berufsbezeichnung ${ }^{448}$. Demnach waren erwerbstätige Frauen in beiden Fallbeispielen am häufigsten als Dienstboten angestellt. Diese Ergebnisse gelten jedoch ausschließlich für Seattle und Conneaut, in Städten mit Textil- oder Tabakindustrie war auch die Beteiligung finnischer Frauen im industriellen Bereich größer als bei diesen Fallbeispielen.

Für die Dienstbotensituation in Kanada in den 1920er Jahren konnte hingegen festgestellt werden, daß der finnische Anteil bei 7\% -8\% innerhalb aller eingewanderten Haus- und Hotelangestellten lag. Der Anteil der im Dienstbotenbereich Beschäftigten innerhalb aller weiblichen Arbeitnehmerinnen betrug 18\%, wonach der Beruf als zweitwichtigster Erwerbszweig für Frauen in Kanada galt ${ }^{449}$. In den beiden größten Städten Ost-Kanadas, Toronto und Montreal, sollen um 1920 schätzungsweise bis zu 66\% aller finnischen Frauen als 'Maids' gearbeitet haben ${ }^{450}$. Auch für Port Arthur

\footnotetext{
${ }^{445}$ Die entsprechenden Prozentwerte betrugen für Frauen aus Deutschland 36,3\%, aus Irland 54\%, aus Dänemark 45,3\% und aus Norwegen 45,6\%, vgl. Wehner-Franco 1994, S. 73 und S. 344, Tab. 3.5.

${ }^{446}$ Zur problematischen Handhabung der Statistiken der Zensus-Behörden siehe Kap. 3.1.

${ }^{447}$ Adams Hegstad 1985, S. 65, Tab. 3. Zu skandinavischen Frauen in Seattle siehe auch Webster 1978.

${ }^{448}$ Kolehmainen 1977, S. 49.

${ }^{449}$ Genevieve 1974, S. 71f., Tab. A.

${ }^{450}$ Lindström-Best 1988, S. 90.
} 
bzw. das heutige Thunder Bay in Ontario konnte das Aufkommen der finnischen Dienstboten, ausgehend von den Zensus-Daten des Jahres 1911, näher bestimmt werden: Demnach waren 40,3\% als 'Hotel Staff' und 12,5\% als 'Domestics' beschäftigt, d.h. immerhin mehr als die Hälfte aller in Port Arthur ansässigen Finninnen ${ }^{451}$.

Obwohl Frauen nach der Jahrhundertwende, auch neben der Dienstbotentätigkeit, bereits ein breiteres Spektrum an Erwerbsmöglichkeiten zur Verfügung stand, hatte der Dienstbotenberuf für die finnischen Einwanderinnen nicht an Attraktivität eingebüßt.

Im Gegensatz zu den meisten Beschäftigungsfeldern, die finnischen Männern zur Verfügung standen, unterlag der Dienstbotenberuf wesentlich seltener konjunkturellen Schwankungen der amerikanischen oder kanadischen Wirtschaft und damit verbundenen Massenentlassungen. Insbesondere in Zeiten ökonomischer Krisen, wie beispielsweise zu Beginn des Ersten Weltkrieges, wirkte sich die Beständigkeit des Arbeitsverhältnisses in einer Privatfamilie positiv auf die Beurteilung der eigenen Lebensumstände der finnischen Frauen aus. Aino Lähteenmäki aus Kanada faßte dieses Sicherheitsgefühl im Sommer 1914 in Worte ${ }^{452}$ :

"Hier sind sehr schlechte Zeiten für Männer angebrochen. Überall wo ich gewesen bin, habe ich nur schlechte Nachrichten gehört. Es gibt schrecklich viele arbeitslose Männer, und im Osten werden alle Gruben geschlossen. Da stehen vielen Familien schwierige Zeiten bevor. Es macht keinen Sinn, aus Finnland hierher zu kommen, vor allem wenn man hier noch nicht gewesen ist, denn es ist sehr schwer Arbeit zu finden.

Im letzten Winter habe ich von einigen Finnen gehört, die nach Chicago gegangen sind und die haben immer noch keine Arbeit bekommen. Lönnquist hieß einer der Jungen. Er hatte versucht, sich als Tellerwäscher durchzuschlagen, damit er etwas zum Essen bekam. Chicago ist ein schlechter Ort für Männer, aber für Frauen ist die Stadt hervorragend. Dort werden die besten Löhne von ganz Amerika gezahlt. Ich weiß nichts von schlechten Zeiten. Ich habe eine gute Stelle und einen guten Lohn. Es fehlt mir nichts. 'Efriting orait' also alles in Ordnung. "

\footnotetext{
${ }^{451}$ Kouhi 1976, S. 25 Tab. 3.

${ }^{452}$ Aino Lähteenmäki an Familie in Jämijärvi, Brief vom 7.5.1914: TYYH:S:m:Satakunta: JÄM:XCIII/1.
} 
Diese Sicherheit bei Bedarf jederzeit eine Anstellung als Dienstbotin zu bekommen, kann - Virtanen zufolge - zudem als ein Grund für die niedrige Rückwanderungsfrequenz finnischer Frauen gewertet werden ${ }^{453}$, obwohl nach Familiengründung in erster Linie die in Amerika aufwachsenden Kinder die Rückwanderungsabsichten der Frauen behinderten. Auch bei den 43 weiblichen Briefschreibern der beiden Untersuchungsgebiete konnte in 23 Fällen der Verbleib der Frauen ermittelt werden, wobei lediglich drei Briefverfasserinnen nachweislich nach Finnland zurückgegangen waren. 20 Finninnen jedoch, allesamt verheiratet, blieben dauerhaft in Amerika oder Kanada ${ }^{454}$.

Die Dienstbotentätigkeit bot den finnischen Einwanderinnen jedoch noch weitere Vorteile: Neben der Notwendigkeit, die englische Sprache zumindest in Ansätzen zu erlernen, erlangten sie vor allem durch das Rollenvorbild der Dienstgeberin einen Einblick in die Normen, Werte und Gebräuche der amerikanischen Gesellschaft. Insofern bot sich den finnischen Hausangestellten die Gelegenheit, die amerikanische Kultur und Lebensform aus der Nahperspektive, gewissermaßen "von innen her", kennenzulernen, in einer Art und Weise, wie sie den meisten finnischen Männern nicht gegeben war.

In diesem Zusammenhang weist Lindström-Best ${ }^{455}$ auf die Vorliebe finnischer Dienstmädchen in Kanada hin, sich in vornehmer Kleidung mit großen Hüten fotografieren zu lassen, um auf diese Weise einen Lebensstil zu imitieren, den ihnen die Dienstgeberinnen vorlebten. Derartige Bilder, die den Briefen an Verwandte und Freunde in die Heimat beigelegt wurden, haben mit Sicherheit Verwunderung über den plötzlichen Wandel von der finnischen Stallmagd zur finnischamerikanischen 'Lady' hervorgerufen. Da die Requisiten für solche Fotos in den Fotoateliers entliehen werden konnten, haben die Fotografien jedoch in den seltensten Fällen eine tatsächliche Statusveränderung der jungen Frauen dokumentiert.

Diese bürgerliche Bildtradition konnte Assion ${ }^{456}$ auch für deutsche Amerikaauswanderer bestätigen. Er weist jedoch darauf hin, daß sich mit wachsendem Wohlstand im Heimatland die Bedeutung solcher zugeschickter Fotografien als Imponiergehabe allmählich verlor, woraufhin neue Bildarrangements in Mode kamen, wie beispielsweise die Verkleidung als Wild-West-Mann mit Flinte, Lederzeug und 'Cow-Boy'-Hut,

\footnotetext{
${ }^{453}$ Virtanen 1979, S. 156.

${ }^{454}$ Siehe Tab. 9 im Anhang: Namentliche Auflistung der Briefschreiber mit Angaben zu Herkunftsort, Auswanderungsjahr, Jahr des 1. Amerika-Briefes und potentieller Rückkehr.

${ }^{455}$ Lindström-Best 1988, S. 93; als Bildbeispiel siehe Lindström-Best/Sutyla 1984, S. 152.

${ }^{456}$ Assion 1983, S. 7. Zu Kommunikationsinhalten von Fotografien vgl. Sinisalo 1987, S. 37-39.
} 
welche auch unter finnischen Männern beliebt war, oder die Abbildung des zumeist männlichen Auswanderers mit einem Statussymbol des technischen Fortschritts ${ }^{457}$.

Dennoch ließen sich die meisten Dienstmädchen in ihrer Arbeitskleidung ablichten, welche aus langen, weißen oder schwarzen Kleidern mit weißen Schürzen bestand; solche Fotografien finden sich auch in der einschlägigen Literatur am häufigsten ${ }^{458}$.

Interessanterweise beurteilten die finnischen Dienstboten ihre Tätigkeit nicht als "Low Status Occupation", d.h. als sozial minderwertige Arbeit, obwohl der Beruf besonders unter Amerikanerinnen sowie in Städten zahlreich vertretenen Italienerinnen und Jüdinnen, zumeist russischer oder polnischer Herkunft, relativ unbeliebt war. Neben den entbehrungsreichen Arbeitsbedingungen waren es vor allem Aspekte wie Minderwertigkeit, Abhängigkeit und Unfreiheit, die mit den Idealen der amerikanischen Gesellschaftsordnung kollidierten, so daß lediglich jede sechste, im Berufsleben stehende Amerikanerin als Dienerin in einem fremden Haushalt wohnte ${ }^{459}$. Die Dienstbotentätigkeit wurde auch als Heiratshindernis angesehen, was besonders für die in jungen Jahren große Familien gründenden Italienerinnen Grund genug war, sich nicht um eine Tätigkeit außerhalb der eigenen vier Wände zu bemühen. Sie fertigten lieber Gebrauchsgegenstände in Heimarbeit an oder wuschen Wäsche gegen Bezahlung, oftmals in der eigenen Wohnung. Jüdinnen hingegen waren am häufigsten im Bereich Handel und Gewerbe zu finden, und nach der Eheschließung blieben sie zumeist erwerbslos ${ }^{460}$.

Die Einstellung der Finninnen und zugleich der anderen Skandinavierinnen distanzierte sich jedoch deutlich von der allgemein üblichen Geringschätzung des Dienstbotenberufes. Ausschlaggebend für die durchweg positivere Beurteilung mag der ungebundene soziale Status der jungen nordischen Frauen gewesen sein. Mit der Absicht eines mehrjährigen Arbeitsaufenthaltes erreichten sie die amerikanischen oder kanadischen Küstenstädte, wobei in vielen Fällen als Hintergedanken eine mögliche Heirat und die baldige Rückwanderung nach Skandinavien mitgespielt haben mögen. Durch ihre Herkunft, vornehmlich aus ländlichen Gebieten, bereits an körperliche Arbeit und einen bescheidenen Lebensstandard gewöhnt, stellten sie zumindest in der Anfangspha-

\footnotetext{
${ }^{457}$ Siehe z.B. Fotografien von drei jungen Finnen in 'Cow-Boy-Look' um 1900 sowie Abbildung zweier Finnen auf Motorrad mit Beiwagen von 1913 bei Lindström-Best/Sutyla 1984, S. 149 und S. 151. Vgl. auch die 'Cow-Boy'-Abbildung bei Nyström 1985, S. 27

${ }^{458}$ Vgl . z.B. Fotografien bei Lindström-Best/Sutyla 1984, S. 76; Penti 1986, S.59; Kero 1996, S. 181.

${ }^{459}$ Dickinson 1980, S. 99, Tab. 18; Wehner-Franco 1994, S. 69.
} 
se ihres Aufenthaltes keine hohen Ansprüche an die Arbeitsbedingungen und Höhe der Bezahlung. Die ersten verdienten Dollar gaben ihnen vielmehr Selbstbewußtsein sowie das Vertrauen in ihre eigenen Fähigkeiten und eine gesicherte Zukunft.

Da außerdem der technische Fortschritt auch die Modernisation der städtischen Haushalte mit sich gebracht hatte, wurden von den Dienstboten Kenntnisse in zeitgemäßer Haushaltsführung sowie im Umgang mit modernen Gerätschaften zur angeblichen Arbeitserleichterung verlangt; neuerworbene Fähigkeiten, die das Selbstwertgefühl der jungen Frauen stärkten und ihnen nicht zuletzt bei Bewerbung um die nächste Anstellung zugute kamen. Der kritisch beobachtende Zeitzeuge Järnefelt beurteilte das Selbstverständnis der finnischen Dienstboten 1899 mit folgenden Worten ${ }^{461}$ :

"Die finnische Frau, die nach Amerika gekommen ist, um in erster Linie als Dienstbotin Geld zu verdienen, bemerkt schon bald, daß ihre Stellung hier eine andere ist als daheim. Es ist schon richtig merkwürdig zu verfolgen, wie schnell sie sich an die fremden Verhältnisse anpaßt. Unsere Mädchen in Amerika sind keine mit allem zufriedenen, willenslosen Geschöpfe, sondern sie kennen ihren Wert und verstehen es eine dementsprechende Behandlung einzufordern. Mit Bedacht wählen sie ihre Arbeitsplätze aus und wechseln diese - häufig sogar zu schnell -, sobald nicht alles ihren Wünschen entspricht."

Durch ihr ehrliches Bemühen, selbstverantwortlich für den Lebensunterhalt und die Schuldenrückzahlung der Reisekosten aufzukommen, erlangten die finnischen Dienstboten unter ihren Landsleuten einen gehobenen Sozialstatus. An den sozialen Aktivitäten der finnischen Gemeinschaft vor Ort, z.B. der Kirchengemeinde oder eines Abstinnenzlervereins, nahmen viele von ihnen aktiv teil und genossen allgemeine Anerkennung. Järnefelt führt ein persönliches Erlebnis aus der Zeit vor der Jahrhundertwende an, nach dem zahlreiche finnische Dienstboten den gesamten Geldbetrag für den Erwerb eines Kirchengebäudes in Brooklyn zusammentrugen. Die einzelnen Dienstmädchen spendeten dabei häufig ihren mehrfachen Monatslohn ${ }^{462}$.

\footnotetext{
${ }^{460}$ Katzman 1978, S. 13 und S. 69. Zur Stellung der Familie bei Italiennerinnen und Jüdinnen: Klaczynska 1976; Kessner/Boyd Caroli 1978; Ewen 1985, S. 90-111 und S. 226-239.

${ }^{461}$ Zitat aus Järnefelt 1899, S. 299.

${ }^{462}$ Järnefelt 1921, S. 104-110.
} 
Demnach galt das soziale Stigma, das den Dienstbotenberuf umgab, nicht innerhalb der eigenen ethnischen Gruppe, und da die Finninnen kaum Interesse an nichtfinnischen Gruppierungen zeigten, war die allgemeine Einstellung dem Dienstbotenberuf gegenüber für sie ohne Relevanz ${ }^{463}$. Wesentlich wichtiger erschienen ihnen die freundliche Behandlung durch die "Herrschaften" sowie die Einhaltung der zuvor vereinbarten Bedingungen über Freizeit und wöchentlichen Verdienst seitens der Arbeitgeber. Des weiteren vermittelte der Dienst in einer mittelständischen Familie den jungen Frauen eine gewisse Sicherheit, da sie schon aus Finnland an große Familienverbände unter einem Dach gewöhnt waren.

Diese größtenteils positive Einstellung dem Berufsfeld gegenüber blieb auch den amerikanischen Dienstgebern nicht verborgen. Trotz der sprachlichen Hindernisse genossen finnische Hausangestellte zumeist einen guten Ruf; sie galten als fleißig, ehrlich und anspruchslos ${ }^{464}$. Einige wenige Finninnen schafften sogar den sozialen Aufstieg in Familien der gehobenen Oberschicht, so daß nicht zuletzt bei Mitgliedern der Familie Rockefeller in New York finnische Dienstboten zu finden waren ${ }^{465}$.

In den beiden Briefsammlungen, die dieser Untersuchung zugrunde liegen, sind nur wenige Briefe von Frauen zu finden, die als Dienstboten in einem städtischen Privathaushalt gearbeitet hatten. Die vollständigste Briefserie stammt von Emmi Niemi, einer jungen Frau aus Ikaalinen in der Provinz Satakunta, die ihrer bereits verheirateten Schwester Hilda Paananen nach Fitchburg in Massachusetts gefolgt war. In 13 Briefen von 1910-16 schildert Emmi Niemi ${ }^{466}$ ihren in Finnland verbliebenen Eltern den Arbeitsalltag in drei verschiedenen Anstellungsverhältnissen, und auch der rege Informationsaustausch mit der in unmittelbarer Nachbarschaft lebenden Schwester wird in schriftlicher Form reflektiert. Über ihr erstes Beschäftigungsverhältnis, das neun Monate andauerte, berichtete sie 1910 folgendermaßen:

” Ich arbeite hier in einer Familie der 'Anderssprachigen'. Ich höre den ganzen Tag lang kein einziges finnisches Wort. Wir sind acht Leute hier, ich bin die Neunte. Ich koche für alle und putze die Zimmer. Hier ist die Arbeit viel leichter als in Finnland. Es braucht nichts von draußen hereingeholt zu werden. Vom Lebensmittelhändler wird al-

\footnotetext{
${ }^{463}$ Sangster 1981, S. 47f.; Ross 1986b, S. 48.

${ }^{464}$ Siehe hierzu Kero 1996, S. 172-182, bes. S.175.

${ }^{465}$ Tommola (1989, S. 45 und S. 57) nennt zwei Fallbeispiele.
} 
les ins Haus gebracht, Wasser kommt direkt in die Küche, und das Holz lagert im Keller unterhalb der Küche. [...]Jetzt am Anfang ist es schon etwas merkwürdig völlig stumm zu sein, aber vielleicht gewöhnt man sich ja an die Sprache in diesem Land, wenn man nur lange genug zuhört.

Ich muß schon sagen, daß ich es wirklich bereue, nicht schon früher in dieses Land gekommen zu sein, in jüngeren Jahren fällt das Lernen noch leichter."

Die von der Briefschreiberin gewählte Formulierung der “Anderssprachigen” für ihre amerikanische Arbeitgeberfamilie findet sich auch in überraschend vielen Briefen und Interviewaussagen von Finnen beiderlei Geschlechts. Grundsätzlich schienen alle englischsprachigen Arbeitskollegen, Vorgesetzte oder Arbeitgeber "anderssprachig" gewesen zu sein, und auch für nicht finnische Ehepartner von Finnen, welche jedoch relativ selten waren, wurde diese Bezeichnung benutzt ${ }^{467}$. Die auf diese Weise zum Ausdruck gebrachte Zugehörigkeit zur finnischen Gemeinschaft führte zugleich zu einer deutlichen Abgrenzung der eigenen ethnischen Gruppe von der multikulturellen amerikanischen Gesellschaft; ein Verhaltensmuster, das besonders stark unter den finnischen Gemeinschaften entlegener Grubenorte und Waldkamps ausgeprägt war und erst im Laufe der Jahre oder Jahrzehnte Abschwächung erfuhr.

Dennoch schien die zitierte Briefschreiberin aus Fitchburg durchaus am Erlernen der amerikanischen Sprache interessiert zu sein, um sich mit ihren Arbeitgebern verständigen zu können. Da Dienstboten ohnehin täglichen Umgang mit Amerikanern pflegten, lernten sie auch, schon allein aufgrund der situationsbedingten Notwendigkeit, schneller die englische Sprache als ihre Landsleute in zahlreichen anderen Berufsfeldern. Allerdings gibt Penti zu bedenken, daß der anfängliche Wortschatz in erster Linie aus 'Kitchen English' bestand. Sprachliche Mißverständnisse waren denn auch beliebte Inhalte für Anekdoten aus dem Dienstbotenalltag der jungen Einwanderinnen, die sich als 'Maid Stories' zu einem eigenen Genre der Erzähltradition unter finnischen Einwanderern beiderlei Geschlechts entwickeln konnten ${ }^{468}$.

\footnotetext{
${ }^{466}$ Emmi Niemi an Schwester in Ikaalinen, Zitate hier und im folgenden aus vier Briefen vom 29.10.1910, 27.6.1911,7.1.1913, und 21.10.1915: TYYH:S:m:Satakunta: IKA: LXVII/ 1,13-15. ${ }^{467}$ Siehe Stichwort: 'toiskielinen' im amerikanisch-finnischen Wörterbuch von Virtaranta 1992, S. 209.

${ }^{468}$ Nach Pentis (1986, S. 56-58) Analyse von 73 Dienstbotengeschichten waren diese in solche mit guten und schlechten Dienstgebern unterteilt. Vgl. auch Lindström-Best 1988, S. 92.
} 
Diese Tradition des Erzählens von Anekdoten und selbsterlebten Situationen wurde denn auch vor allem von den Dienstboten selbst gepflegt. Die regelmäßigen Treffen der finnischen Hausangestellten in größeren Städten führten schon bald zur Gründung von eigenen Interessenverbänden mit vielfältigen sozialen Aktivitäten: Bereits 1893 riefen finnische Frauen in New York City einen Verein ins Leben, der als kulturelles und soziales Zentrum und nicht zuletzt auch als Wohltätigkeitsorganisation für in Not geratene Landsleute diente. Drei Jahre später erlebte die erste, wenn auch nur kurzlebige, finnische Zeitung für Frauen 'Naisten Lehti' (dt. Frauenzeitung) ihre Startauflage, und 1904 befand sich eine Mischung aus Berufsgenossenschaft und Wohnheim für Frauen ${ }^{469}$ mit dem Namen 'Finnish Women's Cooperative Home' in der Stadt. 1912 gründete diese Organisation wiederum in New York City und San Francisco Arbeitsvermittlungsagenturen für finnische Hausangestellte. Bereits ein Jahrzehnt zuvor, um 1900, sollen in New York City bis zu 20 Vermittlungsagenturen auf die Empfehlung von finnischen Dienstboten spezialisiert gewesen sein, von denen jedoch keine in finnischer Hand war $^{470}$. In Toronto hingegen fand sich zumindest eine von einer Finnin gegründete Agentur für finnische Haus- und Hotelangestellte ${ }^{471}$.

Im Jahr 1911, als die sozialistische Vereinigung der Amerika-Finnen, mit Hauptsitz in Hibbing, Minnesota, ihre eigenen Frauensektionen gebildet hatte, erhielten finnische Frauen aus allen Erwerbsbranchen mit der Zeitung 'Toveritar' (dt. die Kameradin) ein Sprachrohr, das in einer Auflage etwa 8000 Exemplaren gegen Ende des Ersten Weltkrieges Verbreitung fand ${ }^{472}$. Zur gleichen Zeit bestand ein Drittel der Mitglieder der 'Finnish Socialist Federation' aus Frauen, nämlich 3790 von insgesamt 13160 Personen. Da diese politische Bewegung wiederum in Städten mit hoher Finnenkonzentration die größten Sektionen bilden konnte, ist davon auszugehen, daß sich die politisch aktiven Frauen in erster Linie aus Dienstboten und Fabrikarbeiterinnen rekrutierten. Neben den politischen Vereinigungen waren finnische Dienstbotinnen jedoch auch in von Finnen initiierten Organisationen religiöser, kultureller und sozialer Natur aktiv,

\footnotetext{
${ }^{469}$ Das Wohnheim diente als Herberge für Dienstboten ohne Anstellung sowie als Ferienpensionat, vgl. Ross 1986b, S. 47. Auch in Montreal befand sich ein Wohnheim, vgl. Lindström-Best 1988, S. 97-99.

${ }^{470}$ Tommola 1989, S. 47. Zur Praxis der Vermittlungsagenturen vgl. Katzman 1978, S. 101-104.

${ }^{471}$ Sangster 1981, S. 46f.

${ }^{472}$ Jede vierte Abonnentin von 'Toveritar' lebte in Kanada, wo sich die Zeitung zum Presseorgan der finnischamerikanischen Frauenbewegung etablieren konnte, vgl. Lindström-Best/Seager 1988, S.139-142.
} 
um vor allem der Isolation und Einsamkeit ihres Arbeitsalltages zu entfliehen und finnische Männer kennenzulernen $^{473}$.

Vor dem Hintergrund des immensen Arbeitspensums jedoch, das eine finnische Dienstbotin täglich zu bewältigen hatte, erscheint die aktive Teilnahme an ethnischen Organisationen jeglicher Art erstaunlich. Die Woche im Dienst kannte sieben Tage, und Arbeitszeiten von 82 Stunden waren keine Seltenheit. Der einzelne Arbeitstag betrug zwischen 12-15 Stunden und war somit mindestens zwei Stunden länger als die Erwerbszeit in der Industrie ${ }^{474}$. Lediglich Mahlzeiten und eine kurze Nachtruhe unterbrachen die Arbeitszeit der Dienstboten. Ansonsten standen sie ihren Dienstgebern jederzeit zur Verfügung, wobei in Stammzeiten und eine Art Bereitschaftsdienst, den der englische Begriff 'to be on call' treffend umschreibt, unterschieden werden muß. Ein einziger freier Nachmittag in der Woche ${ }^{475}$ befriedigte keineswegs den Anspruch auf Erholung und Freizeit der jungen Frauen, wie u.a. aus Leserbriefen an die Redaktion der Zeitung 'Toveritar' hervorgeht ${ }^{476}$. Auch eine finnische Briefschreiberin aus Toronto äuBerte sich zu den langen Arbeitszeiten und dem fehlenden persönlichen Freiraum ${ }^{477}$ :

"Hier kann man den Sommer nicht genießen, da man immer nur wie eine Gefangene eingesperrt ist. Abends immer nur auf dem Zimmer, man kommt nirgendwo hin, selbst wenn man noch so gerne [ausgehen würde] - immer nur allein sitzen und nachdenken. [...] Abends tun mir schon ziemlich die Füße weh, wenn ich den ganzen Tag treppauf und treppab gelaufen und auch noch im Keller mehrere Dutzend Male gewesen bin. Abends, nachdem ich meine Arbeit getan habe, gehe ich auf mein Zimmer und werfe mich aufs Bett, um ein wenig auszuruhen. Meist ist es dann schon acht Uhr, wenn

\footnotetext{
${ }^{473} \mathrm{Zu}$ religiösen, sozialen und politischen Aktivitäten der finnischen Einwanderinnen in Amerika siehe Wargelin-Brown 1986a, S. 21-34 und 1986b; Ross 1986a; zu Kanada siehe Sangster 1981; Lindström-Best 1988, S. 115-160.

${ }^{474}$ Ross 1986b, S. 47. Katzman (1978, S. 111f., Tab. 3.1.) hat die durchschnittliche tägliche Arbeitszeit von Dienstboten um 1900 in verschiedenen Städten miteinander verglichen, wonach in Boston am längsten gearbeitet wurde. Zu den Arbeitszeiten deutscher Dienstboten siehe Wehner-Franco 1994, S. 174-184.

${ }^{475}$ Im Kanada war meist der Mittwoch-Nachmittag Freizeit, in Amerika jeder zweite Donnerstag- und Sonntagnachmittag im Wechsel (Järnefelt 1899, S. 95; Sangster 1981, S. 49).

${ }^{476}$ Zeitung 'Toveritar' vom 9.5.1916, 21.5.1916 und 11.7.1916.

${ }^{477}$ Aino Sainio an Maija Syynimaa in Alahärmä, Brief vom 1.4.1928, Sammlung SüdOstbottnien, Sig.Nr. 2097/1. Dieser Brief wurde hier aufgrund seiner Datierung von 1928 nur ausnahmsweise berücksichtigt und ist nicht in die Aufstellung der beiden Briefsammlungen eingegangen.
} 
wir keine Gäste haben. Aber wenn Gäste im Haus sind, darf ich sie bis um zehn Uhr bedienen."

Dennoch gewinnt sie dem Lebensstil ihrer Arbeitgeber auch Bewunderung ab und ist stolz auf ihre Tätigkeit, da sie im folgenden berichtet:

"Ihr könnt euch nicht vorstellen, welch ein vornehmes Fest wir am vergangenen Sonntag hier hatten. Die Gäste waren so feine 'Missis' und Herren; auch ich mußte mich wie eingefroren [wörtl. 'wie ein Eisstück'] benehmen, gut gekleidet und sauber. Alle Speisen wurden mit dem Tablett serviert. Die Gerichte waren vom Feinsten, und von jeder Sorte war etwas dabei. - Wenn ihr nur hier sein und ein richtig vornehmes kanadisches Abendessen genießen könntet. Ich denke oft daran, wie es wäre, wenn ihr mir hier bei der Arbeit zusehen könntet, wenn ich richtig feine Gerichte zubereite."

Die bereits zitierte Briefschreiberin Emmi Niemi wechselte innerhalb der Kleinstadt Fitchburg mindestens zweimal ihre Stelle als Dienstbotin. Über ihre beiden letzten Anstellungsverhältnisse vor der Heirat mit einem Finnen, welche von 1911 bis etwa 1916 andauerten, resümierte sie in insgesamt sieben Briefen:

"Das Haus der [vorherigen] Familie wurde verkauft. [...] Sie hätten mich gerne behalten, doch ich wollte nicht mitgehen. Aber ich glaube, daß ich auch hier eine gute Stelle gefunden habe. Hier gibt es nur viel mehr Arbeit, da dies ein sehr vornehmes Haus ist, selbst wenn hier nicht mehr als vier Personen wohnen, zwei Kinder und deren Eltern. Dort in Finnland verursachen vier Personen noch nicht viel Arbeit, aber hier ist das anders, auch wenn ich nur das Essen kochen und die Zimmer säubern muß. Wir haben neun Zimmer, in denen ich jeden Tag kehren und Staub wischen muß. Die Böden werden einmal in der Woche feucht gewischt. [...] Dies hier ist eine gute Stelle. Die Herrschaften sind freundlich zu mir. Und weitere Leute gibt es hier auch nicht, nur die beiden Kinder, das eine ist ein und das andere drei Jahre alt. Auch im Moment bin ich mit den Kindern allein, die Herrschaften sind zur Kirche gegangen."

"Obwohl ich in Finnland eine leichte Arbeit hatte, bin ich dort nie richtig gesund gewesen. Hier ist das anders. Hier habe ich überhaupt keine Zeit, um mich hin zusetzten, geschweige denn krank zu werden. Hier muß man immer in Bewegung sein, 
wenn man denn ein wenig Geld verdienen will. Es gibt natürlich auch leichtere Arbeitsstellen, und der Lohn ist dementsprechend. Ich habe bisher immer sehr viel arbeiten dürfen, doch auch mein Gehalt war gut, so daß ich versucht habe so viel zu arbeiten, wie ich nur konnte. [... JIch bin jetzt seit neun Monaten in diesem Haus und erhalte sechs Dollar in der Woche."

Auch zweieinhalb Jahre später, im Herbst 1915, äußert sich die Briefschreiberin weiterhin zufrieden mit ihrer Arbeitsstelle:

"Mir geht es hier ganz gut. Ich habe eine gute Stelle, und die Familie ist sehr freundlich. Ich darf mich so geben wie ich bin und vieles selbst entscheiden."

Eine andere, gleichfalls zufriedene Briefverfasserin aus Brooklyn schrieb 1910 an eine Freundin im südostbottnischen Teuva ${ }^{478}$ :

"Ich bin jetzt mit einer Bekannten in der gleichen Familien im Dienst, ich arbeite als Köchin und sie als Dienstmädchen. Wir hatten Glück und haben eine gute Stelle bekommen. Unsere Dienstgeberin ist eine sehr gutmütige und feine Frau, sie läuft ihren Dienstmädchen nicht unnötig hinterher. Morgens gibt sie ihre Anweisungen und dann sieht man sie vor dem kommenden Tag nicht wieder. [...] Trotzdem werde ich nicht viele Monate hier verbringen, vielleicht nur den Sommer."

Den Grund für den beabsichtigten Wechsel der Arbeitsstelle behielt die Briefschreiberin für sich. Dennoch war ihr Absicht, wie auch der zweifache Stellenwechsel von Emmi Niemi, unter den europäischen Dienstboten eher die Regel als die Ausnahme, was als Ausdruck eines Ungleichgewichts zwischen Nachfrage und Angebot an städtischen Dienstboten gewertet werden kann. Nach den Angaben von Arbeitsvermittlungsagenturen in New York City betrug die durchschnittliche Dauer eines Arbeitsverhältnisses sechs bis elf Monate, und der ständige Arbeitsplatzwechsel der Dienstboten gestaltete sich für die Dienstgeber zu einem großen Problem ${ }^{479}$. Die Entlohnung war

\footnotetext{
${ }^{478}$ Tilda ('Mary') Leidenius an Lempi Kohtala, Brief vom 4.3.1910, Samml. Süd-Ostbottnien, Sig.Nr. 1347/2.

${ }^{479}$ Katzman 1978, S. 138 und bes. Kap. 6: "The Servant Problem", S. 223-247. Siehe auch Wehner-Franco 1994, S. 79-100.
} 
denn auch das wichtigste Mittel, das den "Herrschaften" zur Verfügung stand, um ihr Dienstpersonal zu halten, wovon wiederum die Dienstboten profitierten.

In der zitierten Briefaussage des Jahres 1913 gab Emmi Niemi ihren Wochenlohn mit 6 \$bzw. 24 \$ monatlich an, und eine andere Briefschreiberin aus Massachusetts wußte 1909 von einem Wochenlohn in Höhe von 5 \$ zu berichten ${ }^{480}$. Auch in New York City lag der Monatslohn zwischen 22 \$ - 25 \$ und war abhängig von der Berufserfahrung und den bereits erworbenen englischen Sprachkenntnissen ${ }^{481}$, wie auch Hilda Mukkala ihre Schwester im südostbottnischen Ilmajoki wissen ließ ${ }^{482}$ :

"Ich arbeite jetzt als Dienstmädchen und komme ganz gut zurecht, obwohl ich kaum etwas von der Sprache verstehe. Als Lohn erhalte ich 20 Dollar pro Monat und er wird dann erhöht, sobald ich mehr gelernt habe. Im nächsten Monat bekomme ich dann 22 Dollar."

Järnefelt wiederum listet für die Zeit vor 1899 folgende Lohnskala auf: Dienstmädchen erhielten 14 \$-16 \$ im Monat, Köchinnen 18 - 20 \$ und Waschfrauen 20 \$ 24 \$. Ein noch unbedarftes, gerade erst eingewandertes Mädchen bekam einen Lohn von 8 \$ im ersten Monat, der bald darauf auf 10 \$ angehoben wurde. Erfahrene Finninnen sollen sogar $30 \$$ und mehr im Monat verdient haben ${ }^{483}$.

In Kanada lagen die Verdienstmöglichkeiten in etwa in der gleichen Größenordnung: Ein ungelerntes Dienstmädchen erhielt zu Beginn seiner Stellung etwa 3 \$ wöchentlich bzw. 12 \$ monatlich. Später bewegte sich der Durchschnittsverdienst bei $25 \$$ im Monat und in Spitzenstellungen wurde sogar das Doppelte gezahlt ${ }^{484}$.

Da dieses Lohnniveau bereits die freie Unterkunft und Verpflegung der Dienstboten miteinschloß, waren die zu erzielenden Löhne durchaus mit denen der Männer in Grubenorten zu vergleichen, lediglich in den Bergstaaten und an der Westküste blieben den Männern nach Abzug der Lebenshaltungskosten größere Summen übrig.

\footnotetext{
${ }^{480}$ Liisa ('Lizzie') Tienhaara an Alma Kallio in Lappi/TL, Brief vom 2.4.1909 aus Hingham, Mass.: TYYH:S:m: Satakunta: LAP:VI/7.

${ }^{481}$ Siehe Fallbeispiel bei Kero 1996, S. 181 sowie Brief von Aini Fredman aus New York vom 24.12.1909, Samml. Süd-Ostbottnien, Sig. Nr. 1379/1.

${ }^{482}$ Hilda Mukkala an Schwester Hilda Lammela in Ilmajoki, Brief vom 11.6.1916, Samml. SüdOstbottnien, Sig,Nr.134/8. Aufgrund der Datierung von 1916 wurde dieser Brief hier nur ausnahmsweise berücksichtigt.

${ }^{483}$ Järnefelt 1899, S. 45.

${ }^{484}$ Lindström-Best 1988, S. 88.
} 
Wie jedoch schon aus dem zitierten Briefbeispiel von Aino Lähteenmäki aus Ontario hervorgeht, waren regionale Unterschiede in der Bezahlung durchaus üblich. Chicago, ein Eldorado für schwedische Einwanderer, soll auch ein "Paradies" für Dienstboten gewesen sein. 1913 konnten neu eingereiste Frauen 4 \$ die Woche erhalten mit der Aussicht auf eine Lohnsteigerung von $1 \$-3 \$$, sobald sich Fortschritte im englischen Spracherwerb zeigten. Eine Köchin verdiente sogar zwischen 12 \$ 15 \$ wöchentlich $^{485}$.

Einer 1905 für eine amerikanische Zeitschrift in Auftrag gegebenen Vergleichsuntersuchung zufolge, wurden in New York City 4 , in Boston 4,5 \$ -5 \$, in Chicago $5 \$$ und in San Francisco, mit einer besonders großen Nachfrage an weißen Dienstboten, sogar 6,25 \$ pro Woche gezahlt ${ }^{486}$. Vor diesem Hintergrund kann der Wochenlohn von Emmi Niemi aus Fitchburg von 6 tatsächlich als ein überdurchschnittliches Gehalt bezeichnet werden.

Auf jeden Fall überstieg der Lohn deutlich die Verdienstmöglichkeiten, die der Briefschreiberin in ihrer Heimatgemeinde Ikaalinen in Satakunta zur Auswahl gestanden hätten. Eine abhängige Magd verdiente in Finnland zusätzlich zu ihrer freien Unterbringung und Beköstigung lediglich zwischen 60-120 Finnmark pro Jahr, was einer Summe von etwa 11\$ - 22 \$ gleichkam ${ }^{487}$. Allein dieser Vergleich, nämlich die Möglichkeit als Dienstbotin in Amerika oder Kanada in einem Monat den Jahresverdienst einer finnischen Magd zu verdienen, erklärt die Anzahl von rund 80000 ausgewanderten Frauen in den zwei Jahrzehnten vor Ausbruch des Ersten Weltkrieges.

In Hotels und Gruppenunterkünften, die ebenfalls einen großen Bedarf an Dienstpersonal zeigten, verdienten die finnischen Frauen, zumindest in Kanada, noch besser als in mittelständischen Privathaushalten, da sie bei freier Kost und Logis 30 \$ 40 \$ im Monat für sich behalten durften. Lediglich als Köchinnen in entlegenen Waldkamps konnten Spitzenlöhne von $40 \$-60$ \$ pro Monat erzielt werden, wie unter anderem das bereits zitierte Fallbeispiel von Maria Mäntylä aus Ontario belegt ${ }^{488}$.

Aus Amerika hingegen berichtete eine Briefschreiberin lediglich einen Monatslohn von 12 \&u erhalten. Sie arbeitete in einem, von Finnen geführten 'Boarding Hou-

\footnotetext{
${ }^{485}$ Lintelman 1991, S. 91.

${ }^{486}$ Wehner-Franco 1994, S. 196.

${ }^{487}$ Toivonen (1950, S. 7) nennt die Summe von 60 Finnmark, Kero (1969c, S. 60) gibt 120

Finnmark als durchschnittlichen Jahresverdienst einer Magd an. Der Umrechnung liegt ein Kurs von $1 \$=5,15$ Finnmark zugrunde.

${ }^{488}$ Siehe hierzu Kap. 3.4.2.
} 
se' in Quincy, Massachusetts, wobei jedoch zu vermuten ist, daß auch die drei kleinen Kinder der Verfasserin in den Vorzug von freien Mahlzeiten und freier Unterkunft gelangten und der Lohn dementsprechend gering ausfiel ${ }^{489}$. Es ist jedoch anzunehmen, daß die meisten in Gasthäusern und Gruppenunterkünften beschäftigten Frauen in etwa nach dem Lohnschema der Privathaushalte entlohnt wurden, d.h. daß sich der durchschnittliche Monatslohn bei $20 \$-24 \$$ bewegte.

Erst in den 1920er Jahren stieg das allgemeine Lohnniveau für Dienstboten spürbar an. Auch das Berufsbild begann sich allmählich dahingehend zu verändern, als daß immer weniger Frauen im Haus ihrer Dienstgeber lebten. Viele der um 1900 eingewanderten Frauen hatten inzwischen geheiratet, der Prozentsatz an verheirateten Dienstboten war um 1920 höher als in anderen Berufen, setzten ihre Dienstbotentätigkeit jedoch als Angestellte auf fester Stundenbasis als 'Day Worker' fort. Zudem ergriffen immer weniger Finninnen den Dienstbotenberuf, da mit zunehmender Industrialisierung vielfältigere Berufsfelder als zuvor zur Auswahl standen ${ }^{490}$.

\footnotetext{
${ }^{489}$ Wiktoorina Tienhaara an Eltern in Lappi/TL, Brief vom 26.8.1906: TYYH.S:m: Satakunta: LAP:VI/2.

${ }^{490} \mathrm{Zu}$ den Veränderungen des Berufbildes nach 1920 siehe Genevieve 1974, S. 116f; Ross 1986b, S. 48.
} 


\subsection{Der finnische Auswandererbrief als Brückenschlag zwischen Finnland}

\section{und Amerika}

Vor dem Zeitalter der fernmündlichen Kommunikation kann der Auswandererbrief als die einzige Kommunikationsform zwischen Alter und Neuer Welt angesehen werden. In seiner Funktion auf die Aufrechterhaltung sozialer Netze und Beziehungen ausgerichtet, bedeutete er weit mehr als nur einen reinen Informationsaustausch zwischen daheimgebliebenen und ausgewanderten Briefpartnern. Gerade aufgrund der unterschiedlichen Lebensbedingungen zu beiden Seiten des Atlantik fungierte der Amerika-Brief als soziale Brücke zwischen vertrauten Menschen, die häufig nicht nur aus demselben agrarischen Lebensumfeld, sondern auch aus demselben Ort stammten. Charakteristisch für die Situation der Auswanderung war die Schaffung einer neuen Kommunikationsform, dem Briefmedium, enstanden aus dem Bedürfnis, eine gemeinsame Verständigungsebene zu erhalten ${ }^{491}$.

Während der in Finnland verbliebene Briefpartner in der Lebenswelt neue Erfahrungen sammelte, die beiden Briefpartnern bekannt waren, bewegte sich der Auswanderer zugleich in drei verschiedenen Lebenswelten: Er hielt das zurückgelassene soziale Beziehungsnetz in der finnischen Herkunftsgemeinde durch Briefkontakt mit meist mehreren Personen aufrecht, er nahm an der multikulturellen Gesellschaft in Amerika oder Kanada teil, wobei vor allem das Arbeitsumfeld vielfältige Berührungspunkte bot, und nicht zuletzt engagierte er sich, mehr oder weniger, innerhalb der eigenen ethnischen Gemeinschaft der Amerika-Finnen in Form von Freundschaftsbeziehungen sowie der Teilnahme an verschiedenen religiösen, kulturellen oder politischen Vereinigungen seiner Landsleute ${ }^{492}$.

Bei der Durchsicht tausender Briefe entsteht unweigerlich der Eindruck, daß die Briefwechsel thematisch von den Ereignissen geprägt wurden, welche die Auswanderer zu berichten wußten, d.h. die sich in erster Linie der anfangs noch fremden Lebenswelt in Amerika oder Kanada widmeten. Obwohl die Antwortbriefe aus Finnland größtenteils fehlen, weil solche Briefe nicht gesammelt worden sind, läßt sich mit ziemlicher Sicherheit behaupten, daß die Erfahrungen des Auswanderers in der Fremde auch den in Finnland lebenden Briefpartner beschäftigten. Viele Briefschreiber in Amerika gingen

\footnotetext{
${ }^{491}$ Götz/Löffler/Speckle 1993, S.173; Weß-de Velásquez 1995, S.118.
} 
nämlich auf Fragen ein, die sie von ihren Briefpartnern aus Finnland gestellt bekamen und knüpften somit einen thematischen Dialog fort, der sich über mehrere Briefe erstrecken konnte $^{493}$. Dies bedeutet nicht, daß die Auswanderer keinen Anteil an den sozialen Vorgängen im Leben des Briefpartners bzw. im Heimatort im allgemeinen genommen hätten. Vor allem bei einander nahestehenden Personen, wie beispielsweise Ehepartnern, konnten Erkundigungen nach den Einzelheiten des Alltagslebens des anderen großen Raum einnehmen. In den meisten Briefen berichteten die Emigranten jedoch von sich selber und gaben dem Briefpartner Anweisungen über die Verwendung beigefügter Geldscheine oder Bankwechsel. Einige baten auch um Gefälligkeiten bzw. um die Vertretung ihrer Interessen während ihrer Abwesenheit, insbesondere im Falle von Erbschaftsangelegenheiten. Lediglich bei Briefwechseln in sehr dichtem zeitlichen Abstand, d.h. bei einer Brieffrequenz von ein bis zwei Briefen pro Monat, traten die Amerika und Finnland betreffenden Themen in einem ausgewogenen Gleichgewicht zueinander in Erscheinung.

Hiermit wären allerdings erst zwei der Lebenswelten des Auswanderes beschrieben, die in den Briefen Niederschlag fanden, zum einen die "Neuigkeiten", die Ereignisse des Einwandereralltags und zum anderen das Interesse an den sozialen Entwicklungen in der Heimatgemeinde.Ausgeklammert wurden bisher Erfahrungen, welche die ethnische Gemeinschaft der Amerika-Finnen betrafen, der Kontakt zu anderen Finnen in Amerika, sozusagen die dritte Lebenswelt des Emigranten.

Hinsichtlich dieses Aspektes läßt sich denn auch eine interessante Beobachtung machen: Viele Briefschreiber berichteten von persönlichen und schriftlichen Kontakten, die sie zu anderen Finnen in Amerika oder Kanada pflegten. Lebten die betreffenden Personen nicht am gleichen Ort wie die Briefschreiber, so versuchten diese den Briefkontakt innerhalb von Amerika zu ihren Verwandten aufrecht zu erhalten und informierten zugleich die Daheimgebliebenen in Finnland über den Verbleib der entsprechenden Geschwister oder Bekannten494. Insofern erhielt der bislang nur zwischen

\footnotetext{
${ }^{492} \mathrm{Zu}$ dieser kulturellen Dreifachverhaftung siehe Virtanen 1987, S. 503 und 1993, S. 7.

${ }^{493}$ Beispielsweise die Briefserie von Emmi Niemi aus Fitchburg, Mass., die ihrer Schwester in Ikaalinen in der Provinz Satakunta 13 Briefe (1910-15) schrieb und sowohl über ihren eigenen Werdegang als auch den einer weiteren, ebenfalls in Fitchburg lebenden Schwester berichtete, Sig.:TYYH:S:m: Satakunta:IKA:LXVII/1-15.

${ }^{494}$ Dieses Phänomen war häufig zu beobachten, hier drei Fallbeispiele: Die Brüder Evert und Jalmari Ikala korresponierten zwischen Minneapolis und Ironwood, Mich. [TYYH:S:m:Satakunta:KOK:IX/KOK:VIII]; Brüder John und Herman Korvola aus Roseberry, Idaho und Virginia, Minn [Samml. Süd-Ostbottnien, Briefe nach Isokyrö, Sig. Nr. 241/261];
} 
Finnland und Amerika bestehende Briefwechsel eine neue Dimension, indem nämlich die Informationen aus den inneramerikanischen Briefkontakten die Amerika-Briefe, d.h. die Briefe in die Heimat, bereicherten.

In das Sample 'Satakunta' ist beispielsweise eine Briefserie eingegangen, in der ein Auswanderer, der sich in Chester, Massachusetts niedergelassen hatte, während der Zeitspanne 1905-13 insgesamt 39 Briefe von neun verschiedenen Briefschreibern aus Massachusetts, Wisconsin, Minnesota, Michigan, New Jersey, Conneticut und Québec in Kanada erhielt ${ }^{495}$. Der Auswanderer selbst schrieb zudem noch seinen Eltern nach Lappi in Satakunta und berichtete von u.a. über seine Schwester, die sich aus drei verschiedenen Städten in Massachusetts an ihn wandte. 1913 wanderte dieser Briefverfasser dann mit seinem gesamten Briefbesitz im Gepäck wieder nach Finnland zurück, so daß sowohl seine eigenen als auch die an ihn gerichteten Briefe erhalten geblieben sind.

Dieser hier dargestellte direkte Briefkontakt zweier Briefpartner, dem weitere indirekte Briefwechsel mit Personen zugrunde lagen, die beiden Briefpartnern bekannt waren, hat bislang keine Beachtung in der sonst sehr umfangreichen Literatur zur Funktion und Bedeutung von Amerika-Briefen gefunden. Ebenso ist zwar die allgemeine Themenauswahl der Briefinhalte, nicht jedoch der Bereich der verschwiegenen bzw. Tabu-Themen behandelt worden. Vor allem im Vergleich zu Aussagen aus Interviews und Lebensberichten finnischer Emigranten, welche vor allem von Ahlbäck, Ketonen, Mustonen, Myhrman und Virtaranta ediert wurden ${ }^{496}$, läßt sich allgemein eine einseitige Briefthemenwahl konstatieren. Nüchterne Sachinformationen dominieren in der Mehrzahl der Briefe, die sich um bestimmte, immer wiederkehrende Themenkreise gruppieren. Wertungen der Lebensumstände zu Beginn des Auswandererdaseins hingegen sowie Reflexionen zu Erlebtem finden sich eher in Quellen, die mit zeitlichem Abstand zu entsprechenden Ereignissen entstanden sind, vermutlich da es den Betreffenden leichter fiel, schwierige Lebenssituationen im nachhinein neu zu beurteilen.

Vor diesem Hintergrund verwundert es nicht, daß beim Vergleich zahlreicher Briefe verschiedener Autoren der Eindruck einer starken Homogenität sowohl der Briefthemen als auch ihrer Anordnung im Brieftext entsteht. Dieses Phänomen könnte

Brüder Juho, Isak und Nestori Kuusisto aus Floodwood, Minn. und Newberry, Mich. [TYYH: S:m:Satakunta:HIN:II/III/IV].

${ }^{495} 39$ Briefe an Kustaa Laine nach Chester, Mass., trotz verschiedener Verfasser tragen alle Briefe die gleiche Signatur: TYYH:S:m:Satakunta: LAP:XI/1-39.

${ }^{496}$ Myhrman 1974, 8 Bde; Ahlbäck 1976; Ketonen 1976; Mustonen 1977; Virtaranta 1996. 
auf das Spannungsfeld zwischen der Identität des Briefschreibers als Individuum und dem gesellschaftlichen Kontext, in den die Briefäußerungen eingebettet sind, zurückgeführt werden $^{497}$, womit bereits ein wesentlicher Faktor der Kommunikationssituation benannt wäre. Konkret auf den Briefwechsel zwischen Amerika und Finnland bezogen, bedeutet dies, daß die meisten Emigranten versuchten, der an sie gestellten Erwartungshaltung seitens der Daheimgebliebenen gerecht zu werden. Hatte ein Auswanderer beispielsweise mit dem Versprechen, möglichst schnell Geld zu verdienen, das elterliche Haus verlassen - wie dies bei den meisten der Fall war - , so schickte es sich nicht, über andere Themen als das Wetter, die eigene Gesundheit, den ersten Arbeitsplatz, die Höhe der Bezahlung und möglicherweise die Präsenz weiterer Finnen vor Ort zu berichten.

Es ist anzunehmen, daß aus diesem Grund bestimmte Aspekte des Alltagslebens auch nur sehr selten in den Briefen angesprochen wurden, obwohl sie unter Umständen einen großen Raum im Leben des Einwanderers einnehmen konnten. Am deutlichsten läßt sich dies am Bereich der Freizeitgestaltung belegen, da kaum Briefäußerungen die Teilnahme der Briefschreiber an politischen und kulturellen Vereinigungen ethnischen Charakters erwähnen, obwohl andere Quellen, wie Vereinsprotokolle und Jahresberichte diverser Organisationen, von einem regen sozialen Leben der Amerika-Finnen berichten.Auch zahlreiche Fotografien, die z.B. in der Migrationsliteratur zu finden sind, zeugen von Sport-, Musik-, und Theatergruppen, die häufig in Verbindung zu politischen oder kulturellen Aktivitäten unzähliger Vereine standen. Gemeinsam mit hunderten von Kirchengemeinden, wobei in nahezu jeder Kleinstadt mit nennenswerter finnischer Präsenz ein Gotteshaus zu finden war, brachten sie das Bedürfnis nach einem intakten und vielseitigen ethnischen Gemeinschaftsleben zum Ausdruck.

In den Briefen wiederum wird dieser Bereich des Alltagslebens fast gänzlich ausgespart. Lediglich in wenigen Briefen wird auf die Existenz einer finnischen Kirche vor Ort verwiesen bzw. das Fehlen eines finnischen Geistlichen beklagt, Vereinsfeste oder politische Aufmärsche hingegen werden zumeist verschwiegen. Beispielsweise bei dem bereits zitierten Fallbeispiel des Oskar Harju, der 1910 bei einem Kabelbrand in einer Sprengstoffabrik in Ohio ums Leben kam, fiel in drei Briefen vor 1910 kein Wort zur aktiven Mitgliedschaft in einem Abstinenzlerverein. Erst der Briefwechsel eines

${ }^{497}$ Dieser Gedanke wird für den literarischen Privatbrief allgemein von Bürgel (1976, S. 283f.) geäußert. 
Arbeitskollegen des Verstorbenen mit den Eltern förderte diesen Tatbestand zutage, da der Verein den Hinterbliebenen eine Geldsumme ausbezahlen wollte. In einem anderen Fallbeispiel wiederum benutzt ein Briefverfasser einen Briefbogen, der mit einem gedruckten Spruchband der 'Finnischen Sozialistischen Partei' dekoriert ist, schweigt sich in seinen Briefen jedoch über eine mögliche Teilnahme an politischen Aktivitäten aus $^{498}$. Auch bei anderen Briefschreibern, vor allem aus den Grubengebieten, kann die Sympathie zur sozialistischen Arbeiterbewegung nur erahnt werden, obwohl rund ein Viertel aller Finnen politisch aktiv gewesen war oder aber Zeitungen von sozialistischen Organisationen abonniert hatte ${ }^{499}$.

Es stellt sich die Frage, ob Auswanderer, die lebhaft am sozialen ethnischen Leben teilgenommen hatten, kein Bedürfnis zur schriftlichen Mitteilung empfanden oder aber sich lieber darüber ausschwiegen, um bei den Briefempfängern in Finnland nicht den Eindruck eines bohemischen Lebensstils entstehen zu lassen. Letztere Annahme würde auch die These unterstützen, daß die Erwartungshaltungen, die an die Auswanderer seitens der Daheimgebliebenen gestellt wurden, die allgemeine Themenwahl begrenzten, wobei nicht zuletzt auch die Qualität der persönlichen Beziehung zwischen den Briefpartnern einflußnehmend wirkte.Die Selektion der Themenwahl bei schwedischen Auswandererbriefen wird auch von Barton thematisiert, für die er eine simple Erklärung findet ${ }^{500}$ : "The question of what immigrants did or did not write about is closely connected with the identity of their correspondents."

In den Bereich der angesprochenen Themen wiederum fallen dann wiederholte Äußerungen - daher auch der Eindruck der Homogenität der Briefthemen - zu Reiseerfahrungen, Arbeitsverhältnissen sowie der Präsenz von Finnen insgesamt bzw. Bekannten am gleichen Ort. Ebenfalls von zentraler Bedeutung waren einschneidende Erlebnisse im Lebenslauf wie Hochzeit, Geburt oder Tod. Vor allem Todesfälle in Finnland, zumeist war ein Elternteil des Briefschreibers betroffen, erschütterten die Auswanderer derart, daß mehrere Briefe mit dem Themenmotiv der Trauer und Beileidsbekundungen ausgefüllt werden konnten. Großen Raum nehmen außerdem die, von einigen Migrati-

\footnotetext{
${ }^{498}$ Ludvik Hälli an Paavo Hälli, Brief vom 17.8.1910 aus Port Artur [Thunder Bay], Ontario nach Karvia: TYYH:S:m:Satakunta: KAR:LVI/1.

${ }^{499} \mathrm{Zu}$ politischen Aktivitäten der Finnen siehe Ollila 1975, S. 156-171, hier S. 157 sowie die Gesamtdarstellungen von Hummasti 1975 und Kivisto 1982.

${ }^{500}$ Barton 1993, S. 141f.
} 
onsforschern als banal gewerteten, Schilderungen ${ }^{501}$ des eigenen Gesundheitszustandes, des Wohlergehens weiterer Familienmitglieder, der Wetterverhältnisse und die Erkundigungen nach den sozialen Ereignissen in der Heimatgemeinde des Briefschreibers ein. Hinweise zu Geldsendungen oder beigefügten Fotografien sind sogar in rund einem Drittel der insgesamt 478 Briefe beider Stichprobeneinheiten zu finden, wonach ein beachtlicher Teil der Briefschreiber die Familienangehörigen in Finnland finanziell unterstützte.

Die näheren Beweggründe jedoch, welche zum individuellen Auswanderungsentschluß geführt hatten, lassen sich selten aus den Briefen herauslesen. Die Briefpartner wußten bereits um die Auswanderungsmotive der Emigranten, so daß dieser Themenbereich überflüssig war und in fast allen Briefen ausgeklammert wurde ${ }^{502}$.

Wurden die Briefe nicht nur an einen Adressaten gesandt, sondern an die gesamte Familie gerichtet, war die Weiterreichung der Briefe im Kreise von Verwandt- oder Nachbarschaft durchaus üblich, so daß der Briefwechsel in den seltensten Fällen als intime Zweierkommunikation verstanden werden $\mathrm{kann}^{503}$. Das Bewußtsein um den potentiellen Rezipientenkreis, gewissermaßen die Publikumsorientierung, schien die Selbstdarstellungen der Auswanderer zu einem erheblichen Teil beeinflußt zu haben.

In ihrem formalen Aufbau entsprechen die finnischen Auswandererbriefe dem bereits einleitend ${ }^{504}$ skizzierten Schema von Einleitung, Hauptteil und Schluß. Die obligatorischen Begrüßungsworte und Abschiedsbekundungen zeichnen sich durch formelhafte Redewendungen aus, die bei verschiedenen Briefschreibern bis in den Wortlaut identisch sein können. Die Grußformeln zur Brieferöffnung schließen meist gute Wünsche für die Gesundheit und Gottes Segen mit ein. Typisch waren ein Briefbeginn wie $^{505}$ :

\footnotetext{
${ }^{501}$ Handlin 1973 ( $\left.{ }^{1} 1951\right)$ S. 233f. Nach Schwarzmeier (1978, S. 311) sind Alltagsbriefe "langweilig".

${ }^{502}$ Auf diesen Aspekt weist auch Assion (1989, S. 262) hin.

${ }^{503}$ Der Usus der Briefweitergabe ist auch für andere skandinavische Länder und Deutschland überliefert, siehe hierzu Note 37 in Kap.1.2.2. sowie Blegen 1955, S. 10f., Einleitung; Mesenhöller 1985, S. 117; Barton 1993, S. 138f.; Stilling/Olsen 1994, S. 18.

${ }^{504}$ Siehe Einleitungskapitel 1.2.1.Der formale Briefaufbau der Briefe der Sammlung Satakunta ist auch von Penti (1978) untersucht worden.

${ }^{505}$ Z.B. Selim Kaukonen, Brief vom 11.8.1907: TYYH:S:m: Satakunta: KIIK:II/14 und Viktor Roos, Brief vom 12.3.1905: TYYH: S:m:Satakunta LAP:XI/13. Beide Briefe auch bei Kero abgedruckt (1985, S. 77 und S. 85).
} 
"Nun will ich meine herzlichsten Grüße aus dem fernen Amerika zu Papier bringen und darf mitteilen, daß es mir gut geht, wobei ich hoffe, daß Euch das gleiche Geschenk Gottes gegeben ist."

Ein Zustandsbericht über den eigenen Gesundheitszustand oder eine Beschreibung der Wetterlage vor Ort leiten zum Hauptteil des Brieftextes über. Hierbei lassen sich vor allem drei Informationsebenen unterscheiden, welche Sach-, Emotions- und Beziehungsinformationen enthalten. In den meisten Briefen überwiegen die Sachinformationen, d.h. nüchterne Darstellungen zu den genannten Themenbereichen, wie sie im Zusammenhang mit den vornehmlichen Beschäftigungsfeldern der Einwanderer bereits zahlreich zitiert wurden. Emotionsinformationen wiederum finden sich in Briefen, deren Briefpartner sich nahe standen, beispielsweise bei Geschwistern oder Ehepartnern, und bestehen in erster Linie aus Beurteilungen entweder der eigenen Lebensumstände oder der einflußnehmenden Umwelt. Als Beispiel sei folgendes Briefzitat eines Waldarbeiters aus Hoquiam bei Aberdeen in Washington genannt ${ }^{506}$ :

"Heute ist Ostern. Ich hätte es auch gar nicht bemerkt, falls Arvid mich nicht daran erinnert hätte, als ich von der Arbeit kam. Er sagte, ich habe eine große Sünde begangen, da ich an Ostern gearbeitet habe. Hier merkt man nicht viel von den Feiertagen und auch Gottes Wort hört man hier in Amerika nur selten. [...] In Finnland hätte ich weder heute noch morgen zu arbeiten brauchen."

Sach- und Emotionsinformationen finden sich sowohl in Briefen männlicher als auch weiblicher Verfasser, wobei diesbezüglich kein geschlechtsspezifisches Schreibverhalten festgestellt werden kann. Anders hingegen im Fall der Beziehungsinformationen, welche besonders zahlreich von Frauen vermittelt wurden. Das dieser Informationsform zugrundeliegende Eingehen auf den Briefpartner schien das "Metier" von Auswanderinnen gewesen zu sein, wonach Frauen - zumindest im Licht der AmerikaBriefe - in stärkerem Ausmaß an den Vorgängen bzw. am Ergehen gemeinsamer Bekannter im finnischen Heimatort teilhatten als Männer. Diese Verbindung zu dem sozialen Netzwerk der finnischen Herkunftsgemeinde, das von den Auswanderern zurückge-

\footnotetext{
${ }^{506}$ Kaarlo Pietilä an Schwester Anna Pietilä in Hinnerjoki, Brief vom 16.4.1911: TYYH:S:m: Satakunta:HIN:XVIII/7.
} 
lassen worden war $^{507}$, kann als der Versuch interpretiert werden, das "alte Leben", zumindest in Gedanken, weiterzuführen. Auf diese Weise sollte möglicherweise die Eingliederung in das vertraute Lebensumfeld nach der geplanten Rückwanderung erleichtert werden. Von daher verwundert es auch nicht, daß in Briefen mit zahlreichen Beziehungsinformationen häufig Bemerkungen zu Heimweh und Rückkehrwunsch anklingen, wie jedoch noch eingehend erörtert wird.

Nach Briefäußerungen, die den Haupt- oder Kernteil der Briefes ausfüllen und eine oder mehrere der genannten Informationsebenen charakterisieren, schließen die Briefe inhaltlich mit guten Wünschen und floskelhaften Grüßen für namentlich aufgeführte Personen ab, deren Nennung sich nach der Rangfolge der Familienhierarchie richtet.

Zusammenfassend läßt sich feststellen, daß weniger die Briefinhalte als die Wertungen und der Briefton sehr unterschiedlich gehalten sind. Die persönliche Beziehung zum Briefpartner, die individuellen charakterlichen Dispositionen sowie das Wissen um die mögliche Weitergabe der Briefe haben die Intensität und Intimität der Briefwechsel geprägt.

\subsubsection{Die Anwerbung potentieller Auswanderer}

Da nur wenige Handlungen im menschlichen Leben von derart grundsätzlichen Veränderungen und Risiken begleitet werden wie die Auswanderung, liegt es auf der Hand, daß auch das einzige Kommunikationsmittel, das Briefmedium, einen größeren Stellenwert im Alltag der Beteiligten erfährt, als dies unter anderen, weniger spektakulären Lebensumständen der Fall gewesen wäre, zumal die meisten Briefschreiber daheim nur selten zur Feder gegriffen hätten.

Die Bedeutung der Auswandererbriefe erstreckt sich jedoch nicht ausschließlich auf die Aufrechterhaltung einer sozialen Beziehung zweier oder mehrerer Personen zu beiden Seiten des Atlantik, sondern erhält darüber hinaus eine übergeordnete Funktion für den Migrationsprozeß an sich: Briefe übten zweifellos einen direkten Einfluß auf den Nachwanderungsentschluß von Daheimgebliebenen aus, nicht zuletzt dann, wenn den Briefen im voraus bezahlte Fahrkarten, sogenannte 'Prepaid Tickets' beilagen, wo-

\footnotetext{
${ }^{507}$ Auch für deutsche Briefschreiber in Amerika konnte Helbich (1989, S. 267) ein reges Interesse am sozialen Leben des heimatlichen Umfeldes konstatieren.
} 
nach eine konkrete Korrelation zwischen Briefanwerbung und Nachwanderung bestand. Gedruckte Informationen wiederum, wie beispielsweise Zeitungsberichte oder Broschüren von Auswanderungsagenten, erreichten die Auswanderungswilligen in den abgelegenen Dörfern West- und Südwestfinnlands nicht nur seltener, sie erschienen auch weniger glaubwürdig als die handschriftlich verfaßten Briefmitteilungen von Verwandten, Nachbarn oder Freunden des Heimatdorfes ${ }^{508}$.

Obwohl zahlreiche Briefäußerungen zur gewünschten Nachwanderung von Briefpartnern diesen Eindruck bestätigen, konnte der Zeitzeuge Eugene van Cleef bereits 1918 den Nachweis erbringen: In einer Fragebogenerhebung unter 60 Finnen in Minnesota erfragte er den Grund der Zielortentscheidung und erhielt von 50 Befragten zur Antwort, durch Amerika-Briefe angelockt worden zu sein ${ }^{509}$.

In den finnischen Herkunftsorten der Briefschreiber, in denen die Postsendungen aus Amerika häufig weitergereicht und vielfach gelesen wurden, basierte die emigrationsauslösende Breitenwirkung der Briefe jedoch auf einem Fundament der prinzipiellen Auswanderungsbereitschaft. Dieses Interesse für eine temporäre oder dauerhafte Emigration wurde durch sozio-ökonomische Mißstände und andere Ursachen wachgehalten, die den Nährboden für die wachsende Mobilitätsbewegung geschaffen hatten und sich aus der Perspektive der Betroffenen nicht zu ändern schienen.

Der Einfluß von Auswandererbriefen auf die Belebung des Emigrationsprozesses wird auch von zahlreichen, historisch orientierten Migrationsforschern bestätigt, die sich mit den transatlantischen Wanderungsbewegungen vor allem aus den skandinavischen und westeuropäischen Ländern beschäftigt haben ${ }^{510}$, kann jedoch ebenso für die süd- und südosteuropäische Auswanderung belegt werden. Letztere Feststellung gründet auf einem Bericht der Einwanderungskommission, der sogenannten DillinghamKommission, aus dem Jahr 1911, für den alle zwischen 1899-1910 über die New Yorker

\footnotetext{
${ }^{508}$ Dies galt auch für deutsche Amerika-Briefe, siehe Schwarzmeier 1978, S. 312; Mesenhöller 1985, S. 144; Helbich 1989, S. 271; Nickisch 1991, S. 211; Rößler 1992, S. 150f.; für die norwegische Auswandererbriefsituation belegt bei Blegen 1929, S. 5.

${ }^{509}$ Die Untersuchung von Eugene van Cleef (The Finn in America. Duluth, Minn. 1918) wird hier aus zweiter Hand zitiert, vgl. Wasastjerna 1957, S. 78.

${ }^{510}$ Bereits Blegen (1931, Bd.1, S. 212f.) hatte auf die Relevanz von Amerika-Briefen für den Auswanderungsentschluß hingewiesen, doch erst durch Thistlethwaites klassischen Aufsatz von 1960 (Nachdruck 1991, S. 43) wurden Briefe als Instrument zur Emigrantenanwerbung ernst genommen, siehe Semmingsen 1961, S. 27-31; Erickson 1972, S. 2; Greverus 1972, S. 159; Marschalck 1973, S. 23; Mesenhöller 1985, S. 118; Seller Schwartz 1988, S. 104; Helbich/Haubold 1988, S. 27; Hoerder 1991, S. 97; Kero 1991, S. 128f.; Lintelman 1991, S. 90; Armgort 1991, S. 53; Harzig 1992, S. 137.
} 
Grenzstation 'Ellis Island' eingereisten Europäer nach ihrer Einwanderungsmotivation befragt wurden ${ }^{511}$. Und das eindeutige Ergebnis, wonach Briefe vor anderen schriftlichen Quellen rangierten, sprach für sich, wenngleich nicht alle Befragten lesen und schreiben konnten, da die Analphabetenrate bei einigen süd- und südosteuropäischen Einwanderernationalitäten mehr als $50 \%$ betrug $^{512}$. Als weiteres Resultat der Befragungsauswertung legte der Bericht zutage, daß 77\% der Einwanderer von Verwandten, $17 \%$ von Bekannten und lediglich $6 \%$ von niemanden erwartet wurden, was außerdem die Bedeutung der Briefanwerbung unterstreicht. Lediglich den Berichten und der Mund-zu-Mund-Propaganda durch zurückgekehrte Auswanderer kann ebenfalls eine große Bedeutung für den Emigrationsprozeß zugesprochen werden. Demnach handelt es sich bei der Briefanwerbung nicht nur um eine globale Erscheinung, sondern zugleich um ein wesentliches Charakteristikum der europäischen Überseeauswanderung an sich.

Um nun im folgenden zu erörtern, wie sich die durch Amerika-Briefe motivierte Umsetzung der Emigrationsentscheidung im Einzelfall vollzogen hat, sollen Briefzitate aus drei Fallbeispielen, die für zahlreiche ähnliche Äußerungen in insgesamt 14 Werbebriefen von 12 Verfassern stehen ${ }^{513}$, den Prozeß der Briefanwerbung verdeutlichen und zugleich auf die Bedeutung der 'Prepaid Tickets' aufmerksam machen.

Das erste Fallbeispiel liefert der Auswanderer Anton Hemiä, der 1901 als 31Jähriger die Gemeinde Kankaanpää in Satakunta verließ und in Lanesville, einer küstennahen Ortschaft unweit von Gloucester in Massachusetts, Arbeit gefunden hatte. Zwei Briefe an den Bruder Johan Riihimäki mit dem zeitlichen Abstand von acht Jahren sind erhalten geblieben. Im ersten Brief vom 12.12.1908 schrieb er ${ }^{514}$ :

"Wie alt ist denn jetzt eigentlich dein ältester Sohn Eino? Hat er schon den Konfirmationsunterricht besucht. Ich könnte ihm eine Fahrkarte schicken, damit er hierher kommt. Hier waren gerade Präsidentschaftswahlen, und die bessere Seite hat gewonnen [Republikaner]. Von daher wird es im kommenden Frühjahr wohl viel Arbeit geben. [...] Hat dein Ältester übrigens gesunde Augen? Hier sind neuerdings strenge Augen-

\footnotetext{
${ }^{511}$ Reports of the Immigration Commission, 41 Bde, Washington, D.C. 1911, Bd. 4, S. 56-60.

${ }^{512}$ Easterlin 1981, S. 478, Tab. 2.

${ }^{513}$ Darüberhinaus finden sich noch zahlreiche Fälle, in denen ein Geschwisterpaar zu unterschiedlichen Zeiten ausgewandert ist, eine direkte Briefanwerbung jedoch nicht festgestellt werden konnte.

${ }^{514}$ Anton Hemiä an Johan Riihimäki in Kankaanpää, zwei Briefe aus Lanesville, Mass.:

TYYH:S:m:Satakunta: KAN:XII/3,5.
} 
kontrollen an den Anlegehäfen. Aber ich würde ihm natürlich helfen, wenn es denn nötig sein sollte, falls sie ihn nicht passieren lassen wollen. Aber ich weiß ja noch gar nicht, ob er überhaupt kommen will. Schreibt mir, sobald er eine Fahrkarte haben möchte."

Bei der Durchsicht der Passagierlisten der 'Finnischen Dampfschiffahrtsgesellschafts AG' für das Jahr 1910 konnte festgestellt werden, daß der erst 16Jährige Eino Riihimäki, der Neffe des Briefschreibers, ohne weitere Familienangehörige am 20.7.1910 die Auswanderung in Hanko antrat. Er trug eine nach Boston ausgestellte Fahrkarte der 'White Star Line' in der Tasche, deren Preis mit 46 Dollar angegeben war. Vermutlich wird es sich um das im Brief versprochene, zugeschickte Schiffsbillett gehandelt haben, da es in Dollar anstelle von Finnmark bezahlt worden war und der Anlegehafen, Boston, der Einwanderungsstation des neun Jahre zuvor eingereisten Anton Hemiä entsprach. Von Eino Riihimäki selbst sind keine Briefe vorhanden, doch sein Onkel nimmt im zweiten Brief vom 21.11.1916 noch einmal Stellung zu dem jungen Mann, der sich vermutlich nicht in der gleichen Stadt aufhielt:

"Von Eino weiß ich nicht mehr zu berichten, wie zuvor auch. Soviel habe ich allerdings gehört, daß er noch am Leben und er sehr gewachsen ist, ein stattlicher Mann ist aus ihm geworden. ',

In einem anderen Fallbeispiel wiederum wendet sich der soeben erst ausgewanderte Ludvik Hälli aus Port Arthur, heute Thunder Bay genannt, in Ontario an seinen Bruder Paavo Hälli in Karvia in Satakunta und bereitet dessen Ausreise in einem Brief von 1910 vor $^{515}$ :

"Mir geht es gut, ich habe gearbeitet und bin gesund geblieben. [...] Ich hoffe, daß wenn ich diesen Monat noch auf der gleichen Baustelle arbeiten darf, wo ich zur Zeit bin, dann bekomme ich soviel Geld zusammen, daß es für die Fahrkarte an Dich reicht. Und auch der Juho Peltola hat versprochen, daß er nicht tatenlos zusieht, wenn er seinen Lohn mit mir zusammen ausbezahlt bekommt. Also wenn Du diesen Brief erhältst, dann bekommen wir hier schon auch Geld [...] und so kannst Du denn auch bald

${ }^{515}$ Ludvik Hälli [später Halley] an Paavo Hälli in Karvia:TYYH:S:m:Satakunta:KAR:LVI/1. 
ausreisen. [...] Schreib mir sofort, aber vielleicht hast Du ja auch schon geschrieben, bevor Du diesen Brief bekommst. Und wenn Du tatsächlich bald kommst, dann sehen wir uns wieder. Ich habe Dich nämlich schon sehr vermißt."

Über den Briefempfänger war nur soviel in Erfahrung zu bringen, daß er 1911 einen Ausreisepaß beantragt hatte, wonach er vermutlich im gleichen Jahr ausgewandert ist. In den besagten Passagierlisten findet sich kein Eintrag zu Paavo Hälli aus Karvia.

Im dritten Fallbeispiel ${ }^{516}$ dreier, nacheinander ausgewanderter Brüder aus Hinnerjoki in Satakunta haben 'Prepaid Tickets ' vermutlich keine Rolle gespielt, doch zumindest der jüngste Bruder erhielt im Brief Geldscheine, die zum Fahrkartenkauf bestimmt waren.

Als erster reiste der älteste Bruder Juho Kuusisto am 2.5.1902 zusammen mit einem Bekannten über Kopenhagen und Hull nach Cloquet, einem Zentrum der Holzindustrie, in Minnesota aus, wo sich der Auswanderer dann als Sägewerks- und Gleisarbeiter im Eisenbahngleisbau ein Jahr lang aufhielt und zugleich eifrig in die Heimat schrieb. In seinem 7. Brief vom 8.9.1902 versprach er dem Bruder Isak eine Fahrkarte zu schicken und wiederholte das Versprechen im 13. Brief vom 15.4.1903 noch einmal.

Isak Kuusisto wanderte tatsächlich aus, allerdings erst zwei Jahre später, im Jahr 1905. Da jedoch in den Briefen des zuerst emigrierten Bruders Juho ein Lücke zwischen dem 17. Brief vom 24.5.1904 und dem 18. Brief vom 5.12.1906 klafft, kann die durch Briefanwerbung erfolgte Emigration des zweitältesten Bruders Isak hier nur vermutet werden kann. Dennoch konnte die Ausreise von Isak am 3.5.1905 anhand der Passagierlisten der 'Finnischen Dampfschiffahrtsgesellschafts AG' nachgewiesen werden: Seine in Finnmark anstelle von Dollar bezahlte Fahrkarte wird wahrscheinlich nicht von Bruder Juho zugeschickt worden sein, da zudem der in dem Fahrschein angegebene Zielort in Ohio lag, obwohl sich Juho zu diesem Zeitpunkt in Newberry in Michigan aufhielt.

Wie Isak jedoch in seinem ersten Brief aus Amerika an die Eltern zu berichten wußte, war er nicht allein unterwegs und suchte gleich nach der Ankunft in Warren, Ohio einen anderen Finnen auf, der möglicherweise die nicht näher definierte Reisegruppe angeworben hatte, zu der auch Isak gehörte. Seinen zweiten Brief schickte Isak am

\footnotetext{
${ }^{516} 63$ Briefe der Brüder Kuusisto: 1902-08 (Juho) 1905-07 (Isak) und 1906-14 (Nestor) an die Eltern in Hinnerjoki: TYYH:S:m:Satakunta: HIN: II/III/IV.
} 
25.6.1905 an den noch in Finnland verbliebenen, jüngsten Bruder Nestor, den er zugleich zur Auswanderung ermunterte, wobei diese Anwerbung auf vorheriger Absprache beruhen könnte:

" Was hast Du dir gedacht, hättest Du nicht Lust bald hierher zu kommen. Doch in diesem Staat stehen keine guten Arbeitsplätze zur Auswahl. Wir bekommen auch nicht mehr als 1,45 Dollar pro Tag und die Unterkunft ist teuer, sie kostet in zwei Wochen 7,5 Dollar. Einige verdienen hier auch mehr, doch sie können die Sprache des Landes und arbeiten im Akkord. Wir haben vor bald nach 'Misikan' zu gehen, dort werden 30 und 35 Dollar im Monat gezahlt und die Verpflegung ist frei in den Waldkamps. Hier kommt man schon besser zurecht als dort bei uns im Dorf, du kannst getrost hierher kommen."

Es findet sich noch ein dritter Brief vom 8.8.1905 aus Ohio, in dem Isak 50 Dollar an die Eltern schickt mit der Bitte, die Hälfte von dem Geld einem Finnen namens Isak Arvela zu geben, wobei es sich vermutlich um eine Schuldenrückzahlung der Reisekosten handelt, und die andere Hälfte an Nestor auszubezahlen. Obwohl die Vermutung naheliegt, daß Isak hiermit einen Reisekostenzuschuß zur Atlantiküberquerung seines Bruders Nestor leisten möchte, wandert dieser erst ein Jahr später aus. Zuvor erreichen noch acht weitere Briefe die Familie in Hinnerjoki, wovon drei, vom 8.10.1905, 24.2.1905 und 27.3. 1906, die Auswanderungsvorbereitungen von Nestor zum Thema haben:

"Kommt denn jetzt niemand aus unserem Dorf hierher, in dieses Land, - natürlich würden einige Jungs' schon kommen, aber wenn kein Geld da ist, dann wird da auch nichts daraus. Was hast Du Dir denn jetzt gedacht - obwohl ich immer noch nicht genügend Geld beisammen habe, das ich dir schicken könnte. Bis zum Frühjahr habe ich das Geld dann aber zusammen, wenn Du nur kommen magst."

" Und ihr habt im letzten Brief angefragt, welche Kleider Nestor mitnehmen soll. Er braucht nicht mehr als für die Reise notwendig ist. An Hemden genügen zwei Stück, aus Flanell, Unterhosen braucht er auch nicht mehr als zwei, ein Paar langschaftige Stiefel sind genug, zwei Paar Hosen, das reicht, Strümpfe und Handschuhe, die braucht 
man immer, die sollte er bei sich haben. Für mich soll er nichts mitbringen, ich habe noch genügend Socken und Handschuhe, und die Hemden und Hosen aus Finnland habe ich noch gar nicht getragen. Bis Anfang Mai schicke ich dann auch das Geld, damit er kommen kann."

"Ich schicke Dir heute 80 Dollar, das sind 400 Finnmark. Kauf ein Billett der Allan Line, damit reisen die meisten, und die [Reederei] ist billig und die Fahrkarte kostet nicht mehr als 269 Finnmark. Nimm als Proviant viel trockenes Brot, gesalzenes Fleisch und Käse mit, denn falls du seekrank wirst, magst du die Speisen auf dem Schiff nicht essen. Schreib mir noch, wann du genau kommst, damit ich dich empfangen kann. Und kaufe die Fahrkarte direkt nach Michigan, nach 'Nyperi', ich schreibe Dir hier noch meine Adresse auf, damit du sie bei dir tragen kannst, wenn du unterwegs bist: Mr Isak Kuusisto, Nevberry Vood Camp, Mich US of Amerika”

Die Ausreise des Nestor Kuusisto wiederum läßt sich, im Gegensatz zu den beiden älteren Brüdern, nicht anhand der Passagierlisten des Jahres 1906 rekonstruieren, doch da sich der Auswanderer am 23.5.1906 erstmals aus England meldet, wird er die finnische Küste vermutlich eine Woche zuvor verlassen haben. Auch der im Brief angegebene Fahrpreis von 269 Finnmark hält dem Vergleich mit der Passagierlistenangabe eines anderen Briefschreibers stand, welcher nur ein halbes Jahr zuvor, im September 1905, mit der Allan Line auswanderte und für die nach Sault Ste Marie, unweit von Newberry, ausgestellte Fahrkarte 259 Finnmark zahlte.

In Amerika wandte sich Nestor dann sofort zu seinen Brüdern nach Newberry, doch da der erste erhaltene Brief das Datum vom 9.4.1907 trägt, kann von einem teilweisen Verlust der Korrespondenz ausgegangen werden. In den Briefen des Isak jedoch finden sich Hinweise auf eine gemeinsame Zeit der Brüder als Waldarbeiter in Newberry. Im Sommer 1907 trennten sich dann ihre Wege, wobei Juho und Nestor, der älteste und der jüngste Bruder nach Floodwood in Minneosta gingen, unweit von Clouqet gelegen, und Isak zuerst nach Nashwauck in Minnesota wanderte und sich später an der Westküste in Aberdeen niederließ. Keiner der drei Brüder ist später nach Finnland zurückgekehrt, obwohl Nestor noch bis 1928 den Eltern aus Minnesota geschrieben hat.

Die im letzten Fallbeispiel demonstrierte Nachwanderung durch Briefeinfluß konnte, mit Ausnahme von Nestor Kuusisto, anhand der Passagierlistenangaben der 
einzigen finnischen Reederei, die sich ab 1891 auf den Auswanderertransport nach England spezialisiert hatte, nachgewiesen werden.

Bei dem Versuch, die Namen aller Briefschreiber in den Passagierlisten wiederzufinden, die nach 1891 - dem Beginn der Schiffsverbindung von Hanko nach Hull ausgewandert sind, mußte jedoch festgestellt werden, daß vielfach mehrere Personen gleichen Namens im gleichen Jahr ein Billett gekauft hatten, wonach die exakte Bestimmung einer Person als gesuchtem Briefschreiber schwierig oder gar unmöglich erschien. In anderen Fällen hingegen waren die Namen aus ungeklärten Gründen nicht in den Listen zu finden, wie beispielsweise im Fall des Nestor Kuusisto. Dennoch konnten in 51 von insgesamt 100 Fällen $^{517}$, deren Auswanderungsjahre bekannt waren und zudem in die Zeit von 1891-1914 fielen, mit großer Wahrscheinlichkeit die behandelten Briefverfasser identifiziert werden. Dieser Auswertung zufolge wanderten die 51 Briefschreiber, von England als Zwischenstation, mit sieben verschiedenen transatlantischen Schiffahrtsgesellschaften aus ${ }^{518}$. Lediglich in acht Fällen wurde der Fahrkartenpreis in Dollar angegeben, was auf die Verwendung von 'Prepaid Tickets' schließen läßt.

Die Ausreise mit im voraus bezahlten Fahrkarten hat ohnehin die Migrationsforscher in verschiedenen Ländern beschäftigt und wird in der Fachliteratur wiederholt als emigrationsverstärkender Faktor hervorgehoben ${ }^{519}$. Im Hinblick auf die finnischen Auswanderer wurde das Aufkommen der 'Prepaid Ticket'-Benutzer von Kero ermittelt, wobei ihm die genannten Passagierlisten der 'Finnischen Dampfschiffahrtsgesellschafts AG' für den Zeitraum 1891-1914 als Quellengrundlage dienten ${ }^{520}$. Das Verhältnis der Reisenden mit 'Prepaid Tickets' zu solchen ohne dieses Freibillett lag bei durchschnittlich 30,1\% zu 69,9\%, d.h. daß etwa jeder dritte finnische Amerikafahrer ohne eigene Finanzierung der Schiffspassage ausreisen konnte oder aber erst nach der Ankunft in Amerika das Reisekostengeld verdienen mußte. Auch bei der dänischen Auswanderungsbewegung, welche allerdings vor der Jahrhundertwende ihren Höhepunkt erreich-

\footnotetext{
${ }^{517}$ Insgesamt sind 143 Briefschreiber in dieser Untersuchung berücksichtigt worden, doch bei 43 Fällen konnte das Auswanderungsjahr trotz Fragebogenangaben zur Person der Briefschreiber, nicht ermittelt werden.

${ }^{518}$ Dies waren die Reedereien Cunard, White Star, American, Dominion, Anchor, Allan und Beaver Line, wobei die meisten Briefschreiber die Cunard und White Star Line benutzten. ${ }^{519}$ Siehe Schmidt 1965, S. 355; Hoerder 1991, S. 97; Armgort 1991, S. 53; Rößler 1992, S. 150157.

${ }^{520}$ Kero 1974, S. 174-195, bes. S. 176, Tab. 25. Zum Aufkommen der finnischen 'Prepaid Tickets'-Benutzer, die direkt von Finnland in die Mesabi-Region in Minnesota auswanderten, vgl. Saarelainen (unveröffentlichte Magisterarbeit)1974, S. 46-49.
} 
te, lag der prozentuelle Anteil der 'Prepaid Ticket' - Benutzer in der gleichen Größenordnung $^{521}$.

Innerhalb der finnischen Emigranten reisten 1903 mehr Personen mit 'Prepaid Tickets' aus als in anderen Jahren, was vor dem Hintergrund der 1902 erreichten Rekordspitze bei den jährlichen Auswandererzahlen bemerkenswert erscheint. Dabei fanden, als wenig überraschende Tatsache, verheiratete Frauen mit Kindern sowie alleinreisende Frauen besonders häufig in Amerika gekaufte Fahrkarten im Briefkuvert vor, was auf Familienzusammenführungen schließen läßt $\mathrm{t}^{522}$.

Wie jedoch das Fallbeispiel der Brüder Isak und Nestor Kuusisto verdeutlicht, kam nicht nur den Freifahrscheinen, sondern auch den in Briefen geschickten Banknoten eine wichtige Funktion zu, vor allem wenn das Geld ausschließlich für die Nachwanderung des Briefadressaten bestimmt war. Der überwiegende Teil der finnischen Überseeauswanderer wird demnach die Atlantiküberquerung entweder mit zugeschicktem, geliehenem oder eigenem Geld, beispielsweise aus einer Erbschaft, finanziert haben.War es den Auswanderungswilligen nicht möglich, die erforderliche Summe von rund 400 Finnmark von Familienmitgliedern zu borgen, so wandten sie sich an geschäftstüchtige Privatleute, die für einen Zinsaufschlag von 100-200 Finnmark behilflich waren ${ }^{523}$. Vor dem Hintergrund der späteren Schuldenrückzahlung von Amerika aus verwundert es denn auch nicht, daß das Thema Geld in zahlreichen Briefen eine zentrale Rolle spielte ${ }^{524}$, galt es doch zuerst eine finanzielle Unabhängigkeit zu erlangen, bevor in die eigene Tasche gespart oder die Familie daheim unterstützt werden konnte.

Zusammenfassend laßt sich feststellen, daß bereits ausgewanderte Verwandte deutlich mehr als jedem dritten Auswanderer die Reisekostenfinanzierung ermöglichten. Dennoch stellten diese den Briefen beigefügten 'Prepaid Tickets' und Banknoten lediglich ein Mittel zum Zweck dar: Zwar galt es in die Fremde, doch zu einem vertrauten Menschen zu reisen. Denn erst das Erwartetwerden und die Hilfestellung durch bereits etablierte Kontaktpersonen erleichterten den Ankommenden die Neustrukturierung

\footnotetext{
${ }^{521}$ Nach Hvidt (1971, S. 347-352) sind während der Jahre 1877-95 durchschnittlich 21,3\% aller dänischen Emigranten mit 'Prepaid Tickets' ausgewandert und unter Berücksichtigng des kurzen Zeitraumes von 1883-86 sind sogar rund 50\% der über Göteborg ausgereisten Schweden 'Prepaid Ticket'-Benutzer gewesen.

${ }^{522}$ Für das Stichprobenjahr 1905 bei Kero (1974, S. 185, Tab. 31) belegt.

${ }^{523}$ Toivonen 1950, S. 1-23, hier S. 10.
} 
des Alltagslebens und milderten zugleich den Kulturschock ${ }^{525}$, den viele Finnen, denen bisher lediglich das Leben in einer kleinen Dorfgemeinschaft oder Kleinstadt vertraut war, befürchten mußten. Unter Berücksichtigung des Zweifels und der Ängste, welche die ambivalente Gefühlslage bei der Auswanderungsentscheidung begleiten können, versuchte denn auch die finnische Dienstbotin Aini Fredman ihre Schwester aus Vaasa nach New York zu locken ${ }^{526}$ :

"Jetzt hör mal zu, Sussu - ich habe schon das eine oder andere Mal darüber nachgedacht, weshalb nicht auch Du Deine Sachen zusammenpacken und hierher kommen könntest. Ich bin davon überzeugt, daß Du es nicht bereuen wirst. Ein oder zwei Jahre hier öffnen Dir eher die Augen als 20 Jahre dort. Ich verstehe natürlich, daß Du Dich hier nicht ganz so wohl fühlen würdest wie beispielsweise ich, denn Du hast ja noch alle Deine Freunde dort und bist auch sonst so ganz zu Hause in Vaasa, aber trotzdem glaube ich, daß eine Ausreise besser wirkt als jede Medizin.[...] Ich will ja keine guten Ratschläge geben, aber denk doch mal darüber mit allem Ernst nach und komm dann direkt nach 18 West, 60 Street. In ein bis zwei Wochen lerne ich Dich an, so daß Du sofort eine 25 Dollar-Stelle erhältst."

\subsubsection{Die Warnung vor dem Auswanderungsentschluß}

Neben der Anwerbung von Familienangehörigen bereits ausgewanderter Briefschreiber spielte auch das gezielte Abraten vom Auswanderungsentschluß, insbesondere in ökonomischen Krisenzeiten, eine entscheidende Rolle in finnischen AmerikaBriefen. Obwohl diese Fälle bei der Gesamtdurchsicht der knapp 500 hier behandelten Briefe seltener zum Vorschein kamen als die positiv formulierten Werbebriefe, haben auch sie den Emigrationsprozeß in Form von verzögerter oder unterlassener Auswanderung beeinflu $\AA^{527}$.

\footnotetext{
${ }^{524}$ Auch für deutsche Amerika-Briefe betont Helbich (1989, S. 267) die Dominanz des Themas Geld.

${ }^{525}$ Diese Gedanke wird auch hinsichtlich deutscher Amerikaauswanderer betont, vgl. Kamphoefner 1984, S. 348f.; Helbich/Haubold 1988, S. $26 f$.

${ }^{526}$ Aini Fredman an Schwester 'Sussu' Myntti in Vaasa, Brief vom 24.12.1909; Samml. SüdOstbottnien, Sig.Nr. 1379/1.

${ }^{527}$ Darüber hinaus wurden mindestens 20 vor der Auswanderung warnende Artikel im schwedischsprachigen 'Vaasa-Blatt' (1870-85) veröffentlicht sowie zahlreiche weitere in finnischsprachigen Zeitungen. Es ist jedoch anzunehmen, daß die wenigsten Auswanderungsinteressen-
} 
In beiden Fällen, den Anwerbe- und Abratebriefen, kann vielfach eine im Vorfeld, d.h. noch in Finnland, geführte Absprache der Beteiligten vermutet werden, wonach die potentielle Nachwanderung der zweiten Person bereits vor der Auswanderung der ersten geplant wurde. Demnach ging es in den meisten Briefen weniger um die Anwerbung an sich, als vielmehr um den Zeitpunkt der bereits abgesprochenen Nachwanderung, wie am Briefzitat von Ludvik Hälli verdeutlicht wird.

Da dieser Zeitpunkt an einem äußeren Merkmal festgemacht werden mußte, welches die allgemeinen Krisenzeiten mit Grubenschließungen und Arbeitslosigkeit näher eingrenzte, wurde in zwölf Briefen von neun Verfassern auf die Bedeutung der Präsidentschaftswahlen im Hinblick auf "gute und schlechte Zeiten" hingewiesen ${ }^{528}$. Die Präsidentschaftswahlen galten demnach unter den finnischen Auswanderern als eine Art Beschäftigungsbarometer, wobei in den meisten Briefen die Republikaner mit einer Verbesserung der Arbeitsmarktlage in Verbindung gebracht wurden. Bereits im zitierten Werbebrief des Anton Hemiä aus Massachusetts führte dieser die Wiederwahl der republikanischen Partei als Garantie für zukünftige Erwerbsarbeit an und begründete somit den vorgeschlagenen Zeitpunkt im Frühjahr 1909 als geeignet für die Auswanderung seines Neffen. Auch Vihtori Myllymäki kommentierte die Bestätigung der Republikaner als regierungsführender Partei in gleicher Weise ${ }^{529}$ :

” Hier in den Staaten von Amerika waren wieder Präsidentschaftswahlen. [...] Und wieder kam diese goldene Zeit der Republikaner für die nächsten vier Jahre. [...] Du hast geschrieben, daß Kalle hierher kommen möchte. Falls er das so geplant hat, dann wäre meiner Meinung nach das Frühjahr die beste Zeit zu kommen, denn im Frühjahr gibt es mehr Arbeit, und auch sonst bessern sich die Zeiten für einige Jahre.”

ten Zugang zu Zeitungen hatten, wonach die Breitenwirkung dieser moralisch erhobenen "Zeigefinger" angezweifelt werden kann, vgl. hierzu auch die unveröffentlichte Lizentiatsarbeit von Kero 1970, S. 83f.

${ }^{528}$ Siehe hierzu auch Kero 1996, S. 96-99.

${ }^{529}$ Vihtori Myllymäki an Bruder Heikki Myllymäki in Siikainen, Brief vom 25.11.1908:TYYH:S:m:Satakunta: SIIK:LXVIII/8; Briefzitat auch bei Kero (1996, S. 97f.) abgedruckt. 
Wurden die Hoffnungen auf Arbeit und bessere Entlohnung der Finnen jedoch enttäuscht, so waren die Republikaner eben für die "schlechten Zeiten" verantwortlich gewesen, und die Demokraten sollten die Situation fortan retten: ${ }^{530}$

"Von schlechten Zeiten wird hier jetzt viel gesprochen, da im Frühjahr Präsidentschaftswahlen anstehen. Aber es wird bestimmt eine bessere Zeit kommen [...] vermutlich wird der gleiche Präsident [ein Demokrat] gewählt, der auch zuvor da war, das wird dann eine gute Zeit werden."

Auch in den beiden ältesten Originalbriefen, die in das Sample 'SüdOstbottnien' eingegangen sind, wird bereits 1882 mit dem Hinweis auf "schlechte Zeiten" von der Auswanderung abgeraten, wobei der Hafenarbeiter Antti Kangas aus Astahbula Harbour in Ohio in kaum lesbarer Handschrift seinem Bruder Jacob Kangas in Ylihärmä folgendes mitteilte ${ }^{531}$ :

"Hier war schlechtes Wetter, so daß ich nicht immer arbeiten konnte. Und ein Tag ohne Arbeit bedeutet 9 Mark weniger, denn hier ist Zeit Geld. [...] Soeben habe ich gehört, daß es im Minnesota besser sein soll als hier. Bald werde ich dorthin gehen. Und wollte nicht auch der Kaino Ruspakka hierher kommen, doch ich sage nichts, er muß selber wissen, was er tut.

Abschließend möchte ich noch auf die Reise[pläne]von Kustaa eingehen. Es wird wohl das Beste sein, wenn er zu Hause bleibt. Hier ist jetzt so eine Zeit, von der man zu Hause keine Vorstellung hat."

In einem weiteren Brief ohne Jahresangabe, jedoch vermutlich aus der Zeit um 1883-84, warb Antti Kangas, als er bereits in Minnesota - zuerst in Minneapolis und später im Dorf Franklin lebte - dann seinen Bruder Jacob Kangas sowie zwei weitere Freunde aus Ylihärmä gezielt an:

\footnotetext{
${ }^{530}$ Oskar Heinonen an Ehefrau Josefiina Heinonen in Merikarvia, Brief vom 27.8. 1888 aus Cockburn Island, Ont.:TYYH:S:m:Satakunta:MER:I/11; Briefzitat auch bei Kero (1996, S. 97) abgedruckt. In ähnlicher Weise äußerte sich auch John Mattila im Jahr 1903 aus Minnesota, der die mögliche Wiederwahl der Republikaner negativ beurteilte [Samml. Süd-Ostbottnien, Brief nach Isokyrö, Sig.Nr. 287].
} 
”An Kleidern genügen einige Hemden [...] gleich welcher Farbe, doch keine weißen. Wollkleidung brauchst Du nicht sehr viel, ansonsten nur einige Hosen, aber hier sind Kleider nicht teuer. An Proviant habe ich selbst nicht viel benötigt, doch ich rate Dir zu etwas Käse, getrocknetem Fleisch und Brot. [...] Auf Wiedersehen Jussi Matintupa und Antti Ruspakka. Und im Frühjahr müßt ihr aufbrechen und mir natürlich vorher schreiben, damit ich Bescheid weiß und die National Line - unbedingt. Viele Grüße und Alles Gute Antti Kangas.”

Für diesen frühen Anwerbungsversuch sind Passagierlisten als Quellen zur Überprüfung der möglicherweise erfolgten Auswanderung unbrauchbar. Ein Hinweis findet sich allerdings in der Monographie des Zeitzeugen und Pfarrers Ilmonen, der vom Verbleib des Briefempfängers Jacob Kangas in Holmes City, Minnesota, einer der ersten finnischen Landwirtschaftssiedlungen in den Vereinigten Staaten, zu berichten wußte $^{532}$.

Doch nicht in allen Briefe mit an- oder abratender Intention wurde auf die amerikanischen Präsidentschaftswahlen und die dadurch erhofften gesellschaftlichen Veränderungen eingegangen. Die finnischen Auswanderer führten auch andere Gründe ins Feld, um ihre Geschwister und Bekannten von einer Atlantiküberquerung abzuhalten. Als erstes Beispiel sei hier ein 25jähriger Grubenarbeiter aus Lead City in South Dakota zitiert, der sich 1910 bereits drei Jahre in Amerika aufhielt und entschieden versuchte, seinem Bruder im südostbottnischen Lapua die Auswanderungsabsichten auszureden ${ }^{533}$ :

"Ich habe heute Deinen Brief erhalten, aus dem ich herauslese, daß Du jetzt gerne in dieses Land kommen würdest. Zu gerne würde ich Dir auch helfen, aber hier ist ein Streik ausgebrochen, der schon den dritten Monat anhält, und keiner weiß wie lange er noch dauern wird. Es ist nicht klug jetzt hierher zu kommen. Ich habe zwar das Geld für eine Fahrkarte zusammen, die ich Dir schicken könnte, aber es wäre wohl

\footnotetext{
${ }^{531}$ Antti Kangas an Wilhelm und Jacob Kangas in Ylihärma, zwei Briefe vom 11.2.1882 und 26.3.1882, Samml. Süd-Ostbottnien, unsigniert. Dritter Brief aus Amerika ohne genaue Ortsangabe, als Datum findet sich lediglich die Monatsangabe Februar.

${ }_{532}$ Bei Ilmonen (1923, Bd. 2, S. 191) findet sich nur die Namensangabe und der Herkunftsort Ylihärmä, das Auswanderungsjahr jedoch läßt sich nicht ermitteln.

${ }^{533}$ Matti Mäkynen an Jaakko Mäkynen in Lapua, Brief vom 31.1.1910, Samml. SüdOstbottnien, Sig.Nr. 1094/1.
} 
nicht klug, jetzt alle Ersparnisse dafür aufzubrauchen. Ich weiß ja auch nicht, wann ich wieder Arbeit bekomme, da ich bald von hier fortgehen werde. [...] Es ist auch noch Geld dort in Lapua auf der Bank, das könntest Du nehmen, und wenn sich die Dinge hier zum Besseren wenden, dann könntest Du kommen."

Trotz dieser in Aussicht gestellten Auswanderung zu einem späteren Zeitpunkt ändert der Briefschreiber im Verlauf des Briefes wieder seine Meinung:

"'Eigentlich ist es nicht so gut hierher zu kommen, wenn man denn gar nicht sprechen [kein Englisch] kann, aber falls Du denn unbedingt kommen willst, so finde ich, daß eine Eisenerzgrube irgendwo in Minnesota besser paßt.

Aber ich habe den Eindruck, daß Du Dir die Sache nicht gründlich genug überlegt hast. Es geht mir richtig nahe, wenn ich mir vorstelle, daß mein Bruder in diesem Elend hier leben muß. Ich habe immer geglaubt, daß ich meinen Bruder nicht in diesem Land der Erbärmlichkeit sehen müßte.

Das kann sich dort nämlich niemand vorstellen, welche Zustände hier herrschen, und dort spricht niemand die Wahrheit, so wie sie ist. Und das glaubt dort auch niemand, der es nicht selbst gesehen hat. Ich spreche die Wahrheit, also komm bloß nicht in dem Irrglauben hierher, es könne hier besser sein. [...] Ich verbiete Dir natürlich nicht zu kommen, aber ich rate Dir, die Sache von allen Seiten abzuwägen, bevor Du kommst. Und leiden darf man hier auch, das sage ich Dir.

Ja, und was wird dann aus Mutter? Unsere Mutter bekommt graue Haare vor Kummer, wenn Du auch noch gehst. Ich glaube, sie hält das nicht mehr aus. [...] Ich weiß wohl, daß man dort nichts erreichen kann, aber hier geht es auch nicht besser. Man bekommt zwar einen höheren Lohn, doch auch die Ausgaben sind hier größer, und dann sind hier so viele Arbeitslose. Wenn man Pech hat, kann man lange Zeit ohne Arbeit bleiben, und das Leben ist hier teuer.[...] Es geht mir richtig ans Herz, wenn ich an den Kummer unserer Mutter denke, den ich verursacht habe und den Du nun auch noch vergrößern willst."

Ob der Briefempfänger dem Rat seines Bruders gefolgt ist und in Lapua blieb, war nicht in Erfahrung zu bringen, doch im besagten Jahr 1910 sind insgesamt 297 Auswanderungswillige aus Lapua nach Amerika aufgebrochen, einer Ortschaft, die zu 
diesem Zeitpunkt bereits mehr als 10000 Einwohner zählte. Bis 1909 hielten sich bereits 3897 Lapua-Bewohner in Amerika und Kanada auf ${ }^{534}$, wonach das "AmerikaFieber" unter der Ortsbevölkerung nicht unerheblich gewesen sein kann und die Intensität der im Brief zum Ausdruck gebrachten Emotionen erklärt.

Ebenfalls mit dem Hinweis auf die physische und psychische Unterstützung der alten Eltern in Finnland rät die im Jahr 1900 ihrem Ehemann nachgefolgte Auswanderin Hilja Toopakka ihrer jüngeren Schwester Sanna von der Auswanderung ab. Ihr Brief aus Worcester, Massachusetts, stammt aus dem Jahr 1905 und wendet sich an die Eltern im südostbottnischen Peräseinäjoki ${ }^{535}$ :

”Aus dem Brief von Sampsa [ein Bruder] lese ich, daß die Schwester große Lust hat hierher zu kommen, und sie hat wohl auch schon bei Sampsa nach einer Fahrkarte angefragt. Dennoch wünsche ich, daß sie sich solche Träume aus dem Kopf schlägt. Es wäre falsch, wenn alle Kinder, sobald sie dazu in der Lage sind, die Eltern verließen, wo diese allmählich alt werden. Außerdem weiß ich nur zu gut, daß es Sanna an nichts fehlt. Im Gegenteil, sie könnte hier unzufriedener sein als dort, wenn ich mir die Sache richtig überlege.

Dort in Finnland stellt man sich dieses Amerika so niedlich klein vor und daß es hier keine Not gäbe. Ich bin trotzdem sicher, daß auch Sanna hier schnell die Tränen kämen, wenn sie in einer Familie der Anderssprachigen dienen müßte und kein Wort verstehen würde. Denn ihr werdet doch verstehen, daß ein junges Mädchen auch hier in Amerika seinen Lebensunterhalt verdienen muß, ebenso wie in Finnland. Und weil es eben keine finnischen Arbeitgeber gibt, müssen die Finnen zu den Anderssprachigen gehen, und das macht keinen Spaß, wenn man nicht sprechen kann."

In beiden Briefbeispielen begründen die Briefschreiber ihre ablehnenden Haltungen mit den angeblich in Finnland kursierenden Amerikabildern. Trotz Hilja Toopakkas Behauptung, Amerika stelle man sich in Finnland als ein kleines Land ohne soziale Mißstände vor, wird diese Wahrnehmung von ihr nicht näher erläutert. Auch bei

\footnotetext{
${ }^{534}$ Zur Auswanderung aus Lapua siehe Toivonen 1950, S. 1-23, hier S. 11. Zur Bevölkerungsentwicklung vgl. Tab. 5 im Anhang: Durchschnittlicher jährlicher Bevölkerungszuwachs in 40 Gemeinden aus den Provinzen Süd-Ostbottnien und Satakunta 1865-1914 (Untersuchungsgebiet).

${ }^{535}$ Hilja Toopakka an Eltern in Peräseinäjoki, Brief vom 18.1.1905, Samml. Süd-Ostbottnien, Sig. Nr. 1243/25.
} 
Matti Mäkynen findet sich keine Spezifizierung des "Elends" und der "Erbärmlichkeiten" in Lead City, es läßt sich nur vermuten, daß der Briefschreiber auf schlechte Unterkunftsbedingungen, die 'Locations' sowie Trinkgewohnheiten einiger Landsleute in dem Grubenort anspielte.

Kritisch klang auch die Stimme von John Korvola, der nach 28 Jahren Amerikaaufenthalt folgendermaßen wertete ${ }^{536}$ :

”Der ganze Staat scheint in den Händen von Schiebern und Spekulanten zu sein. Alle wollen nur Geld machen, das gemeinsame Wohl des Vaterlandes wird zur Nebensache, denn Amerika ist, wer weiß, mehr als jedes andere Land ein materialistisches Land."

Auch in den Briefen anderer Schreiber finden sich gelegentlich Klagen über die angeblich in Amerika vorherrschende Mißachtung von Sonn- und Feiertagen sowie den fehlenden Einfluß von Religion und Kirche auf das alltägliche Leben ${ }^{537}$, wobei diese Äußerungen jedoch eher die Wahrnehmungsperspektive der Finnen reflektieren, als daß sie ein verläßliches Bild der amerikanischen Gesellschaft nachzeichnen würden.

Diese in vereinzelten Briefen geäußerten, negativen Blickwinkel stehen im Gegensatz zu einem wesentlich positiveren Amerikabild, das von der Mehrheit der Briefschreiber vertreten wurde und eher den gängigen Stereotypen und Klischeevorstellungen ${ }^{538}$ entsprach. In den positiven Briefäußerungen wurden zumeist Vergleiche zwischen den amerikanischen und finnischen Nahrungs-, Kleidung- und Lebensgewohnheiten gezogen, wobei die amerikanischen Verhältnisse in der Mehrheit der Fälle die

\footnotetext{
${ }^{536}$ John Korvola an Bruder Jaakko Korvola in Isokyrö, Brief vom 1.1.1921 aus Pendleton, Oregon, Samml. Süd-Ostbottnien, Sig.Nr. 261/12. Von John Korvola sind elf Briefe vor 1915 in diese Sammlung eingegangen.

${ }^{537}$ Z.B. Brief von Emmi Niemi aus Fitchburg, Mass. vom 7.1.1913 [TYYH:S:m:Satakunta: IKA: LXVII/1] "In Amerika merkt man nichts von Weihnachten"; Brief von Oskar Heinonen aus Cockburn Island, B.C. vom 29.3.1888 [TYYH:S:m:Satakunta:MER:I/7]: "Hier kennt man keine anderen Feiertage außer Sonntag."; Brief von Lydia W. Lönberg vom 24.6.1900 aus Stambaugh, Mich. [TYYH:S:m:Satakunta: MER:XXII/1]; Brief auch bei Kero (1985, S. 54) abgedruckt: "Wir leben hier wie die Heiden, denn hier gibt es weder einen finnischen Pfarrer noch eine Kirche".

${ }^{538} \mathrm{Zu}$ stereotypen Berichten, Klagen und Lobhymnen in deutschen Amerika-Briefen siehe Helbich 1990, S. 67-69. Lediglich seine Beobachtungen von allgemeinen Klischeevorstellungen über einzelne ethnische Gruppen können nicht für die finnischen Briefschreiber übernommen werden.
} 
finnischen übertrafen ${ }^{539}$. Dies wurde entweder in Lobhymnen auf die amerikanischen Zustände im Stil von "In Finnland kennen selbst die Herren nicht solche Speisen, wie sie der Arbeiter hier jeden Tag serviert bekommt" zum Ausdruck gebracht oder in Schwarzmalerei der finnischen Gesellschaft verdeutlicht: "Dort [in Finnland] sind die Menschen so unglaublich dumm, auch wenn sie noch so gebildet sind - es ist diese Engstirnigkeit, die den Menschen dort in den Knochen sitzt. " 540

Typisch waren auch allgemein bekannte Vorstellungen vom amerikanischen Freiheits- und Gleichheitsideal sowie das bereits im Briefzitat des Antti Kangas ausgedrückte 'Zeit ist Geld'- Stereotyp.

Obwohl Wertungen in Form dieser Schwarz-Weiß-Muster in vielen Briefen zu finden sind, kommen sie nicht bei allen Briefschreibern vor. Beispielsweise bei einem Briefschreiber aus einem Grubenort in Minnesota basierte die Akzeptanz der vorgefundenen Verhältnisse auf einer realistischen Einschätzung beider Gesellschaften, die dem Auswanderer bekannt waren ${ }^{541}$ :

"Ja, hier wird es einem jungen Mann schon langweilig. Hier ist es nicht so lustig wie in Finnland, aber von der Warte eines Arbeiters betrachtet sind die Verhältnisse hier besser."

In den hier dargestellten Briefbeispielen sowohl zu stereotypen Amerikabildern als auch zu Anwerbung und Abraten schienen die Briefempfänger, die "stummen" Briefpartner, mehr oder weniger zur Auswanderung bereit und damit positiv eingestellt gewesen zu sein. Die Briefschreiber hingegen können in die beiden Gruppen der positiven und negativen Amerikabild-Vermittler eingeteilt werden, wobei die zufriedenen Verfasser die Mehrheit bilden.

Dennoch fanden sich natürlich - auch im Auswanderungskerngebiet - Personen, die allen Werbebriefen zum Trotz unter keinen Umständen die Strapazen der Atlantik-

\footnotetext{
${ }^{539}$ Stereotype Vorstellungen von Amerika auch sind anhand von Briefzitaten der Sammlung Satakunta und anhand von frühen Zeitungsberichten untersucht worden, siehe Keros unveröffentlichte Lizentiatsarbeit von 1970, S. 77-80 sowie 1975, S. 73-81.

${ }^{540}$ Briefzitate von Wilhelm Mäkelä (später Mäki) aus Virginia, Minn., Brief vom 27.2.1893

[TYYH:S:m: Satakunta:KAR:XI/1] und Aini Fredman aus New York, Brief vom 24.12.1909, Samml. Süd-Ostbottnien, Sig. Nr. 1379/1.

${ }^{541}$ Kalle Sihto an Bruder Jaakko Sihto in Ilmajoki, Brief vom 5.7.1899 aus Ely, Minn., Samml. Süd-Ostbottnien, Sig. Nr. 2170/1.
} 
überquerung auf sich genommen hätten ${ }^{542}$, ebenso wie es auch unter den Emigranten Individuen gab, die niemals selbst zur Feder gegriffen, noch einen Landsmann um die schriftlichen Abfassung ihrer Gedanken gebeten haben. Penti hat in Interwievs mit finnischen Aus- und Rückwanderern herausfinden können, daß es den meisten NichtSchreibern unmöglich erschien einen einmal unterbrochenen Briefkontakt nach Jahren des Stillschweigens wieder zu aktivieren ${ }^{543}$. Auch der bereits zitierte Briefschreiber Isak Kuusisto, der zweitälteste der Brüder Kuusisto, unterbrach 1907 nach zwei Jahren den intensiv gepflegten Briefkontakt zu den Eltern. Nach neun Jahren der Schreibpause griff er jedoch 1916 wieder zur Feder und bemerkte lediglich lapidar, daß er sich seit vielen Jahren nicht mehr gemeldet habe. Ohne weitere Gründe zu nennen oder jemals auf die Zeitspanne des unterbrochenen Briefkontaktes einzugehen, setzte er den Briefwechsel mit den Eltern noch bis mindestens 1929 fort.

Hinsichtlich schwedischer Auswandererbriefschreiber verweist Barton auf den Tatbe-stand, daß es keinesfalls die Art und Anzahl der erlebten Ereignisse waren, die Schreiber von Nicht-Schreibern trennten ${ }^{544}$. In erweitertem Sinne kann diese Auslegung auch für die Trennung in Werbende und Abratende innerhalb der Briefschreiber gelten, wonach die wahren Ursachen vielmehr in den persönlichen Dispositionen sowie den individuellen Lebensumständen gesucht werden können, die zu der Übernahme einer bestimmten, teilweise extremen Wahrnehmungsperspektive der amerikanischen Gesellschaft geführt haben.

\subsubsection{Heimwehäußerungen und Rückwanderungsabsichten}

Nachdem nun die Aus- und Nachwanderung bzw. zeitlich verzögerte Auswanderung, von einander bekannten Personen besprochen wurde, scheint es angebracht, kurz auf die allgemein übliche Terminologie in der Migrationsliteratur einzugehen. Für die hier bislang als Nachwanderung bezeichnete Erscheinung findet nämlich in deutsch-

\footnotetext{
${ }^{542}$ Die Frage nach der Unterscheidung in den "auswandernden" und den "beharrenden" Menschentyp wird in Kap. 2.6.1. kurz behandelt. Siehe hierzu auch den umstrittenen Ansatz von Raeithel 1981.

${ }^{543}$ Penti 1983, S. 311-318, bes. S. 315 f.

${ }^{544}$ Barton 1993, S. 139; siehe auch Bartons umfangreiche Amerika-Briefediton (engl. Ausg. 1975; schwed. Ausg. 1979). Spieckermann (unveröffentlichte Hausarbeit: 1995, hier S. 5) weist außerdem in seiner unveröffentlichten Studie darauf hin, daß unter Mitgliedern bestimmter Gruppen, wie beispielsweise Analphabeten, Waisen und mit ihrer Familie zerstrittenen Personen, die wenigsten Briefschreiber zu finden sind.
} 
und englischsprachigen Publikationen hauptsächlich der Begriff Kettenwanderung, und als englische Entsprechung 'Chain Migration', Verwendung, welcher dasselbe Phänomen meint ${ }^{545}$ :

Kettenwanderung kann definiert werden als jene Bewegung, in der zukünftige Wanderer von günstigen Gelegenheiten erfahren, Transportmöglichkeiten, anfängliche Unterkunft und Arbeit zu erhalten, die mittels primärer, gemeinschaftlicher Beziehungen mit vorhergehenden Wanderern besorgt wurden."

Bei Albrecht wird der Begriff sogar in direkte Beziehung zu Briefanwerbung gesetzt $^{546}$ :

"....wenn man Kettenwanderung so definiert, daß sie eine Wanderung ist, die durch Briefe und Besuche früherer Auswanderer in der alten Heimat unter den bisher Zurückgebliebenen ausgelöst worden ist."

In diesem Sinne wären auch die zuvor beschriebenen Migrationstraditionen, d.h. die Auswanderung zahlreicher Personen von einer bestimmten Gemeinde in Finnland zu einem bevorzugten Ort oder Staat in Amerika nicht anderes als eine Anhäufung von Kettenwanderungen. Es ist anzunehmen, daß auf diese Weise auch finnische Ortsnamen in Amerika wie beispielsweise Oulu, Salo oder Savo zustande kamen ${ }^{547}$.

Während die Statistiker lediglich zwischen Einzel- und Familienwanderern unterschieden haben, je nachdem wieviele Personen einer Kernfamilie mit gleichem Familiennamen zu einem bestimmten Zeitpunkt eine Grenze passierten, so können die gleichen Personen vor allem auch "Nach- bzw. Kettenwanderer", "Mehrfachauswanderer" oder "Rückwanderer" gewesen sein, je nachdem in welchem Kontext der sozialen Beziehungsstrukturen ihre Grenzüberschreitung zum einem bestimmten Zeitpunkt stand. Aus diesem Grund weist Helbich zu Recht darauf hin, daß die terminologische Vielfalt

\footnotetext{
${ }^{545}$ Zitat aus Kamphoefner 1984, hier S. 340f. Zum englischen Begriff 'Chain Migration' führt Alexander (1991, S. 200-203) das Beispiel von slovakischen Einwanderern an, welche zu 98\% als Kettenwanderer bezeichnet werden können.

${ }^{546}$ Zitat nach Albrecht 1972a, S. 118. Zur briefmotivierten Kettenwanderung siehe auch Rößler 1992, S. 155-157.

${ }^{547}$ Für die deutsche Auswanderungsbewegung ist dies eindeutig belegt mit Ortsnamen wie New Ulm oder New Melle, vgl. Helbich/Haubold 1988, S. 27.
} 
in der Migrationsliteratur verwirrend wirkt und nur eine kontextbezogene Begriffsklärung im Einzelfall die Bezugsebenen der Wanderungsformen zueinander aufdecken $\mathrm{kann}^{548}$.

Vor diesem Hintergrund soll abschließend noch die Rückwanderung von "Auswanderern", d.h. die Heimkehr ins Herkunftsland, behandelt werden, womit sich zugleich der Kreis einer temporären Arbeitswanderung für die "Migranten" schlie $3 \mathrm{t}^{549}$. Denn um von Auswanderern im ursprünglichen Sinne des Wortes sprechen zu können, muß die Lebensfortführung in einem anderen als dem Geburtsland stattfinden und zugleich der Tatbestand eines dauerhaften Aufenthaltes im Zielland gegeben sein.

Die hier behandelten 143 Briefschreiber aus dem Untersuchungsgebiet sind größtenteils nicht nach Finnland zurückgekehrt. Obwohl in lediglich 93 Fällen der Verbleib geklärt werden konnte, blieben 75 Personen bzw. 52\% der Gesamtheit der Briefverfasser bis zu ihrem Lebensende in Amerika oder Kanada. Nur 15 Männer und drei Frauen sind mit Sicherheit nach einigen Jahren zurückgewandert. Demnach ist anzunehmen, daß auch bei den 50 ungeklärten Fällen die Tendenz Bleiben vor Rückkehr vorherrschte.

Diese Vermutung wird zudem durch die Forschungsergebnisse von Virtanen ${ }^{550}$ bestärkt, der sich mit dem Ausmaß der finnischen Rückwanderungsbewegung beschäftigt hat, wobei ihm in erster Linie die Passagierlisten der 'Finnischen Dampfschiffahrtsgesellschaft AG' für die Gegenrichtung des Auswandererstroms, d.h. von Hull nach Hanko, zur Quellengrundlage gedient haben, die den Zeitraum 1892-1914 umfassen.

Wird das Gesamtergebnis von 102740 Rückwanderern für den Zeitraum 18921914 mit der Gesamtauswandererzahl dieser Zeitspanne in Beziehung gesetzt, so ergibt sich eine Rückwandererquote von rund 30\%. Virtanen schätzt die Größenordnung der Mehrfachauswanderer jedoch auf etwa $10 \%$ ein, wonach die wahre Rückwandererquote bei etwa 20\% liegt; ein Ergebnis, das durch Stichprobenuntersuchungen am Rückwandereraufkommen in sechs ländlichen Gemeinden in verschiedenen Regionen Finnlands abgesichert werden konnte.

\footnotetext{
${ }^{548}$ Helbich/Haubold 1988, S. 25f.

${ }^{549}$ Vgl. auch Hoerder 1985b, S. 7-13. Die begriffliche Unterscheidung von Immigranten und Migranten, den dauerhaften Siedlern bzw. temporären Arbeitswanderern wird in Kap. 3.1.2. eingehend behandelt sowie das Thema Rückwanderung kurz gestreift.

${ }^{550}$ Siehe die von Virtanen ermittelten Rückwandererzahlen in Tab. 4 im Anhang sowie Virtanen 1979, S. 61-70, bes. S. 67. Als Kurzversion seiner Untersuchungsergebnisse vgl. Virtanen 1985. S. 381-398.
} 
Vor der Hintergrund des allgemeinen Stimmungsbildes jedoch, welches Hunderte von Amerika-Briefen vermitteln, verwundert sowohl dieses statistische Resultat als auch das Auswertungsergebnis des Rückwanderungsverhaltens der Briefschreiber. Nicht nur, daß Äußerungen zu Finnland als dem geliebten Heimatland und der geplanten Rückkehr relativ häufig zu finden sind, sondern daß dieses Vorhaben auch eher von Frauen als von Männern zu Papier gebracht wurde, Frauen jedoch deutlich seltener den Rückweg angetreten haben als Männer ${ }^{551}$. Die Diskrepanz zwischen vielfach geäußerter Rückwanderungsabsicht und häufig unterlassener Ausführung wird in den Briefen selbst nicht thematisiert. Typisch sind vielmehr emotionsgeladene Heimwehäußerungen, die eng mit einem teilweise idealisierten Heimatbild verknüpft wurden. Diese den Briefton bestimmende Gefühlsebene wird beispielsweise von einer Auswanderin eindrucksvoll zum Ausdruck gebracht, die den Tod ihres Vaters und den Verkauf des elterlichen Anwesens im südostbottnischen Töysä betrauert und im Verlauf ihres Lebens nicht mehr nach Finnland zurückkehrt ${ }^{552}$ :

"Aber den Vater können wir nicht mehr auf Erden sehen. Ich weiß nicht, woher es kommt, doch ich habe den Vater sehr vermißt und auch das Zuhause in Finnland. Jetzt erscheint es als hätte ich kein Heim mehr, ganz gleich wohin ich mich auch wenden würde. Und selbst wenn es noch so schön irgendwo wäre, das erschiene mir wie nichts im Vergleich zu dem kleinen Erdfleck dort am Seeufer, der das Heim meiner Kindheit ist [...] Und jetzt sind uns die Felsen und Häuser genommen, in den Händen von fremden Menschen..."

Auch die Reflexion des in Finnland gelebten Lebens bzw. der zurückgelassenen Lebenswelt schien erst durch die Konfrontation mit den neuen, anfangs noch als fremd empfundenen Verhältnissen in Amerika ausgelöst zu werden, wie ein Waldarbeiter aus Minnesota in reumütigem Tonfall zu Papier brachte ${ }^{553}$ :

\footnotetext{
${ }^{551}$ Auf der Grundlage der Stichprobenauswertung kamen auf eine rückwandernde Frau zwei Männer, vgl. Virtanen 1979, S. 128, Tab. 30.

${ }^{552}$ Anni Dutton an Schwester Elina Rasinmäki in Töysä, Brief vom 10.8.1912 aus Hartford, Conneticut, Samml. Süd-Ostbottnien, Sig. Nr. 1162/1.

${ }^{553}$ Wiliam Perälä an Bruder Frans Perälä in Ylistaro, Brief vom 23.4.1913, Samml. SüdOstbottnien, Sig. Nr. 1007/2.
} 
"Manchmal, da tut es mir richtig leid, daß ich gegangen bin, aber es gab ja auch dort [in Finnland] keine Arbeit im letzten Winter, so daß ich fortging. Ich bin jetzt hier bei Duluth in einem Waldkamp."

Dementsprechend häufig wird eine mögliche Rückkehr, meist zu einem unbestimmten Zeitpunkt, in Aussicht gestellt, wobei der Rückwanderungswunsch entweder mit schlechten Verdienstmöglichkeiten in Amerika oder mit der Sehnsucht nach vertrauten Personen begründet wird ${ }^{554}$ :

"Ja, wer weiß, vielleicht komme ich ja bald schon wieder nach Finnland zurück, falls sich die Zeiten hier weiterhin verschlechtern, dann macht es keinen Sinn, hier lange Zeit arbeitslos zu bleiben, denn hier ist das Leben teuer.[...] Also, es lohnt sich nicht hierher zu kommen, denn bereits etliche Jungs aus dem alten Land haben den Gürtel enger schnallen müssen."

"Ich käme so gerne, um noch einmal unsere alte Mutter zu sehen. Aber die Reise ist so lang und beschwerlich, daß ich nicht weiß, ob ich mit meinen eigenen Augen jemals die Mutter und Dich, Schwester, und Deine Familie wiedersehen darf. Laß uns zum Herren beten, damit er uns Geduld für ein mögliches Wiedersehen geben möge."

Da das Heimweh vor allem auch die Erinnerung an die als schmerzhaft empfundene Abschiedsszene von geliebten Personen in Finnland heraufbeschwören konnte ${ }^{555}$, kann auch folgender Kommentar einer Finnin aus dem Jahr 1898 als typisch angesehen werden $^{556}$ :

\footnotetext{
${ }^{554}$ Erstes Zitat von Lammi Vante an Bruder in Karvia, Brief vom 1.4.1913 aus Larder Lake, Ont.: TYYH:S:m:Satakunta: KAR:LXX/2; zweites Zitat von Sofia Hill an Schwester Hilja Kujala in Ilmajoki, Brief vom 9.2.1914 aus Drummond, Mich., Samml. Süd-Ostbottnien, Sig. Nr. $117 / 3$.

${ }^{555}$ Zur emotionalen Bewältigung der Abschiedserfahrung am Beispiel der hessischen Auswanderer siehe Assion 1985b.

${ }^{556}$ Tilda Laaksonen (später Liikaluoma) an Bekannten Kaarlo Lehtivuori in Säkylä, Brief vom 3.10.1898: TYYH:S:m:Satakunta:SÄK:I/5. Ein sehr ähnlicher Brief mit tiefempfundenen Heimwehäußerungen in Bezug zur Abschiedstrauer stammt von Lydia W. Lönberg [Brief vom 2.1.1901 aus Stambaugh, Mich. nach Merikarvia: TYYH:S.M:Satakunta: MER:XXII/2], die ein Jahr zuvor ihrem Bruder nach Michigan nachgefolgt war und 1904 einen Finnen heiratete, mit dem sie 12 Kinder bekam; die geplante Rückkehr wurde nicht verwirklicht.
} 
"Vor ein paar Tagen war ich in der Stadt am Bahnhof und habe mich von einigen Finnen verabschiedet, die auf dem Weg nach Finnland waren. In Erwartung des Zuges haben wir uns unterhalten, wer wann gekommen und wie lange er schon hier war. Plötzlich fühlte ich eine große Sehnsucht mach Finnland. Zu nah sind noch die Zeiten als ich dort gelebt habe - und die Erinnerung an den Abschiedsschmerz in der Brust war wieder da."

Sieben Jahre später heiratete diese Finnin in Amerika einen Landmann und blieb dauerhaft in Amerika. Ihr letzter erhaltener Brief stammt aus dem Jahr 1934.

Doch nicht nur der im Brief geäußerte Bezug zum Abschiedserlebnis, sondern auch der spätere Werdegang der Briefschreiberin stehen für austauschbare Erfahrungen, wie sie den Lebensweg von tausenden Einwanderinnen markiert haben.

Dem Heimweh als einer rückwärts gewandten Sehnsucht nach Bekanntem bzw. nach vertrauten Menschen in einer bestimmten Umgebung, kurz der Heimat, welche die Auswanderin verlassen hat, stand ein Gefühl der "Sehnsucht nach Neubeheimatung" entgegen, was sich in dem Wunsch nach einer zufriedenstellenden Neustrukturierung der eigenen Lebensumstände im Aufnahmeland äußerte. ”Das Heimweh endet, wenn der Satisfaktionswert Heimat wieder erreicht ist ${ }^{, 557}$.

In den meisten Fällen war es von daher eher eine Frage der Zeit, bis das Heimweh und die Rückwanderungspläne als wiederkehrende Themen aus den Briefen verschwanden und die Anpassung an die Lebensumstände in Amerika Vorrang gewannen, insbesondere wenn Heirat und anschließende Familiengründung dem Leben eine neue Perspektive gegeben hatten. In diesem Zusammenhang kommt auch der ethnischen Gemeinschaft in Amerika, d.h. den zahllosen, von Finnen geführten kulturellen, politischen und kirchlichen Vereinigungen eine integrierende Funktion zu, da sie zwar nicht unmittelbar die Akkulturation an die amerikanische Gesellschaft, wohl aber Ausprägung eines finnisch-amerikanischen Bewußtseins förderten und somit zur allgemeinen Zufriedenheit der Emigranten beitrugen ${ }^{558}$.

${ }^{557}$ Zur Verknüpfung von Heimat- und Heimwehbegriff vgl. Greverus 1965, S 7-9, Zitat von S. 9. Zwingmann (1962, S. 323-327) behandelt vor allem die nostalgische Verklärung von Heimat sowie die Schuldgefühle, die durch das Verlassen der Heimat als Heimweh-Objekt ausgelöst werden.

${ }^{558}$ Zur Bedeutung der ethnischen Organisationen für den Akkulturationsprozeß siehe Kostiainen 1986, S. 18-30. 
Da sich nicht zuletzt mit wachsendem zeitlichen Abstand auch die Lebensverhältnisse der Daheimgebliebenen in Finnland veränderten, schien eine Rückkehr unter Umständen nach einigen Jahren in Amerika weniger attraktiv als im Augenblick des Abschiedschmerzes bei Auswanderungsbeginn.

Die Situation sah auch für finnische Männer, die zumeist noch jung und unverheiratet die Emigration angetreten hatten, ähnlich aus: Waren der elterliche Hof bereits von einem anderen Bruder übernommen worden und die Eltern selbst alt oder womöglich schon gestorben, so schien die Veranlassung gering, in die alte Heimat zurückzukehren.

Für finnische Frauen war es denn auch kein Problem, einen Ehekandidaten aus dem "alten Land" zu finden: Kamen um 1900 noch 182 finnische Männer auf 100 finnische Frauen in Amerika, so balancierte sich dieses Ungleichgewicht bis 1920 mit einem Verhältnis von 132:100 allmählich aus ${ }^{559}$. Demnach trafen sowohl die meisten finnischen Auswanderinnen im allgemeinen, als auch die hier näher betrachteten Briefschreiberinnen ihren zukünfigen Ehepartner fast ausschließlich in Amerika oder Kananda. Unter den 20 dauerhaft in Amerika verbliebenen Briefschreiberinnen dieser Untersuchung konnten 19 Frauen als verheiratet identifiziert werden. Und von lediglich drei Briefschreiberinnen ist bekannt, daß sie dauerhaft zurückgekehrt sind, eine von ihnen war verheiratet.

Wenngleich die Konkurrenz um finnische Frauen groß gewesen sein muß, so gelang es dennoch zahlreichen Männern, die Ehe mit einer Finnin, häufig einem ehemaligen Dienstmädchen, einzugehen. Im Jahr 1920, als die Anzahl der 'In-Door Domestics' bereits zurückging, waren beispielsweise in Detroit $80 \%$ aller Finnen verheiratet, in Chicago lag der Anteil bei $65 \%$ und in Duluth, der Sommerstadt der Waldarbeiter, immerhin noch bei $50 \%{ }^{560}$. Die Tatsache, daß Finnen ihresgleichen heirateten, konnte Kolehmainen ${ }^{561}$ anhand einer Stichprobenuntersuchung unter Finnen der Hafenstadt Connaut in Ohio belegen, wonach bei 128 Eheschließungen innerhalb des Zeitraumes 18951915 ausnahmslos alle zwischen finnischen Partnern der ersten Auswanderergeneration geschlossen worden waren und erst ab 1916 der Anteil der gemischten Ehen allmählich zunahm. Zu dem gleichen Ergebnis kamen auch Wargelin-Brown und Lindström-Best,

\footnotetext{
${ }^{559}$ Hoglund 1981a, S. 365.

${ }^{560}$ Kero 1996, S. 209-221, hier S. 210.

${ }^{561}$ Kolehmainen 1936, S. 372f. Auch für deutsche Einwanderinnen kann eine Tendenz zu ethnisch homogenen Eheschließungen konstatiert werden, siehe Wehner-Franco 1994, S. 316.
} 
die das Heiratsverhalten unter Finnen in Amerika und Kanada auf der Grundlage der Zensus-Daten von 1920 bzw. 1921 untersucht haben. In beiden Fällen betrug der Anteil der ethnisch homogenen Ehen etwa 90\%, wobei zumindest in Kanada finnische Männer häufiger finnische Frauen heirateten als umgekehrt ${ }^{562}$.

Obwohl die Eheschließung in Amerika als ein allgemeines Rückwanderungshindernis angesehen werden kann, wanderten verheiratete und ledige Rückwanderer in etwa zu gleichen Teilen zurück, wie Virtanen anhand von sechs Stichprobengemeinden ermitteln konnte ${ }^{563}$. Da es sich bei den verheirateten Heimkehrern jedoch zum Teil auch um Männer handeln könnte, die bereits vor Auswanderungsbeginn geheiratet hatten und zu ihrer in Finnland verbliebenen Familie zurückkehrten, ist davon auszugehen, daß der Anteil derjenigen Personen, die nicht in Amerika geheiratet hatten, unter den Rückwanderern letztendlich überwog.

Bemerkenswert ist jedoch der Tatbestand, daß die wenigsten dauerhaften Rückwanderer mehr als fünf Jahre, was der Gültigkeitsdauer des Amerika-Paßes entsprach, auf dem amerikanischen Kontinent zugebracht hatten. Daraus folgernd übte die Aufenthaltsdauer eine verstärkende Wirkung auf den Bleibe-Entschluß aus, was vor dem Hintergrund der noch jungen, anpassungsfähigen Auswanderer beiderlei Geschlechts nur folgerichtig erscheint. Des weiteren konnte Virtanen feststellen, daß auch das fortgeschrittene Alter bei Auswanderung eine stärkere Rückwanderungsbereitschaft wachhielt $^{564}$.

Nicht zuletzt war es Virtanen gelungen, in den 1970er Jahren 937 Rückwanderer, die vor 1930 ausgewandert waren, mittels einer Fragebogenaktion nach den persönlichen Beweggründen für ihre Heimkehr zu befragen. Zu den fünf am häufigsten genannten Motivationen zählten Heimweh, Arbeitslosigkeit in Amerika, "Nur auf Besuch in Finnland", Krankheit oder Verletzung sowie Familienzusammenführung in Finnland. Die Stimmen der zufriedenen Personen hielten sich mit den unzufriedenen bzw. erfolglosen die Waage, wonach keine eindeutigen Rückschlüsse, auf beispielsweise beruflichen Mißerfolg und verstärkte Rückwanderungsaktivität möglich sind ${ }^{565}$. Dennoch gibt Virtanen zu bedenken, daß möglicherweise mehr als 20\% der finnischen Auswanderer

\footnotetext{
${ }^{562}$ Wargelin-Brown 1986a, S. 18; Lindström-Best 1988, S. 62-69, bes. S. 64.

${ }^{563}$ Virtanen 1979, S. 139, Tab. 33.

${ }^{564}$ Virtanen 1979, S. 79-83 und S. 222.

${ }^{565}$ Virtanen 1979, S. 175-185; zur individuellen Einschätzung des Erfolges in Amerika siehe auch Kero 1996, S. 255-261. Auch Myhrman (1972, S. 547-550) hat unter Finnlandschweden Heimweh als den vorrangigsten Rückwanderungsgrund ausmachen können.
} 
eine Rückwanderung geplant haben könnten, doch die persönlichen Lebensumstände, insbesondere Verarmung durch lange Phasen der Arbeitslosigkeit, diesen Plan vereitel$\operatorname{ten}^{566}$.

Bei Untersuchungen dieser Art, die nach persönlichen Ursachen und Motivationen fragen, darf jedoch ein wesentlicher datenverzerrender Aspekt nicht außer acht gelassen werden: Waren nämlich bereits die individuell geäußerten Angaben zum Auswanderungsentschluß nur bedingt ehrlich, da nämlich die Befragten einem fremden Interviewer gegenüber nur die halbe Wahrheit aussprachen, so wird dieses Faktum auch für die von den Betroffenen selbst angegebenen Gründe der Rückwanderungsmotivationen gelten. Tiefergehende psychologische Ursachen, die der Aus- oder Rückwanderungsentscheidung zugrunde gelegen haben können, werden sich durch Interviews und schriftliche Fragebogenaktionen nicht ermitteln lassen. Damit schließt sich denn auch wieder der Kreis zu Briefen und anderen, selten aufzufindenden persönlichen Quellen, die zufällig im Ereignisstrom und ohne Beeinflussung von Feldforschern zustande gekommen sind und in ihrem Wahrheitsgehalt als nicht-reaktive Daten die künstlich erzeugten Quellen übertreffen.

In diesem Sinne eignen sich die Amerika-Briefe zwar nicht als universelle Quellen zur Rekonstruktion einer Sozialgeschichte der finnischen Auswanderer, eben weil zu viele Bereiche des Alltagslebens ausgeklammert wurden, wohl aber vermitteln sie ein realitätsgetreues Bild von einem kollektiven, phasenweisen Prozeß der Neuorientierung in Amerika oder Kanada, der entweder zu einer allmählichen Gesellschaftseingliederung oder aber zur bewußten Abkehr des neuen Lebensumfeldes geführt hat.

${ }^{566}$ Virtanen 1979, S. 184 und 1987, S. 405f. 


\title{
QUELLEN- UND LITERATURVERZEICHNIS
}

\author{
UNGEDRUCKTE PRIMÄRQUELLEN:
}

\section{Briefsammlung von Briefen aus Amerika und Kanada nach Süd-Ostbottnien}

Gesammelt und kopiert in den Jahren 1959-60 von Studenten der Landsmannschaft 'Ostbottnien' der Universität Helsinki. Ca. 5.000 Originalbriefe und Postkarten von 2.016 Briefschreibern, inklusive 2.016 Fragebögen mit jeweils 14 Angaben zur Person des Briefschreibers (Fragebögen teilweise unvollständig ausgefüllt) auf 16 Mikrofilmrollen kopiert und archiviert in:

- Universität Turku/Seminar für Allgemeine Geschichte (Migrationsarchiv)

- Universitätsbibliothek Helsinki (Handschriftensammlung)

- Immigration History Research Center/Minneapolis, Minnesota (Abteilung Finnland)

Teilbestand dieser Sammlung, ca. 2000 nicht an die Briefbesitzer zurückgesandte Originalbriefe mit Fragebögen zu Angaben der Briefschreiber in 38 Archivmappen archiviert im Migrationsinstitut in Turku (Sig.: SI/A/1/85-38/85)

Sample mit 125 vor 1915 geschriebenen Amerika-Briefen von 50 Briefschreibern aus 20 Herkunftsgemeinden Süd-Ostbottniens wurde aus dem Originalbestand der Sammlung zusammengestellt.

\section{Briefsammlung von Briefen aus Amerika und Kanada nach Satakunta}

Gesammelt und kopiert 1964 von Prof. V. Niitemaa und R. Kero am Seminar für Allgemeine Geschichte der Universität Turku: 
Ca. 8.000 Briefe und Postkarten von 3186 Briefschreibern aus der Provinz Satakunta, inklusive 3186 Fragebögen mit jeweils 30 Fragen zur Person des Briefschreibers (Fragebögen teilweise unvollständig) auf 25 Mikrofilmrollen kopiert und archiviert in:

- Universität Turku/Seminar für allgemeine Geschichte (Migrationsarchiv) (Sig.: TYYH:S:m:Satakunta)

- Immigration History Research Center/Minneapolis, Minnesota (Abteilung Finnland)

Sample mit 353 vor 1915 geschriebenen Amerika-Briefen von 93 Verfassern aus 20 Herkunftsgemeinden in Satakunta wurde aus folgenden Mikrofilmrollen der Universität Turku/Seminar für Allgemeine Geschichte zusammengestellt:

TYYH:S:m:Satakunta/Nr.: 1-5, 7, 9-13, 15, 21-25.

$\underline{\text { Sammlung von Interviews mit Amerika-Finnen der 1. Generation, geführt und }}$ aufgezeichnet von K. Mustonen in verschiedenen Orten in Florida 1977-78

173 Interviews aus den Jahren 1977-78, maschinenschriftlich transkribiert und in drei Archivmappen archiviert im Migrationsinstitut in Turku:

$\mathrm{S} 1 / \mathrm{A} / 65 / 77-78$

S1/A/69/77-78/80

$\mathrm{S} 1 / \mathrm{A} / 70 / 77-78 / 80$

Berücksichtigung von zehn Interviews, deren Gewährsleute vor 1914 ausgewandert waren und entweder aus der Provinz Süd-Ostbottnien (6 Personen) oder Satakunta (4 Personen) stammten: Nummern der Interviews: 8, 9, 12, 13, 20, 91, 127, 145, 146, 160. 


\section{GEDRUCKTE PRIMÄRQUELLEN:}

\section{Finnischsprachige Wochenzeitungen:}

Oulun Wiikko Sanomia (Ouluer Wochennachrichten) 15. Jahrgänge: 1865-1879 (5 Mikrofimrollen aus Beständen der Universitätsbibliothek Helsinki, Sig. Nr.: 11138 11142)

Keski-Suomi (Mittel-Finnland) 15. Jahrgänge: 1871-1885 (5 Mikrofilmrollen aus Beständen der Universitätsbibliothek Helsinki, Sig. Nr.: 12010-12014)

\section{Schwedischsprachige Wochenzeitung:}

Wasabladet (Vaasa-Blatt) 20 Jahrgänge: 1865-1885 (erschien zweimal pro Woche) (9 Mikrofilmrollen aus der Universitätsbibliothek Helsinki, Sig. Nr.: 5567-5575)

\section{BRIEFEDITIONEN:}

\section{FINNLAND:}

Kero 1985 = Ders.: Kultaa vuolemassa ja "kolia" kaivamassa. Siirtolaiskirjeitä PohjoisAmerikasta Suomeen (Nach Gold und "Kohle" graben. Auswandererbriefe von Nord-Amerika nach Finnland). In: Kuparinen 1985, S. 9-134.

Kuparinen 1985 = Kuparinen, Eero (Hrsg.): "Maitten ja merten takaa". Vuosisata suomalaisia siirtolaiskirjeitä ("Jenseits ferner Länder und Meere". Ein Jahrhundert finnischer Auswandererbriefe). Tammisaari 1985 (Turun Historiallinen Arkisto, 40). 
Nyström 1985 = Nyström, Carita (Hrsg.): Emigrantbreven berättar. En bok om emigrationen från Munsala av studiecirceln Gnistan (Auswandererbriefe berichten. Ein Buch über die Auswanderung aus Munsala vom Studienkreis Gnistan). Vaasa 1985.

\section{SCHWEDEN:}

Barton 1979 = Barton, Arnold H. (Hrsg.): Brev från löftets land. Svenskar berättar om Amerika 1840-1914 (Briefe aus dem gelobten Land. Schweden berichten aus Amerika 1840-1914). Stockholm 1979. (Engl. Original: Letters From the Promised Land. Swedes in America 1840-1914. Minneapolis, Minn. 1975).

Landelius 1957 = Landelius, Otto R. (Hrsg.): Amerikabreven (Amerikabriefe). Halmstad 1957.

Widén 1961 = Widén, Albin (Hrsg.): När Svenk-Amerika grundades. Emigrantbrev med kommentarer av A. Widén (Als Schwedisch-Amerika gegründet wurde. Auswandererbriefe mit Kommentaren von A. Widén). Borås 1961.

Widén 1966 = Ders. (Hrsg.): Amerikaemigrationen i dokument (Die Amerikaemigration in Dokumenten). Stockholm 1966.

\section{NORWEGEN:}

Blegen 1955 = Blegen, Theodore C. (Hrsg.): Land of Their Choice. The Immigrants Write Home. St. Paul, Minn. 1955. [In norweg. Übersetzung: Amerikabrev (Amerikabriefe). Oslo 1958].

Hale 1986 = Hale, Frederick (Hrsg.): Their Own Saga: Letters from the Norwegian Global Migration. Minneapolis, Minn. 1986. 
Jevne 1975 = Jevne, Per (Hrsg.): Brevet hjem. En samling brev fra norske utvandrere (Der Brief heim. Eine Sammlung Auswandererbriefe von norwegischen Auswanderern). Trondheim 1975.

Øverland/Kjærheim 1992-93 = Øverland, Orm/Kjærheim, Steinar (Hrsg.): Fra Amerika til Norge 1-3. Norske utvandererbrev. (Von Amerika nach Norwegen 1-3. Norwegische Auswandererbriefe). Bd. 1: 1838-1857, Oslo 1992; Bd. 2: 1858-1868, Oslo 1992; Bd. 3: 1869-1874, Oslo 1993.

Zempel 1991 = Zempel, Solveig (Hrsg.): In Their Own Words: Letters from Norwegian Immigrants. Minneapolis, Minn. 1991.

\section{DÄNEMARK:}

Hansen 1981 = Hansen, Marianne (Hrsg.): Brev fra Amerika. Danske utvandrerebreve 1874-1922 (Briefe aus Amerika. Dänische Auswandererbriefe 1874-1922). Kopenhagen 1981.

Stilling/Olsen 1994 = Stilling, Niels P./Olsen, Anne L. : A New Life. Danish Emigration to North America as Described by the Emigrants Themselves in Letters 18421946. Aalborg 1994. [Dän. Original: Et nyt liv. Den danske utvandring til Amerika i billeder og breve. Aalborg 1985].

\section{DEUTSCHLAND:}

Haller 1981 = Haller, Reinhard: Alte Briefe aus Amerika. Grafenau 1981.

Helbich/Boesing 1985 = Helbich, Wolfgang J./Boesing, Ursula (Hrsg.): "Amerika ist ein freies Land..." Auswanderer schreiben nach Deutschland. Darmstadt 1985. 
Helbich/Kamphoefner/Sommer 1988 = Helbich, Wolfgang J./Kamphoefner, Walter D./Sommer, Ulrike (Hrsg.): Briefe aus Amerika. Deutsche Auswanderer schreiben aus der Neuen Welt 1830-1930. München 1988. [In engl. Übersetzung: News from the Land of Freedom. German Immigrants Write Home. Ithaca/London 1991].

Kammeier 1989 = Kammeier, Heinz-Ulrich: "So besinnt euch doch nicht lange und kommt herrüber..." Briefe von Amerikaauswanderern aus dem Kreis Lübbeke aus zwei Jahrhunderten. Münster 1989.

Seidenfaden 1987 = Seidenfaden, Marie-Luise (Hrsg.): " ...wir ziehen nach Amerika". Briefe Odenwälder Auswanderer aus den Jahren 1830-1833. Weinheim 1987.

\section{SCHWEIZ:}

Schelbert/Rappolt 1977 = Schelbert, Leo/Rappolt, Hedwig: "Alles ist ganz anders hier." Auswandererschicksale in Briefen aus zwei Jahrhunderten. Olten/Freiburg i. Br. 1977.

Rappolt 1986 = Rappolt, Hedwig: An American Apprenticeship. The Letters of Emil Frey 1860-1865. New York 1986.

Ritter 1980 = Ritter, Darlene Mae: The Letters of Louise Ritter from 1893-1925: A Swiss German Immigrant Women to Antelope County in Nebraska. Ann Arbor, Mich. 1980.

\section{GROSSBRITANNIEN:}

Conway 1961 = Conway, Alan (Hrsg.): The Welsh in America. Letters From Immigrants. St. Paul, Minn. 1961. 
Erickson 1972 = Erickson, Charlotte (Hrsg.): Invisible Immigrants. The Adaption of English and Scottish Immigrants in Nineteenth-Century America. London 1972 [Reprint Ithaca, N.Y. 1990].

\section{POLEN:}

Kula 1986 = Kula, Witold: Writing Home: Immigrants in Brazil and the United Staes 1890-1891. New York 1986. (Poln. Original: Listy emigrantów z Brazylii i Stanów. Zjednoczonych 1890-1891. Warszawa 1973).

Thomas/Znaniecki 1974 = Thomas, William/Znaniecki, Florian: The Polish Peasant in Europe and America 1-5. Reprint New York 1974 (Boston, Mass. ${ }^{1} 1918-21$ ).

Zaretsky 1984 = Zaretsky, Eli (Hrsg.): The Polish Peasant in Europe and America. William I. Thomas and Florian Znaniecki. Urbana/Chicago, Ill. 1984.

\section{BIOGRAPHISCHE WERKE ZU FINNISCHEN AUSWANDERERN:}

Ahlbäck 1976 = Ahlbäck, Ragna (Hrsg.): Amerikatrunken. Emigranter berättar om sig själva (Im Amerikarausch. Auswanderer berichten über sich selbst). Porvoo 1976.

Damrell 1991 = Damrell, Joseph (Hrsg.): Isaac Polvi. The Autobiography of a Finnish Immigrant. St. Cloud, Minn. 1991.

Dye/Dye 1975 = Dye, Jacob/Dye, Rex J.: Lumber Camp Life in Michigan. An Autobiographical Account. Hicksville, N.Y. 1975.

Kaurala/Hohl 1995 = Kaurala Dloniak, Miriam/Hohl, Diane M. (Hrsg.): Miriam. Daugther of Finnish Immigrants. New Brighton, Minn. 1995. 
Ketonen $1976=$ Ketonen, John (Hrsg.): Finnish American Horizons. New York Mills, Minn. 1976.

Myhrman 1974 = Myhrman, Anders M. (Hrsg.): Emigrantbiografier 1-8. En samling rörande finlandssvenskar i Amerika (Biographien von Emigranten 1-8. Eine Sammlung von Finnlandschweden in Amerika). Turku 1974. (Åbo Akademis Bibliotek, Stencilserie).

Pelto 1982 = Pelto, Matti: Memoirs from the Minnesota Iron Ore Mines. In: FinnishAmericana 5 (1982) S. 28-33.

Tokoi 1949 = Tokoi, Oskari: Amerikan Suomalaisia. $($ Finnen in Amerika). Helsinki 1949.

Tokoi 1959 = Ders.: Maanpakolaisen muistelmia (Die Erinnerungen eines Flüchtlings). Helsinki $1959\left({ }^{1} 1947\right)$.

Virtaranta 1996 = Ders.: Hauska tutustua. Amerikansuomalaisia tapaamassa ("Nice to meet you". Die Begegnung mit Amerika-Finnen). Helsinki 1996.

\section{LITERATUR}

\section{UNVERÖFFENTLICHTE WERKE:}

Blomfelt 1968 = Blomfeldt, Frank: Emigrationen från ett skärgårdslandskap. Emigrationen från Åland 1856-1918 med särskild hänsyn till Finström och Föglö socknar (Emigration aus einem Schärengebiet. Ålandemigration 1856-1918 unter besonderer Berücksichtigung der Gemeinden Finström und Föglö). Uppsala 1968 [Unveröffentlichte Lizentiatsabhandlung]. 
Hautamäki 1981 = Hautamäki, Aulis: Etelä-Pohjanmaan järviseudun amerikansiirtolaisuus 1872-1917 (Die Amerikaauswanderung aus dem Seengebiet Süd-Ostbottniens 1872-1917). Jyväskylä 1981 [Unveröffentlichte Magisterarbeit].

Huhta 1982 = Huhta, Miika: Siirtolaisuus Suomesta Kanadaan ennen ensimmäistä maailmansotaa ja suomalaisten sijoittuminen Kanadaan (Die finnische Auswanderung nach Kanada vor dem Ersten Weltkrieg und die Anpassung in Kanada). Turku 1982 [Unveröffentlichte Magisterarbeit].

Kero 1970 = Ders: Satakuntalainen amerikansiirtolaisuus ennen ensimmäistä maailmansotaa (Die Amerikaauswanderung aus Satakunta vor dem Ersten Weltkrieg). Turku 1970 [Unveröffentlichte Lizentiatsabhandlung].

Kuhlman 1987 = Kuhlman, Erika: From Farmland to Coalvillage: Finnish Immigration to Red Lodge, Montana, 1890-1920. Missoula, Mont. 1987 [Unveröffentlichte Magisterarbeit].

Lappalainen-Lilja 1981 = Lappalainen-Lilja, Leena: Kiurujärven rannoilta mainariksi Minnesotaan. Erään amerikansiirtolaisen akkulturaatio (Von den Ufern des Kiuru-Sees in die Bergwerke von Minnesota. Die Akkulturation eines AmerikaFinnen). Turku 1981 [Unveröffentlichte Magisterarbeit].

Saarelainen 1974 = Saarelainen, Harri: Suomalaisyhteisöjen kehitysvaiheet PohjoisMinnesotan Mesabi-vuoriston kaivospaikkakunnilla vuosina 1890-1914 (Die Entwicklung der finnischen Einwanderergruppen in den Bergwerksorten des MesabiGebirges im Norden Minnesotas). Turku 1974 [Unveröffentlichte Magisterarbeit].

Spieckermann 1995 = Spieckermann, Thomas: Vergleich deutscher und britischer Auswanderung im 19. Jahrhundert auf der Grundlage von Auswandererbriefen in die Heimat. [Unveröffentlichte Hauptseminar-Arbeit des Historischen Seminars der Universität Bochum vom WS 1995/96]. 


\section{VERÖFFENTLICHTE WERKE:}

Acton/Goldsmith/Shepard 1974 = Acton, Janice/Goldsmith, Penny/Shepard, Bonnie (Hrsg.): Women at Work. Ontario 1850-1930. Toronto 1974.

Adams 1984 = Adams, Willi Paul: Die Assimilationsfrage in der amerikanischen Einwanderungsdiskussion 1890-1930. In: Bade 1984, Bd. 1, S. 300-320.

Adams Hegstad 1985 = Adams Hegstad, Patsy: Scandinavian Settlement in Seattle, ”Queen City of Puget Sound”. In: Norwegian-American Studies 30 (1985) S. 55-74.

Aho 1993 = Aho, William R.: Finnish American Identity and Sisu. In:

Siirtolaisuus/Migration, Heft 3 (1993) S. 10-15.

Ahvenainen 1982 = Ahvenainen, Jorma (Hrsg.): Suomen taloushistoria 2. Teollistuva Suomi (Finnische Wirtschaftsgeschichte 2. Der Beginn der finnischen Industrialisierung). Helsinki 1982.

Alanen 1981a = Alanen, Arnold R.: In Search of the Pioneer Finnish Homesteader in America. In: Finnish Americana 4 (1981) S. 72-92.

Alanen 1981b = Ders.: Finns and the Corporate Mining Environment of the Lake Superior Region. In: Karni 1981b, S. 33-61.

Alanen 1982 = Ders.: The 'Locations'. Company Communities on Minnesota's Iron Ranges. In: Minnesota History 48 (1982) S. 94-107.

Alanen 1983a = Ders.: The Background in Arctic Norway for Early Finnish Emigration to the American Midwest. In: Finnish Americana 6 (1983) S. 23-33.

Alanen 1983b = Ders.: Kaivosmiehistä maanviljelijöihin: Suomalaiset siirtolaiset pohjoisten suurten järvien alueella yhdysvalloissa (Vom Bergmann zum Farmer: Fin- 
nische Auswanderer im nördlichen Bereich der Großen Seen in den Vereinigten Staaten). In: Siirtolaisuus/Migration, Heft 4 (1983) S. 1-17.

Alanen 1988 = Ders.: Finns and Other Immigrant Groups in the American Upper Midwest: Interactions and Comparisons. In: Karni/Koivukangas/Laine 1988, S. 58-83.

Alanen 1991a = Ders.: From Tower to Soudan: Townsites and Locations on the Vermilion Iron Range. In: Karni 1991, S. 32-39.

Alanen 1991b = Ders.: Companies as Caretakers: Paternalism, Welfare Capitalism, and Immigrants in the Lake Superior Mining Region. In: Vecoli/Sinke 1991, S. $364-$ 391.

Alanen/Tishler 1980 = Alanen, Arnold/Tishler, William H.: Finnish Farmstead Organization in Old and New World Settings. In: Journal of Cultural Geography 1 (1980) S. 66-80.

Alapuro 1985 = Alapuro, Risto: Yhteiskuntaluokat ja sosiaaliset kerrostumat 1870luvulta toiseen maailmansotaan (Gesellschaftsschichten und Sozialstrukturen von 1870 bis zum Zweiten Weltkrieg). In: Valkonen 1985a, S. 36-100.

Alapuro 1988 = Ders.: State and Revolution in Finland. Berkeley, Cal. u.a. 1988.

Alapuro 1995 = Ders.: Suomen synty paikallisena ilmiönä 1890-1933 (Die Entstehung Finnlands als lokales Phänomen 1890-1933). Porvoo 1995.

Albrecht 1972a = Albrecht, Günter: Soziologie der geographischen Mobilität. Zugleich ein Beitrag zur Soziologie des sozialen Wandels. Stuttgart 1972.

Albrecht 1972b = Ders.: Zur Stellung historischer Forschungsmethoden und nichtreaktiver Methoden im System der empirischen Sozialforschung. In: Ludz, Peter C.: (Hrsg.): Soziologie und Sozialgeschichte. Köln/Opladen 1972, S. 242-293 (Kölner Zeitschrift für Soziologie und Sozialpsychologie, Sonderheft Nr. 16). 
Alexander 1991 = Alexander, June Granatir: Moving into and out of Pittsburgh: Ongoing Chain Migration. In: Vecoli/Sinke 1991, S. 200-220.

Ander 1964 = Ander, Fritiof Oscar (Hrsg.): In the Trek of Immigrants. Rock Island, Ill. 1964.

Anderson/Niskala 1981 = Anderson, Alan B./Niskala, Brenda: Finnish Settlements in Saskatchewan: Their Develoment and Perpetuation. In: Karni 1981a, S. 155-182.

Anderson/Blanck 1991 = Anderson, Philip J./Blanck, Dag (Hrsg.): SwedishAmerican Life in Chicago. Cultural and Urban Aspects of Immigrant People, 18501930. Uppsala 1991.

Apunen 1987 = Apunen, Osmo: Rajamaasta tasavallaksi (Vom Grenzland zur Republik). In: Tarkka 1987, S. 46-406.

Armgort 1991 = Armgort, Arno: Bremen, Bremerhaven, New York, 1683-1960. Geschichte der Auswanderung über die bremischen Häfen. Bremen 1991.

Arra 1971 = Arra, Esa: Illinosin Suomalaiset (Finnen in Illinois). New York Mills, Minn. 1971.

Assion 1983 = Assion, Peter: Amerika-Auswanderung und Fotografie 1860 bis 1930. In: Fotogeschichte 3 (1983) S. 3-18.

Assion 1985a = Ders. (Hrsg.): Der große Aufbruch. Studien zur Amerikaauswanderung. Marburg 1985 (Hessische Blätter zur Volkskunde, 17).

Assion 1985b = Ders.: Abschied, Überfahrt und Ankunft. Zur brauchtümlichen Bewältigung des Auswanderungsverlaufs. In: Assion 1985a, S. 125-149.

Assion 1987 = Ders.: Von Hessen in die Neue Welt. Frankfurt/Main 1987. 
Assion 1988 = Ders.: Fremdheitserwartung und Fremdheitserfahrung bei den deutschen Amerikaauswanderern im 19. Jahrhundert. In: Greverus, Ina-Maria (Hrsg.): Kulturkontakt - Kulturkonflikt. Zur Erfahrung des Fremden. Frankfurt/Main 1988, S. 157167 (Notizen, 28).

Assion 1989 = Ders.: Die Ursachen der Massenauswanderung in die Vereinigten Staaten - Objektive Zwänge und subjektive Wahrnehmung. In: Zeitschrift für Kulturaustausch, Heft 3 (1989) S. 258-266.

Atteslander 1975 = Atteslander, Peter: Methoden der empirischen Sozialforschung. Berlin/ New York 1975 ( $\left.{ }^{1} 1969\right)$.

Åkerman 1970 = Åkerman, Sune: General Theory and Models of Explanation. In: Nordic Emigration (Research Conference in Uppsala, Sept. 1969). Uppsala 1970, S. $17-21$.

Åkerman 1973 = Ders.: Migrationen - ett tvärvetenskapligt forskningsomrade (Migration - ein interdisziplinäres Forschungsfeld). In: Kälvemark 1973a, S. 15-52.

Åkerman 1976 = Ders.: Theories and Methods of Migration Research. In: Runblom/Norman 1976, S.19-75.

Åkerman 1978 = Ders.: Towards an Understanding of Emigrational Processes. In: Scandinavian Journal of History 3 (1978) S. 131-154.

Backman 1945 = Backman, Woldemar: Emigrationen från Munsala Socken (Auswanderung aus der Gemeinde Munsala). Helsinki 1945.

Bade 1984 = Bade, Klaus J. (Hrsg.): Auswanderer-Wanderarbeiter-Gastarbeiter. 2 Bde. Ostfildern 1984. 
Bade 1992 = Ders. (Hrsg.): Deutsche im Ausland - Fremde in Deutschland: Migration in Geschichte und Gegenwart. München 1992.

Barton 1993 = Barton, Arnold H.: As They Tell It Themselves: The Testimony of Immigrant Letters. In: Lovoll 1993, S. 138-145.

Barton 1994 = Ders.: A Folk Divided. Homeland Swedes and Swedish Americans, 1840-1940. Uppsala 1994.

Beijbom 1971 = Beijbom, Ulf: Swedes in Chicago. A Demographic and Social Study of the 1846-1880 Immigration. Uppsala 1971.

Beijbom 1973 = Ders.: Från slum till förort. Chicagos Swede Town (Vom Slum zum Vorort. 'Swede Town' in Chicago). In: Kälvemark 1973a, S. 179-211.

Beijbom 1981 = Ders.: Swedes. In: Thernstrom/Olov/Handlin 1981, S. 971-981.

Bender/Flemming Larsen 1991 = Bender, Henning/Flemming Larsen, Birgit (Hrsg.): Danish Emigration to Canada. Aalborg 1991.

Bennett 1963 = Bennett, Marion T.: American Immigration Policies. A History. Washington, D.C. 1963.

Bernard 1981 = Bernard, William S.: Immigration: History of the U.S. Policy. In: Thernstrom/Olov/Handlin 1981, S. 486-495.

Betten 1967 = Betten, Neil: Strike on the Mesabi - 1907. In: Minnesota History 40 (1967) S. 340-347.

Bickelmann 1982 = Bickelmann, Hartmut: Das Abenteuer der Reise; Das Geschäft der Auswanderung. In: Zeitschrift für Kulturaustausch, Heft 4 (1982) S. 330-335; S. 336-341. 
Björkfors 1998 = Björkfors, Peter: The Finns on the Titanic. In: Siirtolaisuus/ Migration, Heft 1 (1998) S. 3-7.

Blake 1963 = Blake, Nelson Manfred: A History of American Life and Thought. New York u.a. 1963.

Blegen 1929 = Blegen, Theodore C.: The "America Letters". In: Avhandlingar utgitt av det Norske Videnskaps-Akademi i Oslo, II. Historisk-Filosofisk Klasse (1928). Oslo 1929 , S. 1-25.

Blegen $1930=$ Ders.: Immigrant Women and American Frontier. Three Early 'America Letters'. In: Norwegian-American Historical Association. Studies and Records 5 (1930) S. 14-29.

Blegen 1931 = Ders.: Norwegian Migration to America 1825-1860, Bd.1. Northfield, Minn. 1931 [Reprint New York 1969].

Blegen 1940 = Ders.: Norwegian Migration to America: The American Transition, Bd.2. Northfield, Minn. 1940.

Blegen 1963 = Ders.: Minnesota. A History of the State. Minneapolis, Minn. 1963.

Bodnar 1987 = Bodnar, John: The Transplanted. A History of Immigrants in Urban America. Bloomington, Ind. 1987 ( $\left.{ }^{1} 1985\right)$.

Brattne 1973 = Brattne, Berit: Bröderna Larsson. En studie i svensk emigrantagentverksamhet under 1880-talet (Die Brüder Larsson. Eine Untersuchung über die Tätigkeit schwedischer Auswandereragenten in den 1880er Jahren). Uppsala 1973.

Brattne/Åkerman 1976 = Brattne, Berit/Åkerman, Sune: The Importance of the Transport for Mass Emigration. In: Runblom/Norman 1976, S. 176-200. 
Brenner 1991 = Brenner, Peter J.: Reisen in die Neue Welt. Die Erfahrung Nordamerikas in deutschen Reise- und Auswandererberichten des 19. Jahrhunderts. Tübingen 1991 (Studien und Texte zur Sozialgeschichte der Literatur, 35).

Bretting 1981 = Bretting, Agnes: Soziale Probleme deutscher Einwanderer in New York City 1800-1860. Wiesbaden 1981.

Bretting 1992 = Diess.: Die Reise. In: Hoerder/Knauf 1992, S. 75-122.

Brinkmann 1971 = Brinkmann, Henning: Die deutsche Sprache.Gestalt und Leistung. Düsseldorf 1971 ( $\left.{ }^{1} 1962\right)$.

Bürgel 1976 = Bürgel, Peter: Der Privatbrief. Entwurf eines heuristischen Modells. In: Deutsche Vierteljahresschrift für Literaturwissenschaft 50 (1976) S. 281-297.

Burchell 1992 = Burchell, Robert A.: Die Einwanderung nach Amerika im 19. und 20. Jahrhundert. In: Adams, Willi P. (Hrsg.): Die Vereinigten Staaten von Amerika. Frankfurt/Main 1992 ( $\left.{ }^{1} 1977\right)$, S. 184-234.

Burton Skårdal 1981 = Burton Skårdal, Dorothy: Danes. In: Thernstrom/Olov/ Handlin 1981, S. 273-282.

Carlsson 1976 = Carlsson, Sten: Chronology and Composition of Swedish Emigration to America. In: Runblom/Norman 1976, S. 114-148.

Carlsson 1988 = Ders.: Kolonisterna i Nya Sverige (Die Koloniegründer von 'New Sweden'). In: Finsk Tidskrift 5 (1988) S. 258-269.

Cleef van 1952 = Cleef van, Eugene: Finnish Settlement in Canada. In: Geographical Review 42 (1952) S. 253-266.

Commager Steele 1961 = Commager Steele, Henry (Hrsg.): Immigration and American History. Minneapolis, Minn. 1961. 
Dahlie/Fernando 1981 = Dahlie, Jörgen/Fernando, Tissa (Hrsg.): Ethnicity, Power and Politics in Canada. Toronto 1981.

Dahms 1991 = Dahms, Hellmuth Günther: Grundzüge der Geschichte der Vereinigten Staaten. Darmstadt $1991\left({ }^{1} 1971\right)$.

Daniels 1990 = Daniels, Roger: Coming to America. A History of Immigration and Ethnicity in American Life. New York 1990.

Dickinson 1980 = Dickinson, Joan Younger: The Role of the Immigrant Women in the U.S. Labor Force 1890-1910. New York 1980.

Dinnerstein/Reimers 1988 = Dinnerstein, Leonard/Reimers, David M.: Ethnic Americans: A History of Immigration. New York 1988 ( $\left.{ }^{1} 1975\right)$.

Dittrich 1985 = Dittrich, Ursula: Die Hamburger Passagierlisten als Quelle für die hessische Amerika-Auswanderung. In: Assion 1985a, S. 221-228.

Djupedal 1989 = Djupedal, Knut: Personal Letters as Research Sources. In: Ethnologia Scandinavia 19 (1989) S. 51-63.

Dublin 1979 = Dublin, Thomas: Women at Work. The Transformation of Work and Community in Lowell, Massachusetts, 1826-1860. New York 1979.

Dunbar 1970 = Dunbar, Willis Frederick: Michigan. A History of the Wolverine State. Grand Rapids, Mich. 1970 ( $\left.{ }^{1} 1965\right)$.

Easterlin 1972 = Easterlin, Richard A.: Lange Wellen im amerikanischen Bevölkerungs- und Wirtschaftswachstum. Einige Ergebnisse zur Untersuchung der historischen Strukturen. In: Köllmann/Marschalck 1972, S. 45-68. [Engl. Original: Economic-Demographic Interactions and Long Swings in Economic Growth. In: The American Economic Review 56, No. 5 (1966) S. 1063-1104]. 
Easterlin 1981 = Ders.: Immigration: Economic and Social Characteristics. In: Thernstrom/Olov/Handlin 1981, S. 476-486. [Dt. Übersetzung: Wirtschaftliche und soziale Aspekte der Einwanderung. In: Elschenbroich 1985, S. 25-52].

Elschenbroich 1985 = Elschenbroich, Donata (Hrsg.): Einwanderung, Integration, ethnische Bindung. Frankfurt/Main 1985.

Elschenbroich 1986 = Diess.: Eine Nation von Einwanderern. Ethnisches Bewußtsein und Integrationspolitik in den USA. Frankfurt/Main 1986.

Emmons 1989= Emmons, David M: The Butte Irish. Class and Ethnicity in an American Mining Town, 1875-1925. Urbana/Chicago, Ill. 1989.

Engberg 1959 = Engberg, George B.: Lumber and Labor in the Lake States. In: Minnesota History 36 (1959) S. 153-166.

Engelberg 1944 = Engelberg, Rafael: Suomi ja Amerikan Suomalaiset. Keskinäinen yhteys ja sen rakentaminen (Finnland und die Amerika-Finnen. Der Kontakt und dessen Aufrechterhaltung). Helsinki 1944.

Engman 1983 = Engman, Max: St. Petersburg och Finland. Migration och influens 1703-1917 (St. Petersburg und Finnland. Migration und Einfluß 1703-1917). Helsinki 1983.

Engman 1990 = Ders.: St. Petersburg und Finnland. In: Hösch, Edgar (Hrsg.): Finnland-Studien 59. Wiesbaden 1990, S. 74-84.

Engman 1992 = Ders.: The Finns in St Petersburg. In: Ders. (Hrsg.): Ethnic Identity in Urban Europe. New York 1992, S. 99-123.

Engman 1995 = Ders.: Petersburgska vägar (Wege nach St. Petersburg). Loviisa 1995. 
Engman/Jungar 1980 = Engman, Max/Jungar, Sune: Flyttningsrörelsen från Finland till Ryssland 1809-1917 (Die Wanderungsbewegung von Finnland nach Russland 1809-1917). In: Suomen Historiallinen Arkisto 75 (1980) S. 23-47.

Erickson 1980 = Diess.: Explanatory Models in Immigration and Migration Research. In: Semmingsen, Ingrid/Seyersted, Per (Hrsg.): Scando Americana. Papers on Scandinavian Emigration to the United States. Oslo 1980, S. 7-20.

Ermert 1979 = Ermert, Karl: Briefsorten. Untersuchungen zu Theorie und Empirie der Textklassifikation. Tübingen 1979. (Germanistische Linguistik, 20).

Ewen 1985 = Ewen, Elizabeth: Immigrant Women in the Land of Dollars. Life and Culture on the Lower East Side 1890-1925. New York 1985.

Fapso 1977 = Fapso, Richard J.: Norwegians in Wisconsin. Madison, Wisc. 1977. (The State Historical Society of Wisconsin).

Ferenczi/Willcox 1969 = Ferenczi, Imre/Willcox, Walter F.: International Migrations, Vol. 1: Statistics. Reprint New York 1969 ( $\left.{ }^{1} 1929\right)$.

Finns/Hoquiam 1987 = Finns of Hoquiam and Aberdeen, Crays Harbor County, Washington. Published by Finnish American Historical Society of the West. Portland, Oreg. 1987. (Pioneer Series Vol. 15, No.1).

Finns/Idaho 1990 = Finnish Settlers of Long Valley, Idaho. Published by Finnish American Historical Society of the West. Portland, Oreg. 1990 (Special Pioneer Edition Vol.18, No.1).

Finns/Washington 1976 = Coal Mining Finns of Washington State. Published by Finnish-American Historical Society of the West. Portland, Oreg. 1976. (Finnish Emigrant Studies Series Vol. 9, No. 2). 
Finns/Worcester 1994 = Strength in Diversity. Worcester's Finnish Community. A Collection of Photographs and Recollections. Publ. by The Finnish-American Club of Rutland. Worcester, Mass. 1994. [Ausstellungskatalog].

Finzsch 1982 = Finzsch, Norbert: Die Goldgräber Kaliforniens. Arbeitsbedingungen, Lebensstandard und politisches System um die Mitte des 19. Jahrhunderts. Göttingen 1982.

Flemming Larsen/Bender 1992 = Flemming Larsen, Birgit/Bender, Henning (Hrsg.): Danish Emigration to the U.S.A. Aalborg 1992.

Forsberg 1977 = Forsberg, Karl-Erik: Befolkningsutvecklingen efter år 1749 (Die Bevölkerungsentwicklung nach 1749). In: Svenska Österbottnes historia 1 (Die Geschichte von Schwedisch-Ostbottnien 1). Hrsg. von Svenska Österbottens Landskapsförbund (Landschaftsverband von Schwedisch-Ostbottnien). Vaasa 1977, S. 213-303.

Fågelbärj 1985 = Fågelbärj, Nelly: En levande mans änka (Die Witwe eines lebenden Mannes). In: Nyström 1985, S. 141-145.

Geer de $1951=$ Geer de, Eric: Migration in the Archipelago of Southwestern Finland During the Last Hundred Years. In: Fennia 84 (1951) S. 67-90.

Geer de 1977 = Ders.: Migration och influensfält. Studier av emigration och intern migration i Finland och Sverige 1816-1972 (Migration und Einflußbereich. Untersuchungen zu Auswanderung und Binnenmigration in Finnland und Schweden 18161972). Uppsala 1977.

Geer de 1981 = Ders.: Siirtolaisuus Suomesta Ruotsiin 1808-1945 (Die Auswanderung von Finnland nach Schweden 1808-1945). In: Koivukangas, Olavi (Hrsg.): Siirtolaisuus Suomesta Ruotsiin kautta aikojen (Die Auswanderung von Finnland nach Schweden im Laufe der Zeit). Turku 1981, S. 45-62. 
Geer de/Wester 1975 = Geer de, Eric/Wester, Holger: Utrikes resor, arbetsvandringar och flyttningar i Finland och Vasa län 1861-1890 (Auslandsreisen, Arbeitswanderungen und Binnenwanderungen in Finnland und dem Regierungsbezirk Vaasa 18611890). Vaasa 1975.

Genevieve 1974 = Genevieve, Leslie: Domestic Service in Canada, 1880-1920. In: Acton/Goldsmith/Shepard 1974, S. 71-125.

Gibbs 1957 = Gibbs, Vernon C. R.: British Passenger Liners of the Five Oceans. A Record of the British Passenger Lines and Their Liners from 1838 to the Present Day. London 1957 ( $\left.{ }^{1} 1952\right)$.

Gleason 1981 = Gleason, Philip: American Identity and Americanization. In: Thernstrom/Olov/Handlin 1981, S. 31-58.

Götz/Löffler/Speckle 1993 = Götz, Irene/Löffler, Klara/Speckle, Birgit: Briefe als Medium der Alltagskommunikation. Eine Skizze zu ihrer kontextorientierten Auswertung. In: Schweizerisches Archiv für Volkskunde 89 (1993) S. 165-183.

Gordon 1964 = Gordon, Milton M.: Assimilation in American Life. The Role of Race, Religion, and National Origins. New York 1964.

Gould 1980 = Gould, J. D.: European Inter-Continental Emigration. The Road Home: Return Migration from the U.S.A. In: The Journal of European Economic History 9 (1980) S. 41-112.

Greverus 1965 = Greverus, Ina-Maria: Heimweh und Tradition. In: Schweizerisches Archiv für Volkskunde 61 (1965) S. 1-31.

Greverus 1971 = Diess.: Auswanderung und Anpassungsbarrieren. Hypothesen zur Integration von Minderheiten. In: Wiegelmann, Günter (Hrsg.): Kultureller Wandel im 19. Jahrhundert (Verhandlungen des 18. Dt. Volkskunde-Kongreßes in Trier). Trier 1971, S. 204-218. 
Greverus 1972 = Diess.: Auswanderung und Zeitwanderung. In: Greverus, Ina-Maria: Der territoriale Mensch. Frankfurt/Main 1972, S. 131-202.

Groneman 1978 = Groneman, Carol: Working-Class Immigrant Women in MidNineteenth-Century New York. The Irish Women's Experience. In: Journal of Urban History 4, No. 3 (1978) S. 255-273.

Guggisberg 1993 = Guggisberg, Hans. R.: Geschichte der USA. Stuttgart/Berlin/Köln $1993\left({ }^{1} 1975\right)$.

Guillet 1963 = Guillet, Edwin C.: The Great Migration. The Atlantic Crossing by Sailing-Ship since 1770. Reprint Toronto $1963\left({ }^{1} 1937\right)$.

Gutman 1973 = Gutman, Herbert G.: Work, Culture, and Society in Industrializing America, 1815-1919. In: American Historical Review 78 (1973) S. 531-588.

Hämäläinen 1985 = Hämäläinen, Vilho: Vanhan Suomen venäläiset huvila-asukkaat (Die russischen Sommervillenbewohner des alten Finnland). In: Kurkinen 1985, S. 115-124.

Hale 1981= Hale, Frederick: Danes in Wisconsin. Madison, Wisc. 1981 (The State Historical Society of Wisconsin).

Hale 1984 = Ders. (Hrsg): Danes in North America. Seattle, Wash. 1984.

Halila 1983 = Halila, Aimo: Kansanopetus (Volksschulbildung). In: Tommila 1983a, S. $165-174$.

Halila 1986 = Ders.: Aleksanteri II (Alexander II.), S. 176; Koulutus, kirkko ja tiede (Schulbildung, Kirche und Wissenschaft), S. 287-303; Sääty-yhteiskunta alkaa hajota (Der beginnende Verfall der Ständegesellschaft), S.203-223; Muuttuva talouselämä 
(Wirtschaftsleben im Wandel), S. 225-243; Ongelmat kasautuvat (Die Probleme häufen sich), S. 305-320. In: Tarkka 1986.

Handlin 1959 = Handlin, Oscar: Boston's Immigrants. A Study of Acculturation. Cambridge, Mass. 1959.

Handlin 1963 = Ders. (Hrsg.): Immigration as a Factor in American History. Englewood Cliffs, Conn. $1963\left({ }^{1} 1959\right)$.

Handlin 1973 = Ders.: The Uprooted. The Epic Story of the Great Migrations that Made the American People. Boston, Mass. 1973 ( $\left.{ }^{1} 1951\right)$.

Hansen 1940 = Hansen, Marcus Lee: The Immigrant in American History. Cambridge, Mass. 1940 [In dt. Übersetz.: Der Einwanderer in der Geschichte Amerikas. Stuttgart 1948].

Hansen 1951 = Ders.: The Atlantic Migration 1607-1860. A History of Continuing Settlement of the United States. Cambridge, Mass. 1951 ( $\left.{ }^{1} 1940\right)$.

Harper/Chase 1975 = Harper, Elizabeth J./Chase, Roland F.: Immigration Laws of the United States. Indianapolis/New York 1975.

Harzig 1992 = Harzig, Christiane: Die Einwanderungsländer. In: Hoerder/Knauf 1992, S. 123-147.

Haugen 1975 = Haugen, Einar: The Norwegians in America 1825-1975. New York $1975\left({ }^{1} 1967\right)$.

Hautala 1956 = Hautala, Kustaa: Suomen tervakauppa 1865-1913 (Der finnische Teerhandel 1865-1913). Helsinki 1956.

Hautala 1967 = Ders.: Merimiesten karkaaminen suomalaisilta laivoilta 1800-luvulla (Finnische Seeleute als Deserteure im 19. Jahrhundert). In: Näkökulmia menneisyy- 
teen (Perspektiven in die Vergangenheit). Porvoo 1967, S. 101-116. [Festschrift für Eino Jutikkala].

Haynes 1971 = Haynes, John E.: Revolt of the "Timber Beasts". IWW Lumber Strike in Minnesota. In: Minnesota History 42 (1971) S. 163-174.

Heervä 1980 = Heervä, Ismo: Merikarvian kirkonkylä (Die Gemeinde Merikarvia). In: Tommila, Päiviö/ Heervä, Ismo (Hrsg.): Muuttuva kylä. Turun Yliopiston kylätutkimusryhmän loppuraportti (Das Dorf im Wandel. Abschlußbericht der Arbeitsgruppe ‘Dorfstrukturen’ der Universität Turku). Turku 1980, S. 64-93.

Heikkinen/Hoffman 1982 = Heikkinen, Sakari/Hoffman, Kai: Teollisuus ja käsityö (Industrie und Handwerk). In: Ahvenainen 1982, S. 52-88.

Helbich 1985 = Helbich, Wolfgang J.: Letters from America: Documents of Adjustment Process of German Immigrants in the United States. In: Anglistik und Englischunterricht 26 (1985) S. 201-215.

Helbich 1987 = Ders.: The Letters They Sent Home: The Subjective Perspective of German Immigrants in the Nineteenth Century. In: Yearbook of German-American Studies 22 (1987) S. 1-20.

Helbich 1989 = Ders.: Die deutsche Auswanderung in die Vereinigten Staaten von Amerika im 19. Jahrhundert: Die Aussage der Auswandererbriefe zu Information, Motivation und nichtinstitutioneller Fürsorge. In: Zeitschrift für Kulturaustausch, Heft 3 (1989) S. 266-278.

Helbich 1990 = Ders.: Stereotypen in Auswandererbriefen. Die USA im 19. Jahrhundert aus der Sicht deutscher Einwanderer. In: Maler, Anselm (Hrsg.): Exotische Welt in populären Lektüren. Tübingen 1990, S. 63-80. 
Helbich/Haubold 1988 = Helbich, Wolfgang J./Haubold, Anette: "Alle Menschen sind dort gleich..." Die deutsche Amerika-Auswanderung im 19. und 20. Jahrhundert. Düsseldorf 1988 (Historisches Seminar, 10).

Hiipakka Lockwood 1988 = Hiipakka Lockwood, Yvonne: Folklore and FinnishAmerican Identity. In: Karni/Koivukangas/Laine 1988, S. 464 -473.

Hill 1976 = Hill, Jack: A History of Iron County Michigan. Norway, Mich. 1976.

Hirvonen 1920 = Hirvonen, Juuso: Michiganin kuparialue ja suomalaiset siirtolaiset (Das Kupferbergwerksgebiet in Michigan und die finnischen Auswanderer). Duluth, Minn. 1920.

Hjerppe 1981 = Hjerppe, Riitta: Käsityöläiset uuden yhteiskunnan murroksessa (Handwerker in einer gesellschaftlichen Umbruchszeit). In:

Kaukiainen/Schybergson/Soikkanen 1981, S. 213-235.

Hoerder 1983 = Hoerder, Dirk (Hrsg.): American Labor and Immigration History 1877-1920’s: Recent European Research. Urbana, Ill. u.a. 1983.

Hoerder 1985a = Ders. (Hrsg.): Labor Migration in the Atlantic Economies. The European and North American Working Classes during the Period of Industrialization. Westport, Conn. 1985.

Hoerder 1985b = Ders.: An Introduction to Labor Migration in the Atlantic Economies, 1815-1914; Acculturation Twice: Return Migration. In: Hoerder 1985a, S. 3-31; S. 353-355.

Hoerder 1986 = Ders. (Hrsg.): "Struggle a Hard Battle": Essays on Working-Class Immigrants. De Kalb, Ill. 1986. 
Hoerder 1989 = Ders.: Auswandererverschiffung über Bremen/Bremerhaven: Staatliche Schutzmaßnahmen und Erfahrungen der Migranten. In: Zeitschrift für Kulturaustausch, Heft 3 (1989) S. 279-291.

Hoerder 1991 = Ders.: International Labor Markets and Community Building by Migrant Workers in the Atlantic Economies. In: Vecoli/Sinke 1991, S. 78-107.

Hoerder/Knauf 1992 = Hoerder, Wolfgang/Knauf, Diethelm (Hrsg.): Aufbruch in die Fremde. Europäische Auswanderung nach Übersee. Bremen 1992.

Hoglund $1960=$ Hoglund, William A.: Finnish Immigrants in America 1880-1920. Madison, Wisc. 1960.

Hoglund 1964 = Ders.: Finnish Immigrant Farmers in New York, 1910-1960. In: Ander 1964, S. 141-155.

Hoglund 1975 = Ders.: No Land for Finns: Critics and Reformers View. The Rural Exodus from Finland to America between the 1880's and World War I. In: Karni/Kaups/Ollila 1975, S. 36-54.

Hoglund 1978 = Ders.: Flight from Industry: Finns and Farming in America. In: Finnish Americana 1 (1978) S. 1-21.

Hoglund 1981a = Ders.: Finns. In: Thernstrom/Olov/Handlin 1981, S. 362-370.

Hoglund 1981b = Ders.: Finnish Immigrant Letter-Writers: Reporting from the United States to Finland, 1870s to World War I. In: Karni 1981b, S. 13-31.

Hoglund 1985 = Ders.: Finnish-Americans and Their Disappering Immigrant Generation. In: Scandinavian Review (1985) S. 62-71.

Hoglund 1991 = Ders.: Minnesota Finns Looking at Themselves. In: Karni 1991, S. 47-54. 
Hoglund 1993 = Ders.: Training for the Class Struggle: Finnish Immigrants and Workers` Education, 1899 to World War II. In: Lovoll 1993, S. 47-60.

Hollingsworth 1982 = Hollingsworth, Sandra: The Atlantic. Copper and Community South of Portage Lake. Hancock, Mich. $1982\left({ }^{1} 1978\right)$.

Holmio 1967 = Holmio, Armas K. E.: Michiganin suomalaisten historia (Die Geschichte der Finnen in Michigan). Hancock, Mich. 1967.

Holmquist 1981 = Holmquist, June D. (Hrsg.): They Chose Minnesota. A Survey of the State's Ethnic Groups. St. Paul, Minn. 1981.

Hummasti 1975 = Hummasti, Paul George: Finnish Radicals in Astoria, Oregon, 1904-1940: A Study in Immigrant Socialism. Portland, Oreg. 1975.

Hummasti 1978 = Ders.: The Establishment of the Finnish Settlement in Astoria, Oregon: A Look at Community Development. In: Finnish Americana 1 (1978) S. 84-98.

Hummasti 1988 = Ders.: From Kälviä to Astoria: Finnish Families in Transition. In: Karni/Koivukangas/Laine 1988, S.154-165.

Hummasti 1990 = Ders.: Children an Social Change: Thoughts on the Second Generation of Finnish Americans. In: Kostiainen 1990, S. 85-95.

Hutchinson 1976 = Hutchinson, E. P.: Immigrants and Their Children, 1850-1950. Reprint New York $1976\left({ }^{1} 1956\right)$.

Hvidt 1971 = Hvidt, Kristian: Flugten til Amerika. Drivkræfter i massudvandringen fra Danmark 1868-1914 (Flucht nach Amerika. Die treibenden Kräfte der Massenauswanderung aus Dänemark 1868-1914). Kopenhagen 1971 [Engl. Übersetzung: Flight to America. The Social Background of 300.000 Danish Emigrants. New York 1975]. 
Hvidt 1978 = Ders.: Emigration Agents. The Development of a Business and its Methods. In: Scandinavian Journal of History 3 (1978) S. 179-203.

Hyde 1975 = Hyde, Francis E.: Cunard and the North Atlantic 1840-1973. A History of Shipping and Financial Management. Liverpool 1975.

Ilmonen 1919-26 = Ilmonen, Salomon: Amerikan suomalaisten historia 1-3 (Die Geschichte der Finnen in Amerika 1-3). Hancock, Mich. Bd. 1(1919), Bd. 2 (1923), Bd. 3 (1926).

Ilmonen 1930-31 = Ders.: Amerikan suomalaisten sivistyshistoria 1-2 (Die Kulturgeschichte der Finnen in Amerika 1-2). Hancock, Mich. Bd. 1(1930), Bd. 2 (1931).

Jaakkola 1987 = Jaakkola, Jouko: Suomen ensimmäinen teollisuustyöväestö (Die erste Industriearbeiterschaft Finnlands). In: Tarkka 1987, S. 76-77.

Jackson 1986 = Jackson, John Archer: Migration. New York 1986.

Järnefelt 1899 = Järnefelt, Akseli: Suomalaiset Amerikassa (Finnen in Amerika). Helsinki 1899.

Järnefelt 1921 = Ders.: Meikäläisiä merten takana. Kuvauksia Amerikan suomalaisista (Unsereins jenseits der Meere. Berichte von Amerika-Finnen). Porvoo 1921.

Järvinen 1994 = Järvinen, Juhani: From Finland to Canada. Siirtolaiselämää Sault Ste. Mariessa vuosina 1890-1914 (Das Leben der Auswanderer in Sault Ste. Marie 18901940). Sault Ste. Marie, Mich. 1994.

Jalkanen 1969 = Jalkanen, Ralph J. (Hrsg.): The Finns in North America. Hancock, Mich. 1969.

Jalkanen 1976 = Ders.: Suomi College. In: Niitemaa/Saukkonen/Aaltio 1976, S. 175179. 
Jensen 1993 =Jensen, Rudolf J.: The Story Told in Denmark Letters: Correspondence from the Old Country. In: Lovoll 1993, S. 199-206.

Jerome 1926 = Jerome, Harry: Migration and Business Cycles. St. Albans, Vt 1926.

Jokinen 1976 = Ders.: Economic Activities of the Finns in the United States. In: Niitemaa/Saukkonen/Aaltio 1976, S. 103-114.

Jokipii 1982 = Jokipii, Mauno: Ruijan suomalaisasutuksen historian päälinjoja (Die Geschichte der finnischen Ruija-Bewohner). In: Maija-Liisa Kalhama (Hrsg.): Suomalaiset jäämeren rannoilla (Die Finnen der Eismeerküste). Turku 1982, S. 1971.

Jones 1974 = Jones, Maldwyn Allen: American Immigration. Chicago/London 1974 $\left({ }^{1} 1960\right)$.

Jones 1976 = Ders.: Destination America. New York 1976.

Juntunen 1986 = Juntunen, Alpo: Pietarin suomalaiset (Die Finnen aus St.

Petersburg). In: Tarkka 1986, S. 210-211.

Just 1988 = Just, Michael: Ost- und südeuropäische Amerikaauswanderung 18811914. Transitprobleme in Deutschland und Aufnahme in den Vereinigten Staaten. Wiesbaden 1988.

Jutikkala 1958 = Jutikkala, Eino: Suomen talonpojan historia (Die Geschichte des finnischen Bauern). Helsinki 1958.

Jutikkala 1963 = Ders.: Etelä-Pohjanmaa ja siirtolaisuus (Süd-Ostbottnien und die Auswanderung). In: Historiallinen Aikakauskirja 61 (1963) S. 329-332. [Rez. von A.-L. Toivonen: Etelä-Pohjanmaan valtamerentakainen siirtolaisuus 1867-1930. Helsinki 1963]. 
Jutikkala 1976 = Ders.: Geschichte Finnlands. Stuttgart $1976\left({ }^{1} 1964\right)$.

Jutikkala 1983 = Ders: Urbanisoituminen. Kaupunkien kasvu 1870-1920 (Urbanisierung. Das Städtewachstum 1870-1920). In: Tommila 1983b, S. 9-26.

Jutikkala 1987 = Ders.: Finlands befolkning och befolknande (Finnlands Besiedlung und Bevölkerung). In: Historisk Tidskrift för Finland 72 (1987) S. 351-373.

Jutikkala/Kaukiainen/Åström 1980 = Jutikkala, Eino/Kaukiainen, Yrjö/, Åström, Sven-Erik (Hrsg.): Suomen taloushistoria 1. Agraarinen Suomi (Finnische Wirtschaftsgeschichte 1. Finnland im Agrarzeitalter). Helsinki 1980.

Juva 1960 = Juva, Einar W.: Laiton asevelvollisuuslaki, kutsuntalakko ja virkamiesten erottamiset (Das gesetzeswidrige Wehrpflichtgesetz, der Musterungsboykott und die Beamtenentlassungen). In: Tommila 1960, S. 63-74.

Kälvemark 1973a = Kälvemark, Ann-Sofie (Hrsg.): Utvandring. Den svenska emigrationen till Amerika i historiskt perspektiv (Auswanderung. Die schwedische Emigration nach Amerika aus historischer Perspektive). Stockholm 1973.

Kälvemark 1973b = Diess.: Flykten från exercisen. Värnplikten som utvandringsorsak (Die Flucht vor dem Exerzieren. Die Wehrpflicht als Auswanderungsursache). In: Kälvemark 1973a, S. 130-150.

Kälevemark 1976 = Diess.: The Causes of Migration. Fear of Military-Service. A Cause of Emigration? In: Runblom/Norman 1976, S. 164-175.

Kallio 1988 = Kallio, Veikko: Taiteen kultakausi (Das goldene Zeitalter der Künste). In: Zetterberg 1988, S. 596-601. 
Kamphoefner 1982 = Kamphoefner, Walter D.: Westfalen in der Neuen Welt. Eine Sozialgeschichte der Auswanderung im 19. Jahrhundert. Münster 1982 (Beiträge zur Volkskultur in Nordwestdeutschland, 26).

Kamphoefner 1984 = Ders.: 'Entwurzelt' oder 'verpflanzt'? Zur Bedeutung der Kettenwanderung für die Einwandererakkulturation in Amerika. In: Bade 1984, S. 321 349.

Kamphoefner 1991 = Ders.: The Volume and Composition of German-American Return Migration. In: Vecoli/Sinke 1991, S. 293-311.

Kananen 1981 = Kananen, Ilkka: Maanviljelijäväestön talouspoliittinen järjestäytyminen (Die Bildung von wirtschaftspolitischen Organisationen für Landarbeiter). In: Kaukiainen/Schybergson/Soikkanen 1981, S. 237-253.

Kapp $1969=$ Kapp, Friedrich: Immigration and the Commissioners of Emigration of the State of New York. Reprint New York 1969 ( $\left.{ }^{1} 1870\right)$.

Karni 1977 = Karni, Michael Gary: The Founding of the Finnish Socialist Federation and the Minnesota Strike of 1907. In: Karni/Ollila 1977, S. 65-86.

Karni 1981a = Ders. (Hrsg.): Finnish Diaspora 1: Canada, South America, Africa, Australia and Sweden. Papers of the Finn Forum-conference 2 (1-3 November 1979). Toronto 1981.

Karni 1981b = Ders. (Hrsg.): Finnish Diaspora 2: United States. Papers of the Finn Forum-conference 2 (1-3 November 1979). Toronto 1981.

Karni 1981c $=$ Ders.: Finnish Temperance and its Clash with Emerging Socialism in Minnesota. In: Karni 1981b, S. 163-174.

Karni 1986 = Ders.: Finnish Immigrant Leftists in America: The Golden Years, 19001918. In: Hoerder 1986, S. 199-226. 
Karni 1990 = Ders.: The Legacy of the Immigrant Finns. In: Kostiainen 1990, S. 97107.

Karni 1991= Ders. (Hrsg.): Entrepreneurs and Immigrants. Life on the Industrial Frontier of Northeastern Minnesota. Chisholm, Minn. 1991.

Karni/Kaups/Ollila 1975= Karni, Michael G./Kaups, Matti E./Ollila, Douglas J. (Hrsg.): The Finnish Experience in the Western Great Lakes Region: New Perspectives. Papers of the Finn-Forum-conference 1 (April 1974). Turku 1975.

Karni/Ollia 1977 = Karni, Michael G./Ollila, Douglas J.(Hrsg.): For the Common Good. Finnish Immigrants and the Radical Response to Industrial America. Superior, Wisc. 1977.

Karni/Koivukangas/Laine 1988 = Karni, Michael G./Koivukangas, Olavi/Laine, Edward W. (Hrsg.): Finns in North America. Proceedings of Finn Forum-conference 3 (5-8 September 1984). Turku 1988.

Katzman 1978 = Katzman, David M.: Seven Days a Week: Women and Domestic Service in Industrializing America. New York 1978.

Kaukiainen 1980 = Kaukiainen, Yrjö: Merenkulku (Seefahrt). In: Jutikkala/ Kaukiainen/Åström 1980, S. 458-474.

Kaukiainen 1991 = Ders.: Sailing into Twilight. Finnish Shipping in an Age of Transport Revolution 1860-1914. Helsinki 1991.

Kaukianen/Schybergson/Soikkanen 1981 = Kaukiainen, Yrjö/ Schybergson, Per/ Soikkanen, Hannu u.a. (Hrsg.): När samhället förändras (Wenn sich die Gesellschaft verändert). Helsinki 1981 (Historiallinen Arkisto, 76). [Festschrift für Sven-Erik Åström zum 60. Geburtstag]. 
Kaups 1966 = Kaups, Matti: Finnish Place Names in Minnesota: A Study in Cultural Transfer. In: The Geographical Review 56 (1966) S. 377-397.

Kaups 1971 = Ders.: Patterns of Finnish Settlement in the Lake Superior Region. In: The Michigan Academican 3 (1971) S. 77-92.

Kaups 1975 = Ders.: The Finns in the Copper and Iron Ore Mines of the Western Great Lakes Region, 1864-1905: Some Preliminary Observations. In: Karni/Kaups/Ollila 1975, S. 55-89.

Kaups 1976 = Ders.: A Finnish Savusauna in Minnesota. In: Minnesota History 45 (1976) S. 11-20.

Kaups 1978 = Ders.: Finnish Place Names as a Form of Ethnic Expression in the Middle West, 1880-1977. In: Finnish Americana 1 (1978) S. 51-70; Finnish Americana 2 (1978) S. 28-49.

Kaups 1981 = Ders.: Finns in Urban America: A View from Duluth. In: Karni 1981b, S. 63-86.

Kero 1969a = Kero, Reino: Suomen kuvernöörien siirtolaisraportit vuosina 1873-74 (Die Emigrationsberichte der finnischen Staatsbeamten der Jahre 1873-74). In: Turun Historiallinen Arkisto 21 (1969) S. 77-109.

Kero 1969b = Ders.: Siirtolaisuus suomesta Amerikkaan vuosien 1849-1865 välisenä aikana (Die Auswanderung von Finnland nach Amerika 1849-1865). Erikoispainos, Sarja 3 [Sonderdruck, Serie 3]. Turku 1969, S. 167-175.

Kero 1969c $=$ Ders.: The Background of Finnish Emigration. In: Jalkanen 1969, S. 5562.

Kero 1972 = Ders.: The Return of Emigrants from America to Finland. In: Publications of the Institute for General History Turku 4 (1972) S. 9-29. 
Kero 1973 = Ders.: The Roots of Finnish-American Left-Wing Radicalism. In: Publications of the General History Institute Turku 5 (1973) S. 45-55.

Kero 1974 = Ders.: Migration from Finland to North America in the Years between the United States Civil War and the First World War. Turku 1974.

Kero 1975 = Ders.: Suomalaisten siirtolaisten "vapaa Amerikaa" (Das "freie Amerika" der finnischen Emigranten). In: Turun Historiallinen Arkisto 30 (1975) S. 73-81.

Kero 1976a = Ders.: Suuren lännen suomalaiset (Die Finnen des Wilden Westens). Helsinki 1976.

Kero 1976b = Ders: Emigration from Finland to Canada before the First World War. In: The Lakehead University Review 9 (1976) S. 7-16.

Kero 1977 = Ders.: The Character and Significance of Migration Traditions from Finland to North America. In: Kronberg/Nilsson/Svalestuen 1977, S. 95-104.

Kero 1978a $=$ Ders.: From Soldier of Fortune to Newspapersman: The Story of Alexander Leinonen. In: Finnish Americana 1 (1978) S. 41-50.

Kero 1978b = Ders.: Miten Amerikan siirtolaisuus levisi Vaasan läänin alueella? (Wie breitete sich die Auswanderungsbewegung im Regierungsbezirk Vaasa aus?) [Rez. von De Geer, E./ Wester, H.: Utrikes resor, arbetsvandringar och flyttningar i Finland och Vasa län 1861-1890. Vaasa 1975]. In: Historiallinen Aikakauskirja 76 (1978) S. 29-35.

Kero 1980 = Ders.: The Finns in North America. Destinations and Composition of Immigrant Societies in North America before World War I. Turku 1980.

Kero 1982 = Ders.: Pohjois-Amerikan suomalaisten järjestötoiminta (Das Vereinsleben der Amerika-Finnen). In: Laaksonen/Virtaranta 1982, S. 9-18. 
Kero 1986 = Ders.: Suomen siirtolaisuuden historia 1. Pohjois-Amerikkaan suuntautuneen siirtolaisuuden tausta, määrä, rakenne, kuljetusorganisaatio ja sijoittuminen päämääräalueelle (Geschichte der finnischen Auswanderung 1. Hintergründe, Ausmaß, Struktur sowie Aspekte der Überfahrt und Zielgebiete im Bezug auf die Amerikaauswanderung). Turku 1986 ( $\left.{ }^{1} 1982\right)$.

Kero 1988 = Ders.: Sjömän från Finland som emigranter i Amerika under 1800-talet (Finnische Seeleute als amerikanische Einwanderer im 19. Jahrhundert). In: Historisk Tidskrift för Finland 73 (1988) S. 395-413.

Kero 1990= Ders.: Child Mortality in the Asthabula Harbor, Ohio, Finnish American Immigrant Community. In: Kostiainen 1990a, S. 71-84.

Kero 1991 = Ders.: Migration Traditions from Finland to North America. In: Vecoli/Sinke 1991, S.111-133.

Kero 1996 = Ders: Suuren Länteen. Siirtolaisuus Suomesta Yhdysvaltoihin ja Kanadaan (In den Wilden Westen. Die Auswanderung von Finnland in die Vereinigten Staaten und nach Kanada). Turku 1996.

Kero 1997 = Ders.: Suomalaisina Pohjois-Amerikassa. Siirtolaiselämää Yhdysvalloissa ja Kanadassa (Als Finne in Nord-Amerika. Emigrantendasein in den Vereinigten Staaten und Kanada). Turku 1997.

Kero/Kostiainen/Kuparinen 1978 = Kero, Reino/Kostiainen, Auvo/Kuparinen u.a.: Toholammin väestön muuttoliikkeet Amerikansiirtolaisuuden alkuvaiheissa, 18701889 (Die Auswanderung aus der Gemeinde Toholampi während der Frühphase der Amerikaemigration 1870-1889). Turku 1978.

Kessler-Harris 1982 = Kessler-Harris, Alice: Out of Work. A History of WageEarning Women in the United States. New York 1982. 
Kessner/Boyd Caroli 1978 = Kessner, Thomas/Boyd Caroli, Betty: New Immigrant Women at Work.: Italians and Jews in New York City, 1880-1905. In: The Journal of Ethnic Studies 5 (1978) S. 19-31.

Kilpi 1917= Kilpi, O. K.: Suomen siirtolaisuus ja 19. vuosisadan kansantalous (Die finnische Auswanderung und die Volkswirtschaft des 19. Jahrhunderts). Helsinki 1917.

Kirkpatrik 1975 = Kirkpatrik, Doris: Around the World in Fitchburg, Vol. II. Fitchburg, Mass. 1975.

Kivisto 1982 = Kivisto, Peter: Immigrant Socialists in the United States: The Case of Finns and the Left. Ann Arbor, Mich. 1982 (Cranbury, N. J. 1984).

Kivisto 1989a = Ders. (Hrsg.): The Ethnic Enigma. The Salience of Ethnicity for European-Origin Groups. Philadelphia 1989.

Kivisto 1989b = Ders.: The Attenuated Ethnicity of Contemporary Finnish-Americans. In: Kivisto 1989a, S. 47-88.

Kivisto 1993 = Ders.: Interpreting the Finnish-American Experience. In: Lovoll 1993, S. 73-89.

Kivisto/Blanck 1990 = Kivisto, Peter/Blanck, Dag (Hrsg.): American Immigrants and Their Generations. Studies and Commentaries on the Hansen Thesis after Fifty Years. Urbana/ Chicago, Ill. 1990.

Kjartansson 1977 = Kjartansson, Helgi Skúli: The Onset of Emigration from Iceland. In: Kronberg/Nilsson/Svalestuen 1977, S. 87-93.

Klaczynska 1976 = Klaczynska, Barbara: Why Women Work: A Comparison of Various Groups - Philadelphia, 1910-1930. In: Labor History 17 (1976) S. 73-87. 
Klinge 1987 = Klinge, Matti: Geschichte Finnlands im Überblick. Helsinki 1987 $\left({ }^{1} 1977\right)$.

Klövekorn 1960 = Klövekorn, Martin: Die sprachliche Struktur Finnlands 1880-1950. Veränderungen im sprachlichen Charakter der finnlandschwedischen Gebiete und deren bevölkerungs-, wirtschafts- und sozialgeographische Ursachen. Helsinki 1960. (Bidrag till kännedom av Finlands natur och folk 105. Beitrag zur Kenntnis von Finnlands Natur und Volk, 105) .

Knipping 1977 = Knipping, Mark: Finns in Wisconsin. Madison, Wisc.1977. (The State Historical Society of Wisconson).

Köllmann 1976 = Köllmann, Wolfgang: Versuch des Entwurfs einer historischsoziologischen Wanderungstheorie. In: Engelhardt,Ulrich/Sellin,Volker/Stuke,Horst (Hrsg.): Soziale Bewegung und politische Verfassung. Beiträge zur Geschichte der modernen Welt. Stuttgart 1976, S. 260-269.

Köllmann/Marschalck 1972 = Köllmann, Wolfgang/Marschalck, Peter (Hrsg.): Bevölkerungsgeschichte. Köln 1972.

Koivukangas 1986 = Koivukangs, Olavi: Sea, Gold and Sugarcane. Attraction versus Distance. Finns in Australia 1851-1947. Turku 1986.

Koivukangas 1988 = Ders.: Amerikan siirtolaisuuden alku. Näyttelyjulkaisu. The Beginning of Finnish Migration to the New World. Exhibition catalogue. Turku 1988.

Koivukangas 1993 = Ders.: Siirtolaisuus (Auswanderung). In: Suomen Kartasto 2 (Finnischer Atlas 2). Hrsg. von Maanmittaushallitus (Landesvermessungsamt). Helsinki 1993, S. 8-10.

Koivukangas 1996 = Ders.: From Midnigth Sun to the Long White Cloud. Finns in New Zealand. Turku 1996. 
Kolehmainen 1936 = Kolehmainen, John I.: A Study of Marriage in a Finnish Community. In: American Journal of Sociology 42 (1936) S. 371-382.

Kolehmainen 1941 = Ders.: Finnish Temperance Societies in Minnesota. In: Minnesota History 22 (1941) S. 391-403.

Kolehmainen 1944 = Ders.: The Finnish Pioneers of Minnesota. In: Minnesota History 25 (1944) S. 317-328.

Kolehmainen 1945 = Ders: Finnish Overseas Emigration from Arctic Norway and Russia. In: Agricultural History 19 (1945) S. 224-232.

Kolehmainen 1946 = Ders.: Suomalaisten siirtolaisuus Norjasta Amerikaan (Die Auswanderung der Finnen von Norwegen nach Amerika). Fitchburg, Mass. 1946.

Kolehmainen 1955 = Ders.: Sow the Golden Seed. A History of the Fitchburgian Finnish-American Newspaper, Raivaaja, 1905-1955. Fitchburg, Mass. 1955.

Kolehmainen 1967 = Ders.: The Finns in America: Settlement and Employment. In: Turun Historiallinen Arkisto 19 (1967) S. 257-268.

Kolehmainen 1976a = Ders.: Americanization and the Search for Identity. In: Niitemaa/Saukkonen/Aaltio 1976, S. 261-278.

Kolehmainen 1976b = Ders.: The Last Days of Matti Kurikka's Utopia. A Historical Vignette. In: Turun Historiallinen Arkisto 31 (1976) S. 388-396.

Kolehmainen 1977 = Ders.: From Lake Erie's Shores to the Mahoning and Monongahela Valleys. A History of Finns in Ohio, Western Pennsylvania and West Virginia. Fairport, Ohio 1977. 
Kolehmainen/Hill 1979 = Kolehmainen, John I./Hill, George W.: Haven in the Woods. The Story of the Finns in Wisconsin. Reprint New York 1979 ( Madison, Wisc. $\left.{ }^{1} 1951\right)$.

Korkiasaari 1989 = Korkiasaari, Jouni: Suomalaiset maailmalla. Suomen siirtolaisuus ja ulkosuomalaiset entisajoista tähän päivään (Finnen in aller Welt. Die finnische Auswanderung und die Auslandsfinnen im Laufe der Zeit). Turku 1989.

Korkiasaari 1993 = Ders.: Siirtolaisuus- ja ulkomaalaistilastot (Auswanderungs- und Ausländerstatistik). Helsinki 1993.

Korkiasaari/Söderling 1994 = Korkiasaari, Jouni/Söderling, Ismo: Muuttoliike (Migration). In: Koskinen/Martelin/Notkola 1994, S. 226-264.

Koskimies 1960 = Koskimies, Rafael: Sortokausien vaikutus kulttuurielämään (Der Einfluß der Unterdrückungsperiode auf das kulturelle Leben). In: Tommila 1960, S. 235-254.

Koskinen/Martelin/Notkola 1994 = Koskinen, Seppo/Martelin, Tuija/Notkola, IrmaLeena u.a. (Hrsg.): Suomen väestö (Die Bevölkerung Finnlands). Helsinki 1994.

Kostiainen 1976 = Kostiainen, Auvo: Finnish-American Workmen's Associations. In: Niitemaa/Saukkonen/Aaltio 1976, S. 205-234.

Kostiainen 1980 = Ders.: Work People's College: An American Immigrant Institution. In: Scandinavian Journal of History 5 (1980) S. 295-309.

Kostiainen 1983a = Ders.: Amerikansuomalainen raittiusliike: Taistelu viinan kauhistusta vastaan (Die Anti-Alkoholbewegung der Amerika-Finnen: Der Kampf gegen den Schnaps) S. 56-82; Suomalaiset siirtolaiset ja politikka (Finnische Auswanderer und Politik) S. 83-135; Poikataloista osuuskauppoihin: siirtolaisten osuustoiminta (Von der Gruppenunterkunft zur Genossenschaft: Genossenschaftliche Aktivitäten der Amerika-Finnen) S. 136-163. In: Kostiainen/Pilli 1983. 
Kostiainen 1983b = Ders.: For or against Americanization? The Case of the Finnish Immigrant Radicals. In: Hoerder 1983, S. 259-275.

Kostiainen 1986 = Ders.: Sulautuminen uuteen yhteiskuntaan (Integration in die neue Gesellschaft). In: Virtanen/Pilli/Kostiainen 1986, S. 11-53.

Kostiainen 1990a = Ders. (Hrsg.): Finnish Identity in America. Turku 1990.

Kostiainen 1990b $=$ Ders: Delaware as a Symbol of Finnish Immigration; To Be or Not To Be - An American, A Finn or A Finnish American. In: Kostiainen 1990a, S. 4970; S. 109-125.

Kostiainen/Pilli 1983 = Kostiainen, Auvo/Pilli, Arja: Suomen siirtolaisuuden historia 2 (Geschichte der finnischen Auswanderung 2). Turku 1983.

Kouhi 1976 = Kouhi, Christine: Labour and Finnish Immigration to Thunder Bay, 1876-1914. In : The Lakehead University Review 9 (1976) S. 17-37.

Kronberg/Nilsson/Svalestuen 1977 = Kronberg, Bo/Nilsson, Thomas/Svalestuen, Anders A. (Hrsg.): Nordic Population Mobility. Comparative Studies of Selected Parishes in the Nordic Countries, 1850-1900. Oslo 1977 (American Studies in Scandinavia, 9).

Kuhlman 1991 = Diess.: On the Move, On Their Own: Female Finnish Immigrants in Red Lodge, Montana. In: Siirtolaisuus/Migration, Heft 1 (1991) S. 14-20.

Kultalahti 1989 = Kultalahti, Olli: Finns in the USA: Patterns of Immigration and Settlement since 1900. In: Siirtolaisuus/Migration, Heft 3 (1989) S. 11-23.

Kummel 1980 = Kummel, Bengt: Emigrationen från Svenska Österbotten 1870-1970 (Die Auswanderung aus Schwedisch-Ostbottnien 1870-1970). In: Svenska Österbottens Historia 3 (Die Geschichte von Schwedisch-Ostbottnien 3). Hrsg. von Svenska 
Österbottens landskapsförbund (Landschaftsverband von Schwedisch-Ostbottnien). Vaasa 1980, S. 433-553.

Kuparinen 1991 = Kuparinen, Eero: An African Alternative. Nordic Migration to South Africa, 1815-1914. Helsinki 1991.

Kurkinen 1985 = Kurkinen, Pauli (Hrsg.): Venäläiset Suomessa 1809-1917 (Die Russen in Finnland 1809-1917). Helsinki 1985.

Laaksonen/Virtaranta 1982 = Laaksonen, Pekka/Virtaranta, Pertti (Hrsg.):

Ulkosuomalaisia (Auslandsfinnen). Helsinki 1982.

Laitila 1991 = Laitila, Lynn Maria: Carrying the Burden: An Historical Remininscence of Vermilion Range Women. In: Karni 1991, S. 40-46.

Lamppa 1991 = Lamppa, Marvin G.: From Art to Science: Mining at Soudan (18821924). In: Karni 1991, S. 26-31.

Landgren 1988 = Landgren, Lars: Kieli ja aate - politisoituva sanomalehdistö 18601889 (Die Sprache und das Ideal. Der politische Einfluß auf die Druckpresse 18601889). In: Tommila 1988a, S. 267-420.

Lauerma 1960 = Lauerma, Matti: Aktivismi (Aktivismus). In: Tommila 1960, S. 137154.

Lee $1966=$ Lee, Everett S.: A Theory of Migration. In: Demography 3 (1966) S. 4757.

Leino-Kaukiainen 1984 = Leino-Kaukiainen, Pirkko: Sensuuri ja sanomalehdistö Suomessa 1891-1905 (Die Druckpresse und Pressezensur in Finnland 1891-1905). Helsinki 1984. 
Lento 1951 = Lento, Reino: Maassamuutto ja siihen vaikuttaneet tekijät Suomessa vuosina 1878-1939 (Faktoren der finnischen Binnenmigration 1878-1939). Helsinki 1951.

Lext 1977 = Lext, Gösta: Studier rörande svensk emigration till Nordamerika 18501880 (Untersuchungen zur schwedischen Auswanderung nach Nordamerika 18501880). Göteborg 1977.

Lindström-Best 1981a = Lindström-Best, Varpu: The Socialist Party of Canada and the Finnish Connection, 1905-1911. In: Dahlie/Fernando 1981, S. 113-122.

Lindström-Best 1981b = Diess.: The Impact of Canadian Immigration Policy on Finnish Immigration, 1890-1978. In: Siirtolaisuus/Migration, Heft 2 (1981) S. 5-15.

Lindström-Best 1981c $=$ Diess. (Hrsg.): Finns in Ontario. Toronto 1981 (Polyphony. The Bulletin of the Multicultural History Society Vol. 3, No. 2).

Lindström-Best 1981d = Diess: The Unbreachable Gulf: The Division in the Finnish Community of Toronto, 1902-1913. In: Karni 1981a, S. 11-18.

Lindström-Best 1985 = Diess.: The Finns in Canada. Ottawa 1985.

Lindström- Best 1988 = Diess.: Defiant Sisters. A Social History of Finnish Women in Canada. Studies in Ethnic and Immigration History. Toronto 1988.

Lindström-Best/Seager $1988=$ Lindström- Best, Varpu/Seager, Allen: Toveritar and Finnish-Canadian Women, 1900-1930. In: Karni/Koivukangas/Laine 1988, S. 133153.

Lindström-Best/Sutyla 1984 = Lindström-Best, Varpu/Sutyla, Charles M. (Hrsg.): Terveisiä Ruusu-tädiltä. Kanadan suomalaisten ensimmäinen sukupolvi (Grüße von Tante Rosa. Kanada-Finnen der ersten Generation). Tampere 1984 (Suomen kirjalli- 
suuden seura: Kansanelämän kuvauksia 24 [Gesellschaft für finnische Literatur: Bilder aus dem Volksleben, 24]).

Lintelman 1991 = Lintelman, Joy K.: "On My Own": Single, Swedish, and Female in the Turn-of-the-Century Chicago. In: Anderson/Blanck 1991, S. 89-99.

Ljungmark $1971=$ Ljungmark, Lars: For Sale - Minnesota. Organized Promotion of Scandinavian Immigration 1866-1873. Stockholm 1971.

Ljungmark 1973 = Ders: Svenska magneter. Kolonisationsområdenas dragningskraft på svenska utvandrare (Schwedische Magneten. Die Anziehungskraft von Kolonisationsgebieten auf schwedische Auswanderer). In: Kälvemark 1973a, S. 151-178.

Löffler 1992 = Löffler, Klara: Aufgehoben: Soldatenbriefe aus dem Zweiten Weltkrieg. Eine Studie zur subjektiven Wirklichkeit des Krieges. Bamberg 1992 (Regensburger Schriften zur Volkskunde, 9).

Loukinen 1981 = Loukinen, Michael M.: Second Generation Finnish-American Migration from the Northwoods to Detroit, 1920-1950. In: Karni 1981b, S. 107-126.

Lovoll 1991 = Lovoll, Odd S.: A Scandinavian Melting Pot in Chicago.In: Anderson/Blanck 1991, S. 60-67.

Lovoll 1993 = Ders. (Hrsg.): Nordics in America. The Future of Their Past. Northfield, Minn. 1993.

Lüthke 1989 = Lüthke, Folkert: Psychologie der Auswanderung. Weinheim 1989.

Lüthke/Cropley 1989 = Lüthke, Folkert/Cropley, Arthur: Motive zur Auswanderung aus pyschologischer Sicht: Empirische Befunde und theoretische Überlegungen. In: Zeitschrift für Kulturaustausch, Heft 3 (1989) S. 363-368. 
Marschalck 1973 = Marschalck, Peter: Deutsche Überseewanderung im 19. Jahrhundert. Ein Beitrag zur soziologischen Theorie der Bevölkerung. Stuttgart 1973.

Mead 1954 = Mead, W. R.: A Finnish Settlement in Central Minnesota. In: Acta Geographica 13, Nr. 3 (1954) S. 3-16.

Mesenhöller 1985 = Mesenhöller, Peter: Der Auswandererbrief. Bedingungen und Typik schriftlicher Kommunikation im Auswanderungsprozeß. In: Assion 1985a, S. 110-124.

Miller 1991 = Miller, Dana: The Vermilion Lake Gold Rush, 1865-1866. In: Karni 1991, S. 13-18.

Moe 1970 = Moe, Thorvald: Demographic Development and Economic Growth in Norway 1740-1914. New York 1970.

Munch 1981 = Munch, Peter A.: Norwegians. In: Thernstrom/Olov/Handlin 1981, S. $750-761$.

Murdoch $1964=$ Murdoch, Angus: Boom Copper. The Story of the First U.S. Mining Boom. Calumet, Mich. 1964 (New York ${ }^{1} 1943$ ).

Myhrman 1963 = Myhrman, Anders M.: The Finland-Swedes in Duluth, Minnesota. In: The Swedish American Quarterly (1963) S. 19-29.

Myhrman 1972 = Ders.: Finlandsvenskar i Amerika. The Finland-Swedes in America. Helsinki 1972.

Myhrman 1976 = Ders: The Finland-Swedish Immigrants in the U.S.A. In:

Niitemaa/Saukkonen/Aaltio 1976, S. 181-204. 
Närhi 1985 = Närhi, Matti: Venäläiset joukot Suomessa autonomian aikana (Russische Streitkräfte in Finnland während der Autonomieepoche). In: Kurkinen 1985, S. 161174.

Neils Conzen 1979 = Neils Conzen, Kathleen: Immigrants, Immigrant Neighborhoods, and Ethnic Identity: Historical Issues. In: The Journal of American History 66, No. 3 (1979) S. 603-615.

Nelson 1943 = Nelson, Helge: The Swedes and the Swedish Settlements in North America I-II. Lund 1943 (Skrifter utg. av Kungl. humanistiska Vetenskapssamfundet i Lund 37) [Schriften des könglichen humanistischen Wissenschaftsverbandes in Lund, 37].

Nelson $1981=$ Nelson, Frank C.: Norwegian-American Attitudes Toward Assimilation During Four Periods of their History in America, 1825-1913. In: Journal of Ethnic Studies 9 (1981) S. 59-68.

Neuman 1985 = Neuman, William: Munsalabor på Titanic (Einwohner aus Munsala auf der Titanic). In: Nyström 1985, S. 59.

Nickisch 1991 = Nickisch, Reinhard M. G.: Brief. Stuttgart 1991 (Sammlung Metzler. Realien zur Literatur, 260).

Niemi $1921=$ Niemi, Clemens: Americanization of the Finnish People in Houghton County, Michigan. Duluth, Minn. 1921.

Niemi 1971 = Niemi, Leslie: Religious History of Finns in America. In: Michigan Academican 3 (1971) S. 65-73.

Niitemaa $1976=$ Niitemaa, Vilho: The Finns in the Great Migratory Movement from Europe to America 1865-1914. In: Niitemaa/Saukkonen/Aaltio 1976, S. 65-99. 
Niitemaa/Saukkonen/Aaltio 1976 = Niitemaa, Vilho/ Saukkonen, Jussi/Aaltio, Tauri u.a. (Hrsg.): Old Friends - Strong Ties. Vaasa 1976.

Nilsson 1970 = Nilsson, Fred: Emigrationen från Stockholm till Nordamerika 18801893. En studie i urban utvandring (Die Auswanderung von Stockholm nach Nordamerika 1880-1893. Eine Untersuchung über städtische Emigration). Stockholm 1970.

Norman 1976 = Norman, Hans: The Causes of Migration. An Attempt of an Multivariate Analysis. In: Runblom/Norman 1976, S. 149-164.

Norman 1982 = Ders.: The Emigration to America from the Nordic Countries. In: Koivukangas, Olavi (Hrsg.): Scandinavian Emigration to Australia and New Zealand. Turku 1982, S. 9-23.

Norman/Runblom $1985=$ Norman, Hans/Runblom, Harald: Migration Patterns in the Nordic Countries. In: Hoerder 1985a, S. 35-68.

Norman/Runblom 1988 = Ders./Ders.: Transatlantic Connections. Nordic Migration to the New World after 1800. Oslo 1988.

Nygård 1983 = Nygård, Toivo: Asustus, väestö ja yhteiskunta (Besiedlung, Bevölkerung und Gesellschaft). In: Ders. (Hrsg.): Järviseudun historia 2 (Geschichte des Seengebiets 2). Vaasa 1983, S. 19-170.

Nygård 1988 = Ders.: Uhattu autonomia (Bedrohte Autonomie). In: Zetterberg 1988, S. 545-560.

Odén 1971 = Odén, Birgitta: Ekonomiska emigrationsmodeller (Ökonomische Emigrationsmodelle). In: Scandia 37 (1971) S. 1-70.

Olkkonen 1988 = Olkkonen, Tuomo: Modernisoituva suurruhtinaskunta (Modernisiertes Großfürstentum). In: Zetterberg 1988, S. 473-543. 
Ollila 1969 = Ollila, Douglas J.: The Suomi Synod in Perspective: An Indigenous Institution. In: Jalkanen 1969, S. 188-196.

Ollila 1975 = Ders.: From Socialism to Industrial Unionism (IWW): Social Factors in the Emergence of Left-Labor Radicalism among Finnish Workers on the Mesabi, 1911-19. In: Karni/Kaups/Ollila 1975, S. 156-171.

Ollila 1976 = Ders.: The Finnish-American Church Organisations. In: Niitemaa/Saukkonen/Aaltio 1976, S. 145-174.

Olson 1991 = Olson, Anita R.: The Community Created: Chicago Swedes, 1880-1920. In: Anderson/Blanck 1991, S. 49-59.

Oman 1986 = Oman, Elizabeth: Swede-Finns on the Iron Ranges of Northeastern Minnesota. In: Finnish-Americana 7 (1986) S. 39-42.

Onnela 1975a = Onnela, Samuli: Emigrationen från Finland till Amerika över Nordnorge 1867-1892 (Emigration von Finnland nach Amerika über Nordnorwegen 1867-1892). Oulu 1975, S. 165-177. (Oulun yleisen historian laitoksen eripainossarja 18. Sonderdruck des Seminars für allgemeine Geschichte der Universität Oulu, 18).

Onnela 1975b = Ders.: Nälkä, agentit, Amerikan kuume vai asevelvollisuus? Oulun läänin virkamiehet ja Kuopion hiippakunnan papit Amerikan siirtolaisuuden arvioijina v. 1880-1892 (Hunger, Agenten, Amerika-Fieber oder Wehrpflicht? Die Beurteilung der Auswanderungsbewegung durch Beamten des Regierungsbezirkes Oulu und Geistliche des Bistums Kuopio 1880-1892). Oulu 1975, S. 92-137. (Oulun Yliopiston historian laitos eripainossarja 24. Sonderdruck des Seminars für allgemeine Geschichte der Universität Oulu, 24).

Orta $1971=$ Orta, Timo (Hrsg.): Emigrationsforskningens problemställningar. Emigrationen och dess bakgrund (Fragestellungen in der Migrationsforschung. Auswande- 
rung und Hintergründe). Tammisaari 1971.(Svenska kulturfondens skrifter 5. Schriften des schwedischen Kulturfondes, 5).

Orta $1975=$ Ders.: Finnish Emigration Prior to 1893: Economic, Demographic and Social Backgrounds. In: Karni/Kaups/Ollila 1975, S. 21-35.

Ostergren 1988 = Ostergren, Robert C.: A Community Transplanted. The TransAtlantic Experience of a Swedish Immigrant Settlement in the Upper Middle West, 1835-1915. Uppsala 1988.

Paasivirta 1978 = Paasivirta, Juhani: Suomi ja Eurooppa 1. Autonomiakausi ja kansainväliset kriisit, 1808-1914 (Finnland und Europa 1. Die Autonomieepoche und internationale Krisen 1808-1914). Helsinki 1978.

Passi 1975 = Passi, Michael: Fishermen on Strike: Finnish Workers and Community Power in Astoria, Oregon 1880-1900. In: Karni/Kaups/Ollila 1975, S. 89-103.

Peltonen 1992 = Peltonen, Matti: Talolliset ja torpparit. Vuosisadan vaihteen maatalouskysymys Suomessa (Grundbesitzer und Pachtbauern. Die finnische Landwirtschaftskrise um die Jahrhundertwende). Helsinki 1992.

Penti 1978 = Penti, Marsha: The America Letter: Immigrant Accounts of Life Overseas. In: Finnish Americana 1 (1978) S. 22-40.

Penti 1981 = Diess.: The Life History of Southwestern Massachusetts Finnish Granberry Growing Community. In: Karni 1981b, S. 87-105.

Penti 1983 = Diess.: The Role of Ethnic Folklore Among Finnish-American Returnees. Bloomington, Ind. 1983.

Penti 1986 = Diess.: Piikajutut: Stories Finnish Maids Told. In: Ross/Wargelin-Brown 1986, S. 55-72. 
Pentikäinen 1988 = Ders.: Towards the Interpretation of Finnish-American Culture. In: Karni/ Koivukangas/Laine 1988, S. 44-57.

Perec/Bober $1998=$ Perec, Georges/Bober, Robert: Geschichten von Ellis Island oder wie man Amerikaner macht. Darmstadt 1998.

Peterson 1958 = Peterson, William: A General Typology of Migration. In: American Sociological Review 23 (1958) S. 256-266.

Peterson/Thomas 1968 = Peterson, William/Thomas, Brinley: Migration: Social Aspects; Economic Aspects. In: Sills, David (Hrsg.): International Encyclopedia of Social Sciences. New York 1968, S. 286-300.

Pilli 1982 = Pilli, Arja: The Finnish-Language Press in Canada, 1901-1939. A Study in the History of Ethnic Journalism. Turku 1982.

Pilli 1983 = Diess.: Amerikansuomalaisten kirkollinen toiminta (Kirchliche Aktivitäten der Amerika-Finnen). In: Kostiainen/Pilli 1983, S. 9-55.

Pilli 1986 = Diess.: Suomalainen lehdistö Pohjois-Amerikassa: Silta vanhasta kotimaasta uuteen (Die finnische Druckpresse in Amerika: Brückenschlag zwischen alter und neuer Heimat). In: Virtanen/Pilli/Kostiainen 1986, S. 54-122.

Pitkänen 1994 = Pitkänen, Kari: Suomen väestön historialliset kehityslinjat (Die historischen Entwicklungslinien der finnischen Bevölkerung). In: Koskinen 1994, S. $19-63$.

Pozetta 1991 = Pozetta, George E. (Hrsg.): Ethnicity and Gender. The Immigrant Woman. New York/London 1991.

Pulma 1988 = Pulma, Panu: Yhteiskunta ja talouselämä (Gesellschaft und Wirtschaftsleben). In: Zetterberg 1988, S. 408-442. 
Puotinen 1975 = Puotinen, Arthur Edwin: Copper Country Finns and the Strike of 1913. In Karni/Kaups/Ollila 1975, S. 143-155.

Puotinen 1979 = Ders.: Finnish Radicals and Religion in Midwestern Mining Towns 1865-1914. New York 1979 (Chicago, Ill. ${ }^{1} 1973$ ).

Qualey 1950 = Qualey, Carlton C.: Some National Groups in Minnesota. In: Minnesota History 31 (1950) S. 18-32.

Qualey/Gjerde 1981 = Qualey, Carlton C./Gjerde, Jon A.: The Norwegians. In: Holmquist 1981, S. 220-247.

Radforth 1981 = Radforth, Ian: Finnish Lumber Workers in Ontario, 1919-46. In: Lindström-Best 1981c, S. 23-34.

Raeithel 1981 = Raeithel, Gert: "Go West". Ein psychohistorischer Versuch über die Amerikaner. Frankfurt/Main 1981.

Raittila 1982 = Raittila, Pekka: Lestadiolaisuus Pohjois-Amerikassa vuoteen 1885 (Die Lestadier-Bewegung in Nord-Amerika bis zum Jahr 1885). Helsinki 1982.

Raivio 1975-79 = Raivio, Yrjö: Kanadan suomalaisten historia (Geschichte der Finnen in Kanada). Band 1: Vancouver, B.C. 1975; Band 2: Thunder Bay, Ont. 1979.

Ranta 1988 = Ranta, Raimo: Talouseläma, asustus ja väestö Etelä-Pohjanmaalla 18091917 (Wirtschaft, Besiedlung und Bevölkerung in Süd-Ostbottnien). In: EteläPohjanmaan historia 5 (Geschichte Süd-Ostbottniens 5). Hrsg. von EteläPohjanmaan maakuntaliitto (Süd-Ostbottnischer Landschaftsverband). Vaasa 1988, S. 423-928.

Rasila 1980 = Rasila, Viljo: Siirtolaisen vaikea valinta - jäädä vai palata (Die schwierige Entscheidung des Auswanderers - bleiben oder zurückkehren). In: Historiallinen 
Aikakauskirja 78 (1980) S. 84-87. [Rez. von K. Virtanen: Settlement or Return.Turku 1979.]

Rasila 1982 = Ders.: Kauppa ja rahaliike (Handel und Geldgeschäfte), S. 89-113; Liikenne (Verkehr), S. 114-131; Väestönkehitys ja sosiaaliset ongelmat (Bevölkerungsentwicklung und soziale Probleme), S. 132-153. In: Ahvenainen 1982.

Ravenstein 1885-89 = Ravenstein, E. G.: The Laws of Migration. In: Journal of the Royal Statistical Society 48 (1885) S. 267-285; 52 (1889) S. 241-305.

Reitala 1987 = Reitala, Aimo: Romantiikasta modernismiin (Von der Romantik zur Moderne). In: Tarkka 1987, S. 8-45.

Rice 1981 = Rice, John. G.: The Swedes. In : Holmquist 1981, S. 248-276.

Riippa 1981 = Riippa, Timo: The Finns and the Swede-Finns. In: Holmquist 1981, S. 296-322.

Rößler 1992 = Rößler, Horst: Massenexodus: die Neue Welt des 19. Jahrhunderts. In: Bade 1992, S. 148-157.

Roinila 1992 = Roinila, Mika: The Atlantic Finns. A Forgotten Ethnic Minority. In: Siirtolaisuus/Migration, Heft 1 (1992) S. 11-21.

Roinila $2000=$ Ders.: Finland-Swedes in Canada. Migration, Settlement and Ethnic Relations. Turku 2000. (Migration Studies, C 14).

Rommi 1986 = Rommi, Pirkko: Merenkulun läpimurto (Der Durchbruch in der Seefahrt); Suomalaisuuden nousu (Das Erwachen des finnischen Nationalgefühls). In: Tarkka 1986, S. 215 und S. 245-265.

Ross 1982 = Ross, Carl: The Finn Factor in American Labor, Culture and Society. New York Mills, Minn. $1982\left({ }^{1} 1978\right)$. 
Ross 1986a = Ders.: The Feminist Dilemma in the Finnish Immigrant Community. In: Ross/Wargelin-Brown 1986, S. 73-82.

Ross 1986b = Ders.: Servant Girls: Community Leaders. Finnish American Women in Transition (1910-1920). In: Ross/Wargelin-Brown 1986, S. 41-54.

Ross/Wargelin-Brown 1986 = Ross, Carl/Wargelin-Brown, Marianne (Hrsg.): Women Who Dared. The History of Finnish American Women. St. Paul, Minn. 1986. (The Immigration History Research Center).

Rotenberg 1974 = Rotenberg, Lori: The Wayward Worker: Toronto's Prostitute at the Turn of the Century. In: Acton/Goldsmith/Shepard 1974, S. 33-69.

Runblom 1991 = Runblom, Harald: Chicago Compared: Swedes and Other Ethnic Groups in American Cities. In: Anderson/Blanck 1991, S. 68-88.

Runblom/Norman 1976 = Runblom, Harald/Norman, Hans (Hrsg.): From Sweden to America. A History of the Migration. Uppsala 1976.

Saarinen 1981 = Saarinen, Oiva: Geographical Perspectives on Finnish Canadian Immigration and Settlement. In: Lindström-Best 1981c, S. 16- 22.

Saarinen 1995 = Ders.: Perspectives on Finnish Settlement in Canada (1901-1991). In: Siirtolaisuus/Migration, Heft 3 (1995) S. 19-25.

Saarinen 1999 = Ders.: Between a Rock and a Hard Place. A Historical Geography of the Finns in the Sudbury Area. Waterloo, Ont. 1999.

Sandlund 1980 = Sandlund, Tom: Till Amerika och till Sverige (Nach Amerika und nach Schweden). In: Finsk Tidskrift 207 (1980) S. 12-19. 
Sandlund 1981 = Ders.: Patterns and Reasons in the Emigration of Swedish Finns. In: Karni 1981a, S. 215-229.

Sandlund 1985 = Ders.: Suomenruotsalaiset (Finnlandschweden). In: Valkonen 1985a, S. 271-290.

Sangster 1981 = Sangster, Joan: Finnish Women in Ontario, 1890-1930. In: Lindström-Best 1981c, S. 46-54.

Santavuori 1981 = Santavuori, Martti: Merikarvian historia 1900-luvun alkuun (Die Geschichte der Gemeinde Merikarvia bis zum Beginn der 20. Jahrhunderts). Merikarvia 1981.

Saressalo 1982 = Saressalo, Lassi: Keitä ovat kveenit? (Wer sind die Kvener?). In: Laaksonen/Virtaranta 1982, S. 101-124.

Sautter 1986 = Sautter, Udo: Geschichte der Vereinigten Staaten von Amerika. Stuttgart $1986\left({ }^{1} 1975\right)$.

Sautter 1992 = Ders.: Geschichte Kanadas. Das Werden einer Nation. Stuttgart 1992 $\left({ }^{1} 1972\right)$.

Savolainen/Kokkonen 1964 = Savolainen, Pekka/Kokkonen, Erkki: Siirtolaisuus Lapin alueelta vv. 1808-1930 seurakuntien kirkonkirjojen mukaan (Auswanderung aus Lappland auf der Grundlage von Kirchenbucheintragungen 1808-1930). In: Historiallinen Arkisto 59 (1964) S. 596-621.

Schmidt 1965= Schmidt, Hans: Die verschiedenen Einwandererwellen in die Vereinigten Staaten von Nordamerika von den Anfängen bis zur Quotengesetzgebung. In: Historisches Jahrbuch 65 (1965) S. 323-361.

Schniedewind 1992 = Schniedewind, Karen: Fremde in der Alten Welt: Die transatlantische Rückwanderung. In: Bade 1992, S.179-185. 
Schwarzmeier 1978 = Schwarzmeier, Hansmartin: Auswandererbriefe aus Nordamerika. Quellen im Grenzbereich von Geschichte, Landeskunde, Wanderungsforschung und Literatursoziologie. In: Zeitschrift für die Geschichte des Oberrheins 126 (1978) S. 303-369.

Seager 1981 = Seager, Allen: Finnish Canadians and the Ontario Miners' Movement. In: Lindström-Best 1981c, S. 35- 45.

Seager 1983 = Ders.: Migration and Proletarization: Aspects of the Finnish Immigrant Experience in Western Canadian Coal Mining, 1880-1940. In: Siirtolaisuus/Migration, Heft 2 (1983) S. 7-15.

Seager 1986 = Ders.: Class, Ethnicity, and Politics in the Alberta Coalfields, 19051945. In: Hoerder 1986, S. 304-324.

Seller Schwartz 1975 = Seller Schwartz, Maxine: Beyond the Stereotype: A New Look at the Immigrant Woman, 1880-1924. In: Journal of Ethnic Studies 3 (1975) S. $59-70$.

Seler Schwartz 1978 = Diess.: The Education of the Immigrant Woman, 1900-1935. In: Journal of Urban History 4 (1978) S. 307-330.

Seller Schwartz 1988 = Diess.: To seek America. A History of Ethnic Life in the United States. Englewood, N.J. 1988.

Seller Schwartz 1994 = Diess. (Hrsg.): Immigrant Women. New York 1994 ( $\left.{ }^{1} 1981\right)$.

Semmingsen $1950=$ Semmingsen, Ingrid: Veien mot Vest. Utvandringen fra Norge 1865-1915, Annen Del (In Richtung Westen. Die Auswanderung aus Norwegen 1865-1915. Bd. 2). Oslo 1950. 
Semmingsen 1960 = Diess.: Norwegian Emigration in the Nineteenth Century. In: The Scandinavian Economic History Review 8 (1960) S. 150-160.

Semmingsen 1961 = Diess.: Emigration and the Image of America in Europe. In: Commager Steele 1961, S. 26-54.

Semmingsen 1972 = Diess.: Emigration from Scandinavia. In: Scandinavian Economic History Review 20 (1972) S. 45-60.

Semmingsen 1975 = Diess.: Drom og Dåd. Utvandringen til Amerika. Oslo 1975. [In engl. Übersetzung: Norway to America. A History of Migration. Minneapolis, Minn. 1978].

Shergold 1983 = Shergold, Peter R.: "Reefs of Roast Beef": The American Worker's Standard of Living in Comparative Perspective. In: Hoerder 1983, S. 78-105.

Sinisalo 1987 = Sinisalo, Hannu: The Photograph as Research Object and Source. In: Ethnologica Fennica 16 (1987) S. 27-42.

Smeds 1935 = Smeds, Helmer: Malaxbygden. Bebyggelse och hushållning i södra delen av österbottens svenskbygd (Die Gemeinde Malax [finn.: Maalahti]. Besiedlung und Bewirtschaftung im südlichen Teil der schwedischsprachigen Gemeinden von Ostbottnien). Helsinki 1935.

Smemo 1991 = Smemo, Kenneth: Reclaiming a Heritage: The Norwegians in Northeastern Minnesota. In: Karni 1991, S. 80-84.

Smith 1969 = Smith, Timothy L.: Immigrant Social Aspirations and American Education, 1880-1930. In: American Quarterly 21 (1969) S. 523-543.

Soikkanen 1960 = Soikkanen, Hannu: Suurlakko (Der Generalstreik). In: Tommila 1960, S. 171-190. 
Soininen 1974 = Soininen, Arvo M.: Vanha maataloutemme. Maatalous ja maatalousväestö Suomessa perinnäisen maatalouden loppukaudella 1720-luvulta 1870-luvulle (Unsere alte Landwirtschaft. Die finnische Landwirtschaft und die Landbevölkerung im Umbruch 1720-1870). Helsinki 1974.

Soininen 1976 = Ders.: Maatalousväestö v. 1910 - tilasto ja todellisuus (Die Landbevölkerung im Jahr 1910 - Statistik und Wirklichkeit). In: Historiallinen Aikakauskirja 74 (1976) S. 211-225.

Soininen 1981 = Ders.: Maatalousväen palkat vv. 1878-1913. (Die Löhne der Landarbeiter 1878-1913). In: Kaukiainen/Schybergson/Soikkanen 1981, S. 91-113.

Soininen 1982 = Ders.: Maa- ja metsätalous (Land- und Forstwirtschaft). In: Ahvenainen 1982, S. 27-51.

Steele 1982 = Steele, Paul T.: Tamarack Town. Mines, People, Memories. Calumet, Mich. 1982.

Steinberg 1989 = Steinberg, Stephen: The Ethnic Myth. Race, Ethnicity, and Class in America. Boston, Mass. $1989\left({ }^{1} 1981\right)$.

Stephenson 1929 = Stephenson, George M.: When America was the Land of Canaan. In: Minnesota History 10 (1929) S. 237-260.

Stökl 1983 = Stökl, Günther: Russische Geschichte. Von den Anfängen bis zur Gegenwart. Stuttgart $1983\left({ }^{1} 1961\right)$.

Strömmer 1969 = Strömmer, Aarno: Väestöllinen muuntuminen Suomessa (Demographischer Wandel in Finnland). Tornio 1969.

Sulkanen 1951 = Sulkanen, Elis: Amerikan Suomalaisen Työväenliikkeen Historia (Geschichte der finnisch-amerikanischen Arbeiterbewegung). Fitchburg, Mass. 1951. 
Syrjälä $1925=$ Syrjälä, F. J.: Historia-aiheita Amerikan suomalaisesta työväenliikkeestä. Fitchburg, Mass. 1925.

Talve 1983 = Talve, Ilmar: Suomen kansankulttuuri teollistumiskaudella (Die finnische Volkskultur während der Industrialisierungsperiode). In: Tommila 1983a, S. 447471.

Tarkka 1986 = Tarkka, Jukka (Hrsg.): Suomen historia 5 (Finnische Geschichte 5). Espoo 1986.

Tarkka 1987 = Ders. (Hrsg.): Suomen historia 6 (Finnische Geschichte 6). Espoo 1987.

Taylor $1971=$ Taylor, Philip: The Distant Magnet. European Emigration to the U.S.A. London 1971.

Taylor $1969=$ Taylor , R. C.: Migration and Motivation: A Study of Determinants and Types. In: Jackson 1969, S. 99-133.

Tedebrand 1972 = Tedebrand, Lars-Göran: Västernorrland och Nordamerika 18751913. Utvandring och återvandring (Västernorrland und Nordamerika 1875-1913. Aus- und Rückwanderung). Uppsala 1972.

Tedebrand 1980 = Ders.: Återinvandringens problematik (Die Problematik der Rückwanderung). In: Historisk Tidskrift för Finland 65 (1980) S. 280-283 [Rez. von K. Virtanen: Settlement or Return. Turku 1979].

Tedebrand 1985 = Ders.: Remigration from America to Sweden. In: Hoerder 1985a, S. 357-380.

Teijula $1921=$ Teijula, Ilmari: Suomen siirtolaisuusolot. Katsaus siirtolaisuustiedustelun tuloksiin (Der Auswanderungszustand in Finnland. Ergebnisse einer Befragung 
zur Auswanderungserscheinung). In: Sosiaalinen Aikakauskirja 15 (1921) S. 899916.

Thernstrom/Olov/Handlin $1981=$ Thernstrom, Stephan/Olov, Ann/Handlin, Oscar (Hrsg.): Havard Encyclopedia of American Ethnic Groups. Cambridge, Mass. 1981 $\left({ }^{1} 1980\right)$.

Thistlethwaite 1991 = Thistlethwaite, Frank: Migration from Europe Overseas in the Nineteenth and Twentieth Centuries. In: Vecoli/Sinke 1991, S. 17-57 [Original erschienen in: XIe Congrès International des Scienes Historique. Stockholm 1960, S. 32-60; als dt. Übersetzung in: Köllmann/Marschalck 1972, S. 323-355].

Thomas 1954 = Thomas, Brinley: Migration and Economic Growth. A Study of Great Britain and the Atlantic Economy. Cambridge 1954.

Thomas 1941 = Thomas, Dorothy S.: Social and Economic Aspects of Swedish Population Movements 1750-1933. New York 1941.

Thurner 1974 = Thurner, Arthur W.: Calumet Copper and People. A History of a Michigan Mining Community 1864-1970. Hancock, Mich. 1974.

Thurner 1984 = Ders: Rebels on the Range. The Michigan Copper Miners Strike of 1913-1914. Lake Linden, Mich. 1984.

Thurner $1994=$ Ders.: Strangers and Sojouners. A History of Michigan`s Keweenaw Penisula. Detroit, Mich. 1994.

Timothy 1995 = Timothy, Dallen J.: Finnish Settlements in Rural Thunder Bay: Changes in an Ethnic Commmunity. In: Siirtolaisuus/Migration, Heft 1 (1995) S. 1624. 
Timothy Laitila 1998 = Timothy Laitila, Vincent: New York City Passenger Manifesta of SS Titanic Survivors Rescued by the SS Carpathia. In: Siirtolaisuus/Migration, Heft 4 (1998) S. 27f.

Toivonen 1950 = Toivonen, Anna-Leena: Lapualta suureen länteen (Von Lapua in den Wilden Westen). Vaasa 1950 (Eripainos Etelä- Pohjalaisen osakunnan julkaisusta Kyrönmaa 7. Sonderdruck aus der Zeitschrift 'Kyrönmaa' der südostbottnischen Landsmannschaft, 7).

Toivonen 1951 = Diess.: Ähtäri - valtamerentakaisen siirtolaisuuden ja sisäisen muuttoliikkeen vedenjakaja ( Die Gemeinde Ähtäri - Grenzlinie zwischen Überseeauswanderung und Binnenmigration). Vaasa 1951 (Eripainos Etelä-Pohjalaisen osakunnan julkaisusta Kyrönmaa 8. Sonderdruck aus der Zeitschrift 'Kyrönmaa' der südostbottnischen Landsmannschaft, 8).

Toivonen 1955 = Diess.: Keskipohjalaista siirtolaisuutta Vetelin näkökulmasta (Die mittelostbottnische Auswanderung im Hinblick auf die Gemeinde Veteli). Vaasa 1955 (Eripainos Etelä-Pohjalaisen osakunnan julkaisusta Kyrönmaa 9.Sonderdruck aus der Zeitschrift 'Kyrönmaa' der südostbottnischen Landsmannschaft, 9).

Toivonen 1963 = Diess.: Etelä-Pohjanmaan valtamerentakainen siirtolaisuus 1867-1930 (Die Auswanderung von Süd-Ostbottnien nach Übersee 1867-1930). Helsinki 1963.

Tommila 1960 = Tommila, Päiviö (Hrsg.): Venäläinen sortokausi Suomessa (Die russische Unterdrückungsperiode in Finnland). Porvoo 1960.

Tommila 1983a = Ders. (Hrsg.): Suomen kulttuurihistoria 2 (Finnische Kulturgeschichte 2). Porvoo $1983\left({ }^{1} 1980\right)$.

Tommila 1983b = Ders. (Hrsg.): Suomen kaupunkilaitoksen historia 2. 1870-luvulta autonomian ajan loppuun (Die Geschichte der finnischen Stadtentwicklung 2. Von 1870 bis zum Ende der Autonomieepoche). Vantaa 1983. 
Tommila 1984 = Ders.: Oulun Wiikko Sanomia 1829-1879. Oulun lehdistön alkutaival. (Die Ouluer Wochennachrichten 1829-1879. Die Anfänge der Druckpresse in Oulu). Oulu 1984.

Tommila 1988a = Ders. (Hrsg.) : Suomen lehdistön historia 1. Sanomalehdistön vaiheet vuoteen 1905 (Die Geschichte der finnischen Druckpresse 1. Die Entwicklung bis zum Jahr 1905). Kuopio 1988.

Tommila 1988b = Ders.: Yhdestä lehdestä sanomalehdistöksi 1809-1859 (Vom einzelnen Blatt zur Zeitung 1809-1859). In: Tommila 1988a, S. 77-265.

Tommola 1989 = Tommola, Esko: Uuden maan rakentajat. New Yorkin suomalaisten tarina (Pioniere in der Neuen Welt. Die Geschichte der Finnen in New York). Helsinki 1989.

Torma 1988 = Torma, Carolyn: The Architecture of Finnish Settlement in South Dakota. In: Karni/Koivukangas/Laine 1988, S. 99-119.

Tuominen 1960 = Tuominen, Uuno: Helmikuun manifesti ja yritykset sen kumoamiseksi ja saattamiseksi sopusointuun suomen lakien kanssa (Das FebruarManifest und der Versuch seiner Annullierung bzw. Anpassung an die finnischen Gesetze). In: Tommila 1960, S. 51-61.

Turpeinen 1985 = Turpeinen, Oiva: Venäjänkielisten määrä Suomessa vuonna 1900 (Anzahl der russischsprachigen Einwohner Finnlands im Jahr 1900). In: Kurkinen 1985, S. 21-28.

Turpeinen 1986 = Ders.: Nälkä vai tauti tappoi? Kauhunvuodet 1866-1868 (Brachte Hunger oder Seuche den Tod? Die Schreckensjahre 1866-1868). Helsinki 1986.

Turpeinen 1991 = Ders.: Näläntorjunta ja hyvinvointivaltion perusteet (Maßnahmen gegen den Hunger und die Grundsätze der Wohlstandsgesellschaft). Helsinki 1991. 
Vainio 1974 = Vainio, Esa: Vuosien 1865-1892 ulkomaanpassiluetteloiden arvo valtamertentakaisen siirtolaisuuden tutkimuksessa (Die Bedeutung von Paßverzeichnissen der Jahre 1865-1892 für die Emigrationsforschung). In: Turun Historiallinen Arkisto 29 (1974) S. 52-62.

Vainio 1978 = Ders.: Muuttoliikkeiden ja sosiaalisen kehityksen välinen suhde teollistumisen kauden alussa (Die Beziehung zwischen Binnenmigration und sozialer Entwicklung zu Beginn des Industriezeitalters). In: Turun Historiallinen Arkisto 32 (1978) S. 96-113.

Valkonen 1985a $=$ Valkonen, Tapani (Hrsg.): Suomalaiset. Yhteiskunnan rakenne teollistumisen aikana (Die Finnen. Die Gesellschaftsstruktur während der Industrialisierungsphase). Porvoo 1985 ( $\left.{ }^{1} 1980\right)$.

Valkonen 1985b = Ders.: Väkiluvun ja ikärakenteen kehitys (Die Entwicklung der Bevölkerungsgröße und Altersstruktur); Alueelliset erot (Regionale Unterschiede) In: Valkonen 1985a, S. 10-35; S. 201-241.

Vattula 1983 = Vattula, Kaarina (Hrsg.): Suomen taloushistoria 3. Historiallinen tilasto (Finnische Wirtschaftsgeschichte 3. Historische Statistik). Helsinki 1983.

Vecoli/Sinke 1991 = Vecoli, Rudolph J./Sinke, Suzanne (Hrsg.): A Century of European Migrations 1830-1930. New York 1991.

Vedder/Gallaway 1970 = Vedder, Richard K./Gallaway, Lowell E.: The Settlement Preferences of Scandinavian Emigrants to the United States, 1850-1960. In: The Scandinavian Economic Review 18 (1970) S. 159-176.

Virrankoski 1983 = Virrankoski, Pentti: Taloudellinen ja sosiaalinen rakentuminen (Wirtschaftlicher und sozialer Aufbau). In: Tommila 1983a, S. 146-162. 
Virtanen 1976 = Virtanen, Keijo: Letters to Finland. The Finns in the United States: The Projekt on Finnish Immigration of the Michigan Historical Collections. In: Michigan Historical Collections, Bulletin 26 (1976) S. 8-25.

Virtanen 1977 = Ders.: The Influence of the Automotive Industry on the Ethnic Picture of Detroit, Michigan, 1900-1940. In: Publications of the Institute for General History Turku 9 (1977) S. 71-88.

Virtanen 1979 = Ders.: Settlement or Return: Finnish Emigrants (1860-1930) in the International Overseas Return Migration Movement. Turku 1979.

Virtanen 1981 = Ders.: Immigrant Adaption to New Environments: A View from the Sending Country. In: Finnish Americana 4 (1981) S.104-112.

Virtanen 1985 = Ders.: Finnish Migrants (1860-1930) in the Overseas Return Migration Movement. In: Hoerder 1985a, S. 381-398.

Virtanen 1986 = Ders.: Siirtolaisten kulttuuritoiminta - osallistumismahdollisuuksia jokaiselle (Kulturelles Leben der Amerika-Finnen - Teilnahmemöglichkeiten für alle) S. 145-208; Pohjois-Amerikassa olevien suomalaisten siirtolaisten ja kotimaan yhteydet (Der Kontakt der Auswanderer mit dem Heimatland S. 209-258; Siirtolaisten paluu kotimaahan (Die Rückkehr nach Finnland) S. 259-292. In: Virtanen/Pilli/Kostiainen 1986.

Virtanen 1987 = Ders.: Labor Migration Ambivalence: Adaption of the Finns to American Society. Their Integration and Impact in Finland after Return. In: Turun Historiallinen Arkisto 42 (1987) S. 499-510.

Virtanen 1988 = Ders.: Atlantin yhteys. Tutkimus amerikkalaisesta kulttuurista, sen suhteesta ja välittymisestä Eurooppaan vuosina 1776-1917 (Der Kontakt zu Amerika. Eine Untersuchung über amerikanische Kultur und ihre Beziehung zu Europa 17761917). Helsinki 1988. 
Virtanen 1989 = Ders.: The Influence of Migration on Finnish Cultural Identity in the Twentieth Century: Some Preliminary Considerations. In: Siirtolaisuus/Migration, Heft 4 (1989) S. 14-19.

Virtanen 1993 = Ders.: The Dialogue between Finland and the United States - and the Finnish-Americans. In: Siirtolaisuus/Migration, Heft 1 (1993) S. 4-11.

Virtanen/Pilli/Kostiainen 1986 = Virtanen, Keijo/Pilli, Arja/Kostiainen, Auvo: Suomen siirtolaisuuden historia 3. Sopeutuminen, kulttuuritoiminta ja paluumuutto (Geschichte der finnischen Auswanderung 3. Anpassung, kulturelles Leben und Rückwanderung). Turku 1986.

Virtaranta 1983 = Virtaranta, Pertti: Uusi Suomi - New Finland. In: FinnishAmericana 6 (1983) S. 34-39.

Virtaranta 1992 = Ders.: Amerikansuomen sanakirja. A Dictionary of American Finnish. Turku 1992.

Wargelin 1987 = Wargelin, Raymond W.: Salomon Ilmonen, Early Finnish-American Historican. In: Siirtolaisuus/Migration, Heft 3 (1987) S. 2-11.

Wargelin-Brown 1986a $=$ Wargelin-Brown, Marianne K.: The Legacy of Mummu's Granddaugthers: Finnish American Women's History. In: Ross/Wargelin-Brown 1986, S. 14-40.

Wargelin-Brown 1986b = Diess.: A Closer Look at Finnish-American Immigrant Women's Issues, 1890-1910. In: Ross/Wargelin-Brown 1986, S. 83-102.

Wasastjerna 1957 = Wasastjerna, Hans R.: Minnesotan suomalaisten historia. Duluth, Minn. 1957. [In engl. Übersetz.: History of the Finns in Minnesota. New York Mills, Minn. 1967]. 
Weatherford $1986=$ Weatherford, Doris: Foreign and Female. Immigrant Women in America, 1840-1930. New York 1986.

Webster 1978 = Webster, Janice: Domestication and Americanization. Scandinavian Women in Seattle, 1888 to 1900. In: Journal of Urban History 4 (1978) S. 275-290.

Wehner-Franco 1994 = Wehner-Franco, Silke: Deutsche Dienstmädchen in Amerika 1850-1914. Münster/New York 1994. (Beiträge zur Volkskultur in Nordwestdeutschland, 87).

Wester 1977 = Wester, Holger: Innovationer i befolkningsrörligheten. En studie av spridningsförlopp i befolkningsrörligheten utgående från Petalax socken i Österbotten (Innovationen der Bevölkerungsmobilität. Eine Untersuchung zur Ausbreitung der Bevölkerungsmobilität ausgehend von der Gemeinde Petalax [finn.: Petolahti] in Ostbottnien). Turku 1977.

Weß de Velásquez 1995 = Weß de Velásquez, Mechthild: Zwischen Hamburg und Haiti. Kommunikationsstrukturen und Erzählmuster in Briefen aus der und in die Ferne. In: Lipp, Carola (Hrsg.): Medien popularer Kultur. Erzählung, Bild, Objekt in der volkskundlichen Forschung. Frankfurt/New York 1995, S. 117-127.

Wetterholm 1988 = Wetterholm, Claes-Göran: Titanic. Uddevalla 1988.

Widén 1972 = Widén, Bill: Finlandsvenkarnas i Brooklyn, N.Y., proveniens (Die Herkunft der Finnland-Schweden in Brooklyn, N.Y.). In: Turun Historiallinen Arkisto 27 (1972) S. 120-127.

Widén 1975 = Ders.: Korpobor i Amerika (Einwohner der Gemeinde Korpo in Amerika). Turku 1975.

Wild 1995 = Wild, Pamela: Sointula: Island Utopia. Madeira Park 1995. 
Wilson 1977 = Wilson, Donald J.: Cultural Adaption, Change and Continuity among Thunder Bay Finns. In: Siirtolaisuus/Migration, Heft 4 (1977) S. 12-24.

Wilson 1981 = Ders.: "Never Believe What You Have Never Doubted": Matti Kurikka's Dream for a New World Utopia. In: Karni 1981a, S. 131-153.

Wittke 1967 = Wittke, Carl: We Who Built America. The Saga of the Immigrant. Cleveland. Reprint Ohio 1967 ( $\left.{ }^{1} 1939\right)$.

Wulff 1987 = Wulff, Reinhold: Die Anfangsphase der Emigration aus Schweden in die USA, 1820-1850. Gesamtdarstellung anhand der amerikanischen Passagierlisten sowie Detailanalyse der Emigration aus Kisa in Östergötland. Frankfurt/Main u.a. 1987.

Yli-Jokipii 1967 = Yli-Jokipii, P.: Die Kleinindustrie in einigen Gemeinden Süd-Ostbottniens. In: Fennia 96 (1967) S. 96-107.

Yli-Jokipii 1971 = Ders.: The Cultural Geography of Kaleva, a Finnish Immigrant Community in Michigan. In: Acta Geographica 22 (1971) S. 5-24.

Ylikangas 1987 = Ylikangas, Heikki: Österbotten i Finlands historia (Ostbottnien in der Geschichte Finnlands). In: Historisk Tidskrift för Finland 72 (1987) S. 397-411.

Yoder 1973 = Yoder, Don: Akkulturationsprobleme deutscher Auswanderer in Nordamerika. In: Wiegelmann, Günter (Hrsg.): Kultureller Wandel im 19. Jahrhundert. Göttingen 1973, S. 184-203.

Zetterberg 1988 = Zetterberg, Seppo (Hrsg.): Suomen historian pikku jättiläinen (Kleiner Atlas der finnischen Geschichte). Porvoo 1988 ( $\left.{ }^{1} 1987\right)$.

Zwingmann 1962 = Zwingmann, Charles: Das nostalgische Phänomen. In: Ders. (Hrsg.): Zur Psychologie der Lebenskrisen. Frankfurt/Main 1962, S. 308-338. 


\section{ANHANG: VERZEICHNIS DER KARTEN UND TABELLEN}

\section{TABELLEN}

Tab. 1: Anzahl der finnischen Überseeauswanderer 1870-1914

Tab. 2: Verteilung der finnischen Auswanderer nach Geschlecht 1870-1914

Tab. 3: Anzahl der finnischen Überseeauswanderer in Beziehung zur ökonomischen Situation in den Vereinigten Staaten und Finnland 1870-1914

Tab. 4: Anzahl der finnischen Rückwanderer 1892-1914

Tab. 5: Durchschnittlicher jährlicher Bevölkerungszuwachs in 40 Gemeinden der Provinzen Süd-Ostbottinen und Satakunta 1865-1914 (Untersuchungsgebiet)

Tab. 6: Auswanderungsintensität in Relation zur durchschnittlichen Bevölkerung nach Gemeinden im Untersuchungsgebiet 1870-1914

Tab. 7: Geographische Verteilung der finnischen Immigranten auf zehn Bundesstaaten der Vereinigten Staaten und fünf kanadische Provinzen 1900, 1910 und 1920 sowie 1901, 1911 und 1921

Tab. 8: Briefanzahl und Briefverfasser in den Gemeinden des Untersuchungsgebietes 1882-1914

Tab. 9: Namentliche Auflistung der Briefschreiber mit Angaben zu Herkunftsort, Auswanderungsjahr, Jahr des 1. Amerika-Briefes und potientieller Rückkehr

\section{KARTEN}

Karte 1a: Geographische Aufteilung Finnlands nach Regierungsbezirken vor 1918

Karte 1b: Geographische Aufteilung Finnlands nach Provinzen 1900

Karte 2: Prozentuale Verteilung der Auswandererkonzentration in Finnland 1870-1914

Karte 3: Das finnische Eisenbahnnetz im westlichen Finnland 1862-1925

Karte 4: Herkunftsgemeinden der Briefschreiber in Süd-Ostbottnien und Satakunta

Karte 5: Verteilung der Amerika-Finnen auf einzelne Bundesstaaten 1900

Karte 6: Geographische Konzentration der Finnen im Bereich der Großen Seen 1900

Karte 7: Geographische Lage der Eisenerz- und Kupferbergwerke in Michigan, Minnesota und Wisconsin 1900 


\section{TABELLEN}

Tab.1 Anzahl der finnischen Überseeauswanderer 1870-1914

\begin{tabular}{|c|c|c|}
\hline Jahr & Passagierlisten & Offizielle Statistik \\
\hline 1870 & 45 & \\
\hline 1871 & 115 & \\
\hline 1872 & 598 & \\
\hline 1873 & 980 & \\
\hline 1874 & 101 & \\
\hline 1875 & 93 & \\
\hline 1876 & 128 & \\
\hline 1877 & 145 & \\
\hline 1878 & 137 & \\
\hline 1879 & 506 & \\
\hline 1880 & 1881 & \\
\hline 1881 & 2914 & \\
\hline 1882 & 3734 & \\
\hline 1883 & 2735 & \\
\hline 1884 & 1775 & \\
\hline 1885 & 1077 & \\
\hline 1886 & 3324 & \\
\hline 1887 & 7857 & \\
\hline 1888 & 4862 & \\
\hline 1889 & 5204 & \\
\hline 1890 & ca.6700 & \\
\hline 1891 & ca. 7800 & \\
\hline 1892 & ca. 8000 & \\
\hline 1893 & ca.9000 & 9177 \\
\hline 1894 & 1284 & 1380 \\
\hline 1895 & 3296 & 4020 \\
\hline 1896 & 5329 & 5185 \\
\hline 1897 & 2772 & 1916 \\
\hline 1898 & 3886 & 3467 \\
\hline 1899 & 12993 & 12075 \\
\hline 1900 & 11316 & 10397 \\
\hline 1901 & 13205 & 12561 \\
\hline 1902 & 23311 & 23152 \\
\hline 1903 & 18216 & 16964 \\
\hline 1904 & 11269 & 10952 \\
\hline 1905 & 18754 & 17427 \\
\hline 1906 & 17556 & 17517 \\
\hline 1907 & 16930 & 16296 \\
\hline 1908 & 6433 & 5812 \\
\hline 1909 & 21009 & 19144 \\
\hline 1910 & 20285 & 19007 \\
\hline 1911 & 10251 & 9372 \\
\hline 1912 & 11795 & 10724 \\
\hline 1913 & 21855 & 20057 \\
\hline 1914 & 5925 & 6474 \\
\hline
\end{tabular}




\begin{tabular}{|l|l|l|}
\hline Jahr & Passagierlisten & Offizielle Statistik \\
\hline $1893-1914$ & ca. 266670 & $\mathbf{2 5 3 0 1 6}$ \\
\hline $1870-1914$ & ca. 327397 & $\mathbf{2 5 3 0 1 6}$ \\
\hline
\end{tabular}

\section{Anmerkung zu Tab.1:}

Tabelle entnommen aus Kero 1986, S. 29-31, Tab.1. Siehe auch Kero 1974, S. 26-28.

Die Zahlenwerte der Rubrik ,Passagierlisten' basieren auf den Angaben mehrerer Reedereien, deren Akten (1870-89) von den Polizeibehörden in Göteborg, Malmö, Stockholm und Trondheim archiviert wurden, auf den Angaben des ,Norddeutschen Lloyd' (1890-93) und der ,Finnischen Dampfschiffahrtsgesellschaft AG' (1892-1914). Für die Jahre 1890-93 stellen die Zahlen lediglich Schätzwerte dar.

Die Angaben der Rubrik, Offizielle Statistik' beruhen auf amtlichen Paßverzeichnissen ab 1893: Suomen Virallinen Tilasto 28. Siirtolaisuustilasto 1-11 (Amtliche Statistik für Finnland 28. Emigrationsstatistik 1-11) Helsinki 1905-15.

Tab. 2 Verteilung der finnischen Auswanderer nach Geschlecht 1870-1914

\begin{tabular}{|l|l|l|l|}
\hline Jahr & Männer \% & Frauen \% & Unbekannt \% \\
\hline 1870 & 66,7 & 33,3 & \\
\hline 1871 & 56,5 & 43,5 & \\
\hline 1872 & 95,7 & 4,3 & \\
\hline 1873 & 82,4 & 17,6 & \\
\hline 1874 & 44,6 & 55,4 & \\
\hline 1875 & 64,5 & 35,5 & \\
\hline 1876 & 56,3 & 43,8 & \\
\hline 1877 & 55,9 & 44,1 & \\
\hline 1878 & 67,2 & 32,8 & \\
\hline 1879 & 82,2 & 17,6 & 0,2 \\
\hline 1880 & 73,2 & 25,7 & 1,1 \\
\hline 1881 & 74,3 & 21,8 & 3,9 \\
\hline 1882 & 74,7 & 22,3 & 3,0 \\
\hline 1883 & 74,0 & 24,1 & 1,9 \\
\hline 1884 & 70,2 & 28,6 & 1,2 \\
\hline 1885 & 58,1 & 39,8 & 2,0 \\
\hline 1886 & 77,9 & 20,7 & 1,4 \\
\hline 1887 & 81,8 & 17,6 & 0,6 \\
\hline 1888 & 72,7 & 26,6 & 0,7 \\
\hline 1889 & 71,2 & 28,6 & 0,2 \\
\hline 1890 & 69,7 & 29,9 & 0,4 \\
\hline 1891 & 66,5 & 33,5 & 1,3 \\
\hline 1892 & 69,6 & 29,1 & \\
\hline 1893 & 68,8 & 31,2 & \\
\hline 1894 & 46,2 & 53,8 & \\
\hline & & & \\
\hline & & & \\
\hline
\end{tabular}




\begin{tabular}{|l|l|l|l|}
\hline 1895 & 51,3 & 48,7 & \\
\hline 1896 & 59,4 & 40,6 & \\
\hline 1897 & 45,2 & 54,8 & \\
\hline 1898 & 57,7 & 42,3 & \\
\hline 1899 & 62,9 & 37,1 & \\
\hline 1900 & 60,3 & 39,7 & \\
\hline 1901 & 65,6 & 34,4 & \\
\hline 1902 & 69,4 & 30,6 & \\
\hline 1903 & 61,6 & 38,4 & \\
\hline 1904 & 56,2 & 43,8 & \\
\hline 1905 & 68,9 & 31,1 & \\
\hline 1906 & 68,1 & 31,9 & \\
\hline 1907 & 64,2 & 35,8 & \\
\hline 1908 & 57,0 & 43,0 & \\
\hline 1909 & 65,3 & 34,7 & \\
\hline 1910 & 65,5 & 34,5 & \\
\hline 1911 & 51,4 & 48,6 & \\
\hline 1912 & 52,7 & 47,3 & \\
\hline 1913 & 64,4 & 35,6 & \\
\hline 1914 & 56,4 & 43,6 & $\mathbf{0 , 2}$ \\
\hline & & & \\
\hline $\mathbf{1 8 7 0 - 1 9 1 4}$ & $\mathbf{6 4 , 7}$ & $\mathbf{3 5 , 1}$ & \\
\hline & & & \\
\hline
\end{tabular}

Anmerkung zu Tab.2:

Tabelle entnommen aus Kero 1974, S. 91f., Tab.12.

Tab. 3 Anzahl der finnischen Überseeauswanderer in Beziehung zur ökonomischen Situation in Finnland und den Vereinigten Staaten 1870-1914

\begin{tabular}{|l|l|l|l|}
\hline Jahr & $\begin{array}{l}\text { Auswandereranzahl } \\
\text { (Passagierlisten) }\end{array}$ & $\begin{array}{l}\text { Ökonomische } \\
\text { Situation in } \\
\text { Finnland }\end{array}$ & $\begin{array}{l}\text { Ökonomische } \\
\text { Situation in den } \\
\text { Verein. Staaten }\end{array}$ \\
\hline 1870 & 45 & Tief & Tief \\
\hline 1871 & 115 & Tief & \\
\hline 1872 & 598 & Tief & \\
\hline 1873 & 980 & Tief & Hoch \\
\hline 1874 & 101 & Tief & \\
\hline 1875 & 93 & Tief & \\
\hline 1876 & 128 & Tief & \\
\hline 1877 & 145 & Tief & \\
\hline 1878 & 137 & Tief & \\
\hline 1879 & 506 & Tief & Tief \\
\hline 1880 & 1881 & Hoch & \\
\hline & & &
\end{tabular}




\begin{tabular}{|c|c|c|c|}
\hline Jahr & $\begin{array}{l}\text { Auswandereranzahl } \\
\text { (Passagierlisten) }\end{array}$ & $\begin{array}{l}\text { Ökonomische } \\
\text { Situation in } \\
\text { Finnland }\end{array}$ & $\begin{array}{l}\text { Ökonomische } \\
\text { Situation in den } \\
\text { Verein. Staaten }\end{array}$ \\
\hline 1881 & 2914 & & \\
\hline 1882 & 3734 & Tief & Hoch \\
\hline 1883 & 2735 & Hoch & \\
\hline 1884 & 1775 & & \\
\hline 1885 & 1077 & Tief & Tief \\
\hline 1886 & 3324 & & \\
\hline 1887 & 7857 & & Hoch \\
\hline 1888 & 4862 & & Tief \\
\hline 1889 & 5204 & & \\
\hline 1890 & ca. 6700 & Hoch & Hoch \\
\hline 1891 & ca. 7800 & & Tief \\
\hline 1892 & ca. 8000 & & \\
\hline 1893 & ca.9000 & Tief & Hoch \\
\hline 1894 & 1284 & & Tief \\
\hline 1895 & 3296 & & Hoch \\
\hline 1896 & 5329 & & \\
\hline 1897 & 2772 & & Tief \\
\hline 1898 & 3886 & Hoch & \\
\hline 1899 & 12.993 & & Hoch \\
\hline 1900 & 11.316 & & Tief \\
\hline 1901 & 13.205 & & \\
\hline 1902 & 23.311 & Tief & Hoch \\
\hline 1903 & 18.216 & Hoch & \\
\hline 1904 & 11.269 & Tief & Tief \\
\hline 1905 & 18.754 & & \\
\hline 1906 & 17.556 & & \\
\hline 1907 & 16.930 & Hoch & Hoch \\
\hline 1908 & 6433 & Hoch & Tief \\
\hline 1909 & 21.009 & Hoch & \\
\hline 1910 & 20.285 & Hoch & Hoch \\
\hline 1911 & 10.251 & Hoch & \\
\hline 1912 & 11.795 & Hoch & Tief \\
\hline 1913 & 21.855 & Hoch & Hoch \\
\hline 1914 & 5925 & Hoch & Tief \\
\hline
\end{tabular}

Anmerkung zu Tab. 3:

Tabelle entnommen aus Virtanen 1979, S. 228-230, Tab.1. Die dargestellten Auswandererzahlen sind identisch mit den Zahlen der Rubrik ,Passagierlisten' der Tabelle 1. 
Tab. 4 Anzahl der finnischen Rückwanderer 1892-1914

\begin{tabular}{|c|c|c|}
\hline Jahr & Offizielle Statistik & Passagierlisten \\
\hline 1892 & & 557 \\
\hline 1893 & & 1286 \\
\hline 1894 & 630 & 2074 \\
\hline 1895 & 646 & 1757 \\
\hline 1896 & 894 & 1880 \\
\hline 1897 & 693 & 1825 \\
\hline 1898 & 572 & 2689 \\
\hline 1899 & 312 & 1619 \\
\hline 1900 & 1043 & 2579 \\
\hline 1901 & 1148 & 3176 \\
\hline 1902 & 901 & 2857 \\
\hline 1903 & 1740 & 5268 \\
\hline 1904 & 1764 & 5406 \\
\hline 1905 & 1259 & 3930 \\
\hline 1906 & 1602 & 6790 \\
\hline 1907 & 3783 & 10809 \\
\hline 1908 & 3183 & 12440 \\
\hline 1909 & 1601 & 4880 \\
\hline 1910 & 1641 & 5348 \\
\hline 1911 & 2423 & 7688 \\
\hline 1912 & 2159 & 6892 \\
\hline 1913 & 2068 & 6533 \\
\hline 1914 & 1840 & 4457 \\
\hline 1892-1914 & 31902 & 102704 \\
\hline
\end{tabular}

Anmerkung zu Tab. 4:

Tabelle entnommen aus Virtanen 1979, S. 229f., Anhang, Tab.1. Virtanen hat bislang die einzige detaillierte Studie zu Umfang und Auswirkungen der finnischen Amerikarückwanderung vorgelegt. Als Kurzversion seiner Untersuchungsergebnisse siehe Virtanen 1985, S. 381-398. 
Tab. 5 Durchschnittlicher jährlicher Bevölkerungszuwachs in 40 Gemeinden aus den Provinzen Süd-Ostbottinen und Satakunta 1865-1914 (Untersuchungsgebiet)

\section{SÜD-OSTBOTTNIEN}

\begin{tabular}{|l|l|l|l|l|}
\hline Gemeinde & $\begin{array}{l}\text { Stand: } \\
\mathbf{3 1 . 1 2 . 1 8 6 5 1}\end{array}$ & $\begin{array}{l}\text { Stand: } \\
\mathbf{3 1 . 1 2 . 1 9 1 4}\end{array}$ & $\begin{array}{l}\text { Prozentuale } \\
\text { Zuwachsrate } \\
\mathbf{1 8 6 5 - 1 9 1 4}\end{array}$ & $\begin{array}{l}\text { Jährlicher, } \\
\text { durchschn. } \\
\text { Bevölkerungs- } \\
\text { zuwachs } \\
\text { in Prozent }\end{array}$ \\
\hline Alajärvi & 3685 & 7826 & 112,4 & 2,25 \\
\hline Ilmajoki & 8250 & 12.207 & 48,0 & 0,96 \\
\hline Isokyrö & 6043 & 8932 & 47,8 & 0,96 \\
\hline Jalasjärvi & 6776 & 13.428 & 98,2 & 1,96 \\
\hline Jurva & 2650 & 6002 & 126,5 & 2,53 \\
\hline Karijoki & 2079 & 2943 & 41,6 & 0,83 \\
\hline Kauhajoki & 6114 & 13.957 & 128,3 & 2,57 \\
\hline Kuortane & 2875 & 6176 & 114,8 & 2,30 \\
\hline Kurikka & 4990 & 9443 & 89,2 & 1,78 \\
\hline Laihia & 5348 & 8023 & 50,0 & 1,00 \\
\hline Lapua & 7500 & 13.326 & 77,7 & 1,55 \\
\hline Peräseinäjoki & 2358 & 5872 & 149,0 & 2,98 \\
\hline Seinäjoki & 1861 & 4408 & 136,9 & 2,74 \\
\hline Teuva & 4798 & 8476 & 76,7 & 1,53 \\
\hline Töysä & 1921 & 3904 & 103,2 & 2,06 \\
\hline Vaasa (Stadt) & 4551 & 24.430 & 436,8 & 8,74 \\
\hline Vimpeli & 1704 & 3747 & 119,9 & 2,40 \\
\hline Vähäkyrö & 4409 & 5253 & 19,1 & 0,38 \\
\hline Ylihärmä & 2480 & 3783 & 52,5 & 1,05 \\
\hline Ylistaro & 8078 & 10.348 & 28,1 & 0,56 \\
\hline & & & & \\
\hline
\end{tabular}

1Die Bevölkerungsangaben des Jahres 1865 stammen aus: Suomenmaan VirallinenTilasto 6 (Amtliche Statistik für Finnland 6) Helsinki 1870, S. 2-9, Tab.1.Für das Jahr 1914: Suomen Tilastollinen Vuosikirja 14 (Statistisches Jahrbuch für Finnland, Jg. 14) Helsinki 1917, S. 13-25, Tab.10. 
SATAKUNTA

\begin{tabular}{|l|l|l|l|l|}
\hline Gemeinde & $\begin{array}{l}\text { Stand: } \\
\mathbf{3 1 . 1 2 . 1 8 6 5}\end{array}$ & $\begin{array}{l}\text { Stand: } \\
\mathbf{3 1 . 1 2 . 1 9 1 4}\end{array}$ & $\begin{array}{l}\text { Prozentuale } \\
\text { Zuwachsrate } \\
\mathbf{1 8 6 5 - 1 9 1 4}\end{array}$ & $\begin{array}{l}\text { Jährlicher } \\
\text { durchschn. } \\
\text { Bevölkerungs- } \\
\text { zuwachs } \\
\text { in Prozent }\end{array}$ \\
\hline Eura & 2213 & 3744 & 69,2 & 1,38 \\
\hline Hinnerjoki & 1234 & 1949 & 57,9 & 1,16 \\
\hline Honkilahti & 1158 & 1702 & 47,0 & 0,94 \\
\hline Ikaalinen & 7036 & 12.771 & 81,5 & 1,63 \\
\hline Jämijärvi & 1794 & 3815 & 112,7 & 2,25 \\
\hline Kankaanpää & 5526 & 9046 & 63,7 & 1,27 \\
\hline Karvia & 2128 & 4332 & 103,6 & 2,07 \\
\hline Kiikka & 2626 & 4203 & 60,1 & 1,20 \\
\hline Kiikoinen & 1526 & 2735 & 79,2 & 1,58 \\
\hline Kokemäki & 5792 & 7807 & 34,8 & 0,70 \\
\hline Kullaa & 2516 & 2795 & 11,1 & 0,22 \\
\hline Köyliö & 2320 & 3527 & 52,0 & 1,04 \\
\hline Lappi/TL 2 & 2364 & 3973 & 68,1 & 1,36 \\
\hline Lavia & 3250 & 5849 & 80,0 & 1,60 \\
\hline Loimaa & 8516 & 10.744 & 26,2 & 0,52 \\
\hline Merikarvia & 5183 & 8528 & 64,5 & 1,29 \\
\hline Siikainen & 3090 & 5222 & 69,0 & 1,38 \\
\hline Pomarkku & 2693 & 4725 & 75,5 & 1,50 \\
\hline Säkylä & 1717 & 2733 & 59,2 & 1,18 \\
\hline Tyrvää & 6222 & 9643 & 55,0 & 1,10 \\
\hline
\end{tabular}

2Die Gemeinde Lappi/TL liegt im Regierungsbezirk Turku/Pori und ist nicht zu verwechseln mit der Provinz Lappland (finn. Lappi). 
Tab. 6 Auswanderungsintensität in Relation zur durchschnittlichen Bevölkerung nach Gemeinden im Untersuchungsgebiet und in Finnland 1870 - 1914

\section{SÜD-OSTBOTTNIEN (REG. BEZIRK VAASA)}

\begin{tabular}{|l|l|l|l|l|}
\hline Gemeinde & Auswanderer & $\begin{array}{l}\text { Durchschnittl. } \\
\text { Einwohnerzahl }\end{array}$ & $\begin{array}{l}\text { Jährliche } \\
\text { Emigration } \\
\text { (Durchschnittswert) }\end{array}$ & $\begin{array}{l}\text { Durchschnittl. } \\
\text { Emigration/1000 } \\
\text { Einwohner }\end{array}$ \\
\hline Alajärvi & 3423 & 5601 & 76,1 & 13,6 \\
\hline Ilmajoki & 2892 & 9969 & 64,3 & 6,4 \\
\hline Isokyrö & 4495 & 7528 & 99,9 & 13,3 \\
\hline Jalasjärvi & 3793 & 9849 & 84,3 & 8,6 \\
\hline Jurva & 1676 & 4667 & 37,2 & 8,0 \\
\hline Karijoki & 1202 & 2452 & 26,7 & 10,9 \\
\hline Kauhajoki & 3608 & 9621 & 80,2 & 8,3 \\
\hline Kuortane & 1822 & 4409 & 40,5 & 9,2 \\
\hline Kurikka & 2231 & 7018 & 49,6 & 7,1 \\
\hline Laihia & 3295 & 6612 & 73,2 & 11,1 \\
\hline Lapua & 4716 & 10399 & 104,8 & 10,1 \\
\hline Peräseinäjoki & 1438 & 3971 & 32,0 & 8,1 \\
\hline Seinäjoki & 838 & 2905 & 18,6 & 6,4 \\
\hline Teuva & 2271 & 5912 & 50,5 & 8,5 \\
\hline Töysä & 902 & 2843 & 20,0 & 7,0 \\
\hline Vaasa(Stadt) & 4904 & 11642 & 109,0 & 9,4 \\
\hline Vimpeli & 1295 & 2693 & 28,8 & 10,7 \\
\hline Vähäkyrö & 2010 & 4719 & 44,7 & 9,5 \\
\hline Ylihärmä & 1402 & 3156 & 31,2 & 9,9 \\
\hline Ylistaro & 4622 & 8922 & 102,7 & 11,5 \\
\hline & & & & $\mathbf{9 , 4}$ \\
\hline $\begin{array}{l}\text { Insg. 20 } \\
\text { Gemeinden }\end{array}$ & $\mathbf{5 2 8 3 5}$ & $\mathbf{1 2 4 8 8 8}$ & $\mathbf{1 1 7 4 , 3}$ & \\
\hline & & & \\
\hline
\end{tabular}

$3 \mathrm{Zu}$ den Auswandererzahlen auf Gemeindeniveau siehe Kero 1974, S. 217-232, bes. S. $220 \mathrm{f}$. und S. 227-229

${ }^{4}$ Die Durchschnittswerte beziehen sich auf die jeweilige Bevölkerungsgröße der einzelnen Gemeinden in den Jahren 1870, 1880, 1890, 1900 und 1910; entnommen aus den statistischen Jahrbüchern Finnlands 'Suomen [bis 1902: Suomenmaan] Tilastollinen Vuosikirja' (Hrsg. Zentralamt für Statistik in Helsinki) der entsprechenden Jahre, vgl. auch Note 1. 
SATAKUNTA (REG. BEZIRK TURKU/PORI)

\begin{tabular}{|l|l|l|l|l|}
\hline Gemeinde & Auswanderer & $\begin{array}{l}\text { Durchschnittl. } \\
\text { Einwohnerzahl }\end{array}$ & $\begin{array}{l}\text { Jährliche } \\
\text { Emigration } \\
\text { (Durchschnittswert) }\end{array}$ & $\begin{array}{l}\text { Durchschnittl. } \\
\text { Emigration/1000 } \\
\text { Einwohner }\end{array}$ \\
\hline Eura & 201 & 2762 & 4,5 & 1,6 \\
\hline Hinnerjoki & 433 & 1542 & 9,6 & 6,2 \\
\hline Honkilahti & 271 & 1430 & 6,0 & 4,2 \\
\hline Ikaalinen & 2134 & 9410 & 47,4 & 5,0 \\
\hline Jämijärvi & 756 & 2731 & 16,8 & 6,2 \\
\hline Kankaanpää & 2063 & 6995 & 45,8 & 6,5 \\
\hline Karvia & 947 & 3093 & 21,0 & 6,8 \\
\hline Kiikka & 275 & 3357 & 6,1 & 1,8 \\
\hline Kiikoinen & 230 & 2081 & 5,1 & 2,5 \\
\hline Kokemäki & 358 & 6712 & 8,0 & 1,2 \\
\hline Kullaa & 127 & 2541 & 2,8 & 1,1 \\
\hline Köyliö & 273 & 3061 & 6,1 & 2,0 \\
\hline Lappi/TL & 503 & 3086 & 11,2 & 3,6 \\
\hline Lavia & 342 & 4524 & 7,6 & 1,7 \\
\hline Loimaa 5 & 765 & 8815 & 17,0 & 1,9 \\
\hline Merikarvia & 1842 & 6662 & 40,9 & 6,1 \\
\hline Siikainen & 1434 & 3983 & 31,9 & 8,0 \\
\hline Pomarkku & 681 & 3659 & 15,1 & 4,1 \\
\hline Säkylä & 288 & 2130 & 6,4 & 3,0 \\
\hline Tyrvää & 455 & 7598 & 10,1 & 1,3 \\
\hline & & & $\mathbf{3 1 9 , 4}$ & \\
\hline Insg. 20 \\
Gemeinden & $\mathbf{1 4 3 7 8}$ & $\mathbf{8 6 1 7 2}$ & & \\
\hline & & & & \\
\hline & & & & \\
\hline
\end{tabular}

5Für die Gemeinde Loimaa konnten nur die Einwohnerangaben der Jahre 1880, 1890, 1900 und 1910 berücksichtigt werden, vgl. Note 4 . 
LÄNDLICHE GEMEINDEN UND STÄDTE IM VERGLEICH

\begin{tabular}{|l|l|l|l|l|}
\hline & Auswanderer & $\begin{array}{l}\text { Durchschnittl. } \\
\text { Einwohnerzahl }\end{array}$ & $\begin{array}{l}\text { Jährliche } \\
\text { Emigration } \\
\text { (Durchschnittswert) }\end{array}$ & $\begin{array}{l}\text { Durchschnittl. } \\
\text { Emigration/1000 } \\
\text { Einwohner }\end{array}$ \\
\hline $\begin{array}{l}\text { Reg.bez. } \\
\text { Vaasa }\end{array}$ & $\mathbf{1 5 8 4 0 8}$ & $\mathbf{4 0 9 6 3 0}$ & $\mathbf{3 5 2 0 , 2}$ & $\mathbf{8 , 6}$ \\
\hline $\begin{array}{l}\text { Ländl. } \\
\text { Gem. }\end{array}$ & 148375 & 384873 & 3297,2 & 8,6 \\
\hline Städte & 10033 & 25458 & 222,9 & 8,8 \\
\hline $\begin{array}{l}\text { Reg.bez. } \\
\text { Turku/Pori }\end{array}$ & $\mathbf{4 3 7 8 3}$ & $\mathbf{3 9 6 1 7 6}$ & $\mathbf{9 7 2 , 3}$ & $\mathbf{2 , 5}$ \\
\hline $\begin{array}{l}\text { Ländl. } \\
\text { Gem. }\end{array}$ & 37510 & 342943 & 833,6 & 2,4 \\
\hline Städte & 6243 & 53233 & 138,7 & 2,6 \\
\hline Finnland & $\mathbf{3 0 2 7 8 2}$ & $\mathbf{2 . 4 0 3 5 2 1}$ & $\mathbf{6 7 2 8 , 5}$ & $\mathbf{2 , 8}$ \\
\hline $\begin{array}{l}\text { Ländl. } \\
\text { Gem. }\end{array}$ & 265435 & 2.137471 & 5898,6 & 3,1 \\
\hline Städte & 37347 & 266050 & 829,9 & \\
\hline
\end{tabular}


Tab. 7 Geographische Verteilung der finnischen Immigranten auf zehn Bundesstaaten der Vereinigten Staaten und fünf kanadische Provinzen 1900, 1910 und 1920 sowie 1901, 1911 und 1921

VEREINIGTE STAATEN

\begin{tabular}{|l|l|l|l|l|l|l|}
\hline Bundesstaat & $\begin{array}{l}\text { Auswand. } \\
\mathbf{1 9 0 0}\end{array}$ & $\begin{array}{l}\text { Proz.Anteil } \\
\mathbf{1 9 0 0}\end{array}$ & $\begin{array}{l}\text { Auswand. } \\
\mathbf{1 9 1 0}\end{array}$ & $\begin{array}{l}\text { Proz.Anteil } \\
\mathbf{1 9 1 0}\end{array}$ & $\begin{array}{l}\text { Auswand. } \\
\mathbf{1 9 2 0}\end{array}$ & $\begin{array}{l}\text { Proz.Anteil } \\
\mathbf{1 9 2 0}\end{array}$ \\
\hline Michigan & 18910 & 29,0 & 31144 & 21,5 & 30096 & 17,6 \\
\hline Minnesota & 10727 & 16,5 & 26637 & 18,3 & 29108 & 17,0 \\
\hline Massachusetts & 5104 & 7,8 & 10744 & 7,4 & 14570 & 8,5 \\
\hline New York & 4048 & 6,2 & 8760 & 6,0 & 12504 & 7,3 \\
\hline Ohio & 2814 & 4,3 & 3988 & 2,7 & 6406 & 3,7 \\
\hline Washington & 2732 & 4,2 & 8719 & 6,0 & 11863 & 6,9 \\
\hline Kalifornien & 2763 & 4,2 & 6159 & 4,2 & 7053 & 4,1 \\
\hline Wisconsin & 2198 & 3,4 & 5705 & 3,9 & 6757 & 3,9 \\
\hline Oregon & 2131 & 3,3 & 4734 & 3,3 & 6050 & 3,5 \\
\hline Montana & 2103 & 3,2 & 4111 & 2,8 & 3577 & 2,1 \\
\hline & & & & & & \\
\hline $\mathbf{1 0}$ Staaten & $\mathbf{5 3 5 3 0}$ & $\mathbf{8 2 , 2}$ & $\mathbf{1 1 0 7 0 1}$ & $\mathbf{7 6 , 3}$ & $\mathbf{1 2 7 9 8 4}$ & $\mathbf{7 4 , 4}$ \\
\hline $\begin{array}{l}\mathbf{4 5 - 4 8} \\
\text { Staaten } 6\end{array}$ & $\mathbf{6 2 6 4 1}$ & $\mathbf{9 6 , 2}$ & $\mathbf{1 2 9 6 8 0}$ & $\mathbf{8 9 , 3}$ & $\mathbf{1 4 9 8 2 4}$ & $\mathbf{8 7 , 5}$ \\
\hline
\end{tabular}

KANADA

\begin{tabular}{|l|l|l|l|l|l|l|}
\hline Provinz & $\begin{array}{l}\text { Auswand. } \\
\mathbf{1 9 0 1 7}\end{array}$ & $\begin{array}{l}\text { Proz.Anteil } \\
\mathbf{1 9 0 1}\end{array}$ & $\begin{array}{l}\text { Auswand. } \\
\mathbf{1 9 1 1}\end{array}$ & $\begin{array}{l}\text { Proz.Anteil } \\
\mathbf{1 9 1 1}\end{array}$ & $\begin{array}{l}\text { Auswand. } \\
\mathbf{1 9 2 1}\end{array}$ & $\begin{array}{l}\text { Proz.Anteil } \\
\mathbf{1 9 2 1}\end{array}$ \\
\hline Ontario & & & 8619 & 5.9 & 12835 & 7,5 \\
\hline B. Columbia & & & 2858 & 2,0 & 3112 & 1,8 \\
\hline Alberta & & & 1588 & 1,1 & 2926 & 1,7 \\
\hline Manitoba & & & 1080 & 0,7 & 506 & 0,3 \\
\hline Saskatchewan & & & 1008 & 0,7 & 1937 & 1,1 \\
\hline & & & & & & \\
\hline 5 Provinzen & & & $\mathbf{1 5 1 5 3}$ & $\mathbf{1 0 , 4}$ & $\mathbf{2 1 3 1 6}$ & $\mathbf{2 , 4}$ \\
\hline $\mathbf{1 2}$ Provinzen & $\mathbf{2 5 0 2}$ & $\mathbf{3 , 8}$ & $\mathbf{1 5 4 9 9}$ & $\mathbf{1 0 , 7}$ & $\mathbf{2 1 4 9 4}$ & $\mathbf{1 2 , 5}$ \\
\hline & & & & & & \\
\hline USA \& KAN & $\mathbf{6 5 1 4 3}$ & $\mathbf{1 0 0}$ & $\mathbf{1 4 5 1 7 9}$ & $\mathbf{1 0 0}$ & $\mathbf{1 7 1 3 1 8}$ & $\mathbf{1 0 0}$ \\
\hline
\end{tabular}

6Im Jahr 1900 gehörten der amerikanischen Union erst 45 Staaten an, bis 1914 wurden dann drei weitere Staaten aufgenommen: Oklahoma, Arizona und New Mexico. Erst 1959 erreichten die Vereinigten Staaten durch die Aufnahme von Alaska und Hawai ihre heutige Größe von 50 Bundesstaaten.

7Bei der kanadischen Volkszählung von 1901 wurde jede Auswanderergruppe lediglich in ihrer Gesamtanzahl erfasst. 
$\underline{\text { Anmerkung zu Tab.7 }}$

Tabelle erstellt in Anlehnung an Tab. 2 bei Kero 1980, S. 69f. Alle Zahlenwerte geben offizielle Zensusdaten der amerikanischen und kanadischen Volkszählungsstatistiken wieder [Quellen: U.S: Bureau of the Census, Historical Statistics of the United States from Colonial Times to 1970. Washington, D.C.; Fourth Census of Canada 1901/Fifth Census of Canada 1911/Sixth Cenus of Canada 1921. Ottawa].

Tab. 8 Briefanzahl und -verfasser in 40 Gemeinden des Untersuchungsgebietes 1882-1914

\section{SÜD-OSTBOTTNIEN}

\begin{tabular}{|l|l|l|l|l|l|}
\hline Gemeinde & Auswanderer & Briefe & Briefverfasser & Männer & Frauen \\
\hline Alajärvi & 3423 & 1 & 1 & 1 & \\
\hline Ilmajoki & 2892 & 3 & 3 & 2 & 1 \\
\hline Isokyrö & 4495 & 19 & 6 & 4 & 2 \\
\hline Jalasjärvi & 3793 & 1 & 1 & 1 & \\
\hline Jurva & 1676 & 11 & 5 & 3 & 2 \\
\hline Karijoki & 1202 & 1 & 1 & 1 & \\
\hline Kauhajoki & 3608 & 1 & 1 & 1 & \\
\hline Kuortane & 1822 & 4 & 3 & 3 & \\
\hline Kurikka & 2231 & 2 & 1 & 1 & \\
\hline Laihia & 3295 & 1 & 1 & 1 & \\
\hline Lapua & 4716 & 2 & 2 & 2 & \\
\hline Peräseinäjoki & 1438 & 36 & 5 & 4 & 1 \\
\hline Seinäjoki & 838 & 2 & 1 & 1 & \\
\hline Teuva & 2271 & 6 & 2 & & 2 \\
\hline Töysä & 902 & 3 & 2 & 1 & 1 \\
\hline Vaasa (Stadt) & 4904 & 5 & 2 & 1 & 1 \\
\hline Vimpeli & 1295 & 2 & 2 & 2 & \\
\hline Vähäkyrö & 2010 & 1 & 1 & & 1 \\
\hline Ylihärmä & 1402 & 16 & 4 & 4 & \\
\hline Ylistaro & 4622 & 8 & 6 & 4 & 2 \\
\hline & & & & $\mathbf{3 7}$ & $\mathbf{1 3}$ \\
\hline Insg. & $\mathbf{5 2 8 3 5}$ & $\mathbf{1 2 5}$ & $\mathbf{5 0}$ & & \\
\hline & & & & & \\
\hline
\end{tabular}

8Zu den Auswandererzahlen auf Gemeindeniveau siehe Note 3. 
SATAKUNTA

\begin{tabular}{|c|c|c|c|c|c|}
\hline Gemeinde & Auswanderer & Briefe & Briefverfasser & Männer & Frauen \\
\hline Eura & 201 & 6 & 2 & 2 & \\
\hline Hinnerjoki & 433 & 90 & 13 & 10 & 3 \\
\hline Honkilahti & 271 & 4 & 3 & 3 & \\
\hline Ikaalinen & 2134 & 35 & 9 & 4 & 5 \\
\hline Jämijärvi & 756 & 6 & 4 & 3 & 1 \\
\hline Kankaanpää & 2063 & 1 & 1 & 1 & \\
\hline Karvia & 947 & 18 & 13 & 11 & 2 \\
\hline Kiikka & 275 & 27 & 3 & 2 & 1 \\
\hline Kiikoinen & 230 & 1 & 1 & 1 & \\
\hline Kokemäki & 358 & 4 & 2 & 2 & 2 \\
\hline Kullaa & 127 & 6 & 1 & & 1 \\
\hline Köyliö & 273 & 2 & 1 & & 1 \\
\hline Lappi/TL & 503 & 64 & 11 & 6 & 5 \\
\hline Lavia & 342 & 2 & 2 & 2 & \\
\hline Loimaa & 765 & 17 & 5 & 2 & 3 \\
\hline Merikarvia & 1842 & 28 & 7 & 5 & 2 \\
\hline Siikainen & 1434 & 25 & 10 & 7 & 3 \\
\hline Pomarkku & 681 & 3 & 1 & & 1 \\
\hline Säkylä & 288 & 3 & 1 & & 1 \\
\hline Tyrvää & 455 & 11 & 3 & 3 & \\
\hline Insg. & 14378 & 353 & 93 & 63 & 30 \\
\hline \begin{tabular}{|l|} 
Beide \\
Sammlungen
\end{tabular} & 67213 & 478 & 143 & 100 & 43 \\
\hline
\end{tabular}


Tab. 9 Namentliche Auflistung der Briefschreiber mit Angaben zum

Herkunftsort, Auswanderungsjahr, Jahr des 1. Amerika-Briefes ${ }^{9}$ und potientieller Rückkehr

\begin{tabular}{|c|c|c|c|c|}
\hline Name & Herkunftsort & \begin{tabular}{|l} 
Jahr des \\
1. Briefes
\end{tabular} & $\begin{array}{l}\text { Jahr der } \\
\text { Auswanderung }\end{array}$ & Rückkehr \\
\hline Aalto, Emil & Eura & 1902 & ca.1900 & $\mathrm{Ja}$ \\
\hline Aalto, Kalle & Lappi/TL & 1910 & 1907 & \\
\hline Andersson, John & Jurva & 1891 & & \\
\hline Bergqvist, John & Ylistaro & 1901 & ca.1890 & Nein \\
\hline $\begin{array}{l}\text { Cannelin,Waldemar } \\
\text { (später Charles C.) }^{10}\end{array}$ & $\begin{array}{l}\text { Mustasaari } \\
\text { (bei Vaasa) }\end{array}$ & 1907 & 1892 & Nein \\
\hline Dutton, Anna & Töysä & 1912 & 1904 & Nein \\
\hline Einola, Evert & Honkilahti & 1909 & & \\
\hline $\begin{array}{l}\text { Fors, Olga } \\
\text { (später O. Nieminen) }\end{array}$ & Siikainen & 1903 & & \\
\hline Fredman, Aina & Vaasa & 1909 & & \\
\hline Hautala, Erik & Karvia & 1901 & 1899 & Nein \\
\hline Hautala, Vihtori & Karvia & 1910 & 1896 & Nein \\
\hline Hautala, Ville & Karvia & 1891 & ca.1895 & Nein \\
\hline Harju, Oskar & Hinnerjoki & 1906 & 1906 & Nein \\
\hline Heikkilä, Robert & Loimaa & 1903 & 1903 & $\mathrm{Ja}$ \\
\hline Heikkuri, Hulda & Teuva & 1905 & 1904 & \\
\hline Heinonen, Oskar & Merikarvia & 1887 & ca.1885 & Nein \\
\hline Heinäjoki, Ida S. & Siikainen & 1913 & 1913 & \\
\hline Heinäjoki, Juho & Siikainen & 1913 & 1912 & \\
\hline Hemiä, Anton & Kankaanpää & 1908 & 1901 & \\
\hline $\begin{array}{l}\text { Heuru, August } \\
\text { (später A.Kulmala) }\end{array}$ & Hinnerjoki & 1901 & & $\mathrm{Ja}$ \\
\hline Hill, Sofia & Ilmajoki & 1914 & 1902 & Nein \\
\hline Hissa, Herman & Isokyrö & 1901 & 1901 & Nein \\
\hline $\begin{array}{l}\text { Hissa, L. [weibl.] } \\
\text { (geb. L. Mattila) }\end{array}$ & Isokyrö & 1911 & ca.1910 & Nein \\
\hline Holma, Juho & Jämijärvi & 1911 & 1910 & $\mathrm{Ja}$ \\
\hline $\begin{array}{l}\text { Häggblom, Otto } \\
\text { (später O. Brosi) }\end{array}$ & Karijoki & 1902 & 1900 & Nein \\
\hline Hulkko, Anselm & Jalasjärvi & 1912 & 1909 & Nein \\
\hline Huovinen, Tili & Jurva & 1906 & & \\
\hline $\begin{array}{l}\text { Hälli, Ludvik } \\
\text { (später L. Halley) }\end{array}$ & Karvia & 1910 & 1910 & Nein \\
\hline
\end{tabular}

${ }^{9}$ Mit der Bezeichnung, Jahr des 1. Briefes' ist der älteste erhaltene Brief des jeweiligen

Verfassers gemeint, der in diese Untersuchung miteingegangen ist. Zum Zustandekommen der

Briefsammlungen von insgesamt 143 Briefverfassern siehe Kap 1.2.

${ }^{10}$ Die Namensangabe bezieht sich auf den Zeitpunkt des ersten erhaltenen Briefes, den der

Briefschreiber aus Amerika nach Finnland sandte. 


\begin{tabular}{|c|c|c|c|c|}
\hline Ikala, Evert & Kokemäki & 1914 & 1914 & Nein \\
\hline Ikala, Jalmari & Kokemäki & 1904 & 1904 & $\mathrm{Ja}$ \\
\hline Jaaksi, Matti & Laihia & 1887 & 1883 & Nein \\
\hline Jalo, August & Hinnerjoki & 1908 & 1908 & $\mathrm{Ja}$ \\
\hline Jalonen, Kustaa & Lappi/TL & 1910 & & \\
\hline Jokinen, Sven & Jämijärvi & 1914 & & Nein \\
\hline Jonson, Ida & Köyliö & 1911 & & \\
\hline Junsala, Jacob & Ylihärmä & 1883 & 1883 & \\
\hline Kallio, Isaac & Lappi/TL & 1913 & 1913 & \\
\hline $\begin{array}{l}\text { Kallio, Maija } \\
\text { (später M. Larson) }\end{array}$ & Lappi/TL & 1909 & & \\
\hline Kallio, Oskar & Hinnerjoki & 1910 & 1910 & \\
\hline Kallio, Richard & Siikainen & 1907 & & \\
\hline Kalliomaa, Jenny & Ylistaro & 1913 & 1913 & \\
\hline Kalström, Hilja & Kiikka & 1912 & & \\
\hline Kangas, Antti & Ylihärmä & 1880 & & $\mathrm{Ja}$ \\
\hline Kangas, Heikki & Ylihärmä & 1893 & & \\
\hline Kangas, Juha & Ylihärmä & 1882 & & \\
\hline Kaukonen, Seelim & Kiikka & 1907 & 1907 & \\
\hline Kesti, Oskar & Kiikka & 1914 & & \\
\hline Koivisto, Frans & Siikainen & 1889 & 1886 & Nein \\
\hline Kortesmäki,Salomon & Seinäjoki & 1905 & 1905 & $\mathrm{Ja}$ \\
\hline Korvola, Juha & Isokyrö & 1895 & 1893 & Nein \\
\hline Korvola, Herman & Isokyrö & 1904 & ca. 1900 & $\mathrm{Ja}$ \\
\hline Koskela, Alexander & Vimpeli & 1907 & 1907 & $\mathrm{Ja}$ \\
\hline Koskela, Antti & Vimpeli & 1907 & 1904 & Nein \\
\hline $\begin{array}{l}\text { Koskela, Maija } \\
\text { (später M. Niemi) }\end{array}$ & Pori/Kullaa & 1914 & 1901 & Nein \\
\hline Koski, Johan & Kurikka & 1895 & 1892 & \\
\hline Koskinen, Toivo & Lavia & 1909 & 1907 & Nein \\
\hline Koskinen, Urho & Lavia & 1911 & 1910 & Nein \\
\hline Kuusisto, Isak & Hinnerjoki & 1905 & 1905 & Nein \\
\hline Kuusisto, Johan & Hinnerjoki & 1902 & 1902 & \\
\hline Kuusisto, Nestor & Hinnerjoki & 1906 & 1906 & Nein \\
\hline Kuuttila, Matti & Ylistaro & 1913 & 1913 & Nein \\
\hline Laakso, Oskar & Hinnerjoki & 1910 & 1910 & \\
\hline Laaksonen, Kaarle & Hinnerjoki & 1903 & 1902 & \\
\hline $\begin{array}{l}\text { Lahtinen, Juho M. } \\
\text { (später John Wilson) }\end{array}$ & Tyrvää & 1909 & 1907 & Nein \\
\hline Lammi, Vante & Karvia & 1911 & 1911 & Nein \\
\hline Lautamäki, Nikolai & Karvia & 1895 & & Nein \\
\hline Lehtinen, Hannes & Kiikoinen & 1908 & & \\
\hline Lehtinen, Kaarlo O. & Loimaa & 1908 & 1906 & Nein \\
\hline Leidenius, Tilda & Teuva & 1910 & 1909 & \\
\hline Lendén, Frans & Honkilahti & 1903 & 1903 & $\mathrm{Ja}$ \\
\hline Lepistö, Akseli & Peräseinäjoki & 1913 & 1913 & Nein \\
\hline Lepola, Johan & Ikaalinen & 1902 & 1902 & Nein \\
\hline $\begin{array}{l}\text { Liikaluoma, Matilda } \\
\text { (geb. M. Laaksonen) }\end{array}$ & Loimaa & 1898 & 1897 & Nein \\
\hline
\end{tabular}




\begin{tabular}{|c|c|c|c|c|}
\hline Luonsi, Amanda & Ikaalinen & 1914 & 1914 & Nein \\
\hline $\begin{array}{l}\text { Lähteenmäki, Aina } \\
\text { (später A. Nurmo) }\end{array}$ & Jämijärvi & 1914 & 1912 & Nein \\
\hline $\begin{array}{l}\text { Lönnberg, Lydia W. } \\
\text { (später L.Andersson) }\end{array}$ & Merikarvia & 1900 & 1900 & Nein \\
\hline Lönnberg, Artur Sven & Merikarvia & 1899 & 1899 & Nein \\
\hline Löyva, Ilo & Kuortane & 1909 & 1906 & Nein \\
\hline Malinen, Otto & Karvia & 1911 & 1911 & Nein \\
\hline Mattila, John & Isokyrö & 1903 & 1902 & \\
\hline Mikkola, Henrik & Merikarvia & 1893 & & $\mathrm{Ja}$ \\
\hline Myllymäki, Hilma & Siikainen & 1914 & 1912 & Nein \\
\hline Myllymäki, Vihtori & Siikainen & 1903 & 1903 & \\
\hline $\begin{array}{l}\text { Mäkelä, Hanna } \\
\text { (später H. Savonen) }\end{array}$ & Jämijärvi & 1914 & 1910 & Nein \\
\hline $\begin{array}{l}\text { Mäkelä, Wilhelm } \\
\text { (später W. Mäki) }\end{array}$ & Karvia & 1893 & & Nein \\
\hline Mäki, Kalle & Siikainen & 1909 & & \\
\hline Mäki, Miina & Karvia & 1904 & & \\
\hline Mäki, Nestor & Karvia & 1903 & 1901 & Nein \\
\hline Mäkynen, Matti & Lapua & 1910 & 1906 & Nein \\
\hline $\begin{array}{l}\text { Nahkaluoma, } \\
\text { Herman } \\
\text { (später H. Luoma) }\end{array}$ & Kauhajoki & 1913 & 1896 & Nein \\
\hline Neva, Anselmi & Merikarvia & 1906 & 1906 & \\
\hline Niemi, Emma & Ikaalinen & 1911 & 1911 & Nein \\
\hline $\begin{array}{l}\text { Niemi, Hilda } \\
\text { (später H. Paananen) }\end{array}$ & Ikaalinen & 1908 & 1902 & Nein \\
\hline Niemi, Tuomas & Jurva & 1903 & 1896 & Nein \\
\hline Nieminen, Niilo & Ylistaro & 1907 & 1907 & Nein \\
\hline Nordling, August & Tyrvää & 1899 & 1895 & Nein \\
\hline Nummela, A. Viktor & Lappi/TL & 1901 & 1901 & Nein \\
\hline Nummela, Vilma & Hinnerjoki & 1905 & 1905 & $\mathrm{Ja}$ \\
\hline Nurmi, Aina & Lappi/TL & 1910 & 1909 & \\
\hline Nurminen, Iisak & Lappi/TL & 1913 & 1912 & \\
\hline Nyman, Frans J. & Eura & 1890 & 1890 & Nein \\
\hline Nytery, Helmi & Hinnerjoki & 1903 & 1903 & \\
\hline Oksa, Robert & Siikainen & 1913 & 1903 & Nein \\
\hline Pakkanen, Taavetti & Ikaalinen & 1908 & 1906 & Nein \\
\hline Papunen, Amalia & Karvia & 1906 & 1906 & Nein \\
\hline Parkkomäki, Johan & Vaasa & 1895 & 1883 & \\
\hline $\begin{array}{l}\text { Peltonen, Ellen } \\
\text { (später E. Luoma) }\end{array}$ & Ikaalinen & 1907 & ca. 1900 & Nein \\
\hline $\begin{array}{l}\text { Peltoniemi, Nikolai } \\
\text { (später N. Nieminen) }\end{array}$ & Karvia & 1890 & 1889 & Nein \\
\hline Peräkoski, Heikki & Ilmajoki & 1905 & 1905 & Nein \\
\hline Perälä, Oskar & Merikarvia & 1902 & 1889 & Nein \\
\hline Perälä, Wiljam & Ylistaro & 1913 & & \\
\hline Pietilä, Kaarlo & Hinnerjoki & 1910 & 1910 & Nein \\
\hline Pihlaja, Laura & Ikaalinen & 1913 & & \\
\hline
\end{tabular}




\begin{tabular}{|c|c|c|c|c|}
\hline Pihlajakoski, Isak & Pomarkku & 1902 & 1902 & Nein \\
\hline Pollari, Antti & Alajärvi & 1899 & 1899 & $\mathrm{Ja}$ \\
\hline Pykälä, Kalle & Tyrvää & 1910 & 1910 & Nein \\
\hline Rantaaho, Matti & Töysä & 1911 & 1911 & Nein \\
\hline $\begin{array}{l}\text { Rinne, Juho } \\
\text { (später J. Rekola) }\end{array}$ & Honkilahti & 1914 & 1896 & \\
\hline Roos, Viktor & Lappi/TL & 1905 & & \\
\hline $\begin{array}{l}\text { Ruikka, Olga } \\
\text { (später O. Koskinen) }\end{array}$ & Hinnerjoki & 1904 & 1903 & $\mathrm{Ja}$ \\
\hline Salty, Liisa & Vähäkyrö & 1889 & & \\
\hline Sania, Frans & Lappi & 1911 & & \\
\hline Sarvela, Heikki & Jurva & 1908 & ca. 1870 & Nein \\
\hline Seppälä, Joonatan & Karvia & 1905 & 1905 & $\mathrm{Ja}$ \\
\hline Sihto, Kalle & Ilmajoki & 1899 & & Nein \\
\hline Sippola, Juho & Kuortane & 1904 & 1899 & Nein \\
\hline Sippola, Matti & Kuortane & 1908 & 1907 & \\
\hline $\begin{array}{l}\text { Suovanniemi, Samuel } \\
\text { (später S. Mattson) }\end{array}$ & Peräseinäjoki & 1903 & 1903 & \\
\hline $\begin{array}{l}\text { Suovanniemi, Matti } \\
\text { (später Tapani } \\
\text { Niemi) }\end{array}$ & Peräseinäjoki & 1902 & 1902 & Nein \\
\hline Tienhaara, Kustaa & Lapua & 1901 & 1901 & \\
\hline $\begin{array}{l}\text { Tienhaara, Liisa } \\
\text { (später L. Tuomi) }\end{array}$ & Lappi/TL & 1907 & 1906 & Nein \\
\hline Tienhaara,Wiktoorina & Lappi/TL & 1906 & 1906 & \\
\hline Toivola, Taavetti & Ikaalinen & 1913 & 1913 & $\mathrm{Ja}$ \\
\hline $\begin{array}{l}\text { Toopakka, Hilja } \\
\text { (geb.H.Suovanniemi) }\end{array}$ & Peräseinäjoki & 1900 & 1900 & Nein \\
\hline Toopakka, Matti & Peräseinäjoki & 1899 & 1899 & Nein \\
\hline $\begin{array}{l}\text { Tupila, Hilma } \\
\text { (geb. H. Mäkelä) }\end{array}$ & Jämijärvi & 1910 & 1909 & Nein \\
\hline Ylkänen, Fiija & Ylistaro & 1890 & 1885 & $\mathrm{Ja}$ \\
\hline Ylismäki, Anna K. & Loimaa & 1911 & 1911 & Nein \\
\hline Ylismäki, Miina & Loimaa & 1908 & & \\
\hline $\begin{array}{l}\text { Vilppula, Manda } \\
\text { (später M.Laaksonen) }\end{array}$ & Säkylä & 1903 & & \\
\hline $\begin{array}{l}\text { Virtanen, Liisa } \\
\text { Matilda } \\
\text { (geb. L. M .Praski) }\end{array}$ & Isokyrö & 1908 & 1902 & Nein \\
\hline Wesentius, Sofia & Jurva & 1896 & & \\
\hline Österby, Amanda & Merikarvia & 1905 & 1900 & Nein \\
\hline
\end{tabular}




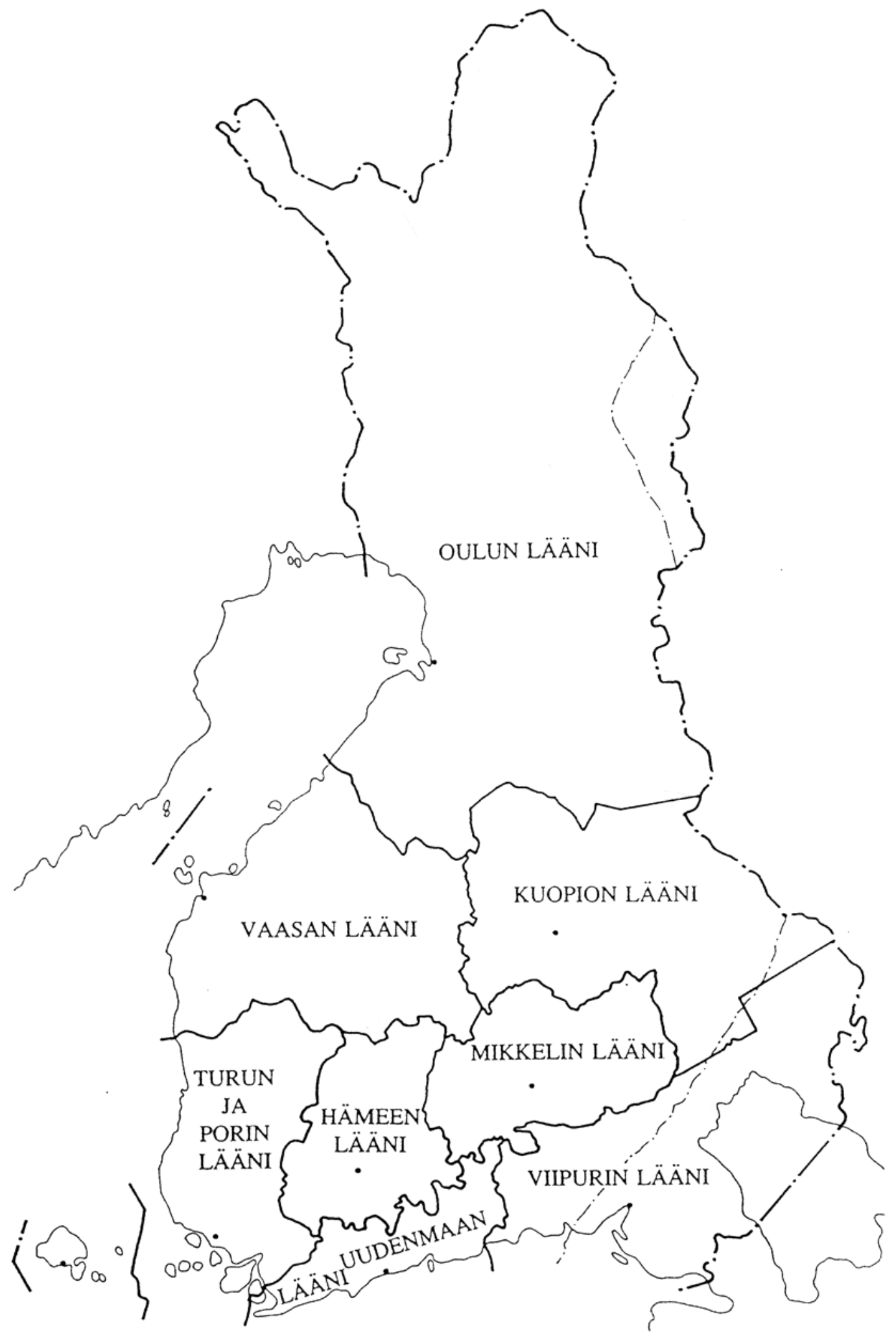

Karte 1a) Geographische Aufteilung Finnlands nach Regierungsbezirken vor 1918 (Karte entnommen aus Vattula 1983, S. 28, Einleitung) 


\section{Erläuterungen zu Karte 1a}

\section{Aufteilung Finnlands in acht Regierungsbezirke (1831-1918) ${ }^{1}$ :}

OULUN LÄÄNI = Regierungsbezirk Oulu (schwed. Uleåborg) [Der Regierungsbezirk Oulu wurde 1938 in die beiden Bezirke Oulu und Lappland aufgeteilt.]

VAASAN LÄÄNI = Regierungsbezirk Vaasa (schwed. Vasa)

KUOPION LÄÄNI = Regierungsbezirk Kuopio [Einige Gemeinden an der Ostgrenze wurden 1944 an die Sowjet-Union abgetreten.]

TURUN JA PORIN LÄÄNI = Regierungsbezirk Turku/Pori (schwed.

Åbo/Björneborg) [Die Ålandinseln (finn. Ahvenanmaa) zählten bis 1918 zum

Regierungsbezirk Turku/Pori, seit 1921 haben sie einen autonomen Status innerhalb der finnischen Republik.]

MIKKELIN LÄÄNI = Regierungsbezirk Mikkeli (schwed. St. Michel)

HÄMEEN LÄÄNI = Regierungsbezirk Häme (schwed. Tavastland)

UUDENMAAN LÄÄNI= Regierungsbezirk Uusimaa (schwed. Nyland)

VIIPURIN LÄÄNI = Regierungsbezirk Viipuri (schwed. Viborg)

[Mehr als die Hälfte der Fläche des Regierungsbezirks Viborg, inklusive der Hafenstadt Viborg, wurde 1944 sowjetisches Territorium. Der bei Finnland verbliebende Teil des Regierungsbezirks erhielt nach dem Fluß ‘Kymi’ seinen neuen Namen 'Kymen Lääni'.]

\footnotetext{
${ }^{1}$ Die Anzahl der Regierungsbezirke änderte sich im Zuge der finnischen Unabhängigkeit nach 1918 mehrfach, wobei diese Entwicklung durch die Statusänderung der Ålandinseln, seit 1921 gesetzlich verankert, eingeleitet wurde. Seit 1998 besteht Finnland nur noch aus fünf Regierungsbezirken, nämlich den bereits 1938 festgelegten Bezirken 'Lappland' und 'Oulu' sowie den neugegründeten Regierungsbezirken Süd-, West- und Ost-Finnland.
} 


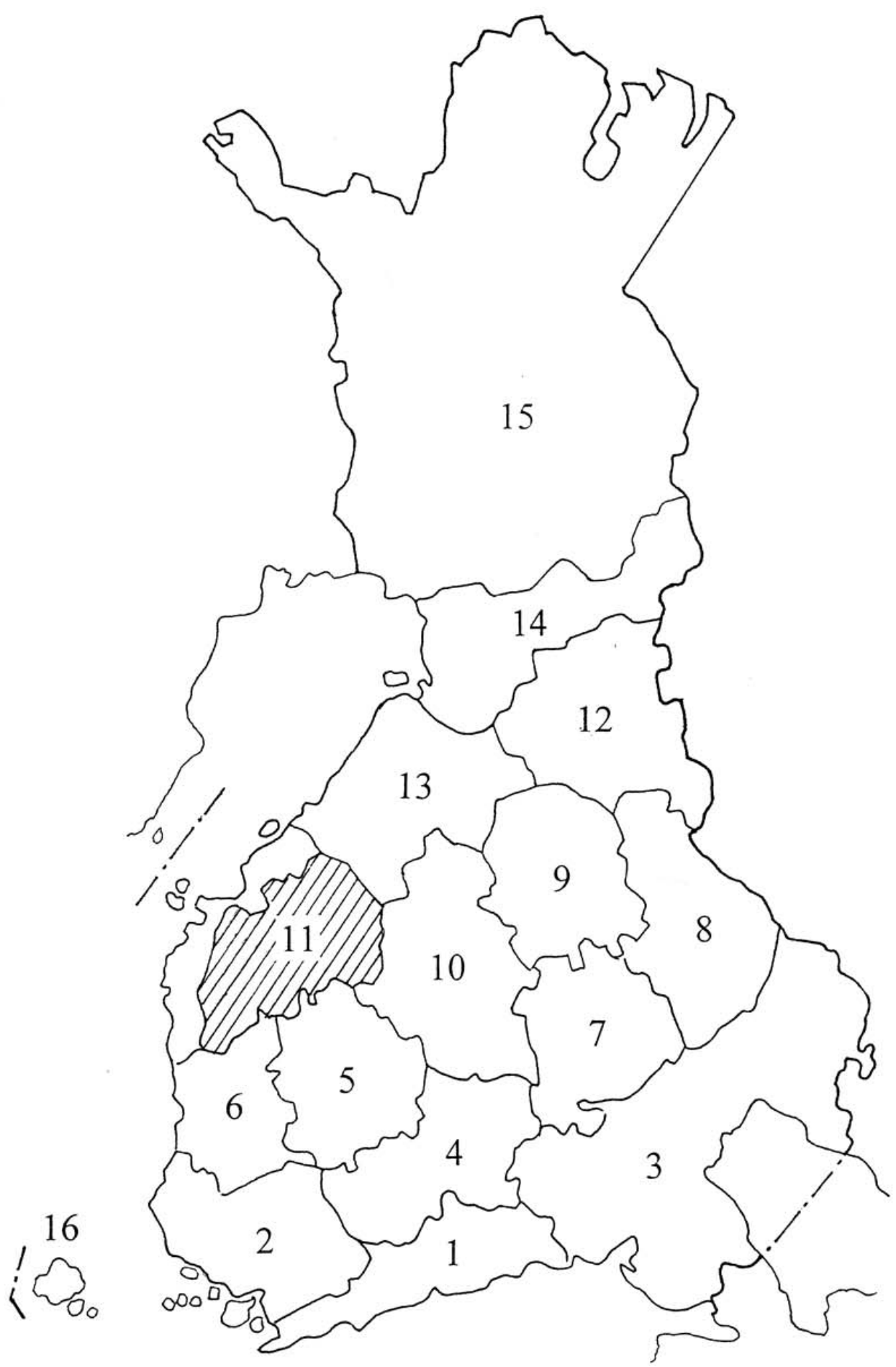

Karte 1b) Geographische Aufteilung Finnlands nach Provinzen 1900

(Karte zusammengestellt nach Angaben des Amtes für Statistik, Helsinki ) 


\section{Erläuterungen zu Karte 1b}

Aufteilung Finnlands in 16 Provinzen ${ }^{1}$ :

1) Neuland [finn. Uusimaa; schwed. Nyland]

2) Eigentliches Finnland [finn. Varsinais-Suomi; schwed. Egentliga Finland]

3) Süd-Karelien [finn. Etelä-Karjala; schwed. Södra Karelen]

4) Süd-Häme [finn. Etelä-Häme; schwed. Södra Tavastland]

5) Pirkkala [finn. Pirkanmaa; schwed. Birkaland]

6) Satakunta [schwed. Satakunda]

7) Süd-Savo [finn. Etelä-Savo; schwed. Södra Savolax]

8) Nord-Karelien [finn. Pohjois-Karjala; schwed. Norra Karelen]

9) Nord-Savo [finn. Pohjois-Savo; schwed. Norra Savolax]

10) Mittel-Finnland [finn. Keski-Suomi; schwed. Mellersta Finland]

11) Süd-Ostbottnien ${ }^{2}$ [finn. Etelä-Pohjanmaa; schwed. Södra Österbotten]

12) Kainuu [schwed. Kajanaland]

13) Mittel-Ostbottnien [finn. Keski-Pohjanmaa; schwed. Mellersta Österbotten]

14) Nord-Ostbottnien [finn. Pohjois-Pohjanmaa; schwed. Norra Österbotten]

15) Lappland [finn. Lappi; schwed. Lappland]

16) Ålandinseln [finn. Ahvenanmaa; schwed. Åland]

\footnotetext{
${ }^{1}$ Um 1900 waren die Provinzen rein landschaftlicher Natur und unterlagen keiner administrativen Grenzziehung. Erst nach 1944 wurden alle Gemeinden und Städte offiziell einzelnen Provinzen zugeordnet sowie Gebietsteile der Provinzen Lappland und Süd-Karelien an die Sowjet-Union abgetreten. Heutzutage besteht Finnland aus 19 Provinzen.

${ }^{2}$ Die Provinz Süd-Ostbottnien umfaßt sowohl finnisch- als auch schwedischsprachige Gemeinden. In Karte 1b werden die finnischsprachigen Inlandsgemeinden, zugleich Herkunftsregion der hier behandelten Briefschreiber aus Süd-Ostbottnien, im Gegensatz zu den schwedischsprachigen Küstenorten straffiert dargestellt.
} 


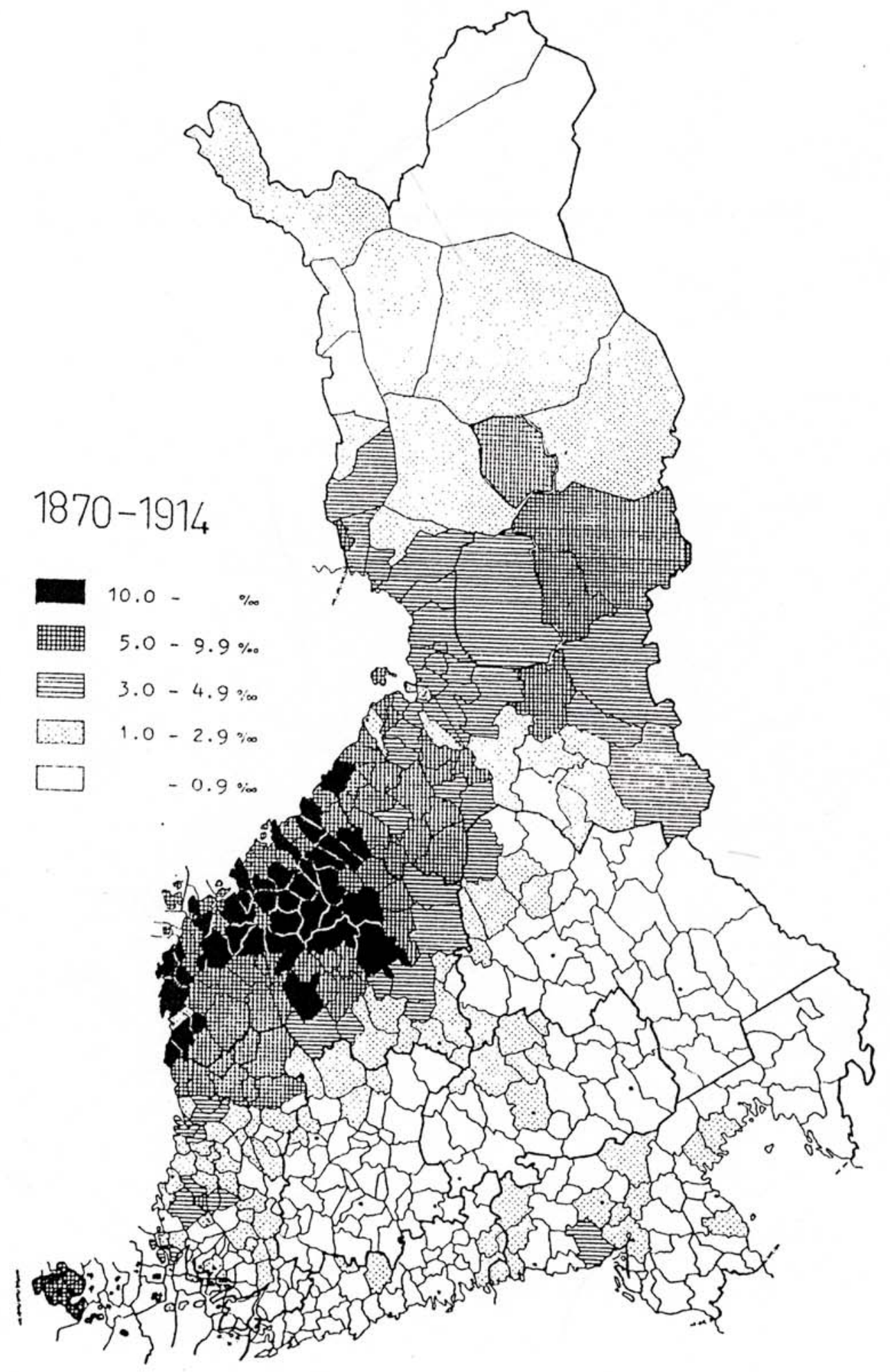

Karte 2) Prozentuale Verteilung der Auswandererkonzentration in Finnland 1870-1914 (Karte entnommen aus Kero 1974, S. 51, Abb. 3) 


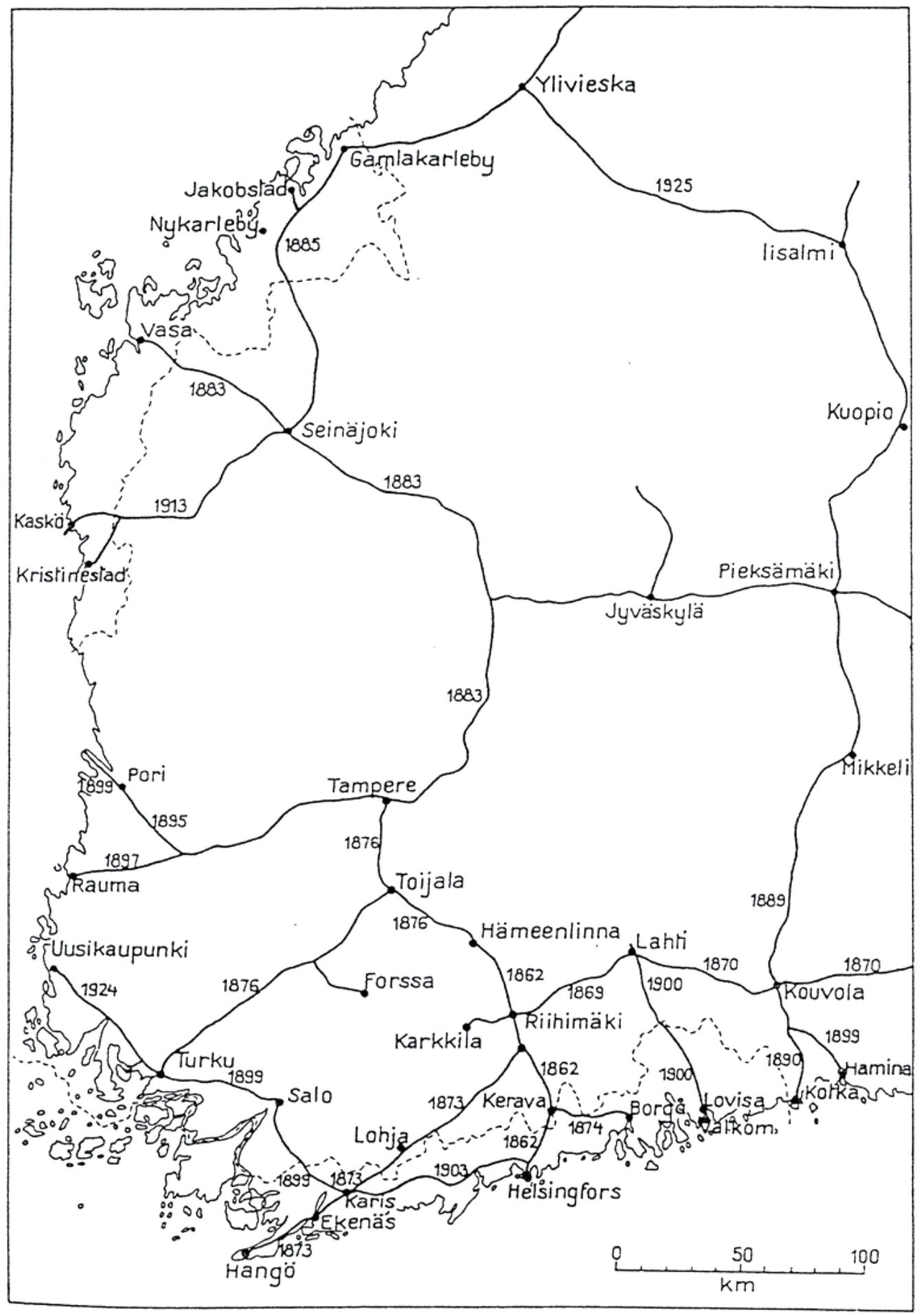

Karte 3) Das finnische Eisenbahnnetz im westlichen Finnland 1862-1925

(Karte entommen aus Klövekorn 1960, S. 191, Abb. 37) 


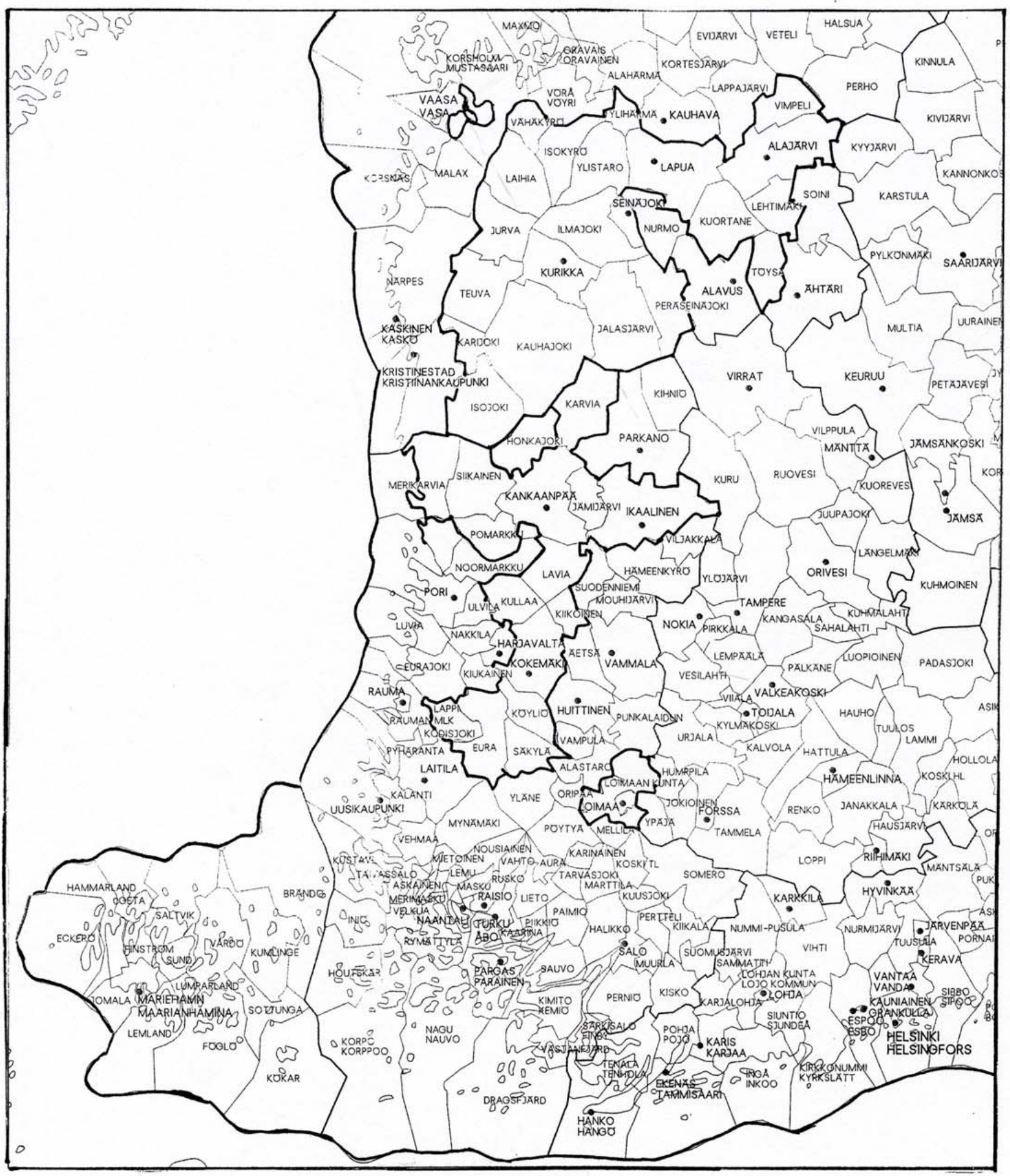

Karte 4) Herkunftsgemeinden der Briefschreiber in Süd-Ostbottnien und Satakunta (Original-Karte herausgegeben vom Amt für Landvermessung, Helsinki 1990) 


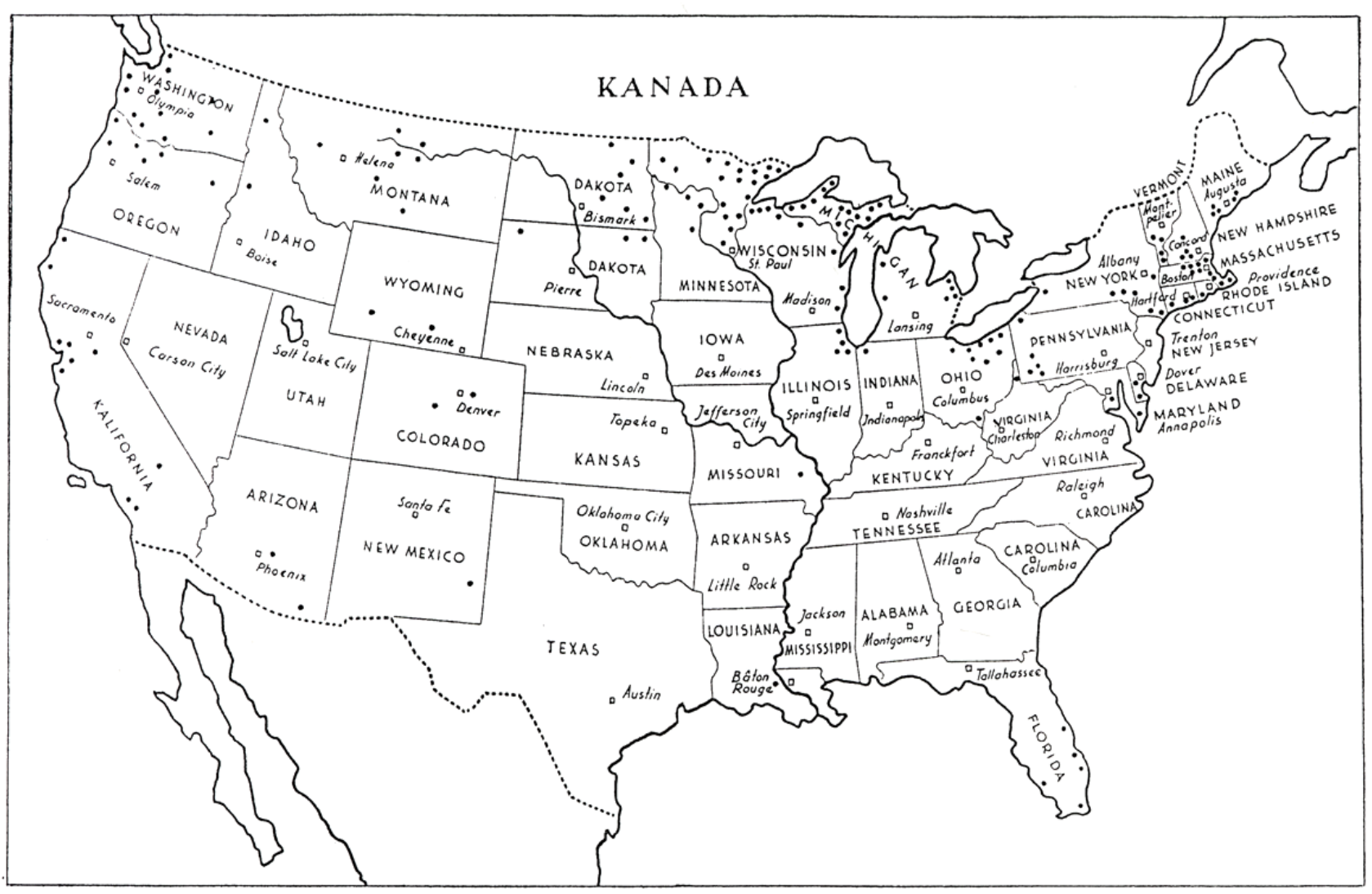

Karte 5) Verteilung der Amerika-Finnen auf einzelne Bundesstaaten 1900 (Karte entnommen aus Tokoi 1949, S. 88f.) 


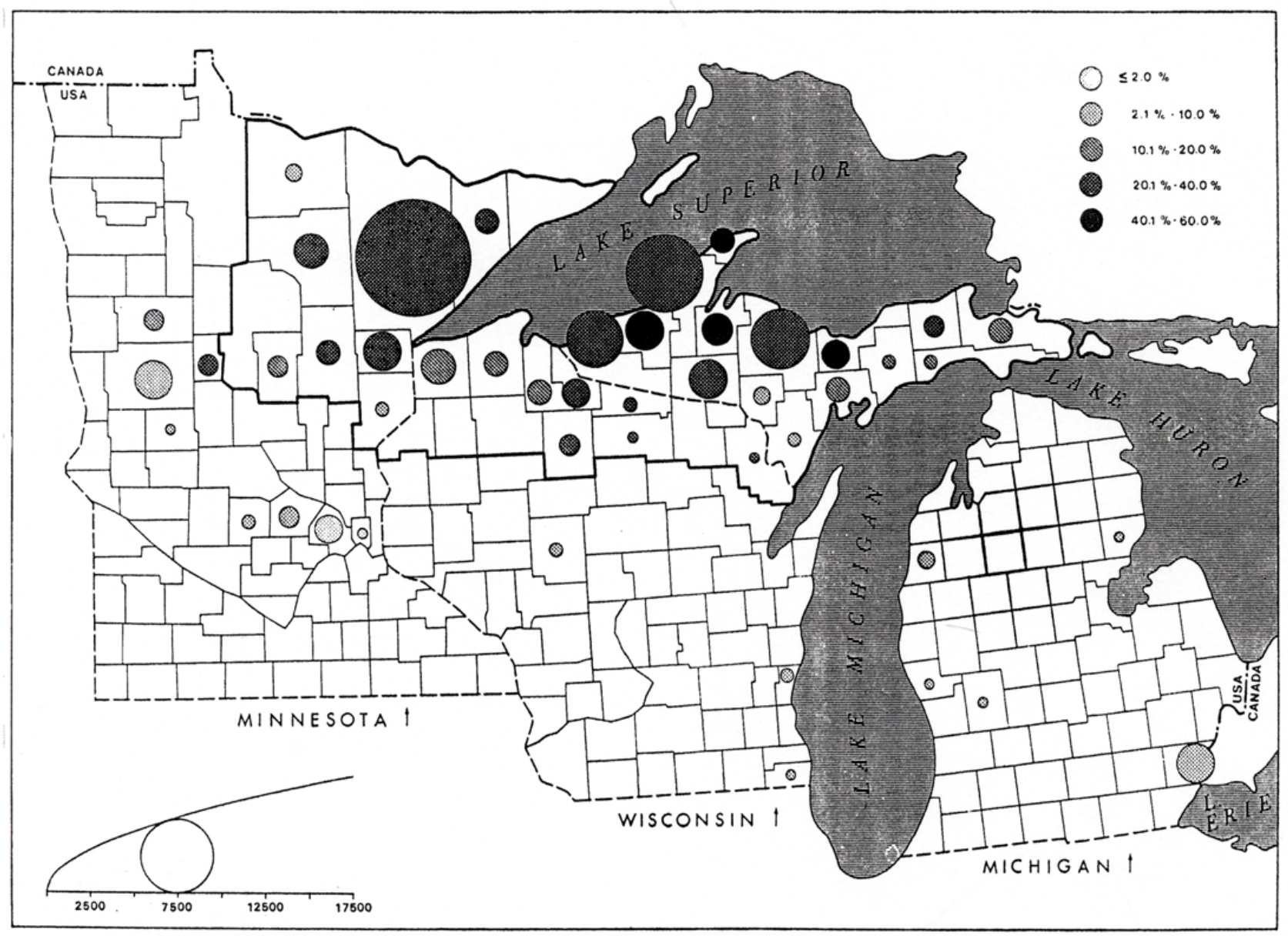

Karte 6) Geographische Konzentration der Finnen im Bereich der Großen Seen 1900 (Karte entnommen aus Alanen 1983b, S. 3, Abb. 2) 


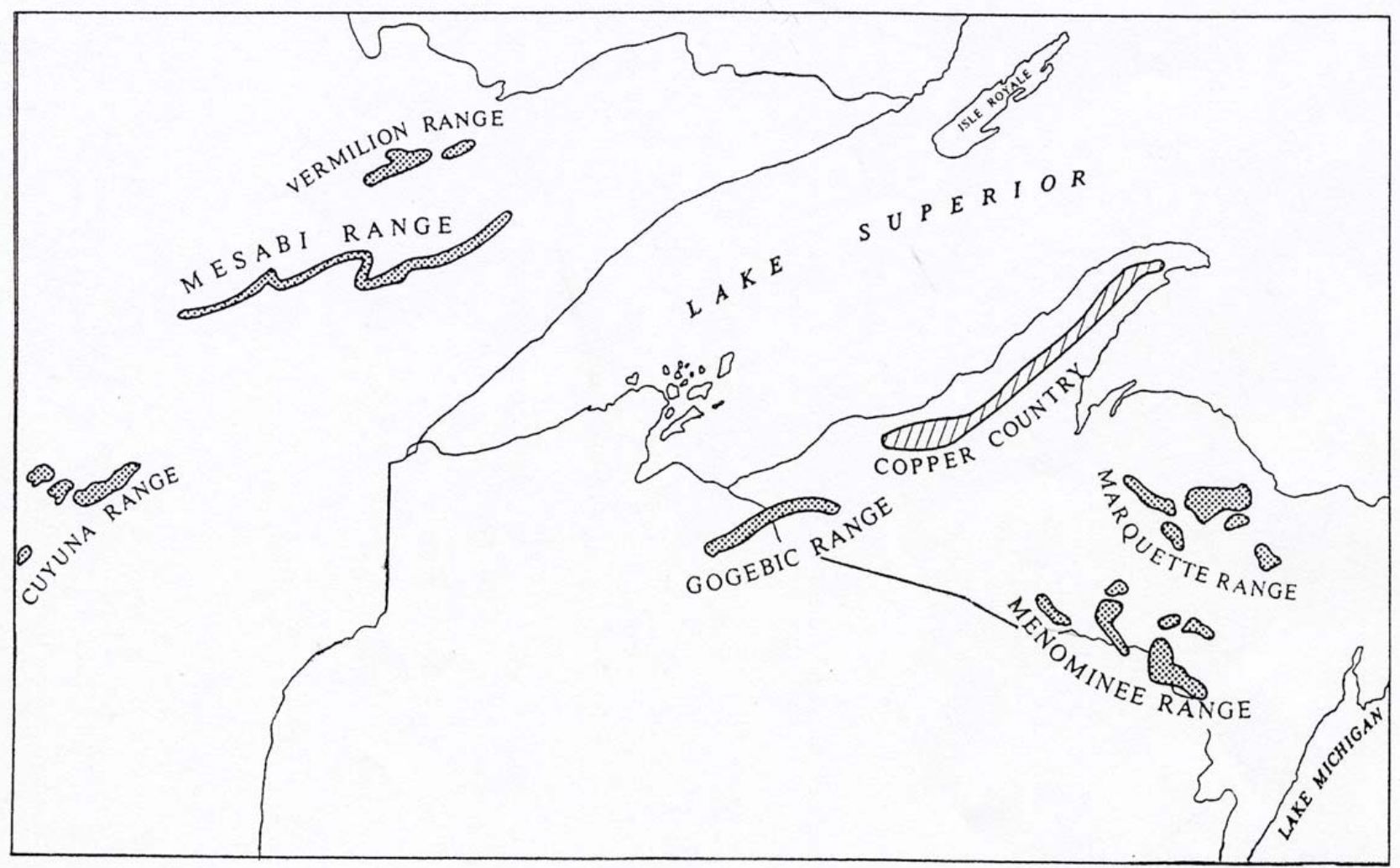

Karte 7) Geographische Lage der Eisenerz- und Kupferbergwerke in Michigan, Minnesota und Wisconsin 1900

(Karte entnommen aus Alanen 1981b, S. 36, Abb. 1) 